\title{
Causes and consequences of microvascular dysfunction
}

Citation for published version (APA):

Rensma, S. P. (2020). Causes and consequences of microvascular dysfunction: focus on the brain. [Doctoral Thesis, Maastricht University]. ProefschriftMaken. https://doi.org/10.26481/dis.20201029sr

Document status and date:

Published: 01/01/2020

DOI:

10.26481/dis.20201029sr

Document Version:

Publisher's PDF, also known as Version of record

\section{Please check the document version of this publication:}

- A submitted manuscript is the version of the article upon submission and before peer-review. There can be important differences between the submitted version and the official published version of record.

People interested in the research are advised to contact the author for the final version of the publication, or visit the DOI to the publisher's website.

- The final author version and the galley proof are versions of the publication after peer review.

- The final published version features the final layout of the paper including the volume, issue and page numbers.

Link to publication

\footnotetext{
General rights rights.

- You may freely distribute the URL identifying the publication in the public portal. please follow below link for the End User Agreement:

www.umlib.nl/taverne-license

Take down policy

If you believe that this document breaches copyright please contact us at:

repository@maastrichtuniversity.nl

providing details and we will investigate your claim.
}

Copyright and moral rights for the publications made accessible in the public portal are retained by the authors and/or other copyright owners and it is a condition of accessing publications that users recognise and abide by the legal requirements associated with these

- Users may download and print one copy of any publication from the public portal for the purpose of private study or research.

- You may not further distribute the material or use it for any profit-making activity or commercial gain

If the publication is distributed under the terms of Article $25 \mathrm{fa}$ of the Dutch Copyright Act, indicated by the "Taverne" license above, 

Causes and consequences of microvascular dysfunction: focus on the brain

door Sytze Pieter Rensma 
(C) copyright Sytze Pieter Rensma, 2020

Printing: ProefschriftMaken || www.proefschriftmaken.nl

All rights reserved. No part of this publication may be reproduced, stored in a retrieval system or transmitted, in any form or by any means, electronic, mechanical, photocopying, recording or otherwise, without prior permission of the author or the copyright-owning journals for previous published chapters. 


\title{
Causes and consequences of microvascular dysfunction: Focus on the brain
}

\author{
PROEFSCHRIFT \\ ter verkrijging van de graad van doctor aan de Universiteit Maastricht, \\ op gezag van de Rector Magnificus, Prof.dr. Rianne M. Letschert \\ volgens het besluit van het College van Decanen, \\ in het openbaar te verdedigen \\ op Donderdag 29 oktober 2020 om 16.00 uur
} door Sytze Pieter Rensma 


\section{Promotor}

Prof. Dr. C.D.A. Stehouwer

\section{Copromotor}

Dr. T.T. van Sloten

\section{Beoordelingscommissie}

Dr. V.P.M. van Empel (voorzitter)

Prof. dr. H.J.G.M. Crijns

Prof. dr. D.E.J. Linden

Prof. dr. F.E. de Leeuw (Radboud Universitair Medisch Centrum, Nijmegen)

Prof. dr. M. Muller (VU Medisch Centrum, Amsterdam)

Prof. dr. P.W. de Leeuw 


\section{Contents}

CHAPTER 1 General introduction

CHAPTER 2 Cerebral small vessel disease and risk of incident stroke, dementia and depression, and all-cause mortality: a systematic review and meta-analysis

CHAPTER 3 Type 2 diabetes, change in depressive symptoms over time, and cerebral small vessel disease - Longitudinal data of the AGESReykjavik Study

CHAPTER 4 Microvascular dysfunction is associated with worse cognitive performance: The Maastricht Study

CHAPTER 5 Associations of arterial stiffness with cognitive performance, and the role of microvascular dysfunction: The Maastricht Study

CHAPTER 6 Blood Pressure Variability And Microvascular Dysfunction: The Maastricht Study

CHAPTER 7 General discussion

Nederlandse samenvatting

Valorisation addendum

Dankwoord

Curriculum Vitae 


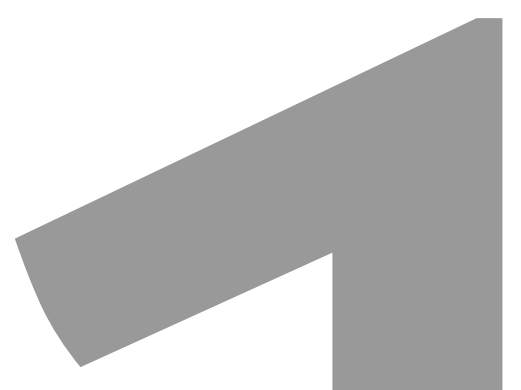

CHAPTER 1 
General introduction 



\section{General introduction}

Ageing is frequently characterized by age-related adverse cerebral outcomes such as dementia, late-life depression and stroke. ${ }^{1}$ The burden of these diseases is high and is likely to increase in future decades as a result of the ageing of the general population. 1 Identifying possible factors contributing to these diseases is needed for future prevention and treatment. One important factor may be the functional and structural deterioration of the microvasculature (i.e., microvascular dysfunction).

The microvasculature facilitates, among other things, oxygen and nutrient delivery to the brain, ${ }^{2}$ and microvascular dysfunction may thus be implicated in the development of adverse cerebral outcome. Microvascular dysfunction has been associated with various cardiovascular risk factors, ${ }^{3}$ and emerging evidence indicates that it may be implicated in the pathways between these risk factors and adverse cerebral outcome..$^{2-5}$ To elucidate the role of microvascular dysfunction in adverse cerebral outcome, this thesis aims to identify possible causes of microvascular dysfunction and to investigate whether microvascular dysfunction is associated with dementia, late-life depression and stroke. In addition, this thesis aims to evaluate whether microvascular dysfunction mediates the pathways between several cardiovascular risk factors and dementia, late-life depression and stroke.

\section{Microvasculature - structure and function}

The microvasculature is, in terms of surface area, the largest component of the vascular system (98\%) and includes all blood vessels with a diameter below 150-200 $\mu \mathrm{m} .{ }^{2}$ This network of blood vessels facilitates local blood perfusion, blood-tissue diffusion and haemostatic balance, ${ }^{6}$ which is needed for nutrient distribution and waste product collection in tissues. In addition, the microvasculature regulates blood pressure via vascular resistance. ${ }^{7}$ The microvasculature consists of three types of small vessels: arterioles, capillaries and venules. Arterioles regulate blood flow according to local metabolic demand using vasomotion. The capillaries consist of only a single endothelial layer, which helps facilitate exchange of substances with the interstitium, both via passive diffusion and active transcellular transport. The latter is especially important in brain tissue, because the uninterrupted endothelial lining making up the blood-brain barrier allows passive diffusion of only small molecules such as water and ions, as well as lipid-soluble molecules, whereas exchange of molecules such as glucose relies on active transcellular transport. ${ }^{8,9}$ Small venules collect capillary blood, regulate capillary pressure, and support recruitment of inflammatory cells (e.g., leukocytes) from blood into tissue., ${ }^{2} 10$

\section{Microvascular dysfunction - potential causes}

Microvascular dysfunction has been associated with cardiovascular risk factors such as arterial stiffening ${ }^{11}$ and type 2 diabetes. ${ }^{12,13}$ Arterial elasticity dampens cardiac pulsatile energy, which protects the microvasculature from high pulsatile damage. Arterial stiffening increases the pulsatile intensity flowing into the microvasculature, which induces a microvascular remodelling response and may cause microvascular damage directly. The remodelling response initially serves to limit the penetration of the pulsatile load into the microvasculature by raising vascular resistance, but may ultimately lead to maladaptive proliferation of the arteriolar wall. ${ }^{14}$ Type 2 diabetes may also induce 
microvascular dysfunction via various mechanisms, including hyperglycaemia, arterial stiffening, impaired insulin-dependent dilation, production of advanced glycation end products, increased oxidative stress and epigenetic changes. ${ }^{13}$ In addition to arterial stiffness and type 2 diabetes, other determinants of microvascular dysfunction, such as inflammatory processes, oxidative stress, hypertension, ageing and obesity, have been

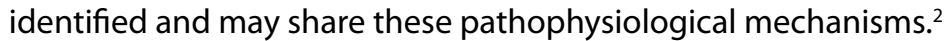

\section{Microvascular dysfunction - consequences: focus on the brain}

Prolonged injury to the microvasculature may result in structural and functional microvascular changes, including capillary rarefaction, glycocalyx degeneration, impaired capillary flow regulation, impaired arteriolar and venular dilation response, blood-brain barrier dysfunction, increased inflammatory response and procoagulant activation. ${ }^{5}$ 6, 15 These changes may lead to inefficient nutrient and oxygen extraction from the microcirculation ${ }^{6}$ and may thus threaten tissue function by lack of nutrients and hypoxia. The effects of microvascular dysfunction could be particularly detrimental to cerebral tissue due to its high microvascular blood flow and metabolic needs. The cerebral microvasculature is involved in the regulation of many processes that are important for cognitive function and mood regulation (i.e., cerebral perfusion, neurogenesis, neurovascular coupling, blood-brain barrier permeability and cerebral autoregulation). ${ }^{15}$ Impairment of these processes may lead to neuronal dysfunction and ischaemia, which could ultimately lead to lower cognitive performance and depression. ${ }^{11,15-18}$ In addition, acute and prolonged cerebral hypoperfusion and impaired haemostatic regulation may predispose to stroke.

\section{Microvascular dysfunction - markers}

Only a few organs can be used to measure microvascular function noninvasively. These measures include brain measures (magnetic resonance imaging features of cerebral small vessel disease); ${ }^{4}$ eye measures (flicker light-induced retinal arteriolar and venular dilation response); ${ }^{19}$ kidney measures (albuminuria); ${ }^{20}$ plasma biomarkers of microvascular dysfunction ${ }^{21}$ and skin measures (heat-induced skin hyperaemia). ${ }^{19}$ Cerebral small vessel disease features are closely linked to brain microvascular structure and evidence indicates that these features originate from cerebral microvascular dysfunction., 4, 6 To the extent that microvascular dysfunction is a generalised phenomenon, measures of microvascular dysfunction in other vascular beds such as the retina, kidney and skin, or plasma biomarkers of microvascular dysfunction may also reflect brain microvascular dysfunction. ${ }^{5,12}$

\section{Contribution of this thesis to current knowledge}

It has been hypothesised that cerebral small vessel disease is an important contributor to adverse cerebral outcome (i.e., dementia, depression and stroke) and increased mortality risk. ${ }^{3}$ However, systematic research on these possible consequences of cerebral small vessel disease is limited. Seven meta-analyses ${ }^{22-28}$ have examined the association of certain features of cerebral small vessel disease (i.e., white matter hyperintensities and cerebral microbleeds) and these outcomes. However, no meta-analysis on incident dementia, depression or stroke, or all-cause mortality has thus far been conducted for other features of cerebral small vessel disease (i.e., lacunes, perivascular spaces and total cerebral atrophy). Furthermore, no meta-analysis has evaluated the prognostic value of 
the presence of combined cerebral small vessel disease features. It is, however, important to investigate the effects of individual and combined cerebral small vessel disease features on incident dementia, depression and stroke, and all-cause mortality, because cerebral small vessel disease is highly prevalent in the general population, ${ }^{29}$ and timely intervention may help prevent or reduce progression of cerebral small vessel disease and these clinical outcomes.

In addition, cerebral small vessel disease is thought to mediate the association between type 2 diabetes and incident depression. ${ }^{17}$ In view of the increased risk of depression in type 2 diabetes, identifying factors that mediate this relation might help to prevent or treat type 2 diabetes-related depression. ${ }^{13,30}$ However, no previous study has investigated whether the association between type 2 diabetes and depressive symptoms is mediated by cerebral small vessel disease.

It has been hypothesised that cerebral small vessel disease reflects microvascular dysfunction, and that microvascular dysfunction contributes to cognitive decline and dementia. ${ }^{3}$ However, it is unknown whether other measures of microvascular dysfunction in various vascular beds, such as the retina, kidney and skin, or plasma biomarkers of microvascular dysfunction, contribute similarly., 12 Multiple measures of generalised microvascular dysfunction may, however, better determine cognitive function than a microvascular dysfunction measure in a single vascular bed, such as cerebral small vessel disease.

In this respect, generalised microvascular dysfunction may also mediate the association between greater arterial stiffness and worse cognitive function. Previous studies have shown an association between arterial stiffness and cognitive function. ${ }^{11,16,31-44}$ However, whether any association between aortic or carotid stiffness and worse cognitive performance is explained, or mediated, by microvascular dysfunction is unknown.

Finally, it has been hypothesised that greater blood pressure variability (i.e., greater fluctuations of blood pressure over time) may lead to microvascular dysfunction ${ }^{45,46}$ via increases in pulsatile pressure ${ }^{45}$ and sudden falls in blood pressure. ${ }^{46}$ Vascular beds of organs with low vascular impedance (i.e., the microvasculature of the brain, eyes and kidneys) may be particularly vulnerable, because pulsatile energy may penetrate deeply into these microvascular beds. ${ }^{45}$ However, no studies have investigated the association between blood pressure variability and measures of microvascular dysfunction in multiple vascular beds. ${ }^{47-49}$

\section{Cohort studies used in this thesis}

In this thesis, data of two cohort studies are used:The Age, Gene/Environment Susceptibility (AGES)-Reykjavik Study and The Maastricht Study. The AGES-Reykjavik Study is an observational population-based cohort study originating from the Reykjavik Study. ${ }^{50}$ The present thesis includes longitudinal data from 3,316 participants of the AGES-Reykjavik Study, who were examined from 2002 to 2006 and re-examined five years later, from 2007 to 2011. The Maastricht Study is an ongoing observational population-based cohort study that focuses on the aaetiology, pathophysiology, complications and comorbidities 
of type 2 diabetes and is characterized by an extensive phenotyping approach. ${ }^{51}$ The present thesis includes cross-sectional data from the 3,451 participants who completed the baseline survey between November 2010 and September 2013.

\section{Outline of this thesis}

Figure 1.1 summarizes the investigated associations in this thesis (see below).

In chapter two, we conducted a systematic review and meta-analysis on the association between various cerebral small vessel disease features and incident stroke, dementia and depression, and all-cause mortality. Additionally, we investigated the effect of presence of two or more individual cerebral small vessel disease features on these outcomes.

In chapter three, we investigated, in the AGES-Reykjavik study, the longitudinal association between baseline type 2 diabetes and change in depressive symptoms over time. In addition, we investigated whether any such association was mediated by cerebral small vessel disease.

In chapter four, we investigated, in The Maastricht Study, whether a composite score of various microvascular dysfunction measures was associated with worse cognitive performance.

In chapter five, we investigated, in The Maastricht Study, the associations between arterial stiffness and worse cognitive performance. In addition we investigated whether any such association is mediated by a composite score of various microvascular dysfunction measures.

In chapter six, we investigated, in The Maastricht Study, whether very short- to midterm blood pressure variability was associated with various microvascular dysfunction measures.

Finally, in chapter seven, we discussed the key findings of this thesis, their clinical implications and recommendations for future research. In addition, we addressed relevant methodological considerations. 


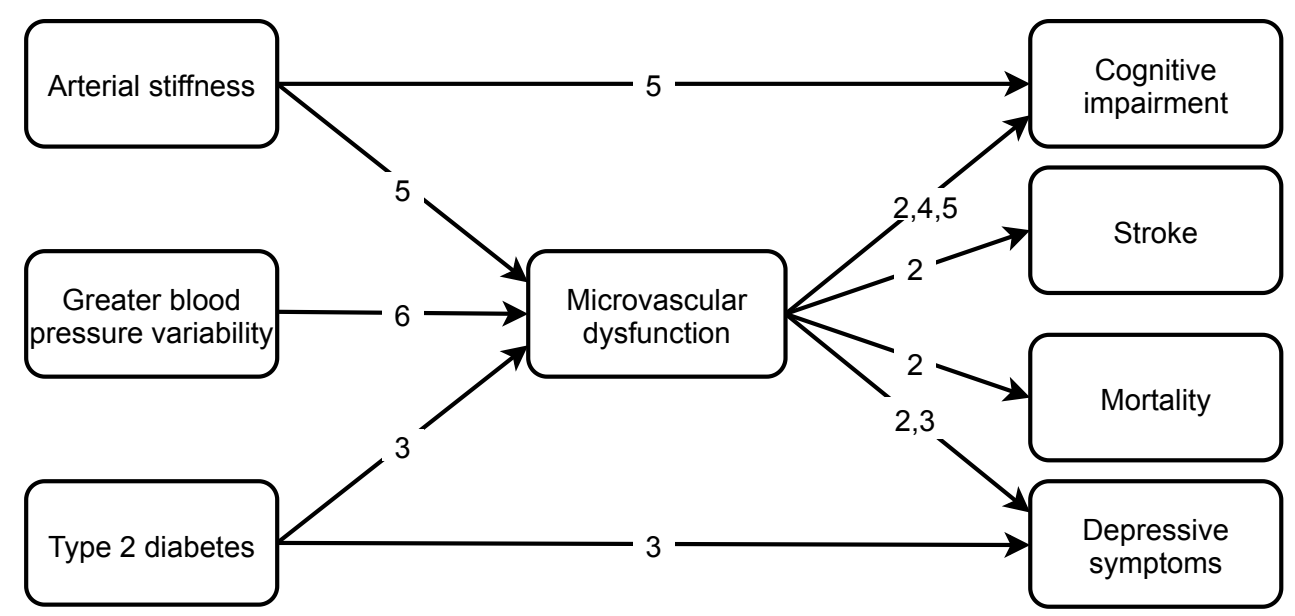

Figure 1.1. Schematic representation of the investigated associations in the present thesis. Numbers indicate corresponding chapters. 
1. Feigin VL, Lawes CM, Bennett DA and Anderson CS. Stroke epidemiology: a review of populationbased studies of incidence, prevalence, and case-fatality in the late 20th century. Lancet Neurol. 2003;2:43-53.

2. Houben A, Martens RJH and Stehouwer CDA. Assessing Microvascular Function in Humans from a Chronic Disease Perspective. J Am Soc Nephrol. 2017;28:3461-3472.

3. Pantoni L. Cerebral small vessel disease: from pathogenesis and clinical characteristics to therapeutic challenges. Lancet Neurol. 2010;9:689-701.

4. Wardlaw JM, Smith EE, Biessels GJ, Cordonnier C, Fazekas F, Frayne R, Lindley RI, O'Brien JT, Barkhof F, Benavente OR, Black SE, Brayne C, Breteler M, Chabriat H, Decarli C, de Leeuw FE, Doubal F, Duering M, Fox NC, Greenberg S, Hachinski V, Kilimann I, Mok V, Oostenbrugge R, Pantoni L, Speck O, Stephan BC, Teipel S, Viswanathan A, Werring D, Chen C, Smith C, van Buchem $M$, Norrving B, Gorelick PB, Dichgans $M$ and nEuroimaging STfRVco. Neuroimaging standards for research into small vessel disease and its contribution to ageing and neurodegeneration. Lancet Neurol. 2013;12:822-38.

5. Muris DM, Houben AJ, Schram MT and Stehouwer CD. Microvascular dysfunction: an emerging pathway in the pathogenesis of obesity-related insulin resistance. Rev Endocr Metab Disord. 2013;14:29-38.

6. Ostergaard L, Engedal TS, Moreton F, Hansen MB, Wardlaw JM, Dalkara T, Markus HS and Muir KW. Cerebral small vessel disease: Capillary pathways to stroke and cognitive decline. $J$ Cereb Blood Flow Metab. 2016;36:302-25.

7. Pries AR, Secomb TW and Gaehtgens P. Structural autoregulation of terminal vascular beds: vascular adaptation and development of hypertension. Hypertension. 1999;33:153-61.

8. Stamatovic SM, Johnson AM, Keep RF and Andjelkovic AV. Junctional proteins of the bloodbrain barrier: New insights into function and dysfunction. Tissue Barriers. 2016;4:e1154641.

9. Wilhelm I, Nyul-Toth A, Suciu M, Hermenean A and Krizbai IA. Heterogeneity of the blood-brain barrier. Tissue Barriers. 2016;4:e1143544.

10. Aird WC. Phenotypic heterogeneity of the endothelium: I. Structure, function, and mechanisms. Circ Res. 2007;100:158-73.

11. van Sloten TT, Protogerou AD, Henry RM, Schram MT, Launer LJ and Stehouwer CD. Association between arterial stiffness, cerebral small vessel disease and cognitive impairment: A systematic review and meta-analysis. Neurosci Biobehav Rev. 2015;53:121-30.

12. Umemura $T$, Kawamura $T$ and Hotta $N$. Pathogenesis and neuroimaging of cerebral large and small vessel disease in type 2 diabetes: A possible link between cerebral and retinal microvascular abnormalities. J Diabetes Investig. 2017;8:134-148.

13. Stehouwer CDA. Microvascular Dysfunction and Hyperglycemia: A Vicious Cycle With Widespread Consequences. Diabetes. 2018;67:1729-1741.

14. van Sloten TT, Mitchell GF, Sigurdsson S, van Buchem MA, Jonsson PV, Garcia ME, Harris TB, Henry RM, Levey AS, Stehouwer CD, Gudnason V and Launer LJ. Associations between arterial stiffness, depressive symptoms and cerebral small vessel disease: cross-sectional findings from the AGES-Reykjavik Study. J Psychiatry Neurosci. 2016;41:162-8.

15. De Silva TM and Faraci FM. Microvascular Dysfunction and Cognitive Impairment. Cell Mol Neurobiol. 2016;36:241-58.

16. Cooper LL, Woodard T, Sigurdsson S, van Buchem MA, Torjesen AA, Inker LA, Aspelund T, Eiriksdottir G, Harris TB, Gudnason V, Launer LJ and Mitchell GF. Cerebrovascular Damage Mediates Relations Between Aortic Stiffness and Memory. Hypertension. 2016;67:176-82. 
17. Alexopoulos GS, Meyers BS, Young RC, Campbell S, Silbersweig D and Charlson M. 'Vascular depression' hypothesis. Arch Gen Psychiatry. 1997;54:915-22.

18. van Sloten TT, Sigurdsson S, van Buchem MA, Phillips CL, Jonsson PV, Ding J, Schram MT, Harris TB, Gudnason V and Launer LJ. Cerebral Small Vessel Disease and Association With Higher Incidence of Depressive Symptoms in a General Elderly Population: The AGES-Reykjavik Study. Am J Psychiatry. 2015;172:570-8.

19. Sorensen BM, Houben AJ, Berendschot TT, Schouten JS, Kroon AA, van der Kallen CJ, Henry RM, Koster A, Sep SJ, Dagnelie PC, Schaper NC, Schram MT and Stehouwer CD. Prediabetes and Type 2 Diabetes Are Associated With Generalized Microvascular Dysfunction: The Maastricht Study. Circulation. 2016;134:1339-1352.

20. Martens RJ, Henry RM, Houben AJ, van der Kallen CJ, Kroon AA, Schalkwijk CG, Schram MT, Sep SJ, Schaper NC, Dagnelie PC, Muris DM, Gronenschild EH, van der Sande FM, Leunissen KM, Kooman JP and Stehouwer CD. Capillary Rarefaction Associates with Albuminuria: The Maastricht Study. J Am Soc Nephrol. 2016;27:3748-3757.

21. van Sloten TT, Schram MT, Adriaanse MC, Dekker JM, Nijpels G, Teerlink T, Scheffer PG, Pouwer F, Schalkwijk CG, Stehouwer CD and Henry RM. Endothelial dysfunction is associated with a greater depressive symptom score in a general elderly population: the Hoorn Study. Psychol Med. 2014;44:1403-16.

22. Debette $\mathrm{S}$ and Markus HS. The clinical importance of white matter hyperintensities on brain magnetic resonance imaging: systematic review and meta-analysis. BMJ. 2010;341:c3666.

23. Charidimou A, Shams S, Romero JR, Ding J, Veltkamp R, Horstmann S, Eiriksdottir G, van Buchem MA, Gudnason V, Himali JJ, Gurol ME, Viswanathan A, Imaizumi T, Vernooij MW, Seshadri S, Greenberg SM, Benavente OR, Launer LJ, Shoamanesh A and International M-MI. Clinical significance of cerebral microbleeds on MRI: A comprehensive meta-analysis of risk of intracerebral hemorrhage, ischemic stroke, mortality, and dementia in cohort studies (v1). Int J Stroke. 2018:1747493017751931.

24. Wang L, Leonards CO, Sterzer P and Ebinger M. White matter lesions and depression: a systematic review and meta-analysis. J Psychiatr Res. 2014;56:56-64.

25. van Agtmaal MJM, Houben A, Pouwer F, Stehouwer CDA and Schram MT. Association of Microvascular Dysfunction With Late-Life Depression: A Systematic Review and Meta-analysis. JAMA Psychiatry. 2017.

26. Wang DN, Hou XW, Yang BW, Lin Y, Shi JP and Wang N. Quantity of Cerebral Microbleeds, Antiplatelet Therapy, and Intracerebral Hemorrhage Outcomes: A Systematic Review and Metaanalysis. J Stroke Cerebrovasc Dis. 2015;24:2728-37.

27. Charidimou A, Kakar P, Fox $Z$ and Werring DJ. Cerebral microbleeds and recurrent stroke risk: systematic review and meta-analysis of prospective ischemic stroke and transient ischemic attack cohorts. Stroke. 2013;44:995-1001.

28. Charidimou A, Imaizumi T, Moulin S, Biffi A, Samarasekera N, Yakushiji Y, Peeters A, Vandermeeren Y, Laloux P, Baron JC, Hernandez-Guillamon M, Montaner J, Casolla B, Gregoire SM, Kang DW, Kim JS, Naka H, Smith EE, Viswanathan A, Jager HR, Al-Shahi Salman R, Greenberg SM, Cordonnier $C$ and Werring DJ. Brain hemorrhage recurrence, small vessel disease type, and cerebral microbleeds: A meta-analysis. Neurology. 2017;89:820-829. 
29. Wardlaw JM, Smith EE, Biessels GJ, Cordonnier C, Fazekas F, Frayne R, Lindley RI, O'Brien JT, Barkhof F, Benavente OR, Black SE, Brayne C, Breteler M, Chabriat H, Decarli C, de Leeuw FE, Doubal F, Duering M, Fox NC, Greenberg S, Hachinski V, Kilimann I, Mok V, Oostenbrugge R, Pantoni L, Speck O, Stephan BC, Teipel S, Viswanathan A, Werring D, Chen C, Smith C, van Buchem M, Norrving B, Gorelick PB and Dichgans M. Neuroimaging standards for research into small vessel disease and its contribution to ageing and neurodegeneration. Lancet Neurol. 2013;12:822-38.

30. Lustman PJ and Clouse RE. Depression in diabetic patients: the relationship between mood and glycemic control. J Diabetes Complications. 2005;19:113-22.

31. Taniguchi Y, Fujiwara Y, Nofuji Y, Nishi M, Murayama H, Seino S, Tajima R, Matsuyama $Y$ and Shinkai S. Prospective Study of Arterial Stiffness and Subsequent Cognitive Decline Among Community-Dwelling Older Japanese. J Epidemiol. 2015;25:592-9.

32. Hajjar I, Goldstein FC, Martin GS and Quyyumi AA. Roles of Arterial Stiffness and Blood Pressure in Hypertension-Associated Cognitive Decline in Healthy Adults. Hypertension. 2016;67:171-5.

33. Tsao CW, Himali JJ, Beiser AS, Larson MG, DeCarli C, Vasan RS, Mitchell GF and Seshadri S. Association of arterial stiffness with progression of subclinical brain and cognitive disease. Neurology. 2016;86:619-26.

34. Meyer ML, Palta P, Tanaka H, Deal JA, Wright J, Knopman DS, Griswold ME, Mosley TH and Heiss G. Association of Central Arterial Stiffness and Pressure Pulsatility with Mild Cognitive Impairment and Dementia: The Atherosclerosis Risk in Communities Study-Neurocognitive Study (ARIC-NCS). J Alzheimers Dis. 2017;57:195-204.

35. Muela HCS, Costa-Hong VA, Yassuda MS, Moraes NC, Memoria CM, Machado MF, Bor-Seng-Shu E, Nogueira RC, Mansur AJ, Massaro AR, Nitrini R, Macedo TA and Bortolotto LA. Higher arterial stiffness is associated with lower cognitive performance in patients with hypertension. $J$ Clin Hypertens (Greenwich). 2018;20:22-30.

36. Rouch L, Cestac P, Sallerin B, Andrieu S, Bailly H, Beunardeau M, Cohen A, Dubail D, Hernandorena I, Seux ML, Vidal JS and Hanon O. Pulse Wave Velocity Is Associated With Greater Risk of Dementia in Mild Cognitive Impairment Patients. Hypertension. 2018;72:1109-1116.

37. Palta P, Sharrett AR, Wei J, Meyer ML, Kucharska-Newton A, Power MC, Deal JA, Jack CR, Knopman D, Wright J, Griswold M, Tanaka H, Mosley TH and Heiss G. Central Arterial Stiffness Is Associated With Structural Brain Damage and Poorer Cognitive Performance: The ARIC Study. J Am Heart Assoc. 2019;8:e011045.

38. Pase MP, Beiser A, Himali JJ, Tsao C, Satizabal CL, Vasan RS, Seshadri S and Mitchell GF. Aortic Stiffness and the Risk of Incident Mild Cognitive Impairment and Dementia. Stroke. 2016;47:2256-61.

39. Huck DM, Hanna DB, Rubin LH, Maki P, Valcour V, Springer G, Xue X, Lazar J, Hodis HN, Anastos K, Kaplan RC and Kizer JR. Carotid Artery Stiffness and Cognitive Decline Among Women With or at Risk for HIV Infection. J Acquir Immune Defic Syndr. 2018;78:338-347.

40. DuBose LE, Voss MW, Weng TB, Kent JD, Dubishar KM, Lane-Cordova A, Sigurdsson G, Schmid P, Barlow PB and Pierce GL. Carotid beta-stiffness index is associated with slower processing speed but not working memory or white matter integrity in healthy middle-aged/older adults. J Appl Physiol (1985). 2017;122:868-876.

41. Lim SL, Gao Q, Nyunt MS, Gong L, Lunaria JB, Lim ML, Ling A, Lam CS, Richards AM, Ling LH and $\mathrm{Ng}$ TP. Vascular Health Indices and Cognitive Domain Function: Singapore Longitudinal Ageing Studies. J Alzheimers Dis. 2016;50:27-40. 
42. Poels MM, van Oijen M, Mattace-Raso FU, Hofman A, Koudstaal PJ, Witteman JC and Breteler MM. Arterial stiffness, cognitive decline, and risk of dementia: the Rotterdam study. Stroke. 2007;38:888-92.

43. Tarumi T, Gonzales MM, Fallow B, Nualnim N, Pyron M, Tanaka H and Haley AP. Central artery stiffness, neuropsychological function, and cerebral perfusion in sedentary and endurancetrained middle-aged adults. J Hypertens. 2013;31:2400-9.

44. Geijselaers SL, Sep SJ, Schram MT, van Boxtel MP, van Sloten TT, Henry RM, Reesink KD, Kroon AA, Koster A, Schaper NC, Dagnelie PC, van der Kallen CJ, Biessels GJ and Stehouwer CD. Carotid stiffness is associated with impairment of cognitive performance in individuals with and without type 2 diabetes. The Maastricht Study. Atherosclerosis. 2016;253:186-193.

45. Mitchell GF. Effects of central arterial aging on the structure and function of the peripheral vasculature: implications for end-organ damage. J Appl Physiol (1985). 2008;105:1652-60.

46. Rothwell PM. Limitations of the usual blood-pressure hypothesis and importance of variability, instability, and episodic hypertension. Lancet. 2010;375:938-48.

47. Goldstein IB, Bartzokis G, Guthrie D and Shapiro D. Ambulatory blood pressure and the brain: a 5-year follow-up. Neurology. 2005;64:1846-52.

48. Gunstad J, Cohen RA, Tate DF, Paul RH, Poppas A, Hoth K, Macgregor KL and Jefferson AL. Blood pressure variability and white matter hyperintensities in older adults with cardiovascular disease. Blood Press. 2005;14:353-8.

49. Madden JM, O'Flynn AM, Dolan E, Fitzgerald AP and Kearney PM. Short-term blood pressure variability over $24 \mathrm{~h}$ and target organ damage in middle-aged men and women. $J$ Hum Hypertens. 2015;29:719-25.

50. Harris TB, Launer LJ, Eiriksdottir G, Kjartansson O, Jonsson PV, Sigurdsson G, Thorgeirsson G, Aspelund T, Garcia ME, Cotch MF, Hoffman HJ and Gudnason V. Age, Gene/Environment Susceptibility-Reykjavik Study: multidisciplinary applied phenomics. Am J Epidemiol. 2007;165:1076-87.

51. Schram MT, Sep SJ, van der Kallen CJ, Dagnelie PC, Koster A, Schaper N, Henry RM and Stehouwer $\mathrm{CD}$. The Maastricht Study: an extensive phenotyping study on determinants of type 2 diabetes, its complications and its comorbidities. Eur J Epidemiol. 2014;29:439-51. 


\section{CHAPTER 2}




\section{Cerebral small vessel disease and risk of incident stroke, dementia and depression, and all-cause mortality: a systematic review and meta- analysis}

SP Rensma, ${ }^{*}$ TT van Sloten,* LJ Launer, CDA Stehouwer

*These authors contributed equally to the manuscript 


\begin{abstract}
MRI features of cerebral small vessel disease, i.e. white matter hyperintensities, lacunes, microbleeds, perivascular spaces, and cerebral atrophy, may be associated with clinical events, but the strength of these associations remains unclear. We conducted a systematic review and meta-analysis on the association between these features and incident ischaemic and haemorrhagic stroke, all-cause dementia and depression, and allcause mortality. For the association with stroke, 36 studies were identified (number of individuals/events $[n]=38,432 / 4,136)$, for dementia 28 ( $n=16,458 / 1,709)$, for depression nine $(n=9,538 / 1,746)$, and for mortality $28(n=23,031 / 2,558)$. Only two studies evaluated perivascular spaces; these results were not pooled. Pooled analyses showed that all other features were associated with all outcomes (hazard ratios ranged 1.22-2.72). Combinations of two features were more strongly associated with stroke than any individual feature. Individual features and combinations of CSVD features are strongly associated with incident ischaemic and haemorrhagic stroke, all-cause dementia and depression, and all-cause mortality. If these associations are causal, the strength of these associations suggests that a substantial burden of disease is attributable to CSVD.
\end{abstract}




\section{Introduction}

Cerebral small vessel disease (CSVD) features include white matter hyperintensities (WMHs) and lacunes of presumed vascular origin, cerebral microbleeds (CMBs), perivascular spaces, and total cerebral atrophy. ${ }^{1}$ These features are related to ageing and vascular risk factors, ${ }^{2}$ and are highly prevalent. ${ }^{1}$ CSVD has been suggested to be an important source of morbidity associated with ischaemic and haemorrhagic stroke, dementia, and depression, ${ }^{2}$ and CSVD may increase mortality risk. ${ }^{2}$

However, systematic evidence for the importance of MRI CSVD features is limited. For instance, no meta-analysis for incident stroke, dementia, depression, or mortality has been conducted for lacunes, perivascular spaces, or total cerebral atrophy. Two meta-analyses, ${ }^{4}$ have examined the association of only $\mathrm{WMHs}^{3}$ or microbleeds ${ }^{4}$ and incident stroke and dementia, and mortality. Of two meta-analyse $\mathrm{s}^{5,6}$ on WMHs and incident depression, only one $^{6}$ found an association. Three other meta-analyses ${ }^{7-9}$ have examined the association between CMBs and incident stroke. However, these studies included only individuals with prior stroke, ${ }^{7-9}$ and evaluated only haemorrhagic stroke., ${ }^{7}$ Finally, no meta-analysis has evaluated the predictive value of presence of combined CSVD features.

We did a systematic review and meta-analysis on the association between CSVD features, including WMHs, lacunes, CMBs, perivascular spaces, and total cerebral atrophy, and incident ischaemic and haemorrhagic stroke, all-cause dementia and depression, and allcause mortality. Additionally, we investigated the effect of two or more individual CSVD features combined on any of these outcomes. 


\section{Methods}

This review was prepared according to the meta-analyses of observational studies in epidemiology (MOOSE) checklist (Appendix A)..$^{10}$ This protocol was published in PROSPERO (CRD42016038521) (Appendix B). ${ }^{11}$

\section{Evaluation procedure}

Two independent investigators (SR and TVS) selected all relevant studies based on title and abstract, retrieved selected full texts, performed eligibility assessments, extracted data, and assessed risk of bias. Disagreement between the reviewers was resolved by consensus. A third independent reviewer (CS) solved any persisting disagreements.

\section{Information sources and search}

We identified relevant studies through a search of MEDLINE and Embase, from inception to March 2017 (for search terms see Tables S1.1-S1.4). We applied no language restrictions. We hand-searched reference lists of eligible studies and related meta-analyses to identify further relevant studies.

\section{Eligibility criteria and study selection}

We included prospective cohort studies in adults (with and without a history of stroke or depression) that evaluated the association between baseline MRI features of CSVD and incident ischaemic or haemorrhagic stroke, dementia or depression, or all-cause mortality. For CSVD, we included WMHs and lacunes of presumed vascular origin, CMBs, perivascular spaces, and total cerebral atrophy. ${ }^{1}$ Studies were also included when they did not specifically assess lacunes but did assess subcortical infarcts (infarcts in the deep brain region not extending into the cortex) and silent infarcts (infarcts detected in individuals without prior stroke), which include lacunes. ' We excluded studies with a sample size $\leq 50$, a mean follow-up $<12$ months, or including only CSVD occurring in longterm inflammatory or neurodegenerative conditions (e.g. multiple sclerosis or Parkinson's disease). In the case of multiple publications from the same cohort, we included the most up-to-date or comprehensive information.

\section{Data collection process}

We used a predesigned extraction form to collect information on the following items: study size; follow-up duration; age; sex; prior stroke; baseline cognitive performance; prior depression; MRI characteristics; definitions of CSVD features; outcome definitions; number of events; statistical analysis used; reported risk estimates; and variables adjusted for in the analyses. Any relevant missing information was requested from corresponding authors.

\section{Risk of bias assessment}

We evaluated risk of bias with the Newcastle-Ottawa scale (NOS) (Appendix C).

\section{Variable definition}

We used definitions of CSVD features and outcomes as reported in the original published papers. Incident stroke included fatal and non-fatal cerebral infarction and intracerebral haemorrhage. Incident dementia included Alzheimer's disease, presumed vascular 
dementia and dementia not further specified. Incident depression subtype was not specified by any of the included studies. For stroke and depression, we included both first and recurrent events.

\section{Statistical analysis}

We pooled results for each CSVD feature when $\geq$ three studies were available with the same outcome. We pooled hazard ratios (HRs) using the random effects inverse variance method. We included the fully adjusted HR (but without adjustments for other CSVD features) (if available). HRs were reported by 49 studies, whereas fifteen studies reported results as odds ratios or relative risks (Table S3); these were treated as HRs.

For WMHs, we separately pooled dichotomous and continuous measures. For dichotomous measures, we compared the HR for a higher vs. a lower category. When $\geq$ two categories for WMHs were present, we selected the two categories with the highest number of participants and events. For total cerebral atrophy, we pooled only studies using a continuous scale (as percentage total intracranial volume or raw volume), as there were few data with atrophy measured dichotomously. We standardized continuous measures per standard deviation. For studies that reported only deep or periventricular WMHs instead of total WMHs, we included the results for periventricular WMHs in the main analysis, because periventricular WMHs more closely represent total WMHs. ${ }^{12}$ Similarly, for studies that reported only deep or lobar CMBs instead of total CMBs, we included the results for deep CMBs in the main analysis, because deep CMBs more closely represent total $\mathrm{CMBs}^{8}$ and are more strongly related to hypertension. ${ }^{1}$ For analyses with combined presence of $\geq$ two individual CSVD features as the determinant, we pooled HRs for any combination of individual features.

We evaluated the level of statistical heterogeneity across pooled studies per CSVD feature using the $\mathrm{I}^{2}$ test. ${ }^{13}$ High statistical heterogeneity was defined as $I^{2}>60 \%$. We assessed potential publication bias using funnel plots and, when $\geq$ ten studies were included in the analysis, by Egger's test. We corrected for the potential effect of significant funnel plot asymmetry using the trim and fill approach. ${ }^{14}$

We did several pre-specified sensitivity analyses. We repeated analyses by subtype of disease (ischaemic or haemorrhagic stroke, and Alzheimer's disease or presumed vascular dementia); using only population-based cohort studies; using only studies with high-risk populations (e.g. individuals with prior stroke or other cardiovascular disease, mild cognitive impairment, prior depression, or chronic kidney disease); including only high-quality studies (defined as NOS score >four); using only studies that measured WMHs on an observerrated semi-quantitative scale; using only studies that measured WMHs on an automated quantitative scale; replacing the results for periventricular WMHs with those for deep WMHs; replacing the risk estimates for deep CMBs with those for lobar CMBs; and replacing adjusted risk estimates with unadjusted risk estimates. In addition, we did several post hoc analyses, including repeating the analyses using only studies that included individuals with prior stroke. Other post hoc analyses are described in the supplemental material (Table S2).

Analyses were done with Review Manager 5.3 and R 3.2.3. 


\section{Results}

\section{Selection process and study characteristics}

Figure 1 shows the selection process of included studies. In the systematic review, we included 36 studies for ischaemic or haemorrhagic stroke ( $n=38,432 / 4,136$ individuals/ events), 28 for all-cause dementia $(n=16,458 / 1,709)$, nine for depression $(n=9,538 / 1,746)$, and 28 for all-cause mortality $(n=23,031 / 2,558)$. Table S3 shows the number of included studies in the pooled analyses and per CSVD feature. Only two studies evaluated perivascular spaces; these results were not pooled (Table S3). Full study characteristics and NOS scores are provided as supplemental material (Tables S4.1-S4.4 and S5.1-S5.4, respectively).

\section{Stroke}

All CSVD features were statistically significantly associated with incident ischaemic or haemorrhagic stroke, with moderate to substantial heterogeneity across studies pooled per CSVD feature (Figure 2, Figures S1.1a-S1.1e). Of all included studies, 95\% found a positive association between any feature and stroke (Figures S1.1a-S1.1e). One study in the systematic review could not be included in the pooled analysis because no risk estimates were presented (Table S3). This study reported a statistically significant association between WMHs and stroke.

For analyses with stroke subtype as the outcome (ischaemic or haemorrhagic), sufficient studies were available for WMHs on a dichotomous scale (14 studies) and CMBs (10 studies) (Table S3). For WMHs, the HRs were qualitatively similar for the risk of ischaemic and haemorrhagic stroke (Figure S2.1). For CMBs, the risk of haemorrhagic stroke was higher than that of ischaemic stroke (Figure S2.4).

\section{Dementia}

All features, except CMBs, were statistically significantly associated with incident allcause dementia, with moderate to substantial heterogeneity across studies pooled per CSVD feature (Figure 2, Figures S1.2a-S1.2e). Of all included studies, $80 \%$ found a positive association between any feature and dementia (Figures S1.2a-S1.2e). 12 studies were excluded from the pooled analysis (Table S3), of which six (four on WMHs, one on perivascular spaces and one on total cerebral atrophy) found a statistically significant association with dementia.

For analyses with dementia subtype as the outcome (Alzheimer's disease or presumed vascular dementia), sufficient studies were available for WMHs on a dichotomous scale (9 studies) (Table S3). For WMHs, the risk of presumed vascular dementia was higher than that of Alzheimer's disease (Figure S2.1).

\section{Depression}

WMHs on a dichotomous scale and total cerebral atrophy were statistically significantly associated with incident depression, with low to substantial heterogeneity across studies pooled per CSVD feature (Figure 2, Figures S1.3a-S1.3c). Of all included studies, 94\% found a positive association between any feature and depression (Figures S1.3a-S1.3c). Four studies were excluded from the pooled analysis (Table S3), of which one, on lacunes, found a statistically significant association with depression. 


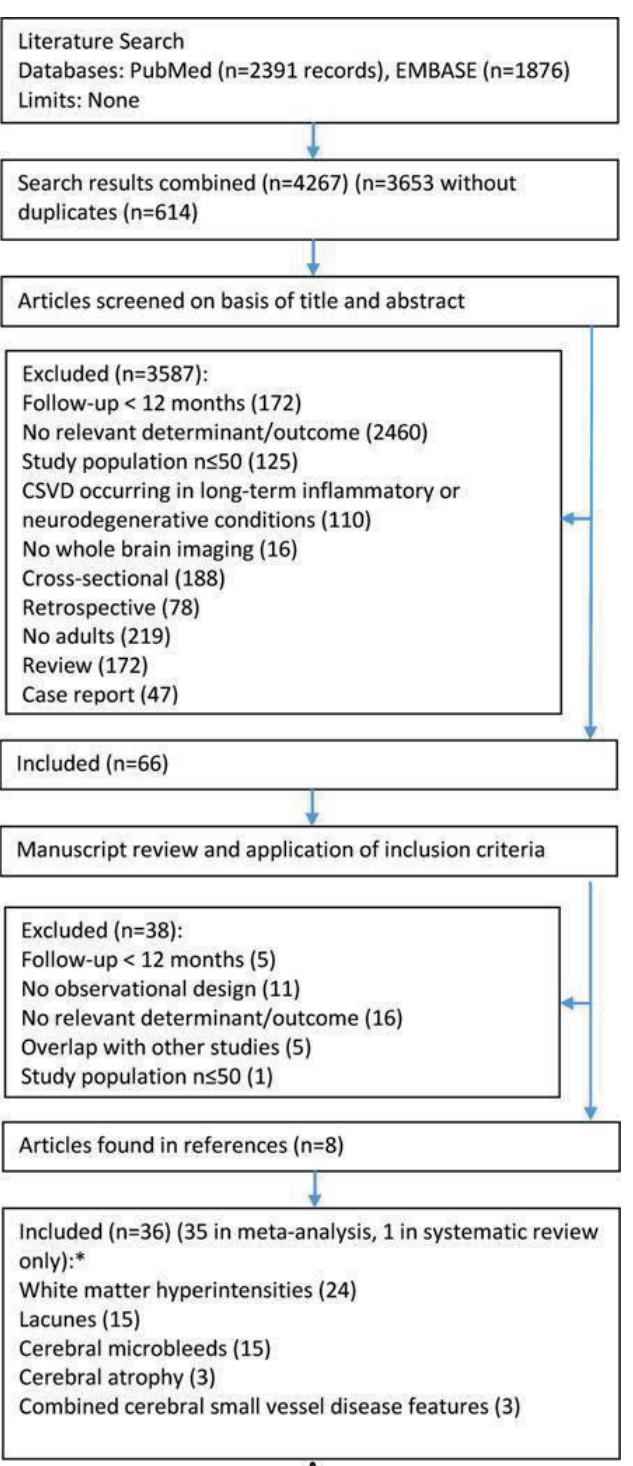

A

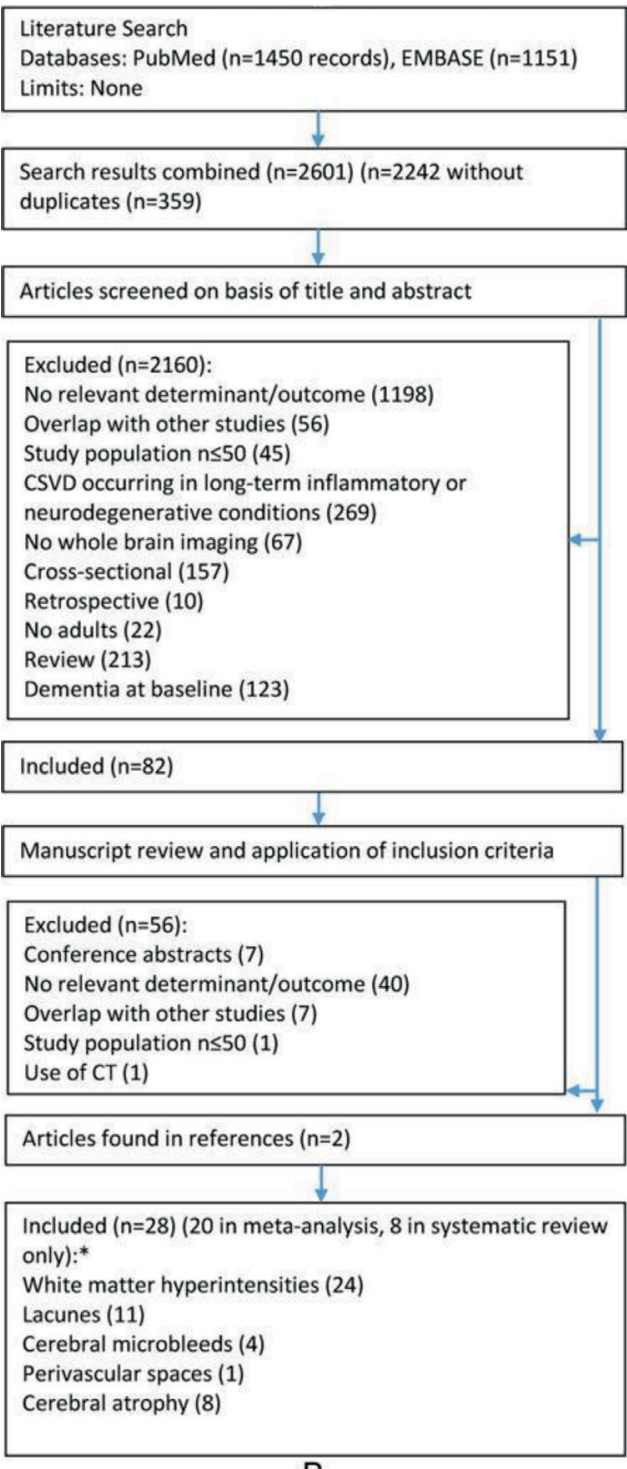

B

Figure 1. $A \& B$

\section{All-cause mortality}

WMHs, lacunes and CMBs were statistically significantly associated with all-cause mortality, with low to moderate heterogeneity across studies pooled per CSVD feature (Figure 2, Figures S1.4a-S1.4d). Of all included studies, 94\% found a positive association between any feature and all-cause mortality (Figures S1.4a-S1.4d). All four studies that were excluded from the pooled analysis (Table S3) showed a statistically significant association with all-cause mortality. 


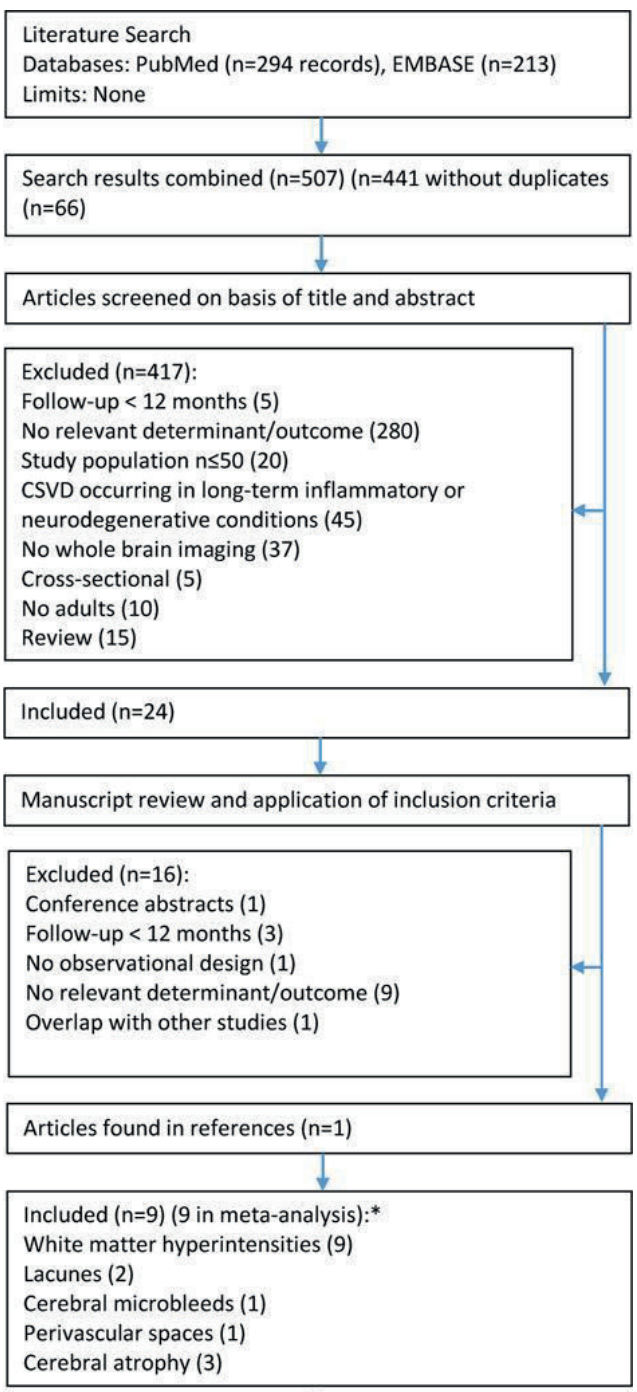

\section{C}

Literature Search

Databases: PubMed ( $n=769$ records), EMBASE $(n=504)$

Limits: None

Limits: None

Search results combined $(n=1273)(n=1201$ without

duplicates $(n=72)$

\section{Articles screened on basis of title and abstract}

Excluded $(n=1166)$ :

Follow-up < 12 months (17)

No relevant determinant/outcome (828)

Study population $n \leq 50$ (51)

CSVD occurring in long-term inflammatory or

neurodegenerative conditions (84)

Retrospective (17)

No adults (101)

Review (68)

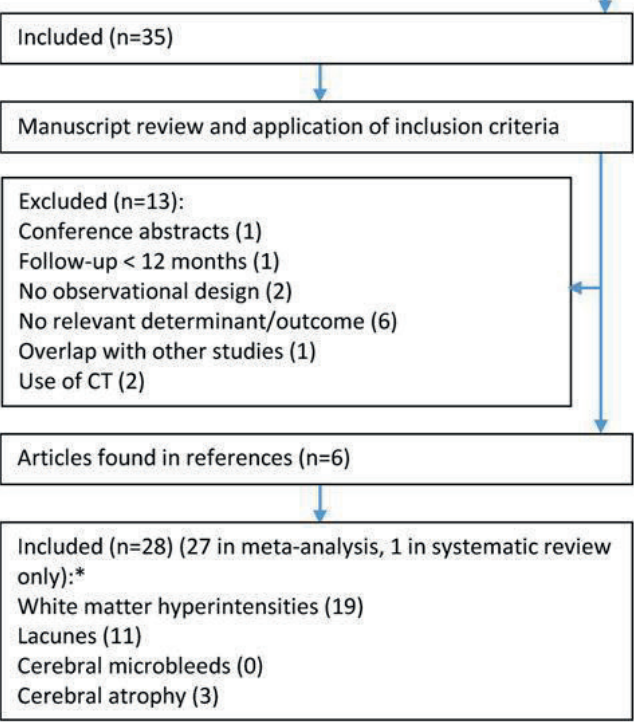

Cerebral atrophy (3)

Figure 1. $C \& D$ 


\section{Combinations of CSVD features}

For incident stroke, two studies examined the combined effect of WMHs and lacunes and one of WMHs and CMBs (Table S3). No study examined the combined effect of $\geq$ three individual features, or examined the association between multiple individual features combined and any of the other outcomes. The combination of two CSVD features was statistically significantly associated with incident ischaemic and haemorrhagic stroke (Figure 2, Figure S1.1f). This risk was higher than the risk of any individual CSVD feature (Figure 2).

\section{Sources of heterogeneity}

Substantial heterogeneity $\left(1^{2}>60 \%\right)$ was present in four of the 17 main analyses (Figure 2 ). Exploration of heterogeneity showed that more concordance was present in analyses with only high-quality studies and with only studies that measured WMHs on an automated quantitative scale (Tables S6.1-S6.4). Results of these analyses were qualitatively similar to the results of the main analyses.

\section{Potential publication bias}

Significant funnel plot asymmetry was found for analyses with stroke (for WMHs on a dichotomous scale, lacunes and $\mathrm{CMBs}$ ) and all-cause mortality (for WMHs on a dichotomous scale) (Table S7, Figure S3). We used the trim and fill approach to adjust the estimates for funnel plot asymmetry. The adjusted estimates were qualitatively similar to those in the main analyses (Table S8).

\section{Sensitivity analyses}

Results were quantitatively similar when analyses were repeated using only populationbased cohort studies; using only high-quality studies; replacing the risk estimates for periventricular WMHs with those for deep WMHs; replacing the risk estimates for deep CMBs with those for lobar CMBs; and replacing adjusted risk estimates with unadjusted risk estimates (Figures S2.1-S2.5). In high-risk populations, the associations between WMHs and lacunes and all-cause dementia were weaker and not statistically significant (Figures S2.1, S2.3). For all studied outcomes, except for depression, the strength of the association was higher for WMHs measured on an automated quantitative scale than for WMHs measured on an observer rated semi-quantitative scale (Figure S2.1). Finally, in the post hoc analyses of studies with only stroke cases, WMHs, lacunes and microbleeds were associated with incident recurrent stroke, and WMHs and microbleeds, but not lacunes, were associated with higher mortality (Figure S2.1-2.5). The results of the other post hoc analyses are provided in the supplemental material (Figures S2.1-S2.5). 


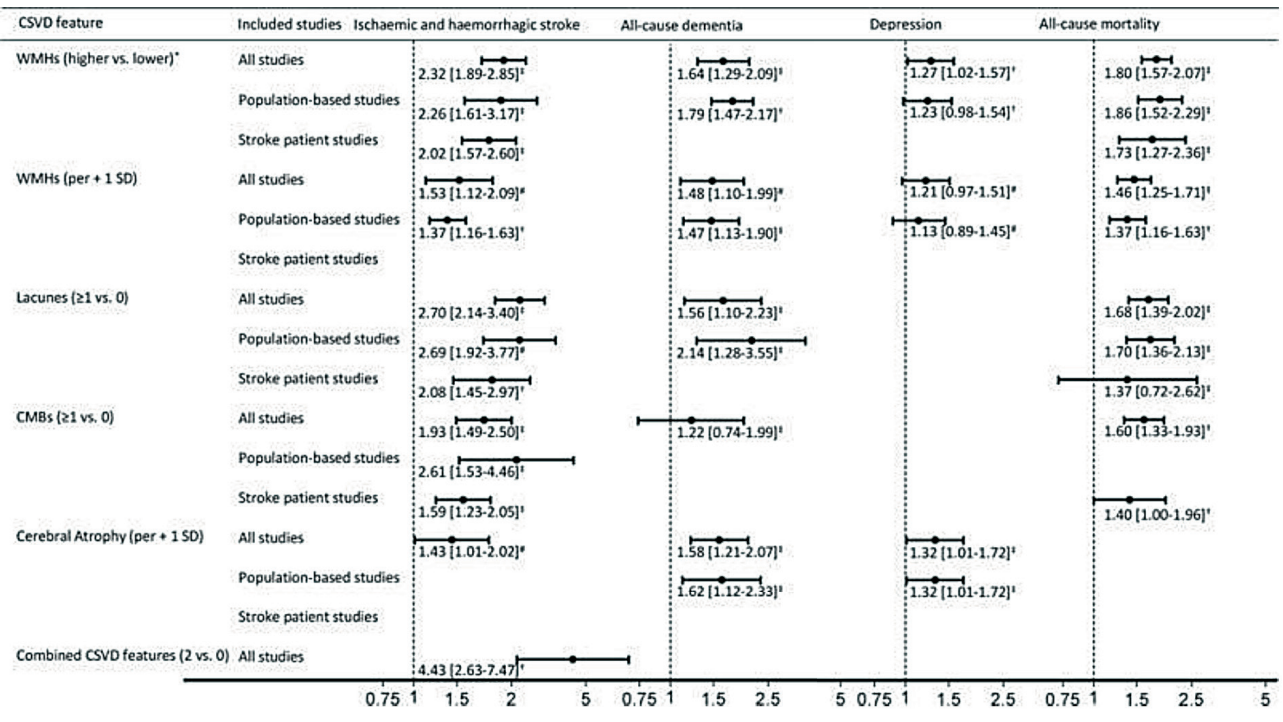

Figure 2. Pooled hazard ratios ( $95 \%$ confidence intervals) for the association between MRI features of cerebral small vessel disease (CSVD) and incident ischaemic and haemorrhagic stroke, all-cause dementia and depression, and all-cause mortality. ${ }^{*}$ Higher vs. lower as defined by the individual studies. ${ }^{+}$Heterogeneity, $\left.\right|^{2}<30 \%,\left.{ }^{\ddagger}\right|^{2}=$ $30-60 \%, " \|^{2}>60 \%$. For the forest plots of each pooled analysis, see supplemental material, Figures S1.1-S1.4. Abbreviations: $\mathrm{WMHs}=$ white matter hyperintensities; $\mathrm{SD}=$ standard deviation

\section{Discussion}

\section{Main findings}

This systematic review and meta-analysis shows that various individual CSVD features are consistently and strongly associated with a higher incidence of ischaemic and haemorrhagic stroke, all-cause dementia and depression, and all-cause mortality. In addition, the combination of two CSVD features is more strongly associated with incident stroke than individual features alone. The combined effect of multiple CSVD features could not be investigated for all-cause dementia or depression, or all-cause mortality. This indicates that, if these associations are causal, the strength of these associations suggests that a substantial burden of disease is attributable to CSVD.

Our findings agree with and extend previous meta-analyses ${ }^{3-9}$ on CSVD. These studies evaluated only $\mathrm{WMHs}^{3,5,6}$ or only $\mathrm{CMBs}^{4,7-9}$ and found an association with incident stroke, dementia, depression or mortality. The present meta-analysis is the first to evaluate the effect of various CSVD features in different study populations on multiple clinical outcomes. 


\section{Methodologic considerations}

Some methodological issues warrant consideration. First, the associations with all outcomes were consistent across the different MRI features. Our analyses suggest individual MRI features of CSVD may not carry a differential risk for a specific clinical event, but may reflect disease severity, consistent with the hypothesis that these features are manifestations of the same disease. ${ }^{1}$ For instance, cerebral microbleeds were associated not only with incident intracerebral haemorrhage, but also with ischaemic stroke. In accordance, a recent study among individuals with CADASIL ${ }^{15}$ found that presence of cerebral microbleeds was associated with ischaemic stroke. Second, there was substantial quantitative heterogeneity in four of the 17 main analyses. More concordance was present among high-quality studies and among studies that measured WMHs on an automated quantitative scale. Third, potential publication bias was present in four of the 17 main analyses. However, additional analyses suggested that this bias may have led to only a slight overestimation of true effect estimates (adjusted estimates calculated using the trim and fill approach were qualitatively similar to the results of the main analysis). Fourth, only two studies evaluated perivascular spaces, and only three studies evaluated the effect of combinations of CSVD features. Evidence for associations between perivascular spaces or combined CSVD features and the outcomes studied is, therefore, weak, and this requires further study. Fifth, effect estimates for stroke were higher than for dementia and depression, and mortality. The assessment of dementia and depression may have a larger measurement error than the assessment of stroke or death. Furthermore, other non-vascular factors may lead to dementia, depression, or greater mortality. Sixth, the association between CMBs and incident dementia was not statistically significant. This needs to be interpreted cautiously, because only four studies with relatively small samples were included in this analysis. Finally, results of most sensitivity analyses were consistent with our main analyses, with few exceptions. For CMBs, risk of haemorrhagic stroke was higher than for ischaemic stroke, which is in accordance with a previous metaanalysis. ${ }^{8}$ This may be due to direct enlargement of CMBs transforming to intracranial haemorrhage. ${ }^{16}$ In addition, in high-risk populations, the associations between WMHs and lacunes and all-cause dementia were weaker than those in the population based studies. Similarly, in stroke populations, the associations between MWHs, lacunes and microbleeds and (recurrent) stroke and mortality were weaker. This may be due to the lower quality and smaller sample size of studies done in high-risk populations (only three of these 12 studies had a NOS score > four and their mean sample size was 209) and stroke populations (four of these 21 studies had a NOS score $>$ four and their mean sample size was 861 ) as compared to population-based studies (11 of these 12 studies had a NOS score $>$ four and their mean sample size was 1,484).

\section{Underlying mechanisms}

CSVD may lead to stroke, dementia, depression, and mortality through multiple mechanisms. First, CSVD may be a direct cause of stroke, dementia, and depression. Notably, MRI features of CSVD may reflect poor cerebral blood flow regulation, predisposing to ischemia (e.g. due to chronic cerebral hypoperfusion), which may lead to stroke. ${ }^{17}$ Furthermore, interruption of prefrontal subcortical structures or loops involved in cognitive function or mood regulation may directly lead to cognitive decline and depression. ${ }^{1,} 18$ Second, CSVD may indirectly lead to cognitive decline and depression 
through incident stroke. Similarly, CSVD may increase mortality risk through incident stroke, dementia, and depression. Third, CSVD has been suggested ${ }^{19}$ to lead to cognitive decline through interaction with Alzheimer's disease pathology. In accordance, the present study showed that CSVD increased the risk not only of presumed vascular dementia, but also of Alzheimer's disease. Fourth, CSVD reflecting an individual's poor health or social economic status might also explain our findings, particularly the association between CSVD and all-cause mortality. Although studies that adjusted for measures of frailty (e.g. walking speed) or education found similar results, we cannot exclude the possibility of residual confounding.

\section{Implications}

This review has several clinical and research implications. It shows that individuals with CSVD features are at high risk of ischaemic and haemorrhagic stroke, all-cause dementia, depression and mortality; a risk similar to that of individuals with diabetes ${ }^{20-23}$ or hypertension. ${ }^{24-28}$ An incidental finding of CSVD should be recognized as implying a substantial risk of stroke, dementia, depression, and mortality, and should prompt work-up and treatment of relevant risk factors. Prevention of CSVD itself could be an important therapeutic goal, although evidence for effective interventions is lacking. Trials are therefore needed that target suspected mechanisms of CSVD, including blood-brain barrier dysfunction, capillary flow pattern dysregulation, and blood pressure variability. ${ }^{17}$ In addition, CSVD may be a surrogate marker of risk of stroke, dementia and depression. CSVD features can be quantified reliably ${ }^{29}$ and their change over time may be more sensitive than change of cognition. ${ }^{30}$ However, only one previous study ${ }^{31}$ found that reduction of progression of CSVD correlated with reduced occurrence of clinical endpoints, while others $^{32,33}$ did not. This requires further study. Finally, the present study showed that the combination of two CSVD features is most strongly associated with incident stroke. This suggests that imaging scales that integrate many CSVD features, such as the scale recently developed by Huijts et al., ${ }^{34}$ are most suitable to assess CSVD and most likely to enable improved risk prediction of clinical outcomes beyond established risk factors.

\section{Limitations}

This review has some limitations. We only evaluated baseline measurements of CSVD. Baseline measurements may, however, not accurately reflect the exposure to new lesions during follow-up. We also did not evaluate the location of CSVD features, although their clinical consequences may depend upon location, so our estimates are an average over possibly different associations per region. In addition, the pooled estimates for WMHs on a dichotomous scale should be interpreted with caution. Different definitions of this measure were used across studies which hampers its interpretation.

\section{Conclusion}

The present systematic review and meta-analysis shows that various CSVD features are strongly and consistently associated with a higher incidence of ischaemic and haemorrhagic stroke, all-cause dementia and depression, and greater all-cause mortality. 


\section{References}

1. Wardlaw JM, Smith EE, Biessels GJ, Cordonnier C, Fazekas F, Frayne R, Lindley RI, O'Brien JT, Barkhof F, Benavente OR, Black SE, Brayne C, Breteler M, Chabriat H, Decarli C, de Leeuw FE, Doubal F, Duering M, Fox NC, Greenberg S, Hachinski V, Kilimann I, Mok V, Oostenbrugge R, Pantoni L, Speck O, Stephan BC, Teipel S, Viswanathan A, Werring D, Chen C, Smith C, van Buchem M, Norrving B, Gorelick PB and Dichgans M. Neuroimaging standards for research into small vessel disease and its contribution to ageing and neurodegeneration. Lancet Neurol. 2013;12:822-38.

2. Pantoni L. Cerebral small vessel disease: from pathogenesis and clinical characteristics to therapeutic challenges. Lancet Neurol. 2010;9:689-701.

3. Debette $\mathrm{S}$ and Markus HS. The clinical importance of white matter hyperintensities on brain magnetic resonance imaging: systematic review and meta-analysis. BMJ. 2010;341:c3666.

4. Charidimou A, Shams S, Romero JR, Ding J, Veltkamp R, Horstmann S, Eiriksdottir G, van Buchem MA, Gudnason V, Himali JJ, Gurol ME, Viswanathan A, Imaizumi T, Vernooij MW, Seshadri S, Greenberg SM, Benavente OR, Launer LJ, Shoamanesh A and International M-MI. Clinical significance of cerebral microbleeds on MRI: A comprehensive meta-analysis of risk of intracerebral hemorrhage, ischemic stroke, mortality, and dementia in cohort studies (v1). Int J Stroke. 2018:1747493017751931.

5. Wang L, Leonards CO, Sterzer P and Ebinger M. White matter lesions and depression: a systematic review and meta-analysis. J Psychiatr Res. 2014;56:56-64.

6. van Agtmaal MJM, Houben A, Pouwer F, Stehouwer CDA and Schram MT. Association of Microvascular Dysfunction With Late-Life Depression: A Systematic Review and Meta-analysis. JAMA Psychiatry. 2017.

7. Wang DN, Hou XW, Yang BW, Lin Y, Shi JP and Wang N. Quantity of Cerebral Microbleeds, Antiplatelet Therapy, and Intracerebral Hemorrhage Outcomes: A Systematic Review and Metaanalysis. J Stroke Cerebrovasc Dis. 2015;24:2728-37.

8. Charidimou A, Kakar P, Fox Z and Werring DJ. Cerebral microbleeds and recurrent stroke risk: systematic review and meta-analysis of prospective ischemic stroke and transient ischemic attack cohorts. Stroke. 2013;44:995-1001.

9. Charidimou A, Imaizumi T, Moulin S, Biffi A, Samarasekera N, Yakushiji Y, Peeters A, Vandermeeren Y, Laloux P, Baron JC, Hernandez-Guillamon M, Montaner J, Casolla B, Gregoire SM, Kang DW, Kim JS, Naka H, Smith EE, Viswanathan A, Jager HR, Al-Shahi Salman R, Greenberg SM, Cordonnier $C$ and Werring DJ. Brain hemorrhage recurrence, small vessel disease type, and cerebral microbleeds: A meta-analysis. Neurology. 2017;89:820-829.

10. Stroup DF, Berlin JA, Morton SC, Olkin I, Williamson GD, Rennie D, Moher D, Becker BJ, Sipe TA and Thacker SB. Meta-analysis of observational studies in epidemiology: a proposal for reporting. Meta-analysis Of Observational Studies in Epidemiology (MOOSE) group. JAMA. 2000;283:2008-12.

11. Booth A, Clarke M, Ghersi D, Moher D, Petticrew M and Stewart L. An international registry of systematic-review protocols. Lancet. 2011;377:108-9.

12. Prasad K, Wiryasaputra L, Ng A and Kandiah N. White matter disease independently predicts progression from mild cognitive impairment to Alzheimer's disease in a clinic cohort. Dement Geriatr Cogn Disord. 2011;31:431-4.

13. Higgins JP and Thompson SG. Quantifying heterogeneity in a meta-analysis. Stat Med. 2002;21:1539-58. 
14. Duval $S$ and Tweedie R. Trim and fill: A simple funnel-plot-based method of testing and adjusting for publication bias in meta-analysis. Biometrics. 2000;56:455-63.

15. Puy L, De Guio F, Godin O, Duering M, Dichgans M, Chabriat H and Jouvent E. Cerebral Microbleeds and the Risk of Incident Ischemic Stroke in CADASIL (Cerebral Autosomal Dominant Arteriopathy With Subcortical Infarcts and Leukoencephalopathy). Stroke. 2017;48:2699-2703.

16. Akoudad S, Portegies MLP, Koudstaal PJ, Hofman A, Van Der Lugt A, Ikram MA and Vernooij MW. Cerebral Microbleeds Are Associated with an Increased Risk of Stroke: The Rotterdam Study. Circulation. 2015;132:509-516.

17. Ostergaard L, Engedal TS, Moreton F, Hansen MB, Wardlaw JM, Dalkara T, Markus HS and Muir KW. Cerebral small vessel disease: Capillary pathways to stroke and cognitive decline. $J$ Cereb Blood Flow Metab. 2016;36:302-25.

18. Alexopoulos GS, Meyers BS, Young RC, Campbell S, Silbersweig D and Charlson M. 'Vascular depression' hypothesis. Arch Gen Psychiatry. 1997;54:915-22.

19. de la Torre JC. Alzheimer disease as a vascular disorder: nosological evidence. Stroke. 2002;33:1152-62.

20. Gregg EW, Li Y, Wang J, Burrows NR, Ali MK, Rolka D, Williams DE and Geiss L. Changes in diabetesrelated complications in the United States, 1990-2010. N Engl J Med. 2014;370:1514-23.

21. Xu WL, Qiu CX, Wahlin A, Winblad B and Fratiglioni L. Diabetes mellitus and risk of dementia in the Kungsholmen project: a 6-year follow-up study. Neurology. 2004;63:1181-6.

22. Yu M, Zhang X, Lu F and Fang L. Depression and Risk for Diabetes: A Meta-Analysis. Can J Diabetes. 2015;39:266-72.

23. Gregg EW, Cheng YJ, Saydah S, Cowie C, Garfield S, Geiss L and Barker L. Trends in death rates among U.S. adults with and without diabetes between 1997 and 2006: findings from the National Health Interview Survey. Diabetes Care. 2012;35:1252-7.

24. Imano H, Kitamura A, Sato S, Kiyama M, Ohira T, Yamagishi K, Noda H, Tanigawa T, Iso H and Shimamoto T. Trends for blood pressure and its contribution to stroke incidence in the middle-aged Japanese population: the Circulatory Risk in Communities Study (CIRCS). Stroke. 2009;40:1571-7.

25. Verdecchia P, Reboldi GP, Angeli F, Schillaci G, Schwartz JE, Pickering TG, Imai Y, Ohkubo T and Kario K. Short- and long-term incidence of stroke in white-coat hypertension. Hypertension. 2005;45:203-208.

26. Li G, Rhew IC, Shofer JB, Kukull WA, Breitner JC, Peskind E, Bowen JD, McCormick W, Teri L, Crane PK and Larson EB. Age-varying association between blood pressure and risk of dementia in those aged 65 and older: a community-based prospective cohort study. J Am Geriatr Soc. 2007;55:1161-7.

27. Sharp SI, Aarsland D, Day S, Sonnesyn H, Ballard C and Syst AsSVD. Hypertension is a potential risk factor for vascular dementia: systematic review. Int J Geriatr Psychiatry. 2011;26:661-669.

28. Barengo NC, Antikainen R, Kastarinen M, Laatikainen T and Tuomilehto J. The effects of control of systolic and diastolic hypertension on cardiovascular and all-cause mortality in a communitybased population cohort. J Hum Hypertens. 2013;27:693-7. 
29. De Guio F, Jouvent E, Biessels GJ, Black SE, Brayne C, Chen C, Cordonnier C, De Leeuw FE, Dichgans M, Doubal F, Duering M, Dufouil C, Duzel E, Fazekas F, Hachinski V, Ikram MA, Linn J, Matthews PM, Mazoyer B, Mok V, Norrving B, O'Brien JT, Pantoni L, Ropele S, Sachdev P, Schmidt R, Seshadri S, Smith EE, Sposato LA, Stephan B, Swartz RH, Tzourio C, van Buchem M, van der Lugt $A$, van Oostenbrugge R, Vernooij MW, Viswanathan A, Werring D, Wollenweber F, Wardlaw $\mathrm{JM}$ and Chabriat $\mathrm{H}$. Reproducibility and variability of quantitative magnetic resonance imaging markers in cerebral small vessel disease. J Cereb Blood Flow Metab. 2016;36:1319-37.

30. Benjamin P, Zeestraten E, Lambert C, Ster IC, Williams OA, Lawrence AJ, Patel B, MacKinnon AD, Barrick TR and Markus HS. Progression of MRI markers in cerebral small vessel disease: Sample size considerations for clinical trials. J Cereb Blood Flow Metab. 2016;36:228-40.

31. Dufouil C, Chalmers J, Coskun O, Besancon V, Bousser MG, Guillon P, MacMahon S, Mazoyer B, Neal B, Woodward M, Tzourio-Mazoyer N, Tzourio C and Investigators PMS. Effects of blood pressure lowering on cerebral white matter hyperintensities in patients with stroke: the PROGRESS (Perindopril Protection Against Recurrent Stroke Study) Magnetic Resonance Imaging Substudy. Circulation. 2005;112:1644-50.

32. Launer LJ, Miller ME, Williamson JD, Lazar RM, Gerstein HC, Murray AM, Sullivan M, Horowitz KR, Ding J, Marcovina S, Lovato LC, Lovato J, Margolis KL, O'Connor P, Lipkin EW, Hirsch J, Coker L, Maldjian J, Sunshine JL, Truwit C, Davatzikos C, Bryan RN and investigators AM. Effects of intensive glucose lowering on brain structure and function in people with type 2 diabetes (ACCORD MIND): a randomised open-label substudy. Lancet Neurol. 2011;10:969-77.

33. Williamson JD, Launer LJ, Bryan RN, Coker LH, Lazar RM, Gerstein HC, Murray AM, Sullivan MD, Horowitz KR, Ding J, Marcovina S, Lovato L, Lovato J, Margolis KL, Davatzikos C, Barzilay J, Ginsberg HN, Linz PE, Miller ME and Action to Control Cardiovascular Risk in Diabetes Memory in Diabetes I. Cognitive function and brain structure in persons with type 2 diabetes mellitus after intensive lowering of blood pressure and lipid levels: a randomized clinical trial. JAMA Intern Med. 2014;174:324-33.

34. Huijts M, Duits A, van Oostenbrugge RJ, Kroon AA, de Leeuw PW and Staals J. Accumulation of MRI Markers of Cerebral Small Vessel Disease is Associated with Decreased Cognitive Function. A Study in First-Ever Lacunar Stroke and Hypertensive Patients. Front Aging Neurosci. 2013;5:72. 


\section{Supplemental material}

\section{Supplemental methods section}

Appendix A. MOOSE Statement - Reporting Checklist for Authors, Editors, and Reviewers of Meta-analyses of Observational Studies

\begin{tabular}{|c|c|}
\hline Reporting Criteria & Reported (Yes/No) \\
\hline \multicolumn{2}{|l|}{ Reporting of Background } \\
\hline Problem definition & Yes \\
\hline Hypothesis statement & Yes \\
\hline Description of Study Outcome(s) & Yes \\
\hline Type of exposure or intervention used & Yes \\
\hline Type of study design used & Yes \\
\hline Study population & Yes \\
\hline \multicolumn{2}{|l|}{ Reporting of Search Strategy } \\
\hline Qualifications of searchers (e.g. librarians and investigators) & Yes \\
\hline $\begin{array}{l}\text { Search strategy, including time period } \\
\text { included in the synthesis and keywords }\end{array}$ & $\begin{array}{l}\text { Yes (Supplemental material, } \\
\text { Tables S1.1 to S1.4) }\end{array}$ \\
\hline $\begin{array}{l}\text { Effort to include all available studies, } \\
\text { including contact with authors }\end{array}$ & Yes \\
\hline Databases and registries searched & Yes \\
\hline $\begin{array}{l}\text { Search software used, name and } \\
\text { version, including special features used } \\
\text { (eg, explosion) }\end{array}$ & Yes \\
\hline $\begin{array}{l}\text { Use of hand searching (eg, reference } \\
\text { lists of obtained articles) }\end{array}$ & Yes \\
\hline $\begin{array}{l}\text { List of citations located and those } \\
\text { excluded, including justification }\end{array}$ & Yes (Figure 1, Table S3) \\
\hline $\begin{array}{l}\text { Method for addressing articles } \\
\text { published in languages other than } \\
\text { English }\end{array}$ & Yes \\
\hline $\begin{array}{l}\text { Method of handling abstracts and } \\
\text { unpublished studies }\end{array}$ & Yes \\
\hline Description of any contact with authors & Yes \\
\hline \multicolumn{2}{|l|}{ Reporting of Methods } \\
\hline $\begin{array}{l}\text { Description of relevance or } \\
\text { appropriateness of studies assembled for } \\
\text { assessing the hypothesis to be tested }\end{array}$ & Yes \\
\hline $\begin{array}{l}\text { Rationale for the selection and coding of } \\
\text { data (e.g. sound clinical principles or } \\
\text { convenience) }\end{array}$ & Yes \\
\hline $\begin{array}{l}\text { Documentation of how data were } \\
\text { classified and coded (e.g. multiple raters, } \\
\text { blinding, and interrater reliability) }\end{array}$ & Yes \\
\hline $\begin{array}{l}\text { Assessment of confounding (e.g. } \\
\text { comparability of cases and controls in } \\
\text { studies where appropriate }\end{array}$ & Yes \\
\hline $\begin{array}{l}\text { Assessment of study quality, including } \\
\text { blinding of quality assessors; } \\
\text { stratification or regression on possible } \\
\text { predictors of study results }\end{array}$ & Yes (Supplemental material, Appendix C) \\
\hline Assessment of heterogeneity & Yes (Supplemental material, Table S2) \\
\hline
\end{tabular}




\begin{tabular}{|c|c|}
\hline Reporting Criteria & Reported (Yes/No) \\
\hline $\begin{array}{l}\text { Description of statistical methods (e.g. } \\
\text { complete description of fixed or random } \\
\text { effects models, justification of whether } \\
\text { the chosen models account for predictors } \\
\text { of study results, dose-response models, } \\
\text { or cumulative meta-analysis) in sufficient } \\
\text { detail to be replicated }\end{array}$ & Yes \\
\hline $\begin{array}{l}\text { Provision of appropriate tables and } \\
\text { graphics }\end{array}$ & Yes (Figure 1, Supplemental material) \\
\hline \multicolumn{2}{|l|}{ Reporting of Results } \\
\hline $\begin{array}{l}\text { Table giving descriptive information for } \\
\text { each study included }\end{array}$ & $\begin{array}{l}\text { Yes (Supplemental material, Tables S4. } 1 \text { to } \\
\text { S4.4, Tables S5.1 to S5.4) }\end{array}$ \\
\hline $\begin{array}{l}\text { Results of sensitivity testing (e.g. } \\
\text { subgroup analysis) }\end{array}$ & $\begin{array}{l}\text { Yes (Supplemental material, Figures S2.1 to } \\
\text { S2.4, Tables S6.1 to S6.4) }\end{array}$ \\
\hline $\begin{array}{l}\text { Indication of statistical uncertainty of } \\
\text { findings }\end{array}$ & Yes \\
\hline \multicolumn{2}{|l|}{ Reporting of Discussion } \\
\hline $\begin{array}{l}\text { Quantitative assessment of bias (e.g. } \\
\text { publication bias) }\end{array}$ & $\begin{array}{c}\text { Yes (Supplemental material, Figure S3, } \\
\text { Table S7 and S8) }\end{array}$ \\
\hline $\begin{array}{l}\text { Justification for exclusion (e.g. exclusion } \\
\text { of non-English-language citations) }\end{array}$ & No \\
\hline Assessment of quality of included studies & $\begin{array}{c}\text { Yes (Supplemental material, Tables S5.1 } \\
\text { to S5.4) }\end{array}$ \\
\hline \multicolumn{2}{|l|}{ Reporting of Conclusions } \\
\hline $\begin{array}{l}\text { Consideration of alternative explanations } \\
\text { for observed results }\end{array}$ & Yes \\
\hline $\begin{array}{l}\text { Generalization of the conclusions (i.e. } \\
\text { appropriate for the data presented and } \\
\text { within the domain of the literature review) }\end{array}$ & Yes \\
\hline Guidelines for future research & Yes \\
\hline Disclosure of funding source & Yes \\
\hline
\end{tabular}




\title{
Appendix B. PROSPERO protocol
}

\author{
UNIVERSITY of Work \\ Centre for Reviews and Dissemination
}

PROSPERO International prospective register of systematic reviews

\section{Cerebral small vessel disease and risk of stroke, dementia, depression, and all-cause mortality: a systematic review and meta-analysis \\ Sytze Rensma, Thomas Van Sloten, Lenore Launer, Coen Stehouwer}

\section{Citation}

Sytze Rensma, Thomas Van Sloten, Lenore Launer, Coen Stehouwer. Cerebral small vessel disease and risk of stroke, dementia, depression, and all-cause mortality: a systematic review and meta-analysis. PROSPERO 2016:CRD42016038521 Available from

http://www.crd.york.ac.uk/PROSPERO_REBRANDING/display_record.asp?ID=CRD42016038521

\section{Review question(s)}

Are different magnetic resonance imaging (MRI) defined manifestations of cerebral small vessel disease (i.e. higher white matter hyperintensity volume, presence of lacunes, cerebral microbleeds and perivascular spaces, and brain atrophy) associated with a higher risk of incident stroke, dementia, depression and/or all-cause mortality?

\section{Searches}

We will identify relevant studies through a search of MEDLINE and EMBASE, from July 1977 (first recorded use of brain MRI) to present, using predefined search terms. In addition, we will identify papers by reviewing the reference list of all relevant articles identified.

There are no language restrictions.

\section{Types of study to be included}

Prospective studies will be included that evaluate the association between manifestations of cerebral small vessel disease and incident stroke, dementia, depression and/or all-cause mortality.

Specific inclusion criteria are:

1. MRI defined manifestations of cerebral small vessel disease (as defined by the STandards for Reporting Vascular changes on nEuroimaging [STRIVE] [1]) determined at baseline:

a. Volume of white matter hyperintensities of presumed vascular origin

b. Lacunes of presumed vascular origin, subcortical infarcts and silent brain infarcts. Subcortical infarcts and silent brain infarcts will be included, because most of these infarcts are lacunes of presumed vascular origin [1].

c. Cerebral microbleeds

d. Perivascular spaces

e. Brain atrophy

2. Any of the following outcomes (as defined by the individual studies):

a. Incident clinical stroke (first or recurrent) (not silent stroke)

b. Incident dementia

c. Incident depression (first or recurrent episode)

d. All-cause mortality 


\section{UNIVERSITY of Work Centre for Reviews and Dissemination}

Health Research

3. Study population of at least 50 subjects

4. Mean/median follow-up duration $=12$ months after brain MRI

5. Studying adults (individuals aged 18 years or older)

6. Full-text article available (no congress abstracts)

Specific exclusion criterion is:

1. Studies only including individuals with cerebral inflammatory or neurodegenerative diseases (e.g. multiple sclerosis, lupus erythematosus, Huntington's disease and Parkinson's disease) or monogenetic cerebrovascular disease (e.g. CADASIL)

\section{Condition or domain being studied}

Manifestations of cerebral small vessel disease detected by MRI include white matter hyperintensities, lacunes of presumed vascular origin, cerebral microbleeds, perivascular spaces and cerebral atrophy. Several studies have evaluated the association between these manifestations and various outcomes, including incident stroke, dementia, depression and mortality. However, the results of these studies have not been consistent. Thus far, no study has systematically evaluated the association between different manifestations of cerebral small vessel disease and incident stroke, dementia, depression and/or all-cause mortality.

\section{Participants/ population}

All adults in whom the association between manifestations of cerebral small vessel disease and incident stroke, dementia, depression and/or all-cause mortality is evaluated as specified above (please see "types of study to be included"), both in the general population and in a hospital-based setting.

\section{Intervention(s), exposure(s)}

The exposure variable is the presence of MRI defined manifestations of cerebral small vessel disease.

\section{Comparator(s)/ control}

The control is the group of participants without or with a lower burden of MRI defined manifestations of cerebral small vessel disease.

\section{Outcome(s)}

Primary outcomes

1. Incident clinical stroke (first or recurrent)

2. Incident dementia

3. Incident depression (first or recurrent episode)

4. All-cause mortality

Secondary outcomes

1. Specific subtypes of stroke (ischaemic vs. haemorrhagic stroke)

2. Specific subtypes of dementia (vascular dementia vs. Alzheimer's disease)

\section{Data extraction, (selection and coding)}

Two independent reviewers (SR and TVS) will select all relevant studies based on title and abstract. Full texts will then be retrieved and assessed for eligibility. In the case of multiple publications from the same cohort, we will include the most up-to-date or comprehensive information. Two independent reviewers (SR, TVS) will extract data with use of a pre-designed data extraction form. Any disagreements between the reviewers will be resolved by consensus. A third independent reviewer is available to solve any persisting disagreements. We will collect information on the following items: study size; follow-up duration; age; sex; diabetes mellitus, prior stroke; other 
UNIVERSITY of Hork Centre for Reviews and Dissemination

prior cardiovascular diseases; hypertension; atrial fibrillation; baseline cognitive performance; prior depression; baseline depression scale score; MRI characteristics; definitions of CSVD features; outcome definitions; number of events; statistical analysis used; reported risk estimates; and other variables adjusted for in the analyses.

\section{Risk of bias (quality) assessment}

Two reviewers (SR and TVS) will independently assess the risk of bias with the Newcastle-Ottawa Scale. Any disagreements between the reviewers will be resolved by consensus. A third independent reviewer (CS) is available to resolve any persisting disagreements.

\section{Strategy for data synthesis}

All analyses will be done with Cochrane Review manager (version 5.3) and R statistical software (version 3.2.3). We will pool results for each manifestation of cerebral small vessel disease when at least three studies are available with the same outcome. For white matter hyperintensity volume and brain atrophy, we will pool results separately for dichotomous and continuous measures. For analysis with combined presence of two or more individual features of CSVD as the determinant, we will pool HRs for any accumulating combination of individual features of CSVD. Continuous measures will be included as per one higher standard deviation (SD). Weighted subgroup SDs will be used when no overall SD is provided. For studies that measure deep and periventricular white matter hyperintensity volumes separately and do not provide a measure of total white matter hyperintensity volume, we will include the results for periventricular white matter hyperintensity volume in the main analysis only, because periventricular white matter hyperintensity volume is more closely related to total white matter hyperintensity volume. For lacunes, cerebral microbleeds and perivascular spaces, we will pool results for dichotomous measures. For studies that measure deep and lobar microbleeds separately and do not provide a total microbleed count, we will include the results for deep microbleeds in the main analysis only, because deep microbleeds are more closely related to the total cerebral microbleed count $[1,4]$. Pooled hazard ratios (HRs) will be calculated using the random effects inverse variance method. Most studies will report HRs. Odds ratios and relative risks will be treated as HRs. For each study, we will include the fully adjusted HR (but without adjustments for other manifestations of cerebral small vessel disease). The level of statistical heterogeneity will be evaluated using the I-squared test. High statistical heterogeneity was defined as I-squared $>60 \%$. Potential publication bias will be assessed with Egger's test and by construction of funnel plots.

\section{Analysis of subgroups or subsets}

The following sensitivity analyses will be done:

1. Analyses will be repeated separately for studies with high risk populations (i.e. individuals with previous stroke or mild cognitive impairment) and population based studies

2. Analyses will be repeated after excluding studies with a relatively high risk of bias (defined as Newcastle-Ottawa scale score <4)

3. Analyses will be repeated including only those studies that defined a lacuna of presumed vascular origin according to STRIVE, i.e. a round or ovoid, subcortical, fluid-filled (cerebrospinal fluid-like) cavity between 3-15 mm on T1 and/or T2 weighted MRI images

4. Analyses will be repeated separately for studies that measured white matter hyperintensity volume on a quantitative scale and those that measured white matter hyperintensity volume on a visual semi-quantitative scale (e.g. Fazekas and Wahlund scale).

5. Analyses will be repeated replacing the results for periventricular white matter hyperintensity volume with those for deep white matter hyperintensity volume

6. Analyses will be repeated replacing the results for deep cerebral microbleeds with those for lobar cerebral microbleeds

7. Analyses will be repeated with unadjusted (or minimally adjusted) risk estimates

8. For white matter hyperintensity volume and brain atrophy, results will be pooled per ten millilitre volume instead 
UNIVERSITY of Vork Centre for Reviews and Dissemination

of per SD.

Contact details for further information

Mr Rensma

s.rensma@maastrichtuniversity.nl

Organisational affiliation of the review

Department of Internal Medicine, Maastricht University Medical Centre, Maastricht, the Netherlands

\section{Review team}

Mr Sytze Rensma, Maastricht University Medical Centre

Dr Thomas Van Sloten, Maastricht University Medical Centre

Dr Lenore Launer, Laboratory of Epidemiology and Population Sciences, National Institute on Aging, National Institutes of Health

Professor Coen Stehouwer, Maastricht University Medical Centre

\section{Anticipated or actual start date}

01 November 2015

\section{Anticipated completion date \\ 01 April 2017}

\section{Funding sources/sponsors}

Sytze Rensma, Thomas van Sloten and Coen Stehouwer are supported by the European Regional Development Fund as part of Het Operationeel Programma Zuid-Nederland (OP-ZUID), the province of Limburg, Department of Economic Affairs of Netherlands (grant 310.041), Stichting de Weijerhorst, Pearl String Initiative Diabetes, Cardiovascular Centre Maastricht, Cardiovascular Research Institute Maastricht (CARIM), School for Nutrition, Toxicology and Metabolism (NUTRIM), Stichting Annadal, and Health Foundation Limburg.

\section{Conflicts of interest}

None known

\section{Language}

English

\section{Country}

Netherlands

\section{Subject index terms status}

Subject indexing assigned by CRD

\section{Subject index terms}

Cerebral Small Vessel Diseases; Dementia; Depression; Depressive Disorder; Humans; Stroke

\section{Any other information}

References 1. Wardlaw, J.M., et al., Neuroimaging standards for research into small vessel disease and its contribution to ageing and neurodegeneration. Lancet Neurol, 2013. 12(8): p. 822-38. 2. Wells GA SB, S.B., O'Connell D, Peterson J et al., The Newcastle-Ottawa Scale (NOS) for assessing the quality of nonrandomized studies in meta-analyses. p. http://www.ohri.ca/programs/clinical_epidemiology/oxford.asp. 3. Prasad, K., et al., White matter disease independently predicts progression from mild cognitive impairment to Alzheimer's disease in a clinic cohort. Dement Geriatr Cogn Disord, 2011. 31(6): p. 431-4. 4. Charidimou, A., et al., Cerebral microbleeds and recurrent stroke risk: systematic review and meta-analysis of prospective ischemic stroke and transient ischemic attack cohorts. Stroke, 2013. 44(4): p. 995-1001. 
UNIVERSITY of Vork

Centre for Reviews and Dissemination

National Institute for Health Research

\section{Stage of review}

Completed but not published

Date of registration in PROSPERO

04 May 2016

Date of publication of this revision

04 May 2017

Stage of review at time of this submission

Preliminary searches

Piloting of the study selection process

Formal screening of search results against eligibility criteria

Data extraction

Risk of bias (quality) assessment

Data analysis

$\begin{array}{cc}\text { Started } & \text { Completed } \\ \text { Yes } & \text { Yes } \\ \text { Yes } & \text { Yes } \\ \text { Yes } & \text { Yes } \\ \text { Yes } & \text { Yes } \\ \text { Yes } & \text { Yes } \\ \text { Yes } & \text { Yes }\end{array}$




\section{Appendix C. Adjusted Newcastle-Ottawa Scale}

For the present study, items 2 and 3 (selection category) of the original Newcastle-Ottawa Scale (NOS) for cohort studies were combined (for the individual items, see below). The original items evaluated the quality of the assessment of the exposed and non-exposed cohorts, respectively. In the present study, however, the total study was "exposed" to the risk factor under study (i.e. cerebral small vessel disease). A study can be awarded a maximum of one star for each numbered item within the selection and outcome categories. A maximum of two stars can be given for comparability.

The individual items of the scale are described below.

\section{Selection}

1) Representativeness of the cohort
a) truly representative of the general population *
b) somewhat representative of the general population *
c) high risk populations (e.g. individuals with: prior stroke, mild cognitive impairment, cardiovascular disease, prior depression (for the association with incident depression), or individuals receiving dialysis)
d) no description or other cohorts

2) Ascertainment of determinant (cerebral small vessel disease)
a) use of an MRI scanner with a field strength of 1.5 Tesla or higher and the following (minimal) sequences: for white matter hyperintensities: T2-weighted and fluid- attenuated inversion recovery (FLAIR); for lacunes: T1- and(or) T2-weighted; for cerebral microbleeds: $\mathrm{T} 2{ }^{*}$-weighted gradient echo sequence; for perivascular spaces: T2-weighted; and for total cerebral atrophy:T1/FLAIR *
b) not a method described above
c) no description

3) Demonstration that outcome of interest was not present at start of study
a) yes *
b) no

Comparability

1) Comparability of cohorts based on of the design or analysis
a) study controls for cardiovascular risk factors; smoking habits, type 2 diabetes, and systolic blood pressure, and/or use of antihypertensive medication. *
b) study controls for age, sex, and (for studies evaluating incident dementia) education * c) other


Outcome

1) Assessment of outcome

a) objective measurements and/or record linkage and/or expert opinion *

For depression: validated criteria, ICD codes

For dementia: validated cognitive tests, ICD codes

For stroke: clinical diagnosis

For mortality: population or hospital register

b) self- and/or peer-report

c) no description/other

2) Was follow-up long enough for outcomes to occur

a) yes (median/mean follow-up duration $>4$ year) *

b) no

3) Adequacy of follow-up of cohorts

a) complete follow-up and/or all subjects accounted for *

b) subjects lost to follow-up unlikely to introduce bias, small number lost (>80\% follow-up), or description provided of those lost *

c) follow up rate $<80 \%$ and no description of those lost to follow-up

d) no statement 


\section{Supplemental results section}

Table S1.1 -Search strategy for incident ischaemic and haemorrhagic stroke

\begin{tabular}{|c|}
\hline PubN \\
\hline 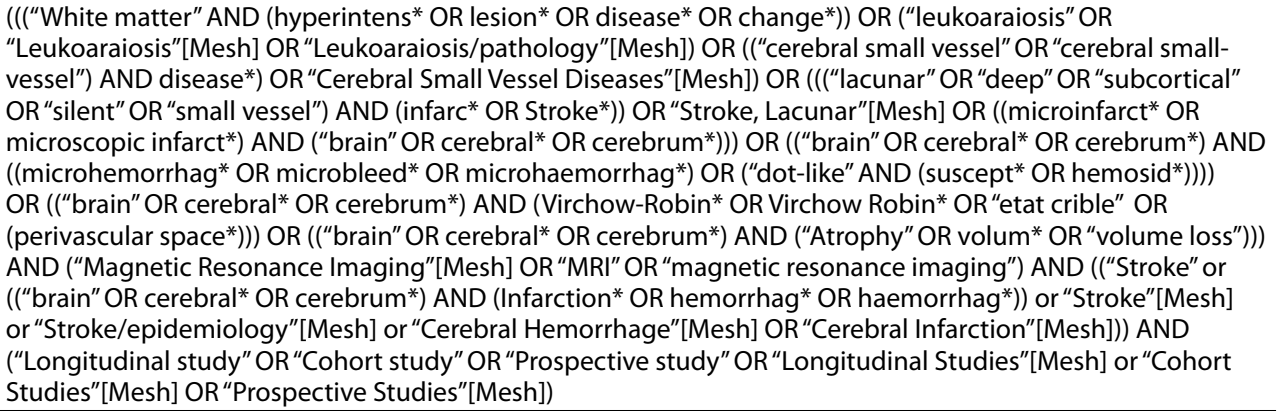 \\
\hline Embase \\
\hline $\begin{array}{l}\text { (((exp white matter/ AND (hyperintensity.mp. OR lesion.mp. OR disease.mp. OR exp diseases/)) OR exp white } \\
\text { matter lesion/ OR leukoaraiosis.mp. OR cerebral small vessel disease.mp. OR exp cerebrovascular disease/) } \\
\text { OR (exp lacunar stroke/ OR ((lacunar.mp. OR deep.mp. OR subcortical.mp. OR silent.mp. OR small vessel.mp.) } \\
\text { AND (exp infarction/ OR exp stroke/)) OR ((microinfarct.mp. OR microscopic infarct.mp.) AND (cerebral.mp. OR } \\
\text { exp brain/ OR cerebrum.mp.))) OR (((cerebral.mp. OR exp brain/ OR cerebrum.mp.) AND (microhaemorrhage. } \\
\text { mp. OR microhemorrhage.mp. OR microbleed.mp.)) OR (dot-like.mp. AND (susceptible.mp. OR hemosiderin. } \\
\text { mp.))) OR ((cerebral.mp. OR exp brain/ OR cerebrum.mp.) AND (virchow-robin.mp. OR Virchow robin.mp. } \\
\text { OR etat crible.mp. OR perivascular space.mp.)) OR (((cerebral.mp. OR exp brain/ OR cerebrum.mp. OR exp } \\
\text { brain size/) AND (exp atrophy/ OR volume loss.mp.)) OR exp brain atrophy/)) AND (((cerebral.mp. OR exp } \\
\text { brain/ OR cerebrum.mp.) AND (exp infarction/ OR exp stroke/ OR exp bleeding/ OR microhaemorrhage. } \\
\text { mp. OR microhemorrhage.mp.)) OR Exp brain infarction/ OR exp cerebrovascular accident/) AND (MRl.mp. } \\
\text { OR magnetic resonance imaging.mp. OR exp nuclear magnetic resonance imaging/) AND (exp longitudinal } \\
\text { study/ OR exp cohort analysis/ OR exp prospective study/) }\end{array}$ \\
\hline
\end{tabular}


Table S1.2 -Search strategy for incident all-cause dementia

\begin{tabular}{|c|}
\hline \\
\hline 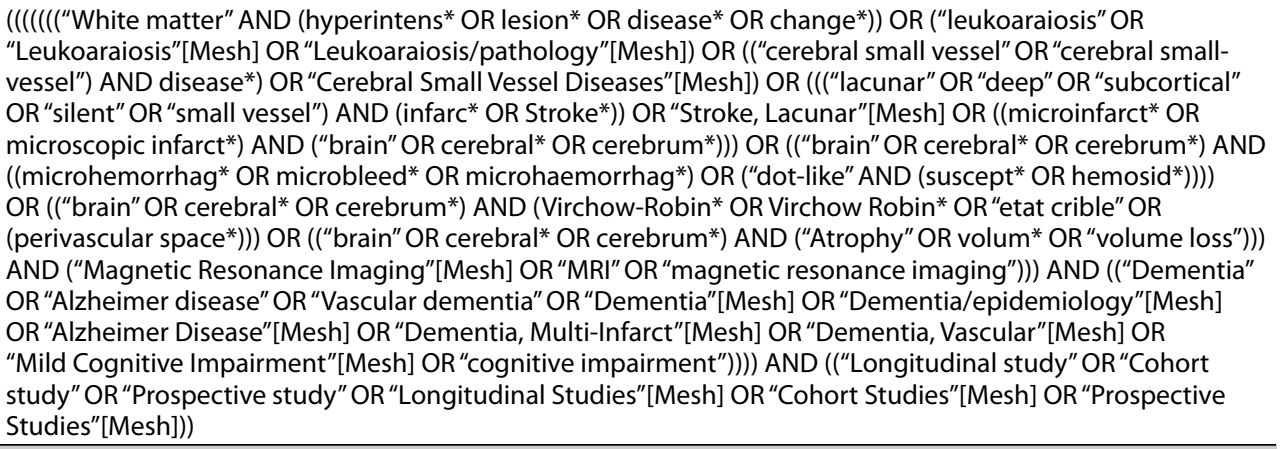 \\
\hline Embase \\
\hline $\begin{array}{l}\text { (((exp white matter/ AND (hyperintensity.mp. OR lesion.mp. OR disease.mp. OR exp diseases/)) OR exp white } \\
\text { matter lesion/ OR leukoaraiosis.mp. OR cerebral small vessel disease.mp. OR exp cerebrovascular disease/) OR } \\
\text { (exp lacunar stroke/ OR ((lacunar.mp. OR deep.mp. OR subcortical.mp. OR silent.mp. OR small vessel.mp.) AND } \\
\text { (exp infarction/ OR exp stroke/)) OR ((microinfarct.mp. OR microscopic infarct.mp.) AND (cerebral.mp. OR exp } \\
\text { brain/ OR cerebrum.mp.))) OR (((cerebral.mp. OR exp brain/ OR cerebrum.mp.) AND (microhaemorrhage.mp. } \\
\text { OR microhemorrhage.mp. OR microbleed.mp.)) OR (dot-like.mp. AND (susceptible.mp. OR hemosiderin.mp.))) } \\
\text { OR ((cerebral.mp. OR exp brain/ OR cerebrum.mp.) AND (virchow-robin.mp. OR Virchow robin.mp. OR etat } \\
\text { crible.mp. OR perivascular space.mp.)) OR (((cerebral.mp. OR exp brain/ OR cerebrum.mp. OR exp brain size/) } \\
\text { AND (exp atrophy/ OR volume loss.mp.)) OR exp brain atrophy/)) AND (exp dementia/ OR exp Alzheimer } \\
\text { disease/ OR exp multinfarct dementia/ OR vascular dementia.mp. OR exp cognitive defect/ OR cognitive } \\
\text { impairment.mp.) AND (MRI.mp. OR magnetic resonance imaging.mp. OR exp nuclear magnetic resonance } \\
\text { imaging/) AND (exp longitudinal study/ OR exp cohort analysis/ OR exp prospective study/) }\end{array}$ \\
\hline
\end{tabular}

Table S1.3 -Search strategy for incident depression

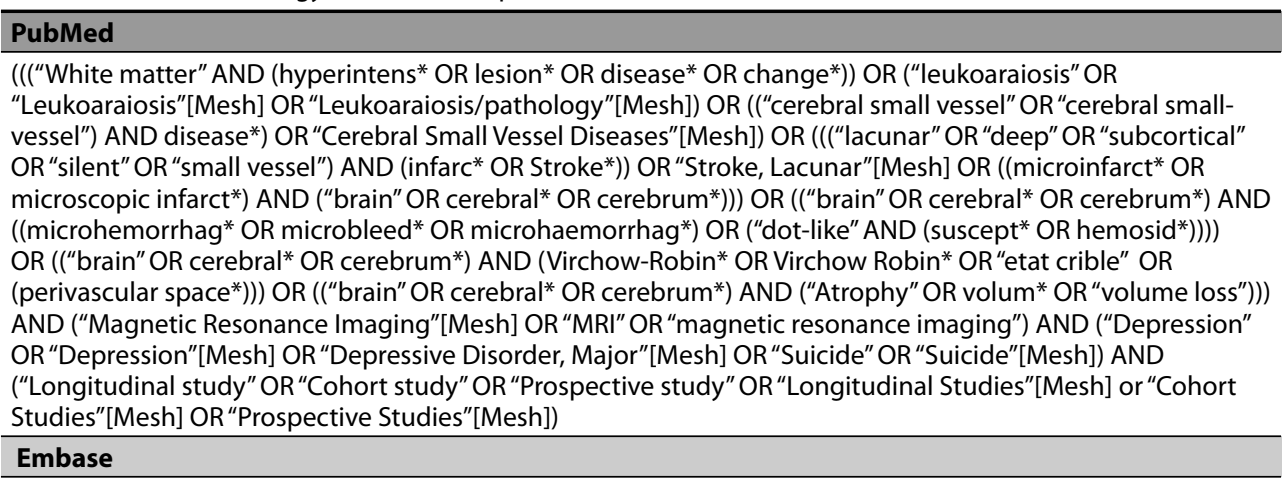

(((exp white matter/ AND (hyperintensity.mp. OR lesion.mp. OR disease.mp. OR exp diseases/)) OR exp white matter lesion/ OR leukoaraiosis.mp. OR cerebral small vessel disease.mp. OR exp cerebrovascular disease/) OR (exp lacunar stroke/ OR ((lacunar.mp. OR deep.mp. OR subcortical.mp. OR silent.mp. OR small vessel.mp.) AND (exp infarction/ OR exp stroke/)) OR ((microinfarct.mp. OR microscopic infarct.mp.) AND (cerebral.mp. OR exp brain/ OR cerebrum.mp.))) OR (((cerebral.mp. OR exp brain/ OR cerebrum.mp.) AND (microhaemorrhage. mp. OR microhemorrhage.mp. OR microbleed.mp.)) OR (dot-like.mp. AND (susceptible.mp. OR hemosiderin. mp.))) OR ((cerebral.mp. OR exp brain/ OR cerebrum.mp.) AND (virchow-robin.mp. OR Virchow robin.mp. OR etat crible.mp. OR perivascular space.mp.)) OR (((cerebral.mp. OR exp brain/ OR cerebrum.mp. OR exp brain size/) AND (exp atrophy/ OR volume loss.mp.)) OR exp brain atrophy/)) AND (exp depression/ OR exp major depression/ OR exp suicide/ OR exp suicide attempt/) AND (MRI.mp. OR magnetic resonance imaging.mp. OR exp nuclear magnetic resonance imaging/) AND (exp longitudinal study/ OR exp cohort analysis/ OR exp prospective study/) 
Table S1.4 -Search strategy for all-cause mortality

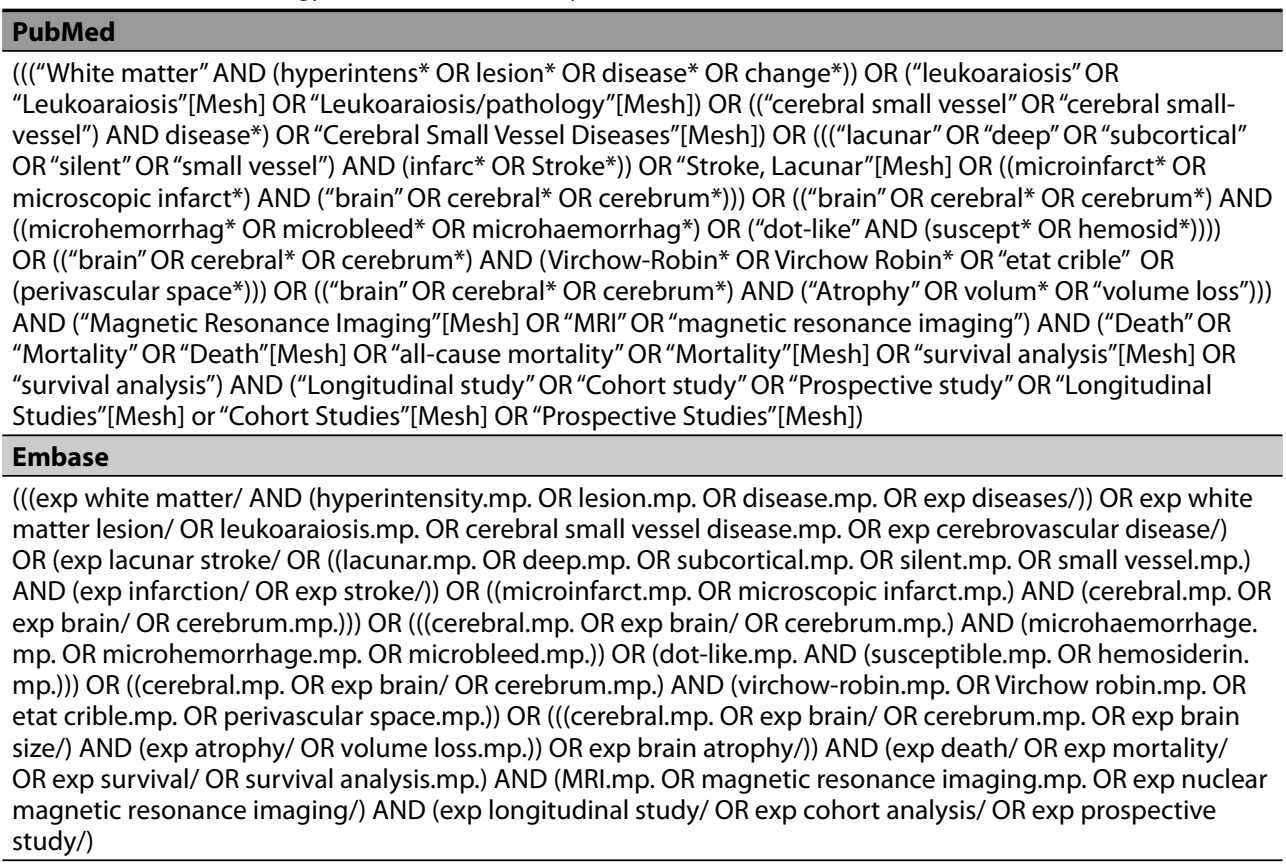

Table S2 - Description of post hoc analyses

Post hoc analyses
Post hoc analyses were done when at least 3 studies were available per outcome. Results were pooled using
only studies with a first episode of ischaemic of haemorrhagic stroke or depression; using only studies with
stroke patients; using only hazard ratios (i.e. excluding studies that reported odds ratios or relative risks);
using risk estimates comparing highest vs. lowest categories of white matter hyperintensities (irrespective of
the number of participants per category), instead of risk estimates comparing higher and lower categories
with the highest number of participants and events; using only risk estimates for silent cerebral infarcts;
excluding studies that reported risk estimates for silent cerebral infarcts only; using only studies with
Newcastle-Ottawa Scale (NOS) score >3; using only studies with NOS score $>5$; using only risk estimates of
periventricular white matter hyperintensities; using only risk estimates of deep white matter hyperintensities;
using only risk estimates for deep cerebral microbleeds; and using only risk estimates for lobar cerebral
microbleeds.




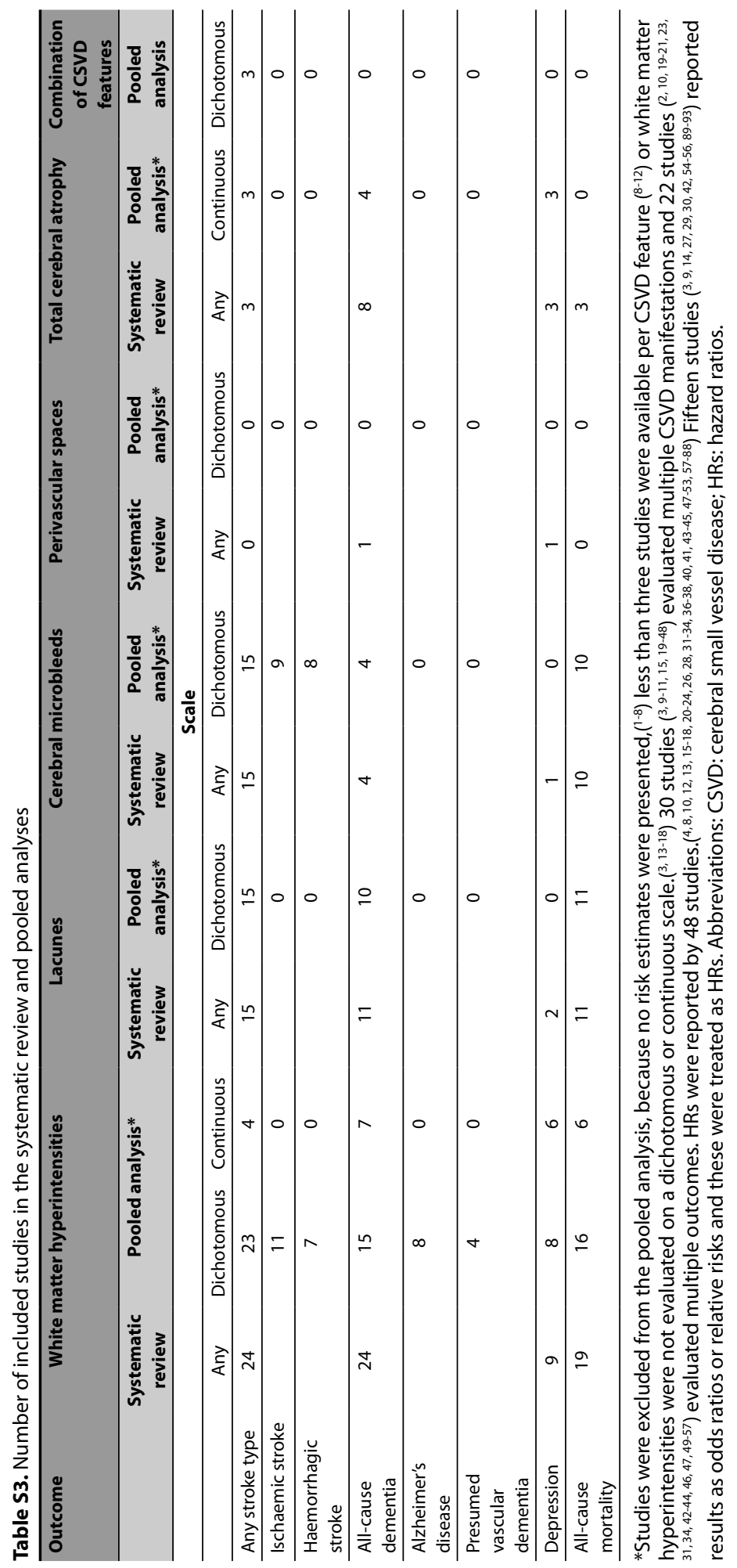




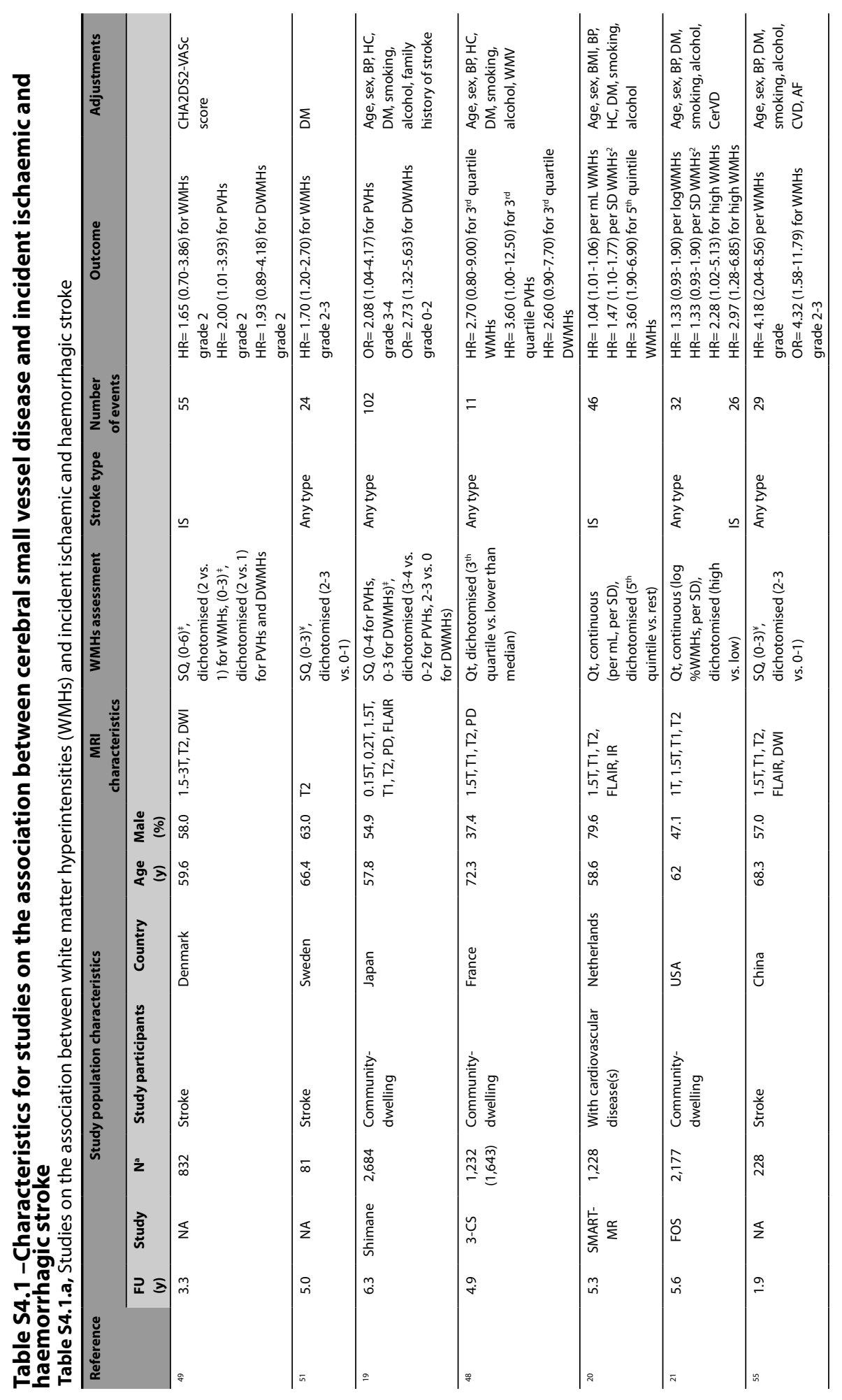




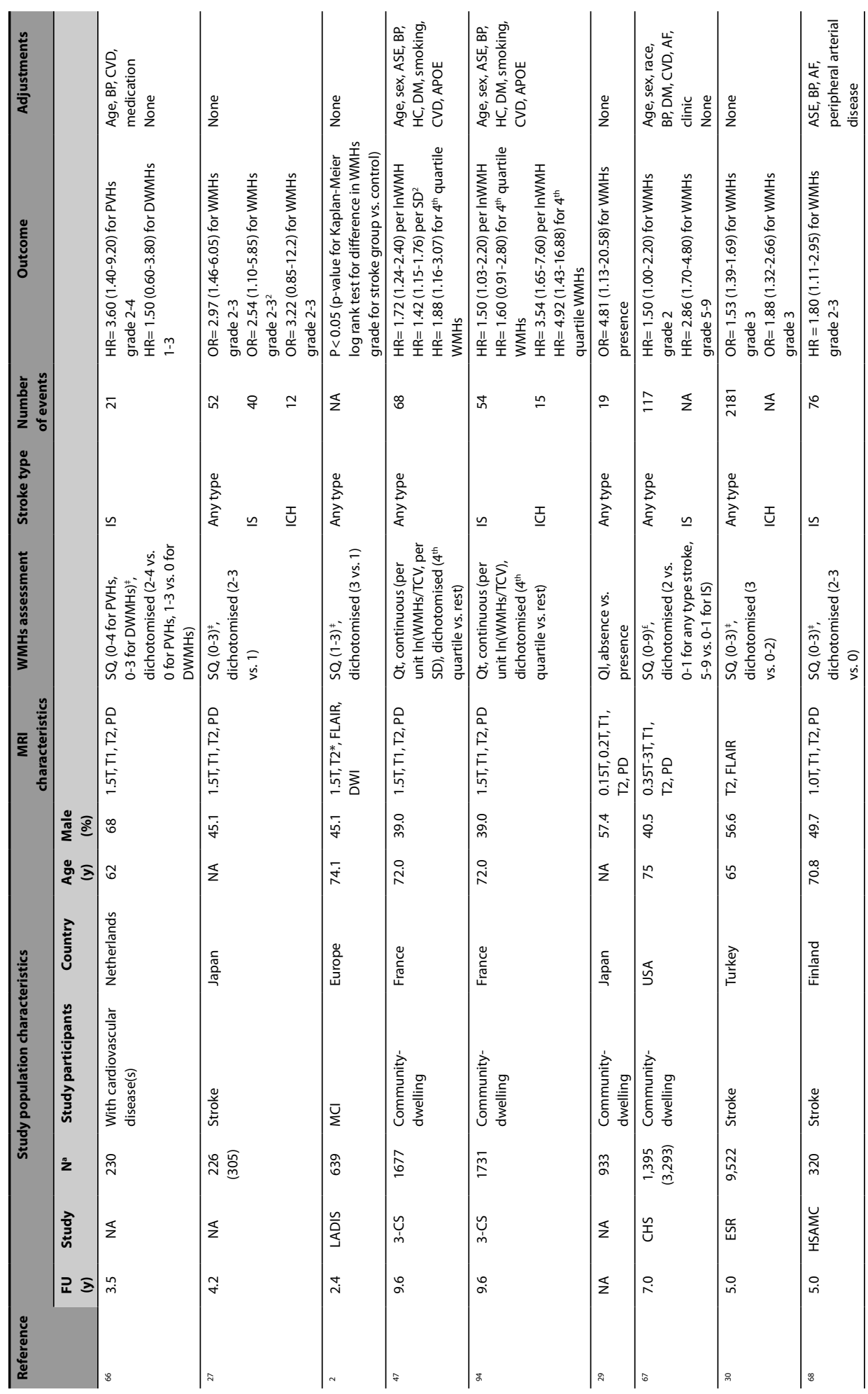




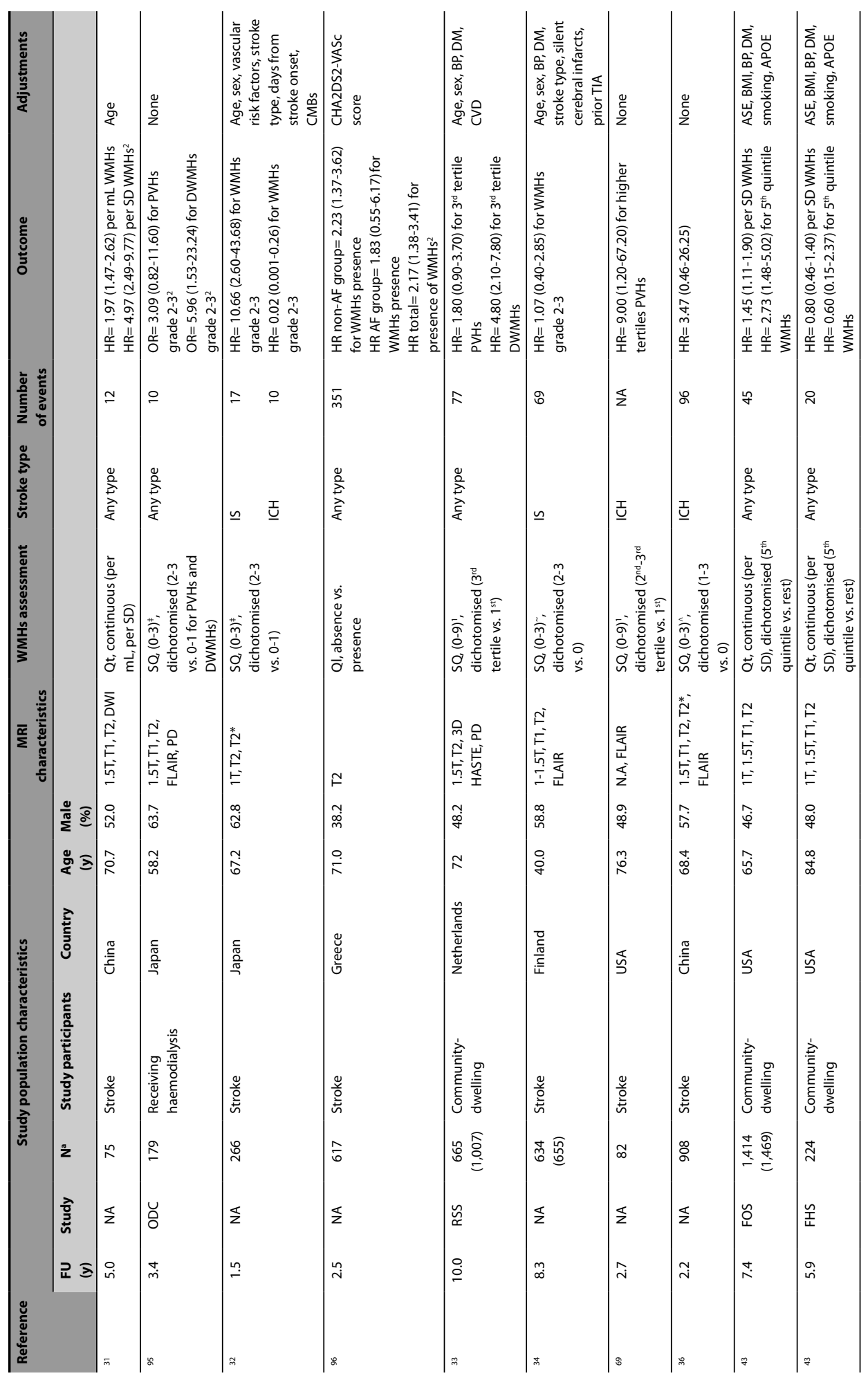




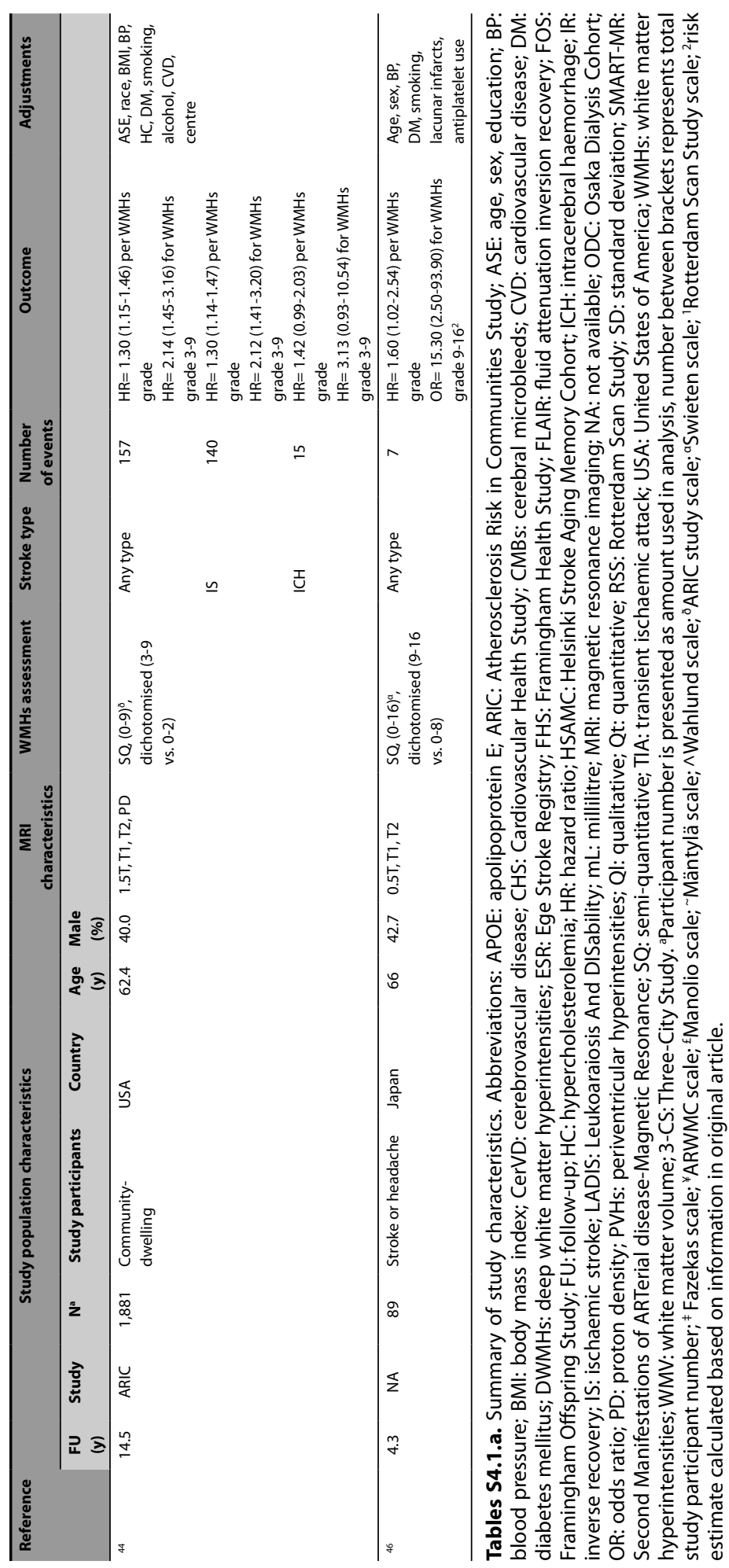




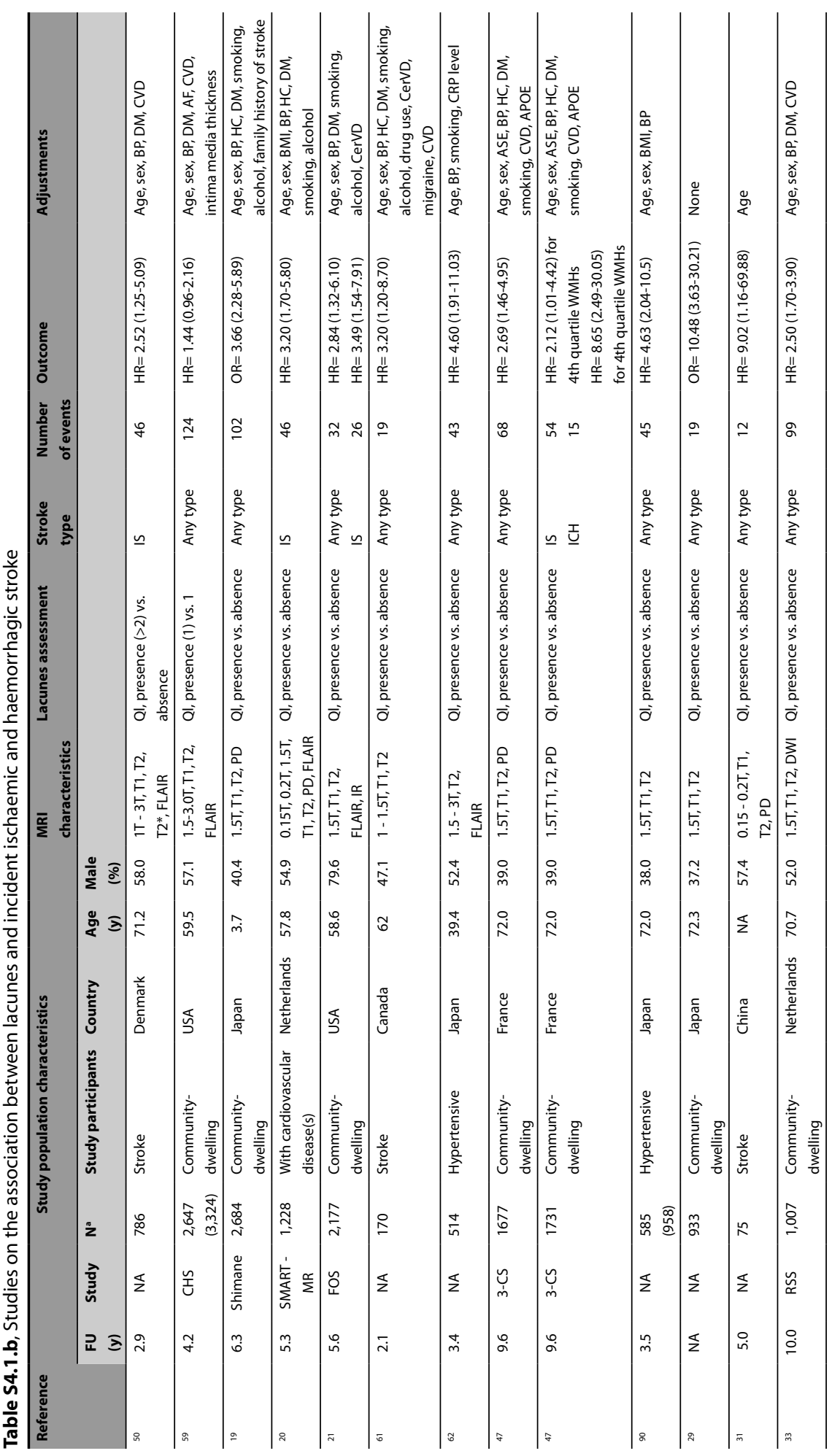




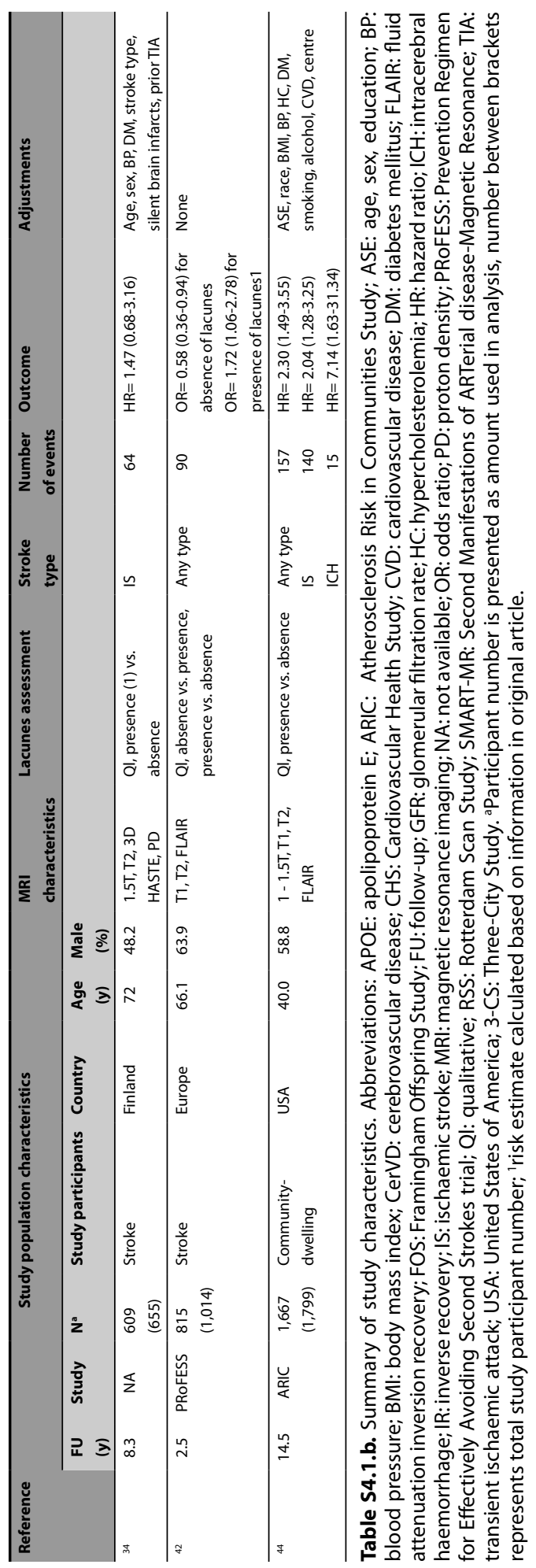




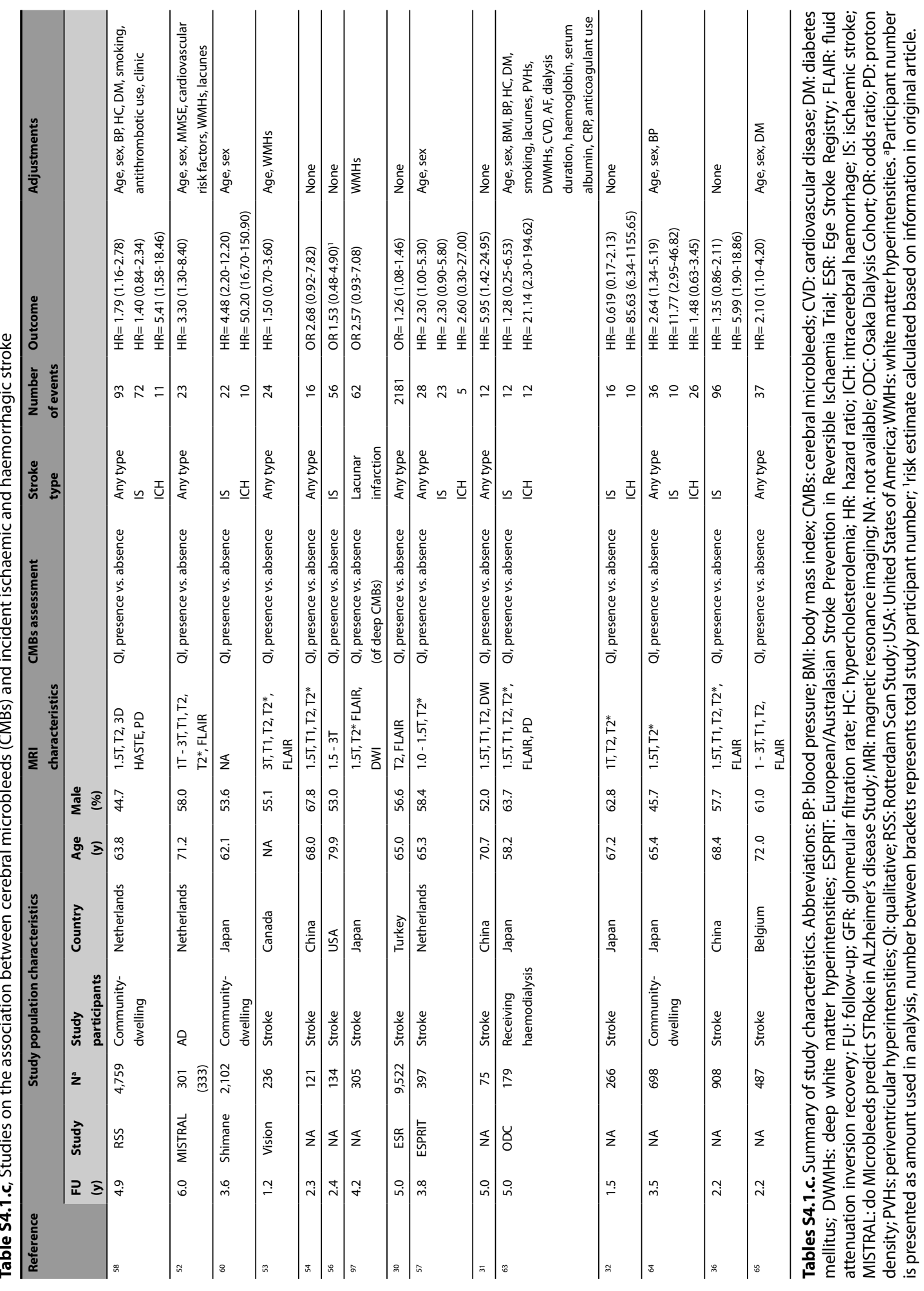




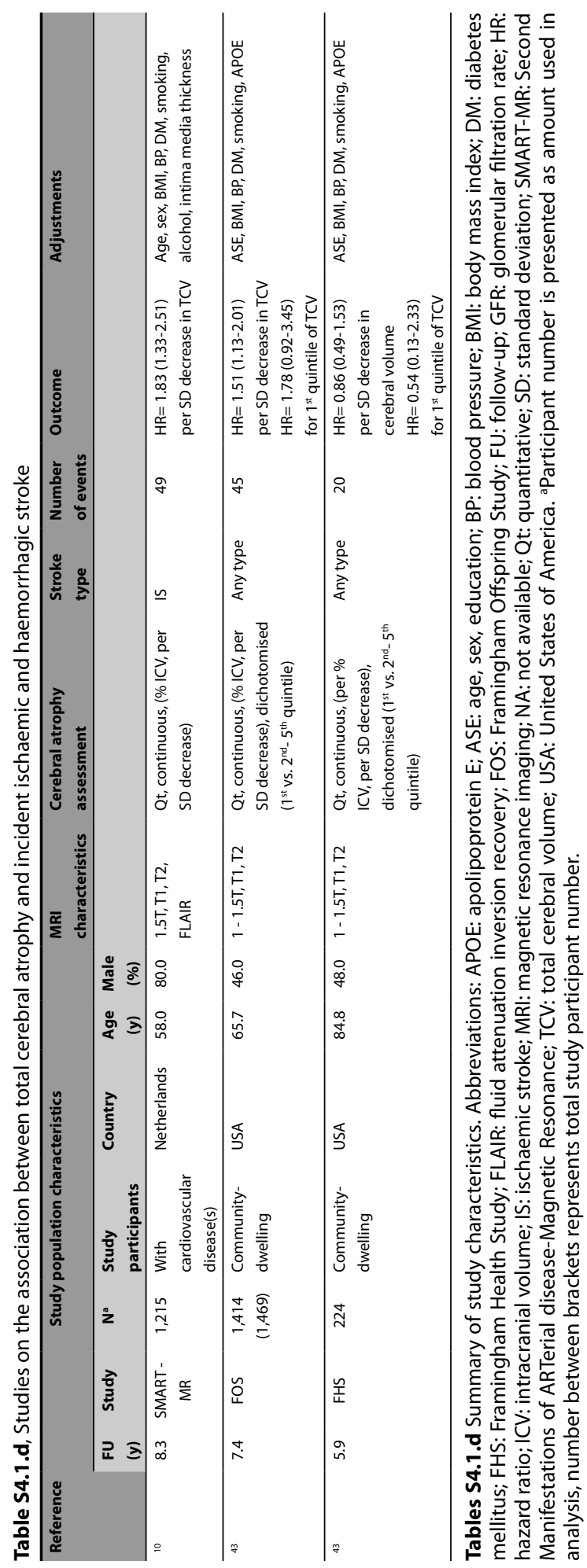




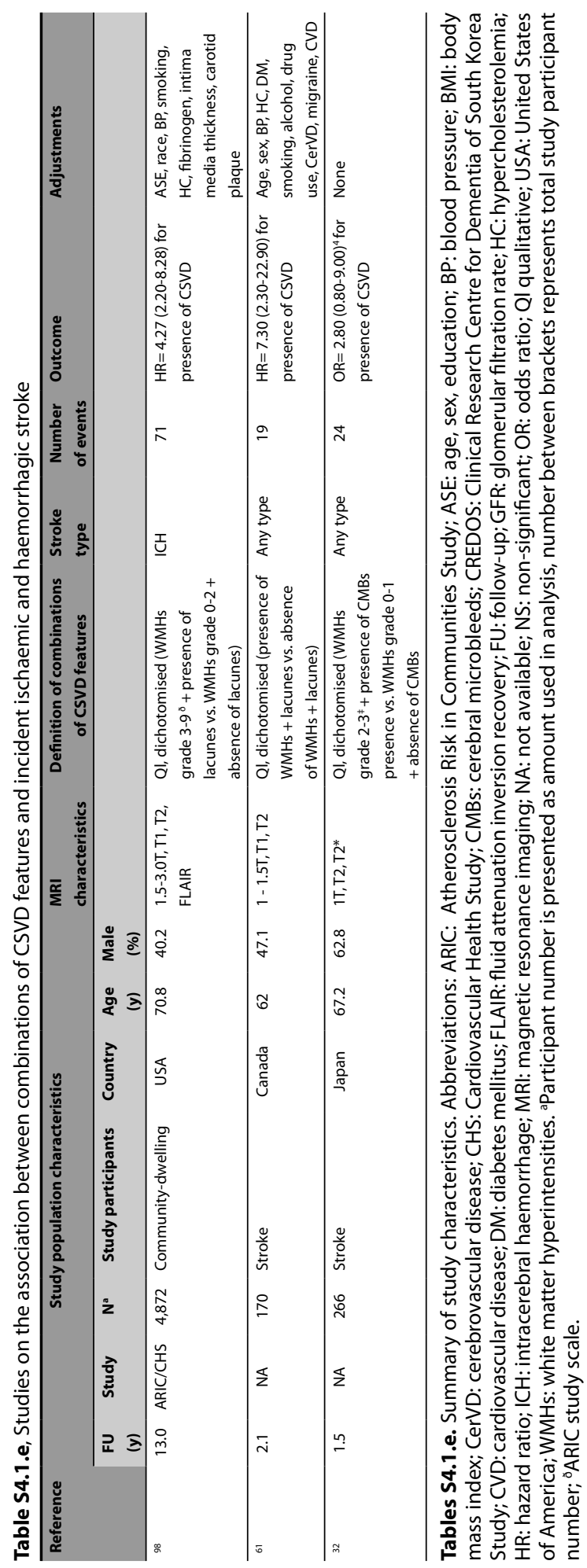




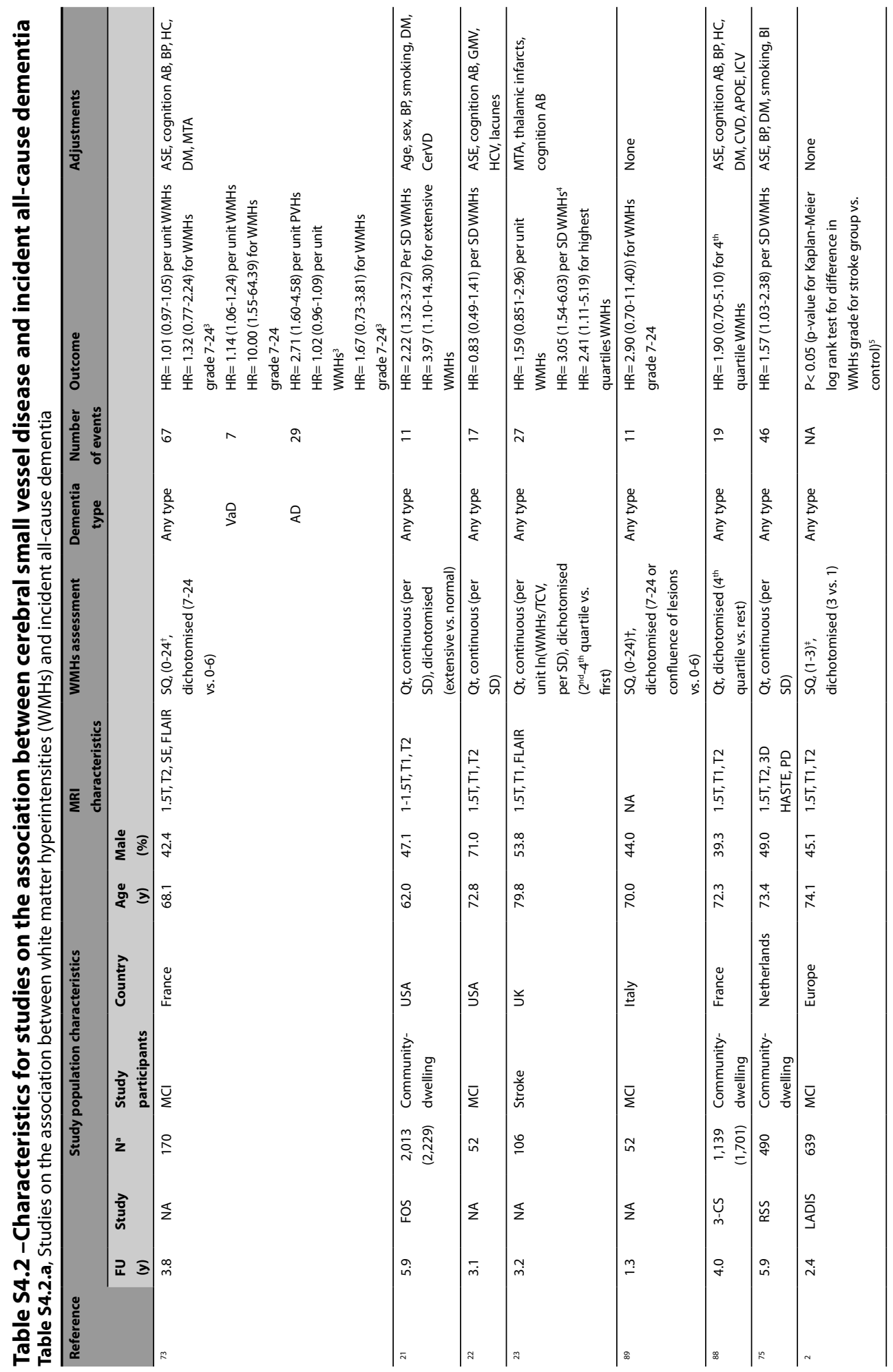




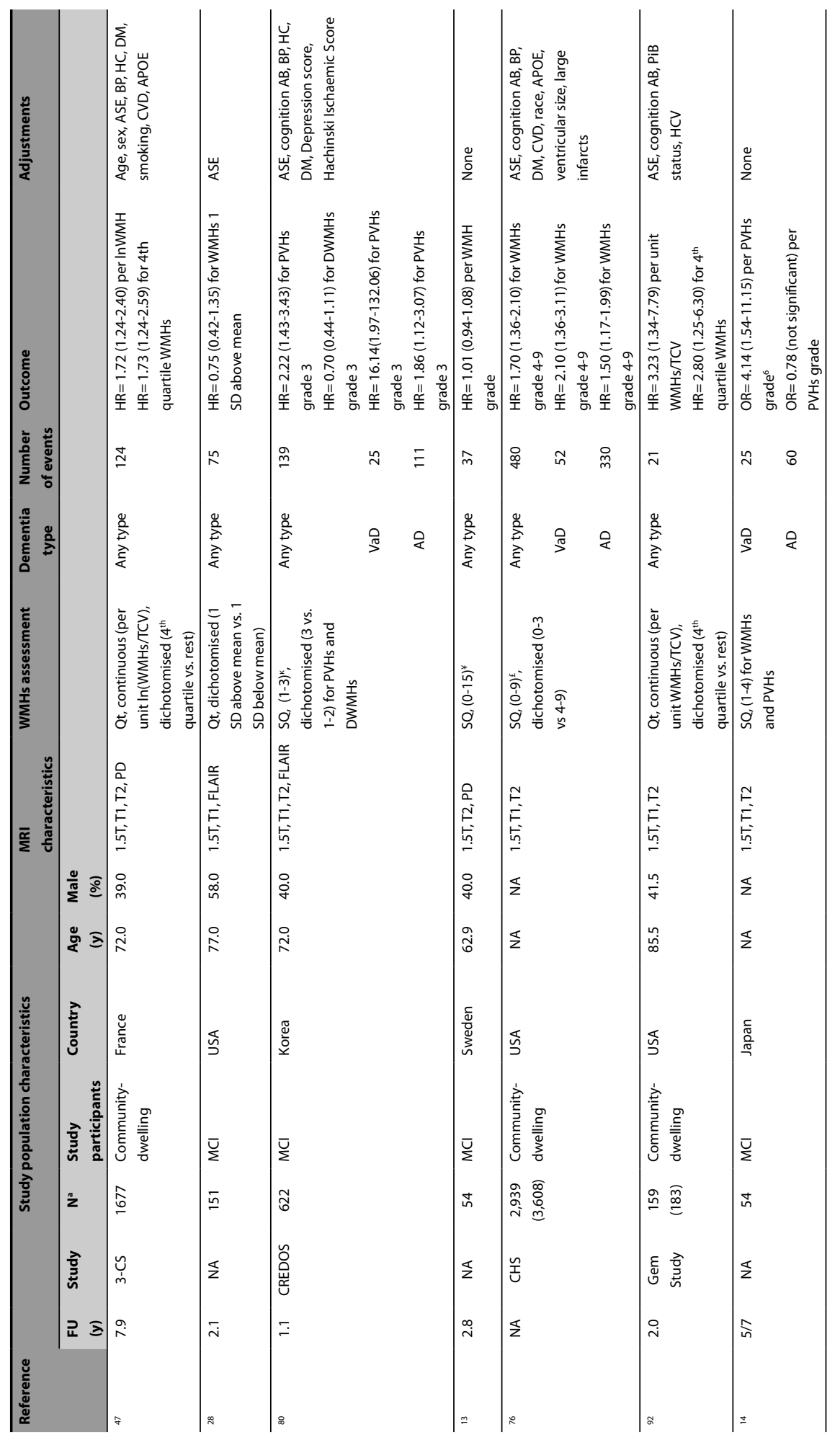




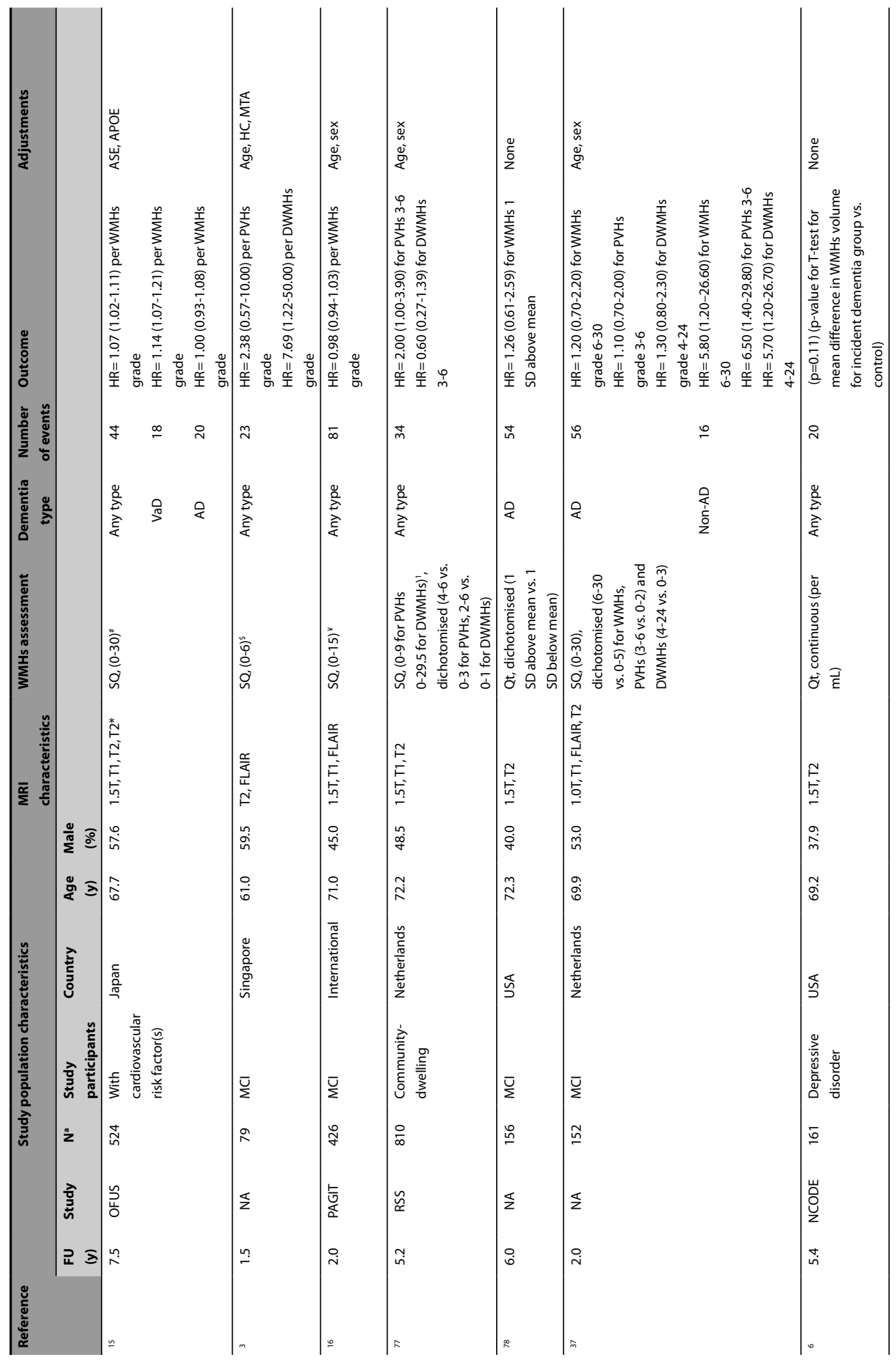




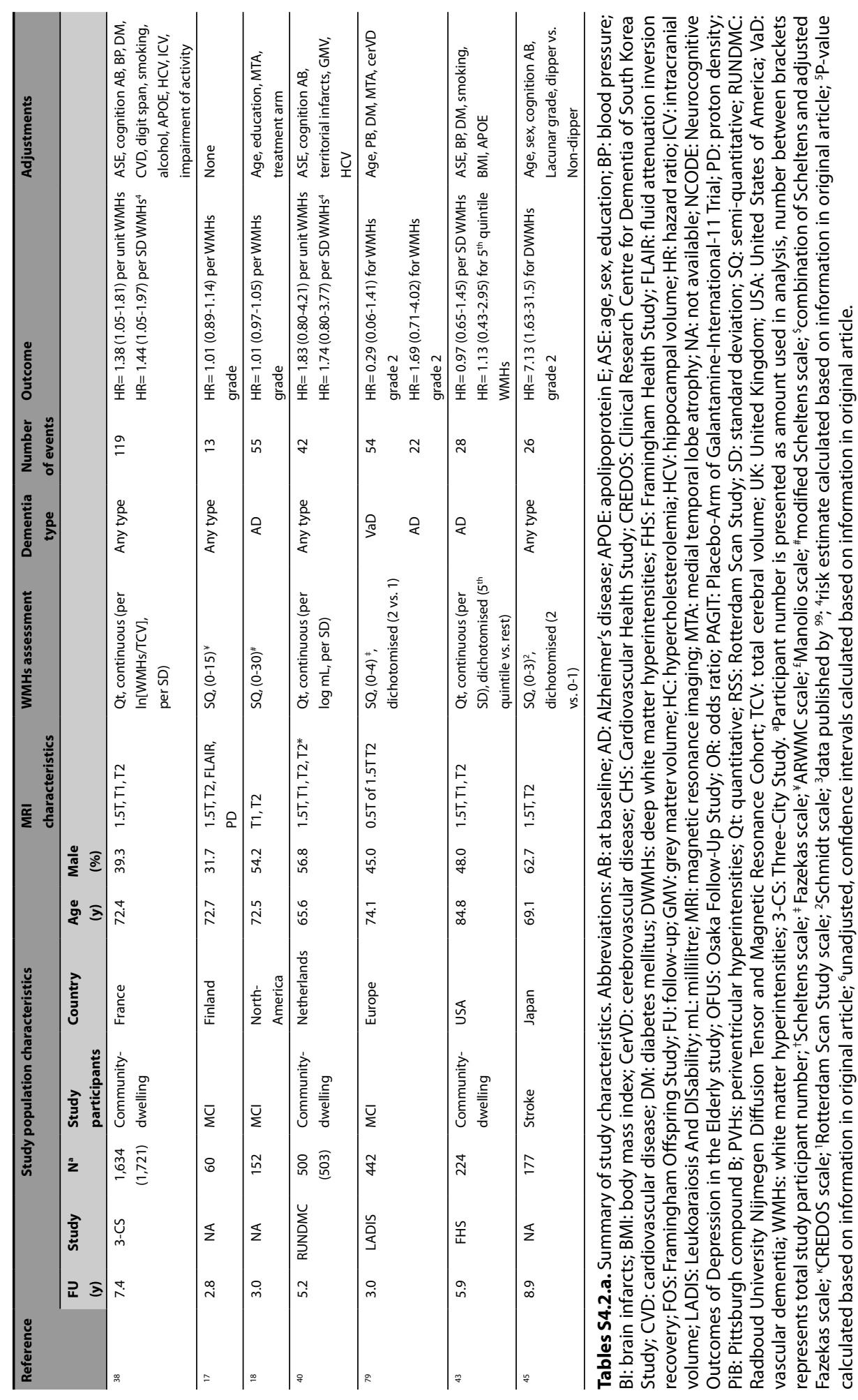




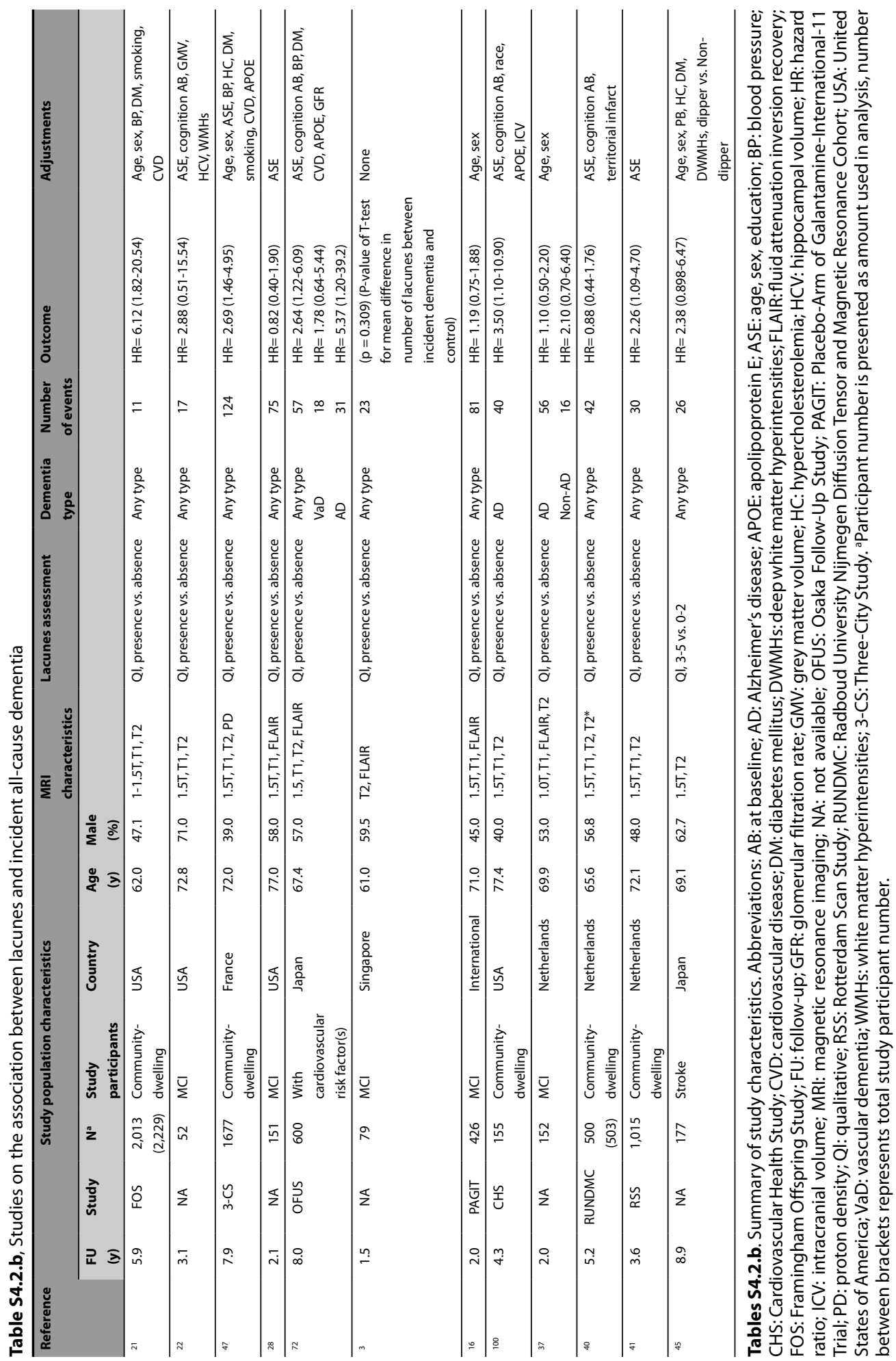



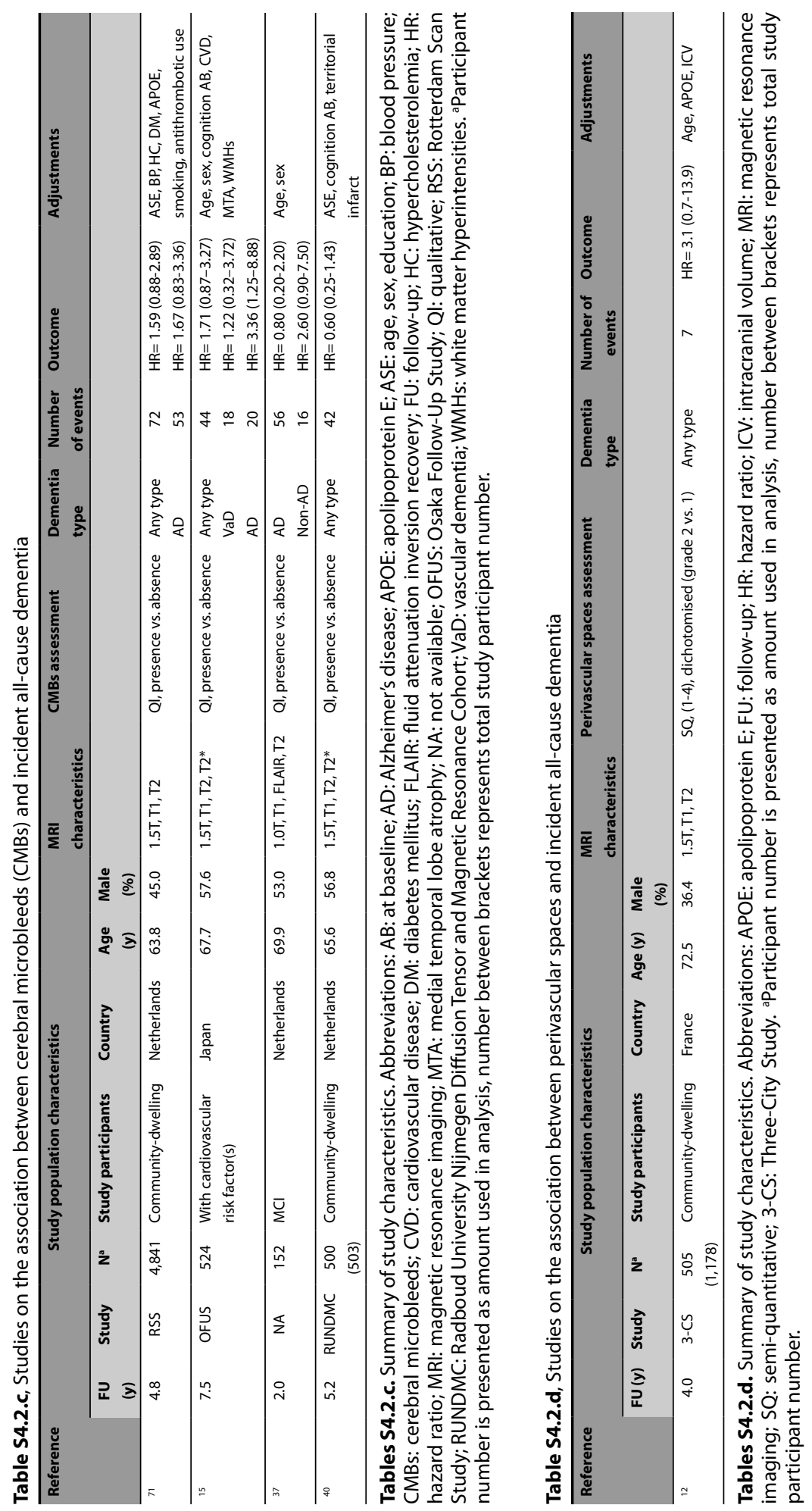


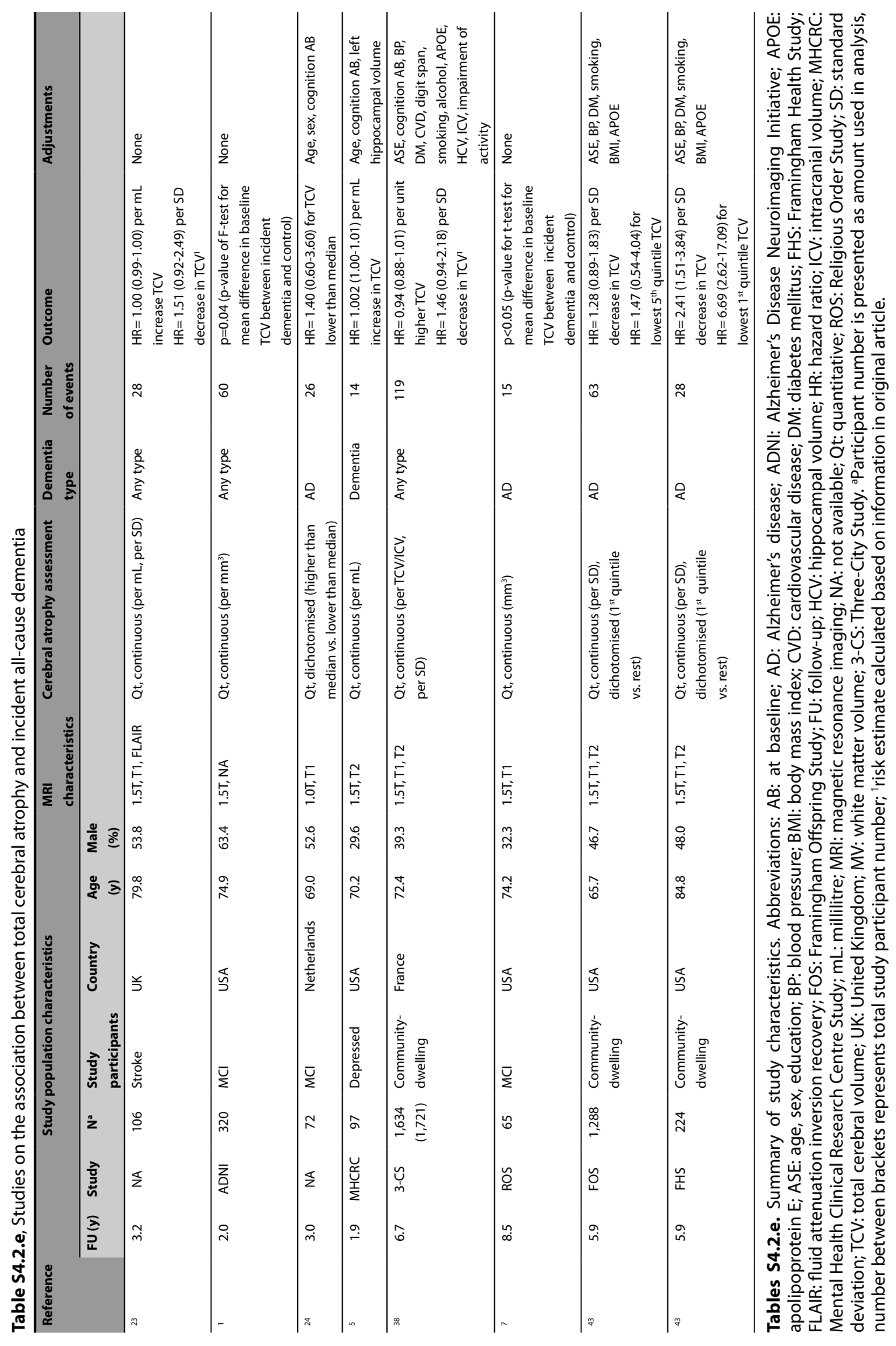




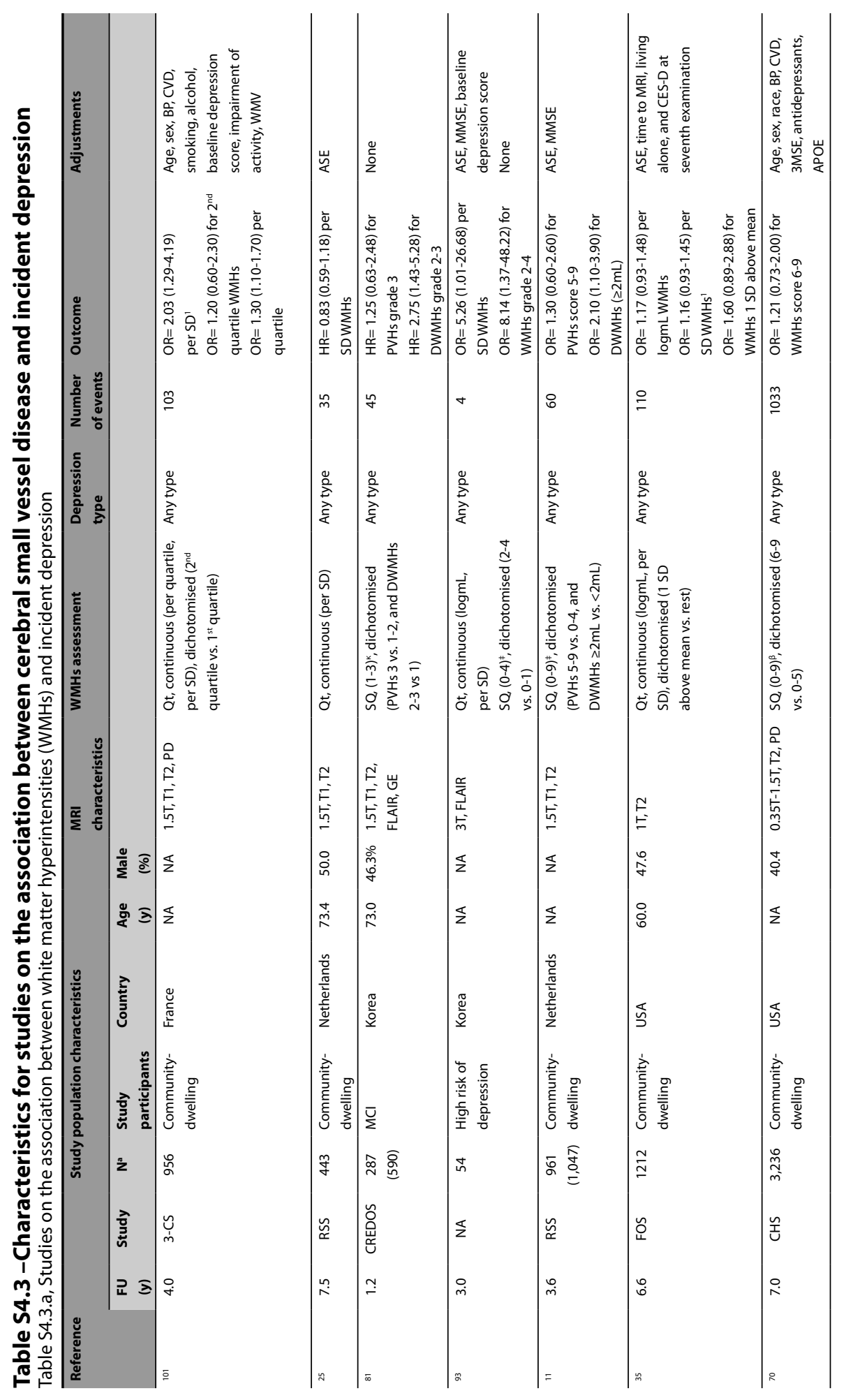




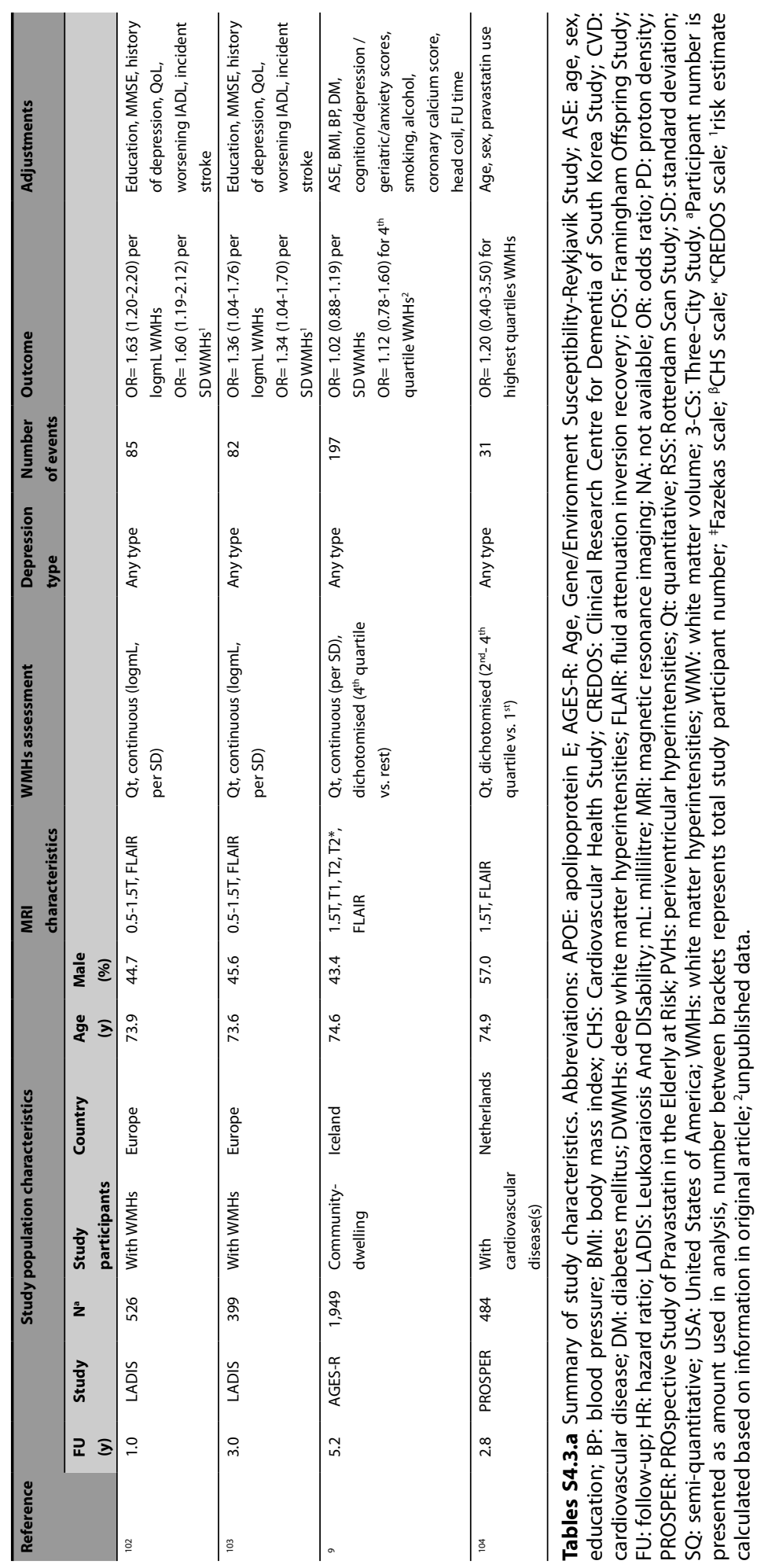




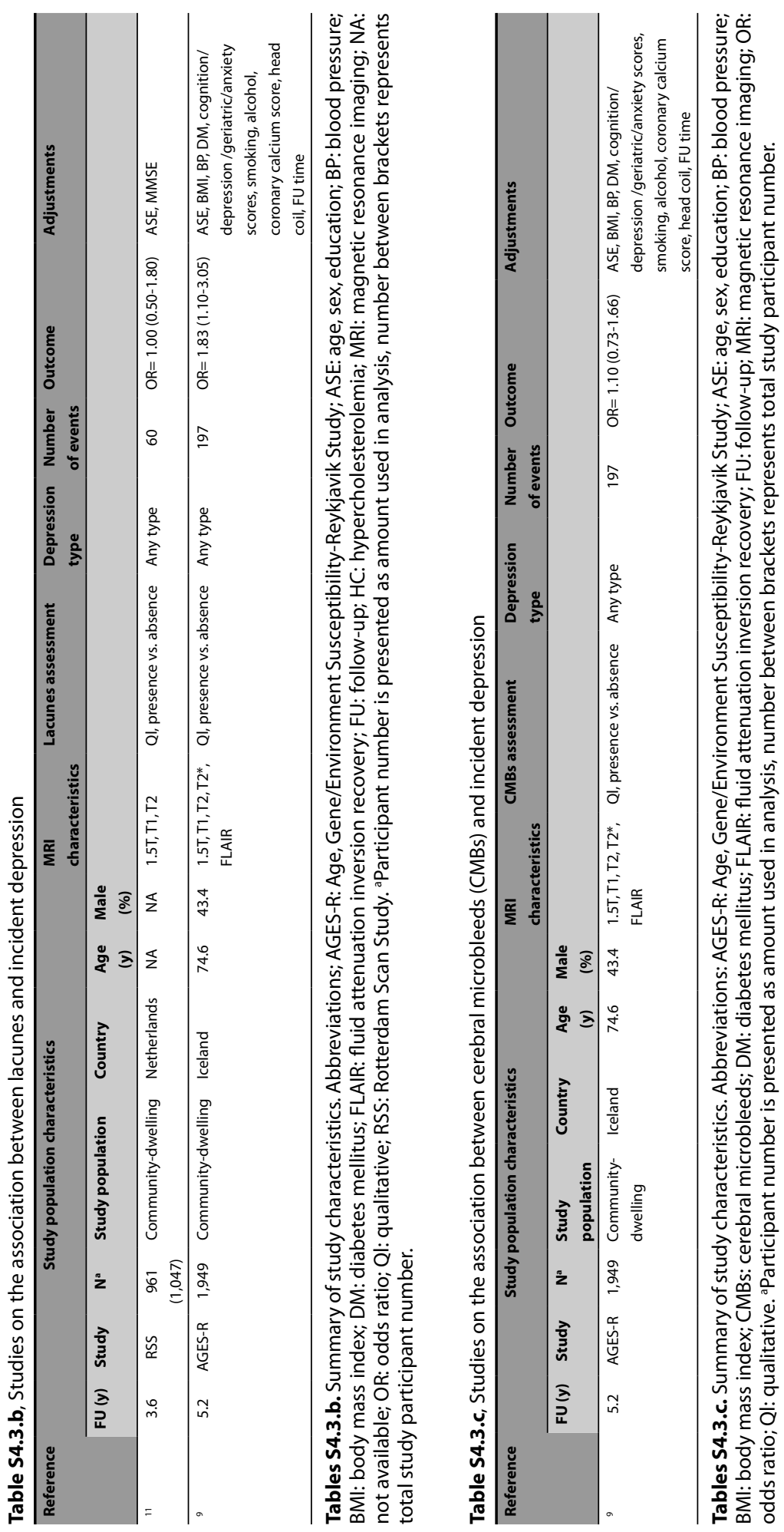




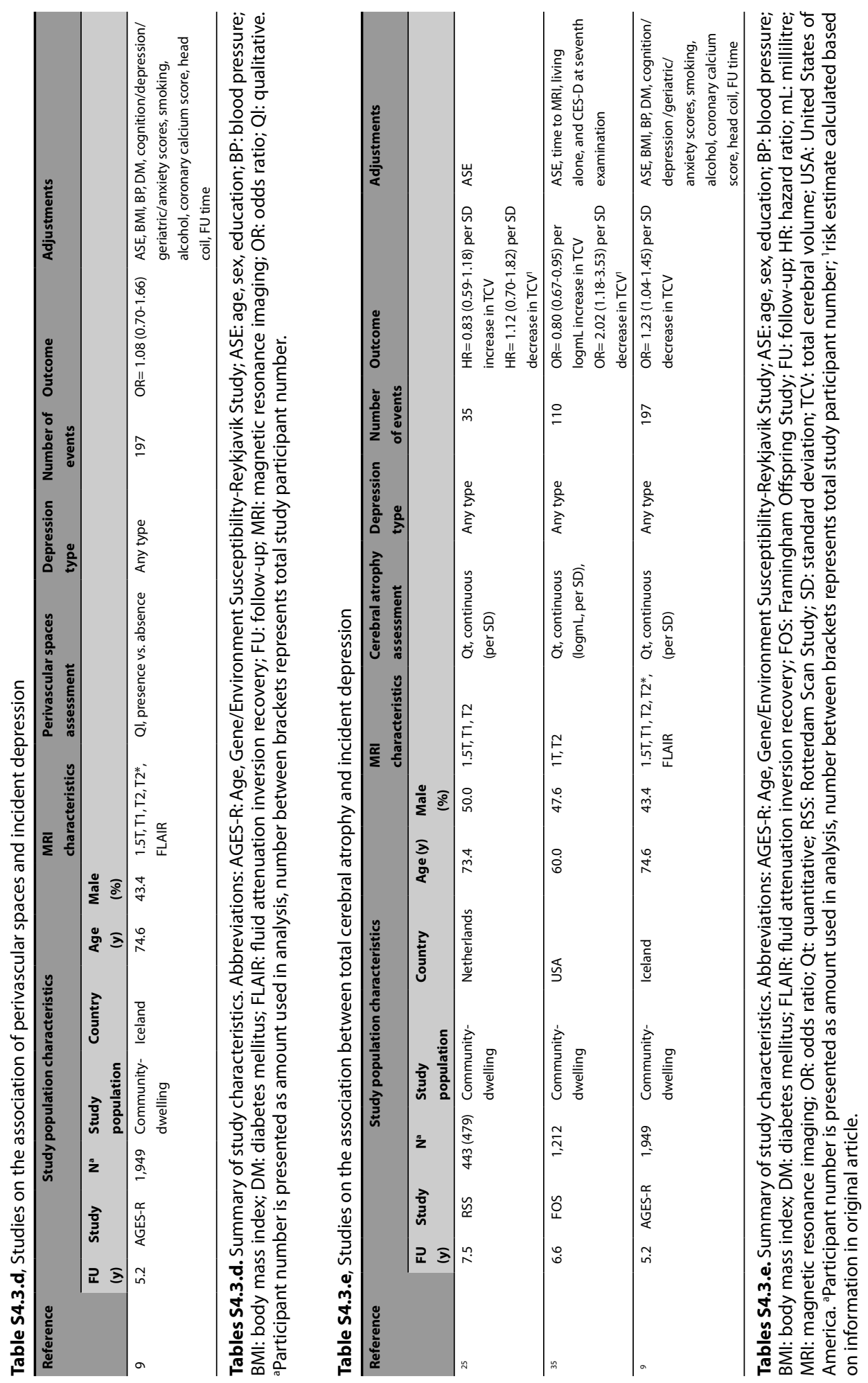




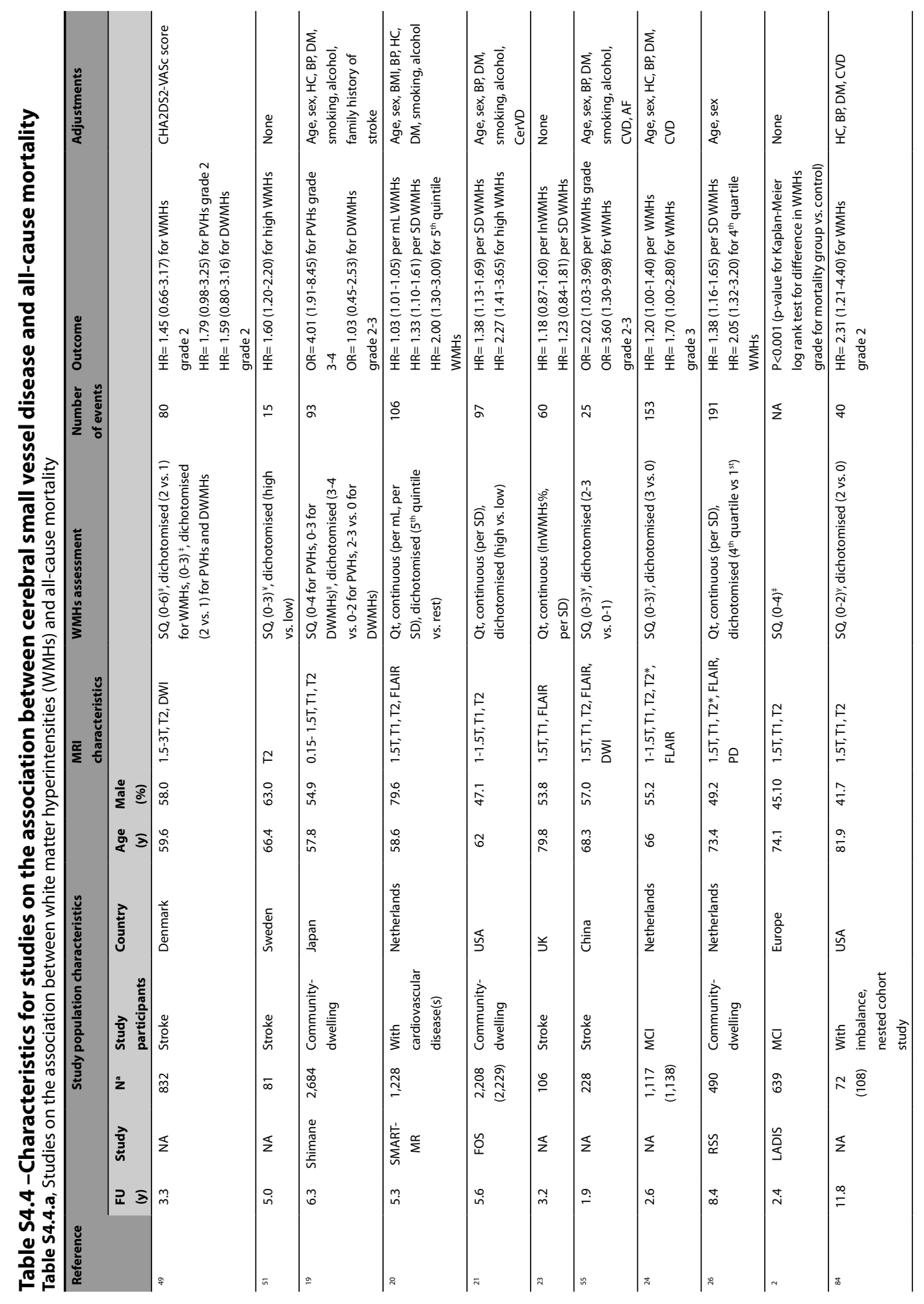




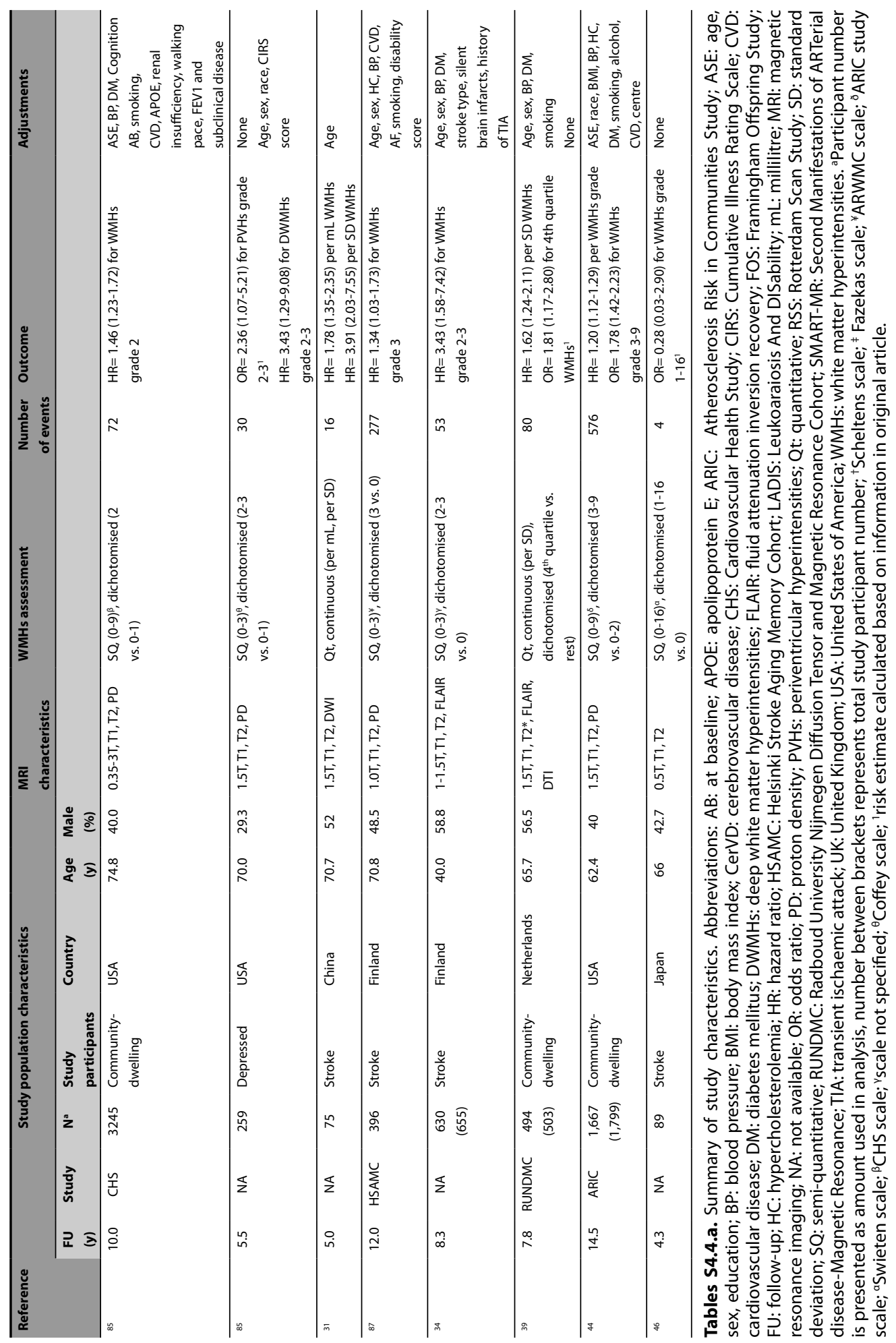




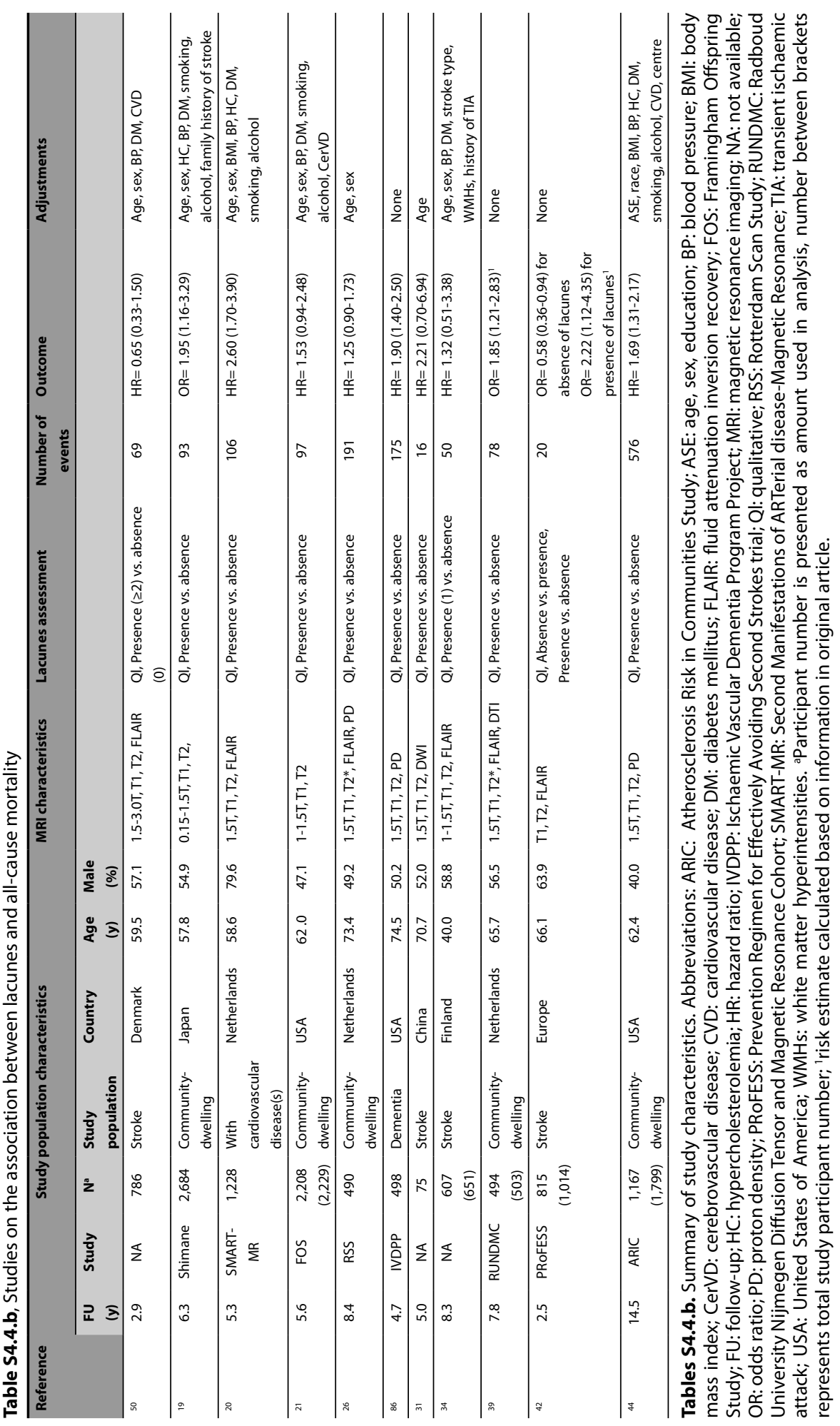




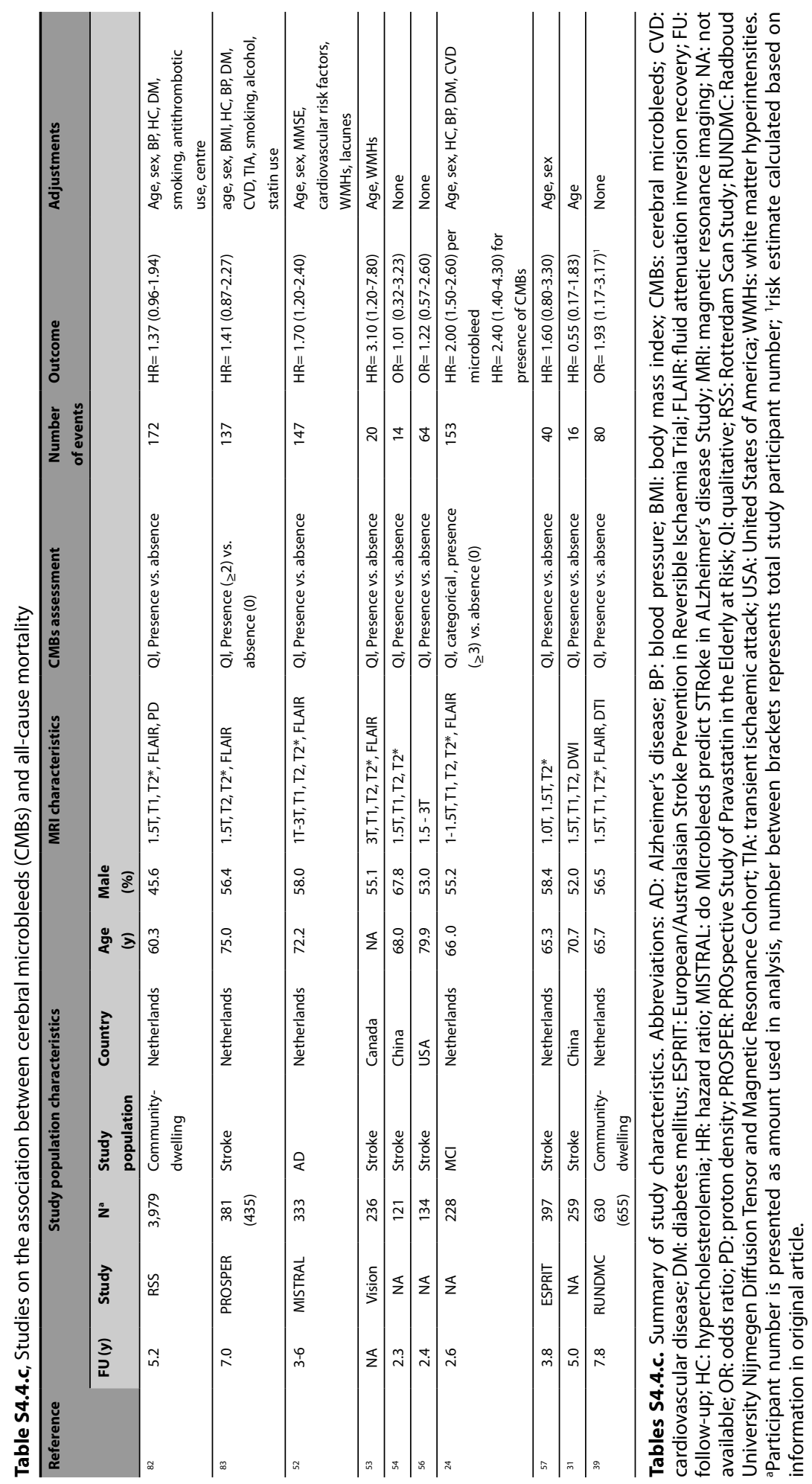




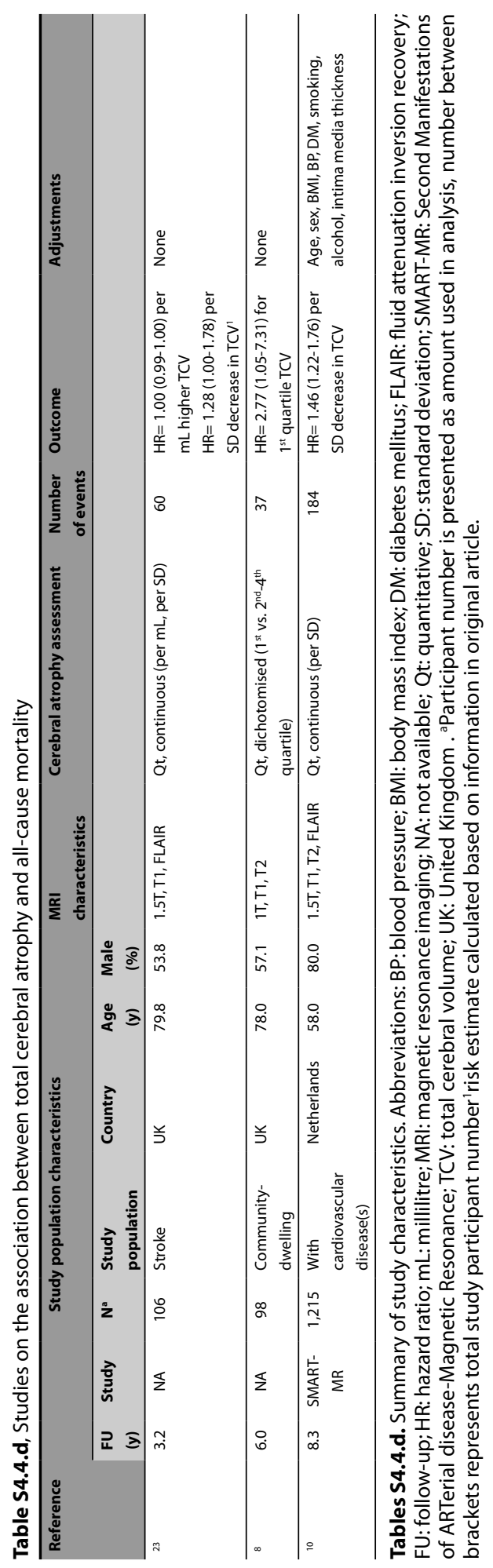




\section{References}

1. Gomar JJ, Bobes-Bascaran MT, Conejero-Goldberg C, Davies P and Goldberg TE. Utility of combinations of biomarkers, cognitive markers, and risk factors to predict conversion from mild cognitive impairment to Alzheimer disease in patients in the Alzheimer's disease neuroimaging initiative. Arch Gen Psychiatry. 2011;68:961-9.

2. Inzitari D, Pracucci G, Poggesi A, Carlucci G, Barkhof F, Chabriat H, Erkinjuntti T, Fazekas F, Ferro JM, Hennerici M, Langhorne P, O'Brien J, Scheltens P, Visser MC, Wahlund LO, Waldemar G, Wallin $A$ and Pantoni L. Changes in white matter as determinant of global functional decline in older independent outpatients: three year follow-up of LADIS (leukoaraiosis and disability) study cohort. BMJ. 2009;339:b2477.

3. Prasad K, Wiryasaputra L, Ng A and Kandiah N. White matter disease independently predicts progression from mild cognitive impairment to Alzheimer's disease in a clinic cohort. Dement Geriatr Cogn Disord. 2011;31:431-4.

4. Sluimer JD, van der Flier WM, Karas GB, Fox NC, Scheltens P, Barkhof F and Vrenken H. Wholebrain atrophy rate and cognitive decline: longitudinal MR study of memory clinic patients. Radiology. 2008;248:590-8.

5. Steffens DC, Payne ME, Greenberg DL, Byrum CE, Welsh-Bohmer KA, Wagner HR and MacFall JR. Hippocampal volume and incident dementia in geriatric depression. Am J Geriatr Psychiatry. 2002;10:62-71.

6. Steffens DC, Potter GG, McQuoid DR, Macfall JR, Payne ME, Burke JR, Plassman BL and WelshBohmer KA. Longitudinal magnetic resonance imaging vascular changes, apolipoprotein e genotype, and development of dementia in the neurocognitive outcomes of depression in the elderly study. Am J Geriatr Psychiatry. 2007;15:839-849.

7. StoubTR, DeToledo-Morrell L and Dickerson BC. Parahippocampal white matter volume predicts Alzheimer's disease risk in cognitively normal old adults. Neurobiol Aging. 2014;35:1855-1861.

8. Staff RT, Murray AD, Ahearn T, Salarirad S, Mowat D, Starr JM, Deary IJ, Lemmon H and Whalley LJ. Brain volume and survival from age 78 to 85 : the contribution of Alzheimer-type magnetic resonance imaging findings. J Am Geriatr Soc. 2010;58:688-95.

9. van Sloten TT, Sigurdsson S, van Buchem MA, Phillips CL, Jonsson PV, Ding J, Schram MT, Harris TB, Gudnason V and Launer LJ. Cerebral Small Vessel Disease and Association With Higher Incidence of Depressive Symptoms in a General Elderly Population: The AGES-Reykjavik Study. Am J Psychiatry. 2015;172:570-8.

10. van der Veen PH, Muller M, Vincken KL, Mali WP, van der Graaf $Y$ and Geerlings MI. Brain volumes and risk of cardiovascular events and mortality. The SMART-MR study. Neurobiol Aging. 2014;35:1624-31.

11. Perez HCS. Silent brain infarcts: A cause of depression in the elderly? Psychiatry Res. 2013:180-182.

12. Zhu YC, Dufouil C, Soumare A, Mazoyer B, Chabriat $H$ and Tzourio C. High degree of dilated Virchow-Robin spaces on MRI is associated with increased risk of dementia. $J$ Alzheimers Dis. 2010;22:663-72.

13. Korf ES, Wahlund LO, Visser PJ and Scheltens P. Medial temporal lobe atrophy on MRI predicts dementia in patients with mild cognitive impairment. Neurology. 2004;63:94-100.

14. Meguro K, Ishii H, Kasuya M, Akanuma K, Meguro M, Kasai M, Lee E, Hashimoto R, Yamaguchi S and Asada T. Incidence of dementia and associated risk factors in Japan: The Osaki-Tajiri Project. J Neurol Sci. 2007;260:175-82. 
15. Miwa K, Tanaka M, Okazaki S, Yagita Y, Sakaguchi M, Mochizuki H and Kitagawa K. Multiple or mixed cerebral microbleeds and dementia in patients with vascular risk factors. Neurology. 2014;83:646-53.

16. Prins ND, van der Flier WM, Brashear HR, Knol DL, van de Pol LA, Barkhof F and Scheltens P. Predictors of progression from mild cognitive impairment to dementia in the placebo-arm of a clinical trial population. J Alzheimers Dis. 2013;36:79-85.

17. Tapiola T, Pennanen C, Tapiola M, Tervo S, Kivipelto M, Hanninen T, Pihlajamaki M, Laakso MP, Hallikainen M, Hamalainen A, Vanhanen M, Helkala EL, Vanninen R, Nissinen A, Rossi R, Frisoni $\mathrm{GB}$ and Soininen H. MRI of hippocampus and entorhinal cortex in mild cognitive impairment: a follow-up study. Neurobiol Aging. 2008;29:31-8.

18. van Straaten EC, Harvey D, Scheltens P, Barkhof F, Petersen RC, Thal LJ, Jack CR, Jr. and DeCarli C. Periventricular white matter hyperintensities increase the likelihood of progression from amnestic mild cognitive impairment to dementia. J Neurol. 2008;255:1302-8.

19. Bokura H, Kobayashi S, Yamaguchi S, lijima K, Nagai A, Toyoda G, Oguro H and Takahashi K. Silent brain infarction and subcortical white matter lesions increase the risk of stroke and mortality: a prospective cohort study. J Stroke Cerebrovasc Dis. 2006;15:57-63.

20. Conijn MM, Kloppenborg RP, Algra A, Mali WP, Kappelle LJ, Vincken KL, van der Graaf Y, Geerlings $\mathrm{MI}$ and Group SS. Cerebral small vessel disease and risk of death, ischemic stroke, and cardiac complications in patients with atherosclerotic disease: the Second Manifestations of ARTerial disease-Magnetic Resonance (SMART-MR) study. Stroke. 2011;42:3105-9.

21. Debette S, Beiser A, Decarli C, Au R, Himali JJ, Kelly-Hayes M, Romero JR, Kase CS, Wolf PA and Seshadri S. Association of MRI markers of vascular brain injury with incident stroke, mild cognitive impairment, dementia, and mortality: The framingham offspring study. Stroke. 2010;41:600-606.

22. DeCarli C, Mungas D, Harvey D, Reed B, Weiner M, Chui H and Jagust W. Memory impairment, but not cerebrovascular disease, predicts progression of MCI to dementia. Neurology. 2004;63:220-7.

23. Firbank MJ, Allan LM, Burton EJ, Barber R, O'Brien JT and Kalaria RN. Neuroimaging predictors of death and dementia in a cohort of older stroke survivors. J Neurol Neurosurg Psychiatry. 2012;83:263-7.

24. Henneman WJ, Sluimer JD, Barnes J, van der Flier WM, Sluimer IC, Fox NC, Scheltens P, Vrenken H and Barkhof F. Hippocampal atrophy rates in Alzheimer disease: added value over whole brain volume measures. Neurology. 2009;72:999-1007.

25. Ikram MA, Luijendijk HJ, Vernooij MW, Hofman A, Niessen WJ, van der Lugt A, Tiemeier $\mathrm{H}$ and Breteler MM. Vascular brain disease and depression in the elderly. Epidemiology. 2010;21:78-81.

26. Ikram MA, Vernooij MW, Vrooman HA, Hofman A and Breteler MM. Brain tissue volumes and small vessel disease in relation to the risk of mortality. Neurobiol Aging. 2009;30:450-6.

27. Imaizumi T, Inamura S, Nomura T, Kanno A and Kim SN. The Severity of White Matter Lesions Possibly Influences Stroke Recurrence in Patients with Histories of Lacunar Infarctions. J Stroke Cerebrovasc Dis. 2015;24:2154-60.

28. Kantarci K, Weigand SD, Przybelski SA, Shiung MM, Whitwell JL, Negash S, Knopman DS, Boeve BF, O'Brien PC, Petersen RC and Jack CR, Jr. Risk of dementia in MCl: combined effect of cerebrovascular disease, volumetric MRI, and 1H MRS. Neurology. 2009;72:1519-25.

29. Kobayashi S, Okada K, Koide H, Bokura H and Yamaguchi S. Subcortical silent brain infarction as a risk factor for clinical stroke. Stroke. 1997;28:1932-9. 
30. Kumral E, Gulluoglu H, Alakbarova N, Karaman B, Deveci EE, Bayramov A, Evyapan D, Gokcay $\mathrm{F}$ and Orman M. Association of leukoaraiosis with stroke recurrence within 5 years after initial stroke. J Stroke Cerebrovasc Dis. 2015;24:573-82.

31. Mok VC, Lau AY, Wong A, Lam WW, Chan A, Leung H, Wong E, Soo Y, Leung T and Wong LK. Longterm prognosis of Chinese patients with a lacunar infarct associated with small vessel disease: a five-year longitudinal study. Int J Stroke. 2009;4:81-8.

32. Naka H, Nomura E, Takahashi T, Wakabayashi S, Mimori Y, Kajikawa H, Kohriyama $T$ and Matsumoto M. Combinations of the presence or absence of cerebral microbleeds and advanced white matter hyperintensity as predictors of subsequent stroke types. AJNR Am J Neuroradiol. 2006;27:830-5.

33. Poels MM, Steyerberg EW, Wieberdink RG, Hofman A, Koudstaal PJ, Ikram MA and Breteler MM. Assessment of cerebral small vessel disease predicts individual stroke risk. J Neurol Neurosurg Psychiatry. 2012;83:1174-9.

34. Putaala J, Haapaniemi E, Kurkinen M, Salonen O, Kaste M and Tatlisumak T. Silent brain infarcts, leukoaraiosis, and long-term prognosis in young ischemic stroke patients. Neurology. 2011;76:1742-9.

35. Qiu WQ, Himali JJ, Wolf PA, DeCarli DC, Beiser A and Au R. Effects of white matter integrity and brain volumes on late life depression in the Framingham Heart Study. Int J Geriatr Psychiatry. 2016.

36. Soo YO, Yang SR, Lam WW, Wong A, Fan YH, Leung HH, Chan AY, Leung C, Leung TW and Wong LK. Risk vs benefit of anti-thrombotic therapy in ischaemic stroke patients with cerebral microbleeds. J Neurol. 2008;255:1679-86.

37. Staekenborg SS, Koedam EL, Henneman WJ, Stokman P, Barkhof F, Scheltens P and van der Flier WM. Progression of mild cognitive impairment to dementia: contribution of cerebrovascular disease compared with medial temporal lobe atrophy. Stroke. 2009;40:1269-74.

38. Stephan BCM, Tzourio C, Auriacombe S, Amieva H, Dufouil C, Alperovitch A and Kurth T. Usefulness of data from magnetic resonance imaging to improve prediction of dementia: Population based cohort study. BMJ 2015;350.

39. van der Holst HM, van Uden IW, Tuladhar AM, de Laat KF, van Norden AG, Norris DG, van Dijk EJ, Rutten-Jacobs LC and de Leeuw FE. Factors Associated With 8-Year Mortality in Older Patients With Cerebral Small Vessel Disease: The Radboud University Nijmegen Diffusion Tensor and Magnetic Resonance Cohort (RUN DMC) Study. JAMA Neurol. 2016;73:402-9.

40. van Uden IW, van der Holst HM, Tuladhar AM, van Norden AG, de Laat KF, Rutten-Jacobs LC, Norris DG, Claassen JA, van Dijk EJ, Kessels RP and de Leeuw FE. White Matter and Hippocampal Volume Predict the Risk of Dementia in Patients with Cerebral Small Vessel Disease: The RUN DMC Study. J Alzheimers Dis. 2015;49:863-73.

41. Vermeer SE, Prins ND, Den Heijer T, Hofman A, Koudstaal PJ and Breteler MMB. Silent brain infarcts and the risk of dementia and cognitive decline. N Eng/ J Med. 2003;348:1215-1222.

42. Weber R, Weimar C, Wanke I, Moller-Hartmann C, Gizewski ER, Blatchford J, Hermansson K, Demchuk AM, Forsting M, Sacco RL, Saver JL, Warach S, Diener HC, Diehl A and Group PRIS. Risk of recurrent stroke in patients with silent brain infarction in the Prevention Regimen for Effectively Avoiding Second Strokes (PRoFESS) imaging substudy. Stroke. 2012;43:350-5.

43. Weinstein G, Beiser AS, Decarli C, Au R, Wolf PA and Seshadri S. Brain imaging and cognitive predictors of stroke and alzheimer disease in the framingham heart study. Stroke. 2013;44:27872794. 
44. Windham BG, Deere B, Griswold ME, Wang W, Bezerra DC, Shibata D, Butler K, Knopman D, Gottesman RF, Heiss $G$ and Mosley TH. Small brain lesions and incident stroke and mortality: A cohort study. Ann Intern Med. 2015;163:22-31.

45. Yamamoto Y, Akiguchi I, Oiwa K, Hayashi M, Kasai T and Ozasa K. Twenty-four-hour blood pressure and MRI as predictive factors for different outcomes in patients with lacunar infarct. Stroke. 2002;33:297-305.

46. Yamauchi $H$, Fukuda $H$ and Oyanagi C. Significance of white matter high intensity lesions as a predictor of stroke from arteriolosclerosis. J Neurol Neurosurg Psychiatry. 2002;72:576-582.

47. Kaffashian S, Soumare A, Zhu YC, Mazoyer B, Debette S and Tzourio C. Long-Term Clinical Impact of Vascular Brain Lesions on Magnetic Resonance Imaging in Older Adults in the Population. Stroke. 2016;47:2865-2869.

48. Buyck JF, Dufouil C, Mazoyer B, Maillard P, Ducimetiere P, Alperovitch A, Bousser MG, Kurth T and Tzourio C. Cerebral white matter lesions are associated with the risk of stroke but not with other vascular events: the 3-City Dijon Study. Stroke. 2009;40:2327-31.

49. Andersen SD, Larsen TB, Gorst-Rasmussen A, Yavarian Y, Lip GY and Bach FW. White Matter Hyperintensities Improve Ischemic Stroke Recurrence Prediction. Cerebrovasc Dis. 2017;43:17-24.

50. Andersen SD, Skjoth F, Yavarian Y, Bach FW, Lip GY and Larsen TB. Multiple Silent Lacunes Are Associated with Recurrent Ischemic Stroke. Cerebrovasc Dis. 2016;42:73-80.

51. Appelros $P$, Samuelsson M and Lindell D. Lacunar infarcts: functional and cognitive outcomes at five years in relation to MRI findings. Cerebrovasc Dis. 2005;20:34-40.

52. Benedictus MR, Prins ND, Goos JD, Scheltens P, Barkhof F and van der Flier WM. Microbleeds, Mortality, and Stroke in Alzheimer Disease: The MISTRAL Study. JAMA Neurol. 2015;72:539-45.

53. Boulanger JM, Coutts SB, Eliasziw M, Gagnon AJ, Simon JE, Subramaniam S, Sohn CH, Scott $\mathrm{J}$ and Demchuk AM. Cerebral microhemorrhages predict new disabling or fatal strokes in patients with acute ischemic stroke or transient ischemic attack. Stroke. 2006;37:911-914.

54. Fan YH, Zhang L, Lam WWM, Mok VCT and Wong KS. Cerebral microbleeds as a risk factor for subsequent intracerebral hemorrhages among patients with acute ischemic stroke. Stroke. 2003;34:2459-2462.

55. Fu JH, Lu CZ, Hong Z, Dong Q, Luo Y and Wong KS. Extent of white matter lesions is related to acute subcortical infarcts and predicts further stroke risk in patients with first ever ischaemic stroke. J Neurol Neurosurg Psychiatry. 2005;76:793-796.

56. Haji S, Zubair A, Planchard R and Flemming K. Clinical relevance of cerebral microbleeds in patients with atrial fibrillation and stroke. Stroke. 2015;46.

57. Kwa VIH, Algra A, Brundel M, Bouvy W and Kappelle LJ. Microbleeds as a predictor of intracerebral hemorrhage in patients receiving oral antithrombotic drugs after a TIA or minor ischemic stroke: A prospective cohort study in Western outpatients. Cerebrovasc Dis. 2012;33:779-780.

58. Akoudad S, Portegies MLP, Koudstaal PJ, Hofman A, Van Der Lugt A, Ikram MA and Vernooij MW. Cerebral Microbleeds Are Associated with an Increased Risk of Stroke: The Rotterdam Study. Circulation. 2015;132:509-516.

59. Bernick C, Kuller L, Dulberg C, Longstreth WT, Jr., Manolio T, Beauchamp N and Price T. Silent MRI infarcts and the risk of future stroke: the cardiovascular health study. Neurology. 2001;57:1222-9.

60. Bokura H, Saika R, Yamaguchi T, Nagai A, Oguro H, Kobayashi S and Yamaguchi S. Microbleeds are associated with subsequent hemorrhagic and ischemic stroke in healthy elderly individuals. Stroke. 2011;42:1867-1871. 
61. Gioia LC, Tollard E, Dubuc V, Lanthier S, Deschaintre Y, Chagnon M and Poppe AY. Silent ischemic lesions in young adults with first stroke are associated with recurrent stroke. Neurology. 2012;79:1208-14.

62. Ishikawa J, Tamura Y, Hoshide S, Eguchi K, Ishikawa S, Shimada K and Kario K. Low-grade inflammation is a risk factor for clinical stroke events in addition to silent cerebral infarcts in Japanese older hypertensives: the Jichi Medical School ABPM Study, wave 1. Stroke. 2007;38:911-7.

63. Naganuma T, Takemoto Y, Shoji T, Ishimura E, Okamura M and Nakatani T. Cerebral Microbleeds Predict Intracerebral Hemorrhage in Hemodialysis Patients. Stroke. 2015;46:2107-12.

64. Nishikawa T, Ueba T, Kajiwara M, Fujisawa I, Miyamatsu N and Yamashita K. Cerebral microbleeds predict first-ever symptomatic cerebrovascular events. Clin Neurol Neurosurg. 2009;111:825-8.

65. Thijs V, Lemmens R, Schoofs C, Gorner A, Van Damme P, Schrooten M and Demaerel P. Microbleeds and the risk of recurrent stroke. Stroke. 2010;41:2005-2009.

66. Gerdes VE, Kwa VI, ten Cate H, Brandjes DP, Buller HR and Stam J. Cerebral white matter lesions predict both ischemic strokes and myocardial infarctions in patients with established atherosclerotic disease. Atherosclerosis. 2006;186:166-72.

67. Kuller LH, Longstreth WT, Jr., Arnold AM, Bernick C, Bryan RN, Beauchamp NJ, Jr. and Cardiovascular Health Study Collaborative Research G. White matter hyperintensity on cranial magnetic resonance imaging: a predictor of stroke. Stroke. 2004;35:1821-5.

68. Melkas S, Sibolt G, Oksala NKJ, Putaala J, Pohjasvaara T, Kaste M, Karhunen PJ and Erkinjuntti T. Extensive white matter changes predict stroke recurrence up to 5 years after a first-ever ischemic stroke. Cerebrovasc Dis. 2012;34:191-198.

69. Smith EE, Gurol ME, Eng JA, Engel CR, Nguyen TN, Rosand J and Greenberg SM. White matter lesions, cognition, and recurrent hemorrhage in lobar intracerebral hemorrhage. Neurology. 2004;63:1606-12.

70. Steffens DC, Krishnan KR, Crump C and Burke GL. Cerebrovascular disease and evolution of depressive symptoms in the cardiovascular health study. Stroke. 2002;33:1636-44.

71. Akoudad S, Wolters FJ, Viswanathan A, de Bruijn RF, van der Lugt A, Hofman A, Koudstaal PJ, Ikram MA and Vernooij MW. Association of Cerebral Microbleeds With Cognitive Decline and Dementia. JAMA Neurol. 2016;73:934-43.

72. Kitagawa K, Miwa K, Yagita Y, Okazaki S, Sakaguchi M and Mochizuki H. Association between carotid stenosis or lacunar infarction and incident dementia in patients with vascular risk factors. Eur J Neurol. 2015;22:187-192.

73. Bombois S, Debette S, Bruandet A, Delbeuck X, Delmaire C, Leys D and Pasquier F. Vascular subcortical hyperintensities predict conversion to vascular and mixed dementia in MCl patients. Stroke. 2008;39:2046-51.

74. Firbank MJ, Teodorczuk A, van der Flier WM, Gouw AA, Wallin A, Erkinjuntti T, Inzitari D, Wahlund LO, Pantoni L, Poggesi A, Pracucci G, Langhorne P and O'Brien JT. Relationship between progression of brain white matter changes and late-life depression: 3-year results from the LADIS study. Br J Psychiatry. 2012;201:40-5.

75. Ikram MA, Vrooman HA, Vernooij MW, Heijer Td, Hofman A, Niessen WJ, van der Lugt A, Koudstaal $\mathrm{PJ}$ and Breteler MMB. Brain tissue volumes in relation to cognitive function and risk of dementia. Neurobiol Aging. 2010;31:378-386.

76. Kuller LH. [Risk factors for dementia in the Cardiovascular Health Study cognition study]. Rev Neurol. 2003;37:122-6.

77. Prins ND, van Dijk EJ, den Heijer T, Vermeer SE, Koudstaal PJ, Oudkerk M, Hofman A and Breteler MM. Cerebral white matter lesions and the risk of dementia. Arch Neurol. 2004;61:1531-4. 
78. Smith EE, Egorova S, Blacker D, Killiany RJ, Muzikansky A, Dickerson BC, Tanzi RE, Albert MS, Greenberg SM and Guttmann CR. Magnetic resonance imaging white matter hyperintensities and brain volume in the prediction of mild cognitive impairment and dementia. Arch Neurol. 2008;65:94-100.

79. Verdelho A, Madureira S, Moleiro C, Ferro JM, Santos CO, Erkinjuntti T, Pantoni L, Fazekas F, Visser $M$, Waldemar G, Wallin A, Hennerici M and Inzitari D. White matter changes and diabetes predict cognitive decline in the elderly: the LADIS study. Neurology. 2010;75:160-7.

80. Kim S, Choi SH, Lee YM, Kim MJ, Kim YD, Kim JY, Park JH, Myung W, Na HR, Han HJ, Shim YS, Kim $\mathrm{JH}$, Yoon SJ, Kim SY and Kim DK. Periventricular white matter hyperintensities and the risk of dementia: a CREDOS study. Int Psychogeriatr. 2015;27:2069-77.

81. Kim S, Woo SY, Kang HS, Lim SW, Choi SH, Myung W, Jeong JH, Lee Y, Hong CH, Kim JH, Na H, Carroll BJ and Kim DK. Factors related to prevalence, persistence, and incidence of depressive symptoms in mild cognitive impairment: vascular depression construct. Int J Geriatr Psychiatry. 2016;31:818-26.

82. Akoudad S, Ikram MA, Koudstaal PJ, Hofman A, Van Der Lugt A and Vernooij MW. Cerebral microbleeds and the risk of mortality in the general population. Eur J Epidemiol. 2013;28:815-821.

83. Altmann-Schneider I, Trompet S, de Craen AJ, van Es AC, Jukema JW, Stott DJ, Sattar N, Westendorp RG, van Buchem MA and van der Grond J. Cerebral microbleeds are predictive of mortality in the elderly. Stroke. 2011;42:638-44.

84. Kerber KA, Whitman GT, Brown DL and Baloh RW. Increased risk of death in community-dwelling older people with white matter hyperintensities on MRI. J Neurol Sci. 2006;250:33-8.

85. Kuller LH, Arnold AM, Longstreth WT, Jr., Manolio TA, O'Leary DH, Burke GL, Fried LP and Newman $A B$. White matter grade and ventricular volume on brain MRI as markers of longevity in the cardiovascular health study. Neurobiol Aging. 2007;28:1307-15.

86. Lavretsky H, Zheng L, Weiner MW, Mungas D, Reed B, Kramer JH, Jagust W, Chui H and Mack WJ. Association of depressed mood and mortality in older adults with and without cognitive impairment in a prospective naturalistic study. Am J Psychiatry. 2010;167:589-597.

87. Oksala NK, Oksala A, Pohjasvaara T, Vataja R, Kaste M, Karhunen PJ and Erkinjuntti T. Age related white matter changes predict stroke death in long term follow-up. J Neurol Neurosurg Psychiatry. 2009;80:762-6.

88. Godin O, Tzourio C, Rouaud O, Zhu Y, Maillard P, Pasquier F, Crivello F, Alperovitch A, Mazoyer $B$ and Dufouil C. Joint effect of white matter lesions and hippocampal volumes on severity of cognitive decline: the 3C-Dijon MRI study. J Alzheimers Dis. 2010;20:453-63.

89. Geroldi C, Rossi R, Calvagna C, Testa C, Bresciani L, Binetti G, Zanetti O and Frisoni GB. Medial temporal atrophy but not memory deficit predicts progression to dementia in patients with mild cognitive impairment. J Neurol Neurosurg Psychiatry. 2006;77:1219-22.

90. Kario K, Shimada K, Schwartz JE, Matsuo T, Hoshide S and Pickering TG. Silent and clinically overt stroke in older Japanese subjects with white-coat and sustained hypertension. J Am Coll Cardiol. 2001;38:238-45.

91. Levy RM, Steffens DC, McQuoid DR, Provenzale JM, MacFall JR and Krishnan KR. MRI lesion severity and mortality in geriatric depression. Am J Geriatr Psychiatry. 2003;11:678-82.

92. Lopez OL, Klunk WE, Mathis C, Coleman RL, Price J, Becker JT, Aizenstein HJ, Snitz B, Cohen A, Ikonomovic M, McDade E, DeKosky ST, Weissfeld L and Kuller LH. Amyloid, neurodegeneration, and small vessel disease as predictors of dementia in the oldest-old. Neurology. 2014;83:1804-11.

93. Park JH, Lee SB, Lee JJ, Yoon JC, Han JW, Kim TH, Jeong HG, Newhouse PA, Taylor WD, Kim JH, Woo $\mathrm{JI}$ and Kim KW. Epidemiology of MRI-defined vascular depression: A longitudinal, communitybased study in Korean elders. J Affect Disord. 2015;180:200-6. 
94. Kaffashian S, Tzourio C, Zhu YC, Mazoyer B and Debette S. Differential Effect of White-Matter Lesions and Covert Brain Infarcts on the Risk of Ischemic Stroke and Intracerebral Hemorrhage. Stroke. 2016;47:1923-5.

95. Naganuma T, Takemoto Y, Shoji T, Shima H, Ishimura E, Okamura M and Nakatani T. Cerebral white matter hyperintensity predicts cardiovascular events in haemodialysis patients. Nephrology. 2013;18:676-81.

96. Ntaios G, Lip GYH, Lambrou D, Papavasileiou V, Manios E, Milionis H, Spengos K, Makaritsis K and Vemmos K. Leukoaraiosis and stroke recurrence risk in patients with and without atrial fibrillation. Neurology. 2015;84:1213-1219.

97. Imaizumi T, Inamura S and Nomura T. Contribution of Deep Microbleeds to Stroke Recurrence: Differences between Patients with Past Deep Intracerebral Hemorrhages and Lacunar Infarctions. J Stroke Cerebrovasc Dis. 2015;24:1855-1864.

98. Folsom AR, Yatsuya H, Mosley Jr TH, Psaty BM and Longstreth Jr WT. Risk of intraparenchymal hemorrhage with magnetic resonance imaging-defined leukoaraiosis and brain infarcts. Annals of Neurology. 2012;71:552-559.

99. Debette $\mathrm{S}$ and Markus HS. The clinical importance of white matter hyperintensities on brain magnetic resonance imaging: systematic review and meta-analysis. BMJ. 2010;341:c3666.

100. Rosano C, Aizenstein HJ, Wu M, Newman AB, Becker JT, Lopez OL and Kuller LH. Focal atrophy and cerebrovascular disease increase dementia risk among cognitively normal older adults. $J$ Neuroimaging. 2007;17:148-55.

101.Godin O, Dufouil C, Maillard P, Delcroix N, Mazoyer B, Crivello F, Alperovitch A and Tzourio C. White matter lesions as a predictor of depression in the elderly: the 3C-Dijon study. Biol Psychiatry. 2008;63:663-9.

102. Teodorczuk A, O'Brien JT, Firbank MJ, Pantoni L, Poggesi A, Erkinjuntti T, Wallin A, Wahlund LO, Gouw A, Waldemar G, Schmidt R, Ferro JM, Chabriat H, Bazner H and Inzitari D. White matter changes and late-life depressive symptoms: longitudinal study. Br J Psychiatry. 2007;191:212-7.

103. Teodorczuk A, Firbank MJ, Pantoni L, Poggesi A, Erkinjuntti T, Wallin A, Wahlund LO, Scheltens P, Waldemar G, Schrotter G, Ferro JM, Chabriat H, Bazner H, Visser M, Inzitari D, O'Brien JT and Group L. Relationship between baseline white-matter changes and development of late-life depressive symptoms: 3-year results from the LADIS study. Psychol Med. 2010;40:603-10.

104. Versluis CE, van der Mast RC, van Buchem MA, Bollen EL, Blauw GJ, Eekhof JA, van der Wee NJ and de Craen AJ. Progression of cerebral white matter lesions is not associated with development of depressive symptoms in elderly subjects at risk of cardiovascular disease: The PROSPER Study. Int J Geriatr Psychiatry. 2006;21:375-81. 
Table S5.1 - Newcastle-Ottawa Scale scores for studies on the association between cerebral small vessel disease and incident ischaemic and haemorrhagic stroke

\begin{tabular}{|c|c|c|c|c|c|c|c|c|}
\hline Study & S1 & S2 & S3 & C1 & 01 & 02 & 03 & Total score \\
\hline Akoudad et al., $2011^{5}$ & 1 & 1 & 0 & 2 & 1 & 1 & 1 & 7 \\
\hline Andersen et al., $2016^{2}$ & 0 & 1 & 0 & 1 & 1 & 0 & 1 & 4 \\
\hline Andersen et al., $2017^{3}$ & 0 & 1 & 0 & 0 & 1 & 1 & 1 & 4 \\
\hline Appelros et al., $2005^{4}$ & 0 & 0 & 0 & 0 & 1 & 0 & 1 & 2 \\
\hline Benedictus et al., $2015^{5}$ & 0 & 0 & 0 & 1 & 1 & 0 & 1 & 3 \\
\hline Bernick et al., $2001^{6}$ & 1 & 1 & 1 & 1 & 0 & 1 & 0 & 5 \\
\hline Bokura et al., $2011^{7}$ & 1 & 0 & 1 & 1 & 0 & 0 & 1 & 4 \\
\hline Bokura et al., $2006^{8}$ & 1 & 0 & 0 & 2 & 1 & 1 & 0 & 5 \\
\hline Boulanger et al., $2006^{9}$ & 0 & 1 & 0 & 0 & 0 & 0 & 1 & 2 \\
\hline Buyck et al., $2009^{10}$ & 1 & 1 & 1 & 2 & 1 & 1 & 1 & 8 \\
\hline Conijn et al., $2011^{11}$ & 0 & 1 & 0 & 2 & 1 & 1 & 1 & 6 \\
\hline Debette et al., $2010^{12}$ & 1 & 0 & 1 & 2 & 1 & 1 & 0 & 6 \\
\hline Fan et al., $2003^{13}$ & 0 & 1 & 0 & 0 & 0 & 0 & 1 & 2 \\
\hline Fu et al., $2005^{14}$ & 0 & 1 & 0 & 0 & 0 & 0 & 1 & 2 \\
\hline Gerdes et al., $2006^{15}$ & 0 & 1 & 0 & 0 & 0 & 0 & 0 & 1 \\
\hline Gioia et al., $2012^{16}$ & 0 & 1 & 0 & 2 & 0 & 0 & 0 & 3 \\
\hline Haji et al., $2015^{17}$ & 0 & 0 & 0 & 0 & 0 & 0 & 0 & 0 \\
\hline Imaizumi et al., $2015^{18}$ & 0 & 1 & 0 & 0 & 0 & 0 & 1 & 2 \\
\hline Inzitari et al., $2009^{19}$ & 0 & 0 & 0 & 0 & 1 & 0 & 0 & 1 \\
\hline Ishikawa et al., $2007^{20}$ & 1 & 1 & 1 & 0 & 0 & 0 & 0 & 3 \\
\hline Kaffashian et al., 2016a ${ }^{21}$ & 1 & 1 & 1 & 2 & 1 & 1 & 1 & 8 \\
\hline Kaffashian et al., 2016b 22 & 1 & 1 & 1 & 2 & 1 & 1 & 1 & 8 \\
\hline Kario et al., $2001^{23}$ & 0 & 1 & 1 & 1 & 1 & 0 & 1 & 5 \\
\hline Kobayashi et al., $1997^{24}$ & 1 & 0 & 1 & 0 & 0 & 0 & 1 & 3 \\
\hline Kuller et al., $2004^{25}$ & 1 & 0 & 1 & 1 & 1 & 0 & 0 & 4 \\
\hline Kumral et al., $2015^{26}$ & 0 & 0 & 0 & 0 & 0 & 1 & 1 & 2 \\
\hline Kwa et al., $2012^{27}$ & 0 & 0 & 0 & 1 & 0 & 0 & 1 & 2 \\
\hline Melkas et al., $2012^{28}$ & 0 & 0 & 0 & 1 & 1 & 1 & 0 & 3 \\
\hline Mok et al., $2009^{29}$ & 0 & 1 & 0 & 0 & 0 & 1 & 1 & 3 \\
\hline Naganuma et al., $2013^{30}$ & 0 & 1 & 1 & 0 & 0 & 0 & 1 & 3 \\
\hline Naganuma et al., $2015^{31}$ & 0 & 1 & 1 & 2 & 0 & 1 & 1 & 6 \\
\hline Naka et al., $2006^{32}$ & 0 & 0 & 0 & 2 & 1 & 0 & 1 & 4 \\
\hline Nishikawa et al., $2009^{33}$ & 1 & 1 & 1 & 1 & 1 & 0 & 0 & 5 \\
\hline Ntaios et al., $2015^{34}$ & 0 & 0 & 0 & 0 & 1 & 0 & 0 & 1 \\
\hline Poels et al., $2012^{35}$ & 1 & 1 & 1 & 2 & 1 & 1 & 1 & 8 \\
\hline Putaala et al., $2011^{36}$ & 0 & 0 & 0 & 1 & 0 & 1 & 1 & 3 \\
\hline Smith et al., $2004^{37}$ & 0 & 0 & 0 & 0 & 0 & 0 & 0 & 0 \\
\hline Soo et al., $2008^{38}$ & 0 & 1 & 0 & 0 & 1 & 0 & 1 & 3 \\
\hline Thijs et al., $2010^{39}$ & 0 & 0 & 0 & 1 & 1 & 0 & 1 & 3 \\
\hline van der Veen et al., $2014^{40}$ & 0 & 1 & 0 & 2 & 1 & 1 & 0 & 5 \\
\hline Weber et al., $2012^{41}$ & 0 & 0 & 0 & 0 & 0 & 0 & 0 & 0 \\
\hline Weinstein et al., $2013^{42}$ & 1 & 0 & 1 & 2 & 1 & 1 & 0 & 6 \\
\hline Windham et al., $2015^{43}$ & 1 & 1 & 1 & 2 & 1 & 1 & 1 & 8 \\
\hline Yamauchi et al., $2002^{44}$ & 0 & 0 & 0 & 2 & 1 & 1 & 0 & 4 \\
\hline
\end{tabular}

Newcastle-Ottawa Scale score (NOS) for studies on the association between cerebral small vessel disease and incident haemorrhagic and ischaemic stroke. For an explanation of the individual items, see the provided adjusted NOS (Appendix C). Maximal NOS score is 8 . Articles indicated in bold are of high methodologic quality (NOS score >4). S1= Representativeness of the cohort; S2 = ascertainment of determinant; S3= presence of outcome of interest at start of study; $\mathrm{C} 1=$ Comparability of cohorts: use of adjustments; $\mathrm{O} 1=$ assessment of outcome; $\mathrm{O} 2=$ follow up duration; $\mathrm{O} 3=$ adequacy of follow up. 
Table S5.2 - Newcastle-Ottawa Scale scores for studies on the association between cerebral small vessel disease and incident all-cause dementia

\begin{tabular}{|c|c|c|c|c|c|c|c|c|}
\hline Study & S1 & S2 & S3 & C1 & 01 & 02 & 03 & Total score \\
\hline Akoudad et al., $\mathbf{2 0 1 5 ^ { 6 4 }}$ & 1 & 1 & 1 & 2 & 1 & 0 & 1 & 7 \\
\hline Bombois et al., 2008 ${ }^{46}$ & 0 & 1 & 1 & 2 & 1 & 0 & 1 & 6 \\
\hline Debette et al., 2010 ${ }^{12}$ & 1 & 1 & 1 & 1 & 1 & 1 & 1 & 7 \\
\hline DeCarli et al., $2004^{47}$ & 0 & 0 & 0 & 0 & 0 & 0 & 1 & 1 \\
\hline Firbank et al., $2012^{48}$ & 0 & 1 & 1 & 0 & 1 & 0 & 0 & 3 \\
\hline Geroldi et al., $2006^{49}$ & 0 & 0 & 1 & 0 & 1 & 0 & 0 & 2 \\
\hline Godin et al., $2010^{50}$ & 1 & 1 & 1 & 2 & 0 & 1 & 1 & 7 \\
\hline Gomar et al., $2011^{51}$ & 0 & 0 & 1 & 0 & 1 & 0 & 0 & 2 \\
\hline Ikram et al., $2010^{52}$ & 1 & 1 & 1 & 2 & 1 & 1 & 1 & 8 \\
\hline Kaffashian et al., 2016a ${ }^{21}$ & 1 & 1 & 1 & 2 & 1 & 1 & 1 & 8 \\
\hline Kaffashian et al., $016 b^{22}$ & 1 & 1 & 1 & 2 & 1 & 1 & 1 & 8 \\
\hline Kantarci et al., $2009^{53}$ & 0 & 1 & 1 & 1 & 1 & 0 & 1 & 5 \\
\hline Kim et al., $2015^{54}$ & 0 & 1 & 1 & 1 & 1 & 0 & 1 & 5 \\
\hline Kitagawa et al., $2015^{55}$ & 1 & 1 & 1 & 2 & 1 & 1 & 0 & 7 \\
\hline Korf et al., $2004^{56}$ & 0 & 1 & 1 & 0 & 1 & 0 & 0 & 3 \\
\hline Kuller, $\mathbf{2 0 0 3}^{57}$ & 1 & 1 & 1 & 1 & 0 & 1 & 0 & 5 \\
\hline Lopez et al., $2014^{58}$ & 1 & 1 & 1 & 1 & 1 & 0 & 1 & 6 \\
\hline Meguro et al., $2007^{59}$ & 0 & 1 & 1 & 0 & 1 & 1 & 0 & 4 \\
\hline Miwa et al., $2014^{60}$ & 0 & 1 & 1 & 1 & 1 & 1 & 0 & 5 \\
\hline Prasad et al., $2011^{61}$ & 0 & 0 & 1 & 0 & 1 & 0 & 0 & 2 \\
\hline Prins et al., 2004 ${ }^{62}$ & 1 & 1 & 1 & 0 & 1 & 1 & 1 & 6 \\
\hline Prins et al., $2013^{63}$ & 0 & 1 & 1 & 0 & 0 & 0 & 1 & 3 \\
\hline Rosano et al., $\mathbf{2 0 0 7}^{64}$ & 1 & 1 & 1 & 1 & 1 & 1 & 0 & 6 \\
\hline Sluimer et al., $2008^{65}$ & 0 & 0 & 1 & 0 & 1 & 0 & 0 & 2 \\
\hline Smith et al., $2008^{66}$ & 0 & 1 & 1 & 0 & 1 & 1 & 0 & 4 \\
\hline Staekenborg et al., $2009^{67}$ & 0 & 0 & 1 & 0 & 1 & 0 & 0 & 2 \\
\hline Steffens et al., $2002^{68}$ & 0 & 0 & 1 & 0 & 1 & 0 & 0 & 2 \\
\hline Steffens et al., $2007^{69}$ & 0 & 0 & 1 & 0 & 1 & 1 & 0 & 3 \\
\hline Stephan et al., $2015^{70}$ & 1 & 1 & 1 & 2 & 1 & 1 & 1 & 8 \\
\hline Stoub et al., 2014 ${ }^{71}$ & 1 & 1 & 1 & 0 & 1 & 1 & 0 & 5 \\
\hline Tapiola et al., $2008^{72}$ & 0 & 1 & 1 & 0 & 1 & 0 & 0 & 3 \\
\hline van Straaten et al., $2008^{73}$ & 0 & 1 & 1 & 0 & 1 & 0 & 0 & 3 \\
\hline van Uden et al., $\mathbf{2 0 1 5}^{74}$ & 0 & 1 & 1 & 1 & 1 & 1 & 1 & 6 \\
\hline Verdelho et al., $2010^{75}$ & 0 & 1 & 1 & 0 & 1 & 0 & 0 & 3 \\
\hline Vermeer et al., $\mathbf{2 0 0 3}^{76}$ & 1 & 1 & 1 & 1 & 1 & 0 & 1 & 6 \\
\hline Weinstein et al., $2013^{42}$ & 1 & 1 & 1 & 2 & 1 & 1 & 0 & 7 \\
\hline Yamamoto et al., $2002^{77}$ & 0 & 1 & 1 & 0 & 1 & 1 & 0 & 4 \\
\hline Zhu et al., 2010 & 1 & 1 & 1 & 0 & 1 & 0 & 1 & 5 \\
\hline
\end{tabular}

Newcastle-Ottawa Scale score (NOS) for studies on the association between cerebral small vessel disease and incident dementia. For an explanation of the individual items, see the provided adjusted NOS (Appendix C). Maximal NOS score is 8 . Articles indicated with bold are of high methodologic quality (NOS score $>4$ ). S1= Representativeness of the cohort; S2 = ascertainment of determinant; S3= presence of outcome of interest at start of study; $\mathrm{C} 1=$ Comparability of cohorts: use of adjustments; $\mathrm{O} 1=$ assessment of outcome; $\mathrm{O} 2=$ follow up duration; $\mathrm{O} 3=$ adequacy of follow up. 
Table S5.3 - Newcastle-Ottawa Scale scores for studies on the association between cerebral small vessel disease and incident depression

\begin{tabular}{|c|c|c|c|c|c|c|c|c|}
\hline Study & S1 & S2 & S3 & C1 & 01 & $\mathbf{O 2}$ & 03 & Total score \\
\hline Godin et al., 200987 & 1 & 1 & 1 & 1 & 1 & 1 & 0 & 6 \\
\hline Ikram et al., 2009 & 1 & 1 & 1 & 1 & 1 & 1 & 1 & 7 \\
\hline Kim et al., $2016^{81}$ & 0 & 1 & 1 & 0 & 1 & 0 & 0 & 3 \\
\hline Park et al., $2015^{82}$ & 1 & 1 & 1 & 1 & 1 & 0 & 0 & 5 \\
\hline Perez, 2013 ${ }^{83}$ & 1 & 1 & 1 & 1 & 1 & 0 & 1 & 6 \\
\hline Qiu et al., 2016 ${ }^{84}$ & 1 & 0 & 1 & 1 & 1 & 1 & 0 & 5 \\
\hline Steffens et al., $\mathbf{2 0 0 2}^{85}$ & 1 & 0 & 1 & 1 & 1 & 1 & 0 & 5 \\
\hline Teodorczuk et al., $2007^{86}$ & 0 & 1 & 1 & 0 & 1 & 0 & 1 & 4 \\
\hline Teodorczuk et al., $2010^{87}$ & 0 & 1 & 1 & 0 & 1 & 0 & 1 & 4 \\
\hline van Sloten et al., $2015^{88}$ & 1 & 1 & 1 & 1 & 1 & 1 & 1 & 7 \\
\hline Versluis et al., 2006 ${ }^{89}$ & 1 & 1 & 1 & 1 & 1 & 0 & 1 & 6 \\
\hline
\end{tabular}

Newcastle-Ottawa Scale score (NOS) for studies on the association between cerebral small vessel disease and incident depression. For an explanation of the individual items, see the provided adjusted NOS (Appendix C). Maximal NOS score is 8 . Articles indicated with bold are of high methodologic quality (NOS score $>4$ ). S1= Representativeness of the cohort; S2 = ascertainment of determinant; S3= presence of outcome of interest at start of study; $\mathrm{C} 1=$ Comparability of cohorts: use of adjustments; $\mathrm{O} 1=$ assessment of outcome; $\mathrm{O} 2=$ follow up duration; $\mathrm{O3}=$ adequacy of follow up. 
Table S5.4 - Newcastle-Ottawa Scale scores for studies on the association between cerebral small vessel disease and incident all-cause mortality

\begin{tabular}{|c|c|c|c|c|c|c|c|c|}
\hline Study & S1 & S2 & S3 & C1 & 01 & 02 & 03 & Total score \\
\hline Akoudad et al., $2015^{1}$ & 1 & 1 & 1 & 2 & 1 & 1 & 1 & 8 \\
\hline Altmann-Schneider et al., $2011^{90}$ & 0 & 1 & 1 & 2 & 1 & 1 & 1 & 7 \\
\hline Andersen et al., $2016^{2}$ & 0 & 1 & 1 & 1 & 0 & 0 & 1 & 4 \\
\hline Andersen et al., $2017^{3}$ & 0 & 1 & 1 & 0 & 1 & 1 & 1 & 5 \\
\hline Appelros et al., $2005^{4}$ & 0 & 0 & 1 & 0 & 1 & 1 & 0 & 3 \\
\hline Benedictus et al., $2015^{5}$ & 0 & 0 & 1 & 1 & 1 & 0 & 1 & 4 \\
\hline Bokura et al., $2006^{8}$ & 1 & 0 & 1 & 2 & 0 & 1 & 0 & 5 \\
\hline Boulanger et al., $2006^{9}$ & 0 & 1 & 1 & 0 & 0 & 0 & 1 & 3 \\
\hline Conijn et al., 2011 ${ }^{11}$ & 0 & 1 & 1 & 2 & 1 & 1 & 1 & 7 \\
\hline Debette et al., $\mathbf{2 0 1 0}^{12}$ & 1 & 0 & 1 & 2 & 1 & 1 & 0 & 6 \\
\hline Fan et al., $2003^{13}$ & 0 & 1 & 1 & 0 & 0 & 0 & 1 & 3 \\
\hline Firbank et al., $2012^{48}$ & 0 & 1 & 1 & 0 & 0 & 0 & 0 & 2 \\
\hline Fu et al., $2005^{14}$ & 0 & 1 & 1 & 0 & 0 & 0 & 1 & 3 \\
\hline Haji et al., $2015^{17}$ & 0 & 0 & 1 & 0 & 1 & 0 & 0 & 2 \\
\hline Henneman et al., $2009^{91}$ & 0 & 1 & 1 & 1 & 1 & 0 & 0 & 4 \\
\hline Ikram et al., 2009 & 1 & 1 & 1 & 1 & 1 & 1 & 1 & 7 \\
\hline Inzitari et al., $2009^{19}$ & 0 & 0 & 1 & 0 & 0 & 0 & 0 & 1 \\
\hline Kerber et al., 2006 ${ }^{92}$ & 1 & 1 & 1 & 0 & 1 & 1 & 1 & 6 \\
\hline Kuller et al., $2007^{93}$ & 1 & 0 & 1 & 2 & 1 & 1 & 1 & 7 \\
\hline Kwa et al., $2012^{27}$ & 0 & 0 & 1 & 1 & 0 & 0 & 1 & 3 \\
\hline Lavretsky et al., $2010^{94}$ & 0 & 1 & 1 & 0 & 0 & 1 & 0 & 3 \\
\hline Levy et al., $\mathbf{2 0 0 3}^{95}$ & 0 & 1 & 1 & 1 & 1 & 1 & 0 & 5 \\
\hline Mok et al., $2009^{29}$ & 0 & 1 & 1 & 0 & 0 & 1 & 1 & 4 \\
\hline Oksala et al., 200996 & 0 & 0 & 1 & 1 & 2 & 1 & 1 & 6 \\
\hline Putaala et al., $2011^{36}$ & 0 & 0 & 1 & 1 & 1 & 1 & 1 & 5 \\
\hline Staff et al., $2010^{97}$ & 1 & 0 & 1 & 0 & 1 & 1 & 0 & 4 \\
\hline van der Holst et al., $2016^{98}$ & 1 & 1 & 1 & 2 & 1 & 1 & 1 & 8 \\
\hline van der Veen et al., $\mathbf{2 0 1 4 ^ { 4 0 }}$ & 0 & 1 & 1 & 2 & 1 & 1 & 0 & 6 \\
\hline Weber et al., $2012^{41}$ & 0 & 0 & 1 & 0 & 0 & 0 & 0 & 1 \\
\hline Windham et al., $2015^{43}$ & 1 & 1 & 1 & 2 & 1 & 1 & 1 & 8 \\
\hline Yamauchi et al., $2002^{44}$ & 0 & 0 & 1 & 0 & 1 & 1 & 0 & 3 \\
\hline
\end{tabular}

Newcastle-Ottawa Scale score (NOS) for studies on the association between cerebral small vessel disease and all-cause mortality. For an explanation of the individual items, see the provided adjusted NOS (Appendix C). Maximal NOS score is 8 . Articles indicated with bold are of high methodologic quality (NOS score $>4$ ). S1= Representativeness of the cohort; S2 = ascertainment of determinant; S3= presence of outcome of interest at start of study; $\mathrm{C} 1=$ Comparability of cohorts: use of adjustments; $\mathrm{O} 1=$ assessment of outcome; $\mathrm{O} 2=$ follow up duration; $\mathrm{O} 3=$ adequacy of follow up. 
Table S6.1 - Heterogeneity for analyses with incident ischaemic and haemorrhagic stroke

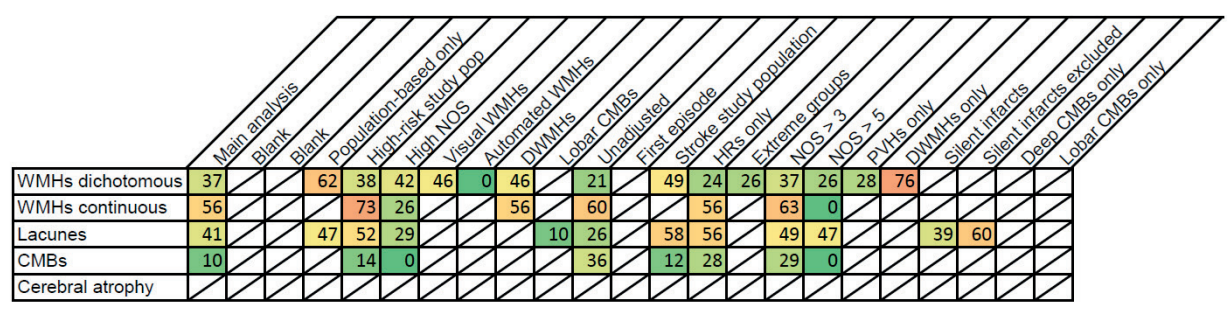

Heterogeneity $\left(\mathrm{I}^{2}\right)$ in the main and sensitivity analyses for the association of cerebral small vessel disease with incident ischaemic and haemorrhagic stroke. For a description of the sensitivity analyses, see Figures S2.1 to S2.5. Abbreviations: CMBs: cerebral microbleeds; DWMHs: deep white matter hyperintensities; HRs: hazard ratios; $\mathrm{ICH}$ : intracerebral haemorrhage; NOS: Newcastle-Ottawa scale score; pop: population; PVHs: periventricular hyperintensities; WMHs: white matter hyperintensities. 
S6.2 - Heterogeneity for analyses with incident all-cause dementia

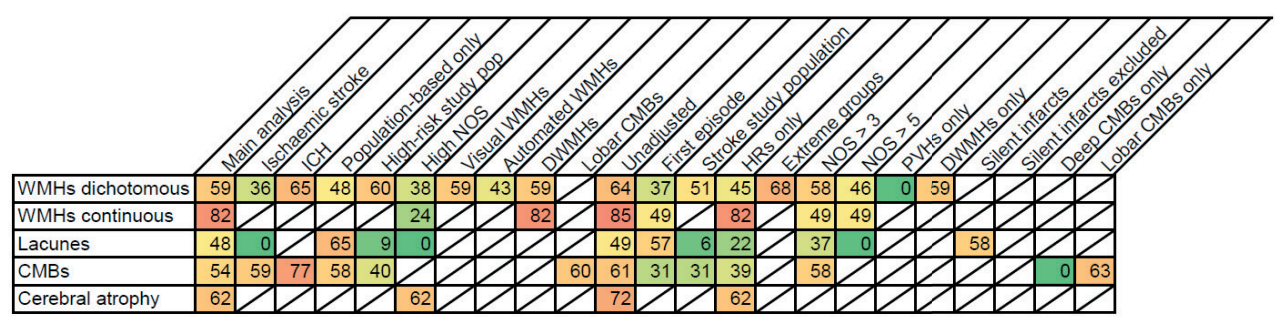

Stroke

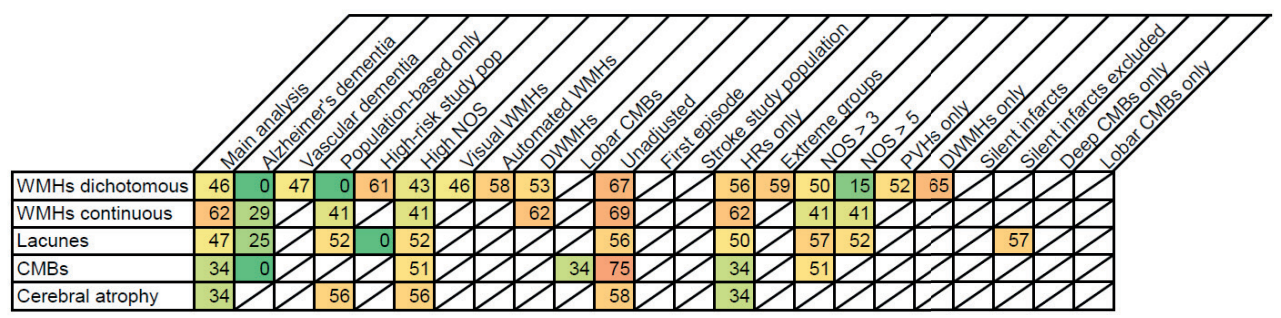

Dementia

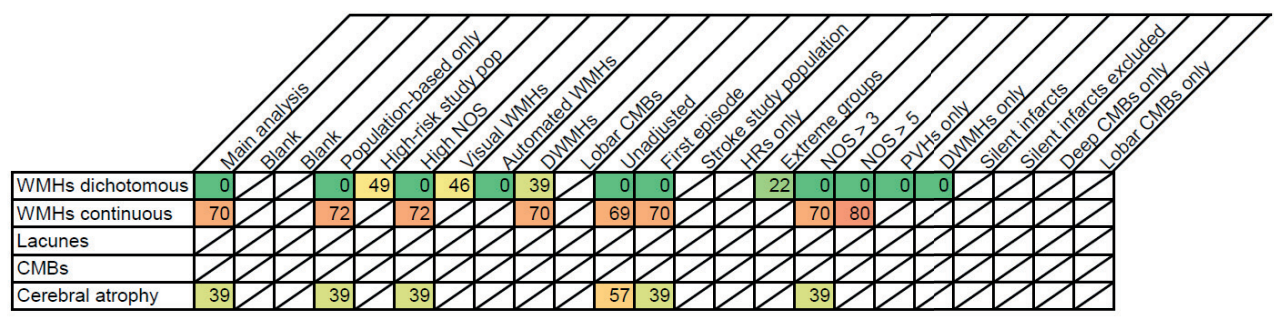

Depression

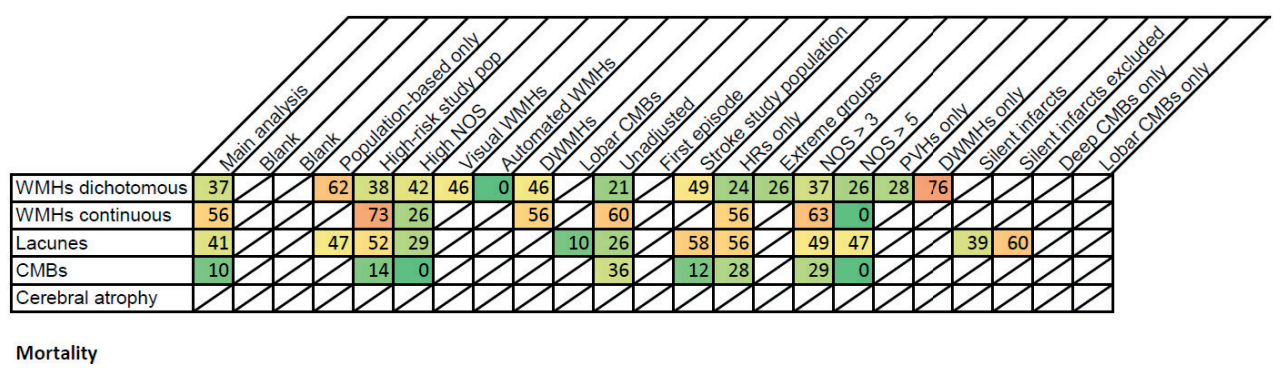

Heterogeneity $\left(\mathrm{I}^{2}\right)$ in the main and sensitivity analyses for the association of cerebral small vessel disease with incident all-cause dementia. For a description of the sensitivity analyses, see Figures S2.1 to S2.5. Abbreviations: CMBs: cerebral microbleeds; DWMHs: deep white matter hyperintensities; HRs: hazard ratios; ICH: intracerebral haemorrhage; NOS: Newcastle-Ottawa scale score; pop: population; PVHs: periventricular hyperintensities; WMHs: white matter hyperintensities. 
Table S6.3 - Heterogeneity for analysis with incident depression

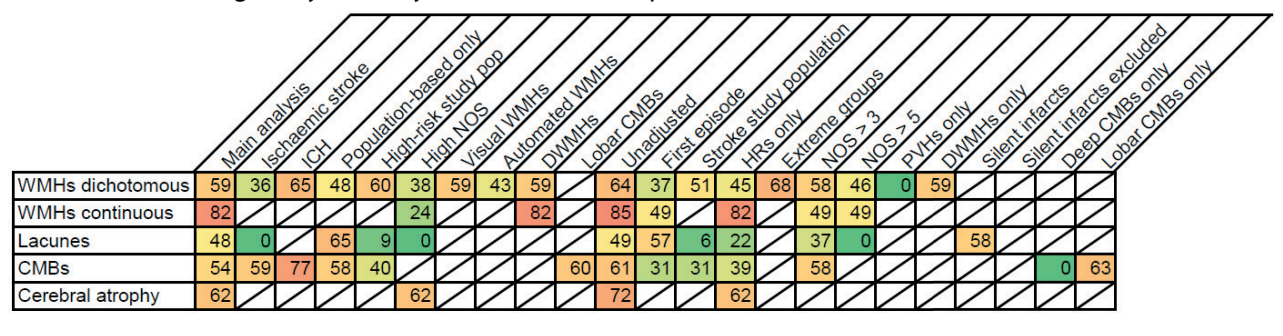

Stroke

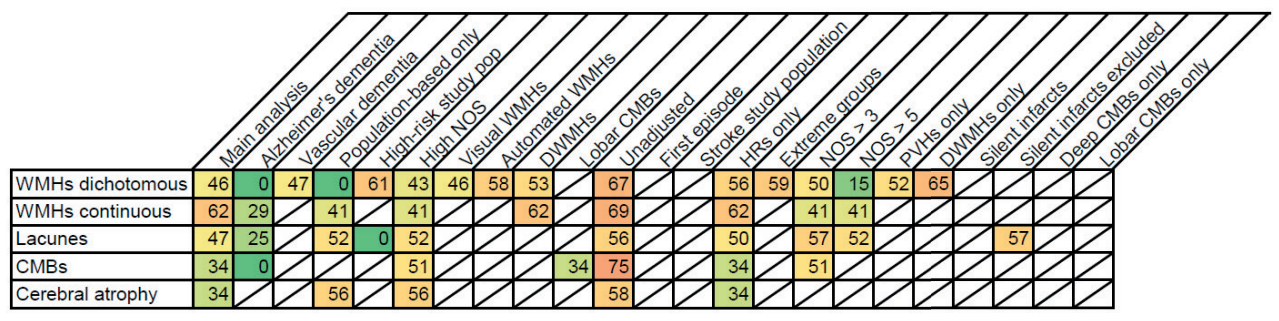

Dementia

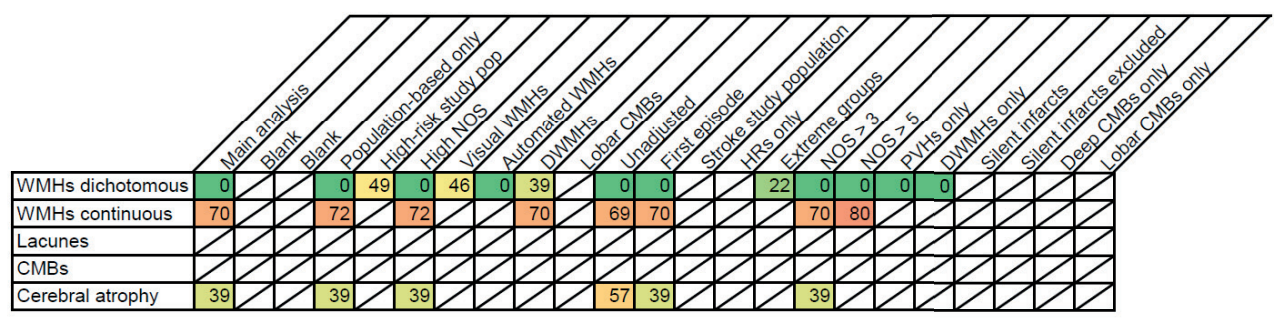

Depression

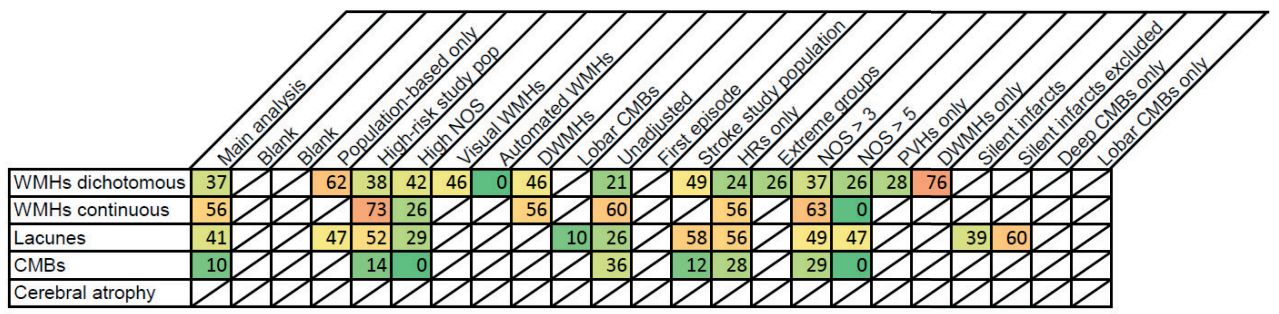

Mortality

Heterogeneity $\left(\mathrm{I}^{2}\right)$ in the main and sensitivity analyses for the association of cerebral small vessel disease with incident depression. For a description of the sensitivity analyses, see Figures S2.1 to S2.5. Abbreviations: CMBs: cerebral microbleeds; DWMHs: deep white matter hyperintensities; HRs: hazard ratios; ICH: intracerebral haemorrhage; NOS: Newcastle-Ottawa scale score; pop: population; PVHs: periventricular hyperintensities; WMHs: white matter hyperintensities. 
Table S6.4 - Heterogeneity for analysis with all-cause mortality

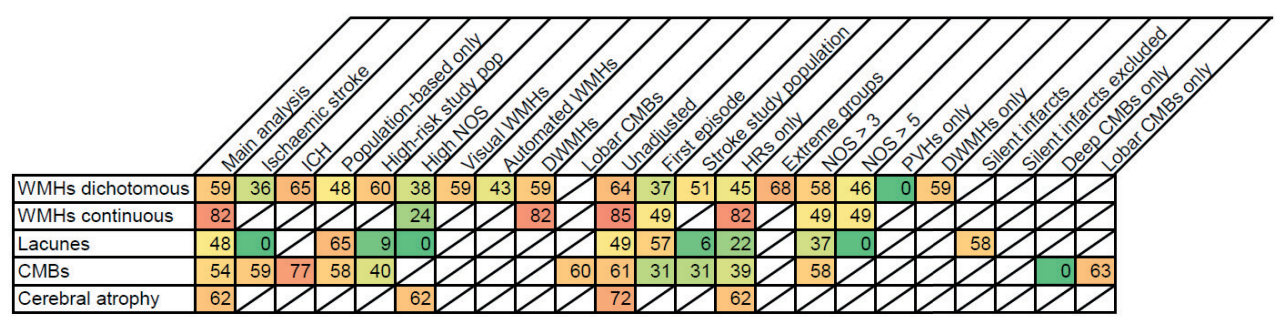

Stroke

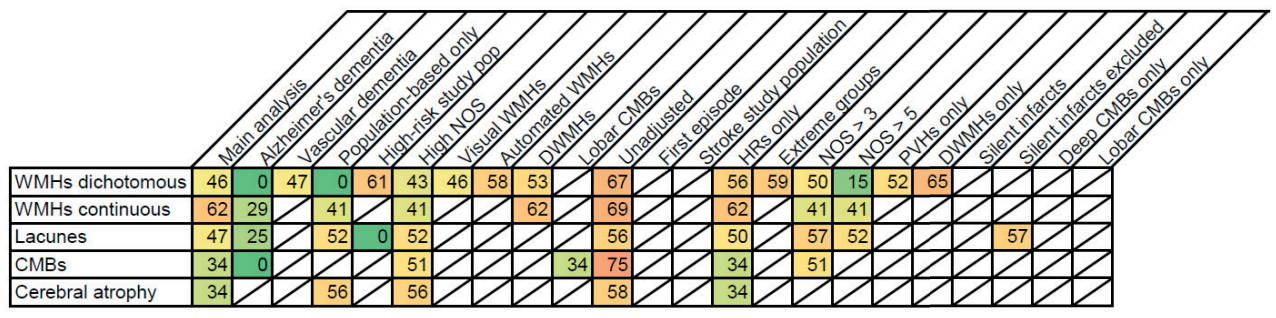

Dementia

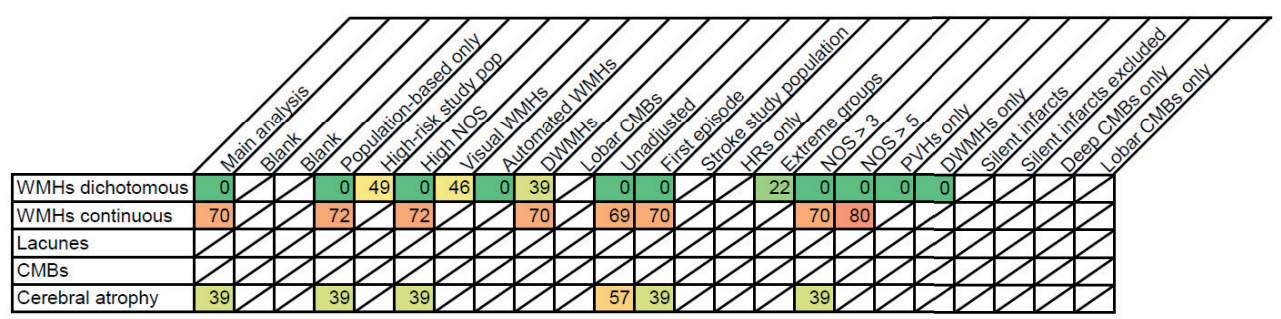

Depression

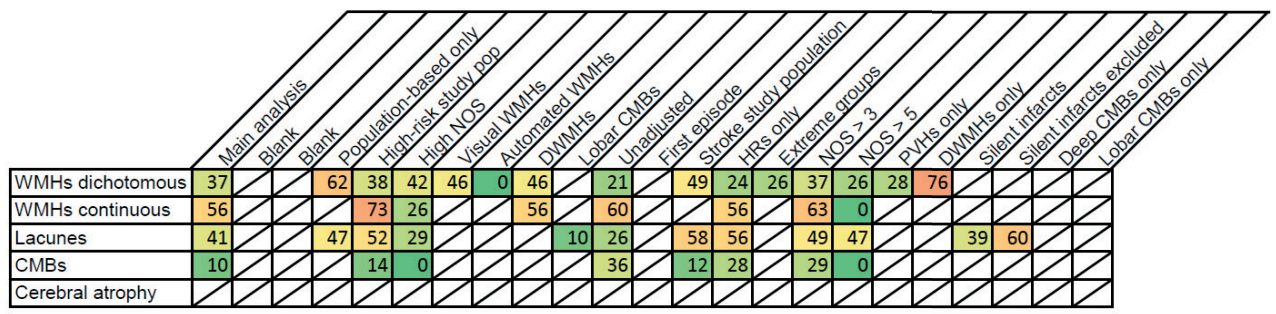

Mortality

Heterogeneity $\left(\mathrm{I}^{2}\right)$ in the main and sensitivity analyses for the association of cerebral small vessel disease with all-cause mortality. For a description of the sensitivity analyses, see Figures S2.1 to S2.5. Abbreviations: CMBs: cerebral microbleeds; DWMHs: deep white matter hyperintensities; HRs: hazard ratios; ICH: intracerebral haemorrhage; NOS: Newcastle-Ottawa scale score; pop: population; PVHs: periventricular hyperintensities; WMHs: white matter hyperintensities. 
Table S7 -Egger's Tests to detect significant funnel plot asymmetry

\begin{tabular}{llll}
\hline Association & T-value & df & p-value \\
\hline $\begin{array}{l}\text { WMHs on a dichotomous scale with ischaemic or } \\
\text { haemorrhagic stroke }\end{array}$ & 4.70 & 21 & 0.0001 \\
\hline Lacunes with ischaemic or haemorrhagic stroke & 2.55 & 13 & 0.02 \\
\hline CMBs with ischaemic or haemorrhagic stroke & 3.01 & 13 & 0.01 \\
\hline $\begin{array}{l}\text { WMHs on a dichotomous scale with all-cause } \\
\text { dementia }\end{array}$ & 0.22 & 13 & 0.83 \\
\hline Lacunes with all-cause dementia & 2.00 & 8 & 0.08 \\
\hline $\begin{array}{l}\text { WMHs on a dichotomous scale with all-cause } \\
\text { mortality }\end{array}$ & 2.33 & 14 & 0.04 \\
\hline Lacunes with all-cause mortality & -0.33 & 9 & 0.75 \\
\hline CMBs with all-cause mortality & -0.56 & 8 & 0.59
\end{tabular}

Tests were done when more than 10 studies were available per analysis. Abbreviations: CMBs: cerebral microbleeds; df: degrees of freedom; WMHs: white matter hyperintensities.

Table S8- Trim and fill test for analyses with significant funnel plot asymmetry

\begin{tabular}{|c|c|c|c|c|}
\hline \multirow[t]{2}{*}{ Association } & \multirow{2}{*}{$\begin{array}{c}\text { Estimated } \\
\text { hazard ratio }\end{array}$} & \multicolumn{2}{|c|}{ Estimated $95 \% \mathrm{Cl}$ interval } & \multirow{2}{*}{$\begin{array}{c}\text { Estimated number of } \\
\text { missing studies }\end{array}$} \\
\hline & & Lower limit & Upper limit & \\
\hline $\begin{array}{l}\text { WMHs on a dichotomous scale } \\
\text { with stroke }\end{array}$ & 1.94 & 1.54 & 2.45 & 7 \\
\hline Lacunes with stroke & 2.36 & 1.84 & 3.02 & 4 \\
\hline CMBs with stroke & 1.62 & 1.23 & 2.13 & 4 \\
\hline $\begin{array}{l}\text { WMHs on a dichotomous scale } \\
\text { with mortality }\end{array}$ & 1.68 & 1.48 & 1.90 & 4 \\
\hline
\end{tabular}

Abbreviations: $\mathrm{Cl}$ : confidence interval; CMBs: cerebral microbleeds; WMHs: white matter hyperintensities. 
Figure S1.1a, Forest plot for the association between white matter hyperintensities on a dichotomous scale and incident ischaemic and haemorrhagic stroke

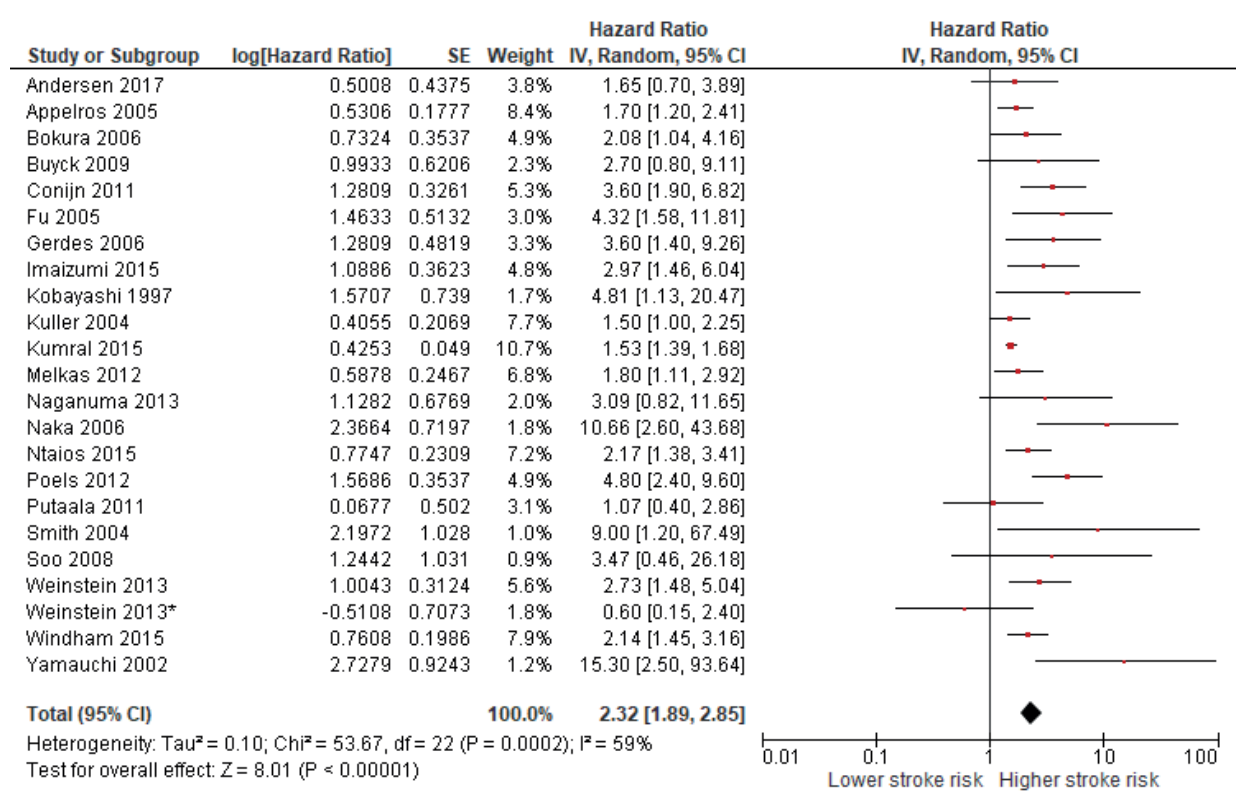

* data from the original cohort of the Framingham Health Study, the main study used data from the Framingham Offspring study.

Figure S1.1b, Forest plot for the association between white matter hyperintensities on a continuous scale and incident ischaemic and haemorrhagic stroke

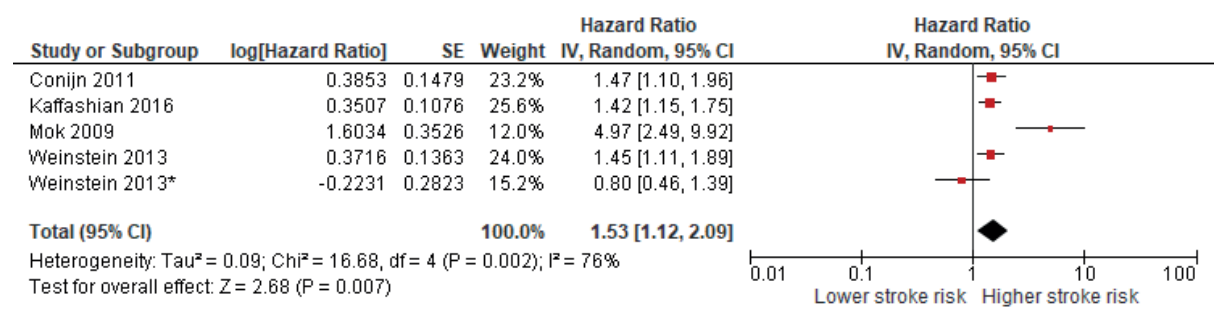

* data from the original cohort of the Framingham Health Study, the main study used data from the Framingham Offspring study. 
Figure S1.1C, Forest plot for the association between lacunes and incident ischaemic and haemorrhagic stroke

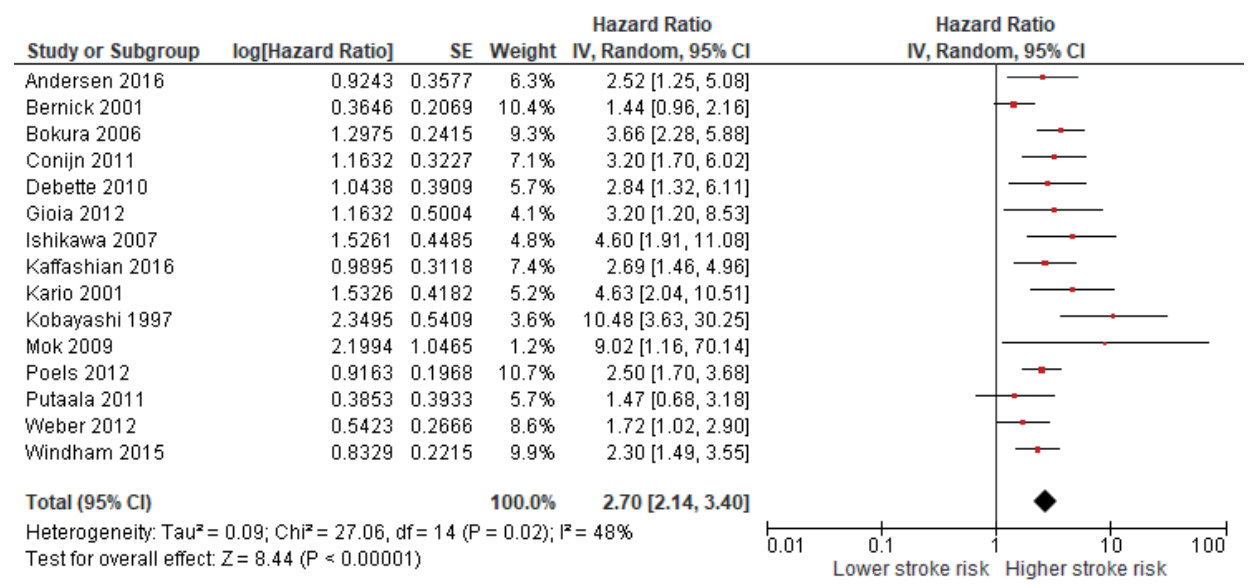

Figure S1.1d, Forest plot for the association between cerebral microbleeds and incident ischaemic and haemorrhagic stroke

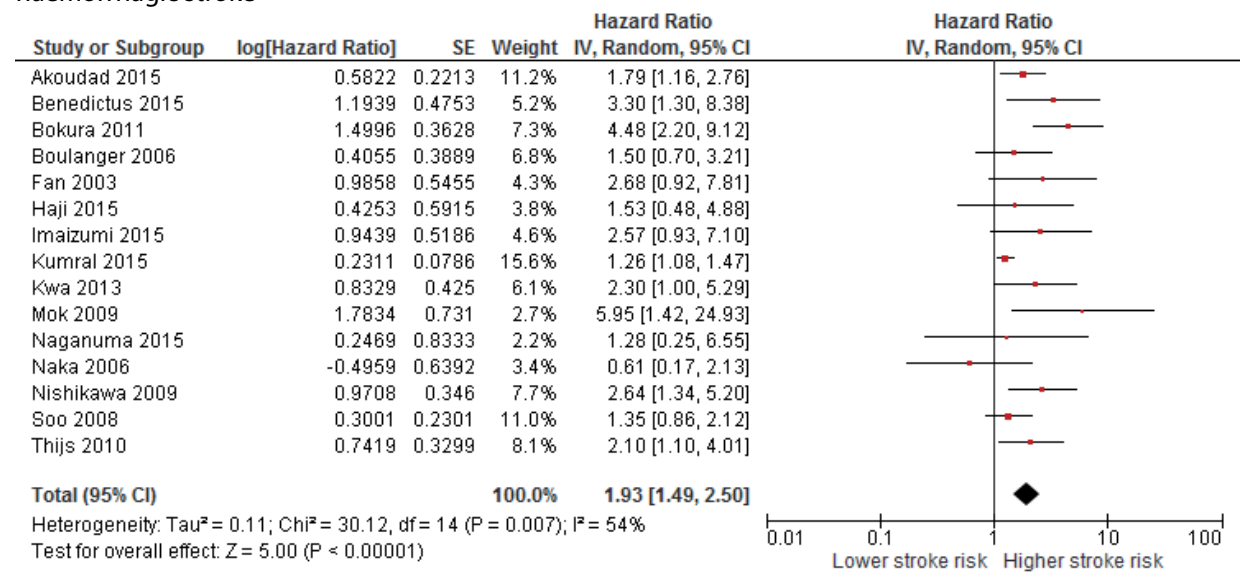

Figure S1.1e, Forest plot for the association between total cerebral atrophy and incident ischaemic and haemorrhagic stroke

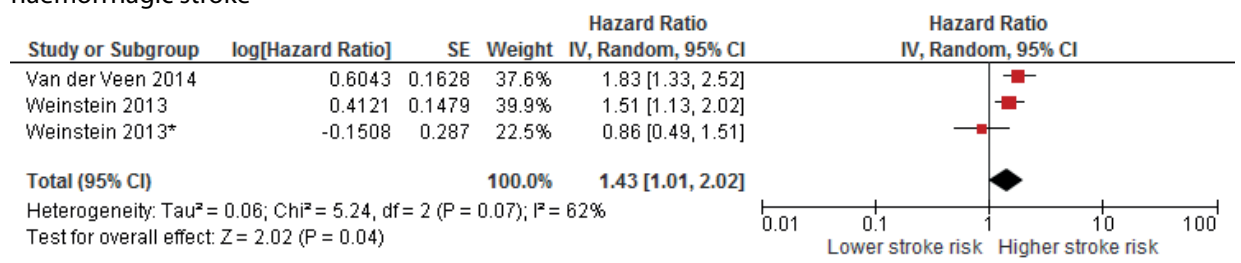

${ }^{*}$ data from the original cohort of the Framingham Health Study, the main study used data from the Framingham Offspring study. 
Figure S1.1f, Forest plot for the association between combinations of cerebral small vessel disease features and incident ischaemic and haemorrhagic stroke

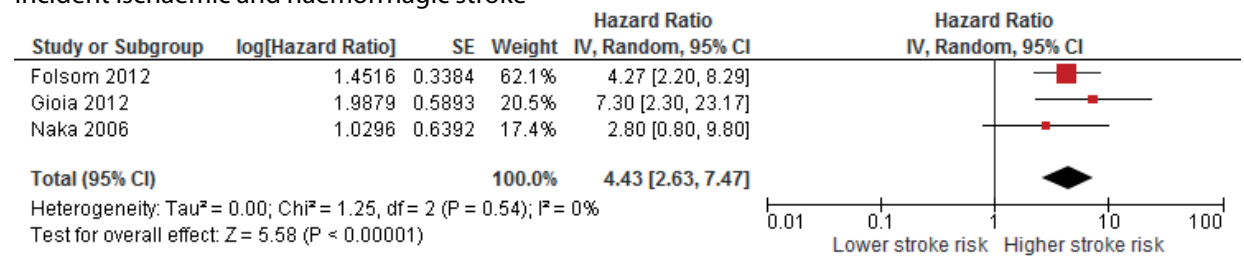

Figure S1.2a, Forest plot for the association between white matter hyperintensities on a dichotomous scale and incident all-cause dementia

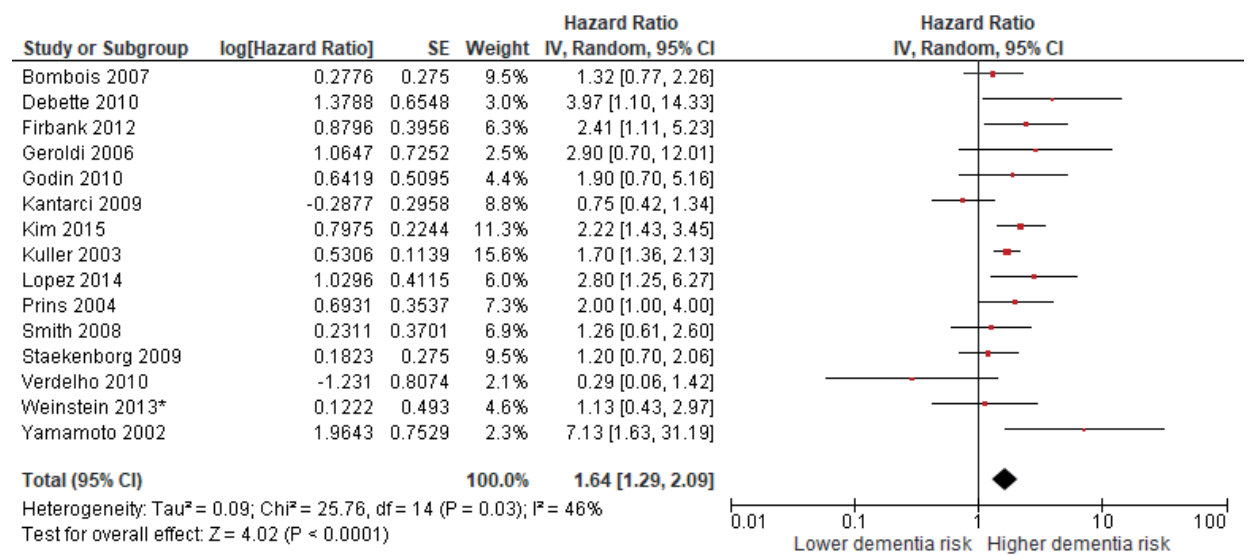

* data from the original cohort of the Framingham Health Study, the main study used data from the Framingham Offspring study.

Figure S1.2b, Forest plot for the association between white matter hyperintensities on a continuous scale and incident all-cause dementia

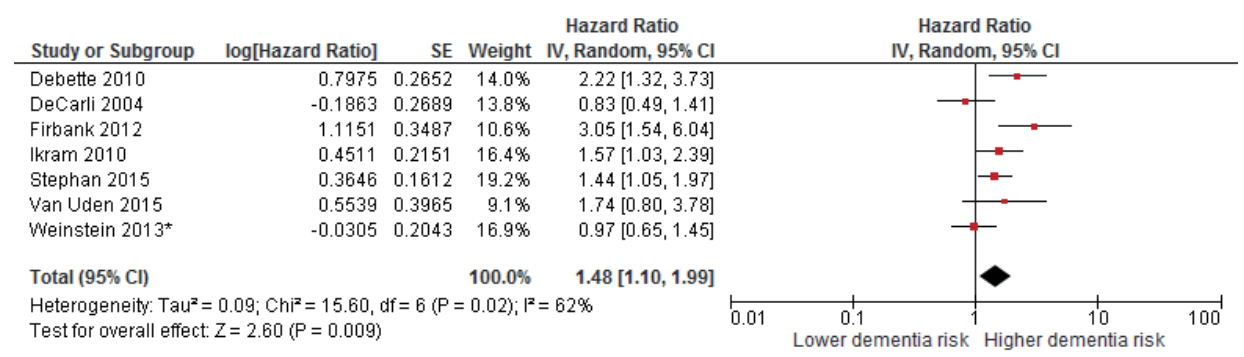

* data from the original cohort of the Framingham Health Study, the main study used data from the Framingham Offspring study. 
Figure S1.2c, Forest plot for the association between lacunes and incident all-cause dementia

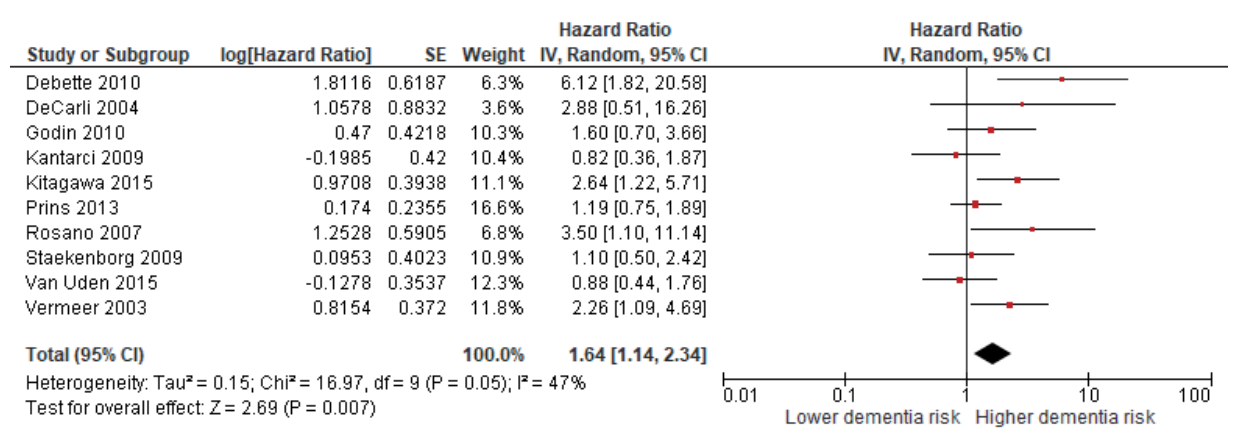

Figure S1.2d, Forest plot for the association between cerebral microbleeds and incident all-cause dementia

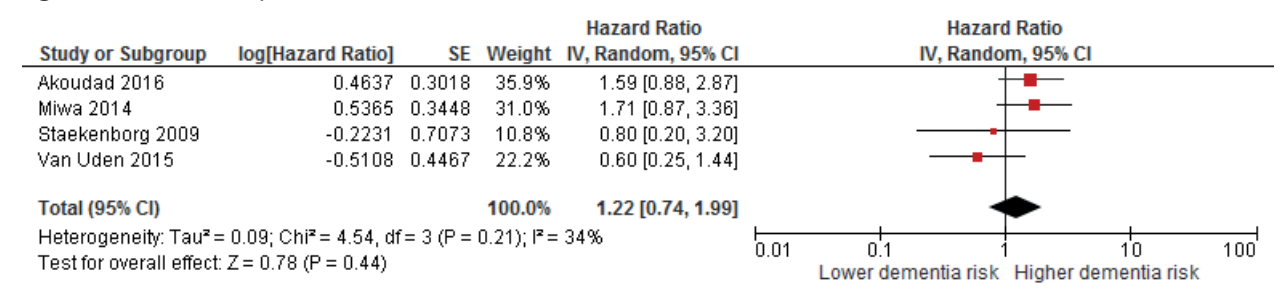

Figure S1.2e, Forest plot for the association between total cerebral atrophy and incident all-cause dementia

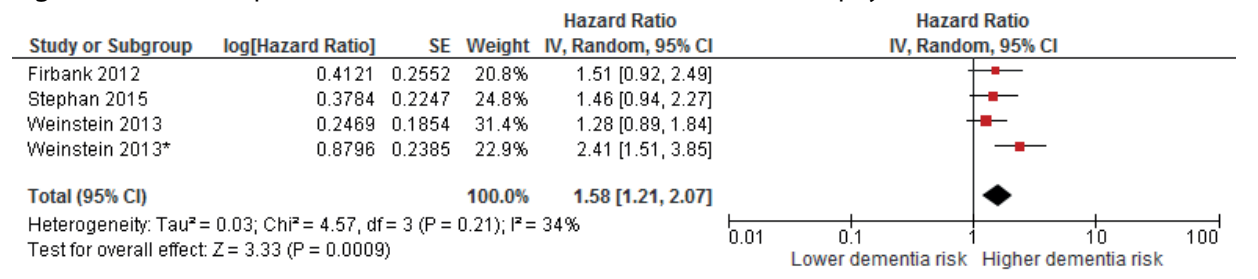

* data from the original cohort of the Framingham Health Study, the main study used data from the Framingham Offspring study.

Figure S1.3a, Forest plot for the association between white matter hyperintensities on a dichotomous scale and incident depression

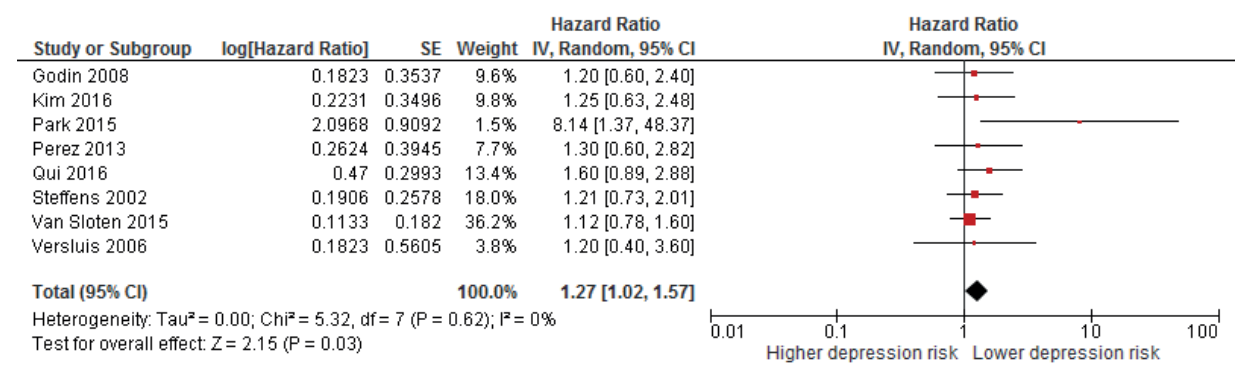


Figure S1.3b, Forest plot for the association between white matter hyperintensities on a continuous scale and incident depression

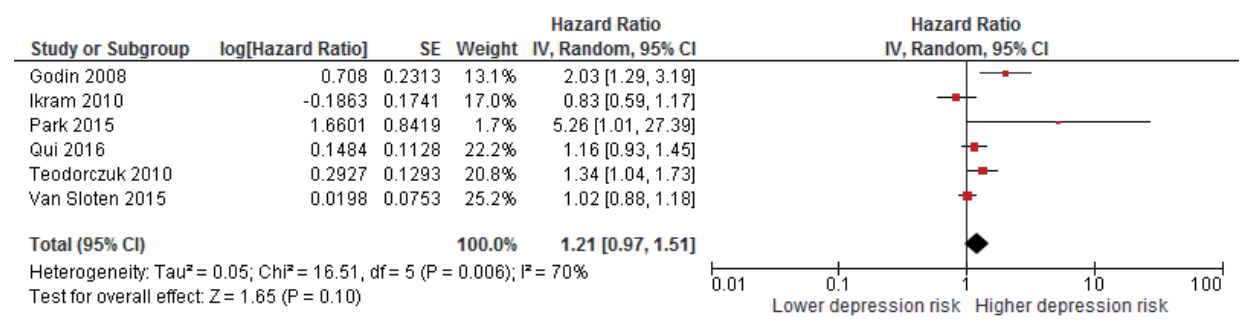

Figure S1.3c, Forest plot for the association between total cerebral atrophy and incident depression

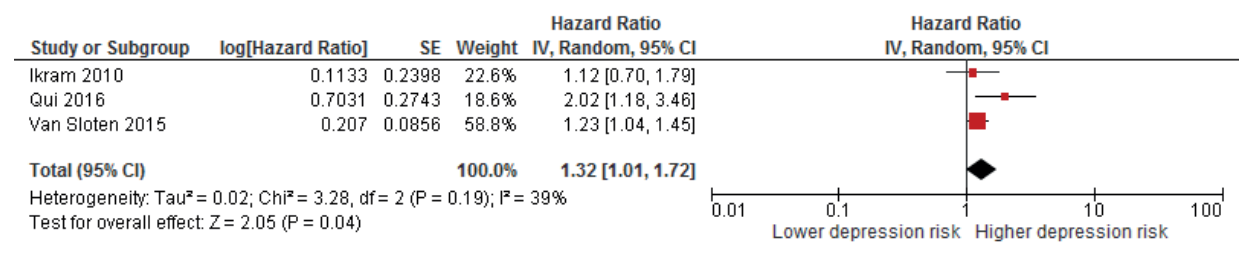

Figure S1.4a, Forest plot for the association between white matter hyperintensities on a dichotomous scale and all-cause mortality

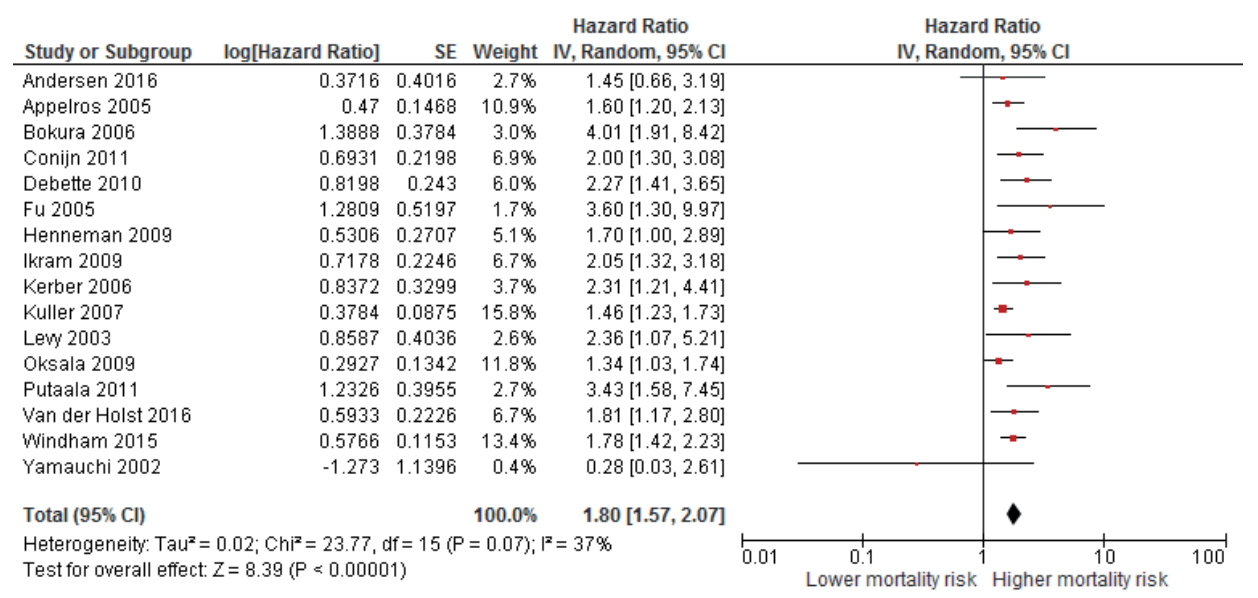


Figure S1.4b, Forest plot for the association between white matter hyperintensities on a continuous scale and all-cause mortality

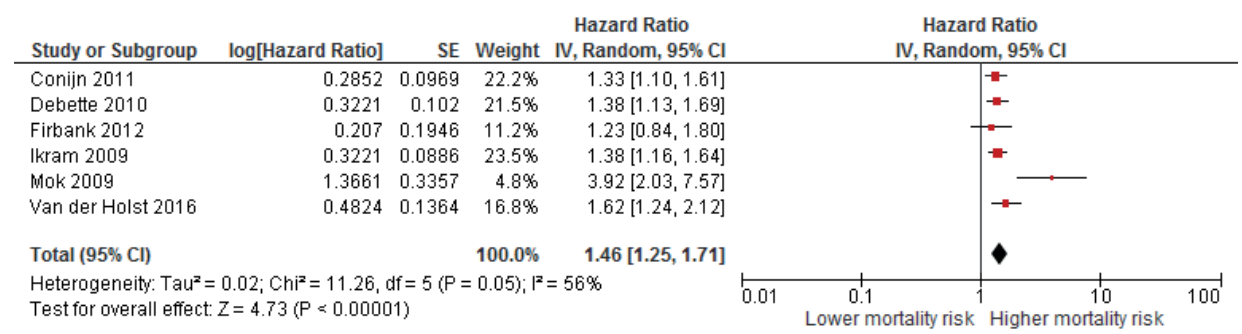

Figure S1.4c, Forest plot for the association between lacunes and all-cause mortality

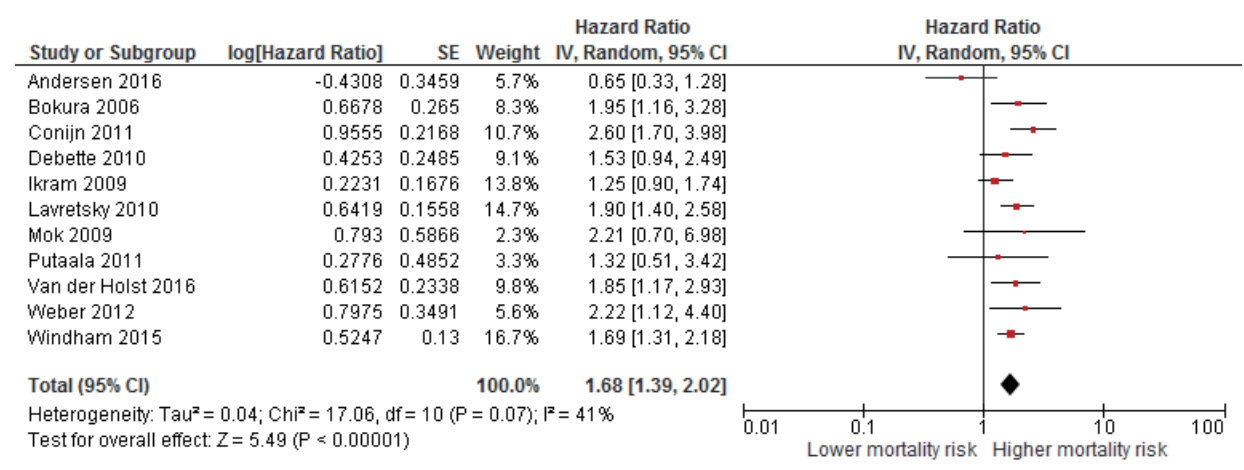

Figure S1.4d, Forest plot for the association between cerebral microbleeds and all-cause mortality

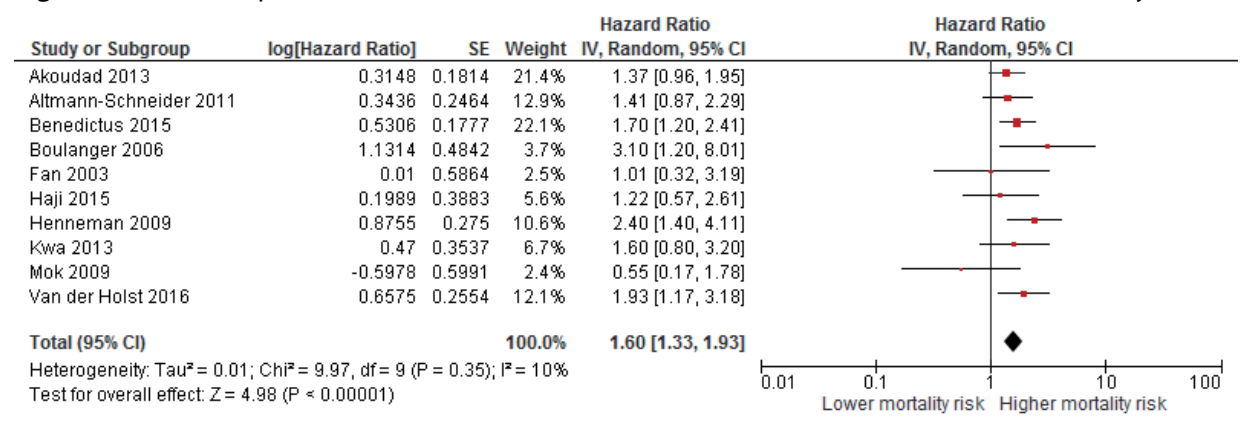

Figures S1.1 to S1.4. Forest plots for the associations between features of cerebral small vessel disease and incident ischaemic and haemorrhagic stroke, all-cause dementia and depression, and all-cause mortality. Abbreviations: $\mathrm{Cl}$ : confidence interval; df: degrees of freedom; IV: inverse variance; SE: standard error; 
Figure S2.1 - Pooled hazard ratios for sensitivity analyses for white matter hyperintensities on a dichotomous scale (High vs. low)*

Sensitivity analysis
Main analysis
IS/AD
ICH/VaD

Figures S2.1. Pooled hazard ratios (HRs) (95\% confidence intervals) for the association between features of white matter hyperintensities on a dichotomous scale and incident ischaemic and haemorrhagic stroke, allcause dementia, depression, and all-cause mortality. ${ }^{*}$ High vs. low as defined by the individual studies. Results were pooled when at least 3 studies were available. The following pre-specified analyses were done: analyses were repeated using only subtypes of stroke (ischaemic and haemorrhage) or dementia (Alzheimer's disease and presumed vascular dementia) as the outcome; using only population-based cohort studies; using only studies with high-risk populations; using only high-quality studies (defined as Newcastle-Ottawa Scale (NOS) score >4); using only studies that measured white matter hyperintensities (WMHs) on an observer-rated semi-quantitative scale; using only studies that measured WMHs on an automated quantitative scale; replacing the risk estimates for periventricular WMHs with those for deep WMHs; and replacing adjusted risk estimates with unadjusted risk estimates. The following post hoc analyses were done: analyses were repeated using only studies with a first episode of stroke or depression; using only studies with stroke patients; using only hazard ratios (i.e. excluding studies that reported odds ratios or relative risks); using risk estimates comparing highest vs. lowest categories of WMHs (irrespective of the number of participants per category) (indicated in the figures as "extreme groups"), instead of risk estimates comparing higher and lower categories with the highest number of participants and events; using only studies with NOS score $>3$; using only studies with NOS score $>5$; using only risk estimates of periventricular white matter hyperintensities (PVHs); and using only risk estimates of deep white matter hyperintensities (DWMHs). Abbreviations: AD: Alzheimer's disease; CMBs: cerebral microbleeds; DWMHs: deep white matter hyperintensities; HRs: hazard ratios; ICH: intracerebral haemorrhage; IS: ischaemic stroke; NOS: Newcastle-Ottawa scale score; pop: population; PVHs: periventricular hyperintensities; VaD: presumed vascular dementia; WMHs: white matter hyperintensities. 
Figure S2.2 - Pooled hazard ratios for sensitivity analyses for white matter hyperintensities on a continuous scale (per 1 SD increase)

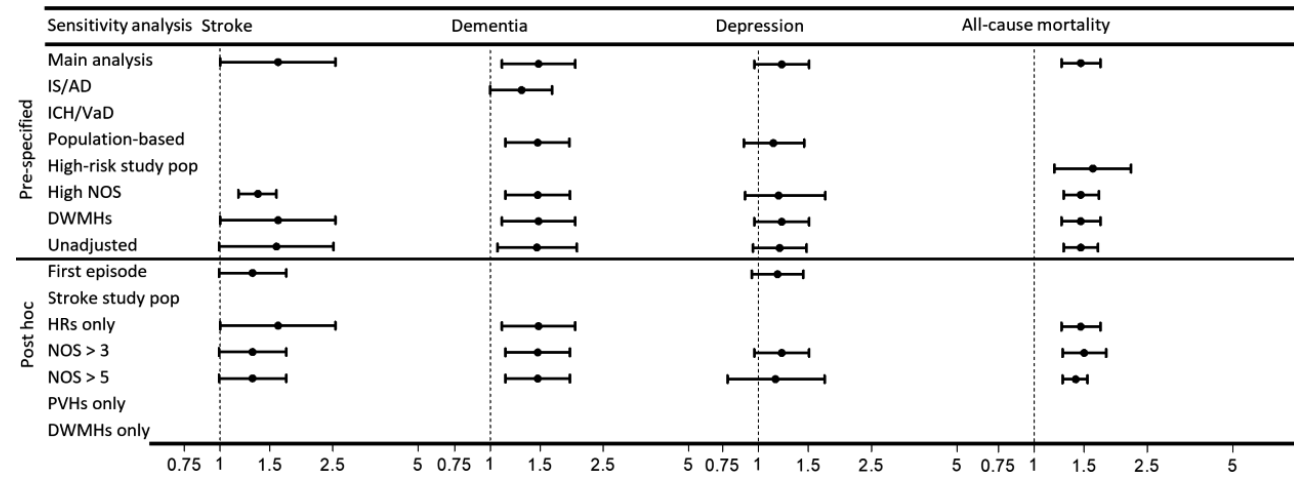

Figures S2.2. Pooled hazard ratios (HRs) (95\% confidence intervals) for the association between white matter hyperintensities on a continuous scale and incident ischaemic and haemorrhagic stroke, all-cause dementia, depression, and all-cause mortality. Results were pooled when at least 3 studies were available. The following pre-specified analyses were done: analyses were repeated using only subtypes of stroke (ischaemic and haemorrhage) or dementia (Alzheimer's disease and presumed vascular dementia) as the outcome; using only population-based cohort studies; using only studies with high-risk populations; using only high-quality studies (defined as Newcastle-Ottawa Scale (NOS) score >4); replacing the risk estimates for periventricular WMHs with those for deep WMHs; and replacing adjusted risk estimates with unadjusted risk estimates. The following post hoc analyses were done: analyses were repeated using only studies with a first episode of stroke or depression; using only studies with stroke patients; using only hazard ratios (i.e. excluding studies that reported odds ratios or relative risks); using only studies with NOS score $>3$; using only studies with NOS score $>5$; using only risk estimates of periventricular white matter hyperintensities (PVHs); and using only risk estimates of deep white matter hyperintensities (DWMHs). Abbreviations: AD: Alzheimer's disease; DWMHs: deep white matter hyperintensities; HRs: hazard ratios; ICH: intracerebral haemorrhage; IS: ischaemic stroke; NOS: NewcastleOttawa scale score; pop: population; PVHs: periventricular hyperintensities; SD: standard deviation; VaD: presumed vascular dementia; WMHs: white matter hyperintensities. 
Figure S2.3 - Pooled hazard ratios for sensitivity analyses for lacunes (absence vs. presence)

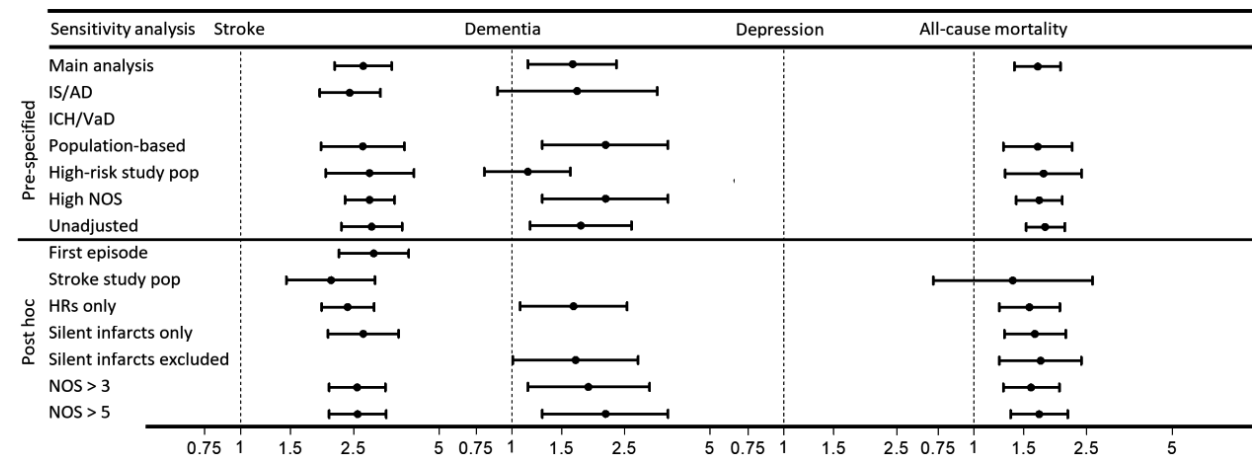

Figures S2.3. Pooled hazard ratios (HRs) (95\% confidence intervals) for the association between lacunes and incident ischaemic and haemorrhagic stroke, all-cause dementia, depression, and all-cause mortality. Results were pooled when at least 3 studies were available. The following pre-specified analyses were done: analyses were repeated using only subtypes of stroke (ischaemic and haemorrhage) or dementia (Alzheimer's disease and presumed vascular dementia) as the outcome; using only population-based cohort studies; using only studies with high-risk populations; using only high-quality studies (defined as Newcastle-Ottawa Scale (NOS) score $>4$ ); and replacing adjusted risk estimates with unadjusted risk estimates. The following post hoc analyses were done: analyses were repeated using only studies with a first episode of stroke or depression; using only studies with stroke patients; using only hazard ratios (i.e. excluding studies that reported odds ratios or relative risks); using only risk estimates for silent infarcts; excluding studies that reported risk estimates for silent infarcts only; using only studies with NOS score $>3$; and using only studies with NOS score $>5$. Abbreviations: AD: Alzheimer's disease; HRs: hazard ratios; ICH: intracerebral haemorrhage; IS: ischaemic stroke; NOS: Newcastle-Ottawa scale score; pop: population; VaD: presumed vascular dementia. 
Figure S2.4 - Pooled hazard ratios for sensitivity analyses for cerebral microbleeds (absence vs. presence)

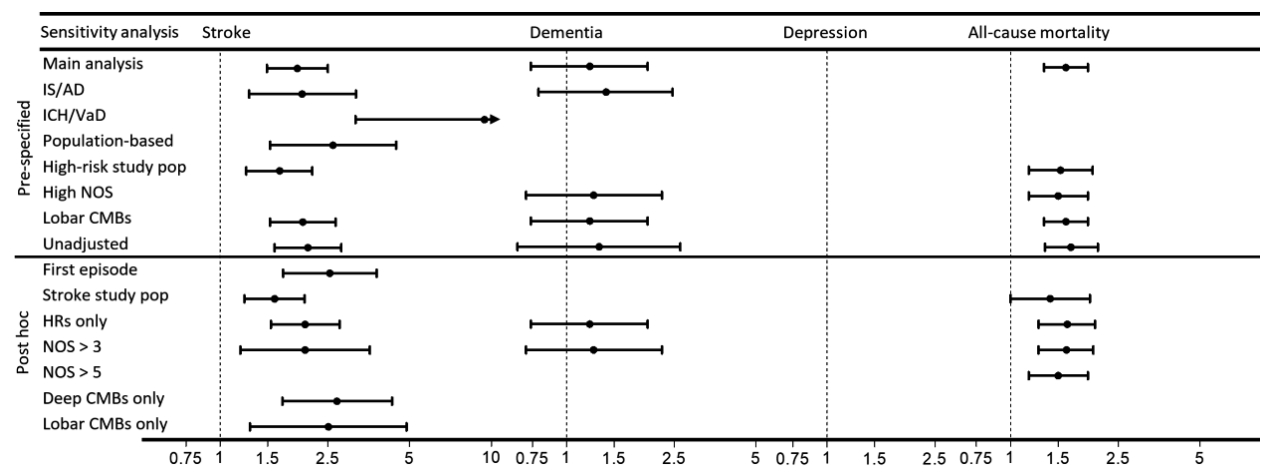

Figures S2.4. Pooled hazard ratios (HRs) (95\% confidence intervals) for the association between cerebral microbleeds and incident ischaemic and haemorrhagic stroke, all-cause dementia, depression, and all-cause mortality. Results were pooled when at least 3 studies were available. The following pre-specified analyses were done: analyses were repeated using only subtypes of stroke (ischaemic and haemorrhage) or dementia (Alzheimer's disease and presumed vascular dementia) as the outcome; using only population-based cohort studies; using only studies with high-risk populations; using only high-quality studies (defined as NewcastleOttawa Scale (NOS) score >4); replacing the risk estimates for deep cerebral microbleeds (CMBs) with those for lobar CMBs; and replacing adjusted risk estimates with unadjusted risk estimates. The following post hoc analyses were done: analyses were repeated using only studies with a first episode of stroke or depression; using only studies with stroke patients; using only hazard ratios (i.e. excluding studies that reported odds ratios or relative risks); using only studies with NOS score $>3$; using only studies with NOS score $>5$; using only risk estimates for deep CMBs; and using only risk estimates for lobar CMBs. Abbreviations: AD: Alzheimer's disease; CMBs: cerebral microbleeds; HRs: hazard ratios; ICH: intracerebral haemorrhage; IS: ischaemic stroke; NOS: Newcastle-Ottawa scale score; pop: population; VaD: presumed vascular dementia. 
Figure S2.5 - Pooled hazard ratios for sensitivity analyses for total cerebral atrophy (per 1 SD decrease)

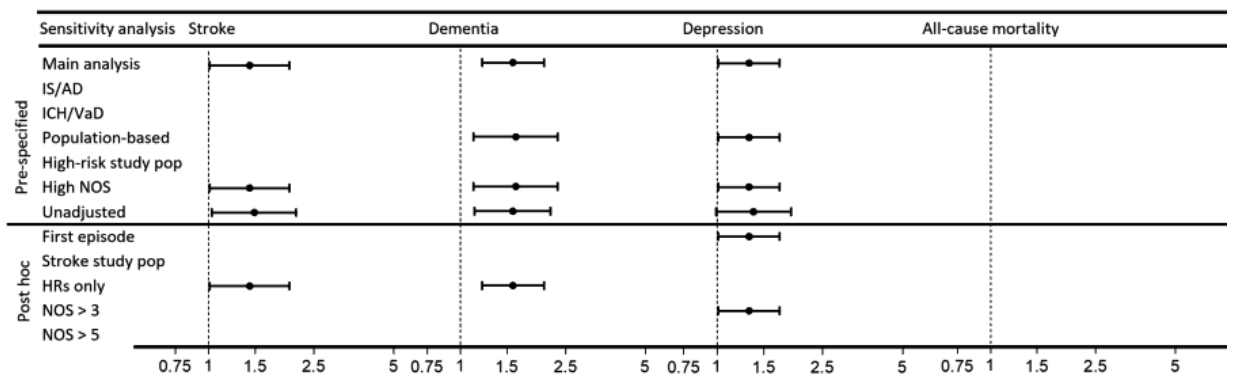

Figures S2.5. Pooled hazard ratios (HRs) (95\% confidence intervals) for the association between cerebral atrophy and incident ischaemic and haemorrhagic stroke, all-cause dementia, depression, and all-cause mortality. Results were pooled when at least 3 studies were available. The following pre-specified analyses were done: analyses were repeated using only subtypes of stroke (ischaemic and haemorrhage) or dementia (Alzheimer's disease and presumed vascular dementia) as the outcome; using only population-based cohort studies; using only studies with high-risk populations; using only high-quality studies (defined as Newcastle-Ottawa Scale (NOS) score $>4$ ); and replacing adjusted risk estimates with unadjusted risk estimates. The following post hoc analyses were done: analyses were repeated using only studies with a first episode of stroke or depression; using only studies with stroke patients; using only hazard ratios (i.e. excluding studies that reported odds ratios or relative risks); using only studies with NOS score $>3$; and using only studies with NOS score $>5$. Abbreviations: AD: Alzheimer's disease; HRs: hazard ratios; ICH: intracerebral haemorrhage; IS: ischaemic stroke; NOS: Newcastle-Ottawa scale score; pop: population; SD: standard deviation; VaD: presumed vascular dementia. 
Figure S3 - Funnel plots for analyses with significant funnel plot asymmetry

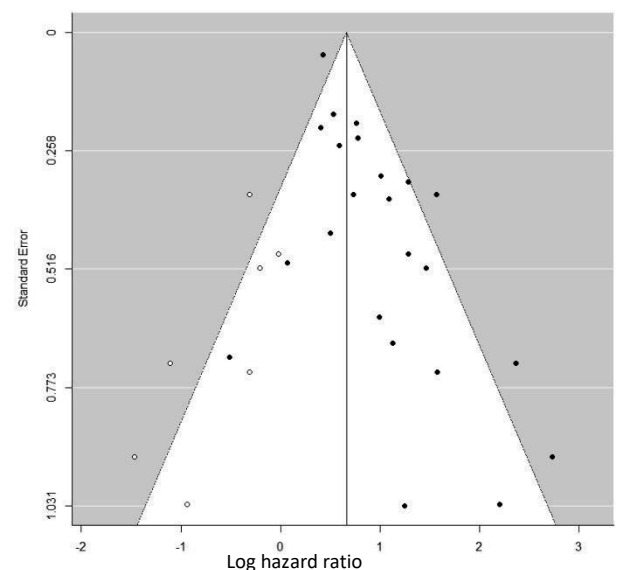

A

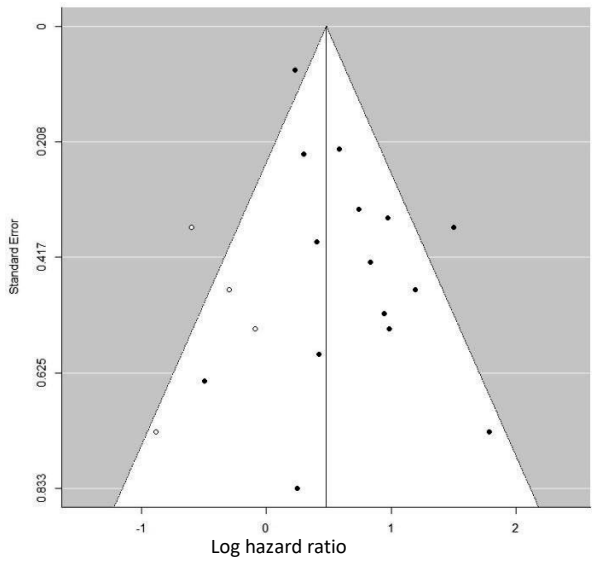

C

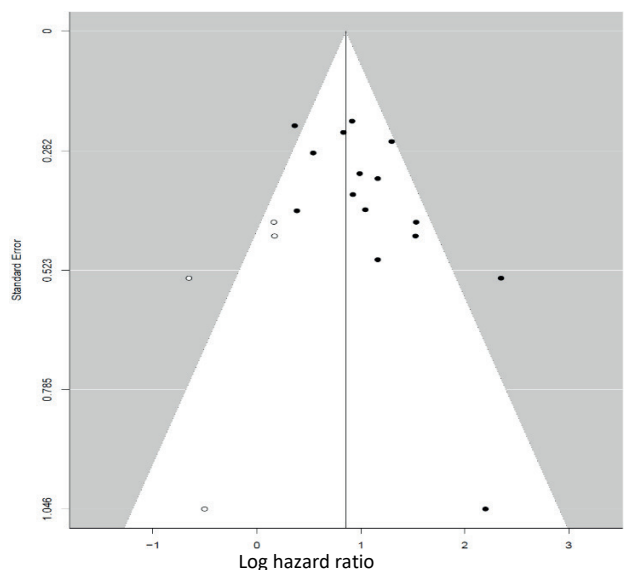

B

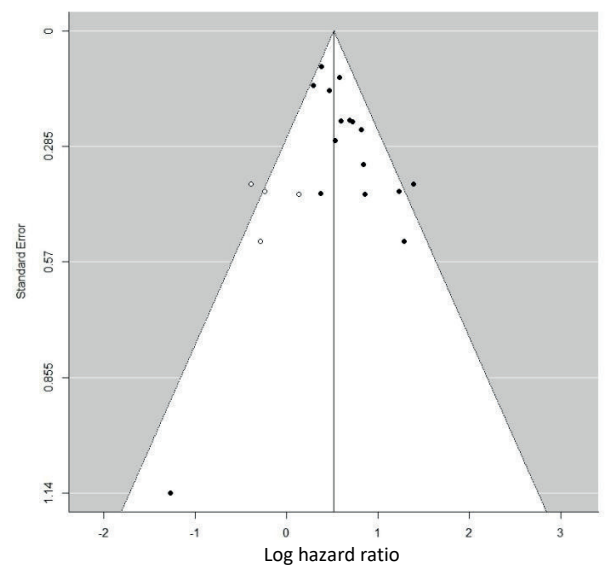

D

Funnel plot for the association between white matter hyperintensities on a dichotomous scale and incident haemorrhagic and ischaemic stroke (A), lacunes and incident haemorrhagic and ischaemic stroke (B), cerebral microbleeds and incident haemorrhagic and ischaemic stroke (C), and white matter hyperintensities on a dichotomous scale and all-cause mortality (D). Filled dots correspond to the observed risk estimates, blank dots represent missed studies imputed using the trim and fill test. Diagonal lines indicate the expected $95 \%$ confidence intervals around the summary estimate. Hazard ratios are plotted on a natural log scale. 


\section{References}

1. Akoudad S, Portegies MLP, Koudstaal PJ, Hofman A, Van Der Lugt A, Ikram MA and Vernooij MW. Cerebral Microbleeds Are Associated with an Increased Risk of Stroke: The Rotterdam Study. Circulation. 2015;132:509-516.

2. Andersen SD, Skjoth F, Yavarian Y, Bach FW, Lip GY and Larsen TB. Multiple Silent Lacunes Are Associated with Recurrent Ischemic Stroke. Cerebrovasc Dis. 2016;42:73-80.

3. Andersen SD, Larsen TB, Gorst-Rasmussen A, Yavarian Y, Lip GY and Bach FW. White Matter Hyperintensities Improve Ischemic Stroke Recurrence Prediction. Cerebrovasc Dis. 2017;43:17-24.

4. Appelros P, Samuelsson M and Lindell D. Lacunar infarcts: functional and cognitive outcomes at five years in relation to MRI findings. Cerebrovasc Dis. 2005;20:34-40.

5. Benedictus MR, Prins ND, Goos JD, Scheltens P, Barkhof F and van der Flier WM. Microbleeds, Mortality, and Stroke in Alzheimer Disease: The MISTRAL Study. JAMA Neurol. 2015;72:539-45.

6. Bernick C, Kuller L, Dulberg C, Longstreth WT, Jr., Manolio T, Beauchamp N and Price T. Silent MRI infarcts and the risk of future stroke: the cardiovascular health study. Neurology. 2001;57:1222-9.

7. Bokura H, Saika R, Yamaguchi T, Nagai A, Oguro H, Kobayashi S and Yamaguchi S. Microbleeds are associated with subsequent hemorrhagic and ischemic stroke in healthy elderly individuals. Stroke. 2011;42:1867-1871.

8. Bokura H, Kobayashi S, Yamaguchi S, lijima K, Nagai A, Toyoda G, Oguro H and Takahashi K. Silent brain infarction and subcortical white matter lesions increase the risk of stroke and mortality: a prospective cohort study. J Stroke Cerebrovasc Dis. 2006;15:57-63.

9. Boulanger JM, Coutts SB, Eliasziw M, Gagnon AJ, Simon JE, Subramaniam S, Sohn CH, Scott $\mathrm{J}$ and Demchuk AM. Cerebral microhemorrhages predict new disabling or fatal strokes in patients with acute ischemic stroke or transient ischemic attack. Stroke. 2006;37:911-914.

10. Buyck JF, Dufouil C, Mazoyer B, Maillard P, Ducimetiere P, Alperovitch A, Bousser MG, Kurth T and Tzourio C. Cerebral white matter lesions are associated with the risk of stroke but not with other vascular events: the 3-City Dijon Study. Stroke. 2009;40:2327-31.

11. Conijn MM, Kloppenborg RP, Algra A, Mali WP, Kappelle LJ, Vincken KL, van der Graaf Y, Geerlings $\mathrm{MI}$ and Group SS. Cerebral small vessel disease and risk of death, ischemic stroke, and cardiac complications in patients with atherosclerotic disease: the Second Manifestations of ARTerial disease-Magnetic Resonance (SMART-MR) study. Stroke. 2011;42:3105-9.

12. Debette S, Beiser A, Decarli C, Au R, Himali JJ, Kelly-Hayes M, Romero JR, Kase CS, Wolf PA and Seshadri S. Association of MRI markers of vascular brain injury with incident stroke, mild cognitive impairment, dementia, and mortality: The framingham offspring study. Stroke. 2010;41:600-606.

13. Fan YH, Zhang L, Lam WWM, Mok VCT and Wong KS. Cerebral microbleeds as a risk factor for subsequent intracerebral hemorrhages among patients with acute ischemic stroke. Stroke. 2003;34:2459-2462.

14. Fu JH, Lu CZ, Hong Z, Dong Q, Luo Y and Wong KS. Extent of white matter lesions is related to acute subcortical infarcts and predicts further stroke risk in patients with first ever ischaemic stroke. J Neurol Neurosurg Psychiatry. 2005;76:793-796.

15. Gerdes VE, Kwa VI, ten Cate H, Brandjes DP, Buller HR and Stam J. Cerebral white matter lesions predict both ischemic strokes and myocardial infarctions in patients with established atherosclerotic disease. Atherosclerosis. 2006;186:166-72. 
16. Gioia LC, Tollard E, Dubuc V, Lanthier S, Deschaintre Y, Chagnon M and Poppe AY. Silent ischemic lesions in young adults with first stroke are associated with recurrent stroke. Neurology. 2012;79:1208-14.

17. Haji S, Zubair A, Planchard R and Flemming K. Clinical relevance of cerebral microbleeds in patients with atrial fibrillation and stroke. Stroke. 2015;46.

18. Imaizumi T, Inamura S, Nomura T, Kanno A and Kim SN. The Severity of White Matter Lesions Possibly Influences Stroke Recurrence in Patients with Histories of Lacunar Infarctions. J Stroke Cerebrovasc Dis. 2015;24:2154-60.

19. Inzitari D, Pracucci G, Poggesi A, Carlucci G, Barkhof F, Chabriat H, Erkinjuntti T, Fazekas F, Ferro JM, Hennerici M, Langhorne P, O'Brien J, Scheltens P, Visser MC, Wahlund LO, Waldemar G, Wallin $A$ and Pantoni L. Changes in white matter as determinant of global functional decline in older independent outpatients: three year follow-up of LADIS (leukoaraiosis and disability) study cohort. BMJ. 2009;339:b2477.

20. Ishikawa J, Tamura Y, Hoshide S, Eguchi K, Ishikawa S, Shimada K and Kario K. Low-grade inflammation is a risk factor for clinical stroke events in addition to silent cerebral infarcts in Japanese older hypertensives: the Jichi Medical School ABPM Study, wave 1. Stroke. 2007;38:911-7.

21. Kaffashian S, Soumare A, Zhu YC, Mazoyer B, Debette S and Tzourio C. Long-Term Clinical Impact of Vascular Brain Lesions on Magnetic Resonance Imaging in Older Adults in the Population. Stroke. 2016;47:2865-2869.

22. Kaffashian S, Tzourio C, Zhu YC, Mazoyer B and Debette S. Differential Effect of White-Matter Lesions and Covert Brain Infarcts on the Risk of Ischemic Stroke and Intracerebral Hemorrhage. Stroke. 2016;47:1923-5.

23. Kario K, Shimada K, Schwartz JE, Matsuo T, Hoshide S and Pickering TG. Silent and clinically overt stroke in older Japanese subjects with white-coat and sustained hypertension. J Am Coll Cardiol. 2001;38:238-45.

24. Kobayashi S, Okada K, Koide H, Bokura H and Yamaguchi S. Subcortical silent brain infarction as a risk factor for clinical stroke. Stroke. 1997;28:1932-9.

25. Kuller LH, Longstreth WT, Jr., Arnold AM, Bernick C, Bryan RN, Beauchamp NJ, Jr. and Cardiovascular Health Study Collaborative Research G. White matter hyperintensity on cranial magnetic resonance imaging: a predictor of stroke. Stroke. 2004;35:1821-5.

26. Kumral E, Gulluoglu H, Alakbarova N, Karaman B, Deveci EE, Bayramov A, Evyapan D, Gokcay $F$ and Orman M. Association of leukoaraiosis with stroke recurrence within 5 years after initial stroke. J Stroke Cerebrovasc Dis. 2015;24:573-82.

27. Kwa VIH, Algra A, Brundel M, Bouvy W and Kappelle LJ. Microbleeds as a predictor of intracerebral hemorrhage in patients receiving oral antithrombotic drugs after a TIA or minor ischemic stroke: A prospective cohort study in Western outpatients. Cerebrovasc Dis. 2012;33:779-780.

28. Melkas S, Sibolt G, Oksala NKJ, Putaala J, Pohjasvaara T, Kaste M, Karhunen PJ and Erkinjuntti T. Extensive white matter changes predict stroke recurrence up to 5 years after a first-ever ischemic stroke. Cerebrovasc Dis. 2012;34:191-198.

29. Mok VC, Lau AY, Wong A, Lam WW, Chan A, Leung H, Wong E, Soo Y, Leung T and Wong LK. Longterm prognosis of Chinese patients with a lacunar infarct associated with small vessel disease: a five-year longitudinal study. Int J Stroke. 2009;4:81-8.

30. Naganuma T, Takemoto Y, Shoji T, Shima H, Ishimura E, Okamura M and Nakatani T. Cerebral white matter hyperintensity predicts cardiovascular events in haemodialysis patients. Nephrology. 2013;18:676-81. 
31. Naganuma T, Takemoto Y, Shoji T, Ishimura E, Okamura M and Nakatani T. Cerebral Microbleeds Predict Intracerebral Hemorrhage in Hemodialysis Patients. Stroke. 2015;46:2107-12.

32. Naka H, Nomura E, Takahashi T, Wakabayashi S, Mimori Y, Kajikawa H, Kohriyama $T$ and Matsumoto M. Combinations of the presence or absence of cerebral microbleeds and advanced white matter hyperintensity as predictors of subsequent stroke types. AJNR Am J Neuroradiol. 2006;27:830-5.

33. Nishikawa T, Ueba T, Kajiwara M, Fujisawa I, Miyamatsu N and Yamashita K. Cerebral microbleeds predict first-ever symptomatic cerebrovascular events. Clin Neurol Neurosurg. 2009;111:825-8.

34. Ntaios G, Lip GYH, Lambrou D, Papavasileiou V, Manios E, Milionis H, Spengos K, Makaritsis K and Vemmos K. Leukoaraiosis and stroke recurrence risk in patients with and without atrial fibrillation. Neurology. 2015;84:1213-1219.

35. Poels MM, Steyerberg EW, Wieberdink RG, Hofman A, Koudstaal PJ, Ikram MA and Breteler MM. Assessment of cerebral small vessel disease predicts individual stroke risk. J Neurol Neurosurg Psychiatry. 2012;83:1174-9.

36. Putaala J, Haapaniemi E, Kurkinen M, Salonen O, Kaste $M$ and Tatlisumak T. Silent brain infarcts, leukoaraiosis, and long-term prognosis in young ischemic stroke patients. Neurology. 2011;76:1742-9.

37. Smith EE, Gurol ME, Eng JA, Engel CR, Nguyen TN, Rosand J and Greenberg SM. White matter lesions, cognition, and recurrent hemorrhage in lobar intracerebral hemorrhage. Neurology. 2004;63:1606-12.

38. Soo YO, Yang SR, Lam WW, Wong A, Fan YH, Leung HH, Chan AY, Leung C, Leung TW and Wong LK. Risk vs benefit of anti-thrombotic therapy in ischaemic stroke patients with cerebral microbleeds. J Neurol. 2008;255:1679-86.

39. Thijs V, Lemmens R, Schoofs C, Gorner A, Van Damme P, Schrooten M and Demaerel P. Microbleeds and the risk of recurrent stroke. Stroke. 2010;41:2005-2009.

40. van der Veen PH, Muller M, Vincken KL, Mali WP, van der Graaf $Y$ and Geerlings MI. Brain volumes and risk of cardiovascular events and mortality. The SMART-MR study. Neurobiol Aging. 2014;35:1624-31.

41. Weber R, Weimar C, Wanke I, Moller-Hartmann C, Gizewski ER, Blatchford J, Hermansson K, Demchuk AM, Forsting M, Sacco RL, Saver JL, Warach S, Diener HC, Diehl A and Group PRIS. Risk of recurrent stroke in patients with silent brain infarction in the Prevention Regimen for Effectively Avoiding Second Strokes (PRoFESS) imaging substudy. Stroke. 2012;43:350-5.

42. Weinstein G, Beiser AS, Decarli C, Au R, Wolf PA and Seshadri S. Brain imaging and cognitive predictors of stroke and alzheimer disease in the framingham heart study. Stroke. 2013;44:27872794.

43. Windham BG, Deere B, Griswold ME, Wang W, Bezerra DC, Shibata D, Butler K, Knopman D, Gottesman RF, Heiss $\mathrm{G}$ and Mosley TH. Small brain lesions and incident stroke and mortality: A cohort study. Ann Intern Med. 2015;163:22-31.

44. Yamauchi $\mathrm{H}$, Fukuda $\mathrm{H}$ and Oyanagi $\mathrm{C}$. Significance of white matter high intensity lesions as a predictor of stroke from arteriolosclerosis. J Neurol Neurosurg Psychiatry. 2002;72:576-582.

45. Akoudad S, Wolters FJ, Viswanathan A, de Bruijn RF, van der Lugt A, Hofman A, Koudstaal PJ, Ikram MA and Vernooij MW. Association of Cerebral Microbleeds With Cognitive Decline and Dementia. JAMA Neurol. 2016;73:934-43.

46. Bombois S, Debette S, Bruandet A, Delbeuck X, Delmaire C, Leys D and Pasquier F. Vascular subcortical hyperintensities predict conversion to vascular and mixed dementia in $\mathrm{MCl}$ patients. Stroke. 2008;39:2046-51. 
47. DeCarli C, Mungas D, Harvey D, Reed B, Weiner M, Chui H and Jagust W. Memory impairment, but not cerebrovascular disease, predicts progression of MCI to dementia. Neurology. 2004;63:220-7.

48. Firbank MJ, Allan LM, Burton EJ, Barber R, O'Brien JT and Kalaria RN. Neuroimaging predictors of death and dementia in a cohort of older stroke survivors. J Neurol Neurosurg Psychiatry. 2012;83:263-7.

49. Geroldi C, Rossi R, Calvagna C, Testa C, Bresciani L, Binetti G, Zanetti O and Frisoni GB. Medial temporal atrophy but not memory deficit predicts progression to dementia in patients with mild cognitive impairment. J Neurol Neurosurg Psychiatry. 2006;77:1219-22.

50. Godin O, Tzourio C, Rouaud O, Zhu Y, Maillard P, Pasquier F, Crivello F, Alperovitch A, Mazoyer $B$ and Dufouil $C$. Joint effect of white matter lesions and hippocampal volumes on severity of cognitive decline: the 3C-Dijon MRI study. J Alzheimers Dis. 2010;20:453-63.

51. Gomar JJ, Bobes-Bascaran MT, Conejero-Goldberg C, Davies P and Goldberg TE. Utility of combinations of biomarkers, cognitive markers, and risk factors to predict conversion from mild cognitive impairment to Alzheimer disease in patients in the Alzheimer's disease neuroimaging initiative. Arch Gen Psychiatry. 2011;68:961-9.

52. Ikram MA, Vrooman HA, Vernooij MW, Heijer Td, Hofman A, Niessen WJ, van der Lugt A, Koudstaal $\mathrm{PJ}$ and Breteler MMB. Brain tissue volumes in relation to cognitive function and risk of dementia. Neurobiol Aging. 2010;31:378-386.

53. Kantarci K, Weigand SD, Przybelski SA, Shiung MM, Whitwell JL, Negash S, Knopman DS, Boeve BF, O'Brien PC, Petersen RC and Jack CR, Jr. Risk of dementia in MCl: combined effect of cerebrovascular disease, volumetric MRI, and 1H MRS. Neurology. 2009;72:1519-25.

54. Kim S, Choi SH, Lee YM, Kim MJ, Kim YD, Kim JY, Park JH, Myung W, Na HR, Han HJ, Shim YS, Kim $\mathrm{JH}$, Yoon SJ, Kim SY and Kim DK. Periventricular white matter hyperintensities and the risk of dementia: a CREDOS study. Int Psychogeriatr. 2015;27:2069-77.

55. Kitagawa K, Miwa K, Yagita Y, Okazaki S, Sakaguchi M and Mochizuki H. Association between carotid stenosis or lacunar infarction and incident dementia in patients with vascular risk factors. Eur J Neurol. 2015;22:187-192.

56. Korf ES, Wahlund LO, Visser PJ and Scheltens P. Medial temporal lobe atrophy on MRI predicts dementia in patients with mild cognitive impairment. Neurology. 2004;63:94-100.

57. Kuller LH. [Risk factors for dementia in the Cardiovascular Health Study cognition study]. Rev Neurol. 2003;37:122-6.

58. Lopez OL, Klunk WE, Mathis C, Coleman RL, Price J, Becker JT, Aizenstein HJ, Snitz B, Cohen A, Ikonomovic M, McDade E, DeKosky ST, Weissfeld L and Kuller LH. Amyloid, neurodegeneration, and small vessel disease as predictors of dementia in the oldest-old. Neurology. 2014;83:1804-11.

59. Meguro K, Ishii H, Kasuya M, Akanuma K, Meguro M, Kasai M, Lee E, Hashimoto R, Yamaguchi S and Asada T. Incidence of dementia and associated risk factors in Japan: The Osaki-Tajiri Project. J Neurol Sci. 2007;260:175-82.

60. Miwa K, Tanaka M, Okazaki S, Yagita Y, Sakaguchi M, Mochizuki H and Kitagawa K. Multiple or mixed cerebral microbleeds and dementia in patients with vascular risk factors. Neurology. 2014;83:646-53.

61. Prasad K, Wiryasaputra L, Ng A and Kandiah N. White matter disease independently predicts progression from mild cognitive impairment to Alzheimer's disease in a clinic cohort. Dement Geriatr Cogn Disord. 2011;31:431-4.

62. Prins ND, van Dijk EJ, den Heijer T, Vermeer SE, Koudstaal PJ, Oudkerk M, Hofman A and Breteler MM. Cerebral white matter lesions and the risk of dementia. Arch Neurol. 2004;61:1531-4. 
63. Prins ND, van der Flier WM, Brashear HR, Knol DL, van de Pol LA, Barkhof F and Scheltens P. Predictors of progression from mild cognitive impairment to dementia in the placebo-arm of a clinical trial population. J Alzheimers Dis. 2013;36:79-85.

64. Rosano C, Aizenstein HJ, Wu M, Newman AB, Becker JT, Lopez OL and Kuller LH. Focal atrophy and cerebrovascular disease increase dementia risk among cognitively normal older adults. $J$ Neuroimaging. 2007;17:148-55.

65. Sluimer JD, van der Flier WM, Karas GB, Fox NC, Scheltens P, Barkhof F and Vrenken H. Wholebrain atrophy rate and cognitive decline: longitudinal MR study of memory clinic patients. Radiology. 2008;248:590-8.

66. Smith EE, Egorova S, Blacker D, Killiany RJ, Muzikansky A, Dickerson BC, Tanzi RE, Albert MS, Greenberg SM and Guttmann CR. Magnetic resonance imaging white matter hyperintensities and brain volume in the prediction of mild cognitive impairment and dementia. Arch Neurol. 2008;65:94-100.

67. Staekenborg SS, Koedam EL, Henneman WJ, Stokman P, Barkhof F, Scheltens P and van der Flier WM. Progression of mild cognitive impairment to dementia: contribution of cerebrovascular disease compared with medial temporal lobe atrophy. Stroke. 2009;40:1269-74.

68. Steffens DC, Payne ME, Greenberg DL, Byrum CE, Welsh-Bohmer KA, Wagner HR and MacFall JR. Hippocampal volume and incident dementia in geriatric depression. Am J Geriatr Psychiatry. 2002;10:62-71.

69. Steffens DC, Potter GG, McQuoid DR, Macfall JR, Payne ME, Burke JR, Plassman BL and WelshBohmer KA. Longitudinal magnetic resonance imaging vascular changes, apolipoprotein e genotype, and development of dementia in the neurocognitive outcomes of depression in the elderly study. Am J Geriatr Psychiatry. 2007;15:839-849.

70. Stephan BCM, Tzourio C, Auriacombe S, Amieva H, Dufouil C, Alperovitch A and Kurth T. Usefulness of data from magnetic resonance imaging to improve prediction of dementia: Population based cohort study. BMJ 2015;350.

71. StoubTR, DeToledo-Morrell L and Dickerson BC. Parahippocampal white matter volume predicts Alzheimer's disease risk in cognitively normal old adults. Neurobiol Aging. 2014;35:1855-1861.

72. Tapiola T, Pennanen C, Tapiola M, Tervo S, Kivipelto M, Hanninen T, Pihlajamaki M, Laakso MP, Hallikainen M, Hamalainen A, Vanhanen M, Helkala EL, Vanninen R, Nissinen A, Rossi R, Frisoni GB and Soininen H. MRI of hippocampus and entorhinal cortex in mild cognitive impairment: a follow-up study. Neurobiol Aging. 2008;29:31-8.

73. van Straaten EC, Harvey D, Scheltens P, Barkhof F, Petersen RC, Thal LJ, Jack CR, Jr. and DeCarli C. Periventricular white matter hyperintensities increase the likelihood of progression from amnestic mild cognitive impairment to dementia. J Neurol. 2008;255:1302-8.

74. van Uden IW, van der Holst HM, Tuladhar AM, van Norden AG, de Laat KF, Rutten-Jacobs LC, Norris DG, Claassen JA, van Dijk EJ, Kessels RP and de Leeuw FE. White Matter and Hippocampal Volume Predict the Risk of Dementia in Patients with Cerebral Small Vessel Disease: The RUN DMC Study. J Alzheimers Dis. 2015;49:863-73.

75. Verdelho A, Madureira S, Moleiro C, Ferro JM, Santos CO, Erkinjuntti T, Pantoni L, Fazekas F, Visser $M$, Waldemar G, Wallin A, Hennerici M and Inzitari D. White matter changes and diabetes predict cognitive decline in the elderly: the LADIS study. Neurology. 2010;75:160-7.

76. Vermeer SE, Prins ND, Den Heijer T, Hofman A, Koudstaal PJ and Breteler MMB. Silent brain infarcts and the risk of dementia and cognitive decline. N Eng/ J Med. 2003;348:1215-1222. 
77. Yamamoto Y, Akiguchi I, Oiwa K, Hayashi M, Kasai T and Ozasa K. Twenty-four-hour blood pressure and MRI as predictive factors for different outcomes in patients with lacunar infarct. Stroke. 2002;33:297-305.

78. Zhu YC, Dufouil C, Soumare A, Mazoyer B, Chabriat H and Tzourio C. High degree of dilated Virchow-Robin spaces on MRI is associated with increased risk of dementia. $J$ Alzheimers Dis. 2010;22:663-72.

79. Godin O, Dufouil C, Maillard P, Delcroix N, Mazoyer B, Crivello F, Alperovitch A and Tzourio C. White matter lesions as a predictor of depression in the elderly: the 3C-Dijon study. Biol Psychiatry. 2008;63:663-9.

80. Ikram MA, Vernooij MW, Vrooman HA, Hofman A and Breteler MM. Brain tissue volumes and small vessel disease in relation to the risk of mortality. Neurobiol Aging. 2009;30:450-6.

81. Kim S, Woo SY, Kang HS, Lim SW, Choi SH, Myung W, Jeong JH, Lee Y, Hong CH, Kim JH, Na H, Carroll BJ and Kim DK. Factors related to prevalence, persistence, and incidence of depressive symptoms in mild cognitive impairment: vascular depression construct. Int J Geriatr Psychiatry. 2016;31:818-26.

82. Park JH, Lee SB, Lee JJ, Yoon JC, Han JW, Kim TH, Jeong HG, Newhouse PA, Taylor WD, Kim JH, Woo $\mathrm{JI}$ and Kim KW. Epidemiology of MRI-defined vascular depression: A longitudinal, communitybased study in Korean elders. J Affect Disord. 2015;180:200-6.

83. Perez HCS. Silent brain infarcts: A cause of depression in the elderly? Psychiatry Res. 2013:180-182.

84. Qiu WQ, Himali JJ, Wolf PA, DeCarli DC, Beiser A and Au R. Effects of white matter integrity and brain volumes on late life depression in the Framingham Heart Study. Int J Geriatr Psychiatry. 2016.

85. Steffens DC, Krishnan KR, Crump C and Burke GL. Cerebrovascular disease and evolution of depressive symptoms in the cardiovascular health study. Stroke. 2002;33:1636-44.

86. Teodorczuk A, O'Brien JT, Firbank MJ, Pantoni L, Poggesi A, Erkinjuntti T, Wallin A, Wahlund LO, Gouw A, Waldemar G, Schmidt R, Ferro JM, Chabriat H, Bazner H and Inzitari D. White matter changes and late-life depressive symptoms: longitudinal study. Br J Psychiatry. 2007;191:212-7.

87. Teodorczuk A, Firbank MJ, Pantoni L, Poggesi A, Erkinjuntti T, Wallin A, Wahlund LO, Scheltens P, Waldemar G, Schrotter G, Ferro JM, Chabriat H, Bazner H, Visser M, Inzitari D, O'Brien JT and Group L. Relationship between baseline white-matter changes and development of late-life depressive symptoms: 3-year results from the LADIS study. Psychol Med. 2010;40:603-10.

88. van Sloten TT, Sigurdsson S, van Buchem MA, Phillips CL, Jonsson PV, Ding J, Schram MT, Harris TB, Gudnason V and Launer LJ. Cerebral Small Vessel Disease and Association With Higher Incidence of Depressive Symptoms in a General Elderly Population: The AGES-Reykjavik Study. Am J Psychiatry. 2015;172:570-8.

89. Versluis CE, van der Mast RC, van Buchem MA, Bollen EL, Blauw GJ, Eekhof JA, van der Wee NJ and de Craen AJ. Progression of cerebral white matter lesions is not associated with development of depressive symptoms in elderly subjects at risk of cardiovascular disease: The PROSPER Study. Int J Geriatr Psychiatry. 2006;21:375-81.

90. Altmann-Schneider I, Trompet S, de Craen AJ, van Es AC, Jukema JW, Stott DJ, Sattar N, Westendorp RG, van Buchem MA and van der Grond J. Cerebral microbleeds are predictive of mortality in the elderly. Stroke. 2011;42:638-44.

91. Henneman WJ, Sluimer JD, Barnes J, van der Flier WM, Sluimer IC, Fox NC, Scheltens P, Vrenken H and Barkhof F. Hippocampal atrophy rates in Alzheimer disease: added value over whole brain volume measures. Neurology. 2009;72:999-1007. 
92. Kerber KA, Whitman GT, Brown DL and Baloh RW. Increased risk of death in community-dwelling older people with white matter hyperintensities on MRI. J Neurol Sci. 2006;250:33-8.

93. Kuller LH, Arnold AM, Longstreth WT, Jr., Manolio TA, O'Leary DH, Burke GL, Fried LP and Newman $A B$. White matter grade and ventricular volume on brain MRI as markers of longevity in the cardiovascular health study. Neurobiol Aging. 2007;28:1307-15.

94. Lavretsky H, Zheng L, Weiner MW, Mungas D, Reed B, Kramer JH, Jagust W, Chui H and Mack WJ. Association of depressed mood and mortality in older adults with and without cognitive impairment in a prospective naturalistic study. Am J Psychiatry. 2010;167:589-597.

95. Levy RM, Steffens DC, McQuoid DR, Provenzale JM, MacFall JR and Krishnan KR. MRI lesion severity and mortality in geriatric depression. Am J Geriatr Psychiatry. 2003;11:678-82.

96. Oksala NK, Oksala A, Pohjasvaara T, Vataja R, Kaste M, Karhunen PJ and Erkinjuntti T. Age related white matter changes predict stroke death in long term follow-up. J Neurol Neurosurg Psychiatry. 2009;80:762-6.

97. Staff RT, Murray AD, Ahearn T, Salarirad S, Mowat D, Starr JM, Deary IJ, Lemmon H and Whalley LJ. Brain volume and survival from age 78 to 85 : the contribution of Alzheimer-type magnetic resonance imaging findings. J Am Geriatr Soc. 2010;58:688-95.

98. van der Holst HM, van Uden IW, Tuladhar AM, de Laat KF, van Norden AG, Norris DG, van Dijk EJ, Rutten-Jacobs LC and de Leeuw FE. Factors Associated With 8-Year Mortality in Older Patients With Cerebral Small Vessel Disease: The Radboud University Nijmegen Diffusion Tensor and Magnetic Resonance Cohort (RUN DMC) Study. JAMA Neurol. 2016;73:402-9. 



\section{CHAPTER 3}

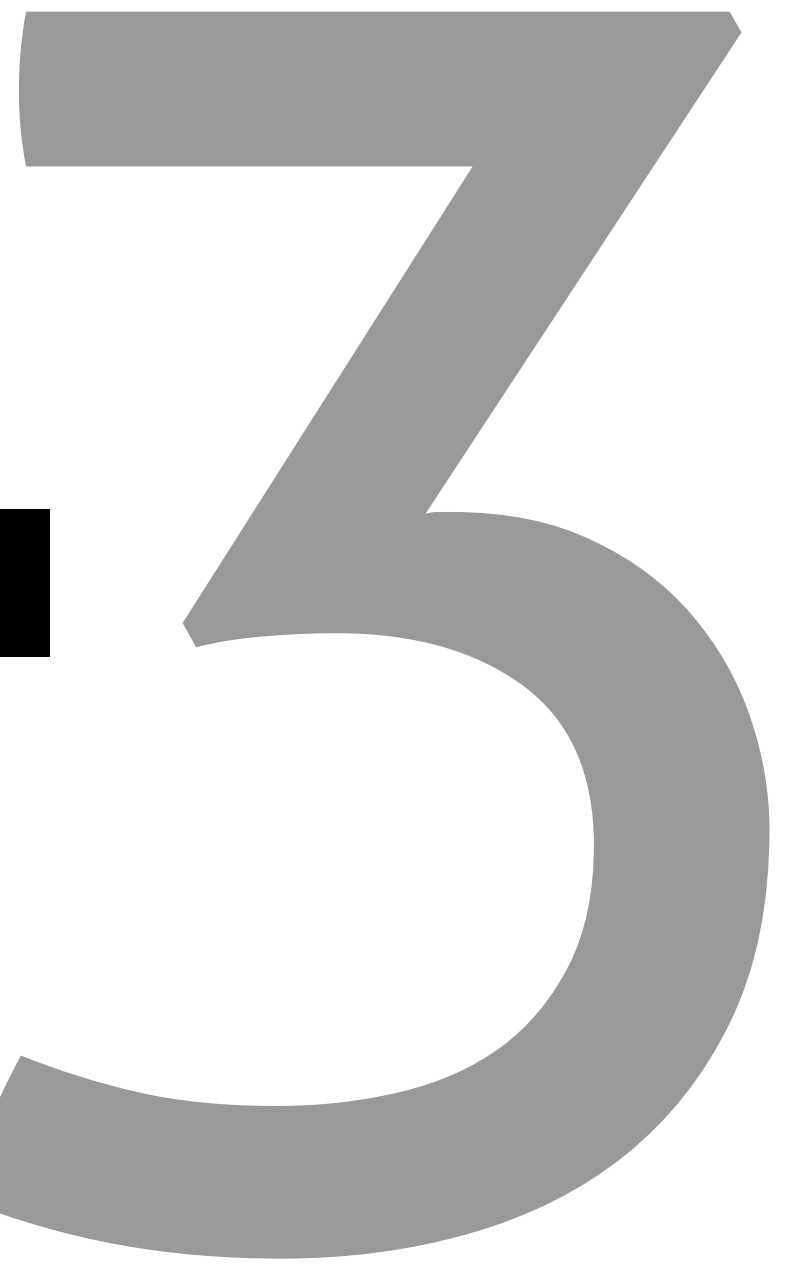




\section{Type 2 diabetes, change in depressive symptoms over time, and cerebral small vessel disease - Longitudinal data of the AGES- Reykjavik Study}

SP Rensma, TT van Sloten, J Ding, S Sigurdsson, CDA Stehouwer, $\checkmark$ Gudnason, LJ Launer 


\begin{abstract}
Importance: The association between type 2 diabetes and depression has been frequently reported. However, the pathophysiologic mechanisms for this association are not well known. Cerebral small vessel disease is a consequence of type 2 diabetes and may mediate this association.
\end{abstract}

Objective: To evaluate whether cerebral small vessel disease explains, or mediates, the association between type 2 diabetes and risk of depressive symptoms.

Design, setting and participants: Longitudinal cohort study in a Iceland general community (Age, Gene/Environment Susceptibility-Reykjavik Study) with examinations from 2002/2006 (baseline) and five years later.

Exposures: Type 2 diabetes defined as self-reported history of type 2 diabetes, use of blood glucose-lowering drugs, or fasting blood glucose level $\geq 7.0 \mathrm{mmol} / \mathrm{L}$, and cerebral small vessel disease load that was quantified with a scale reflecting MRI features of high white matter hyperintensity volume, low total brain parenchyma volume and presence of subcortical infarcts, cerebral microbleeds and large perivascular spaces.

Main Outcome: Change in 15-item Geriatric Depression Scale score between baseline and follow-up.

Results: The study population included 2,135 individuals free of dementia and baseline depression (mean age [SD 4.6] at baseline 74.5 years, 1,245 [58.3\%] women and 197 [9.2\%] with type 2 diabetes). On average, the GDS-15 score increased 0.4 points (SD 1.6) over time. Baseline type 2 diabetes was associated with a greater increase in depressive symptoms score over time $(\beta 0.316 ; 95 \% \mathrm{Cl} 0.074,0.558)$, adjusted for age, sex, education and cardiovascular risk factors. Baseline cerebral small vessel disease features and change of cerebral small vessel disease features over time statistically significantly explained, or mediated, a part of this association.

Conclusions and Relevance: Type 2 diabetes is associated with a greater increase in depressive symptoms score over time, and cerebral small vessel disease in part explains this association. 


\section{Introduction}

Depression is an important health concern in type 2 diabetes. It is twice as common in individuals with type 2 diabetes as in the general population and is associated with a higher risk of diabetes-related complications and mortality. ${ }^{1}$ The factors that mediate the relation between type 2 diabetes and depression are, however, incompletely understood. Cerebral microvascular dysfunction and damage may be such a mediator. Cerebral microvascular dysfunction may disrupt deep and frontal brain structures involved in mood regulation, leading to depressive symptoms. ${ }^{2,3}$

Cerebral small vessel disease (CSVD), a marker of cerebral microvascular dysfunction and damage ${ }^{4}$ can be measured on brain magnetic resonance imaging (MRI) as higher white matter hyperintensity (WMH) volume, lower total brain parenchyma volume, subcortical infarcts, cerebral microbleeds, and large perivascular spaces. ${ }^{4}$ These MRI features are more prevalent in individuals with type 2 diabetes than in those without. ${ }^{5}$ In addition, CSVD is associated with a higher incidence of depressive symptoms. ${ }^{6}$ However, no previous study has investigated whether the association between type 2 diabetes and depressive symptoms is explained, or mediated, by CSVD.

In view of the above, we investigated in a large population-based cohort the association between baseline type 2 diabetes and change in depressive symptoms over time. In addition, we evaluated whether this association was explained by MRI features of CSVD, i.e. higher WMH volume, lower total brain parenchyma volume, subcortical infarcts, cerebral microbleeds, and large perivascular spaces.

\section{Methods}

\section{Participants}

Participants were from the population-based Age, Gene/Environment Susceptibility (AGES)-Reykjavik Study cohort originating from the Reykjavik Study, described previously. ${ }^{7}$ Briefly, from 2002-2006, 5,764 surviving participants of the Reykjavik Study were examined and 3,316 (57.5\%) were re-examined five years later, from 2007-2011. Reasons for not attending the follow-up examination included: death $(n=1,039)$; refusal $(n=1,198)$; and lost to follow-up $(n=211)$. The AGES-Reykjavik Study was approved by the National Bioethics Committee in Iceland (approval number=VSN-00-063), and by the Institutional Review Board overseeing the National Institute on Aging and the National Insititutes of Health. After complete description of the study to the subject, written informed consent was obtained.

\section{Type 2 diabetes mellitus}

Baseline type 2 diabetes was defined as self-reported history of type 2 diabetes, use of blood glucose-lowering drugs, or a fasting blood glucose level $\geq 7.0 \mathrm{mmol} / \mathrm{L}^{8}$ 


\section{Depressive symptoms}

Depressive symptoms were assessed with use of the 15-item Geriatric Depression Scale (GDS-15; score range 0-15) at baseline and at follow-up five years later. ${ }^{9,10}$ We calculated the change in GDS-15 score over time by subtracting the GDS-15 score at baseline from the GDS-15 score at follow-up. In addition, we distinguished an apathy subscale including all three apathy items of the GDS-15 (GDS-3A, range 0-3) and a subscale including the remaining depression items (GDS-12D, range $0-12$ ), as described previously. ${ }^{11}$ Additionally, use of antidepressant medication (tricyclics, selective serotonin reuptake inhibitors, other nontricyclics and monoamine oxidase inhibitors) was assessed from medication bottles brought to the clinic at baseline and at follow-up.

\section{Brain MRI measures Image acquisition}

All eligible participants were offered high-resolution 1.5T brain MRI (Signa Twinspeed, General Electric Medical Systems). A standardized imaging protocol, described previously, ${ }^{12,13}$ was used both at baseline and follow-up and included the following sequences: 3D spoiled-gradient recalled T1-weighted, proton density/T2-weighted fast spin-echo, fluid-attenuated inversion recovery (FLAIR) and T2*-weighted gradient-echo type echoplanar image (GRE-EPI). All images were acquired to give full brain coverage with slices angled parallel to the anterior commissure-posterior commissure line to give reproducible image views in the oblique-axial plane.

\section{Image analysis}

Five features of CSVD were evaluated: WMH volume, total brain parenchyma volume, subcortical infarcts, cerebral microbleeds and large perivascular spaces. WMH volume and total brain parenchyma volume were computed automatically with a previously described image analysis pipeline, ${ }^{14}$ and were expressed as the percentage of total intracranial volume. Subcortical infarcts were defined as subcortical brain parenchyma defects as described previously, ${ }^{13}$ with a diameter of $\geq 4 \mathrm{~mm}$ and a signal intensity similar to cerebrospinal fluid on all pulse sequences (T2-weighted, proton density-weighted and FLAIR), surrounded by an area of high signal intensity on FLAIR images, and without evidence of hemosiderin on T2*-weighted GRE-EPI sequence. Cerebral microbleeds were defined as focal areas of signal void visible on T2*-weighted GRE-EPI sequence. ${ }^{12}$ Large perivascular spaces were defined as defects in the subcortical area without a rim or area of high signal intensity on FLAIR and without evidence of hemosiderin on T2*-weighted GRE-EPI sequence. ${ }^{15}$

\section{Confounding variables}

Selection of confounding and co-varying measures was based on previous studies ${ }^{16,17}$ showing their association with type 2 diabetes or depressive symptoms. The following variables were assessed by questionnaire: education level (primary, secondary and college/university education), alcohol use (high [above median] vs. low [below median], stratified by sex), and smoking history (never, former, current). Body mass index (BMI) was calculated as measured weight in $\mathrm{kg}$ divided by height in $\mathrm{cm}$ squared. Hypertension was defined as systolic pressure $\geqq 140 \mathrm{mmHg}$, diastolic pressure $\geqq 90 \mathrm{mmHg}$ or use of anti-hypertensive medication. Total/HDL cholesterol ratio, baseline coronary artery 
disease and stroke, and incident stroke during follow-up were determined as described previously. ${ }^{7}$ Dementia was diagnosed according to international guidelines ${ }^{18}$ by a panel that included a geriatrician, a neurologist, a neuropsychologist and a neuroradiologist as described previously. ${ }^{7}$

\section{Analytic sample}

Of the 3,316 participants who attended the follow-up examination, 207 were excluded because of a diagnosis of dementia at baseline $(n=47)$ or at follow-up $(n=160)$. In addition, participants were excluded if they had missing data on brain MRI ( $n=701), G D S-15$ score at baseline or at follow-up ( $n=149)$, or confounders $(n=18)$. Finally, we excluded participants with baseline clinically relevant depressive symptoms defined as a GDS-15 score $\geq 6$ $(n=106)$. In the main analysis, we did not exclude participants using antidepressant medication, because these medications are also prescribed for indications other than depression (e.g. diabetic polyneuropathy). The final study sample for the main analysis consisted of 2,135 participants.

\section{Statistical analysis}

We summarized the baseline CSVD features and the change in CSVD features over time into a composite score of baseline CSVD and a composite score of CSVD change over time because we hypothesize that each CSVD feature may mediate the association between type 2 diabetes and depressive symptoms according to similar mechanisms. A composite score reduces the influence of the biological variability of its components ${ }^{19}$ and requires fewer statistical tests. We calculated a composite score of baseline CSVD as described previously; ${ }^{3}$ one point per CSVD feature at baseline was assigned based on the following cut-offs: for high WMH volume quartile 4 vs. quartiles 1 to 3 ; for low total brain parenchyma volume quartile 1 vs. quartiles 2 to 4; and for subcortical infarcts, cerebral microbleeds and large perivascular spaces presence vs. absence. The points for each feature were summed up to compute the composite score of baseline CSVD (range 0-5). Subsequently, we calculated a composite score of CSVD change over time between the baseline and follow-up examination by assigning one point per change in each CSVD feature over time based on the following cut-offs: for high increase in WMH volume quartile 4 vs. quartiles 1 to 3; for high decrease in total brain parenchyma quartile $4 \mathrm{vs}$. quartiles 1 to 3; and for new subcortical infarcts, cerebral microbleeds and large perivascular spaces $\geq 1$ new lesion(s) vs. no new lesions.

The statistical analysis proceeded in two stages. First, multivariable linear regression analyses were used to estimate the associations between type 2 diabetes at baseline, the composite score of baseline CSVD, the composite score of CSVD change over time, and the change in the GDS-15 score over time. Analyses were adjusted for age, sex, education level (model 1), and additionally for alcohol use, smoking history, BMI and total/HDL cholesterol ratio (model 2). Second, we performed a mediation analysis ${ }^{20}$ to test the hypothesis that CSVD features explain the association between type 2 diabetes at baseline and change in the GDS-15 score over time. The mediation model quantifies the degree to which a variable statistically explains the association between a determinant and an outcome variable. We tested the potential explained associations of the composite score of baseline CSVD and the composite score of CSVD change over time separately. We used bootstrapping $(10,000$ 
samples) to calculate bias-corrected $95 \%$ confidence intervals ( $95 \% \mathrm{Cls}$ ) of the explained associations using the PROCESS statistical package for PASW statistics. ${ }^{20}$

We did several additional analyses. First, we repeated the analysis with adjustment for each individual CSVD feature in the model separately. Second, we repeated the analysis with the GDS-15 score at follow-up as the outcome instead of the change in GDS-15 score over time, and with additional adjustment for the GDS-15 score at baseline. Third, we repeated the analysis after excluding participants using antidepressant medication at baseline. Fourth, it has been suggested that CSVD features may be most strongly associated with apathyrelated symptoms of depression. ${ }^{11}$ Therefore, we repeated the analysis with the change in GDS3-A and GDS12-D score over time as the outcome, respectively. Fifth, we repeated the analysis additionally adjusting for baseline coronary artery disease. Adjustment for coronary artery disease was not done in the main analysis, because data on coronary artery disease were missing in a relatively large number of participants $(n=220)$. Sixth, we repeated the analysis additionally adjusting for hypertension, baseline stroke or incident stroke during follow-up. Adjustments for hypertension and stroke were not done in the main analysis, because of the risk of overadjustment bias: hypertension and stroke may be confounders, but may also mediate the associations between type 2 diabetes, CSVD features and change in depressive symptoms over time. ${ }^{21,22}$

All analyses were done with PASW Statistics (version 23). A P value of $<.05$ was considered statistically significant. 


\section{Results}

The mean age of the participants at baseline was 74.5 (SD 4.6) years, $58.3 \%$ were women and $9.2 \%$ had type 2 diabetes. On average, the GDS-15 score increased 0.4 points (SD 1.6) over time. In participants with type 2 diabetes, the GDS-15 score increased 0.7 (SD 1.9) and in participants without type 2 diabetes 0.3 (SD 1.6). The mean time between baseline and follow-up was 5.2 (SD 0.2) years. Characteristics of the total study population according to presence of type 2 diabetes are given in Table 1. Characteristics of the individuals excluded from the analyses are provided in the Supplementary Material (eTable 1).

Participants with type 2 diabetes as compared to those without had a greater increase in GDS-15 score over time between the baseline and follow-up examination after adjustment for age, sex, education, alcohol use, smoking history, BMI, and total/HDL cholesterol ratio (Table 2). In addition, participants with type 2 diabetes had a higher composite score of baseline CSVD and a higher composite score of CSVD change over time after full adjustment (Table 2). A higher composite score of baseline CSVD and a higher composite score of CSVD change over time were associated with greater increase in GDS-15 score over time after full adjustment (Table 2).

Mediation analysis showed that the composite scores of baseline CSVD and CSVD change over time each statistically significantly explained part of the total association between type 2 diabetes and greater increase in GDS-15 score over time (Figure 1, panels A and B).

\section{Additional analyses}

Most individual CSVD features attenuated the association between baseline type 2 diabetes and greater increase in GDS-15 score over time (eFigures 1 and 2). Results were similar when we used the GDS-15 score at follow-up as the outcome, instead of the change in GDS-15 score over time, and with additional adjustment for the GDS-15 score at baseline (eTable 2). The association between type 2 diabetes and change in GDS15 score over time was qualitatively similar when we excluded participants that used antidepressant medication at baseline (eTable 3). Type 2 diabetes was associated with a greater increase in the GDS3-A score over time, but not with change in the GDS12-D score over time (eTable 4). In addition, the composite score of CSVD change over time explained part of the total association of type 2 diabetes and a greater increase in GDS3-A score over time (eFigures 3 and 4). The results of the main analysis were comparable when we additionally adjusted for baseline coronary artery disease, hypertension, or baseline stroke and incident stroke during follow-up (eTable 5). 


\section{Discussion}

In this study, type 2 diabetes was independently associated with a greater increase in depressive symptoms over time, and CSVD features explained, or mediated, part of this association.

The study findings are in accordance with the vascular depression hypothesis, ${ }^{2}$ and suggest that cerebral microvascular damage may contribute to the development of depressive symptoms, in individuals with type 2 diabetes. A previous meta-analysis found that CSVD features are associated with a higher risk of incident depressive symptoms. ${ }^{6}$ In addition, a previous systematic review found that type 2 diabetes is associated with presence of CSVD features. ${ }^{5}$ This study extends these previous studies by showing that the association between type 2 diabetes and greater increase in depressive symptoms over time is partially explained by CSVD features.

Type 2 diabetes may lead to CSVD via various mechanisms including impaired insulindependent arteriolar dilation, advanced glycation, excessive oxidative stress and epigenetic changes. ${ }^{23,24}$ The cerebral microvasculature, in turn, is involved in the regulation of many cerebral processes, including cerebral perfusion, neurovascular coupling, bloodbrain barrier permeability and neurogenesis. ${ }^{24}$ Impairment of these processes may lead to neuronal dysfunction, ischemia and cell death, which may ultimately contribute to depressive symptoms via damage in deep and frontal brain structures involved in mood regulation. ${ }^{24}$

Other mechanisms may, however, explain the observed associations. First, CSVD may indirectly lead to depression through incident stroke. However, adjusting for stroke at baseline or incident stroke during follow-up did not change our results. Second, CSVD may indirectly lead to depression through cognitive impairment. For the present study, however, we excluded individuals with dementia at baseline or at follow-up. Third, other confounding factors may explain the association between type 2 diabetes, CSVD features and change in depressive symptoms over time, such as lower socio-economic status and cardiovascular factors. However, the associations between type 2 diabetes, CSVD and depressive symptoms were independent of education level and cardiovascular risk factors. ${ }^{25,26}$ Nevertheless, we cannot exclude the possibility of residual confounding.

Some part of the association between type 2 diabetes and higher depressive symptoms over time remained unexplained after taking into account the effect of CSVD features. This remaining association may be due to microvascular dysfunction that is not directly captured in the MRI scans in the present study (e.g. microinfarctions, increased bloodbrain permeability and lower cerebral vasoreactivity). In addition, it is possible that only a subset of individuals with type 2 diabetes develop depressive symptoms that are related to CSVD. Depressive symptoms in type 2 diabetes may be related to other mediators such as psychosocial factors, ${ }^{1}$ diabetes-related comorbidities ${ }^{1}$ and glucose neurotoxicity. ${ }^{27}$ 
Strengths of the present study are the large population-based sample of older participants, the comprehensive brain MRI assessment of various CSVD features at baseline and followup five years later and the extensive adjustment for a series of potential confounders.

Our study has certain limitations. First, the construction of a composite score of CSVD assumes that all its components are of equal importance in the association between type 2 diabetes and higher depressive symptoms over time, which may not be necessarily true. However, we found that most individual CSVD features contributed to the effect of CSVD on the association between type 2 diabetes and higher depressive symptoms over time. Second, unavoidable survival bias may change the associations if among the persons who died, associations among type 2 diabetes, CVSD features and depressive symptoms differ from those in the sample. Third, we lacked power to investigate the association of baseline type 2 diabetes to incident depressive symptoms (GDS-15 score $\geq 6$ ). Fourth, because we study associations of change in depressive symptoms with change in CSVD features, we cannot investigate the temporality of the association. However, it is likely that only many repeated measures made at short intervals will resolve temporal relations.

In view of the increased risk of depression in type 2 diabetes, efforts to favorably influence cerebral microvascular function through lifestyle and pharmacological therapy might help to prevent or treat microvascular dysfunction-related depression. ${ }^{24,28}$ Evidence suggests that weight loss and exercise may improve microvascular function and symptoms of depression. ${ }^{24}$ In addition, drugs, such as renin-angiotensin-aldosterone system inhibitors and antihyperglycemic agents (i.e. metformin and glucagon-like peptide 1 receptor (GLP$1 \mathrm{R}$ ) agonists), may improve microvascular function, possibly beyond their blood pressureor glucose-lowering effects. ${ }^{24}$

In conclusion, the present study found that type 2 diabetes is independently associated with greater increase depressive symptoms over time, and that this association is in part explained by MRI features of CSVD. 


\section{References}

1. Badescu SV, Tataru C, Kobylinska L, Georgescu EL, Zahiu DM, Zagrean AM and Zagrean L. The association between Diabetes mellitus and Depression. J Med Life. 2016;9:120-5.

2. Alexopoulos GS, Meyers BS, Young RC, Campbell S, Silbersweig D and Charlson M. 'Vascular depression' hypothesis. Arch Gen Psychiatry. 1997;54:915-22.

3. van Sloten TT, Sigurdsson S, van Buchem MA, Phillips CL, Jonsson PV, Ding J, Schram MT, Harris TB, Gudnason V and Launer LJ. Cerebral Small Vessel Disease and Association With Higher Incidence of Depressive Symptoms in a General Elderly Population: The AGES-Reykjavik Study. Am J Psychiatry. 2015;172:570-8.

4. Wardlaw JM, Smith EE, Biessels GJ, Cordonnier C, Fazekas F, Frayne R, Lindley RI, O'Brien JT, Barkhof F, Benavente OR, Black SE, Brayne C, Breteler M, Chabriat H, Decarli C, de Leeuw FE, Doubal F, Duering M, Fox NC, Greenberg S, Hachinski V, Kilimann I, Mok V, Oostenbrugge R, Pantoni L, Speck O, Stephan BC, Teipel S, Viswanathan A, Werring D, Chen C, Smith C, van Buchem $M$, Norrving B, Gorelick PB, Dichgans $M$ and nEuroimaging STfRVco. Neuroimaging standards for research into small vessel disease and its contribution to ageing and neurodegeneration. Lancet Neurol. 2013;12:822-38.

5. Geijselaers SLC, Sep SJS, Stehouwer CDA and Biessels GJ. Glucose regulation, cognition, and brain MRI in type 2 diabetes: a systematic review. Lancet Diabetes Endocrinol. 2015;3:75-89.

6. Rensma SP, van Sloten TT, Launer LJ and Stehouwer CDA. Cerebral small vessel disease and risk of incident stroke, dementia and depression, and all-cause mortality: A systematic review and meta-analysis. Neurosci Biobehav Rev. 2018;90:164-173.

7. Harris TB, Launer LJ, Eiriksdottir G, Kjartansson O, Jonsson PV, Sigurdsson G, Thorgeirsson G, Aspelund T, Garcia ME, Cotch MF, Hoffman HJ and Gudnason V. Age, Gene/Environment Susceptibility-Reykjavik Study: multidisciplinary applied phenomics. Am J Epidemiol. 2007;165:1076-87.

8. Marathe PH, Gao HX and Close KL. American Diabetes Association Standards of Medical Care in Diabetes 2017. J Diabetes. 2017;9:320-324.

9. Almeida OP and Almeida SA. Short versions of the geriatric depression scale: a study of their validity for the diagnosis of a major depressive episode according to ICD-10 and DSM-IV. Int J Geriatr Psychiatry. 1999;14:858-65.

10. Yesavage JA, Brink TL, Rose TL, Lum O, Huang V, Adey M and Leirer VO. Development and validation of a geriatric depression screening scale: a preliminary report. $J$ Psychiatr Res. 1982;17:37-49.

11. Ligthart SA, Richard E, Fransen NL, Eurelings LS, Beem L, Eikelenboom P, van Gool WA and Moll van Charante EP. Association of vascular factors with apathy in community-dwelling elderly individuals. Arch Gen Psychiatry. 2012;69:636-42.

12. Sveinbjornsdottir $S$, Sigurdsson $S$, Aspelund T, Kjartansson O, Eiriksdottir G, Valtysdottir B, Lopez OL, van Buchem MA, Jonsson PV, Gudnason V and Launer LJ. Cerebral microbleeds in the population based AGES-Reykjavik study: prevalence and location. J Neurol Neurosurg Psychiatry. 2008;79:1002-6.

13. Scher Al, Gudmundsson LS, Sigurdsson S, Ghambaryan A, Aspelund T, Eiriksdottir G, van Buchem MA, Gudnason V and Launer LJ. Migraine headache in middle age and late-life brain infarcts. JAMA. 2009;301:2563-70. 
14. Sigurdsson $S$, Aspelund T, Forsberg L, Fredriksson J, Kjartansson O, Oskarsdottir B, Jonsson PV, Eiriksdottir G, Harris TB, Zijdenbos A, van Buchem MA, Launer LJ and Gudnason V. Brain tissue volumes in the general population of the elderly: the AGES-Reykjavik study. Neuroimage. 2012;59:3862-3870.

15. Ding J, Sigurethsson S, Jonsson PV, Eiriksdottir G, Charidimou A, Lopez OL, van Buchem MA, Guethnason V and Launer LJ. Large Perivascular Spaces Visible on Magnetic Resonance Imaging, Cerebral Small Vessel Disease Progression, and Risk of Dementia: The Age, Gene/Environment Susceptibility-Reykjavik Study. JAMA Neurol. 2017;74:1105-1112.

16. Oladeji BD and Gureje O. The comorbidity between depression and diabetes. Curr Psychiatry Rep. 2013;15:390.

17. Renn BN, Feliciano $L$ and Segal DL. The bidirectional relationship of depression and diabetes: $a$ systematic review. Clin Psychol Rev. 2011;31:1239-46.

18. Association AP. American Psychiatric Association, Diagnostic and Statistical Manual of Mental Disorders, DMS-IV (4th edition). 1994.

19. O'Brien PC. Procedures for comparing samples with multiple endpoints. Biometrics. 1984;40:1079-87.

20. Preacher $\mathrm{KJ}$ and Hayes AF. Asymptotic and resampling strategies for assessing and comparing indirect effects in multiple mediator models. Behav Res Methods. 2008;40:879-91.

21. Lastra G, Syed S, Kurukulasuriya LR, Manrique $C$ and Sowers JR. Type 2 diabetes mellitus and hypertension: an update. Endocrinol Metab Clin North Am. 2014;43:103-22.

22. Garcia-Fabela L, Melano-Carranza E, Aguilar-Navarro S, Garcia-Lara JM, Gutierrez-Robledo LM and Avila-Funes JA. Hypertension as a risk factor for developing depressive symptoms among community-dwelling elders. Rev Invest Clin. 2009;61:274-80.

23. Forbes JM and Cooper ME. Mechanisms of diabetic complications. Physiol Rev. 2013;93:137-88.

24. Stehouwer CDA. Microvascular Dysfunction and Hyperglycemia: A Vicious Cycle With Widespread Consequences. Diabetes. 2018;67:1729-1741.

25. Kaplan GA and Keil JE. Socioeconomic factors and cardiovascular disease: a review of the literature. Circulation. 1993;88:1973-98.

26. Lopez AD, Mathers CD, Ezzati M, Jamison DT and Murray CJ. Global and regional burden of disease and risk factors, 2001: systematic analysis of population health data. Lancet. 2006;367:1747-57.

27. Tomlinson DR and Gardiner NJ. Glucose neurotoxicity. Nat Rev Neurosci. 2008;9:36-45.

28. Lustman PJ and Clouse RE. Depression in diabetic patients: the relationship between mood and glycemic control. J Diabetes Complications. 2005;19:113-22. 
Table 1. Baseline characteristics of the total study population, and according to presence of type 2 diabetes at baseline

\begin{tabular}{|c|c|c|c|}
\hline & $\begin{array}{l}\text { Total study } \\
\text { population } \\
(n=2,135)\end{array}$ & $\begin{array}{l}\text { Participants with } \\
\text { type } 2 \text { diabetes } \\
\text { (n=197;9.2\%) }\end{array}$ & $\begin{array}{c}\text { Participants without } \\
\text { type } 2 \text { diabetes } \\
\text { (n=1,938; 90.8\%) }\end{array}$ \\
\hline \multicolumn{4}{|l|}{ Age } \\
\hline Baseline & $74.5(4.6)$ & $74.6(4.3)$ & $74.5(4.6)$ \\
\hline Follow-up & $79.7(4.6)$ & $79.7(4.3)$ & $79.7(4.6)$ \\
\hline Women & $1,245(58.3)$ & $94(47.7)$ & $1,151(59.4)$ \\
\hline \multicolumn{4}{|l|}{ Education level } \\
\hline Primary & $410(19.2)$ & $33(16.8)$ & $377(19.5)$ \\
\hline Secondary & $1,106(51.8)$ & $103(52.3)$ & $1,003(51.8)$ \\
\hline College/university & $619(29.0)$ & $61(31.0)$ & $558(28.8)$ \\
\hline \multicolumn{4}{|l|}{ Smoking history } \\
\hline Former smoker & $985(46.1)$ & $101(51.3$ & $884(45.6)$ \\
\hline Current smoker & $220(10.3)$ & $18(9.1)$ & $202(10.4)$ \\
\hline High alcohol use $^{1}$ & $881(41.3)$ & $78(39.6)$ & $803(41.4)$ \\
\hline Body mass index $\left(\mathrm{kg} / \mathrm{m}^{2}\right)$ & $27.2(4.0)$ & $28.9(4.0)$ & $27.1(4.0)$ \\
\hline Baseline coronary artery disease $^{2}$ & $488(26.2)$ & $62(31.5)$ & $426(22.0)$ \\
\hline \multicolumn{4}{|l|}{ Stroke } \\
\hline Baseline & $94(4.4)$ & $9(4.6)$ & $85(4.4)$ \\
\hline Incident & $24(1.1)$ & $4(2.0)$ & $20(1.0)$ \\
\hline $\begin{array}{l}\text { Incident depressive symptoms (GDS-15 } \\
\text { score } \geq 6 \text { ) }\end{array}$ & $92(4.3)$ & $13(6.6)$ & $79(4.1)$ \\
\hline Hypertension & $1,651(77.3)$ & $179(90.9)$ & $1,472(76.0)$ \\
\hline Total/HDL cholesterol ratio & $3.7(1.1)$ & $3.9(1.2)$ & $3.7(1.1)$ \\
\hline \multicolumn{4}{|l|}{ GDS-15 score } \\
\hline Baseline, median (IQR) & $1(0-3)$ & $1(1-2.5)$ & $1(1-3)$ \\
\hline Change over time & $+0.4(1.6)$ & $+0.7(1.9)$ & $+0.3(1.6)$ \\
\hline Follow-up & $2(1-3)$ & $2(1-3)$ & $2(1-3)$ \\
\hline \multicolumn{4}{|l|}{ Use of antidepressant medication } \\
\hline Baseline & $215(10.1)$ & $19(9.6)$ & $196(10.1)$ \\
\hline Follow-up & $287(13.4)$ & $23(11.7)$ & $264(13.6)$ \\
\hline \multicolumn{4}{|c|}{ Composite scores of cerebral small vessel disease features } \\
\hline Baseline & $0.8(0.9)$ & $1.0(1.0)$ & $0.7(0.9)$ \\
\hline Change over time & $+0.6(0.8)$ & $+0.8(0.9)$ & $+0.6(0.8)$ \\
\hline Follow-up & $0.9(1.0)$ & $1.3(1.2)$ & $0.9(1.0)$ \\
\hline \multicolumn{4}{|l|}{ Total brain parenchyma volume, ml } \\
\hline Baseline & $1,097.0(102.4)$ & $1,089.1(112.7)$ & $1,097.9(101.3)$ \\
\hline Change over time & $-31.7(17.1)$ & $-35.6(18.8)$ & $-31.3(16.9)$ \\
\hline Follow-up & $1,065.4(99.4)$ & $1,053.4(110.5)$ & $1,066.6(98.1)$ \\
\hline \multicolumn{4}{|l|}{ White matter hyperintensity volume, ml } \\
\hline Baseline, median (IQR) & $11.2(6.4-20.7)$ & $13.2(7.3-22.2)$ & $11.1(6.3-20.5)$ \\
\hline Change over time & $+5.6(7.4)$ & $+6.0(8.2)$ & $+5.6(7.3)$ \\
\hline Follow-up & $15.0(8.1-28.9)$ & $17.2(9.9-31.9)$ & $14.8(7.9-28.7)$ \\
\hline \multicolumn{4}{|l|}{ Subcortical infarcts } \\
\hline Baseline & $154(7.2)$ & $31(15.7)$ & $123(6.3)$ \\
\hline Incident & $87(4.1)$ & $13(6.6)$ & $74(3.8)$ \\
\hline Follow-up & $212(9.9)$ & $37(18.8)$ & $175(9.0)$ \\
\hline
\end{tabular}




\begin{tabular}{|c|c|c|c|}
\hline & $\begin{array}{c}\text { Total study } \\
\text { population } \\
(n=2,135)\end{array}$ & $\begin{array}{l}\text { Participants with } \\
\text { type } 2 \text { diabetes } \\
\text { (n=197;9.2\%) }\end{array}$ & $\begin{array}{c}\text { Participants without } \\
\text { type } 2 \text { diabetes } \\
(n=1,938 ; 90.8 \%)\end{array}$ \\
\hline \multicolumn{4}{|c|}{ Cerebral microbleeds } \\
\hline Baseline & 355 (16.6) & 38 (19.3) & $317(16.4)$ \\
\hline Incident & $377(17.7)$ & $45(22.8)$ & $332(17.1)$ \\
\hline Follow-up & $630(29.5)$ & 74 (37.6) & $556(28.7)$ \\
\hline \multicolumn{4}{|c|}{ Large perivascular spaces } \\
\hline Baseline & $341(16.0)$ & 39 (19.8) & $302(15.6)$ \\
\hline Incident & $60(2.8)$ & $10(5.1)$ & $50(2.6)$ \\
\hline Follow-up & 373 (17.5) & $45(22.8)$ & 328 (16.9) \\
\hline
\end{tabular}

Numbers indicate mean (SD) or number of participants, unless otherwise stated. ${ }^{1}$ High alcohol use was defined as alcohol use above median, stratified by sex; ${ }^{2}$ Data missing in $n=220$. Abbreviations: GDS-15: 15 -item Geriatric Depression Scale; IQR: interquartile range.

Table 2. Associations between type 2 diabetes at baseline, composite score of baseline cerebral small vessel disease, composite score of cerebral small vessel disease change over time, and change in GDS-15 score over time

\begin{tabular}{lcccc}
\hline & Model & $\begin{array}{l}\text { Change in 15-item } \\
\text { Geriatric Depression } \\
\text { Scale score over } \\
\text { time }\end{array}$ & $\begin{array}{l}\text { Composite score of } \\
\text { baseline cerebral } \\
\text { small vessel disease }\end{array}$ & $\begin{array}{l}\text { Composite score of } \\
\text { cerebral small vessel } \\
\text { disease change over } \\
\text { time }\end{array}$ \\
\hline $\begin{array}{l}\text { Type 2 diabetes vs. no } \\
\text { diabetes at baseline }\end{array}$ & 1 & $0.339(0.099 ; 0.579)$ & $0.219(0.093 ; 0.345)$ & $0.205(0.094 ; 0.316)$ \\
\hline & 2 & $0.316(0.074 ; 0.558)$ & $0.244(0.117 ; 0.371)$ & $0.226(0.114 ; 0.338)$ \\
\hline $\begin{array}{l}\text { Composite score of } \\
\text { baseline cerebral small } \\
\text { vessel disease }\end{array}$ & 1 & $0.102(0.014 ; 0.176)$ & - & - \\
\hline & & & & - \\
\hline $\begin{array}{l}\text { Composite score of } \\
\text { cerebral small vessel } \\
\text { disease change over time }\end{array}$ & 1 & $0.207(0.116 ; 0.298)$ & - & - \\
\hline & 2 & $0.202(0.111 ; 0.294)$ & & - \\
\hline
\end{tabular}

Model 1: adjusted for age, sex, and education level; model 2: model $1+$ alcohol use, smoking history, body mass index, and total/HDL cholesterol ratio.

Abbreviations: $\mathrm{Cl}$ : confidence interval. 


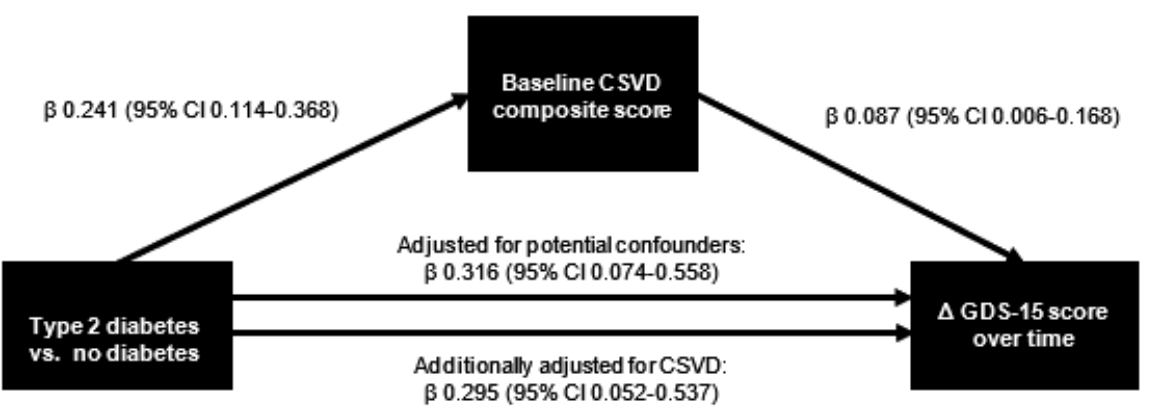

A

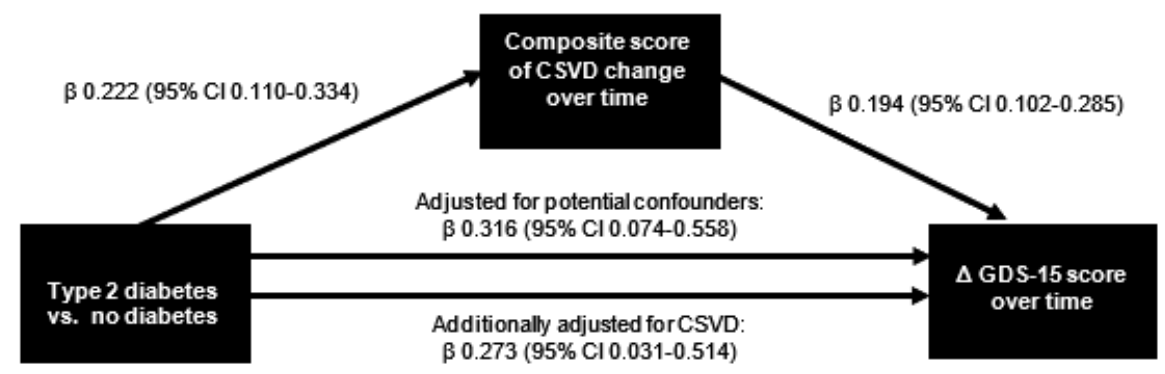

B

Figure 1. Association between type 2 diabetes at baseline and higher 15-item Geriatric Depression Scale score over time between baseline and follow-up examination, and the proportion explained by the composite score of baseline cerebral small vessel disease (panel A), and the composite score of cerebral small vessel disease change over time (panel B). Solid lines indicate associations that are statistically significant; dashed lines indicate associations that are not statistically significant. Associations are given as regression coefficients $(\beta)$ and corresponding 95\% confidence intervals. All associations are adjusted for age, sex, education level, alcohol use, smoking history, body mass index and total/HDL cholesterol ratio. Abbreviations: Cl: confidence interval; CSVD: cerebral small vessel disease; GDS-15: 15-item Geriatric Depression Scale. 


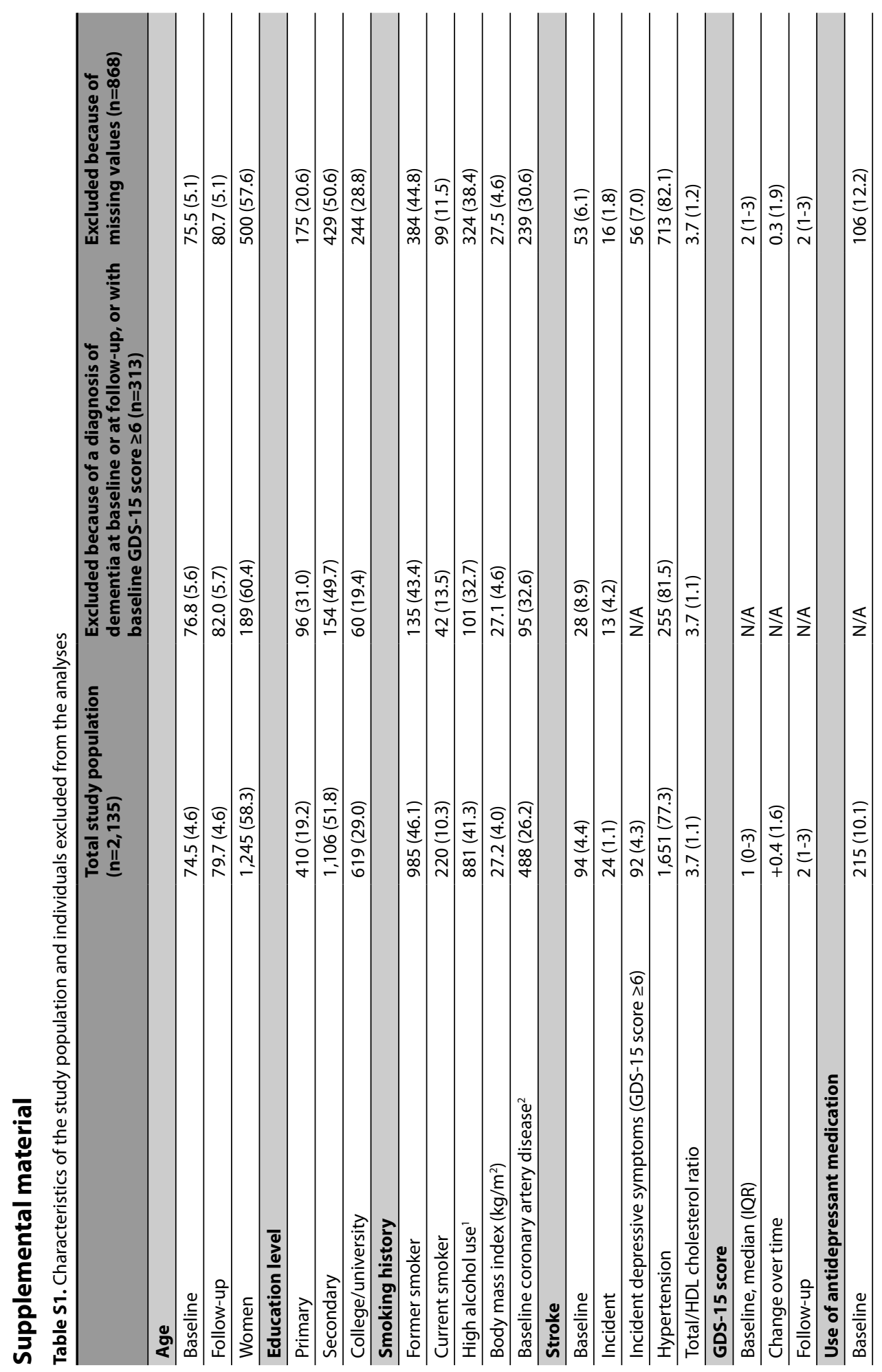




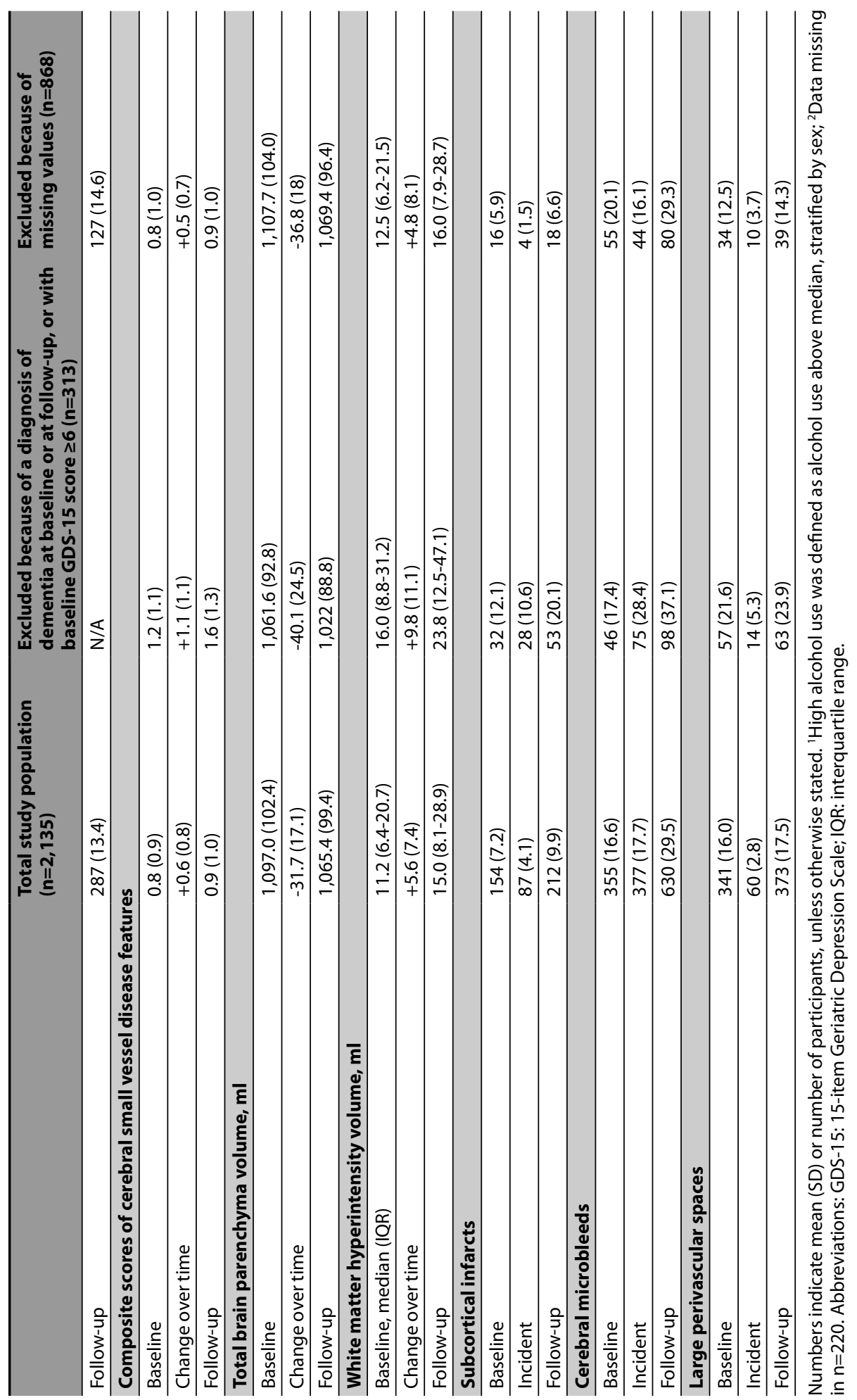


Table S2. Association between type 2 diabetes at baseline and 15-item Geriatric Depression Scale score at follow-up, additionally adjusted for 15-item Geriatric Depression Scale score at baseline

\begin{tabular}{|c|c|c|c|c|}
\hline & & \multicolumn{2}{|c|}{$\begin{array}{l}\text { Change in 15- } \\
\text { item Geriatric } \\
\text { Depression Scale } \\
\text { score over time }\end{array}$} & \multirow[b]{2}{*}{$95 \% \mathrm{Cl}$} \\
\hline & Model & $\beta$ & $95 \% \mathrm{Cl}$ & \\
\hline \multirow[t]{3}{*}{$\begin{array}{l}\text { Type } 2 \text { diabetes vs. no } \\
\text { diabetes }\end{array}$} & 1 & 0.299 & 0.043 & 0.554 \\
\hline & 2 & 0.219 & -0.037 & 0.475 \\
\hline & 3 & 0.276 & 0.047 & 0.505 \\
\hline
\end{tabular}

Model 1: adjusted for age, sex, and education level; model 2: model $1+$ alcohol use, smoking history, body mass index, and total/HDL cholesterol ratio; model 3: model $2+$ Geriatric Depression Scale score at baseline.

Number of participants (n) available: 2,135.

Abbreviations: $\mathrm{Cl}$ : confidence interval.

Table S3. Association between type 2 diabetes at baseline and change in 15-item Geriatric Depression Scale score over time - participants excluded using antidepressant medication at baseline

\begin{tabular}{|c|c|c|c|c|}
\hline & & \multicolumn{2}{|c|}{$\begin{array}{l}\text { Change in } 15- \\
\text { item Geriatric } \\
\text { Depression Scale } \\
\text { score over time }\end{array}$} & \multirow[b]{2}{*}{$95 \% \mathrm{Cl}$} \\
\hline & Model & $\beta$ & $95 \% \mathrm{Cl}$ & \\
\hline \multirow[t]{2}{*}{$\begin{array}{l}\text { Type } 2 \text { diabetes vs. no } \\
\text { diabetes }\end{array}$} & 1 & 0.239 & -0.003 & 0.481 \\
\hline & 2 & 0.226 & 0.004 & 0.493 \\
\hline
\end{tabular}

Model 1: adjusted for age, sex, and education level; model 2: model $1+$ alcohol use, smoking history, body mass index, and total/HDL cholesterol ratio.

Number of participants ( $\mathrm{n}$ ) available: 1,920.

Abbreviations: $\mathrm{Cl}$ : confidence interval.

Table S4. Associations between type 2 diabetes at baseline and change in the apathy and remaining depression items of the 15-item Geriatric Depression Scale score over time

\begin{tabular}{|c|c|c|c|c|c|c|c|}
\hline & & \multicolumn{3}{|c|}{$\begin{array}{l}\text { Change in GDS-3A score } \\
\text { over time, excluding } \\
\text { participants with apathy } \\
(G D S-3 A \geq 2) \text { at baseline } \\
(n=922)^{1}\end{array}$} & \multicolumn{3}{|c|}{$\begin{array}{l}\text { Change in GDS-12D score over } \\
\text { time, excluding participants with } \\
\text { remaining depression items (GDS- } \\
12 D \geq 2) \text { at baseline }(n=298)^{2}\end{array}$} \\
\hline & Model & $\boldsymbol{\beta}$ & $95 \% \mathrm{Cl}$ & & $\boldsymbol{\beta}$ & $95 \% \mathrm{Cl}$ & \\
\hline \multirow[t]{2}{*}{$\begin{array}{l}\text { Type } 2 \\
\text { diabetes vs. } \\
\text { no diabetes }\end{array}$} & 1 & 0.214 & 0.043 & 0.386 & 0.172 & 0.007 & 0.337 \\
\hline & 2 & 0.191 & 0.019 & 0.363 & 0.160 & -0.007 & 0.326 \\
\hline
\end{tabular}

Model 1: adjusted for age, sex, and education level; model 2: model 1 + alcohol use, smoking history, body mass index, total/HDL cholesterol ratio

${ }^{1}$ Number of participants ( $n$ ) available: 1,$301 ;{ }^{2}$ Number of participants (n) available: $1,898$.

Abbreviations: $\mathrm{Cl}$ : confidence interval; GDS-3A: apathy items of the 15-item Geriatric Depression Scale; GDS-12D: remaining depression items of the 15-item Geriatric Depression Scale. 


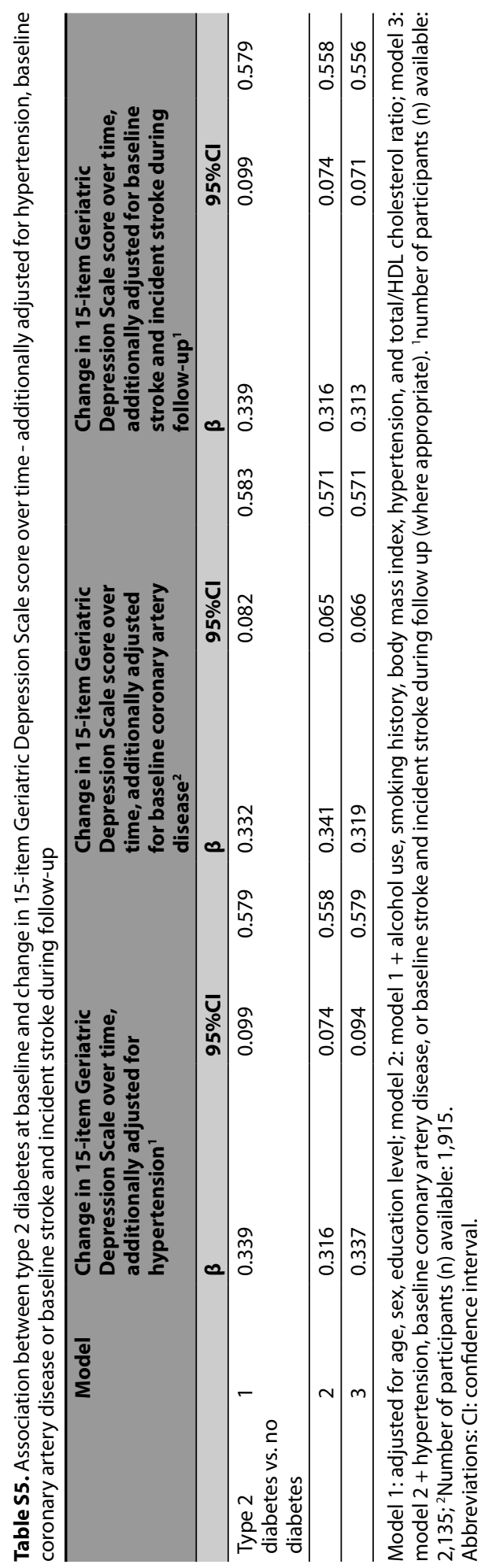




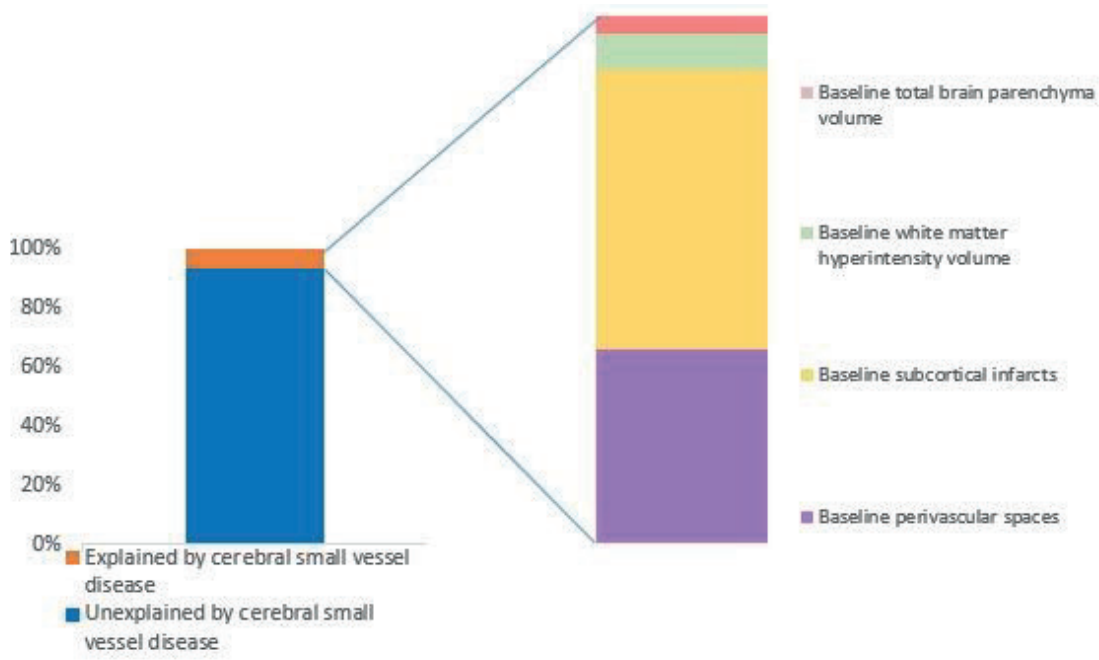

Figure S1. Explained proportion by combined and individual cerebral small vessel disease features at baseline on the association between type 2 diabetes at baseline and higher 15-item Geriatric Depression Scale score over time. Cerebral small vessel disease features explained $6.7 \%$ of the association between type 2 diabetes and higher 15-item Geriatric Depression Scale score over time. The proportion of the association explained by individual cerebral small vessel disease features were: for baseline total brain parenchyma volume $3.3 \%$; for baseline white matter hyperintensity volume $6.7 \%$; for baseline subcortical infarcts $53.3 \%$; for baseline large perivascular spaces $36.7 \%$. Baseline cerebral microbleeds did not explain the association between type 2 diabetes and higher 15-item Geriatric Depression Scale score over time.

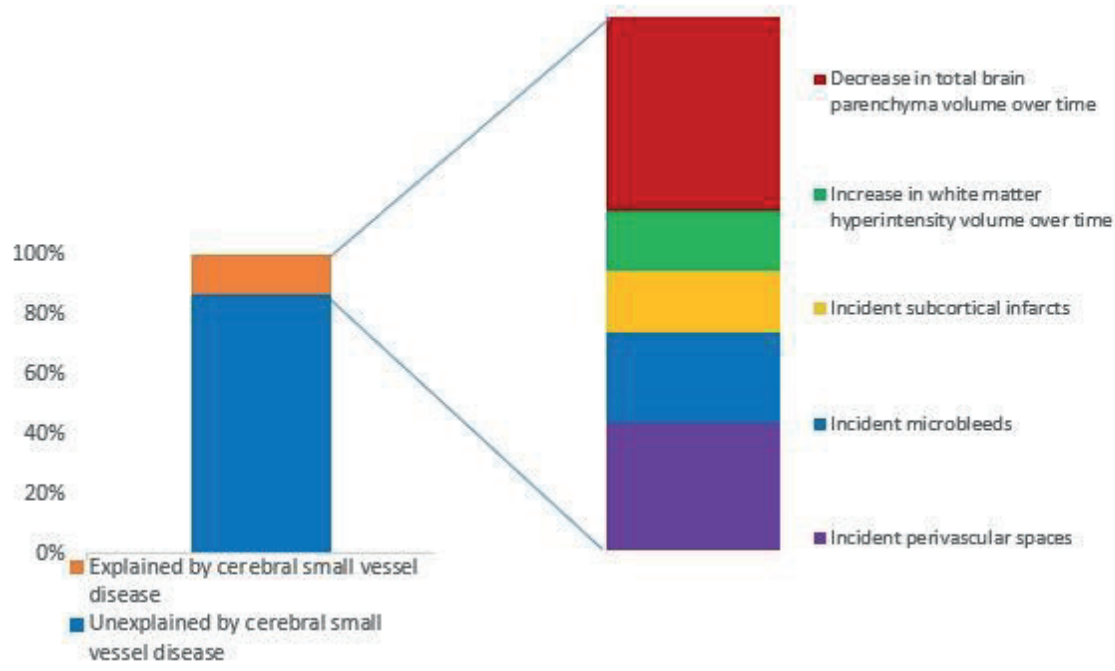

Figure S2. Explained proportion by combined and individual cerebral small vessel disease features change over time on the association between type 2 diabetes at baseline and higher 15 -item Geriatric Depression Scale score over time. Cerebral small vessel disease features explained $13.6 \%$ of the association between type 2 diabetes and higher 15-item Geriatric Depression Scale score over time. The proportion of the association explained by individual cerebral small vessel disease features were: for decrease in total brain parenchyma volume over time 19.3\%; for increase in white matter hyperintensity volume over time $9.7 \%$; for incident subcortical infarcts $14.5 \%$; for incident cerebral microbleeds $8.1 \%$; and for incident large perivascular spaces $48.4 \%$. Baseline cerebral microbleeds did not explain the association between type 2 diabetes and higher 15 -item Geriatric Depression Scale score over time. 


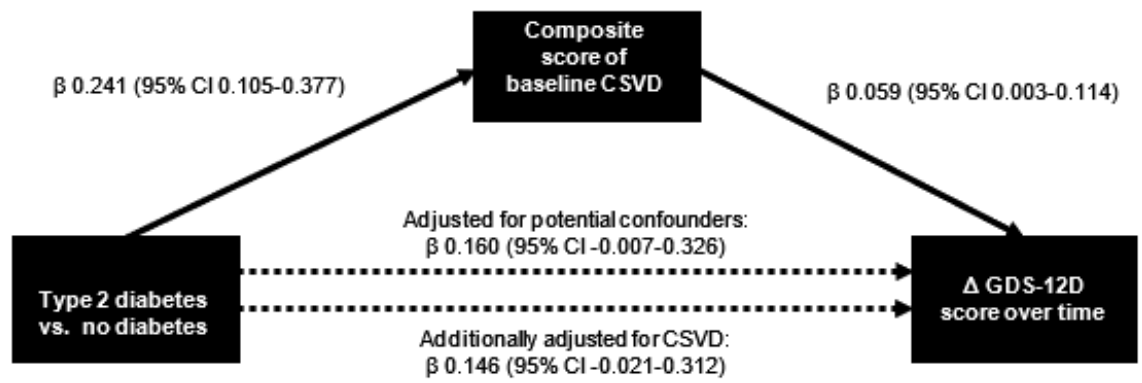

A

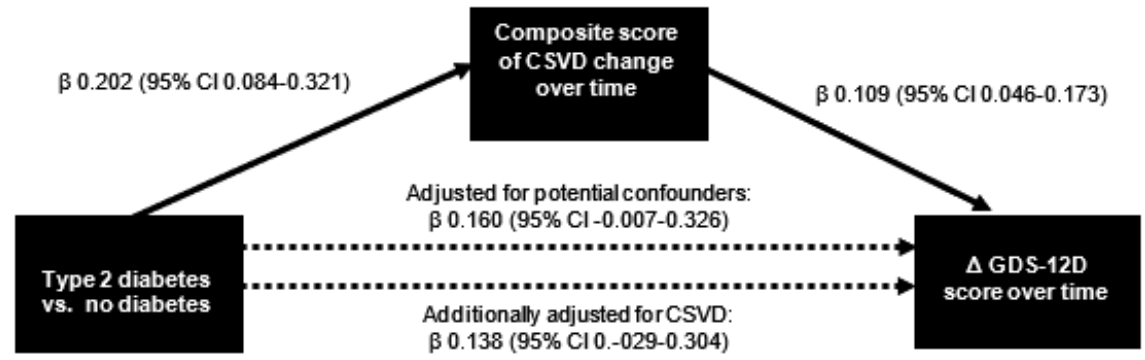

B

Figure S3. Association between type 2 diabetes at baseline and higher apathy items of the 15 -item Geriatric Depression Scale score over time, and the proportion explained by the composite score of baseline cerebral small vessel disease (panel A), and the composite score of cerebral small vessel disease change over time (panel B). Solid lines indicate associations that are statistically significant; dashed lines indicate associations that are not statistically significant. Associations are given as regression coefficients $(\beta)$ and corresponding 95\% confidence intervals. All associations are adjusted for: age, sex, education level, alcohol use, smoking history, body mass index, and total/HDL cholesterol ratio. Number of participants $(\mathrm{n})$ available: 1,301. Abbreviations: Cl: confidence interval; CSVD: cerebral small vessel disease; GDS-3A: apathy items of the 15-item Geriatric Depression Scale. 

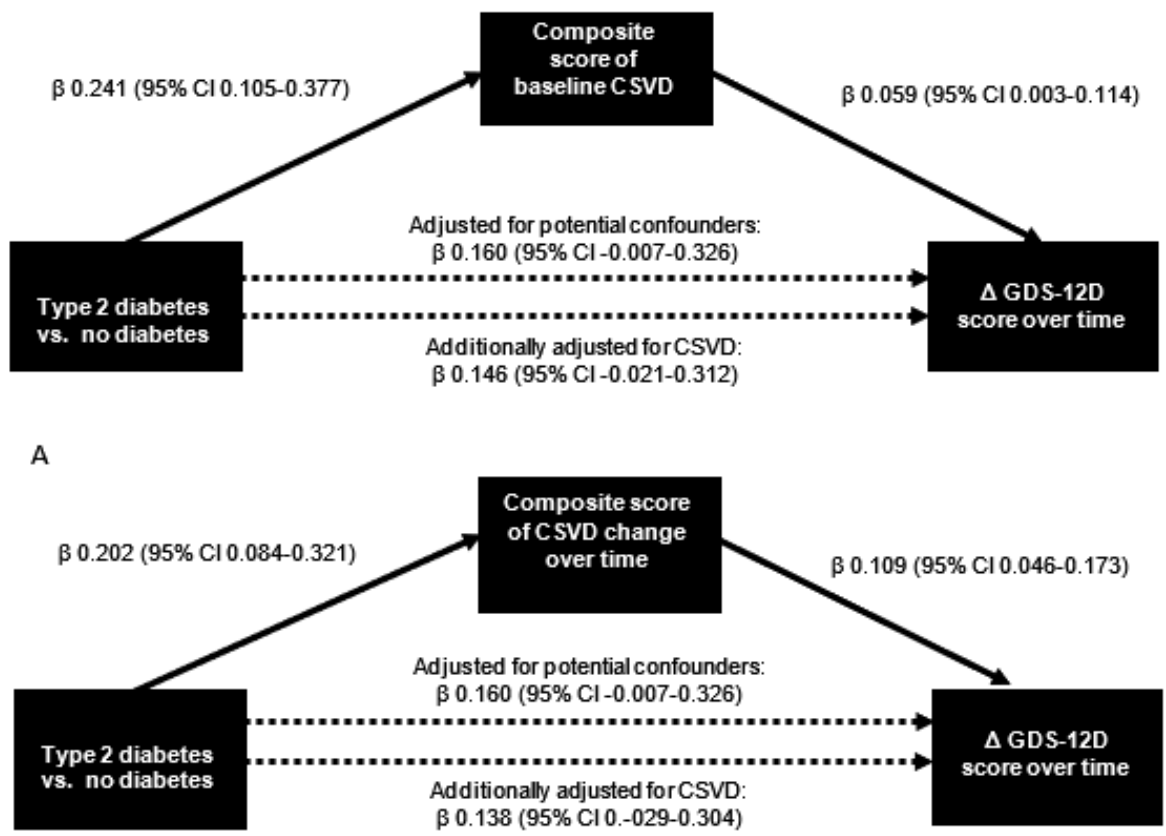

B

Figure S4. Association between type 2 diabetes at baseline and higher remaining items of the 15-item Geriatric Depression Scale score over time, and the proportion explained by the composite score of baseline cerebral small vessel disease (panel A), and the composite score of cerebral small vessel disease change over time (panel B). Solid lines indicate associations that are statistically significant; dashed lines indicate associations that are not statistically significant. Associations are given as regression coefficients $(\beta)$ and corresponding $95 \%$ confidence intervals. All associations are adjusted for: age, sex, education level, alcohol use, smoking history, body mass index, and total/HDL cholesterol ratio. Number of participants (n) available: 1,898. Abbreviations: Cl: confidence interval; CSVD: cerebral small vessel disease; GDS-12D: remaining items of the 15item Geriatric Depression Scale. 
CHAPTER 4 


\section{Microvascular dysfunction is associated with worse cognitive performance: The Maastricht Study}

Sytze P. Rensma, Thomas T. van Sloten, Alfons J.H.M. Houben, Sebastian Köhler, Martin P.J. van Boxtel, Tos T.J.M. Berendschot, Jacobus F.A. Jansen, Frans R.J. Verhey, Abraham A. Kroon, Annemarie Koster, Walter H. Backes, Nicolaas Schaper, Geert-Jan Dinant, Casper G. Schalkwijk, Ronald M.A. Henry, Else M.L. Wolfs, Mike J.A. van Heumen, Miranda T. Schram, Coen D.A. Stehouwer 


\section{Abstract}

Microvascular dysfunction may be associated with worse cognitive performance. Most previous studies did not adjust for important confounders, evaluated only individual measures of microvascular dysfunction, and showed inconsistent results. We evaluated the association between a comprehensive set of measures of microvascular dysfunction and cognitive performance in the population-based Maastricht Study.

We used cross-sectional data including 3011 participants (age 59.5 \pm 8.2 ; 48.9\% women; $26.5 \%$ type 2 diabetes [oversampled by design]). Measures of microvascular dysfunction included MRI features of cerebral small vessel disease, plasma biomarkers of microvascular dysfunction, albuminuria, flicker light-induced retinal arteriolar and venular dilation response and heat-induced skin hyperaemia. These measures were summarized into a microvascular dysfunction composite score. Cognitive domains assessed were memory, processing speed and executive function. A cognitive function score was calculated as the sum of the scores on these three cognitive domains.

The microvascular dysfunction score was associated with a worse cognitive function score (standardized $\beta,-0.087 ; 95 \% \mathrm{Cl}-0.127 ;-0.047$ ), independent of age, education level, sex, type 2 diabetes, smoking, alcohol use, hypertension, total/HDL cholesterol ratio, triglycerides, lipid-modifying medication, prior cardiovascular disease, depression and plasma biomarkers of low-grade inflammation. The fully adjusted beta-coefficient of the association between the microvascular dysfunction score and the cognitive function score was equivalent to two (range: one to three) years of aging for each standard deviation higher microvascular dysfunction score. The microvascular dysfunction score was associated with worse memory and processing speed, but not with worse executive function.

The present study shows that microvascular dysfunction is associated with worse cognitive performance. 


\section{Introduction}

Cognitive impairment and dementia are major health problems and their prevalence rises with the aging of the population'. The mechanisms underlying cognitive impairment remain, however, incompletely understood, and may include microvascular dysfunction and damage ("microvascular dysfunction", MVD)².

The microvasculature is involved in the regulation of many cerebral processes, notably neurovascular coupling, cerebral autoregulation, blood-brain barrier permeability and neurogenesis ${ }^{2}$. Impairment of these processes may lead to neuronal dysfunction, ischemia and cell death, which may contribute to cognitive impairment ${ }^{2}$.

Microvascular function can be measured noninvasively in various organs. Indirect measures include magnetic resonance imaging (MRI) features of cerebral small vessel disease (CSVD, e.g. total brain parenchyma volume, white matter hyperintensity volume, and presence of lacunar infarcts and cerebral microbleeds) ${ }^{3}$; plasma biomarkers of MVD (e.g. soluble intercellular adhesion molecule-1 [sICAM-1], soluble vascular adhesion molecule-1 [sVCAM-1], soluble E-selectin [sE-selectin] and von Willebrand factor [VWF]) and albuminuria ("urinary albumin excretion", UAE) ${ }^{5}$. In addition, direct measures include flicker light-induced retinal arteriolar and venular dilation response ${ }^{6}$ and heat-induced skin hyperaemia ${ }^{6}$. CSVD features are closely linked to brain microvasculature structure and evidence indicates that these features originate from cerebral microvascular dysfunction ${ }^{3}$ 7, 8; retinal arteriolar and venular dilation response are also closely linked to the brain microvasculature ${ }^{9}$; in addition, to the extent that MVD is a generalised phenomenon, plasma biomarkers of MVD, UAE, and skin hyperaemia may also reflect brain MVD ${ }^{10}$.

These various measures of MVD (i.e. features of CSVD, plasma biomarkers of MVD, UAE, retinal arteriolar and venular dilation response and skin hyperaemia) may therefore be summarized into a total MVD composite score. A composite score reduces the influence of the biological variability of its components, as we assume substantial overlap among mechanisms underlying the associations between the MVD measures and cognitive performance. Furthermore, it reduces the chance of a type 1 error. However, no study evaluated the association between such a MVD composite score and cognitive performance.

Some individual MVD measures, i.e. CSVD features, plasma biomarkers of MVD and UAE, have been associated with worse cognitive performance ${ }^{11-19}$, although not all measures consistently So $^{15,20,21}$. In the Maastricht Study, we previously found a cross-sectional association between higher UAE and worse cognitive performance ${ }^{22}$. Previous studies, but not all, were relatively small $(n<200)^{11,20}$, used selected populations ${ }^{11,20,21}$, and may have been affected by residual confounding due to incomplete adjustment for education level and cardiovascular risk factors ${ }^{11,12,14}$. Furthermore, most studies did not adjust for depression or low-grade inflammation, although both factors are linked to MVD and worse cognitive performance ${ }^{14,23,24}$. Moreover, the associations between retinal arteriolar and venular dilation response and skin hyperaemia, and cognitive performance have not been investigated. 
We therefore investigated, in a large population-based cohort with participants aged 40-75 years, whether a composite score of MVD measures, including CSVD features, plasma biomarkers of MVD, UAE, retinal arteriolar and venular dilation response and skin hyperaemia, is associated with worse cognitive performance. We additionally evaluated whether any such association was independent of age, education level, sex, lifestyle factors, cardiovascular risk factors, current depression and low-grade inflammation.

\section{Methods}

\section{Study population}

We used data from The Maastricht Study, an observational population-based cohort study. The rationale and methodology have been described previously ${ }^{25}$. In brief, the study focuses on the aetiology, pathophysiology, complications, and comorbidities of diabetes mellitus type 2 (T2D) and is characterized by an extensive phenotyping approach. Eligible for participation were all individuals aged 40-75 years and living in the southern part of the Netherlands. Participants were recruited through mass media campaigns, the municipal registries, and the regional Diabetes Patient Registry via mailings. Recruitment was stratified according to known T2D status, with an oversampling of individuals with T2D, for reasons of efficiency. The present study includes cross-sectional data from 3451 participants who completed the baseline survey between November 2010 and September 2013. The examinations of each participant were performed within a time window of three months. The study has been approved by the institutional medical ethical committee (NL31329.068.10) and the Ministry of Health, Welfare, and Sports of the Netherlands (Permit 131088-105234-PG). All participants gave written informed consent. Data are available from The Maastricht Study for any researcher who meets the criteria for access to confidential data, and the corresponding author may be contacted to request data.

\section{Microvascular dysfunction}

For all MVD measures, participants were asked to refrain from smoking and drinking caffeine-containing beverages three hours before the measurement. A light meal was allowed until $\geq 90$ minutes prior to the examination. For retinal measurements, pupils were dilated with $0.5 \%$ tropicamide and $2.5 \%$ phenylephrine at least 15 minutes before the start of the examination. Skin blood flow measurements were performed in a climatecontrolled room at $24^{\circ} \mathrm{C}$.

\section{Cerebral small vessel disease}

Brain MRI measurements were implemented from December 2013 onwards and were available in 2313 of 3451 participants (67\%). Brain MRI was performed on a 3T MRI scanner (Siemens Magnetom Prisma-fit Syngo MR D13D, Erlangen, Germany). We evaluated four CSVD features, i.e. total brain parenchyma volume, white matter hyperintensity volume, and presence of lacunar infarcts and cerebral microbleeds ${ }^{3}$. A detailed description of the MRI protocol and the definitions of the CSVD features is provided in Item S1 (Supplementary Material). The MRI protocol consisted of a 3D $\mathrm{T}_{1}$-weighted sequence, a fluid-attenuated inversion recovery sequence, a combined proton density and $\mathrm{T}_{2}$-weighted turbo spin echo 
sequence and a susceptibility-weighted imaging sequence ${ }^{26}$. Volumes were determined semi-automatically, and lacunar infarcts and cerebral microbleeds were scored manually.

\section{Plasma biomarkers of microvascular dysfunction}

We measured four plasma biomarkers of MVD: sICAM-1, sVCAM-1, sE-selectin and $\mathrm{VWF}^{4}$. sICAM-1, sVCAM-1 and sE-selectin were measured in EDTA plasma samples with commercially available 4-plex sandwich immunoassay kits with different standards and antibodies (Meso Scale Discovery, Rockville, Maryland, United States of America). For this technique in this study, the intra- and inter-assay coefficients of variation were 10.3 and $8.4 \%$ for sICAM-1, 5.0 and $4.7 \%$ for sVCAM-1, and 2.9 and $7.4 \%$ for sE-selectin, respectively. Von Willebrand Factor (VWF) was quantified in citrate plasma using ELISA (Dako, Glostrup, Denmark). The intra- and inter-assay coefficients of variation were 3.0 and $4.3 \%$, respectively.

\section{Urinary albumin excretion}

We assessed UAE in two 24-hour urine samples. Urinary albumin concentration was measured with a standard immunoturbidimetric assay by an automatic analyzer (due to a change of supplier, by the Beckman Synchron LX20 and the Roche Cobas 6000) and multiplied by collection volume to obtain 24-hour UAE ${ }^{22}$. A urinary albumin concentration below the detection limit of the assay was set at $1.5 \mathrm{mg} / \mathrm{L}(2 \mathrm{mg} / \mathrm{L}$ for the Beckman Synchron LX20 and $3 \mathrm{mg} / \mathrm{L}$ for the Roche Cobas 6000 ) before multiplying by collection volume. Only urine collections with a collection time between 20 and 28 hours were considered valid. If needed, UAE was extrapolated to 24-hour excretion. For this study, UAE was preferably based on the average of two (available in $91.3 \%$ of participants) 24-hour urine collections.

\section{Flicker light-induced retinal arteriolar and venular dilation response}

We measured retinal arteriolar and venular dilation response to flicker light exposure by the Dynamic Vessel Analyzer (Imedos, Jena, Germany), as previously described ${ }^{6,27}$. A baseline recording of 50 seconds was followed by 40 -second flicker light exposure followed by a 60 -second recovery period. We calculated baseline diameters (in measurement units) as the average diameter during the $20-50$ seconds recording. For both the arteriolar and venular dilation response, percentage dilation over baseline was calculated using the average dilation achieved at time points 10 and 40 seconds during the flicker stimulation period.

\section{Heat-induced skin hyperaemia}

We measured heat-induced skin hyperaemia by laser Doppler flowmetry (Perimed, Järfälla, Sweden), as previously described ${ }^{6}$. We recorded unheated skin blood flow at the wrist, expressed in arbitrary perfusion units (PU), for two minutes to serve as a baseline. After two minutes, the temperature of the laser Doppler probe was rapidly and locally increased to $44^{\circ} \mathrm{C}$ and was kept constant until the end of the registration. Skin hyperaemia was expressed as the percentage increase in average PU during the 23 minutes heating phase over the two minutes average baseline PU. 


\section{Cognitive performance}

We assessed cognitive performance by a concise neuropsychological test battery ${ }^{25}$. For statistical efficiency, we constructed a cognitive function score by summation of standardized test scores of three cognitive domains: memory, information processing speed and executive function. A detailed description of methods used to calculate domain-specific cognitive scores is provided in Item S2 (Supplementary material). We evaluated memory with the Verbal Learning Test ${ }^{28}$. Information processing speed was evaluated with the Stroop Color-Word Test Part I and $\mathrm{II}^{29}$, Concept Shifting Test Part A and $\mathrm{B}^{30}$, and Letter-Digit Substitution Test ${ }^{31}$. Executive function was evaluated with the Stroop Color-Word Test Part III and Concept Shifting Test Part C.

\section{Covariates}

We determined diabetes status according to the World Health Organization 2006 criteria as normal glucose metabolism, prediabetes or $\mathrm{T}^{2} \mathrm{D}^{25}$. Education level was classified into three groups: low (none, primary or lower vocational education only), intermediate (intermediate general secondary, intermediate vocational or higher general secondary education) and high (higher vocational education or university level of education). Alcohol consumption (none, low, high), smoking status (never, former, current), prior cardiovascular disease (CVD), medication use, body mass index (BMI), office and ambulatory blood pressure, plasma lipid levels were determined as described previously ${ }^{5}$ 6,25 . Hypertension was defined as an office blood pressure $\geq 140 / 90 \mathrm{mmHg}$ and/or use of antihypertensive medication. The Mini-International Neuropsychiatric Interview was used to assess the presence of a current DSM-IV defined minor or major depressive episode, as described previously ${ }^{25}$. Plasma biomarkers of low-grade inflammation were determined as described previously ${ }^{32}$. These included high-sensitive C-reactive protein (CRP), serum amyloid A (SAA), interleukin-6 (IL-6), interleukin-8 (IL-8) and tumor necrosis factor alpha (TNF-a).

\section{Statistical analysis}

We selected all participants that had data available on all potential confounders, at least one individual MVD measure, and cognitive function. We did not impute missing values. We inversed total brain parenchyma volume, retinal arteriolar and venular dilation response and skin hyperaemia so higher values indicated MVD. White matter hyperintensity volume was log-transformed (base 2) to normalize its skewed distribution. We analyzed UAE as a categorically ( $<15$ [reference], $15-<30$, and $\geq 30 \mathrm{mg} / 24 \mathrm{~h}$ ), because UAE and cognitive performance were non-linearly associated.

We calculated a MVD composite score ("MVD score") of all individual MVD measures. For the total MVD score, the individual 12 MVD measures (i.e. four CSVD features, four plasma biomarkers of MVD, UAE, retinal arteriolar and venular dilation responses and skin hyperaemia) were standardized into z-scores. These z-scores were averaged, and this average was standardized into the MVD score. The MVD score was calculated only in participants with data available on at least nine of the 12 individual MVD measures. The Cronbach's alpha for measuring internal consistency ${ }^{33}$ among the individual MVD measures was .52. This is considered acceptable internal consistency for different measures that may reflect, at least in part, the same underlying construct ${ }^{34}$. 
We used linear regression to investigate the association between the MVD score and the cognitive function score. All analyses were adjusted for age, education level, sex, T2D, BMI, smoking, alcohol use, hypertension, total/HDL cholesterol ratio, triglycerides and lipidmodifying medication (model 1), and additionally for prior CVD, current depression and the plasma biomarkers of low-grade inflammation, i.e. CRP, SAA, IL-6, IL-8 and TNF-a (model 2). Prior CVD, current depression and low-grade inflammation were entered into a separate model, because of the risk of overadjustment bias: these factors may be confounders but may also mediate the association between MVD and cognitive performance.

We tested interaction terms with age (dichotomized into $<65$ and $\geq 65$ years), education level, sex and T2D to evaluate whether the association between MVD and cognitive performance differed according to these factors. Interaction with age and education level was tested because MVD may be more strongly associated with worse cognitive performance in individuals with lower cognitive reserve, i.e. in those with higher age and lower education level ${ }^{35}$.

Several sensitivity analyses were performed. First, we repeated the analysis using domain-specific cognitive function scores as the outcome, i.e. memory, processing speed and executive function. Second, we repeated the analysis using each individual MVD measure as the determinant. Third, we repeated the analysis with the MVD score in participants with data available on at least one, eight and ten of the 12 individual MVD measures, respectively. Fourth, to test whether the association between the MVD score and cognitive function score was primarily determined by individual MVD measures, we repeated the analysis five times after consecutively excluding from the MVD score the CSVD features, plasma biomarkers of MVD, UAE, retinal arteriolar and venular dilation response and skin hyperaemia, respectively. Fifth, we calculated composite scores for the CSVD features, plasma biomarkers of MVD and retinal arteriolar and venular dilation response, respectively, and evaluated the association between these composite scores and cognitive function score. The CSVD composite score was calculated as described previously ${ }^{36}$. One point per CSVD feature was assigned for: $4^{\text {th }}$ quartile lower total brain parenchyma volume and higher white matter hyperintensity volume; and presence of lacunar infarcts and cerebral microbleeds. The points for each feature were combined into the CSVD score (range 0-4). For the plasma biomarkers of MVD score and retinal arteriolar and venular dilation response scores, the z-scores of the four plasma biomarkers of MVD and the arteriolar and venular dilation responses were summed and standardized, respectively. Sixth, we repeated the analysis with additional adjustment for average 24hour ambulatory systolic blood pressure ${ }^{37}$, and class of antihypertensive medication (i.e. angiotensin-converting-enzyme inhibitors or angiotensin II receptor blockers versus other classes $)^{38,39}$. Ambulatory systolic blood pressure is a better predictor of cognitive decline than office blood pressure ${ }^{40}$. However, we did not adjust for ambulatory systolic blood pressure in the main analysis, because data on ambulatory systolic blood pressure were missing in a relatively large number of participants $(n=424)$. Seventh, we repeated the analysis after stratification by T2D status, because by design individuals with T2D were oversampled in our cohort. 
All analyses were performed with SPSS software (v22.0;IBM, Chicago, USA). A P value of $<.05$, and a $P$ value for interaction of $<.10$ for interaction with sex and T2D were considered statistically significant. For interaction with age and education level, a Bonferroni-corrected $P$ value of $<.05$ was used instead of $<.10$, because higher age and lower education level are considered reflections of the same construct, i.e. lower cognitive reserve.

\section{Results}

Figure 1 shows the derivation of the final study population. In total, 3011 participants had data available on all potential confounders and at least one individual MVD measure. The MVD score was available in 2034 participants, CSVD features in 2002, plasma biomarkers of MVD in 2991, UAE in 2987, retinal arteriolar and venular dilation response in 1998, and skin hyperaemia in 1457. These populations were comparable with regard to age, sex and cardiovascular risk profile (Supplementary Table S1). Table 1 shows the characteristics of the study population and according to tertiles of the cognitive function score. Populationcharacteristics according to tertiles of memory, processing speed and executive function are provided in the Supplementary Material (Tables S2-S4). The study population had a mean age of 59.5 years, $48.9 \%$ were women, $26.5 \%$ had T2D (oversampled by design), and $41.1 \%$ had a high education level.

The MVD score was statistically significantly associated with a worse cognitive function score (Figure 2, models 1 and 2). The regression coefficients of all covariates included in the fully adjusted model are provided in the Supplementary material (Table S5). The fully adjusted beta-coefficient of the association between one standard deviation higher MVD score and the cognitive function score was equivalent to two (range: one-three) years of aging.

Statistically significant interaction was found between the MVD score and age ( $P$ value for interaction .045), indicating that the association between MVD and worse cognitive function was stronger in participants aged $\geq 65$ as compared to those aged $<65$ years. The association between the MVD score and cognitive function score stratified by age is provided in the Supplementary Material (Table S6). We found no interactions with education level, sex, and T2D.

\section{Sensitivity analyses}

The MVD score was statistically significantly associated with worse memory and processing speed, but not with executive function (Figure 3). The individual MVD measures lower total brain parenchyma volume, higher white matter hyperintensity volume, sE-selectin, and UAE $>30$ vs. $<15 \mathrm{mg} / 24 \mathrm{~h}$ were statistically significantly associated with a worse cognitive function score, but not lacunar infarcts, microbleeds, sICAM-1, sVCAM-1, vWF, UAE 15-<30 vs. $<15 \mathrm{mg} / 24 \mathrm{~h}$, retinal arteriolar and venular dilation responses or skin hyperaemia (Figure 4 and Supplementary Table S7). Results were similar when we repeated the analyses in participants with data available on at least one $(n=3011)$, eight $(n=2364)$ or ten $(n=1658)$ of the 12 individual MVD measures (Supplementary Table S8), and when we consecutively excluded, from the MVD score, the CSVD features, plasma biomarkers of MVD, UAE, retinal 
arteriolar and venular dilation response or skin hyperaemia (Supplementary Table S9). The composite scores of CSVD features and plasma biomarkers of MVD, but not of retinal arteriolar and venular dilation responses, were statistically significantly associated with a worse cognitive function score (Supplementary Table S10). Results were similar when we additionally adjusted for ambulatory blood pressure (Supplementary Table S11), or for class of antihypertensive medication (Supplementary Table S12). Furthermore, no statistically significant interaction was found for T2D status in our main analysis ( $P$ value for interaction .94), and analysis stratified by T2D status showed that results were qualitatively similar in individuals with and without T2D (Supplementary Table S13).

\section{Discussion}

The present cross-sectional study found that MVD is associated with worse cognitive performance. This association was present for various MVD measures, including CSVD features, plasma biomarkers of MVD and UAE, but not retinal arteriolar and venular dilation responses or skin hyperaemia. Furthermore, this association was independent of age, education level, sex, lifestyle factors, cardiovascular risk factors, current depression and low-grade inflammation. The strength of the association of each standard deviation higher MVD score on the cognitive function score was equivalent to the effect of one to three years of aging.

Our study agrees with previous studies that showed an association between individual MVD measures, i.e. CSVD features ${ }^{15,41}$, plasma biomarkers of $\mathrm{MVD}^{11-14}$ and $\mathrm{UAE}^{16}$, and worse cognitive performance. Some of these studies, but not all, found an association between MVD and worse cognitive performance or cognitive impairment. Our study expands this knowledge, as it is the first to comprehensively evaluate the association between MVD measures in various vascular beds and cognitive performance in a large population-based study with extensive adjustment for confounders.

The results were consistent across various MVD measures, except for retinal arteriolar and venular dilation responses and skin hyperaemia, which were not statistically significantly associated with cognitive performance. Retinal arteriolar and venular dilation response and skin hyperaemia may mostly reflect a more subtle form of endothelium-dependent MVD, which may change acutely and may be reversible ${ }^{27}$. For example, microvascular dilation responses in the retina or skin are transiently decreased directly after smoking ${ }^{42}$ and consumption of caffeine ${ }^{43}$. In contrast, CSVD features, plasma biomarkers of MVD and UAE (all indirect measures of microvascular dysfunction) may reflect a more advanced stage of $M V D^{10}$. However, this study is the first to evaluate the association between retinal arteriolar and venular dilation response and skin hyperaemia and cognitive function, and this issue, therefore, requires further study.

In the present study, the association between MVD and worse cognitive performance was stronger in participants aged $\geq 65$ years vs. $<65$ years. This corresponds to our previous study on UAE and cognitive performance ${ }^{22}$, and may be explained by a higher susceptibility for the detrimental effects of MVD on cognitive performance in the presence 
of a lower cognitive reserve with increasing age, in accordance with the cognitive reserve hypothesis ${ }^{35}$.

The observation that various MVD measures were associated with worse cognitive performance in our study supports the hypothesis that MVD may play a role in the pathophysiology of cognitive impairment. Earlier studies showed that impaired neurovascular coupling, cerebral autoregulation ${ }^{2}$, blood-brain barrier leakage ${ }^{44}$, and impaired neurogenesis ${ }^{45}$ are present in individuals with mild cognitive impairment and Alzheimer's disease, and these disturbances may be the consequence of MVD².

Other underlying mechanisms may, however, explain the observed associations. First, MVD often coexists with CVD, and CVD is associated with worse cognitive performance ${ }^{46}$. However, our results were independent of a large set of cardiovascular risk factors and prior CVD. Second, depression and low-grade inflammation are related to both MVD and worse cognitive performance. Our results remained, however, after adjustment for these factors. Third, other biological mechanisms may underlie both MVD and worse cognitive performance. For example, oxidative stress and lower brain-derived neurotrophic factor have been associated with both MVD and worse cognitive performance ${ }^{47-50}$. However, data on oxidative stress and brain-derived neurotrophic factor were unavailable in our study; this requires further study.

Our study has several limitations. First, the cross-sectional observational design precludes reaching causal conclusions about the study findings. Second, the construction of the composite scores assumes that all its components reflect cerebral MVD, which is not necessarily true. Our a-priori defined composite score was calculated with use of indirect and direct measures, which may reflect different forms of microvascular dysfunction (acute and reversible vs. more advanced), and this may have led to an underestimation of the association between (a more advanced stage of) microvascular dysfunction and worse cognitive function. Third, no data were available on Alzheimer's disease pathologies, such as amyloid and tau deposition. It has been hypothesized that these pathologies and MVD may act synergistically (i.e. interact) in the development of cognitive impairment ${ }^{51}$. Such interaction might explain our observed association between MVD and worse memory, a domain most strongly associated with Alzheimer's disease, and this issue requires further study. Fourth, lower total brain parenchyma volume is also determined by factors other than microvascular disease, particularly the process of neurodegeneration. Fifth, the study population consisted of middle and early-old aged participants without dementia who were relatively well-educated and whose cardiovascular risk factors were relatively well-controlled. This may have led to an underestimation of the reported findings due to lower variation in cognitive performance and relatively high cognitive reserve.

In conclusion, the present study shows that MVD is associated with worse cognitive performance. 


\section{Perspectives}

This study supports the hypothesis that MVD contributes to the development cognitive impairment. MVD might therefore be a target for prevention strategies of cognitive impairment. Evidence suggests that lifestyle modifications, such as weight loss and exercise, may, at least in part, favorably influence $\mathrm{MVD}^{52}$. In addition, drugs, such as reninangiotensin-aldosterone system inhibitors and antihyperglycemic agents (i.e. metformin and glucagon-like peptide 1 receptor (GLP-1R) agonists), may improve microvascular function ${ }^{52}$, possibly beyond their blood pressure- or glucose-lowering effects ${ }^{52}$. Future longitudinal studies are needed to further evaluate the association of MVD and cognitive decline and dementia. 


\section{References}

1. Prince M. World Alzheimer Report 2015: the global impact of dementia: an analysis of prevalence, incidence, cost and trends. Alzheimer's Disease International. 2015.

2. De Silva TM and Faraci FM. Microvascular Dysfunction and Cognitive Impairment. Cell Mol Neurobiol. 2016;36:241-58.

3. Wardlaw JM, Smith EE, Biessels GJ, Cordonnier C, Fazekas F, Frayne R, Lindley RI, O'Brien JT, Barkhof F, Benavente OR, Black SE, Brayne C, Breteler M, Chabriat H, Decarli C, de Leeuw FE, Doubal F, Duering M, Fox NC, Greenberg S, Hachinski V, Kilimann I, Mok V, Oostenbrugge R, Pantoni L, Speck O, Stephan BC, Teipel S, Viswanathan A, Werring D, Chen C, Smith C, van Buchem $M$, Norrving B, Gorelick PB, Dichgans $M$ and nEuroimaging STfRVco. Neuroimaging standards for research into small vessel disease and its contribution to ageing and neurodegeneration. Lancet Neurol. 2013;12:822-38.

4. van Sloten TT, Schram MT, Adriaanse MC, Dekker JM, Nijpels G, Teerlink T, Scheffer PG, Pouwer F, Schalkwijk CG, Stehouwer CD and Henry RM. Endothelial dysfunction is associated with a greater depressive symptom score in a general elderly population: the Hoorn Study. Psychol Med. 2014;44:1403-16.

5. Martens RJ, Henry RM, Houben AJ, van der Kallen CJ, Kroon AA, Schalkwijk CG, Schram MT, Sep SJ, Schaper NC, Dagnelie PC, Muris DM, Gronenschild EH, van der Sande FM, Leunissen KM, Kooman JP and Stehouwer CD. Capillary Rarefaction Associates with Albuminuria: The Maastricht Study. J Am Soc Nephrol. 2016;27:3748-3757.

6. Sorensen BM, Houben AJ, Berendschot TT, Schouten JS, Kroon AA, van der Kallen CJ, Henry RM, Koster A, Sep SJ, Dagnelie PC, Schaper NC, Schram MT and Stehouwer CD. Prediabetes and Type 2 Diabetes Are Associated With Generalized Microvascular Dysfunction: The Maastricht Study. Circulation. 2016;134:1339-1352.

7. Pantoni L. Cerebral small vessel disease: from pathogenesis and clinical characteristics to therapeutic challenges. Lancet Neurol. 2010;9:689-701.

8. Ostergaard L, Engedal TS, Moreton F, Hansen MB, Wardlaw JM, Dalkara T, Markus HS and Muir KW. Cerebral small vessel disease: Capillary pathways to stroke and cognitive decline. J Cereb Blood Flow Metab. 2016;36:302-25.

9. Umemura T, Kawamura T and Hotta N. Pathogenesis and neuroimaging of cerebral large and small vessel disease in type 2 diabetes: A possible link between cerebral and retinal microvascular abnormalities. J Diabetes Investig. 2017;8:134-148.

10. Muris DM, Houben AJ, Schram MT and Stehouwer CD. Microvascular dysfunction: an emerging pathway in the pathogenesis of obesity-related insulin resistance. Rev Endocr Metab Disord. 2013;14:29-38.

11. Huang CW, Tsai MH, Chen NC, Chen WH, Lu YT, Lui CC, Chang YT, Chang WN, Chang AY and Chang CC. Clinical significance of circulating vascular cell adhesion molecule-1 to white matter disintegrity in Alzheimer's dementia. Thromb Haemost. 2015;114:1230-40.

12. Rafnsson SB, Deary IJ, Smith FB, Whiteman MC, Rumley A, Lowe GD and Fowkes FG. Cognitive decline and markers of inflammation and hemostasis: the Edinburgh Artery Study. J Am Geriatr Soc. 2007;55:700-7.

13. Yoon CY, Steffen LM, Gross MD, Launer LJ, Odegaard A, Reiner A, Sanchez O, Yaffe K, Sidney S and Jacobs DR, Jr. Circulating Cellular Adhesion Molecules and Cognitive Function: The Coronary Artery Risk Development in Young Adults Study. Front Cardiovasc Med. 2017;4:37. 
14. Heringa SM, van den Berg E, Reijmer YD, Nijpels G, Stehouwer CD, Schalkwijk CG, Teerlink T, Scheffer PG, van den Hurk K, Kappelle LJ, Dekker JM and Biessels GJ. Markers of low-grade inflammation and endothelial dysfunction are related to reduced information processing speed and executive functioning in an older population - the Hoorn Study. Psychoneuroendocrinology. 2014;40:108-18.

15. Debette $\mathrm{S}$ and Markus HS. The clinical importance of white matter hyperintensities on brain magnetic resonance imaging: systematic review and meta-analysis. BMJ. 2010;341:c3666.

16. Georgakis MK, Dimitriou NG, Karalexi MA, Mihas C, Nasothimiou EG, Tousoulis D, Tsivgoulis $G$ and Petridou ET. Albuminuria in Association with Cognitive Function and Dementia: A Systematic Review and Meta-Analysis. J Am Geriatr Soc. 2017;65:1190-1198.

17. Li X, Yuan J, Yang L, Qin W, Yang S, Li Y, Fan H and Hu W. The significant effects of cerebral microbleeds on cognitive dysfunction: An updated meta-analysis. PLoS One. 2017;12:e0185145.

18. Saczynski JS, Sigurdsson S, Jonsdottir MK, Eiriksdottir G, Jonsson PV, Garcia ME, Kjartansson O, Lopez O, van Buchem MA, Gudnason V and Launer LJ. Cerebral infarcts and cognitive performance: importance of location and number of infarcts. Stroke. 2009;40:677-82.

19. Vibha D, Tiemeier H, Mirza SS, Adams HHH, Niessen WJ, Hofman A, Prasad K, van der Lugt A, Vernooij MW and Ikram MA. Brain Volumes and Longitudinal Cognitive Change: A Populationbased Study. Alzheimer Dis Assoc Disord. 2017.

20. Kearney-Schwartz A, Rossignol P, Bracard S, Felblinger J, Fay R, Boivin JM, Lecompte T, Lacolley P, Benetos $A$ and Zannad F. Vascular structure and function is correlated to cognitive performance and white matter hyperintensities in older hypertensive patients with subjective memory complaints. Stroke. 2009;40:1229-36.

21. Trollor JN, Smith E, Agars E, Kuan SA, Baune BT, Campbell L, Samaras K, Crawford J, Lux O, Kochan $\mathrm{NA}$, Brodaty $\mathrm{H}$ and Sachdev P. The association between systemic inflammation and cognitive performance in the elderly: the Sydney Memory and Ageing Study. Age (Dordr). 2012;34:1295308.

22. Martens RJ, Kooman JP, Stehouwer CD, Dagnelie PC, van der Kallen CJ, Koster A, Kroon AA, Leunissen KM, Nijpels G, van der Sande FM, Schaper NC, Sep SJ, van Boxtel MP, Schram MT and Henry RM. Estimated GFR, Albuminuria, and Cognitive Performance: The Maastricht Study. Am J Kidney Dis. 2017;69:179-191.

23. van Agtmaal MJM, Houben A, Pouwer F, Stehouwer CDA and Schram MT. Association of Microvascular Dysfunction With Late-Life Depression: A Systematic Review and Meta-analysis. JAMA Psychiatry. 2017;74:729-739.

24. Beaudreau SA and O'Hara R. The association of anxiety and depressive symptoms with cognitive performance in community-dwelling older adults. Psychol Aging. 2009;24:507-12.

25. Schram MT, Sep SJ, van der Kallen CJ, Dagnelie PC, Koster A, Schaper N, Henry RM and Stehouwer $\mathrm{CD}$. The Maastricht Study: an extensive phenotyping study on determinants of type 2 diabetes, its complications and its comorbidities. Eur J Epidemiol. 2014;29:439-51.

26. van Agtmaal MJM, Houben A, de Wit V, Henry RMA, Schaper NC, Dagnelie PC, van der Kallen CJ, Koster A, Sep SJ, Kroon AA, Jansen JFA, Hofman PA, Backes WH, Schram MT and Stehouwer CDA. Prediabetes Is Associated With Structural Brain Abnormalities: The Maastricht Study. Diabetes Care. 2018;41:2535-2543.

27. Houben A, Martens RJH and Stehouwer CDA. Assessing Microvascular Function in Humans from a Chronic Disease Perspective. J Am Soc Nephrol. 2017;28:3461-3472. 
28. Van der Elst W, van Boxtel MP, van Breukelen GJ and Jolles J. Rey's verbal learning test: normative data for 1855 healthy participants aged 24-81 years and the influence of age, sex, education, and mode of presentation. J Int Neuropsychol Soc. 2005;11:290-302.

29. Van der Elst W, Van Boxtel MP, Van Breukelen GJ and Jolles J. The Stroop color-word test: influence of age, sex, and education; and normative data for a large sample across the adult age range. Assessment. 2006;13:62-79.

30. Van der Elst W, Van Boxtel MP, Van Breukelen GJ and Jolles J. The Concept Shifting Test: adult normative data. Psychol Assess. 2006;18:424-32.

31. van der Elst W, van Boxtel MP, van Breukelen GJ and Jolles J. The Letter Digit Substitution Test: normative data for 1,858 healthy participants aged 24-81 from the Maastricht Aging Study (MAAS): influence of age, education, and sex. J Clin Exp Neuropsychol. 2006;28:998-1009.

32. van Dooren FE, Schram MT, Schalkwijk CG, Stehouwer CD, Henry RM, Dagnelie PC, Schaper NC, van der Kallen CJ, Koster A, Sep SJ, Denollet J, Verhey FR and Pouwer F. Associations of low grade inflammation and endothelial dysfunction with depression - The Maastricht Study. Brain Behav Immun. 2016;56:390-6.

33. European Commission. Joint Research Centre., Organisation for Economic Co-operation and Development. and SourceOECD (Online service). Handbook on constructing composite indicators : methodology and user guide. Paris: OECD; 2008.

34. Field AP. Discovering statistics using IBM SPSS statistics : and sex and drugs and rock ' $n$ ' roll. 4th edition. ed. Los Angeles: Sage; 2013.

35. Whalley LJ, Deary IJ, Appleton CL and Starr JM. Cognitive reserve and the neurobiology of cognitive aging. Ageing Res Rev. 2004;3:369-82.

36. van Sloten TT, Sigurdsson S, van Buchem MA, Phillips CL, Jonsson PV, Ding J, Schram MT, Harris TB, Gudnason V and Launer LJ. Cerebral Small Vessel Disease and Association With Higher Incidence of Depressive Symptoms in a General Elderly Population: The AGES-Reykjavik Study. Am J Psychiatry. 2015;172:570-8.

37. Yaneva-Sirakova T, Traykov L, Petrova J and Vassilev D. Comparison of Central, Ambulatory, Home and Office Blood Pressure Measurement as Risk Markers for Mild Cognitive Impairment in Hypertensive Patients. Dement Geriatr Cogn Dis Extra. 2017;7:274-282.

38. Redon J. Renal protection by antihypertensive drugs: insights from microalbuminuria studies. $J$ Hypertens. 1998;16:2091-100.

39. Suhrs HE, Michelsen MM and Prescott E. Treatment strategies in coronary microvascular dysfunction: a systematic review of interventional studies. Microcirculation. 2017.

40. White WB, Wolfson L, Wakefield DB, Hall CB, Campbell P, Moscufo N, Schmidt J, Kaplan RF, Pearlson G and Guttmann CR. Average daily blood pressure, not office blood pressure, is associated with progression of cerebrovascular disease and cognitive decline in older people. Circulation. 2011;124:2312-9.

41. Rensma SP, van Sloten TT, Launer LJ and Stehouwer CDA. Cerebral small vessel disease and risk of incident stroke, dementia and depression, and all-cause mortality: A systematic review and meta-analysis. Neurosci Biobehav Rev. 2018;90:164-173.

42. Ijzerman RG, Serne EH, van Weissenbruch MM, de Jongh RT and Stehouwer CD. Cigarette smoking is associated with an acute impairment of microvascular function in humans. Clin Sci (Lond). 2003;104:247-52.

43. Terai N, Spoerl E, Pillunat LE and Stodtmeister R. The effect of caffeine on retinal vessel diameter in young healthy subjects. Acta Ophthalmol. 2012;90:524-8. 
44. van de Haar HJ, Burgmans S, Jansen JF, van Osch MJ, van Buchem MA, Muller M, Hofman PA, Verhey FR and Backes WH. Blood-Brain Barrier Leakage in Patients with Early Alzheimer Disease. Radiology. 2016;281:527-535.

45. Lazarov O and Marr RA. Neurogenesis and Alzheimer's disease: at the crossroads. Exp Neurol. 2010;223:267-81.

46. Frazier DT, Seider T, Bettcher BM, Mack WJ, Jastrzab L, Chao L, Weiner MW, DeCarli C, Reed BR, Mungas D, Chui HC and Kramer JH. The role of carotid intima-media thickness in predicting longitudinal cognitive function in an older adult cohort. Cerebrovasc Dis. 2014;38:441-7.

47. Hajjar I, Hayek SS, Goldstein FC, Martin G, Jones DP and Quyyumi A. Oxidative stress predicts cognitive decline with aging in healthy adults: an observational study. J Neuroinflammation. 2018;15:17.

48. Higashi Y, Maruhashi T, Noma K and Kihara Y. Oxidative stress and endothelial dysfunction: clinical evidence and therapeutic implications. Trends Cardiovasc Med. 2014;24:165-9.

49. Huang CC, Liu ME, Chou KH, Yang AC, Hung CC, Hong CJ, Tsai SJ and Lin CP. Effect of BDNF Val66Met polymorphism on regional white matter hyperintensities and cognitive function in elderly males without dementia. Psychoneuroendocrinology. 2014;39:94-103.

50. Liu ME, Huang CC, Chen MH, Yang AC, Tu PC, Yeh HL, Hong CJ, Chen JF, Hwang JP, Lin CP and Tsai SJ. Effect of the BDNF Val66Met polymorphism on regional gray matter volumes and cognitive function in the Chinese population. Neuromolecular Med. 2014;16:127-36.

51. Attems $J$ and Jellinger KA. The overlap between vascular disease and Alzheimer's disease-lessons from pathology. BMC Med. 2014;12:206.

52. Stehouwer CDA. Microvascular Dysfunction and Hyperglycemia: A Vicious Cycle With Widespread Consequences. Diabetes. 2018;67:1729-1741. 
Table 1. Characteristics of the study population

\begin{tabular}{|c|c|c|c|c|}
\hline \multirow[t]{2}{*}{ Baseline characteristics } & \multirow{2}{*}{$\begin{array}{c}\text { Total study } \\
\text { population } \\
(\mathrm{n}=3011) \\
\end{array}$} & \multicolumn{3}{|c|}{ Tertiles of cognitive function score } \\
\hline & & $\begin{array}{c}\text { Lowest } \\
(n=1003)\end{array}$ & $\begin{array}{c}\text { Middle } \\
(n=1004)\end{array}$ & $\begin{array}{c}\text { Highest } \\
(n=1004)\end{array}$ \\
\hline Age, years & $59.5(8.2)$ & $64.0(6.8)$ & $59.9(7.3)$ & $54.7(7.8)$ \\
\hline Women, \% & $48.9(1471)$ & $36.5(366)$ & $45.4(456)$ & $64.6(649)$ \\
\hline $\begin{array}{l}\text { Education level, \% } \\
\text { - low } \\
\text { - intermediate } \\
\text { - high }\end{array}$ & $\begin{array}{c}15.7(472) \\
43.2(1301) \\
41.1(1238) \\
\end{array}$ & $\begin{array}{l}31.6(317) \\
44.8(449) \\
23.6(237) \\
\end{array}$ & $\begin{array}{l}11.8(118) \\
45.1(453) \\
43.1(433) \\
\end{array}$ & $\begin{array}{c}3.7(37) \\
39.7(399) \\
56.6(568) \\
\end{array}$ \\
\hline $\begin{array}{l}\text { Smoking status, \% } \\
\text { - never } \\
\text { - former } \\
\text { - current }\end{array}$ & $\begin{array}{c}34.9(1051) \\
51.9(1564) \\
13.2(396) \\
\end{array}$ & $\begin{array}{l}31.8(319) \\
52.8(530) \\
15.4(154) \\
\end{array}$ & $\begin{array}{l}33.9(340) \\
53.8(540) \\
12.4(124) \\
\end{array}$ & $\begin{array}{l}39.0(392) \\
49.2(494) \\
11.8(118) \\
\end{array}$ \\
\hline $\begin{array}{l}\text { Alcohol use, \% } \\
\text { - none } \\
\text { - low } \\
\text { - high }\end{array}$ & $\begin{array}{c}18.0(543) \\
55.5(1671) \\
26.5(797) \\
\end{array}$ & $\begin{array}{l}21.7(218) \\
54.1(543) \\
24.1(242) \\
\end{array}$ & $\begin{array}{l}16.0(161) \\
58.6(588) \\
25.4(255) \\
\end{array}$ & $\begin{array}{l}16.3(164) \\
53.8(540) \\
29.9(300) \\
\end{array}$ \\
\hline Body mass index $\left(\mathrm{kg} / \mathrm{m}^{2}\right)$ & $27.1(4.5)$ & $28.0(4.5)$ & $27.0(4.6)$ & $26.2(4.2)$ \\
\hline Type 2 diabetes, $\%$ & $26.5(797)$ & $41.2(413)$ & $25.0(251)$ & $13.2(133)$ \\
\hline Hypertension, \% & $55.4(1667)$ & $71.9(721)$ & $54.9(551)$ & $39.3(395)$ \\
\hline Total/HDL cholesterol ratio & $3.7(1.2)$ & $3.7(1.2)$ & $3.8(1.2)$ & $3.6(1.2)$ \\
\hline Triglycerides (mmol/L) & $1.4(0.9)$ & $1.5(0.9)$ & $1.4(0.8)$ & $1.3(0.8)$ \\
\hline Lipid-modifying medication, $\%$ & $34.9(1050)$ & $50.3(505)$ & $33.9(340)$ & $20.4(205)$ \\
\hline Prior cardiovascular disease, $\%$ & $16.1(486)$ & $24.6(247)$ & $13.9(140)$ & $9.9(99)$ \\
\hline Current depression, $\%$ & $3.7(112)$ & $5.4(54)$ & $3.6(36)$ & $2.2(22)$ \\
\hline $\begin{array}{l}\text { Plasma biomarkers of low-grade } \\
\text { inflammation composite score }(S D)^{*}\end{array}$ & $0.0(1.0)$ & $0.2(1.0)$ & $0.0(1.0)$ & $-0.3(1.0)$ \\
\hline \multicolumn{5}{|l|}{ Microvascular dysfunction measures ${ }^{\dagger}$} \\
\hline $\begin{array}{l}\text { Microvascular dysfunction composite } \\
\text { score (SD) }\end{array}$ & $0.0(1.0)$ & $0.4(1.1)$ & $0.0(0.9)$ & $-0.4(0.8)$ \\
\hline \multicolumn{5}{|l|}{ Cerebral small vessel disease features } \\
\hline Total brain parenchyma volume (ml) & $1138.4(111.7)$ & $1123.9(111.8)$ & $1150.3(117.3)$ & $1138.8(104.6)$ \\
\hline White matter hyperintensity volume (ml) & $0.2(0.1-0.7)$ & $0.4(0.1-1.3)$ & $0.2(0.1-0.8)$ & $0.1(<0.1-0.4)$ \\
\hline Presence of cerebral microbleeds & $11.8(237)$ & $9.2(92)$ & $10.5(73)$ & $9.9(72)$ \\
\hline Presence of lacunar infarcts & $5.4(110)$ & $6.7(40)$ & $6.4(45)$ & $3.4(25)$ \\
\hline \multicolumn{5}{|l|}{$\begin{array}{l}\text { Plasma biomarkers of microvascular } \\
\text { dysfunction }\end{array}$} \\
\hline Soluble ICAM-1 ( $\mu \mathrm{g} / \mathrm{I})$ & $352.7(98.1)$ & $372.3(116.4)$ & $348.1(86.7)$ & $337.8(84.7)$ \\
\hline Soluble VCAM-1 ( $\mu \mathrm{g} / \mathrm{l})$ & $425.1(99.8)$ & $445.2(111.4)$ & $422.9(97.9)$ & $407.1(84.6)$ \\
\hline Soluble E-selectin $(\mu \mathrm{g} / \mathrm{l})$ & $117.5(64.2)$ & $130.1(76.4)$ & $117.6(56.3)$ & $104.9(55.4)$ \\
\hline Von Willebrand Factor (\%) & $131.7(47.8)$ & $140.9(51.1)$ & $130.8(45.9)$ & $123.5(44.7)$ \\
\hline \multicolumn{5}{|l|}{ Urinary albumin excretion } \\
\hline Urinary albumin excretion $\geq 30 \mathrm{mg} / 24 \mathrm{~h}$ & $8.1(242)$ & $13.4(133)$ & $7.0(70)$ & $3.9(39)$ \\
\hline
\end{tabular}




\begin{tabular}{|c|c|c|c|c|}
\hline \multirow[t]{2}{*}{ Baseline characteristics } & \multirow{2}{*}{$\begin{array}{l}\text { Total study } \\
\text { population } \\
(\mathrm{n}=3011)\end{array}$} & \multicolumn{3}{|c|}{ Tertiles of cognitive function score } \\
\hline & & $\begin{array}{l}\text { Lowest } \\
(n=1003)\end{array}$ & $\begin{array}{c}\text { Middle } \\
(n=1004)\end{array}$ & $\begin{array}{c}\text { Highest } \\
(n=1004)\end{array}$ \\
\hline $\begin{array}{l}\text { Urinary albumin excretion } \\
15-<30 \mathrm{mg} / 24 \mathrm{~h}\end{array}$ & $10.3(308)$ & $13.1(130)$ & $9.3(93)$ & $8.5(85)$ \\
\hline \multicolumn{5}{|l|}{$\begin{array}{l}\text { Flicker light-induced arteriolar and } \\
\text { venular dilation response }\end{array}$} \\
\hline $\begin{array}{l}\text { Flicker light-induced arteriolar dilation } \\
\text { response (\%) }\end{array}$ & $3.1(2.8)$ & $2.7(2.9)$ & $3.1(2.7)$ & $3.3(2.7)$ \\
\hline $\begin{array}{l}\text { Flicker light-induced venular dilation } \\
\text { response (\%) }\end{array}$ & $3.9(2.2)$ & $3.7(2.2)$ & $3.9(2.1)$ & $4.0(2.2)$ \\
\hline Heat-induced skin hyperaemia (\%) & $1133.2(781.5)$ & $1006.2(760.5)$ & $1208.6(859.6)$ & $1192.0(701.6)$ \\
\hline
\end{tabular}

Data are presented as percentage of participants (n), mean \pm standard deviation (SD) or median (interquartile range). *Expressed per standard deviation; tData available for microvascular dysfunction composite score $\mathrm{n}=2034$; total brain parenchyma volume and white matter hyperintensity volume $\mathrm{n}=2049$; lacunar infarcts $\mathrm{n}=2046$; cerebral microbleeds $\mathrm{n}=2012$; sICAM-1; sVCAM-1; and sE-selectin $\mathrm{n}=3011$; vWF $\mathrm{n}=2991$; urinary albumin excretion $n=2987$; retinal arteriolar dilation response $n=2018$; retinal venular dilation response $n=2049$; and skin hyperaemia $n=1457$. 


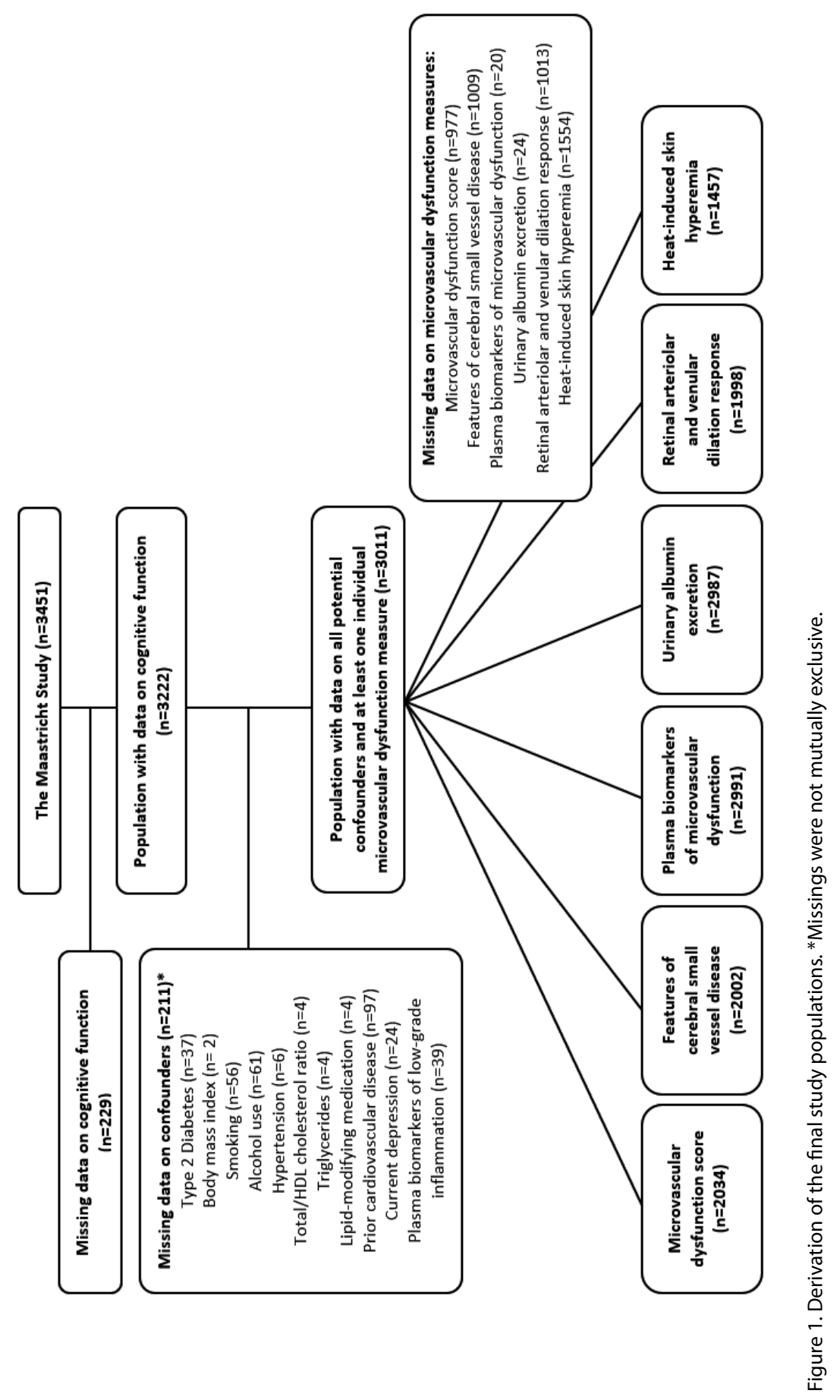




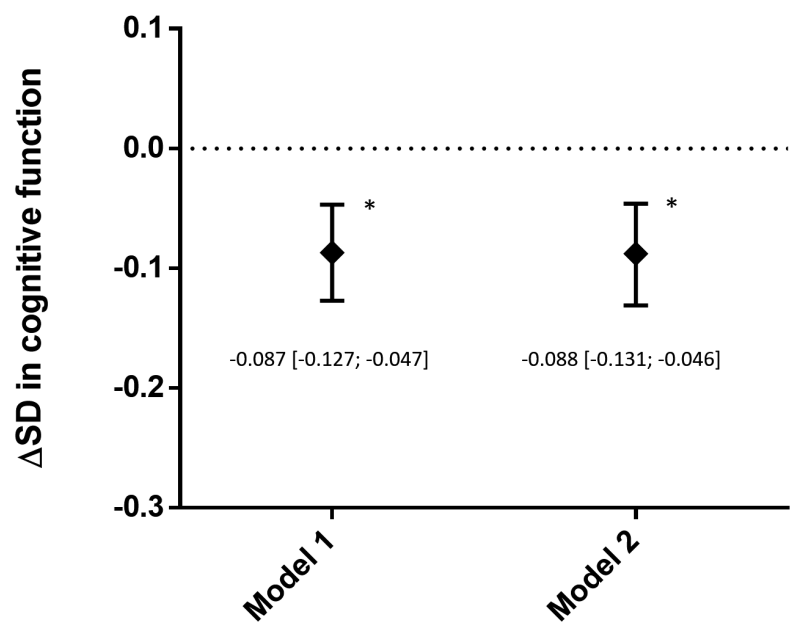

Figure 2. Association between microvascular dysfunction score and cognitive function score.

* Statistical significance $(p<0.05)$. Data available in $n=2,034$. Results are expressed as SD ( $95 \%$ confidence interval) worse cognitive function score per SD higher microvascular dysfunction score. Results were adjusted for age, education level, sex, diabetes mellitus type 2, body mass index, smoking status, alcohol use, hypertension, total/ HDL cholesterol ratio, triglycerides, and lipid-modifying medication use (model 1), and additionally for prior cardiovascular disease, current depression and plasma biomarkers of low-grade inflammation (model 2).

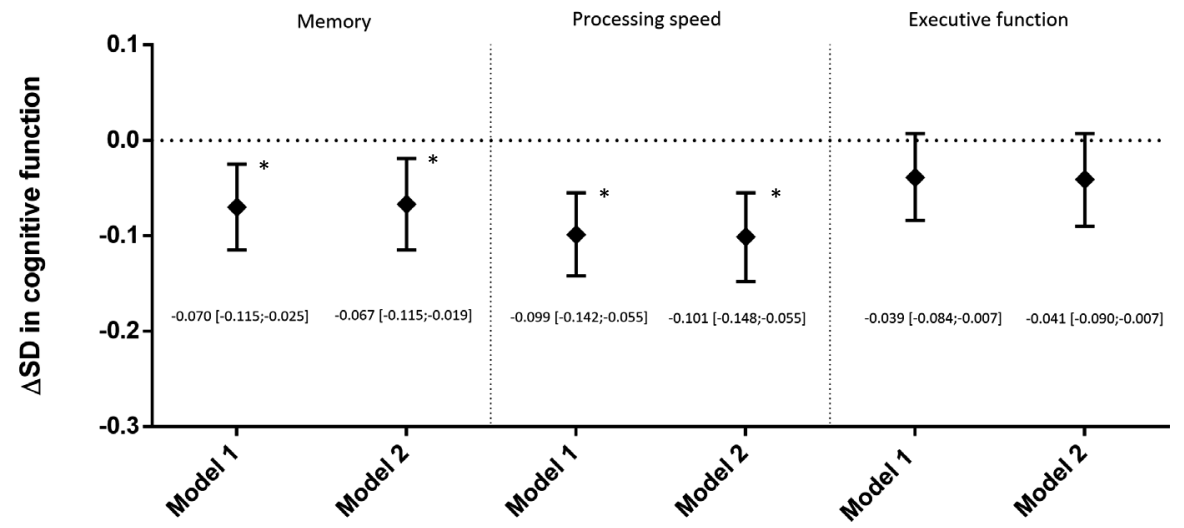

Figure 3. Associations between microvascular dysfunction score and domain-specific cognitive function score. *Statistical significance $(p<0.05)$. Data available in $n=2,034$. Results are expressed as SD (95\% confidence interval) worse domain-specific cognitive function score per SD higher microvascular dysfunction score. Adjustments as in Figure 2. 


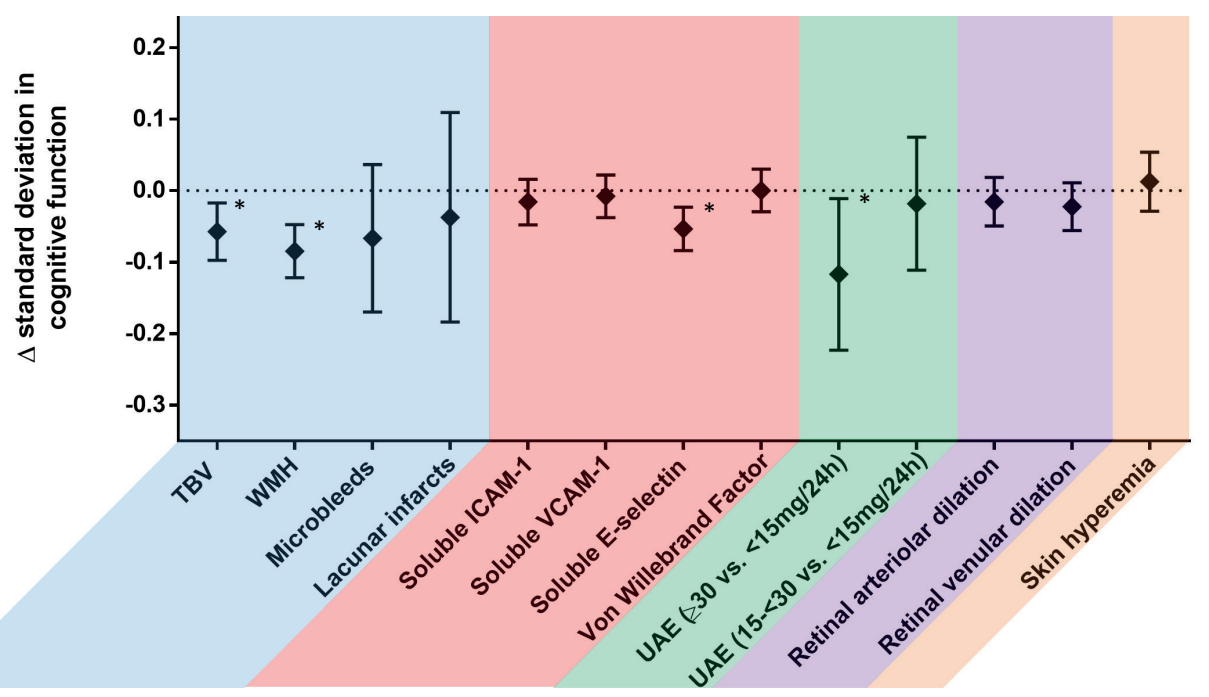

Figure 4. Associations between individual measures of microvascular dysfunction and cognitive function score. * Statistical significance $(p<0.05)$. Results are expressed as (SD (95\% confidence interval) worse cognitive function score per SD lower total brain parenchyma volume and higher white matter hyperintensity volume, presence of lacunar infarcts and microbleeds, per SD higher plasma biomarkers of microvascular dysfunction, urinary albumin excretion $\geq 30$ versus $<15 \mathrm{mg} / 24 \mathrm{~h}$, urinary albumin excretion between 15 and $<30$ versus $<15 \mathrm{mg} / 24 \mathrm{~h}$, per SD lower retinal arteriolar and venular dilation response, and per SD lower skin hyperaemia. Adjustments as in Figure 2, model 2. Abbreviations: TBV, total brain parenchyma volume; $\mathrm{WMH}$, white matter hyperintensity volume. 


\section{Supplemental material}

\section{Item S1. Brain magnetic resonance imaging}

Brain magnetic resonance imaging (MRI) was performed on a 3T MRI scanner (Siemens Magnetom Prisma-fit Syngo MR D13D, Erlangen, Germany) by use of a 64-element head/neck coil for parallel imaging. The MRI protocol consisted of a 3D $\mathrm{T}_{1}$-weighted magnetization prepared rapid acquisition gradient echo (MPRAGE) sequence (TR/TI/ TE $2300 / 900 / 2.98 \mathrm{~ms}, 176$ slices, $256 \times 240$ matrix size, $1.00 \mathrm{~mm}$ cubic voxel size); a fluidattenuated inversion recovery (FLAIR) sequence (TR/TI/TE 5000/1800/394 ms, 176 slices, $512 \times 512$ matrix size, $0.49 \times 0.49 \times 1.00 \mathrm{~mm}$ voxel size); a combined proton density (PD) and $\mathrm{T}_{2}$-weighted turbo spin echo (TSE) pulse sequence (TR/TE1/TE2 3200/9.4/94 ms, 30 slices, $640 \times 540$ matrix size, $0.36 \times 0.36 \times 4.00 \mathrm{~mm}$ voxel size); and a susceptibility-weighted imaging (SWI) sequence (TR/TE $28 / 20 \mathrm{~ms}$, 144 slices, $384 \times 312$ matrix size, $0.57 \times 0.57 \times 1.00$ $\mathrm{mm}$ voxel size).

Contra-indications for MRI assessments were the presence of a cardiac pacemaker or implantable cardioverter-defibrillator, neurostimulator, non-detachable insulin pump, metallic vascular clips or stents in the head, cochlear implant, metal-containing intrauterine device, metal splinters or shrapnel, dentures with magnetic clip, an inside bracket, pregnancy, epilepsy, and claustrophobia.

$\mathrm{T}_{1}$-weighted images and FLAIR images were analyzed by use of an ISO-13485:2012 certified, automated method (which included visual inspection) ${ }^{1,2}$. T $_{1}$-weighted images were segmented into grey matter, white matter and cerebrospinal fluid volumes ( 1 voxel $\left.=1.00 \mathrm{~mm}^{3}=0.001 \mathrm{ml}\right)^{1}$. Intracranial volume was calculated as the sum of grey matter, white matter (including white matter hyperintensity volume) and cerebrospinal fluid volumes. Total brain parenchyma volume was calculated as the sum of grey and white matter volumes. White matter hyperintensities identified were summed to assess total white matter hyperintensities burden in milliliter. Lacunar infarcts were defined as focal brain parenchyma defects of $\geq 3 \mathrm{~mm}$ and $<15 \mathrm{~mm}$ in size with a similar signal intensity as cerebrospinal fluid on all sequences and a hyperintense rim on $T_{2}$ and FLAIR images ${ }^{3}$. Cerebral microbleeds were rated on $\mathrm{T}_{2}$-weighted and SWI images by use of the Microbleed Anatomical Rating Scale ${ }^{4}$, and were defined as focal lesions of $\geq 2 \mathrm{~mm}$ and $\leq 10 \mathrm{~mm}$ in size with a hypointense signal ${ }^{3}$. The presence of lacunar infarcts and cerebral microbleeds was rated manually by three neuroradiologists. The two-way mixed effects, consistency, intraclass correlation coefficients for the three raters based on 50 randomly selected scans were $0.84(95 \%$ confidence interval $0.74 ; 0.91)$ and $0.83(0.72 ; 0.90)$ for the presence of lacunar infarcts and cerebral microbleeds, respectively.

\section{Item S2. Cognitive assessment}

The composite memory score was derived from the Verbal Learning Test by weighting total immediate and delayed recall scores. The domain information processing speed included the Stroop Color-Word Test Part I and II, the Concept Shifting Test Part A and $B$, and the Letter-Digit Substitution Test. Executive function was assessed by the Stroop Color-Word Test Part III and the Concept Shifting Test Part C. A description of the individual tests is provided below. 
Raw test scores were transformed into z-scores. Standardized scores of the Stroop Color-Word Test and Concept Shifting Test were inverted so that higher scores indicated better cognitive performance. Thereafter, domain-specific scores were calculated as the standardized average of the z-scores from (sub)tests within that domain (e.g. memory = $z$-score of ( $z$-score immediate recall $+z$-score delayed recall/2)). The standardized average of these domain scores was then considered a measure of overall cognitive performance (i.e. overall cognitive performance $=z$-score of (memory + information processing speed + executive function / 3)).

\section{Description of the individual cognitive tests used in the present study Verbal Learning Test: 5}

Fifteen unrelated, monosyllabic, words were presented on a computer screen in five subsequent trials. After each trial, participants were instructed to recall as many words as possible in any order. Twenty minutes after the last trial, participants were asked again to reproduce the words. Outcomes recorded included the total number of words correctly recalled over the five trials (total immediate recall) and the number of correctly recalled words during delayed recall (delayed recall).

\section{Stroop Color-Word Test: ${ }^{6}$}

In this test, which consisted of three parts, participants were firstly asked to read aloud color names (i.e. red, blue, yellow, and green) that were printed in black ink (Part I). Secondly, they were instructed to name solid color patches (Part II). Finally, participants had to name the ink color of color names that were printed in an incongruent color (e.g. participants were asked to say red when the word yellow was printed in red) (Part III). The time needed to complete Part III was adjusted for the average time needed to complete Part I and II.

\section{Concept Shifting Test: ${ }^{7}$}

This test, a modification of the Trailing Making Test, consisted of four subtasks. During each subtask, participants were shown 16 small circles aligned along a larger imaginary circle. The small circles contained (a combination of) digits, letters, or were empty. Participants were instructed to cross-out as quickly as possible the digits in ascending order (Part A), the letters in alphabetic order (Part B), and the letters and digits in alternating order (Part C). Thereafter, participants were asked to cross-out empty circles in a clockwise fashion in two consecutive trials (Part 0 ). In this way, test results could be accounted for basic motor speed. The time needed to complete subtasks $A$ and $B$ was adjusted for the average time needed to complete Part 0 , the time needed to completed Part $C$ for the average time of Part $A$ and $B$.

\section{Letter-Digit Substitution Test: ${ }^{8}$}

Participants were requested to match digits to letters according to a given key. This key included the numbers 1 to 9 , each paired with a different letter. The outcome of interest was the number of correct substitutions within 90 seconds. 
1. Vrooman HA, Cocosco CA, van der Lijn F, Stokking R, Ikram MA, Vernooij MW, Breteler MM and Niessen WJ. Multi-spectral brain tissue segmentation using automatically trained k-NearestNeighbor classification. Neurolmage. 2007;37:71-81.

2. de Boer R, Vrooman HA, van der Lijn F, Vernooij MW, Ikram MA, van der Lugt A, Breteler MM and Niessen WJ. White matter lesion extension to automatic brain tissue segmentation on MRI. Neurolmage. 2009;45:1151-61.

3. Wardlaw JM, Smith EE, Biessels GJ, Cordonnier C, Fazekas F, Frayne R, Lindley RI, O'Brien JT, Barkhof F, Benavente OR, Black SE, Brayne C, Breteler M, Chabriat H, Decarli C, de Leeuw FE, Doubal F, Duering M, Fox NC, Greenberg S, Hachinski V, Kilimann I, Mok V, Oostenbrugge R, Pantoni L, Speck O, Stephan BC, Teipel S, Viswanathan A, Werring D, Chen C, Smith C, van Buchem $M$, Norrving B, Gorelick PB, Dichgans $M$ and nEuroimaging STfRVco. Neuroimaging standards for research into small vessel disease and its contribution to ageing and neurodegeneration. Lancet Neurol. 2013;12:822-38.

4. Gregoire SM, Chaudhary UJ, Brown MM, Yousry TA, Kallis C, Jager HR and Werring DJ. The Microbleed Anatomical Rating Scale (MARS): reliability of a tool to map brain microbleeds. Neurology. 2009;73:1759-66.

5. Van der Elst W, van Boxtel MP, van Breukelen GJ and Jolles J. Rey's verbal learning test: normative data for 1855 healthy participants aged 24-81 years and the influence of age, sex, education, and mode of presentation. J Int Neuropsychol Soc. 2005;11:290-302.

6. Van der Elst W, Van Boxtel MP, Van Breukelen GJ and Jolles J. The Stroop color-word test: influence of age, sex, and education; and normative data for a large sample across the adult age range. Assessment. 2006;13:62-79.

7. Van der Elst W, Van Boxtel MP, Van Breukelen GJ and Jolles J. The Concept Shifting Test: adult normative data. Psychol Assess. 2006;18:424-32.

8. van der Elst W, van Boxtel MP, van Breukelen GJ and Jolles J. The Letter Digit Substitution Test: normative data for 1,858 healthy participants aged 24-81 from the Maastricht Aging Study (MAAS): influence of age, education, and sex. J Clin Exp Neuropsychol. 2006;28:998-1009. 


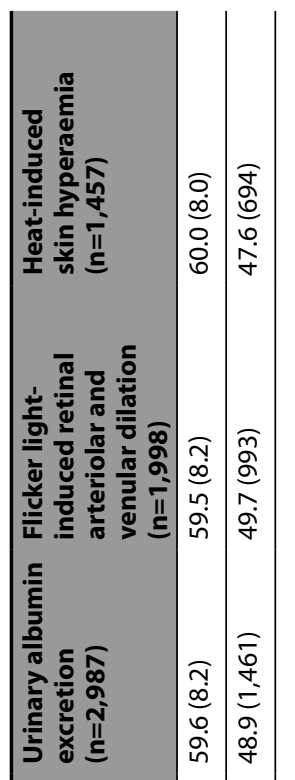

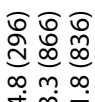

三霄

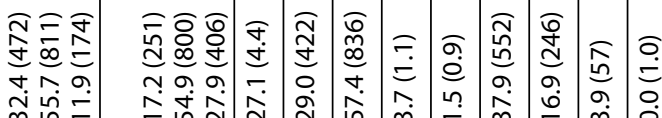
$\stackrel{0}{\check{c}}$ ホீ守守

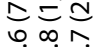

ผึ่

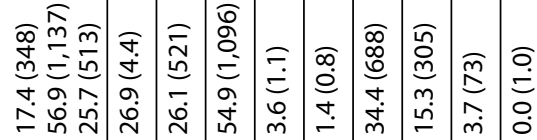

$\underset{\substack{0 \\ \hdashline}}{\stackrel{0}{0}}$

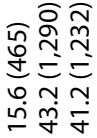

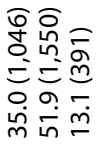

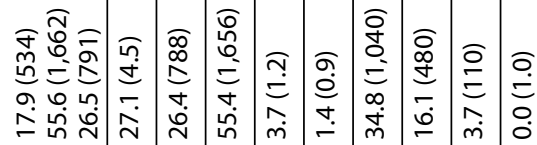

$\underset{\substack{0 \\ \hdashline}}{\stackrel{0}{0}}$

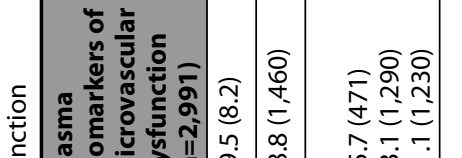

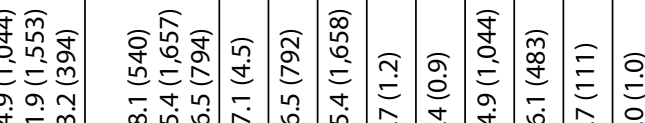

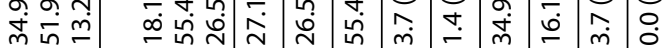

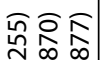

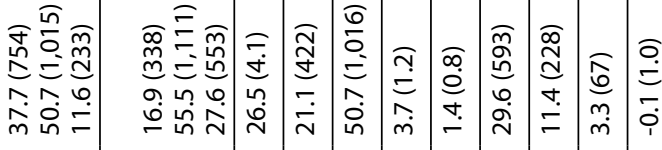

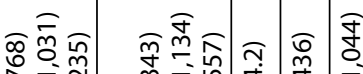

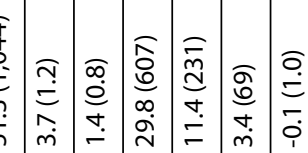

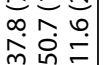

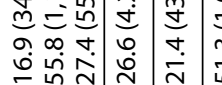

$\stackrel{0}{\stackrel{0}{\circ}}$ 


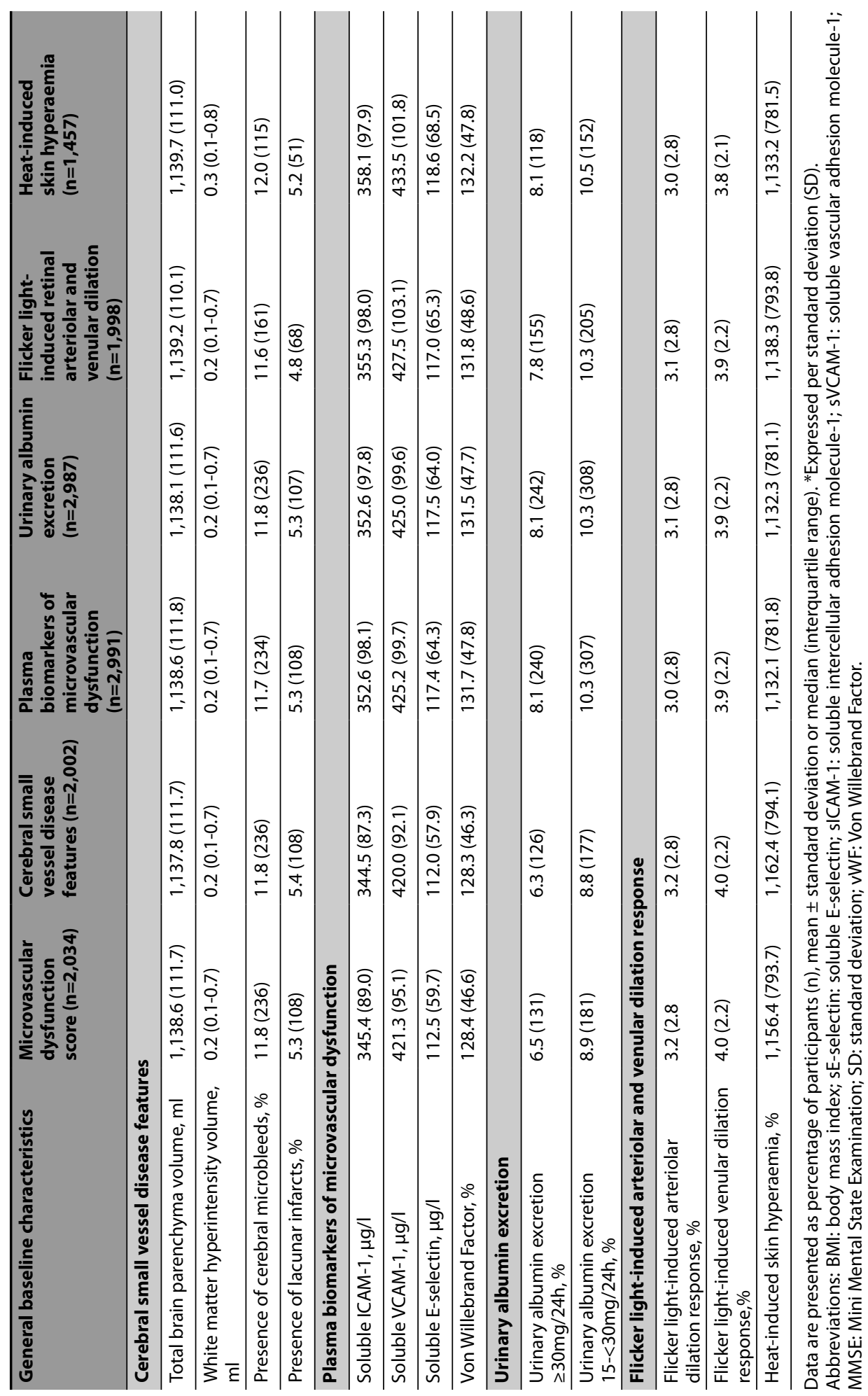


Table S2. Characteristics of the total study population and according to tertiles of memory

\begin{tabular}{|c|c|c|c|c|}
\hline & $\begin{array}{l}\text { Total study } \\
\text { population } \\
(n=3,011) \\
\end{array}$ & $\begin{array}{c}\text { Lowest tertile } \\
\text { memory } \\
(n=1,006)\end{array}$ & $\begin{array}{c}\text { Middle tertile } \\
\text { memory } \\
(n=1,002)\end{array}$ & $\begin{array}{c}\text { Highest tertile } \\
\text { memory } \\
(n=1,003)\end{array}$ \\
\hline \multicolumn{5}{|l|}{ General baseline characteristics } \\
\hline Age, years & $59.5(8.2)$ & $62.5(7.5)$ & $59.6(7.9)$ & $56.5(8.1)$ \\
\hline Women, \% & $48.9(1,471)$ & $28.4(286)$ & $46.9(470)$ & $71.3(715)$ \\
\hline $\begin{array}{l}\text { Education level, \% } \\
\text { - low } \\
\text { - intermediate } \\
\text { - high } \\
\end{array}$ & $\begin{array}{c}15.7(472) \\
43.2(1,301) \\
41.1(1,238) \\
\end{array}$ & $\begin{array}{l}24.1(242) \\
44.5(448) \\
31.4(316) \\
\end{array}$ & $\begin{array}{l}15.4(154) \\
44.2(443) \\
40.4(405) \\
\end{array}$ & $\begin{array}{c}7.6(76) \\
40.9(410) \\
51.5(517) \\
\end{array}$ \\
\hline $\begin{array}{l}\text { Smoking status, \% } \\
\text { - never } \\
\text { - former } \\
\text { - current }\end{array}$ & $\begin{array}{c}34.9(1,051) \\
51.9(1,564) \\
13.2(396) \\
\end{array}$ & $\begin{array}{l}32.0(322) \\
53.6(539) \\
14.4(145)\end{array}$ & $\begin{array}{l}35.0(351) \\
51.7(518) \\
13.3(133)\end{array}$ & $\begin{array}{l}37.7(378) \\
50.5(507) \\
11.8(118)\end{array}$ \\
\hline $\begin{array}{l}\text { Alcohol use, \% } \\
\text { - none } \\
\text { - low } \\
\text { - high }\end{array}$ & $\begin{array}{c}18.0(543) \\
55.5(1,671) \\
26.5(797) \\
\end{array}$ & $\begin{array}{l}20.4(205) \\
56.4(567) \\
23.3(234) \\
\end{array}$ & $\begin{array}{l}16.5(165) \\
56.0(561) \\
27.5(276) \\
\end{array}$ & $\begin{array}{l}17.2(173) \\
54.1(543) \\
28.6(287) \\
\end{array}$ \\
\hline Body mass index, $\mathrm{kg} / \mathrm{m}^{2}$ & $27.1(4.5)$ & $27.9(4.5)$ & $26.9(4.3)$ & $26.4(4.5)$ \\
\hline Type 2 diabetes, $\%$ & $26.5(797)$ & $36.4(366)$ & $27.4(275)$ & $15.6(156)$ \\
\hline Hypertension, \% & $55.4(1,667)$ & $68.9(693)$ & $53.8(539)$ & $43.4(435)$ \\
\hline Total/HDL cholesterol ratio & $3.7(1.2)$ & $3.8(1.2)$ & $3.7(1.2)$ & $3.6(1.2)$ \\
\hline Triglycerides, mmol/L & $1.4(0.9)$ & $1.5(0.9)$ & $1.4(0.8)$ & $1.3(0.8)$ \\
\hline Lipid-modifying medication, $\%$ & $34.9(1,050)$ & $47.0(473)$ & $34.3(344)$ & $23.2(233)$ \\
\hline Prior cardiovascular disease, $\%$ & $16.1(486)$ & $20.9(210)$ & $17.2(172)$ & $10.4(104)$ \\
\hline Current depression, $\%$ & $3.7(112)$ & $4.7(47)$ & $3.4(34)$ & $3.1(31)$ \\
\hline $\begin{array}{l}\text { Plasma biomarkers of low-grade } \\
\text { inflammation composite score, SD* }\end{array}$ & $0.0(1.0)$ & $0.2(1.0)$ & $-0.1(1.0)$ & $-0.2(1.0)$ \\
\hline \multicolumn{5}{|l|}{ Microvascular dysfunction measures ${ }^{\dagger}$} \\
\hline $\begin{array}{l}\text { Microvascular dysfunction composite } \\
\text { score, SD }\end{array}$ & $0.0(1.0)$ & $0.3(1.1)$ & $0.0(0.9)$ & $-0.3(0.8)$ \\
\hline \multicolumn{5}{|l|}{ Cerebral small vessel disease features } \\
\hline Total brain parenchyma volume, $\mathrm{ml}$ & $1,138.4(111.7)$ & $1,157.2(114.2)$ & $1,136.6(112.9)$ & $1,123.5(105.8)$ \\
\hline $\begin{array}{l}\text { White matter hyperintensity volume, } \\
\mathrm{ml}\end{array}$ & $0.2(0.1-0.7)$ & $0.4(0.1-1.3)$ & $0.2(0.1-0.6)$ & $0.2(<0.1-0.5)$ \\
\hline Presence of cerebral microbleeds, $\%$ & $11.8(237)$ & $15.1(94)$ & $11.4(77)$ & $9.2(66)$ \\
\hline Presence of lacunar infarcts, $\%$ & $5.4(110)$ & $7.3(46)$ & $4.8(33)$ & $4.3(31)$ \\
\hline \multicolumn{5}{|c|}{ Plasma biomarkers of microvascular dysfunction } \\
\hline Soluble ICAM-1, $\mu \mathrm{g} / \mathrm{I}$ & $352.7(98.1)$ & $367.0(112.1)$ & $349.6(91.9)$ & $341.5(86.9)$ \\
\hline Soluble VCAM-1, $\mu \mathrm{g} / \mathrm{l}$ & $425.1(99.8)$ & $441.8(109.4)$ & $425.4(100.6)$ & $407.9(84.9)$ \\
\hline Soluble E-selectin, $\mu \mathrm{g} / \mathrm{l}$ & $117.5(64.2)$ & $127.8(75.5)$ & $116.3(58.4)$ & $108.5(55.5)$ \\
\hline Von Willebrand Factor, \% & $131.7(47.8)$ & $139.0(49.6)$ & $131.4(47.7)$ & $124.8(45.0)$ \\
\hline \multicolumn{5}{|l|}{ Urinary albumin excretion } \\
\hline $\begin{array}{l}\text { Urinary albumin excretion } \\
\geq 30 \mathrm{mg} / 24 \mathrm{~h}, \%\end{array}$ & $8.1(242)$ & $12.1(121)$ & $7.4(74)$ & $4.7(47)$ \\
\hline
\end{tabular}




\begin{tabular}{lcccc}
\hline & $\begin{array}{c}\text { Total study } \\
\text { population } \\
(\mathbf{n = 3 , 0 1 1 )}\end{array}$ & $\begin{array}{c}\text { Lowest tertile } \\
\text { memory } \\
(\mathbf{n = 1 , 0 0 6 )}\end{array}$ & $\begin{array}{c}\text { Middle tertile } \\
\text { memory } \\
(\mathbf{n = 1 , 0 0 2})\end{array}$ & $\begin{array}{c}\text { Highest tertile } \\
\text { memory } \\
(\mathbf{n}=1,003)\end{array}$ \\
\hline $\begin{array}{l}\text { Urinary albumin excretion } \\
15-<30 \mathrm{mg} / 24 \mathrm{~h}, \%\end{array}$ & $10.3(308)$ & $12.8(127)$ & $10.4(103)$ & $7.8(78)$ \\
\hline
\end{tabular}

\section{Flicker light-induced arteriolar and venular dilation response}

\begin{tabular}{lcccc}
\hline $\begin{array}{l}\text { Flicker light-induced arteriolar } \\
\text { dilation response, } \%\end{array}$ & $3.1(2.8)$ & $3.1(2.8)$ & $3.2(2.7)$ & $3.1(2.8)$ \\
\hline $\begin{array}{l}\text { Flicker light-induced venular dilation } \\
\text { response, } \%\end{array}$ & $3.9(2.2)$ & $3.9(2.2)$ & $4.0(2.2)$ & $3.9(2.2)$ \\
\hline Heat-induced skin hyperaemia, \% & $1,133.2(781.5)$ & $1,005.1(745.4)$ & $1,164.3(827.1)$ & $1,230.4(753.0)$ \\
\hline
\end{tabular}

Data are presented as percentage of participants $(n)$, mean \pm standard deviation or median (interquartile range). *Expressed per standard deviation (SD); tData available for total brain parenchyma volume and white matter hyperintensity volume $n=2,049$; for lacunar infarctions $n=2,046$ and for cerebral microbleeds $n=2,012$; for sICAM-1; sVCAM-1; and sE-selectin $n=3,011$; for vWF $n=2,991$; for albuminuria $n=2,987$; for flicker lightinduced arteriolar dilation $n=2,018$; for flicker light-induced venular dilation $n=2,049$; and for heat-induced skin hyperaemia $n=1,457$.

Abbreviations: BMI: body mass index; sE-selectin: soluble E-selectin; sICAM-1: soluble intercellular adhesion molecule-1; sVCAM-1: soluble vascular adhesion molecule-1; MMSE: Mini Mental State Examination; SD: standard deviation; vWF: Von Willebrand Factor. 
Table S3. Characteristics of the total study population and according to tertiles of processing speed

\begin{tabular}{|c|c|c|c|c|}
\hline & $\begin{array}{l}\text { Total study } \\
\text { population } \\
(n=3,011)\end{array}$ & $\begin{array}{c}\text { Lowest tertile } \\
\text { processing } \\
\text { speed } \\
(n=1,003)\end{array}$ & $\begin{array}{c}\text { Middle tertile } \\
\text { processing } \\
\text { speed } \\
(n=1,004)\end{array}$ & $\begin{array}{c}\text { Highest tertile } \\
\text { processing } \\
\text { speed } \\
(n=1,004)\end{array}$ \\
\hline \multicolumn{5}{|l|}{ General baseline characteristics } \\
\hline Age, years & $59.5(8.2)$ & $63.6(7.1)$ & $60.0(7.3)$ & $55.1(7.9)$ \\
\hline Women, \% & $48.9(1,471)$ & $41.2(413)$ & $46.3(465)$ & $59.1(593)$ \\
\hline $\begin{array}{l}\text { Education level, \% } \\
\text { - low } \\
\text { - intermediate } \\
\text { - high } \\
\end{array}$ & $\begin{array}{c}15.7(472) \\
43.2(1,301) \\
41.1(1,238) \\
\end{array}$ & $\begin{array}{l}30.6(307) \\
43.9(440) \\
25.5(256) \\
\end{array}$ & $\begin{array}{l}11.8(118) \\
43.2(434) \\
45.0(452) \\
\end{array}$ & $\begin{array}{c}4.7(47) \\
42.5(427) \\
52.8(530) \\
\end{array}$ \\
\hline $\begin{array}{l}\text { Smoking status, \% } \\
\text { - never } \\
\text { - former } \\
\text { - current }\end{array}$ & $\begin{array}{c}34.9(1,051) \\
51.9(1,564) \\
13.2(396) \\
\end{array}$ & $\begin{array}{l}31.5(316) \\
53.1(533) \\
15.4(154) \\
\end{array}$ & $\begin{array}{l}33.8(339) \\
53.5(537) \\
12.7(128) \\
\end{array}$ & $\begin{array}{l}39.4(396) \\
49.2(494) \\
11.4(114) \\
\end{array}$ \\
\hline $\begin{array}{l}\text { Alcohol use, \% } \\
\text { - none } \\
\text { - low } \\
\text { - high }\end{array}$ & $\begin{array}{c}18.0(543) \\
55.5(1,671) \\
26.5(797) \\
\end{array}$ & $\begin{array}{l}21.2(213) \\
56.4(566) \\
22.3(224) \\
\end{array}$ & $\begin{array}{l}15.9(160) \\
54.1(543) \\
30.0(301) \\
\end{array}$ & $\begin{array}{l}16.9(170) \\
56.0(562) \\
27.1(272) \\
\end{array}$ \\
\hline Body mass index, $\mathrm{kg} / \mathrm{m}^{2}$ & $27.1(4.5)$ & $27.8(4.6)$ & $27.0(4.4)$ & $26.4(4.3)$ \\
\hline Type 2 diabetes, $\%$ & $26.5(797)$ & $39.5(396)$ & $24.8(249)$ & $15.1(152)$ \\
\hline Hypertension, \% & $55.4(1,667)$ & $68.6(688)$ & $54.9(551)$ & $42.6(428)$ \\
\hline Total/HDL cholesterol ratio & $3.7(1.2)$ & $3.7(1.2)$ & $3.7(1.2)$ & $3.7(1.2)$ \\
\hline Triglycerides, mmol/L & $1.4(0.9)$ & $1.5(0.9)$ & $1.4(0.9)$ & $1.4(0.8)$ \\
\hline Lipid-modifying medication, $\%$ & $34.9(1,050)$ & $48.0(481)$ & $33.8(339)$ & $22.9(230)$ \\
\hline Prior cardiovascular disease, $\%$ & $16.1(486)$ & $23.8(239)$ & $13.6(137)$ & $11.0(110)$ \\
\hline Current depression, $\%$ & $3.7(112)$ & $5.1(51)$ & $3.3(33)$ & $2.8(28)$ \\
\hline $\begin{array}{l}\text { Plasma biomarkers of low-grade } \\
\text { inflammation composite score, SD* }\end{array}$ & $0.0(1.0)$ & $0.2(1.0)$ & $0.0(1.0)$ & $-0.2(1.0)$ \\
\hline \multicolumn{5}{|l|}{ Microvascular dysfunction measures $^{\dagger}$} \\
\hline $\begin{array}{l}\text { Microvascular dysfunction composite } \\
\text { score, SD }\end{array}$ & $0.0(1.0)$ & $0.4(1.2)$ & $0.0(0.9)$ & $-0.3(0.8)$ \\
\hline \multicolumn{5}{|l|}{ Cerebral small vessel disease features } \\
\hline Total brain parenchyma volume, $\mathrm{ml}$ & $1,138.4(111.7)$ & $1,115.5(112.2)$ & $1,148.0(110.7)$ & $1,148.8(109.4)$ \\
\hline White matter hyperintensity volume, $\mathrm{ml}$ & $0.2(0.1-0.7)$ & $0.3(0.1-1.2)$ & $0.2(0.1-0.8)$ & $0.1(<0.1-0.4)$ \\
\hline Presence of cerebral microbleeds, \% & $11.8(237)$ & $15.2(93)$ & $11.4(78)$ & $9.2(66)$ \\
\hline Presence of lacunar infarcts, $\%$ & $5.4(110)$ & $7.4(46)$ & $5.8(40)$ & $3.3(24)$ \\
\hline \multicolumn{5}{|c|}{ Plasma biomarkers of microvascular dysfunction } \\
\hline Soluble ICAM-1, $\mu \mathrm{g} / \mathrm{I}$ & $352.7(98.1)$ & $365.0(112.4)$ & $352.8(95.4)$ & $340.3(82.8)$ \\
\hline Soluble VCAM-1, $\mu \mathrm{g} / \mathrm{l}$ & $425.1(99.8)$ & $439.1(109.4)$ & $424.9(99.6)$ & $411.1(87.2)$ \\
\hline Soluble E-selectin, $\mu \mathrm{g} / \mathrm{l}$ & $117.5(64.2)$ & $126.4(71.1)$ & $119.2(65.3)$ & $107.0(53.6)$ \\
\hline Von Willebrand Factor, \% & $131.7(47.8)$ & $139.1(50.9)$ & $132.2(47.6)$ & $123.9(43.4)$ \\
\hline \multicolumn{5}{|l|}{ Urinary albumin excretion } \\
\hline $\begin{array}{l}\text { Urinary albumin excretion } \geq 30 \mathrm{mg} / 24 \mathrm{~h} \text {, } \\
\%\end{array}$ & $8.1(242)$ & $12.6(125)$ & $7.4(74)$ & $4.3(43)$ \\
\hline
\end{tabular}




\begin{tabular}{|c|c|c|c|c|}
\hline & $\begin{array}{l}\text { Total study } \\
\text { population } \\
(n=3,011)\end{array}$ & $\begin{array}{l}\text { Lowest tertile } \\
\text { processing } \\
\text { speed } \\
(n=1,003)\end{array}$ & $\begin{array}{c}\text { Middle tertile } \\
\text { processing } \\
\text { speed } \\
(n=1,004)\end{array}$ & $\begin{array}{l}\text { Highest tertile } \\
\text { processing } \\
\text { speed } \\
(n=1,004)\end{array}$ \\
\hline $\begin{array}{l}\text { Urinary albumin excretion } \\
15-<30 \mathrm{mg} / 24 \mathrm{~h}, \%\end{array}$ & $10.3(308)$ & $11.9(118)$ & $10.2(102)$ & $8.8(88)$ \\
\hline \multicolumn{5}{|c|}{ Flicker light-induced arteriolar and venular dilation response } \\
\hline $\begin{array}{l}\text { Flicker light-induced arteriolar dilation } \\
\text { response, } \%\end{array}$ & $3.1(2.8)$ & $2.6(2.8)$ & $3.1(2.8)$ & $3.4(2.7)$ \\
\hline $\begin{array}{l}\text { Flicker light-induced venular dilation } \\
\text { response, } \%\end{array}$ & $3.9(2.2)$ & $3.7(2.2)$ & $4.0(2.1)$ & $4.0(2.2)$ \\
\hline Heat-induced skin hyperaemia, \% & $1,133.2(781.5)$ & $1,022.7(728.4)$ & $1,164.1(791.6)$ & $1,220.8(813.5)$ \\
\hline
\end{tabular}

Data are presented as percentage of participants $(n)$, mean \pm standard deviation or median (interquartile range). *Expressed per standard deviation (SD); +Data available for total brain parenchyma volume and white matter hyperintensity volume $n=2,049$; for lacunar infarctions $n=2,046$ and for cerebral microbleeds $n=2,012$; for sICAM-1; sVCAM-1; and sE-selectin $n=3,011$; for vWF $n=2,991$; for albuminuria $n=2,987$; for flicker lightinduced arteriolar dilation $n=2,018$; for flicker light-induced venular dilation $n=2,049$; and for heat-induced skin hyperaemia $n=1,457$.

Abbreviations: BMI: body mass index; sE-selectin: soluble E-selectin; sICAM-1: soluble intercellular adhesion molecule-1; sVCAM-1: soluble vascular adhesion molecule-1; MMSE: Mini Mental State Examination; SD: standard deviation; vWF: Von Willebrand Factor. 
Table S4. Characteristics of the total study population and according to tertiles of executive function

\begin{tabular}{|c|c|c|c|c|}
\hline & $\begin{array}{l}\text { Total study } \\
\text { population } \\
(n=3,011)\end{array}$ & $\begin{array}{l}\text { Lowest tertile } \\
\text { executive } \\
\text { function } \\
(n=1,003)\end{array}$ & $\begin{array}{c}\text { Middle tertile } \\
\text { executive } \\
\text { function } \\
(n=1,004)\end{array}$ & $\begin{array}{c}\text { Highest tertile } \\
\text { executive } \\
\text { function } \\
(n=1,004)\end{array}$ \\
\hline \multicolumn{5}{|l|}{ General baseline characteristics } \\
\hline Age, years & $59.5(8.2)$ & $63.2(7.2)$ & $59.4(7.8)$ & $56.0(8.0)$ \\
\hline Women, \% & $48.9(1,471)$ & $45.9(460)$ & 49.7 (499) & $51.0(512)$ \\
\hline $\begin{array}{l}\text { Education level, \% } \\
\text { - low } \\
\text { - intermediate } \\
\text { - high }\end{array}$ & $\begin{array}{c}15.7(472) \\
43.2(1,301) \\
41.1(1,238) \\
\end{array}$ & $\begin{array}{l}28.1(282) \\
46.7(468) \\
25.2(253) \\
\end{array}$ & $\begin{array}{l}13.6(137) \\
42.9(431) \\
43.4(436) \\
\end{array}$ & $\begin{array}{c}5.3(53) \\
40.0(402) \\
54.7(549) \\
\end{array}$ \\
\hline $\begin{array}{l}\text { Smoking status, \% } \\
\text { - never } \\
\text { - former } \\
\text { - current }\end{array}$ & $\begin{array}{c}34.9(1,051) \\
51.9(1,564) \\
13.2(396) \\
\end{array}$ & $\begin{array}{l}31.8(319) \\
53.3(535) \\
14.9(149) \\
\end{array}$ & $\begin{array}{l}35.7(358) \\
52.0(522) \\
12.4(124) \\
\end{array}$ & $\begin{array}{l}37.3(374) \\
50.5(507) \\
12.3(123) \\
\end{array}$ \\
\hline $\begin{array}{l}\text { Alcohol use, \% } \\
\text { - none } \\
\text { - low } \\
\text { - high }\end{array}$ & $\begin{array}{c}18.0(543) \\
55.5(1,671) \\
26.5(797) \\
\end{array}$ & $\begin{array}{l}21.4(215) \\
54.5(547) \\
24.0(241) \\
\end{array}$ & $\begin{array}{l}16.4(165) \\
57.6(578) \\
26.0(261) \\
\end{array}$ & $\begin{array}{l}16.2(163) \\
54.4(546) \\
29.4(295) \\
\end{array}$ \\
\hline Body mass index, $\mathrm{kg} / \mathrm{m}^{2}$ & $27.1(4.5)$ & $27.7(4.5)$ & $26.9(4.5)$ & $26.5(4.4)$ \\
\hline Type 2 diabetes, $\%$ & $26.5(797)$ & $37.2(373)$ & $24.4(245)$ & $17.8(179)$ \\
\hline Hypertension, \% & $55.4(1,667)$ & $68.4(686)$ & $52.6(528)$ & $45.1(453)$ \\
\hline Total/HDL cholesterol ratio & $3.7(1.2)$ & $3.7(1.2)$ & $3.7(1.2)$ & $3.7(1.2)$ \\
\hline Triglycerides, $\mathrm{mmol} / \mathrm{L}$ & $1.4(0.9)$ & $1.5(0.9)$ & $1.4(0.9)$ & $1.4(0.8)$ \\
\hline Lipid-modifying medication, \% & $34.9(1,050)$ & $47.2(473)$ & $30.4(305)$ & $27.1(272)$ \\
\hline Prior cardiovascular disease, $\%$ & $16.1(486)$ & $21.4(215)$ & $15.2(153)$ & $11.8(118)$ \\
\hline Current depression, $\%$ & $3.7(112)$ & $5.0(50)$ & $3.5(35)$ & $2.7(27)$ \\
\hline $\begin{array}{l}\text { Plasma biomarkers of low-grade } \\
\text { inflammation composite score, } \mathrm{SD}^{*}\end{array}$ & $0.0(1.0)$ & $0.2(1.0)$ & $0.0(1.0)$ & $-0.2(1.0)$ \\
\hline \multicolumn{5}{|l|}{ Microvascular dysfunction measures ${ }^{\dagger}$} \\
\hline $\begin{array}{l}\text { Microvascular dysfunction composite } \\
\text { score, SD }\end{array}$ & $0.0(1.0)$ & $0.3(1.1)$ & $0.0(1.0)$ & $-0.2(0.9)$ \\
\hline \multicolumn{5}{|l|}{ Cerebral small vessel disease features } \\
\hline Total brain parenchyma volume, $\mathrm{ml}$ & $1,138.4(111.7)$ & $1,110.7(109.4)$ & $1,144.2(113.0)$ & $1,156.0(108.0)$ \\
\hline White matter hyperintensity volume, $\mathrm{ml}$ & $0.2(0.1-0.7)$ & $0.4(0.1-1.1)$ & $0.2(0.1-0.7)$ & $0.2(<0.1-0.5)$ \\
\hline Presence of cerebral microbleeds, $\%$ & $11.8(237)$ & $13.8(84)$ & $11.8(80)$ & $10.0(73)$ \\
\hline Presence of lacunar infarcts, $\%$ & $5.4(110)$ & $6.3(39)$ & $5.6(38)$ & $4.4(33)$ \\
\hline \multicolumn{5}{|c|}{ Plasma biomarkers of microvascular dysfunction } \\
\hline Soluble ICAM-1, $\mu \mathrm{g} / \mathrm{I}$ & $352.7(98.1)$ & $365.3(105.4)$ & $353.4(98.2)$ & $339.4(88.4)$ \\
\hline Soluble VCAM-1, $\mu \mathrm{g} / \mathrm{l}$ & $425.1(99.8)$ & $436.7(106.6)$ & $423.1(97.5)$ & $415.4(93.7)$ \\
\hline Soluble E-selectin, $\mu \mathrm{g} / \mathrm{l}$ & $117.5(64.2)$ & $127.6(72.5)$ & $119.4(64.8)$ & $105.5(51.8)$ \\
\hline Von Willebrand Factor, \% & $131.7(47.8)$ & $138.6(49.8)$ & $129.9(47.1)$ & $126.8(45.7)$ \\
\hline \multicolumn{5}{|l|}{ Urinary albumin excretion } \\
\hline Urinary albumin excretion $\geq 30 \mathrm{mg} / 24 \mathrm{~h}, \%$ & $8.1(242)$ & $11.7(116)$ & $7.6(76)$ & $5.0(50)$ \\
\hline Urinary albumin excretion $15-<30 \mathrm{mg} / 24 \mathrm{~h}, \%$ & $10.3(308)$ & $12.6(125)$ & $9.5(95)$ & $8.8(88)$ \\
\hline
\end{tabular}




\begin{tabular}{|c|c|c|c|c|}
\hline & $\begin{array}{l}\text { Total study } \\
\text { population } \\
(n=3,011)\end{array}$ & $\begin{array}{l}\text { Lowest tertile } \\
\text { executive } \\
\text { function } \\
(n=1,003)\end{array}$ & $\begin{array}{l}\text { Middle tertile } \\
\text { executive } \\
\text { function } \\
(n=1,004)\end{array}$ & $\begin{array}{l}\text { Highest tertile } \\
\text { executive } \\
\text { function } \\
(n=1,004)\end{array}$ \\
\hline \multicolumn{5}{|c|}{ Flicker light-induced arteriolar and venular dilation response } \\
\hline $\begin{array}{l}\text { Flicker light-induced arteriolar dilation } \\
\text { response, } \%\end{array}$ & $3.1(2.8)$ & $2.8(2.8)$ & $3.1(2.8)$ & $3.2(2.7)$ \\
\hline $\begin{array}{l}\text { Flicker light-induced venular dilation } \\
\text { response,\% }\end{array}$ & $3.9(2.2)$ & $3.8(2.1)$ & $3.9(2.2)$ & $3.9(2.2)$ \\
\hline Heat-induced skin hyperaemia, \% & $1,133.2(781.5)$ & $1,097.9(828.3)$ & $1,159.8(793.4)$ & $1,144.2(716.6)$ \\
\hline
\end{tabular}

Data are presented as percentage of participants $(n)$, mean \pm standard deviation or median (interquartile range). *Expressed per standard deviation (SD); †Data available for total brain parenchyma volume and white matter hyperintensity volume $n=2,049$; for lacunar infarctions $n=2,046$ and for cerebral microbleeds $n=2,012$; for sICAM-1; sVCAM-1; and sE-selectin $n=3,011$; for vWF $n=2,991$; for albuminuria $n=2,987$; for flicker lightinduced arteriolar dilation $n=2,018$; for flicker light-induced venular dilation $n=2,049$; and for heat-induced skin hyperaemia $n=1,457$.

Abbreviations: BMI: body mass index; sE-selectin: soluble E-selectin; sICAM-1: soluble intercellular adhesion molecule-1; sVCAM-1: soluble vascular adhesion molecule-1; MMSE: Mini Mental State Examination; SD: standard deviation; vWF: Von Willebrand Factor.

Table S5. Associations between the individual covariates and cognitive function score

\begin{tabular}{|c|c|c|c|c|}
\hline \multirow[t]{2}{*}{ Covariates } & \multirow[t]{2}{*}{$\boldsymbol{\beta}$} & \multicolumn{2}{|c|}{ 95\% Confidence Interval } & \multirow[t]{2}{*}{ P value } \\
\hline & & Lower Bound & Upper Bound & \\
\hline Microvascular dysfunction score (per SD) & -0.088 & -0.131 & -0.046 & $<0.001$ \\
\hline Age (per year) & -0.045 & -0.050 & -0.041 & $<0.001$ \\
\hline Education level (per category) & 0.419 & 0.369 & 0.469 & $<0.001$ \\
\hline Sex (men vs. women) & 0.351 & 0.279 & 0.423 & $<0.001$ \\
\hline T2D (without T2D vs. with T2D) & -0.099 & -0.197 & -0.001 & 0.047 \\
\hline Body Mass Index (per point) & -0.003 & -0.012 & 0.006 & 0.486 \\
\hline Active smoker (non-smoker vs. active smoker) & -0.141 & -0.252 & -0.030 & 0.013 \\
\hline Former smoker (non-smoker vs. former smoker) & 0.091 & 0.018 & 0.163 & 0.014 \\
\hline Alcohol use (per category) & 0.042 & -0.011 & 0.094 & 0.123 \\
\hline $\begin{array}{l}\text { Hypertension (without hypertension vs. with } \\
\text { hypertension) }\end{array}$ & -0.054 & -0.129 & 0.021 & 0.160 \\
\hline Total/HDL cholesterol ratio (per point) & -0.024 & -0.062 & 0.013 & 0.200 \\
\hline Triglycerides (per mmol) & -0.008 & -0.061 & 0.045 & 0.761 \\
\hline $\begin{array}{l}\text { Lipid-modifying medication (without medication } \\
\text { use vs. with medication 4use) }\end{array}$ & 0.000 & -0.091 & 0.091 & 0.999 \\
\hline Prior CVD (without prior CVD vs. with prior CVD) & 0.020 & -0.088 & 0.128 & 0.717 \\
\hline $\begin{array}{l}\text { Current depression (without current depression } \\
\text { vs. with current depression) }\end{array}$ & -0.121 & -0.303 & 0.061 & 0.191 \\
\hline $\begin{array}{l}\text { Plasma markers of low-grade inflammation score } \\
\text { (per SD) }\end{array}$ & 0.004 & -0.057 & 0.065 & 0.901 \\
\hline
\end{tabular}

Results are expressed as standard deviation difference in the cognitive function score per unit difference in covariate. Abbreviations: CVD: cardiovascular disease; T2D: type 2 diabetes. 
Table S6. Associations between the microvascular dysfunction score and cognitive function score in individuals $<65$ years and $\geq 65$ years

\begin{tabular}{|c|c|c|c|c|c|c|c|c|}
\hline \multirow{3}{*}{ Model } & \multicolumn{4}{|c|}{ Participants $<65$ years $(n=1,459)$} & \multicolumn{4}{|c|}{ Participants $\geq 65$ years $(n=575)$} \\
\hline & \multirow[t]{2}{*}{$\beta$} & \multicolumn{2}{|c|}{ 95\% Confidence Interval } & \multirow[t]{2}{*}{$P$ value } & \multirow[t]{2}{*}{$\beta$} & \multicolumn{2}{|c|}{ 95\% Confidence Interval } & \multirow[t]{2}{*}{$P$ value } \\
\hline & & Lower Bound & Upper Bound & & & Lower Bound & Upper Bound & \\
\hline 1 & -0.067 & -0.117 & -0.016 & 0.003 & -0.118 & -0.185 & -0.051 & 0.003 \\
\hline 2 & -0.063 & -0.116 & -0.010 & 0.004 & -0.134 & -0.207 & -0.060 & 0.004 \\
\hline
\end{tabular}

Results are expressed as standard deviation worse cognitive function score per standard deviation higher microvascular dysfunction score. Results were adjusted for age, education level, sex, diabetes mellitus type 2, body mass index, smoking status, alcohol use, hypertension, total/HDL cholesterol ratio, triglycerides, and lipidmodifying medication use (model 1), and additionally for prior cardiovascular disease, current depression and plasma biomarkers of low-grade inflammation (model 2).

Table S7. Associations between individual measures of microvascular dysfunction and cognitive function score

\begin{tabular}{|c|c|c|c|c|c|}
\hline \multirow{2}{*}{$\begin{array}{l}\text { Individual microvascular dysfunction } \\
\text { measure }\end{array}$} & \multirow[t]{2}{*}{ Model } & \multirow[t]{2}{*}{$\boldsymbol{\beta}$} & \multicolumn{2}{|c|}{ 95\% Confidence Interval } & \multirow[t]{2}{*}{ P value } \\
\hline & & & Lower Bound & Upper Bound & \\
\hline \multirow{2}{*}{$\begin{array}{l}\text { Total brain parenchyma volume (per lower } \\
\text { SD) }(n=2,049)\end{array}$} & 1 & -0.059 & -0.099 & -0.019 & 0.004 \\
\hline & 2 & -0.057 & -0.097 & -0.017 & 0.005 \\
\hline \multirow{2}{*}{$\begin{array}{l}\text { White matter hyperintensities (per higher } \\
\text { SD) }(n=2,049)\end{array}$} & 1 & -0.087 & -0.124 & -0.050 & $<0.001$ \\
\hline & 2 & -0.085 & -0.122 & -0.048 & $<0.001$ \\
\hline \multirow{2}{*}{$\begin{array}{l}\text { Cerebral microbleeds (presence vs. } \\
\text { absence) }(n=2,012)\end{array}$} & 1 & -0.072 & -0.174 & 0.031 & 0.170 \\
\hline & 2 & -0.067 & -0.170 & 0.037 & 0.206 \\
\hline \multirow{2}{*}{$\begin{array}{l}\text { Lacunar infarcts (presence vs. absence) } \\
(n=2,046)\end{array}$} & 1 & -0.044 & -0.190 & 0.101 & 0.550 \\
\hline & 2 & -0.037 & -0.183 & 0.109 & 0.619 \\
\hline \multirow{2}{*}{$\begin{array}{l}\text { Soluble intercellular adhesion molecule- } 1 \\
\text { (per SD) }(n=3,011)\end{array}$} & 1 & -0.024 & -0.053 & 0.006 & 0.113 \\
\hline & 2 & -0.016 & -0.048 & 0.016 & 0.330 \\
\hline \multirow{2}{*}{$\begin{array}{l}\text { Soluble vascular adhesion molecule-1 (per } \\
\text { SD) }(n=3,011)\end{array}$} & 1 & -0.014 & -0.043 & 0.015 & 0.341 \\
\hline & 2 & -0.008 & -0.038 & 0.022 & 0.603 \\
\hline \multirow[t]{2}{*}{ Soluble E-selectin (per SD) $(n=3,011)$} & 1 & -0.058 & -0.089 & -0.028 & $<0.001$ \\
\hline & 2 & -0.054 & -0.084 & -0.023 & 0.001 \\
\hline \multirow[t]{2}{*}{ Von Willebrand factor (per SD) $(n=2,991)$} & 1 & -0.005 & -0.034 & 0.023 & 0.714 \\
\hline & 2 & 0.000 & -0.029 & 0.030 & 0.986 \\
\hline \multirow{2}{*}{$\begin{array}{l}\text { Urinary albumin excretion ( } \geq 30 \mathrm{mg} / 24 \mathrm{~h} \text { vs. } \\
<15 \mathrm{mg} / 24 \mathrm{~h})(\mathrm{n}=2,987)\end{array}$} & 1 & -0.131 & -0.237 & -0.025 & 0.015 \\
\hline & 2 & -0.117 & -0.223 & -0.011 & 0.031 \\
\hline \multirow{2}{*}{$\begin{array}{l}\text { Urinary albumin excretion }(15-<30 \mathrm{mg} / 24 \mathrm{~h} \\
\text { vs. }<15 \mathrm{mg} / 24 \mathrm{~h})(\mathrm{n}=2,987)\end{array}$} & 1 & -0.032 & -0.124 & 0.061 & 0.505 \\
\hline & 2 & -0.018 & -0.111 & 0.075 & 0.701 \\
\hline \multirow{2}{*}{$\begin{array}{l}\text { Flicker light-induced retinal arteriolar } \\
\text { dilation (per lower SD) }(n=2,018)\end{array}$} & 1 & -0.016 & -0.050 & 0.018 & 0.349 \\
\hline & 2 & -0.016 & -0.050 & 0.019 & 0.371 \\
\hline \multirow{2}{*}{$\begin{array}{l}\text { Flicker light-induced retinal venular dilation } \\
\text { (per lower SD) }(n=2,049)\end{array}$} & 1 & -0.023 & -0.057 & 0.010 & 0.173 \\
\hline & 2 & -0.022 & -0.056 & 0.011 & 0.190 \\
\hline \multirow{2}{*}{$\begin{array}{l}\text { Skin hyperemic response (per lower SD) } \\
(n=1,457)\end{array}$} & 1 & 0.010 & -0.031 & 0.052 & 0.626 \\
\hline & 2 & 0.013 & -0.029 & 0.054 & 0.552 \\
\hline
\end{tabular}

Results are expressed as standard deviation worse cognitive function score per standard deviation higher microvascular dysfunction score. Results were adjusted for age, education level, sex, diabetes mellitus type 2 , body mass index, smoking status, alcohol use, hypertension, total/HDL cholesterol ratio, triglycerides, lipidmodifying medication use (model 1), and additionally for prior cardiovascular disease, current depression and plasma biomarkers of low-grade inflammation (model 2). 
Table S8. Associations between the microvascular dysfunction score and cognitive function in individuals with data available on at least one, eight and ten of the 12 individual measures of microvascular dysfunction

\begin{tabular}{|c|c|c|c|c|c|}
\hline \multirow[t]{2}{*}{ Determinant } & \multirow[t]{2}{*}{ Model } & \multirow[t]{2}{*}{$\boldsymbol{\beta}$} & \multicolumn{2}{|c|}{ 95\% Confidence Interval } & \multirow[t]{2}{*}{ P value } \\
\hline & & & Lower Bound & Upper Bound & \\
\hline \multirow{2}{*}{$\begin{array}{l}\text { Microvascular dysfunction score calculated } \\
\text { in individuals with data on at least one of the } \\
12 \text { measures (per higher SD) }(n=3,011)\end{array}$} & 1 & -0.077 & -0.111 & -0.044 & $<0.001$ \\
\hline & 2 & -0.073 & -0.109 & -0.037 & $<0.001$ \\
\hline \multirow{2}{*}{$\begin{array}{l}\text { Microvascular dysfunction score calculated } \\
\text { in individuals with data on at least eight of } \\
\text { the } 12 \text { measures (per higher SD) }(n=2,364)\end{array}$} & 1 & -0.087 & -0.124 & -0.050 & $<0.001$ \\
\hline & 2 & -0.083 & -0.123 & -0.043 & $<0.001$ \\
\hline \multirow{2}{*}{$\begin{array}{l}\text { Microvascular dysfunction score calculated } \\
\text { in individuals with data on at least ten of the } \\
12 \text { measures (per higher SD) }(n=1,658)\end{array}$} & 1 & -0.077 & -0.121 & -0.033 & 0.001 \\
\hline & 2 & -0.079 & -0.126 & -0.033 & 0.001 \\
\hline
\end{tabular}

Results are expressed as standard deviation worse cognitive function score per standard deviation higher microvascular dysfunction score. Results were adjusted for age, education level, sex, diabetes mellitus type 2, body mass index, smoking status, alcohol use, hypertension, total/HDL cholesterol ratio, triglycerides, lipidmodifying medication use (model 1), and additionally for prior cardiovascular disease, current depression and plasma biomarkers of low-grade inflammation (model 2).

Table S9. Associations between the microvascular dysfunction score and cognitive function after excluding consecutively each individual measure of microvascular dysfunction

\begin{tabular}{|c|c|c|c|c|c|}
\hline \multirow{2}{*}{$\begin{array}{l}\text { Variable excluded from the } \\
\text { microvascular dysfunction score }\end{array}$} & \multirow[t]{2}{*}{ Model } & \multirow[t]{2}{*}{$\boldsymbol{\beta}$} & \multicolumn{2}{|c|}{ 95\% Confidence Interval } & \multirow[t]{2}{*}{ P value } \\
\hline & & & Lower Bound & Upper Bound & \\
\hline \multirow[t]{2}{*}{ Cerebral small vessel disease features } & 1 & -0.046 & -0.081 & -0.012 & 0.009 \\
\hline & 2 & -0.042 & -0.079 & -0.005 & 0.026 \\
\hline \multirow{2}{*}{$\begin{array}{l}\text { Plasma biomarkers of microvascular } \\
\text { dysfunction }\end{array}$} & 1 & -0.087 & -0.130 & -0.043 & $<0.001$ \\
\hline & 2 & -0.085 & -0.129 & -0.042 & $<0.001$ \\
\hline \multirow[t]{2}{*}{ Urinary albumin excretion } & 1 & -0.079 & -0.119 & -0.040 & $<0.001$ \\
\hline & 2 & -0.080 & -0.122 & -0.038 & $<0.001$ \\
\hline \multirow{2}{*}{$\begin{array}{l}\text { Flicker light-induced retinal arteriolar and } \\
\text { venular dilation responses }\end{array}$} & 1 & -0.090 & -0.130 & -0.051 & $<0.001$ \\
\hline & 2 & -0.090 & -0.132 & -0.048 & $<0.001$ \\
\hline \multirow[t]{2}{*}{ Heat-induced skin hyperaemia } & 1 & -0.092 & -0.131 & -0.052 & $<0.001$ \\
\hline & 2 & -0.094 & -0.136 & -0.052 & $<0.001$ \\
\hline
\end{tabular}

${ }^{\dagger}$ Data available for analyses after excluding cerebral small vessel disease features $n=2,426$; for plasma biomarkers of microvascular dysfunction $n=1,659$, for urinary albumin excretion $n=2,039$; for flicker light-induced retinal arteriolar and venular dilation response $n=2,050$ and for heat-induced skin hyperaemia $n=2,051$. Results are expressed as standard deviation worse cognitive function score per standard deviation higher microvascular dysfunction score. Results were adjusted for age, education level, sex, diabetes mellitus type 2, body mass index, smoking status, alcohol use, hypertension, total/HDL cholesterol ratio, triglycerides, lipid-modifying medication use (model 1), and additionally for prior cardiovascular disease, current depression and plasma biomarkers of low-grade inflammation (model 2). 
Table S10. Associations between composite scores of cerebral small vessel disease features, plasma biomarkers of microvascular dysfunction and retinal arteriolar and venular dilation responses and cognitive function

\begin{tabular}{lcccccc}
\hline Determinant & Model & $\boldsymbol{\beta}$ & \multicolumn{2}{c}{$\mathbf{9 5 \%}$ Confidence Interval } & P value \\
\hline & & & Lower Bound & Upper Bound \\
\hline $\begin{array}{l}\text { Cerebral small vessel disease features (per } \\
\text { point) ( }=2,002)\end{array}$ & 1 & -0.085 & -0.133 & -0.038 & $<\mathbf{0 . 0 0 1}$ \\
\cline { 2 - 7 } $\begin{array}{l}\text { Plasma biomarkers of microvascular } \\
\text { dysfunction (per SD) ( } \mathrm{n}=2,991)\end{array}$ & 2 & -0.082 & -0.129 & -0.035 & $\mathbf{0 . 0 0 1}$ \\
\hline $\begin{array}{l}\text { Flicker light-induced retinal arteriolar } \\
\begin{array}{l}\text { and venular dilation responses (per SD) } \\
\text { (n=1,998) }\end{array}\end{array}$ & $\mathbf{2}$ & -0.040 & -0.071 & -0.009 & $\mathbf{0 . 0 1 0}$ \\
\hline
\end{tabular}

Results are expressed as standard deviation worse cognitive function score per standard deviation higher microvascular dysfunction score. Results were adjusted for age, education level, sex, diabetes mellitus type 2, body mass index, smoking status, alcohol use, hypertension, total/HDL cholesterol ratio, triglycerides, lipidmodifying medication use (model 1), and additionally for prior cardiovascular disease, current depression and plasma biomarkers of low-grade inflammation (model 2).

Table S11. Associations between the microvascular dysfunction score and cognitive function additionally adjusted for ambulatory blood pressure

\begin{tabular}{lcccc}
\hline Model & B & \multicolumn{2}{c}{$\mathbf{9 5 \% \text { Confidence Interval }}$} & P value \\
\hline 1 & & Lower Bound & Upper Bound & \\
\hline 2 & -0.092 & -0.135 & -0.050 & $<\mathbf{0 . 0 0 1}$ \\
\hline
\end{tabular}

${ }^{+}$Data available for analyses $n=1,799$. Results are expressed as standard deviation worse cognitive function score per standard deviation higher microvascular dysfunction score. Results were adjusted for age, education level, sex, diabetes mellitus type 2, body mass index, smoking status, alcohol use, total/HDL cholesterol ratio, triglycerides, lipid-modifying medication use, antihypertensive medication use, and ambulatory blood pressure (model 1), and additionally for prior cardiovascular disease, current depression and plasma biomarkers of lowgrade inflammation (model 2).

Table S12. Associations between the microvascular dysfunction score and cognitive function additionally adjusted for class of antihypertensive medication

\begin{tabular}{lcccc}
\hline Model & B & \multicolumn{2}{c}{ 95\% Confidence Interval } & P value \\
\hline \multicolumn{4}{c}{ Lower Bound } & Upper Bound \\
\hline 2 & -0.083 & -0.123 & -0.043 & $<\mathbf{0 . 0 0 1}$ \\
\hline
\end{tabular}

tData available for analyses $n=2,034$. Results are expressed as standard deviation worse cognitive function score per standard deviation higher microvascular dysfunction score. Results were adjusted for age, education level, sex, diabetes mellitus type 2, body mass index, smoking status, alcohol use, total/HDL cholesterol ratio, triglycerides, lipid-modifying medication use, use of angiotensin-converting-enzyme inhibitors or angiotensin II receptor blockers, use of other antihypertensive medications, office systolic and diastolic blood pressure (model 1), and additionally for prior cardiovascular disease, current depression and plasma biomarkers of low-grade inflammation (model 2). This additional analysis was performed, because angiotensin-converting enzyme inhibitors and angiotensin II receptor blockers have additional beneficial effects on microvascular function independent of their antihypertensive properties. ${ }^{1}$ 
Table S13. Associations between the microvascular dysfunction score and cognitive function score, stratified by diabetes status (without type 2 diabetes and with type 2 diabetes)

\begin{tabular}{|c|c|c|c|c|c|c|c|c|}
\hline \multirow{3}{*}{ Model } & \multicolumn{4}{|c|}{ Participants without type 2 diabetes $(n=1,598)$} & \multicolumn{4}{|c|}{ Participants with type 2 diabetes $(n=436)$} \\
\hline & $\boldsymbol{\beta}$ & 95\% Confiden & ce Interval & P value & $\boldsymbol{\beta}$ & 95\% Confiden & Ice Interval & P value \\
\hline & & Lower Bound & Upper Bound & & & Lower Bound & Upper Bound & \\
\hline 1 & -0.081 & -0.130 & -0.032 & 0.001 & -0.099 & -0.171 & -0.028 & 0.007 \\
\hline 2 & -0.073 & -0.124 & -0.021 & 0.005 & -0.140 & -0.222 & -0.058 & 0.001 \\
\hline
\end{tabular}

Results are expressed as standard deviation worse cognitive function score per standard deviation higher microvascular dysfunction score. Results were adjusted for age, education level, sex, body mass index, smoking status, alcohol use, hypertension, total/HDL cholesterol ratio, triglycerides, and lipid-modifying medication use (model 1), and additionally for prior cardiovascular disease, current depression and plasma biomarkers of lowgrade inflammation (model 2). 
CHAPTER 5

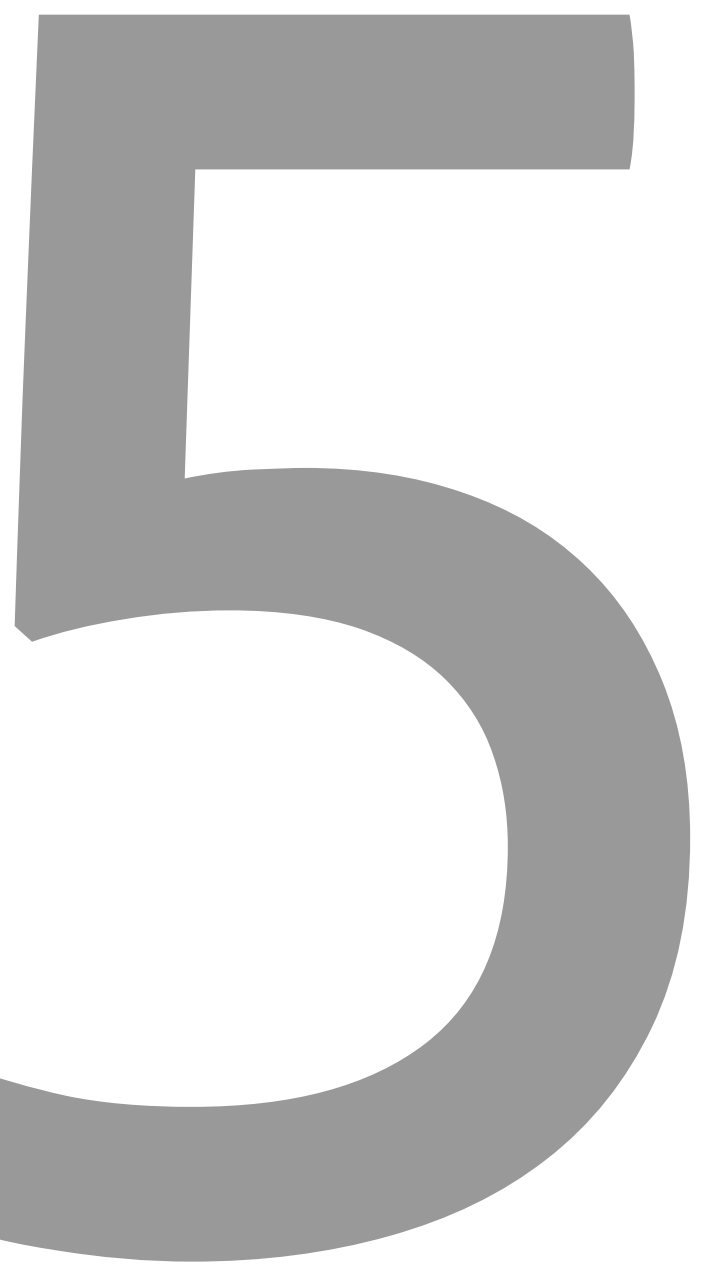




\section{Associations of arterial stiffness with cognitive performance, and the role of microvascular dysfunction: The Maastricht Study}

S.P. Rensma, C.D.A. Stehouwer, M.P.J. Van Boxtel, A.J.H.M. Houben, T.T.J.M. Berendschot, J.F.A. Jansen, C.G. Schalkwijk, F.R.J. Verhey, A.A. Kroon, R.M.A. Henry, W.H. Backes, P.C. Dagnelie, M.C.J.M van Dongen, S.J.P.M. Eussen, J.H.A. Bosma, S. Köhler, K. Reesink, M.T. Schram, T.T. van Sloten 


\section{Abstract}

\section{Background and aims}

The mechanisms underlying cognitive impairment and dementia are incompletely understood but may include arterial stiffness and microvascular dysfunction. We investigated, in the population-based Maastricht Study, the association between greater arterial stiffness and worse cognitive performance, and whether any such association was statistically explained, or mediated, by various measures of microvascular dysfunction.

\section{Materials and methods}

We included cross-sectional data of 2,544 participants (age 59.7 years; $51.0 \%$ men; $26.0 \%$ type 2 diabetes [oversampled by design]). We used carotid-femoral pulse wave velocity and carotid distensibility coefficient as measures of aortic and carotid stiffness, respectively. We calculated a composite score of microvascular dysfunction based on MRI features of cerebral small vessel disease (lower total brain parenchymal volume, higher white matter hyperintensity volume, lacunar infarcts and cerebral microbleeds), retinal arteriolar and venular dilation response, albuminuria, and plasma biomarkers of microvascular dysfunction (sICAM-1, sVCAM-1, sE-selectin and von Willebrand Factor). Cognitive domains assessed were memory, processing speed and executive function. A cognitive function composite score was calculated as the average of the scores on these three cognitive domains.

\section{Results}

Higher carotid-femoral pulse wave velocity was associated with a lower cognitive function composite score after adjustment for age, sex, education level, glucose metabolism status, body mass index, smoking, alcohol use, total/high density cholesterol ratio, triglycerides, mean arterial pressure, heart rate and use of anti-hypertensive and/or lipidmodifying medication. Higher carotid stiffness was not associated with the cognitive function composite score. Mediation analysis showed that higher carotid-femoral pulse wave velocity was associated with a higher microvascular dysfunction score, and a higher microvascular dysfunction score was associated with a lower cognitive function composite score. Thus, a higher microvascular dysfunction score statistically significantly explained $16.2 \%$ of the total effect of carotid-femoral pulse wave velocity on the cognitive function composite score.

\section{Conclusion}

The present study found that aortic stiffness, but not carotid stiffness, is independently associated with worse cognitive performance, and that this association is in part explained by microvascular dysfunction. 


\section{Introduction}

Cognitive impairment and dementia have an enormous impact on patients, their families and society, and the prevalence of dementia is rising. ${ }^{2}$ The mechanisms underlying cognitive impairment and dementia remain, however, incompletely understood, but may include arterial stiffness and microvascular dysfunction (MVD). ${ }^{3}$

Greater arterial stiffness leads to excessive intra-arterial pressure and flow pulsatility which may transmit distally and damage the cerebral microcirculation. ${ }^{4,5}$ The cerebral microvasculature is involved in the regulation of many processes potentially affecting cognition, i.e. cerebral perfusion, neurogenesis, neurovascular coupling, blood-brain barrier permeability and cerebral autoregulation. ${ }^{6}$ Impairment of these processes may lead to neuronal dysfunction and ischemia, which may ultimately lead to lower cognitive performance. ${ }^{3,6-8}$ In accordance, previous studies ${ }^{3-22}$ have shown an association between greater arterial stiffness and both cognitive decline and incident dementia. Most of these studies $^{3,9-16,19-22}$ focused on carotid-femoral pulse wave velocity (cfPWV), a measure of aortic stiffness, but only some ${ }^{17-22}$ on carotid stiffness. In addition, MVD has been associated with worse cognitive performance. ${ }^{8,23}$ However, whether any association between aortic or carotid stiffness and worse cognitive performance is explained, or mediated, by MVD remains largely unknown.

Microvascular function and structure can be measured noninvasively in various organs. These measures include magnetic resonance imaging (MRI) features of cerebral small vessel disease (CSVD, e.g. lower total brain parenchyma volume, higher white matter hyperintensity volume, and presence of lacunar infarcts and cerebral microbleeds) ${ }_{i}^{24}$ flicker light-induced retinal arteriolar and venular dilation response, ${ }^{25}$ albuminuria ("urinary albumin excretion", UAE) ${ }_{i}^{26}$ and plasma biomarkers of MVD (e.g. soluble intercellular adhesion molecule-1 [sICAM-1], soluble vascular adhesion molecule-1 [sVCAM-1], soluble E-selectin [sE-selectin] and von Willebrand factor [vWF]). ${ }^{27}$

These various measures of MVD (i.e. CSVD features, retinal arteriolar and venular dilation response, UAE and plasma biomarkers of MVD) can be summarized into a total MVD composite score. The CSVD features and the retinal arteriolar and venular dilation responses are closely linked to the cerebral microvasculature and, thus, may reflect its function. ${ }^{28,29}$ In addition, to the extent that MVD is a generalised phenomenon, UAE, and plasma biomarkers of MVD may also reflect cerebral MVD. ${ }^{30}$ We previously showed that such a total MVD composite score is associated with worse cognitive performance.

In view of the above, the aims of the present study were to investigate the associations between aortic and carotid stiffness and cognitive performance, and whether any such associations are statistically mediated by a composite score of various MVD measures, including CSVD features, retinal arteriolar and venular dilation response, UAE and plasma biomarkers of MVD. 


\section{Material and methods}

\section{Study population and design}

We used data from The Maastricht Study, an observational population-based cohort study. The rationale and methodology have been described previously. ${ }^{31}$ In brief, the study focuses on the aetiology, pathophysiology, complications and comorbidities of diabetes mellitus type 2 (T2D) and is characterized by an extensive phenotyping approach. Eligible for participation were all individuals aged between 40 and 75 years and living in the southern part of the Netherlands. Participants were recruited through mass media campaigns, the municipal registries and the regional Diabetes Patient Registry via mailings. Recruitment was stratified according to known T2D status, with an oversampling of individuals with T2D for reasons of efficiency. The present report includes cross-sectional data from 3,451 participants who completed the baseline survey between November 2010 and September 2013. The examinations of each participant were performed within a time window of three months. The study has been approved by the institutional medical ethical committee (NL31329.068.10) and the Ministry of Health, Welfare, and Sports of the Netherlands (Permit 131088-105234-PG). All participants gave written informed consent.

\section{Vascular measures}

For all vascular measures, participants were asked to refrain from smoking and drinking caffeine-containing beverages three hours before the measurement. ${ }^{32} \mathrm{~A}$ light meal was allowed until $\geq 90$ minutes prior to the examination. For retinal measurements, pupils were dilated with $0.5 \%$ tropicamide and $2.5 \%$ phenylephrine $\geq 15$ minutes before the start of the examination.

\section{Assessment of arterial stiffness}

A more detailed description of the arterial stiffness measures is provided in the Supplementary Material (Item S1), and has been described previously. ${ }^{33,}{ }^{34}$ During the arterial stiffness measurements, brachial blood pressure and heart rate were obtained with a validated commercial oscillometric device (Accutorr Plus, Datascope Inc., Montvale, NJ, USA).

\section{Carotid-femoral pulse wave velocity}

We determined cfPWV with the use of applanation tonometry (SphygmoCor, Atcor Medical, Sydney, Australia). ${ }^{35}$ Pressure waveforms were determined at the right common carotid and right common femoral arteries. Difference in the time of pulse wave arrival from the R-wave of the electrocardiogram between the two sites (transit time) was determined. The pulse wave travel distance was calculated as $80 \%$ of the direct straight distance between the two arterial sites. The median of three consecutive cfPWV (defined as traveled distance/transit time) recordings was used in the analyses.

\section{Carotid stiffness}

We assessed local diameter, distension and intima-media thickness of the left common carotid artery with the use of an ultrasound scanner equipped with a 7.5-MHz linear probe (MyLab 70, Esaote Europe B.V., Maastricht, the Netherlands). ${ }^{36}$ We quantified carotid stiffness by calculating the carotid distensibility coefficient (carDC) based on the following 
formula: carDC $=\left(2^{*} \Delta D^{*} D+\Delta D^{2}\right) /\left(P P^{*} D^{2}\right)$, where $D$ is arterial diameter, $\Delta D$ distension, and PP brachial pulse pressure. ${ }^{37}$ Carotid compliance coefficient and Young's elastic modulus were also determined.

\section{Microvascular dysfunction measures Features of cerebral small vessel disease}

Brain MRI measurements were implemented from December 2013 onwards and were available in 2,313 of 3,451 participants (67\%). Brain MRI was performed on a 3T MRI scanner (Siemens Magnetom Prisma-fit Syngo MR D13D, Erlangen, Germany). We evaluated four CSVD features, i.e. lower total brain parenchyma volume, higher white matter hyperintensity volume, and presence of lacunar infarcts and cerebral microbleeds. ${ }^{24}$ A detailed description of the MRI protocol and the definitions of the CSVD features is provided in the Supplementary Material (Item S2), and has been described previously. ${ }^{38}$ The MRI protocol consisted of a 3DT -weighted sequence, a fluid-attenuated inversion recovery sequence, a combined proton density and $\mathrm{T}_{2}$-weighted turbo spin echo sequence and a susceptibility-weighted imaging sequence. ${ }^{38}$ Volumes were determined semi-automatically, and lacunar infarcts and cerebral microbleeds were scored manually.

\section{Flicker light-induced retinal arteriolar and venular dilation response}

We measured retinal arteriolar and venular dilation response to flicker light exposure by the Dynamic Vessel Analyzer (Imedos, Jena, Germany), as previously described. ${ }^{25,39} \mathrm{~A}$ baseline recording of 50 seconds was followed by 40 -second flicker light exposure followed by a 60 -second recovery period. We calculated baseline diameters (in measurement units) as the average diameter during the $20-50$ seconds recording. For both the arteriolar and venular dilation, percentage dilation over baseline was calculated using the average dilation achieved at time points 10 and 40 seconds during the flicker light stimulation period.

\section{Urinary albumin excretion}

We assessed UAE in two 24-hour urine samples. Urinary albumin concentration was measured with a standard immunoturbidimetric assay by an automatic analyzer (due to a change of supplier, by the Beckman Synchron LX20 and the Roche Cobas 6000) and multiplied by collection volume to obtain 24 -hour UAE. ${ }^{40} \mathrm{~A}$ urinary albumin concentration below the detection limit of the assay was set at $1.5 \mathrm{mg} / \mathrm{L}(2 \mathrm{mg} / \mathrm{L}$ for the Beckman Synchron LX20 and 3mg/L for the Roche Cobas 6000) before multiplying by collection volume. Only urine collections with a collection time between 20 and 28 hours were considered valid. If needed, UAE was extrapolated to 24-hour excretion. For this study, UAE was preferably based on the average of two (available in $91.3 \%$ of participants) 24-hour urine collections.

\section{Plasma biomarkers of microvascular dysfunction}

We measured four plasma biomarkers of MVD: sICAM-1, sVCAM-1, sE-selectin and VWF. ${ }^{30}$ sICAM-1, sVCAM-1 and sE-selectin were measured in EDTA plasma samples with commercially available 4-plex sandwich immunoassay kits with different standards and antibodies (Meso Scale Discovery, Rockville, Maryland, United States of America). For this technique in this study, the intra- and inter-assay coefficients of variation were 10.3 and $8.4 \%$ for sICAM-1, 5.0 and $4.7 \%$ for sVCAM-1, and 2.9 and $7.4 \%$ for sE-selectin, 
respectively. Von Willebrand Factor (VWF) was quantified in citrate plasma using ELISA (Dako, Glostrup, Denmark). The intra- and inter-assay coefficients of variation were 3.0 and $4.3 \%$, respectively.

\section{Cognitive performance}

We assessed cognitive performance using a concise neuropsychological test battery, as described previously. ${ }^{31}$ For statistical efficiency, we constructed a cognitive function composite score by averaging of standardized test scores in three cognitive domains: memory, processing speed and executive function. A detailed description of methods used to calculate domain-specific cognitive function scores is provided in Item S3 (Supplementary material). We evaluated memory with the Verbal Learning Test; ${ }^{41}$ processing speed with the Stroop Color-Word Test Part I and II, ${ }^{42}$ Concept Shifting Test Part $\mathrm{A}$ and $\mathrm{B},{ }^{43}$ and Letter-Digit Substitution Test; ${ }^{44}$ and executive function with the Stroop Color-Word Test Part III ${ }^{42}$ and Concept Shifting Test Part C. ${ }^{43}$

\section{Covariates}

We determined glucose metabolism status according to the World Health Organization 2006 criteria as normal glucose metabolism, prediabetes or T2D. ${ }^{45}$ Education level was classified into three groups: low (none, primary or lower vocational education only), intermediate (intermediate general secondary, intermediate vocational or higher general secondary education) and high (higher vocational education or university level of education). Body mass index (BMI), smoking status (never, former, current), alcohol use (none, low, high), office blood pressure, plasma lipid levels, medication use and prior cardiovascular disease (CVD) were determined as described previously. ${ }^{25,26,31} \mathrm{We}$ used questionnaires to assess adherence to the Mediterranean diet score ("diet score"), ${ }^{46}$ moderate-to-vigorous physical activity (CHAMPS questionnaire), ${ }^{31}$ and socio-economic status (income level and occupational status). ${ }^{47}$ The Mini-International Neuropsychiatric Interview (MINI) was used to assess the presence of a current DSM-IV defined major depressive episode. ${ }^{31}$ Plasma biomarkers of low-grade inflammation were determined as described previously. ${ }^{31,48}$ These included high-sensitive C-reactive protein (CRP), serum amyloid A (SAA), interleukin-6 (IL-6), interleukin-8 (IL-8) and tumor necrosis factor alpha (TNF-a). In addition, 24-hour ambulatory systolic blood pressure was determined. ${ }^{49}$

\section{Statistical analysis}

We inversed (multiplying by -1 ) total brain parenchyma volume, and the flicker lightinduced retinal arteriolar and venular dilation responses so that higher values indicated worse microvascular function. White matter hyperintensity volume and UAE were logtransformed (base 2) to normalize their skewed distribution.

We summarized the 11 MVD measures (i.e. four CSVD features, flicker light-induced retinal arteriolar and venular dilation responses, UAE and four plasma biomarkers of MVD) into a MVD composite score, as done previously. We hypothesized that each MVD measure is associated with arterial stiffness and cognitive performance according to similar underlying mechanisms. The use of a composite score reduces the influence of the biological variability of its components ${ }^{50}$ and it reduces the chance of a type 1 error. The 
MVD composite score was calculated when at least data on one of the 11 MVD measures were available. The composite score was calculated by averaging the 11 standardized MVD measures, respectively. On average, individuals included in the analysis had data available on nine of the 11 measures (Figure S1).

The statistical analysis proceeded in two stages. First, we used linear regression analysis to evaluate associations between cfPWV and carDC and the cognitive function composite score. We adjusted for the following potential confounders: age, sex, and education level (model 1), additionally for glucose metabolism status, BMI, smoking, alcohol use, total/ high density cholesterol (HDL) ratio and triglycerides (model 2 ) and then additionally for mean arterial pressure, heart rate and use of anti-hypertensive and/or lipid-modifying medication (model 3). Second, we performed a formal mediation analysis to test the hypothesis that MVD explains the association between greater arterial stiffness and worse cognitive performance..$^{51}$ The mediation model quantifies the degree to which a variable statistically explains the association between a determinant and an outcome variable. We used bootstrapping (10,000 samples) to calculate bias-corrected $95 \%$ confidence intervals (95\% Cls) of the explained associations using the PROCESS statistical package for PASW statistics. ${ }^{51}$ The magnitude of the explained association was calculated as a percentage of the total association.

We tested interaction terms with age, ${ }^{52}$ sex $_{1}^{53}$ education level ${ }^{54}$ and glucose metabolism status $^{16}$ to evaluate whether the association between arterial stiffness and cognitive performance differed according to these factors.

We performed several additional analyses. First, we repeated the analysis using carotid compliance coefficient and Young's elastic modulus instead of carDC as the determinant. Second, we repeated the analysis using domain-specific cognitive function scores, i.e. memory, processing speed and executive function, as the outcome. Third, to test whether the association between the MVD score and cognitive function composite score was primarily determined by any individual MVD measure, we repeated the analysis five times after consecutively excluding from the MVD score the four CSVD features, the retinal arteriolar and venular dilation responses, UAE and the four plasma biomarkers of MVD. Fifth, we repeated the analysis additionally adjusting for prior CVD, current depression and the plasma biomarkers of low-grade inflammation. Adjustments for these covariates were not included in the main analysis, because of the risk of overadjustment bias: these factors may be confounders but may also mediate the associations between arterial stiffness, MVD and cognitive performance. Sixth, we repeated the analysis additionally adjusting for type of antihypertensive medication (i.e. beta blockers, diuretics, calcium channel blockers, angiotensin-converting enzyme inhibitors and angiotensin II receptor blockers). Seventh, we repeated the analysis additionally adjusting for the diet score, for moderate-to-vigorous physical activity and for the socio-economic status variables income level and occupational status. Adjustments for these covariates were not included in the main analysis, because data were missing in a relatively large number of participants ( $n=774$ missed data on one or more of these variables).

All analyses were performed with SPSS software (v22.0, IBM, Chicago, USA). A P value of $<.05$ was considered statistically significant. 


\section{Results}

Figure 1 shows the derivation of the final study population. In total, 2,544 participants had data available on arterial stiffness, at least one MVD measure, the cognitive function composite score and all potential confounders. Table 1 shows the characteristics of the study population and according to tertiles of the cognitive function composite score. Characteristics of the individuals excluded from the analyses due to missing values are provided in the Supplementary Material (Table S1). On average, these individuals were older, more often male, had received lower education and had a worse cardiovascular risk profile. The study population for current analyses had a mean age of 59.7 years, $51.0 \%$ were men, $26.0 \%$ had T2D (oversampled by design) and $41.5 \%$ had received a high education.

Higher cfPWV was associated with a lower cognitive function composite score after adjustments for all potential confounders but without adjustment for the total MVD score (Table 2). CarDC was not associated with the cognitive function composite score after adjustment for all potential confounders (Table 2).

Mediation analysis showed that higher cfPWV was associated with a higher MVD score, and a higher MVD score was associated with a lower cognitive function composite score (Figure 2). When we additionally adjusted the association between cfPWV and the cognitive function composite score for the MVD score, the association was attenuated and no longer statistically significant. The effect explained by the MVD score was statistically significant and was $16.2 \%$ of the total direct effect of cfPWV on the cognitive function composite score (Figure 2). CarDC was not associated with a higher MVD score, and the MVD score did not statistically significantly mediate the association between CarDC and the cognitive function composite score (Figure S2).

We found no interactions with age, sex, education level and glucose metabolism status ( $P$ values for interaction $>.10$ ).

\section{Additional analyses}

The carotid compliance coefficient and Young's elastic modulus were not statistically significantly associated with the cognitive function composite score (Table S2). CfPWV and carDC were not statistically significantly associated with domain-specific cognitive function scores, i.e. memory, processing speed and executive function (Table S3). Results were similar when we consecutively excluded from the MVD score the CSVD features, the retinal arteriolar and venular dilation responses, UAE and the plasma biomarkers of MVD (Table S4). Results did not materially change when we additionally adjusted for prior CVD, current depression or the plasma biomarkers of low-grade inflammation (Table S5), type of antihypertensive medication (Table S6), or the diet score, moderate-to-vigorous physical activity or income level and occupational status (Table S7). 


\section{Discussion}

In this cross-sectional study, higher cfPWV, but not lower carDC, was associated with a lower cognitive function composite score. In addition, the association between cfPWV and the cognitive function composite score was in part (16.2\%) explained or mediated by a composite score of various MVD measures, including CSVD features, flicker light-induced retinal arteriolar and venular dilation response, UAE and plasma biomarkers of MVD.

The study findings are in accordance with the hypothesis that higher aortic stiffness increases the risk of worse cognitive performance in part via cerebral MVD. ${ }^{3,55}$ Higher aortic stiffness may lead to MVD via an increased pulsatile load on the microcirculation. This increased load may cause direct microvascular damage and may induce a microvascular remodelling response. This response initially serves to limit the penetration of the pulsatile load into the microvasculature by raising vascular resistance. ${ }^{56}$ However, this protective response may ultimately become unfavorable, leading to cerebral hypoperfusion, impaired neurogenesis and vasoreactivity, and blood-brain barrier hyperpermeability.

Previous studies have shown associations between higher cfPWV and various measures of MVD, including MRI features of CSVD $^{3}$ and albuminuria. ${ }^{57-60}$ In addition, previous studies have shown an association between various MVD measures (i.e. CSVD features, albuminuria and plasma biomarkers of MVD) and worse cognitive performance, ${ }^{8,61-69}$ and higher cfPWV and worse cognitive performance., ${ }^{3,16,70}$ However, only one previous study ${ }^{7}$ evaluated arterial stiffness, cognitive performance and MVD at the same time. This study found an association between higher cfPWV and worse memory, and showed that this association was attenuated after adjustments for higher white matter hyperintensity volume. ${ }^{7}$ The present study extends previous research by showing, with use of a formal mediation analysis, that the association between higher cfPWV and worse cognitive performance is in part mediated, or explained, by a composite score of various direct and indirect measures of MVD. It thereby provides additional evidence consistent with the role of arterial stiffness as a contributor to MVD and cognitive decline.

Surprisingly, carotid stiffness was not associated with worse cognitive performance in our study, although the $95 \%$ confidence intervals of the effect estimates do not exclude the possibility of such an association. In contrast, we previously found, in a smaller dataset of The Maastricht Study of the first 866 individuals included in the study i.e. from November 2010 to March 2012, that greater carotid stiffness was weakly associated with worse cognitive performance. ${ }^{22}$ We cannot fully explain this difference, although it may be related to the slightly different characteristics of the two data samples. Although individuals included in the first study period were of the same age (60 years), they were more often men $(54.6 \%$ vs $51.0 \%)$ and had a slightly worse cardiovascular risk profile, i.e. had more often type 2 diabetes ( $27.2 \%$ vs. $26.0 \%$ ), were more often current smokers (15.9\% vs. $13.4 \%$ ), and more often had a high level of alcohol consumption (30.9\% vs. $26.9 \%$ ) and prior CVD (17.2\% vs. $16.2 \%)$. Although both analyses adjusted for these potential confounders, we cannot exclude the possibility of residual confounding. In addition, we cannot exclude that the difference in results are due to the play of chance. Only six other studies ${ }^{17-21,71}$ evaluated the association between carotid stiffness and cognitive performance and also 
had inconsistent results. Some, ${ }^{17-19,21}$ but not all, ${ }^{2071}$ studies found an association between higher carotid stiffness and worse cognitive performance. These conflicting results may be due to the differences in cognitive tests used and inconsistent adjustments for potential confounders (e.g. only on $\mathrm{e}^{20}$ study adjusted for heart rate, whereas the others ${ }^{17-19,21,71}$ did not). The association between carotid stiffness and cognitive performance, therefore, remains unclear, and requires further study.

A relatively large part of the association between cfPWV and cognitive performance remained unexplained after taking into account the effect of MVD. This remaining association may be due to MVD that is not directly captured in our MVD composite score (e.g. blood-brain barrier leakage and altered cerebrovascular reactivity). In addition, it is possible that only a subset of individuals with cognitive impairment have vascular-related disease. Finally, although we adjusted for a large set of potential confounders, we cannot exclude the possibility of residual confounding.

Strengths of the present study are the large population-based sample, the comprehensive assessment of various measures of MVD, and the extensive characterization of participants, which enabled us to adjust for a series of potential confounders.

Our study has certain limitations. First, the cross-sectional observational design precludes reaching strong causal conclusions about the study findings. Second, the construction of the composite scores assumes that all its components either directly or indirectly reflect cerebral MVD, which is not necessarily true. However, results did not materially change after exclusion of individual MVD measures from the MVD composite score. Third, the study population consisted mostly of middle-aged participants without dementia who were relatively well-educated and whose cardiovascular risk factors were relatively wellcontrolled. This may have led to an underestimation of the reported findings due to lower variation in cognitive performance and relatively high cognitive reserve.

From a clinical point of view, the present study is important, because insight in the pathophysiological mechanisms between arterial stiffness, MVD and cognitive performance might help to design prevention strategies of cognitive impairment. Evidence suggests that lifestyle modifications, such as weight loss and exercise, may favorably influence arterial stiffness and MVD. ${ }^{72,73}$ In addition, drugs, such as renin-angiotensinaldosterone system inhibitors, antihyperglycemic agents (i.e. metformin and glucagonlike peptide 1 receptor (GLP-1R) agonists) and statins, may improve arterial elasticity and microvascular function, ${ }^{72,74-76}$ possibly beyond their blood pressure- , glucose- or lipidlowering effects. ${ }^{72,76}$

In conclusion, the present study found that aortic stiffness, but not carotid stiffness, is independently associated with worse cognitive performance, and that this association is in part explained by MVD. 


\section{References}

1. Suhrs HE, Michelsen MM and Prescott E. Treatment strategies in coronary microvascular dysfunction: a systematic review of interventional studies. Microcirculation. 2017.

2. Prince M. World Alzheimer Report 2015: the global impact of dementia: an analysis of prevalence, incidence, cost and trends. Alzheimer's Disease International. 2015.

3. van Sloten TT, Protogerou AD, Henry RM, Schram MT, Launer LJ and Stehouwer CD. Association between arterial stiffness, cerebral small vessel disease and cognitive impairment: A systematic review and meta-analysis. Neurosci Biobehav Rev. 2015;53:121-30.

4. Fazekas F, Kleinert R, Offenbacher H, Payer F, Schmidt R, Kleinert G, Radner H and Lechner H. The morphologic correlate of incidental punctate white matter hyperintensities on MR images. AJNR Am J Neuroradiol. 1991;12:915-21.

5. Saji N, Toba K and Sakurai T. Cerebral Small Vessel Disease and Arterial Stiffness: Tsunami Effect in the Brain? Pulse (Basel). 2016;3:182-9.

6. De Silva TM and Faraci FM. Microvascular Dysfunction and Cognitive Impairment. Cell Mol Neurobiol. 2016;36:241-58.

7. Cooper LL, Woodard T, Sigurdsson S, van Buchem MA, Torjesen AA, Inker LA, Aspelund T, Eiriksdottir G, Harris TB, Gudnason V, Launer LJ and Mitchell GF. Cerebrovascular Damage Mediates Relations Between Aortic Stiffness and Memory. Hypertension. 2016;67:176-82.

8. Rensma SP, van Sloten TT, Launer LJ and Stehouwer CDA. Cerebral small vessel disease and risk of incident stroke, dementia and depression, and all-cause mortality: A systematic review and meta-analysis. Neurosci Biobehav Rev. 2018;90:164-173.

9. Taniguchi $Y$, Fujiwara $Y$, Nofuji $Y$, Nishi M, Murayama $H$, Seino S, Tajima R, Matsuyama $Y$ and Shinkai S. Prospective Study of Arterial Stiffness and Subsequent Cognitive Decline Among Community-Dwelling Older Japanese. J Epidemiol. 2015;25:592-9.

10. Hajjar I, Goldstein FC, Martin GS and Quyyumi AA. Roles of Arterial Stiffness and Blood Pressure in Hypertension-Associated Cognitive Decline in Healthy Adults. Hypertension. 2016;67:171-5.

11. Tsao CW, Himali JJ, Beiser AS, Larson MG, DeCarli C, Vasan RS, Mitchell GF and Seshadri S. Association of arterial stiffness with progression of subclinical brain and cognitive disease. Neurology. 2016;86:619-26.

12. Meyer ML, Palta P, Tanaka H, Deal JA, Wright J, Knopman DS, Griswold ME, Mosley TH and Heiss G. Association of Central Arterial Stiffness and Pressure Pulsatility with Mild Cognitive Impairment and Dementia: The Atherosclerosis Risk in Communities Study-Neurocognitive Study (ARIC-NCS). J Alzheimers Dis. 2017;57:195-204.

13. Muela HCS, Costa-Hong VA, Yassuda MS, Moraes NC, Memoria CM, Machado MF, Bor-Seng-Shu E, Nogueira RC, Mansur AJ, Massaro AR, Nitrini R, Macedo TA and Bortolotto LA. Higher arterial stiffness is associated with lower cognitive performance in patients with hypertension. $J$ Clin Hypertens (Greenwich). 2018;20:22-30.

14. Rouch L, Cestac P, Sallerin B, Andrieu S, Bailly H, Beunardeau M, Cohen A, Dubail D, Hernandorena I, Seux ML, Vidal JS and Hanon O. Pulse Wave Velocity Is Associated With Greater Risk of Dementia in Mild Cognitive Impairment Patients. Hypertension. 2018;72:1109-1116.

15. Palta P, Sharrett AR, Wei J, Meyer ML, Kucharska-Newton A, Power MC, Deal JA, Jack CR, Knopman D, Wright J, Griswold M, Tanaka H, Mosley TH and Heiss G. Central Arterial Stiffness Is Associated With Structural Brain Damage and Poorer Cognitive Performance: The ARIC Study. J Am Heart Assoc. 2019;8:e011045. 
16. Pase MP, Beiser A, Himali JJ, Tsao C, Satizabal CL, Vasan RS, Seshadri S and Mitchell GF. Aortic Stiffness and the Risk of Incident Mild Cognitive Impairment and Dementia. Stroke. 2016;47:2256-61.

17. Huck DM, Hanna DB, Rubin LH, Maki P, Valcour V, Springer G, Xue X, Lazar J, Hodis HN, Anastos K, Kaplan RC and Kizer JR. Carotid Artery Stiffness and Cognitive Decline Among Women With or at Risk for HIV Infection. J Acquir Immune Defic Syndr. 2018;78:338-347.

18. DuBose LE, Voss MW, Weng TB, Kent JD, Dubishar KM, Lane-Cordova A, Sigurdsson G, Schmid P, Barlow PB and Pierce GL. Carotid beta-stiffness index is associated with slower processing speed but not working memory or white matter integrity in healthy middle-aged/older adults. J Appl Physiol (1985). 2017;122:868-876.

19. Lim SL, Gao Q, Nyunt MS, Gong L, Lunaria JB, Lim ML, Ling A, Lam CS, Richards AM, Ling LH and $\mathrm{Ng}$ TP. Vascular Health Indices and Cognitive Domain Function: Singapore Longitudinal Ageing Studies. J Alzheimers Dis. 2016;50:27-40.

20. Poels MM, van Oijen M, Mattace-Raso FU, Hofman A, Koudstaal PJ, Witteman JC and Breteler MM. Arterial stiffness, cognitive decline, and risk of dementia: the Rotterdam study. Stroke. 2007;38:888-92.

21. Tarumi T, Gonzales MM, Fallow B, Nualnim N, Pyron M, Tanaka H and Haley AP. Central artery stiffness, neuropsychological function, and cerebral perfusion in sedentary and endurancetrained middle-aged adults. J Hypertens. 2013;31:2400-9.

22. Geijselaers SL, Sep SJ, Schram MT, van Boxtel MP, van Sloten TT, Henry RM, Reesink KD, Kroon AA, Koster A, Schaper NC, Dagnelie PC, van der Kallen CJ, Biessels GJ and Stehouwer CD. Carotid stiffness is associated with impairment of cognitive performance in individuals with and without type 2 diabetes. The Maastricht Study. Atherosclerosis. 2016;253:186-193.

23. Wardlaw JM, Smith $C$ and Dichgans M. Small vessel disease: mechanisms and clinical implications. Lancet Neurol. 2019;18:684-696.

24. Wardlaw JM, Smith EE, Biessels GJ, Cordonnier C, Fazekas F, Frayne R, Lindley RI, O'Brien JT, Barkhof F, Benavente OR, Black SE, Brayne C, Breteler M, Chabriat H, Decarli C, de Leeuw FE, Doubal F, Duering M, Fox NC, Greenberg S, Hachinski V, Kilimann I, Mok V, Oostenbrugge R, Pantoni L, Speck O, Stephan BC, Teipel S, Viswanathan A, Werring D, Chen C, Smith C, van Buchem $M$, Norrving B, Gorelick PB, Dichgans $M$ and nEuroimaging STfRVco. Neuroimaging standards for research into small vessel disease and its contribution to ageing and neurodegeneration. Lancet Neurol. 2013;12:822-38.

25. Sorensen BM, Houben AJ, Berendschot TT, Schouten JS, Kroon AA, van der Kallen CJ, Henry RM, Koster A, Sep SJ, Dagnelie PC, Schaper NC, Schram MT and Stehouwer CD. Prediabetes and Type 2 Diabetes Are Associated With Generalized Microvascular Dysfunction: The Maastricht Study. Circulation. 2016;134:1339-1352.

26. Martens RJ, Henry RM, Houben AJ, van der Kallen CJ, Kroon AA, Schalkwijk CG, Schram MT, Sep SJ, Schaper NC, Dagnelie PC, Muris DM, Gronenschild EH, van der Sande FM, Leunissen KM, Kooman JP and Stehouwer CD. Capillary Rarefaction Associates with Albuminuria: The Maastricht Study. J Am Soc Nephrol. 2016;27:3748-3757.

27. van Sloten TT, Schram MT, Adriaanse MC, Dekker JM, Nijpels G, Teerlink T, Scheffer PG, Pouwer F, Schalkwijk CG, Stehouwer CD and Henry RM. Endothelial dysfunction is associated with a greater depressive symptom score in a general elderly population: the Hoorn Study. Psychol Med. 2014;44:1403-16.

28. Pantoni L. Cerebral small vessel disease: from pathogenesis and clinical characteristics to therapeutic challenges. Lancet Neurol. 2010;9:689-701. 
29. Umemura T, Kawamura $T$ and Hotta N. Pathogenesis and neuroimaging of cerebral large and small vessel disease in type 2 diabetes: A possible link between cerebral and retinal microvascular abnormalities. J Diabetes Investig. 2017;8:134-148.

30. Muris DM, Houben AJ, Schram MT and Stehouwer CD. Microvascular dysfunction: an emerging pathway in the pathogenesis of obesity-related insulin resistance. Rev Endocr Metab Disord. 2013;14:29-38.

31. Schram MT, Sep SJ, van der Kallen CJ, Dagnelie PC, Koster A, Schaper N, Henry RM and Stehouwer CD. The Maastricht Study: an extensive phenotyping study on determinants of type 2 diabetes, its complications and its comorbidities. Eur J Epidemiol. 2014;29:439-51.

32. Garhofer G, Resch H, Sacu S, Weigert G, Schmidl D, Lasta M and Schmetterer L. Effect of regular smoking on flicker induced retinal vasodilatation in healthy subjects. Microvasc Res. 2011;82:351-5.

33. Geijselaers SL, Sep SJ, Schram MT, van Boxtel MP, van Sloten TT, Op Het Roodt J, Henry RM, Reesink KD, Schaper NC, Dagnelie PC, van der Kallen CJ, Biessels GJ and Stehouwer CD. Carotid circumferential wall stress is not associated with cognitive performance among individuals in late middle age: The Maastricht Study. Atherosclerosis. 2018;276:15-22.

34. van Sloten TT, Czernichow S, Houben AJ, Protogerou AD, Henry RM, Muris DM, Schram MT, Sep SJ, Dagnelie PC, van der Kallen CJ, Schaper NC, Blacher J, Hercberg S, Levy BI and Stehouwer CD. Association Between Arterial Stiffness and Skin Microvascular Function: The SUVIMAX2 Study and The Maastricht Study. Am J Hypertens. 2015;28:868-76.

35. Laurent S, Cockcroft J, Van Bortel L, Boutouyrie P, Giannattasio C, Hayoz D, Pannier B, Vlachopoulos C, Wilkinson I, Struijker-Boudier $\mathrm{H}$ and European Network for Non-invasive Investigation of Large A. Expert consensus document on arterial stiffness: methodological issues and clinical applications. Eur Heart J. 2006;27:2588-605.

36. Willekes C, Hoeks AP, Bots ML, Brands PJ, Willigers JM and Reneman RS. Evaluation of off-line automated intima-media thickness detection of the common carotid artery based on M-line signal processing. Ultrasound Med Biol. 1999;25:57-64.

37. Reneman RS, Meinders JM and Hoeks AP. Non-invasive ultrasound in arterial wall dynamics in humans: what have we learned and what remains to be solved. Eur Heart J. 2005;26:960-6.

38. van Agtmaal MJM, Houben A, de Wit V, Henry RMA, Schaper NC, Dagnelie PC, van der Kallen CJ, Koster A, Sep SJ, Kroon AA, Jansen JFA, Hofman PA, Backes WH, Schram MT and Stehouwer CDA. Prediabetes Is Associated With Structural Brain Abnormalities: The Maastricht Study. Diabetes Care. 2018;41:2535-2543.

39. Houben A, Martens RJH and Stehouwer CDA. Assessing Microvascular Function in Humans from a Chronic Disease Perspective. J Am Soc Nephrol. 2017;28:3461-3472.

40. Martens RJ, Kooman JP, Stehouwer CD, Dagnelie PC, van der Kallen CJ, Koster A, Kroon AA, Leunissen KM, Nijpels G, van der Sande FM, Schaper NC, Sep SJ, van Boxtel MP, Schram MT and Henry RM. Estimated GFR, Albuminuria, and Cognitive Performance: The Maastricht Study. Am J Kidney Dis. 2017;69:179-191.

41. Van der Elst W, van Boxtel MP, van Breukelen GJ and Jolles J. Rey's verbal learning test: normative data for 1855 healthy participants aged 24-81 years and the influence of age, sex, education, and mode of presentation. J Int Neuropsychol Soc. 2005;11:290-302.

42. Van der Elst W, Van Boxtel MP, Van Breukelen GJ and Jolles J. The Stroop color-word test: influence of age, sex, and education; and normative data for a large sample across the adult age range. Assessment. 2006;13:62-79. 
43. Van der Elst W, Van Boxtel MP, Van Breukelen GJ and Jolles J. The Concept Shifting Test: adult normative data. Psychol Assess. 2006;18:424-32.

44. van der Elst W, van Boxtel MP, van Breukelen GJ and Jolles J. The Letter Digit Substitution Test: normative data for 1,858 healthy participants aged 24-81 from the Maastricht Aging Study (MAAS): influence of age, education, and sex. J Clin Exp Neuropsychol. 2006;28:998-1009.

45. World Health Organization \& International Diabetes Federation. ( $(2006) \bigotimes$. Definition and diagnosis of diabetes mellitus and intermediate hyperglycaemia : report of a WHO/IDF consultation. Geneva : World Health Organization.

46. Trichopoulou A, Orfanos $P$, Norat $T$, Bueno-de-Mesquita B, Ocke MC, Peeters PH, van der Schouw YT, Boeing H, Hoffmann K, Boffetta P, Nagel G, Masala G, Krogh V, Panico S, Tumino R, Vineis P, Bamia C, Naska A, Benetou V, Ferrari P, Slimani N, Pera G, Martinez-Garcia C, Navarro C, Rodriguez-Barranco M, Dorronsoro M, Spencer EA, Key TJ, Bingham S, Khaw KT, Kesse E, ClavelChapelon F, Boutron-Ruault MC, Berglund G, Wirfalt E, Hallmans G, Johansson I, Tjonneland A, Olsen A, Overvad K, Hundborg HH, Riboli E and Trichopoulos D. Modified Mediterranean diet and survival: EPIC-elderly prospective cohort study. BMJ. 2005;330:991.

47. Qi Y, Koster A, van Boxtel M, Kohler S, Schram M, Schaper N, Stehouwer C and Bosma H. Adulthood Socioeconomic Position and Type 2 Diabetes Mellitus-A Comparison of Education, Occupation, Income, and Material Deprivation: The Maastricht Study. Int J Environ Res Public Health. 2019;16.

48. van Dooren FE, Schram MT, Schalkwijk CG, Stehouwer CD, Henry RM, Dagnelie PC, Schaper NC, van der Kallen CJ, Koster A, Sep SJ, Denollet J, Verhey FR and Pouwer F. Associations of low grade inflammation and endothelial dysfunction with depression - The Maastricht Study. Brain Behav Immun. 2016;56:390-6.

49. Zhou TL, Kroon AA, Reesink KD, Schram MT, Koster A, Schaper NC, Dagnelie PC, van der Kallen CJH, Sep SJS, Stehouwer CDA and Henry RMA. Blood pressure variability in individuals with and without (pre)diabetes: The Maastricht Study. J Hypertens. 2018;36:259-267.

50. O'Brien PC. Procedures for comparing samples with multiple endpoints. Biometrics. 1984;40:1079-87.

51. Preacher $\mathrm{KJ}$ and Hayes AF. Asymptotic and resampling strategies for assessing and comparing indirect effects in multiple mediator models. Behav Res Methods. 2008;40:879-91.

52. Elias MF, Robbins MA, Budge MM, Abhayaratna WP, Dore GA and Elias PK. Arterial pulse wave velocity and cognition with advancing age. Hypertension. 2009;53:668-73.

53. Schiebinger L, Leopold SS and Miller VM. Editorial policies for sex and gender analysis. Lancet. 2016;388:2841-2842.

54. Whalley LJ, Deary IJ, Appleton CL and Starr JM. Cognitive reserve and the neurobiology of cognitive aging. Ageing Res Rev. 2004;3:369-82.

55. Cooper LL and Mitchell GF. Aortic Stiffness, Cerebrovascular Dysfunction, and Memory. Pulse (Basel). 2016;4:69-77.

56. van Sloten TT, Mitchell GF, Sigurdsson S, van Buchem MA, Jonsson PV, Garcia ME, Harris TB, Henry RM, Levey AS, Stehouwer CD, Gudnason V and Launer LJ. Associations between arterial stiffness, depressive symptoms and cerebral small vessel disease: cross-sectional findings from the AGES-Reykjavik Study. J Psychiatry Neurosci. 2016;41:162-8.

57. Huang N, Foster MC, Mitchell GF, Andresdottir MB, Eiriksdottir G, Gudmundsdottir H, Harris TB, Launer LJ, Palsson R, Gudnason V, Levey AS and Inker LA. Aortic stiffness and change in glomerular filtration rate and albuminuria in older people. Nephrol Dial Transplant. 2017;32:677684. 
58. Wu S, Chen D, Zeng X, Wen J, Zhou C, Xiao K, Hu P and Chen W. Arterial stiffness is associated with target organ damage in subjects with pre-hypertension. Arch Med Sci. 2018;14:1374-1380.

59. Michener KH, Mitchell GF, Noubary F, Huang N, Harris T, Andresdottir MB, Palsson R, Gudnason $\mathrm{V}$ and Levey AS. Aortic stiffness and kidney disease in an elderly population. Am J Nephrol. 2015;41:320-8.

60. Bouchi R, Babazono T, Mugishima M, Yoshida N, Nyumura I, Toya K, Hanai K, Tanaka N, Ishii A, Uchigata $Y$ and Iwamoto $Y$. Arterial stiffness is associated with incident albuminuria and decreased glomerular filtration rate in type 2 diabetic patients. Diabetes Care. 2011;34:2570-5.

61. Huang CW, Tsai MH, Chen NC, Chen WH, Lu YT, Lui CC, Chang YT, Chang WN, Chang AY and Chang CC. Clinical significance of circulating vascular cell adhesion molecule-1 to white matter disintegrity in Alzheimer's dementia. Thromb Haemost. 2015;114:1230-40.

62. Rafnsson SB, Deary IJ, Smith FB, Whiteman MC, Rumley A, Lowe GD and Fowkes FG. Cognitive decline and markers of inflammation and hemostasis: the Edinburgh Artery Study. J Am Geriatr Soc. 2007;55:700-7.

63. Yoon CY, Steffen LM, Gross MD, Launer LJ, Odegaard A, Reiner A, Sanchez O, Yaffe K, Sidney S and Jacobs DR, Jr. Circulating Cellular Adhesion Molecules and Cognitive Function: The Coronary Artery Risk Development in Young Adults Study. Front Cardiovasc Med. 2017;4:37.

64. Heringa SM, van den Berg E, Reijmer YD, Nijpels G, Stehouwer CD, Schalkwijk CG, Teerlink T, Scheffer PG, van den Hurk K, Kappelle LJ, Dekker JM and Biessels GJ. Markers of low-grade inflammation and endothelial dysfunction are related to reduced information processing speed and executive functioning in an older population - the Hoorn Study. Psychoneuroendocrinology. 2014;40:108-18.

65. Debette $\mathrm{S}$ and Markus HS. The clinical importance of white matter hyperintensities on brain magnetic resonance imaging: systematic review and meta-analysis. BMJ. 2010;341:c3666.

66. Georgakis MK, Dimitriou NG, Karalexi MA, Mihas C, Nasothimiou EG, Tousoulis D, Tsivgoulis $G$ and Petridou ET. Albuminuria in Association with Cognitive Function and Dementia: A Systematic Review and Meta-Analysis. J Am Geriatr Soc. 2017;65:1190-1198.

67. Li X, Yuan J, Yang L, Qin W, Yang S, Li Y, Fan H and Hu W. The significant effects of cerebral microbleeds on cognitive dysfunction: An updated meta-analysis. PLoS One. 2017;12:e0185145.

68. Saczynski JS, Sigurdsson S, Jonsdottir MK, Eiriksdottir G, Jonsson PV, Garcia ME, Kjartansson O, Lopez O, van Buchem MA, Gudnason V and Launer LJ. Cerebral infarcts and cognitive performance: importance of location and number of infarcts. Stroke. 2009;40:677-82.

69. Vibha D, Tiemeier H, Mirza SS, Adams HHH, Niessen WJ, Hofman A, Prasad K, van der Lugt A, Vernooij MW and Ikram MA. Brain Volumes and Longitudinal Cognitive Change: A Populationbased Study. Alzheimer Dis Assoc Disord. 2017.

70. Rabkin SW. Arterial stiffness: detection and consequences in cognitive impairment and dementia of the elderly. J Alzheimers Dis. 2012;32:541-9.

71. Nieboer D, Douw L, van Dijk BW, Heymans MW, Stam CJ and Twisk JW. Relation between carotid stiffness, cognitive performance and brain connectivity in a healthy middle-aged population: an observational neurophysiological cohort study with magnetoencephalography. BMJ Open. 2016;6:e013441.

72. Stehouwer CDA. Microvascular Dysfunction and Hyperglycemia: A Vicious Cycle With Widespread Consequences. Diabetes. 2018;67:1729-1741.

73. Ferreira I, Boreham CA and Stehouwer CD. The benefits of exercise for arterial stiffness. Am J Hypertens. 2006;19:1037-8. 
74. Batzias K, Antonopoulos AS, Oikonomou E, Siasos G, Bletsa E, Stampouloglou PK, Mistakidi CV, Noutsou M, Katsiki N, Karopoulos P, Charalambous G, Thanopoulou A, Tentolouris N and Tousoulis D. Effects of Newer Antidiabetic Drugs on Endothelial Function and Arterial Stiffness: A Systematic Review and Meta-Analysis. J Diabetes Res. 2018;2018:1232583.

75. Upala S, Wirunsawanya K, Jaruvongvanich V and Sanguankeo A. Effects of statin therapy on arterial stiffness: A systematic review and meta-analysis of randomized controlled trial. Int $J$ Cardiol. 2017;227:338-341.

76. D'Elia L, La Fata E, lannuzzi A and Rubba PO. Effect of statin therapy on pulse wave velocity: A meta-analysis of randomized controlled trials. Clin Exp Hypertens. 2018;40:601-608. 


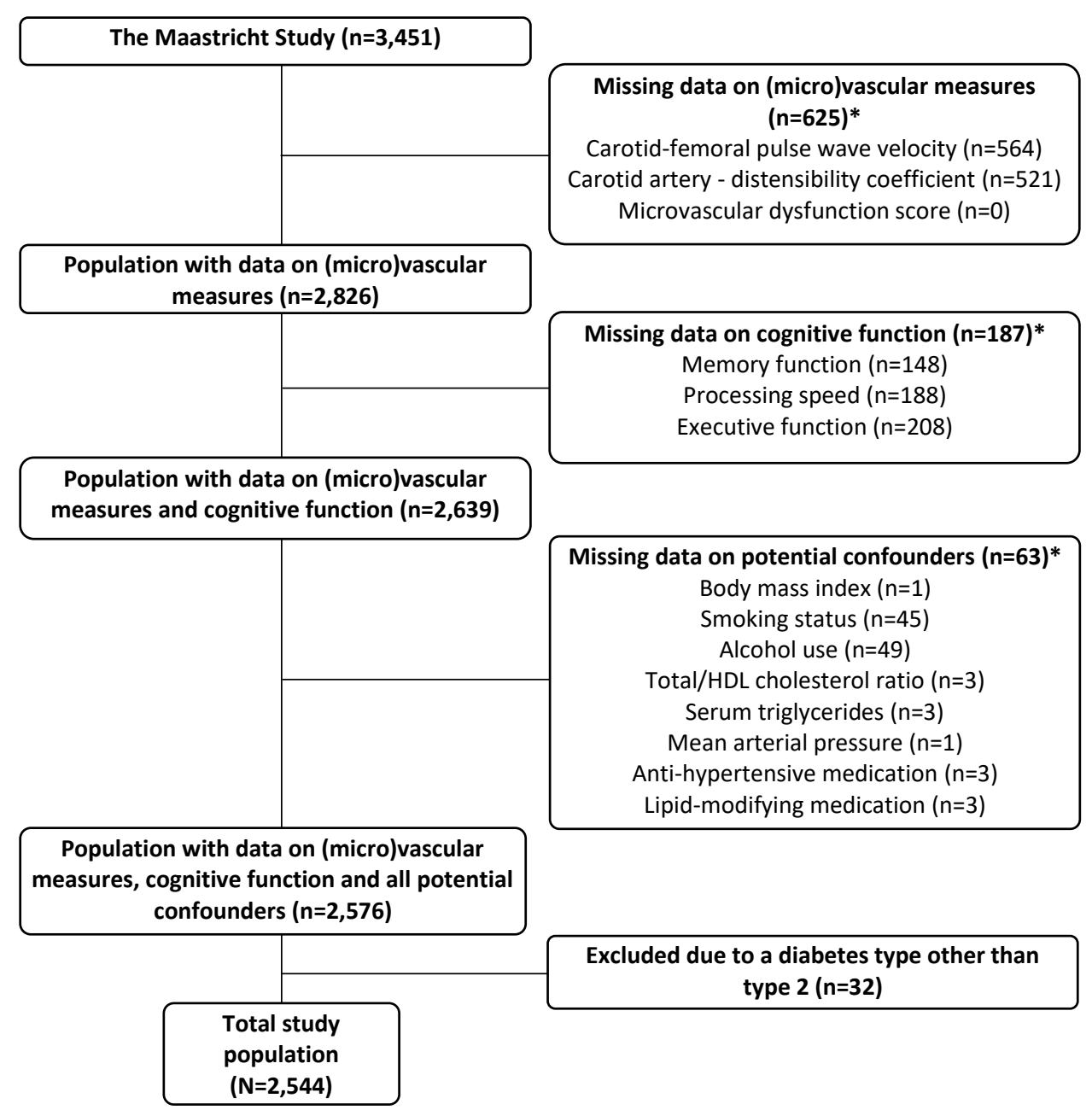

Figure 1. Flowchart showing the derivation of the total study population. *Missings not mutually exclusive. 
Table 1 General study population characteristics

\begin{tabular}{|c|c|c|c|c|}
\hline & & Tertiles of the $c$ & ognitive functior & composite score \\
\hline & $\begin{array}{l}\text { Total study } \\
\text { population } \\
(n=2,544)\end{array}$ & $\begin{array}{l}\text { Lowest tertile } \\
(n=848)\end{array}$ & $\begin{array}{l}\text { Middle tertile } \\
(n=848)\end{array}$ & $\begin{array}{l}\text { Highest tertile } \\
(n=848)\end{array}$ \\
\hline \multicolumn{5}{|l|}{ Demographics } \\
\hline Age, years & $59.7 \pm 8.1$ & $64.1 \pm 6.7$ & $60.2 \pm 7.1$ & $54.9 \pm 7.7$ \\
\hline Men & $51.0(1,297)$ & $63.7(540)$ & $53.2(451)$ & $36.1(306)$ \\
\hline $\begin{array}{l}\text { Education level } \\
\text { Low } \\
\text { Intermediate } \\
\text { High }\end{array}$ & $\begin{array}{l}15.4(393) \\
43.1(1,096) \\
41.5(1,055)\end{array}$ & $\begin{array}{l}29.7(252) \\
45.3(384) \\
25.0(212) \\
\end{array}$ & $\begin{array}{l}12.4(105) \\
45.5(386) \\
42.1(357) \\
\end{array}$ & $\begin{array}{l}4.2(36) \\
38.4(326) \\
57.3(486) \\
\end{array}$ \\
\hline \multicolumn{5}{|l|}{ Cardiovascular risk factors } \\
\hline $\begin{array}{l}\text { Glucose metabolism status } \\
\text { Normal glucose metabolism } \\
\text { Prediabetes } \\
\text { Type } 2 \text { diabetes }\end{array}$ & $\begin{array}{l}58.8(1,496) \\
15.2(387) \\
26.0(661) \\
\end{array}$ & $\begin{array}{l}42.6(361) \\
16.7(142) \\
40.7(345) \\
\end{array}$ & $\begin{array}{l}59.9(508) \\
15.7(133) \\
24.4(207) \\
\end{array}$ & $\begin{array}{l}73.9(627) \\
13.2(112) \\
12.9(109) \\
\end{array}$ \\
\hline Body mass index, kg/m² & $26.9 \pm 4.4$ & $27.8 \pm 4.3$ & $26.9 \pm 4.5$ & $26.1 \pm 4.1$ \\
\hline $\begin{array}{l}\text { Smoking status: } \\
\text { Never } \\
\text { Former } \\
\text { Current }\end{array}$ & $\begin{array}{l}33.8(860) \\
52.8(1,342) \\
13.4(342) \\
\end{array}$ & $\begin{array}{l}30.7(260) \\
53.4(453) \\
15.9(135) \\
\end{array}$ & $\begin{array}{l}32.3(274) \\
55.2(468) \\
12.5(106) \\
\end{array}$ & $\begin{array}{l}38.4(326) \\
49.6(421) \\
11.9(101) \\
\end{array}$ \\
\hline $\begin{array}{l}\text { Alcohol consumption } \\
\text { None } \\
\text { Low, women } \leq 7 \text {; men } \leq 14 \text { units/week } \\
\text { High, women }>7 \text {; men }>14 \text { units/week }\end{array}$ & $\begin{array}{l}17.7(451) \\
55.4(1,409) \\
26.9(684) \\
\end{array}$ & $\begin{array}{l}21.7(184) \\
54.7(464) \\
23.6(200) \\
\end{array}$ & $\begin{array}{l}15.7(133) \\
57.3(486) \\
27.0(229) \\
\end{array}$ & $\begin{array}{l}15.8(134) \\
54.1(459) \\
30.1(255) \\
\end{array}$ \\
\hline Total/HDL cholesterol ratio & $3.7 \pm 1.2$ & $3.8 \pm 1.2$ & $3.8 \pm 1.2$ & $3.6 \pm 1.2$ \\
\hline Triglycerides, $\mathrm{mmol} / \mathrm{L}$ & $1.4 \pm 0.9$ & $1.5 \pm 0.9$ & $1.4 \pm 0.9$ & $1.3 \pm 0.8$ \\
\hline Office systolic pressure, $\mathrm{mmHg}$ & $134.9 \pm 18.2$ & $139.6 \pm 18.8$ & $135.7 \pm 17.6$ & $129.3 \pm 16.6$ \\
\hline Office diastolic pressure, $\mathrm{mmHg}$ & $76.2 \pm 9.9$ & $76.4 \pm 9.9$ & $76.6 \pm 9.6$ & $75.7 \pm 10.2$ \\
\hline $\begin{array}{l}\text { Heart rate during vascular measurement, } \\
\text { bpm }\end{array}$ & $62.5 \pm 9.3$ & $63.0 \pm 9.8$ & $62.0 \pm 9.0$ & $62.6 \pm 9.0$ \\
\hline Use of antihypertensive medication & $37.7(959)$ & $53.7(455)$ & $35.7(303)$ & $23.7(201)$ \\
\hline Use of lipid-modifying medication & $35.1(893)$ & $49.5(420)$ & $35.1(298)$ & $20.6(175)$ \\
\hline Prior cardiovascular disease & $16.2(405)$ & $24.5(204)$ & $14.7(123)$ & $9.3(78)$ \\
\hline Current depression & $3.5(88)$ & $4.8(40)$ & $3.6(30$ & $2.1(18)$ \\
\hline $\begin{array}{l}\text { Composite score of plasma biomarkers } \\
\text { of low-grade inflammation, SD }\end{array}$ & $0.0 \pm 1.0$ & $0.2 \pm 0.7$ & $0.0 \pm 0.6$ & $-0.2 \pm 0.6$ \\
\hline \multicolumn{5}{|l|}{ Measures of arterial stiffness } \\
\hline $\begin{array}{l}\text { Carotid-femoral pulse wave velocity, } \mathrm{m} / \mathrm{s} \\
\text { Carotid distensibility coefficient, } 10^{-3} / \mathrm{kPa} \\
\text { Carotid compliance coefficient, } \mathrm{mm}^{2} / \mathrm{kPa} \\
\text { Carotid Young's elastic modulus, } 10^{3} / \mathrm{kPa}\end{array}$ & $\begin{array}{l}9.0 \pm 2.1 \\
14.3 \pm 5.1 \\
0.7 \pm 0.7 \\
0.7 \pm 0.4\end{array}$ & $\begin{array}{l}9.7 \pm 2.4 \\
12.9 \pm 4.7 \\
0.7 \pm 0.3 \\
0.8 \pm 0.4\end{array}$ & $\begin{array}{l}8.9 \pm 2.0 \\
14.2 \pm 4.8 \\
0.7 \pm 0.3 \\
0.7 \pm 0.3\end{array}$ & $\begin{array}{l}8.3 \pm 1.7 \\
15.9 \pm 5.3 \\
0.7 \pm 0.3 \\
0.7 \pm 0.3\end{array}$ \\
\hline \multicolumn{5}{|c|}{ Measures of microvascular dysfunction* } \\
\hline $\begin{array}{l}\text { Microvascular dysfunction composite } \\
\text { score }\end{array}$ & $0.0 \pm 1.0$ & $0.4 \pm 1.2$ & $-0.1 \pm 0.8$ & $-0.3 \pm 0.7$ \\
\hline \multicolumn{5}{|l|}{ Cerebral small vessel disease features } \\
\hline $\begin{array}{l}\text { Total brain parenchyma volume, } \mathrm{ml} \\
\text { White matter hyperintensity volume, } \mathrm{ml} \\
\text { Presence of cerebral microbleeds } \\
\text { Presence of lacunar infarcts }\end{array}$ & $\begin{array}{l}1,136.1 \pm 111.4 \\
0.23[0.07-0.75] \\
12.0(203) \\
5.3(91)\end{array}$ & $\begin{array}{l}1,123.0 \pm 113.4 \\
0.40[0.15-1.35] \\
15.8(79) \\
6.3(32)\end{array}$ & $\begin{array}{l}1,146.0 \pm 116.7 \\
0.25[0.08-0.90] \\
10.9(64) \\
6.6(39) \\
\end{array}$ & $\begin{array}{l}1,137.4 \pm 103.3 \\
0.13[0.04-0.38] \\
9.8(60) \\
3.2(20) \\
\end{array}$ \\
\hline
\end{tabular}




\begin{tabular}{|c|c|c|c|c|}
\hline & & \multicolumn{3}{|c|}{ Tertiles of the cognitive function composite score } \\
\hline & $\begin{array}{l}\text { Total study } \\
\text { population } \\
(n=2,544)\end{array}$ & $\begin{array}{l}\text { Lowest tertile } \\
(n=848)\end{array}$ & $\begin{array}{l}\text { Middle tertile } \\
(n=848)\end{array}$ & $\begin{array}{l}\text { Highest tertile } \\
(n=848)\end{array}$ \\
\hline \multicolumn{5}{|l|}{$\begin{array}{l}\text { Flicker light-induced arteriolar and } \\
\text { venular dilation }\end{array}$} \\
\hline $\begin{array}{l}\text { Flicker light-induced arteriolar dilation, } \\
\% \\
\text { Flicker light-induced venular dilation, \% }\end{array}$ & $\begin{array}{l}3.1 \pm 2.8 \\
3.9 \pm 2.2\end{array}$ & $\begin{array}{l}2.7 \pm 2.9 \\
3.7 \pm 2.1\end{array}$ & $\begin{array}{l}3.1 \pm 2.8 \\
3.9 \pm 2.2\end{array}$ & $\begin{array}{l}3.3 \pm 2.8 \\
4.0 \pm 2.3\end{array}$ \\
\hline $\begin{array}{l}\text { Urinary albumin excretion } \\
0-15 \mathrm{mg} / 24 \mathrm{~h} \\
15-30 \mathrm{mg} / 24 \mathrm{~h} \\
\geq 30 \mathrm{mg} / 24 \mathrm{~h}\end{array}$ & $\begin{array}{l}81.9(2,066) \\
10.5(266) \\
7.5(190) \\
\end{array}$ & $\begin{array}{l}73.9(618) \\
13.6(114) \\
12.4(104) \\
\end{array}$ & $\begin{array}{l}83.9(706) \\
10.0(84) \\
6.1(51) \\
\end{array}$ & $\begin{array}{l}87.8(742) \\
8.0(68) \\
4.1(35) \\
\end{array}$ \\
\hline \multicolumn{5}{|l|}{$\begin{array}{l}\text { Plasma biomarkers of microvascular } \\
\text { dysfunction }\end{array}$} \\
\hline $\begin{array}{l}\text { Soluble ICAM-1, } \mathrm{ng} / \mathrm{ml} \\
\text { Soluble VCAM-1, ng/ml } \\
\text { Soluble E-selectin, } \mathrm{ng} / \mathrm{ml} \\
\text { Von Willebrand Factor, } \%\end{array}$ & $\begin{array}{l}352.6 \pm 96.8 \\
425.4 \pm 98.1 \\
117.1 \pm 64.8 \\
131.8 \pm 47.2\end{array}$ & $\begin{array}{l}372.4 \pm 116.3 \\
447.1 \pm 111.3 \\
130.2 \pm 79.1 \\
141.4 \pm 50.1\end{array}$ & $\begin{array}{l}349.2 \pm 85.9 \\
423.1 \pm 94.4 \\
116.9 \pm 55.2 \\
131.0 \pm 45.7\end{array}$ & $\begin{array}{l}336.4 \pm 81.1 \\
406.2 \pm 82.1 \\
104.1 \pm 54.4 \\
123.2 \pm 43.9\end{array}$ \\
\hline $\begin{array}{l}\text { Cognitive performance } \\
\text { Cognitive function composite score, SD } \\
\text { Memory, SD } \\
\text { Processing speed, SD } \\
\text { Executive function, SD }\end{array}$ & $\begin{array}{l}0.0 \pm 1.0 \\
0.0 \pm 1.0 \\
0.0 \pm 1.0 \\
0.0 \pm 1.0\end{array}$ & $\begin{array}{l}-1.1 \pm 0.6 \\
-0.9 \pm 0.8 \\
-0.9 \pm 0.8 \\
-0.9 \pm 0.8\end{array}$ & $\begin{array}{l}0.1 \pm 0.2 \\
0.0 \pm 0.7 \\
0.0 \pm 0.6 \\
0.1 \pm 0.6\end{array}$ & $\begin{array}{l}1.1 \pm 0.5 \\
0.8 \pm 0.7 \\
0.9 \pm 0.6 \\
0.8 \pm 0.7\end{array}$ \\
\hline
\end{tabular}

Data are presented as mean \pm standard deviation (SD), median [interquartile range] or $\mathrm{n}(\%)$.

*We calculated a microvascular dysfunction (MVD) composite score ("MVD composite score") of all individual MVD measures. For the total MVD composite score, the individual 11 MVD measures (i.e. four cerebral small vessel disease features, the flicker light-induced retinal arteriolar and venular dilation responses, urinary albumin excretion and the four plasma biomarkers of MVD) were standardized into z-scores. These $z$-scores were then averaged into the MVD composite score. The MVD composite score was calculated when data were available on at least one of the 11 individual MVD measures. Data available for: total brain parenchyma volume, $n=1,726$; white matter hyperintensity volume, $n=1,726$; cerebral microbleeds, $n=1,697$; lacunar infarcts, $n=1,724$; flicker light-induced arteriolar dilation, $n=1,649$; flicker light-induced venular dilation, $n=1679$; urinary albumin excretion, $n=2,522$; soluble intercellular adhesion molecule-1, $n=2,520$; soluble vascular adhesion molecule-1, $n=2,520$; soluble E-selectin, $n=2,520$; von Willebrand factor, $n=2,517$.

Abbreviations: HDL, high-density lipoprotein; ICAM-1: intracellular adhesion molecule-1; VCAM-1: vascular adhesion molecule-1.

Table 2. Associations between arterial stiffness and the cognitive function composite score

\begin{tabular}{lcc}
\hline & \multicolumn{2}{c}{ Cognitive function composite score, per SD } \\
\hline Arterial stiffness measure & Model & $\boldsymbol{\beta}(\mathbf{9 5 \%} \mathbf{C l})$ \\
\hline Carotid-femoral pulse wave velocity, $\mathrm{m} / \mathrm{s}$ & 1 & $\mathbf{- 0 . 0 3 2}(\mathbf{- 0 . 0 4 8 ; - 0 . 0 1 6 )}$ \\
\cline { 2 - 3 } & 2 & $\mathbf{- 0 . 0 1 9}(\mathbf{- 0 . 0 3 5 ; - 0 . 0 0 3 )}$ \\
\hline Carotid distensibility coefficient, $10^{-3} / \mathrm{kPa}$ & 3 & $\mathbf{- 0 . 0 1 8}(\mathbf{- 0 . 0 3 6 ; - 0 . 0 0 0 )}$ \\
\cline { 2 - 3 } & 1 & $\mathbf{- 0 . 0 0 7}(\mathbf{- 0 . 0 1 4 ; - 0 . 0 0 0 )}$ \\
\hline
\end{tabular}

Results indicate SD (95\% confidence intervals) lower cognitive function composite score per m/s higher carotidfemoral pulse wave velocity and per $10^{-3} / \mathrm{kPa}$ lower in carotid distensibility. Model 1: adjusted for age, sex, education level, Model 2: additionally adjusted for glucose metabolism status, body mass index, smoking, alcohol use, total/high density cholesterol ratio and triglycerides, and Model 3: additionally adjusted for mean arterial pressure, heart rate and use of anti-hypertensive and/or lipid-modifying medication. $\mathrm{Abbreviations:} \mathrm{Cl}=$ confidence interval; SD = standard deviation. 


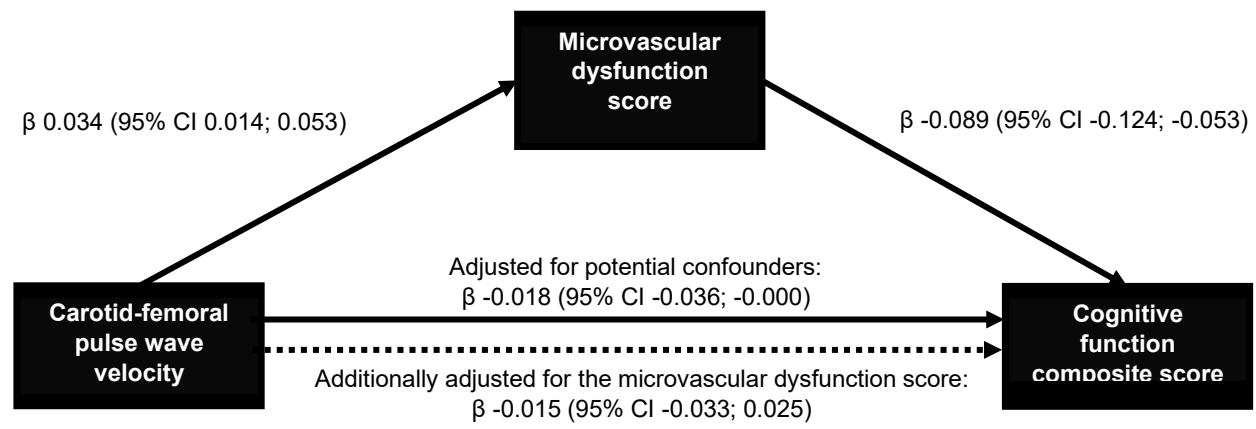

Figure 2. Association between carotid-femoral pulse wave velocity (per $\mathrm{m} / \mathrm{s})$ and the cognitive function composite score (per SD), and the proportion explained by the microvascular dysfunction score (per SD). Solid lines indicate associations that are statistically significant; dashed lines indicate associations that are not statistically significant. Associations are presented as regression coefficients $(\beta)$ and corresponding $95 \%$ confidence intervals. All associations are adjusted for potential confounders: age, sex, education level, glucose metabolism status, body mass index, smoking, alcohol use, total/high density cholesterol ratio, triglycerides, mean arterial pressure, heart rate and use of anti-hypertensive and/or lipid-modifying medication. 


\section{Supplemental Material}

\section{Item S1. Assessment of arterial stiffness}

All measurements were done by trained vascular technicians unaware of the participants' clinical or diabetes status, in a dark, quiet, temperature-controlled room $\left(21-23^{\circ} \mathrm{C}\right)$. Participants were asked to refrain from smoking and drinking coffee or tea or alcoholic beverages three hours prior to the study. Participants were allowed to have a light meal (breakfast and(or) lunch). All measurements were performed in a supine position after 10 minutes of rest. Talking or sleeping was not allowed during the examination. During the vascular measurements (approximately 45 minutes), brachial systolic, diastolic and mean arterial pressure (MAP) were determined every five minutes with an oscillometric device (Accutorr Plus, Datascope Inc., Montvale, NJ, USA). The mean MAP and heart rate (HR) of these measurements were used in the statistical analysis. A three-lead electrocardiogram was recorded continuously during the measurements to facilitate automatic signal processing.

\section{Carotid-femoral pulse wave velocity}

Carotid-femoral pulse wave velocity (cfPWV) was determined according to recent guidelines ${ }^{1}$ with the use of applanation tonometry (SphygmoCor, Atcor Medical, Sydney, Australia). Pressure waveforms were determined at the right common carotid and right common femoral arteries. Difference in the time of pulse arrival from the R-wave of the electrocardiogram between the two sites (transit time) was determined with the intersecting tangents algorithm. The pulse wave travel distance was calculated as $80 \%$ of the direct straight distance (measured with an infantometer) between the two arterial sites. The median of three consecutive cfPWV (defined as traveled distance/transit time) recordings was used in the analyses.

\section{Local arterial elastic properties}

Data acquisition. Measurements were done at the left common carotid $(10 \mathrm{~mm}$ proximal to the carotid bulb) artery, with the use of an ultrasound scanner equipped with a 7.5MHz linear probe (MyLab 70, Esaote Europe B.V., Maastricht, the Netherlands). This setup enables the measurement of diameter, distension and intima-media thickness (IMT) as described previously. ${ }^{2,3}$ Briefly, during the ultrasound measurements a B-mode image on the basis of $19 \mathrm{M}$-lines was depicted on screen and an online echo-tracking algorithm showed real-time anterior and posterior arterial wall displacements. The M-mode recordings were composed of 19 simultaneous recordings at a frame rate of $498 \mathrm{~Hz}$. The distance between the M-line recording positions was $0.96 \mathrm{~mm}$; thus, a total segment of $18.24 \mathrm{~mm}$ of each artery was covered by the scan plane. For offline processing, the radiofrequency signal was fed into a dedicated PC-based acquisition system (ART.LAB, Esaote Europe B.V. Maastricht, the Netherlands) with a sampling frequency of $50 \mathrm{MHz}$ Data processing was performed in MatLab (version 7.5, Mathworks, Natick, MA, USA). The distension waveforms were obtained from the radio frequency data with the use of a wall track algorithm. ${ }^{2}$ Carotid IMT was defined as the distance of the posterior wall from the leading edge interface between lumen and intima to the leading edge interface between 
media and adventitia. ${ }^{3}$ The median diameter, distension, and IMT of three measurements were used in the analyses.

Data analysis. Local arterial elastic properties were quantified by calculating the following indices:4

- Carotid Distensibility Coefficient (CarDC)

- $\mathrm{DC}=\left(2 \Delta \mathrm{D} * \mathrm{D}+\Delta \mathrm{D}^{2}\right) /\left(\mathrm{PP} * \mathrm{D}^{2}\right)$

- Carotid Young's elastic modulus (CarYEM)

- $\quad \mathrm{YEM}=\mathrm{D} /(\mathrm{IMT} * \mathrm{DC})$

- Carotid Compliance Coefficient (CarCC)

- $\mathrm{CC}=\pi^{*}\left(2 \mathrm{D} * \Delta \mathrm{D}+\Delta \mathrm{D}^{2}\right) / 4 \mathrm{PP}$

$\left(\mathrm{mm}^{2} \mathrm{kPa}^{-1}\right)$

Where $\mathrm{D}$ is arterial diameter; $\Delta \mathrm{D}$ distension; IMT intima-media thickness; and PP brachial pulse pressure (calculated as systolic minus diastolic blood pressure).

CarDC represents arterial stiffness; CarYEM, the stiffness of the arterial wall material at operating pressure; and CarCC, arterial buffering capacity.

\section{Reproducibility}

Reproducibility was assessed in 12 individuals ( 6 men; $60.8 \pm 6.8$ years; 6 type 2 diabetes) who were examined by two observers at two occasions spaced one week apart. The intraand inter-observer intra-class correlation coefficients were for cfPWV 0.87 and 0.69; for carDC 0.85 and 0.73; for CarYEM 0.72 and 0.71; for CarCC 0.95 and 0.72. 


\section{Item S2. Brain magnetic resonance imaging measures}

Brain magnetic resonance imaging (MRI) was performed on a 3T MRI scanner (Siemens Magnetom Prisma-fit Syngo MR D13D, Erlangen, Germany) by use of a 64-element head/neck coil for parallel imaging. The MRI protocol consisted of a 3D $\mathrm{T}_{1}$-weighted magnetization prepared rapid acquisition gradient echo (MPRAGE) sequence (TR/TI/ TE 2300/900/2.98 ms, 176 slices, $256 \times 240$ matrix size, $1.00 \mathrm{~mm}$ cubic voxel size); a fluidattenuated inversion recovery (FLAIR) sequence (TR/TI/TE 5000/1800/394 ms, 176 slices, $512 \times 512$ matrix size, $0.49 \times 0.49 \times 1.00 \mathrm{~mm}$ voxel size); a combined proton density (PD) and $\mathrm{T}_{2}$-weighted turbo spin echo (TSE) pulse sequence (TR/TE1/TE2 3200/9.4/94 ms, 30 slices, $640 \times 540$ matrix size, $0.36 \times 0.36 \times 4.00 \mathrm{~mm}$ voxel size); and a susceptibility-weighted imaging (SWI) sequence (TR/TE $28 / 20 \mathrm{~ms}, 144$ slices, $384 \times 312$ matrix size, $0.57 \times 0.57 \times 1.00$ $\mathrm{mm}$ voxel size).

Contra-indications for MRI assessments were the presence of a cardiac pacemaker or implantable cardioverter-defibrillator, neurostimulator, non-detachable insulin pump, metallic vascular clips or stents in the head, cochlear implant, metal-containing intrauterine device, metal splinters or shrapnel, dentures with magnetic clip, an inside bracket, pregnancy, epilepsy, and claustrophobia.

$\mathrm{T}_{1}$-weighted images and FLAIR images were analyzed by use of an ISO-13485:2012 certified, automated method (which included visual inspection). ${ }^{5,6} \mathrm{~T}_{1}$-weighted images were segmented into grey matter, white matter and cerebrospinal fluid volumes ( 1 voxel $\left.=1.00 \mathrm{~mm}^{3}=0.001 \mathrm{ml}\right) .{ }^{5}$ Intracranial volume was calculated as the sum of grey matter, white matter (including white matter hyperintensity volume) and cerebrospinal fluid volumes. Total brain parenchyma volume was calculated as the sum of grey and white matter volumes. White matter hyperintensities identified were summed to assess total white matter hyperintensities burden in milliliter. Lacunar infarcts were defined as focal brain parenchyma defects of $\geq 3 \mathrm{~mm}$ and $<15 \mathrm{~mm}$ in size with a similar signal intensity as cerebrospinal fluid on all sequences and a hyperintense rim on $T_{2}$ and FLAIR images ${ }^{7}$. Cerebral microbleeds were rated on $\mathrm{T}_{2}$-weighted and SWI images by use of the Microbleed Anatomical Rating Scale ${ }^{8}$, and were defined as focal lesions of $\geq 2 \mathrm{~mm}$ and $\leq 10 \mathrm{~mm}$ in size with a hypointense signal ${ }^{7}$. The presence of lacunar infarcts and cerebral microbleeds was rated manually by three neuroradiologists. The two-way mixed effects, consistency, intraclass correlation coefficient for the three raters based on 50 randomly selected scans was $0.84(95 \%$ confidence interval $0.74 ; 0.91)$ and $0.83(0.72 ; 0.90)$ for the presence of lacunar infarcts and cerebral microbleeds, respectively. 


\section{Item S3. Assessment of cognitive performance}

The composite memory score was derived from the Verbal Learning Test by weighting total immediate and delayed recall scores. The domain information processing speed included the Stroop Color-Word Test Part I and II, the Concept Shifting Test Part A and $B$, and the Letter-Digit Substitution Test. Executive function was assessed by the Stroop Color-Word Test Part III and the Concept Shifting Test Part C. A description of the individual tests is provided below.

Raw test scores were transformed into z-scores. Standardized scores of the Stroop ColorWord Test and Concept Shifting Test were inverted so that higher scores indicated better cognitive function. Thereafter, domain-specific scores were calculated as the standardized average of the z-scores from (sub)tests within that domain (e.g. memory $=z$-score of ( $z$-score immediate recall $+z$-score delayed recall/ 2$)$ ). The standardized average of these domain scores was then considered a measure of overall cognitive function (i.e. overall cognitive function $=z$-score of (memory + information processing speed + executive function / 3)).

\section{Description of the individual cognitive tests used in the present study Verbal Learning Test: ${ }^{9}$}

Fifteen unrelated, monosyllabic, words were presented on a computer screen in five subsequent trials. After each trial, participants were instructed to recall as many words as possible in any order. Twenty minutes after the last trial, participants were asked again to reproduce the words. Outcomes recorded included the total number of words correctly recalled over the five trials (total immediate recall) and the number of correctly recalled words during delayed recall (delayed recall).

\section{Stroop Color-Word Test: ${ }^{10}$}

In this test, which consisted of three parts, participants were firstly asked to read aloud color names (i.e. red, blue, yellow, and green) that were printed in black ink (Part I). Secondly, they were instructed to name solid color patches (Part II). Finally, participants had to name the ink color of color names that were printed in an incongruent color (e.g. participants were asked to say red when the word yellow was printed in red) (Part III). The time needed to complete Part III was adjusted for the average time needed to complete Part I and II.

\section{Concept Shifting Test: ${ }^{11}$}

This test, a modification of the Trailing Making Test, consisted of four subtasks. During each subtask, participants were shown 16 small circles aligned along a larger imaginary circle. The small circles contained (a combination of) digits, letters, or were empty. Participants were instructed to cross-out as quickly as possible the digits in ascending order (Part A), the letters in alphabetic order (Part B), and the letters and digits in alternating order (Part C). Thereafter, participants were asked to cross-out empty circles in a clockwise fashion in two consecutive trials (Part 0 ). In this way, test results could be accounted for basic motor speed. The time needed to complete subtasks A and B was adjusted for the average time 
needed to complete Part 0 , the time needed to completed Part $C$ for the average time of Part A and B.

\section{Letter-Digit Substitution Test: ${ }^{12}$}

Participants were requested to match digits to letters according to a given key. This key included the numbers 1 to 9 , each paired with a different letter. The outcome of interest was the number of correct substitutions within 90 seconds. 


\section{References}

1. Van Bortel LM, Laurent S, Boutouyrie P, Chowienczyk P, Cruickshank JK, De Backer T, Filipovsky J, Huybrechts S, Mattace-Raso FU, Protogerou AD, Schillaci G, Segers P, Vermeersch S, Weber T, Artery S, European Society of Hypertension Working Group on Vascular S, Function and European Network for Noninvasive Investigation of Large A. Expert consensus document on the measurement of aortic stiffness in daily practice using carotid-femoral pulse wave velocity. J Hypertens. 2012;30:445-8.

2. Hermeling E, Reesink KD, Kornmann LM, Reneman RS and Hoeks AP. The dicrotic notch as alternative time-reference point to measure local pulse wave velocity in the carotid artery by means of ultrasonography. J Hypertens. 2009;27:2028-35.

3. Willekes C, Hoeks AP, Bots ML, Brands PJ, Willigers JM and Reneman RS. Evaluation of off-line automated intima-media thickness detection of the common carotid artery based on M-line signal processing. Ultrasound in medicine \& biology. 1999;25:57-64.

4. Reneman RS, Meinders JM and Hoeks AP. Non-invasive ultrasound in arterial wall dynamics in humans: what have we learned and what remains to be solved. European heart journal. 2005;26:960-6.

5. Vrooman HA, Cocosco CA, van der Lijn F, Stokking R, Ikram MA, Vernooij MW, Breteler MM and Niessen WJ. Multi-spectral brain tissue segmentation using automatically trained k-NearestNeighbor classification. Neurolmage. 2007;37:71-81.

6. de Boer R, Vrooman HA, van der Lijn F, Vernooij MW, Ikram MA, van der Lugt A, Breteler MM and Niessen WJ. White matter lesion extension to automatic brain tissue segmentation on MRI. Neurolmage. 2009;45:1151-61.

7. Wardlaw JM, Smith EE, Biessels GJ, Cordonnier C, Fazekas F, Frayne R, Lindley RI, O'Brien JT, Barkhof F, Benavente OR, Black SE, Brayne C, Breteler M, Chabriat H, Decarli C, de Leeuw FE, Doubal F, Duering M, Fox NC, Greenberg S, Hachinski V, Kilimann I, Mok V, Oostenbrugge R, Pantoni L, Speck O, Stephan BC, Teipel S, Viswanathan A, Werring D, Chen C, Smith C, van Buchem $M$, Norrving $B$, Gorelick PB, Dichgans $M$ and nEuroimaging STfRVco. Neuroimaging standards for research into small vessel disease and its contribution to ageing and neurodegeneration. Lancet Neurol. 2013;12:822-38.

8. Gregoire SM, Chaudhary UJ, Brown MM, Yousry TA, Kallis C, Jager HR and Werring DJ. The Microbleed Anatomical Rating Scale (MARS): reliability of a tool to map brain microbleeds. Neurology. 2009;73:1759-66.

9. Van der Elst W, van Boxtel MP, van Breukelen GJ and Jolles J. Rey's verbal learning test: normative data for 1855 healthy participants aged 24-81 years and the influence of age, sex, education, and mode of presentation. J Int Neuropsychol Soc. 2005;11:290-302.

10. Van der Elst W, Van Boxtel MP, Van Breukelen GJ and Jolles J. The Stroop color-word test: influence of age, sex, and education; and normative data for a large sample across the adult age range. Assessment. 2006;13:62-79.

11. Van der Elst W, Van Boxtel MP, Van Breukelen GJ and Jolles J. The Concept Shifting Test: adult normative data. Psychol Assess. 2006;18:424-32.

12. van der Elst W, van Boxtel MP, van Breukelen GJ and Jolles J. The Letter Digit Substitution Test: normative data for 1,858 healthy participants aged 24-81 from the Maastricht Aging Study (MAAS): influence of age, education, and sex. J Clin Exp Neuropsychol. 2006;28:998-1009. 
Table S1. Characteristics of the study population and individuals excluded from the analyses due to missing values

\begin{tabular}{|c|c|c|}
\hline & $\begin{array}{l}\text { Complete } \\
(\mathrm{N}=2,544)\end{array}$ & $\begin{array}{l}\text { Missing } \\
(n=907)\end{array}$ \\
\hline \multicolumn{3}{|l|}{ Demographics } \\
\hline Age, years & $59.7 \pm 8.1$ & $59.9 \pm 8.7$ \\
\hline Men & $51.0(1,297)$ & $52.7(478)$ \\
\hline $\begin{array}{l}\text { Education level } \\
\text { Low } \\
\text { Intermediate } \\
\text { High }\end{array}$ & $\begin{array}{c}15.4(393) \\
43.1(1,096) \\
41.5(1,055)\end{array}$ & $\begin{array}{l}22.0(175)^{*} \\
42.5(338)^{*} \\
35.5(282)^{*}\end{array}$ \\
\hline \multicolumn{3}{|l|}{ Cardiovascular risk factors } \\
\hline $\begin{array}{l}\text { Glucose metabolism status } \\
\text { Normal glucose metabolism } \\
\text { Prediabetes } \\
\text { Type } 2 \text { diabetes }\end{array}$ & $\begin{array}{c}58.8(1,496) \\
15.2(387) \\
26.0(661) \\
\end{array}$ & $\begin{array}{l}49.4(428)^{*} \\
14.3(124)^{*} \\
36.3(314)^{*}\end{array}$ \\
\hline Body mass index, $\mathrm{kg} / \mathrm{m}^{2}$ & $26.9 \pm 4.4$ & $27.5 \pm 5.1^{*}$ \\
\hline $\begin{array}{l}\text { Smoking status: } \\
\text { Never } \\
\text { Former } \\
\text { Current }\end{array}$ & $\begin{array}{c}33.8(860) \\
52.8(1,342) \\
13.4(342) \\
\end{array}$ & $\begin{array}{l}36.7(310) \\
48.2(407) \\
15.0(127) \\
\end{array}$ \\
\hline $\begin{array}{l}\text { Alcohol consumption } \\
\text { None } \\
\text { Low, women } \leq 7 \text {; men } \leq 14 \text { units/week } \\
\text { High, women }>7 \text {; men }>14 \text { units/week }\end{array}$ & $\begin{array}{c}17.7(451) \\
55.4(1,409) \\
26.9(684)\end{array}$ & $\begin{array}{l}21.2(178)^{*} \\
55.6(466)^{*} \\
23.2(194)^{*}\end{array}$ \\
\hline Total/high-density lipoprotein cholesterol ratio & $3.7 \pm 1.2$ & $3.5 \pm 1.1^{*}$ \\
\hline Triglycerides, $\mathrm{mmol} / \mathrm{L}$ & $1.4 \pm 0.9$ & $1.5 \pm 0.8$ \\
\hline Office systolic pressure, $\mathrm{mmHg}$ & $134.9 \pm 18.2$ & $135.6 \pm 18.3$ \\
\hline Office diastolic pressure, $\mathrm{mmHg}$ & $76.2 \pm 9.9$ & $75.8 \pm 9.6$ \\
\hline Heart rate during vascular measurement, bpm & $62.5 \pm 9.3$ & $64.1 \pm 9.9^{*}$ \\
\hline Use of antihypertensive medication & 37.7 (959) & $46.4(419)^{*}$ \\
\hline Use of lipid-modifying medication & $35.1(893)$ & $40.4(365)^{*}$ \\
\hline Prior cardiovascular disease & $16.2(405)$ & $18.3(153)$ \\
\hline Current depression & $3.5(88)$ & $34(4.4)$ \\
\hline Composite score of plasma biomarkers of low-grade inflammation, SD & $0.0 \pm 1.0$ & $0.0 \pm 0.6$ \\
\hline \multicolumn{3}{|l|}{ Measures of arterial stiffness } \\
\hline $\begin{array}{l}\text { Carotid-femoral pulse wave velocity, } \mathrm{m} / \mathrm{s} \\
\text { Carotid artery - distensibility coefficient, } 10^{-3} \mathrm{kPa} \\
\text { Carotid artery - compliance coefficient, } \mathrm{mm}^{2} / \mathrm{kPa} \\
\text { Carotid artery - Young's elastic modulus, } 10^{3} \mathrm{kPa} \\
\end{array}$ & $\begin{array}{c}9.0 \pm 2.1 \\
14.3 \pm 5.1 \\
0.7 \pm 0.7 \\
0.7 \pm 0.4\end{array}$ & $\begin{array}{l}9.5 \pm 2.4^{*} \\
14.1 \pm 5.4 \\
0.7 \pm 0.3 \\
0.8 \pm 0.4\end{array}$ \\
\hline \multicolumn{3}{|l|}{ Measures of microvascular dysfunction } \\
\hline Microvascular dysfunction composite score & $0.0 \pm 1.0$ & - \\
\hline \multicolumn{3}{|l|}{ Cerebral small vessel disease features } \\
\hline $\begin{array}{l}\text { Total brain parenchyma volume, } \mathrm{ml} \\
\text { White matter hyperintensity volume, } \mathrm{ml} \\
\text { Presence of cerebral microbleeds } \\
\text { Presence of lacunar infarcts }\end{array}$ & $\begin{array}{l}1,136.1 \pm 111.4 \\
0.23[0.07-0.75] \\
12.0(203) \\
5.3(91)\end{array}$ & $\begin{array}{c}1,131.5 \pm 113.7^{*} \\
0.22[0.07-0.74] \\
68(12.1) \\
5.7(33)\end{array}$ \\
\hline \multicolumn{3}{|l|}{ Flicker light-induced arteriolar and venular dilation } \\
\hline $\begin{array}{l}\text { Flicker light-induced arteriolar dilation, } \% \\
\text { Flicker light-induced venular dilation, } \%\end{array}$ & $\begin{array}{l}3.1 \pm 2.8 \\
3.9 \pm 2.2\end{array}$ & $\begin{array}{l}2.9 \pm 2.7 \\
3.8 \pm 2.3\end{array}$ \\
\hline
\end{tabular}




\begin{tabular}{lcc}
\hline & $\begin{array}{c}\text { Complete } \\
(\mathbf{N}=\mathbf{2 , 5 4 4 )}\end{array}$ & $\begin{array}{c}\text { Missing } \\
(\mathbf{n = 9 0 7 )}\end{array}$ \\
\hline Urinary albumin excretion & & $77.5(687)^{*}$ \\
$0-15 \mathrm{mg} / 24 \mathrm{~h}$ & $81.9(2,066)$ & $10.3(91)^{*}$ \\
$15-30 \mathrm{mg} / 24 \mathrm{~h}$ & $10.5(266)$ & $12.3(109)^{*}$ \\
$\geq 30 \mathrm{mg} / 24 \mathrm{~h}$ & $7.5(190)$ & \\
\hline Plasma biomarkers of microvascular dysfunction & & $361.6 \pm 107.6^{*}$ \\
\hline Soluble ICAM-1, $\mathrm{ng} / \mathrm{ml}$ & $352.6 \pm 96.8$ & $437.4 \pm 110.8^{*}$ \\
Soluble VCAM-1, $\mathrm{ng} / \mathrm{ml}$ & $425.4 \pm 98.1$ & $122.6 \pm 66.1^{*}$ \\
Soluble E-selectin, $\mathrm{ng} / \mathrm{ml}$ & $117.1 \pm 64.8$ & $135.9 \pm 51.9^{*}$ \\
von Willebrand Factor, \% & $131.8 \pm 47.2$ & - \\
\hline Cognitive performance & & - \\
Cognitive function composite score, SD & $0.0 \pm 1.0$ & - \\
Memory function, SD & $0.0 \pm 1.0$ & - \\
Processing speed, SD & $0.0 \pm 1.0$ & - \\
Executive function, SD & $0.0 \pm 1.0$ & - \\
\hline
\end{tabular}

Data are presented as mean \pm standard deviation, median [interquartile range] or $\mathrm{n}(\%) .{ }^{*}$ denotes a statistically significantly difference from the complete group, assessed by the student's t-test for normally distributed variables, Mann-Whitney U-test for skewed variables or Chi-square test for categorical variables.

Table S2. Associations between carotid artery compliance coefficient and Young's elastic modulus and the cognitive function composite score

\begin{tabular}{lcrl}
\hline & \multicolumn{2}{c}{ Cognitive function composite score, per SD } \\
\hline Carotid stiffness measure & Model & \multicolumn{2}{c}{$\boldsymbol{\beta}(\mathbf{9 5 \%} \mathbf{C l})$} \\
\hline Compliance coefficient, $10^{-3} / \mathrm{kPa}$ & 1 & $-0.086(-0.209 ; 0.037)$ \\
\cline { 2 - 4 } & 2 & $-0.075(-0.197 ; 0.046)$ \\
\hline Young's elastic modulus, 103/kPa & 3 & $-0.062(-0.189 ; 0.066)$ \\
\hline
\end{tabular}

Participants included in the analyses were $n=2,544$. Model 1: adjusted for age, sex, education level, Model 2: additionally adjusted for glucose metabolism status, body mass index, smoking, alcohol use, total/high-density lipoprotein ratio, triglycerides, and Model 3: additionally adjusted for mean arterial pressure, heart rate and use of anti-hypertensive and/or lipid-modifying medication. Abbreviations: $\mathrm{Cl}=$ confidence interval; $\mathrm{SD}=\mathrm{standard}$ deviation.

Table S3. Associations between arterial stiffness and domain-specific cognitive function scores

\begin{tabular}{|c|c|c|c|c|c|c|c|}
\hline & & \multicolumn{2}{|c|}{$\begin{array}{l}\text { Memory function, } \\
\text { per SD }\end{array}$} & \multicolumn{2}{|c|}{$\begin{array}{l}\text { Processing speed, per } \\
\text { SD }\end{array}$} & \multicolumn{2}{|c|}{$\begin{array}{l}\text { Executive function, per } \\
\text { SD }\end{array}$} \\
\hline Arterial stiffness & Model & \multicolumn{2}{|c|}{$\beta(95 \% \mathrm{Cl})$} & \multicolumn{2}{|r|}{$\beta(95 \% \mathrm{Cl})$} & \multicolumn{2}{|r|}{$\beta(95 \% \mathrm{Cl})$} \\
\hline \multirow{3}{*}{$\begin{array}{l}\text { Carotid-femoral } \\
\text { pulse wave } \\
\text { velocity, } \mathrm{m} / \mathrm{s}^{-1}\end{array}$} & 1 & -0.022 & $(-0.04 ;-0.004)$ & -0.024 & $(-0.041 ;-0.007)$ & -0.030 & $(-0.048 ;-0.012)$ \\
\hline & 2 & -0.016 & $(-0.034 ; 0.002)$ & -0.013 & $(-0.030 ; 0.004)$ & -0.017 & $(-0.035 ; 0.001)$ \\
\hline & 3 & -0.013 & $(-0.033 ; 0.007)$ & -0.019 & $(-0.038 ; 0.000)$ & -0.012 & $(-0.032 ; 0.008)$ \\
\hline \multirow{3}{*}{$\begin{array}{l}\text { Carotid } \\
\text { distensibility } \\
\text { coefficient, } 10^{-3} \text { / } \\
\mathrm{kPa}\end{array}$} & 1 & -0.001 & $(-0.008 ; 0.007)$ & -0.006 & $(-0.013 ; 0.001)$ & -0.010 & $(-0.018 ;-0.003)$ \\
\hline & 2 & 0.000 & $(-0.007 ; 0.008)$ & -0.004 & $(-0.011 ; 0.003)$ & -0.008 & $(-0.016 ;-0.001)$ \\
\hline & 3 & 0.003 & $(-0.005 ; 0.012)$ & -0.007 & $(-0.015 ; 0.001)$ & -0.007 & $(-0.015 ; 0.002)$ \\
\hline
\end{tabular}

Participants included in the analyses were $n=2,544$. Model 1: adjusted for age, sex, education level, Model 2: additionally adjusted for glucose metabolism status, body mass index, smoking, alcohol use, total/high-density lipoprotein ratio, triglycerides, and Model 3: additionally adjusted for mean arterial pressure, heart rate and use of anti-hypertensive and/or lipid-modifying medication. Abbreviations: $\mathrm{Cl}=$ confidence interval; $\mathrm{SD}=\mathrm{standard}$ deviation. 
Table S4. Associations between arterial stiffness and the cognitive function composite score, and the proportion explained by the microvascular dysfunction score after consecutively excluding from the microvascular dysfunction score each individual measure of microvascular dysfunction

\begin{tabular}{|c|c|c|c|}
\hline & & $\begin{array}{l}\text { Cognitive function } \\
\text { composite score, per } \\
\text { SD } \\
\end{array}$ & $\begin{array}{l}\text { \% effect explained } \\
\text { by microvascular } \\
\text { dysfunction* }\end{array}$ \\
\hline $\begin{array}{l}\text { Arterial stiffness } \\
\text { measure }\end{array}$ & $\begin{array}{l}\text { Variable excluded from the } \\
\text { microvascular dysfunction score }\end{array}$ & $\beta(95 \% \mathrm{Cl})$ & \\
\hline \multirow[t]{4}{*}{$\begin{array}{l}\text { Carotid-femoral pulse } \\
\text { wave velocity, } \mathrm{m} / \mathrm{s}\end{array}$} & $\begin{array}{l}\text { Cerebral small vessel disease } \\
\text { features }\end{array}$ & $-0.018 \quad(-0.036 ;-0.000)$ & $10.8 \%$ \\
\hline & $\begin{array}{l}\text { Flicker light-induced retinal } \\
\text { arteriolar and venular dilation } \\
\text { response }\end{array}$ & $-0.018 \quad(-0.036 ;-0.000)$ & $14.1 \%$ \\
\hline & Urinary albumin excretion & $(-0.036 ;-0.000)$ & $11.5 \%$ \\
\hline & $\begin{array}{l}\text { Plasma biomarkers of } \\
\text { microvascular disease }\end{array}$ & $-0.018 \quad(-0.036 ;-0.000)$ & $9.4 \%$ \\
\hline \multirow[t]{4}{*}{$\begin{array}{l}\text { Carotid distensibility } \\
\text { coefficient, } 10^{-3} / \mathrm{kPa}\end{array}$} & $\begin{array}{l}\text { Cerebral small vessel disease } \\
\text { features }\end{array}$ & $-0.004 \quad(-0.012 ; 0.003)$ & - \\
\hline & $\begin{array}{l}\text { Flicker light-induced retinal } \\
\text { arteriolar and venular dilation } \\
\text { response }\end{array}$ & $-0.004 \quad(-0.012 ; 0.003)$ & - \\
\hline & Urinary albumin excretion & $-0.004 \quad(-0.012 ; 0.003)$ & - \\
\hline & $\begin{array}{l}\text { Plasma biomarkers of } \\
\text { microvascular disease }\end{array}$ & $-0.004 \quad(-0.012 ; 0.003)$ & - \\
\hline
\end{tabular}

*The effect explained by the 'total' microvascular dysfunction score was $16.2 \%$ of the total direct effect of cfPWV on the cognitive function composite score. †Data available for analyses after excluding cerebral small vessel disease features $n=2,544$; after excluding flicker light-induced retinal arteriolar and venular dilation response $n=2,544$; after excluding urinary albumin excretion $n=2,541$; and after excluding plasma biomarkers of microvascular dysfunction $n=2,541$. Results were adjusted for age, sex, education level, glucose metabolism status, body mass index, smoking, alcohol use, total/high density cholesterol ratio, triglycerides, mean arterial pressure, heart rate and use of antihypertensive and/or lipid-modifying medication. Abbreviations: $\mathrm{Cl}=$ confidence interval; $\mathrm{SD}=$ standard deviation .

Table S5. Associations between arterial stiffness and the cognitive function composite score additionally adjusted for prior cardiovascular disease, current depression, and plasma biomarkers of low-grade inflammation

\begin{tabular}{|c|c|c|}
\hline \multirow[b]{2}{*}{ Arterial stiffness } & \multicolumn{2}{|r|}{ Cognitive function composite score, per SD } \\
\hline & Model & $\beta(95 \% \mathrm{Cl})$ \\
\hline \multirow[t]{6}{*}{ Carotid-femoral pulse wave velocity, per m/s } & 1 & $-0.032 \quad(-0.048 ;-0.016)$ \\
\hline & 2 & $(-0.035 ;-0.003)$ \\
\hline & 3 & $(-0.036 ;-0.000)$ \\
\hline & $4 a$ & $(-0.037 ;-0.001)$ \\
\hline & $4 b$ & $-0.016 \quad(-0.034 ; 0.002)$ \\
\hline & $4 c$ & $(-0.037 ;-0.001)$ \\
\hline \multirow[t]{6}{*}{ Carotid artery distensibility coefficient, $10^{-3} / \mathrm{kPa}$} & 1 & $(-0.014 ;-0.000)$ \\
\hline & 2 & $-0.005 \quad(-0.012 ; 0.002)$ \\
\hline & 3 & $-0.004 \quad(-0.012 ; 0.003)$ \\
\hline & $4 a$ & $-0.004 \quad(-0.011 ; 0.004)$ \\
\hline & $4 b$ & $-0.004 \quad(-0.011 ; 0.004)$ \\
\hline & $4 c$ & $-0.005 \quad(-0.012 ; 0.003)$ \\
\hline
\end{tabular}

Participants included in the analyses in model 1 to 3 were $n=2,544$. For analysis adjusted for prior cardiovascular disease, $n=2,505$; for analysis adjusted for current depression $n=2,526$; and for analysis adjusted for plasma biomarkers of low-grade inflammation $n=2520$. Model 1: adjusted for age, sex, education level, Model 2: additionally adjusted for glucose metabolism status, body mass index, smoking, alcohol use, total/high-density lipoprotein ratio, triglycerides, Model 3: additionally adjusted for mean arterial pressure, heart rate and use of anti-hypertensive and/or lipid-modifying medication, Model 4a: Model 3 + prior cardiovascular disease, Model 4b: Model 3 + current depression, and Model 4c: Model 3 + plasma biomarkers of low-grade inflammation. Abbreviations: $\mathrm{Cl}=$ confidence interval; $\mathrm{SD}=$ standard deviation. 
Table S6. Associations between arterial stiffness and the cognitive function composite score additionally adjusted for type of antihypertensive medication

\begin{tabular}{lccc}
\hline & \multicolumn{3}{c}{ Cognitive function composite score, per SD } \\
\hline Arterial stiffness & Model & \multicolumn{2}{c}{$\boldsymbol{\beta}(\mathbf{9 5 \%} \mathbf{C l})$} \\
\hline Carotid-femoral pulse wave velocity, per $\mathrm{m} / \mathrm{s}$ & 1 & $-0.032(-0.048 ;-0.016)$ \\
\cline { 2 - 4 } & 2 & $-0.019(-0.035 ;-0.003)$ \\
\cline { 2 - 4 } & 3 & $-0.018(-0.036 ; 0.000)$ \\
\hline Carotid artery distensibility coefficient, $10^{-3} / \mathrm{kPa}$ & 1 & $-0.007(-0.014 ;-0.000)$ \\
\cline { 2 - 4 } & 2 & $-0.005(-0.012 ; 0.002)$ \\
\hline
\end{tabular}

Participants included in the analyses were $n=2,544$. Model 1: adjusted for age, sex, education level, Model 2: additionally adjusted for glucose metabolism status, body mass index, smoking, alcohol use, total/high-density lipoprotein ratio, triglycerides, Model 3: additionally adjusted for mean arterial pressure, heart rate, use of lipidmodifying medication and the individual classes of antihypertensive medication (i.e. beta blockers, diuretics, calcium channel blockers, angiotensin-converting enzyme inhibitors and angiotensin II receptor blockers). Abbreviations: $\mathrm{Cl}=$ confidence interval; $\mathrm{SD}=$ standard deviation.

Table S7. Associations between arterial stiffness and the cognitive function composite score additionally adjusted for the diet score, moderate-to-vigorous physical activity, income level and occupational status

\begin{tabular}{lccc}
\hline & \multicolumn{2}{c}{ Cognitive function composite score, per SD } \\
\hline Arterial stiffness & Model & \multicolumn{3}{c}{$\mathbf{( 9 5 \% ~ C l )}$} \\
\hline Carotid-femoral pulse wave velocity, per $\mathrm{m} / \mathrm{s}$ & 1 & $-0.036(-0.055 ;-0.016)$ \\
\cline { 2 - 4 } & 2 & $-0.024(-0.043 ;-0.004)$ \\
\hline & 3 & $-0.028(-0.050 ;-0.007)$ \\
\hline Carotid artery distensibility coefficient, 10-3/kPa & 4 & $-0.029(-0.051 ;-0.007)$ \\
\cline { 2 - 4 } & 2 & $-0.003(-0.011 ; 0.005)$ \\
\cline { 2 - 4 } & 3 & $-0.000(-0.008 ; 0.008)$ \\
\hline
\end{tabular}

Participants included in the analyses were $n=1,752$. Model 1: adjusted for age, sex, education level, Model 2: additionally adjusted for glucose metabolism status, body mass index, smoking, alcohol use, total/high-density lipoprotein ratio, triglycerides, Model 3: additionally adjusted for mean arterial pressure, heart rate and use of anti-hypertensive and/or lipid-modifying medication, and Model 4: additionally adjusted for the diet score, moderate-to-vigorous physical activity and income level and occupational status. Abbreviations: $\mathrm{Cl}=\mathrm{confidence}$ interval; SD = standard deviation. 


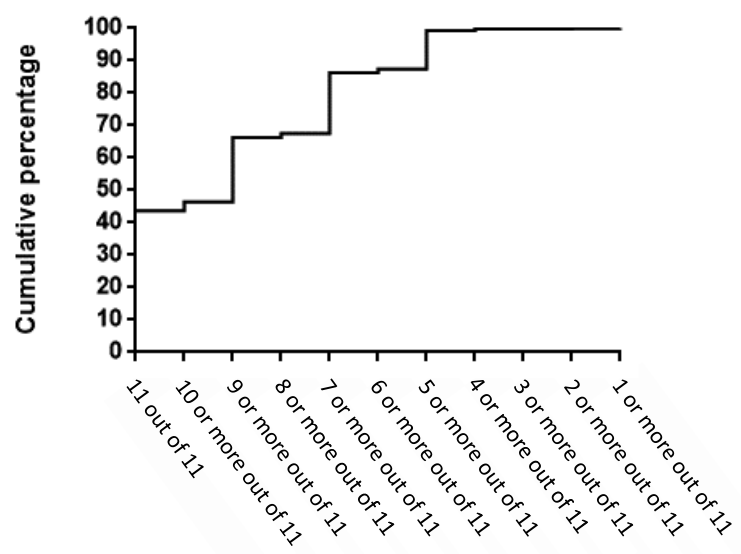

Figure S1. Cumulative percentage of participants with data available on microvascular dysfunction measures

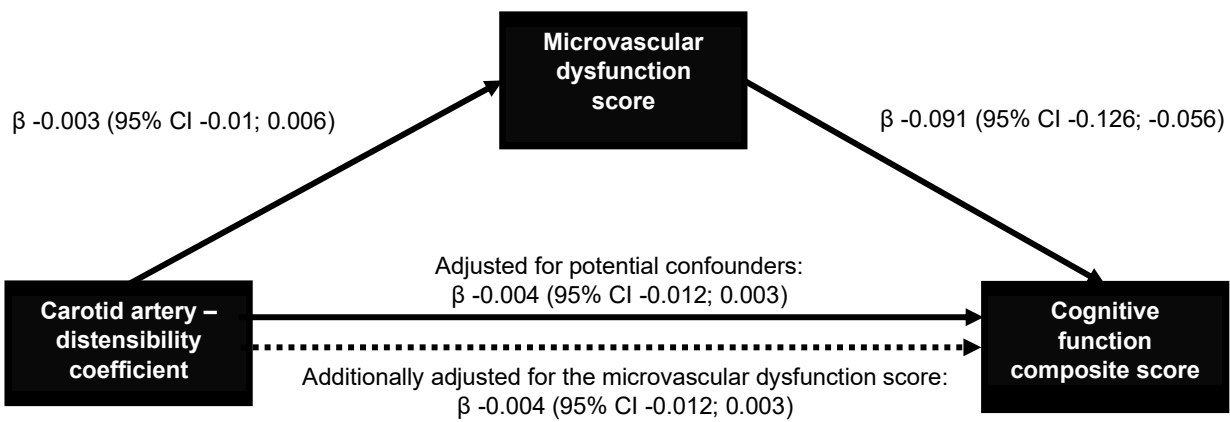

Figure S2. Association between lower carotid artery distensibility coefficient (per $10^{-3} / \mathrm{kPa}$ ) and a lower cognitive function composite score (per SD), and the proportion explained by the microvascular dysfunction score (per SD). Solid lines indicate associations that are statistically significant; dashed lines indicate associations that are not statistically significant. Associations are presented as regression coefficients $(\beta)$ and corresponding $95 \%$ confidence intervals. All associations are adjusted for the potential confounders age, sex, education level, glucose metabolism status, body mass index, smoking, alcohol use, total/high-density lipoprotein ratio, triglycerides, mean arterial pressure, heart rate and use of anti-hypertensive and/or lipid-modifying medication. 
CHAPTER 6 


\section{Blood Pressure Variability And Microvascular Dysfunction: The Maastricht Study}

Tan Lai Zhou*, Sytze P. Rensma*, Frank C.T. van der Heide*, Ronald M.A. Henry, Abraham A. Kroon, Alfons J.H.M. Houben, Jacobus F.A. Jansen, Walter H. Backes, Tos T.J.M. Berendschot, Jan S.A.G. Schouten, Martien C.J.M van Dongen, Simone J.P.M. Eussen, Pieter C. Dagnelie, Carroll A.B. Webers, Miranda T. Schram, Casper G. Schalkwijk, Thomas T. van Sloten, Coen D.A. Stehouwer

*These authors contributed equally to the manuscript 


\begin{abstract}
Microvascular dysfunction (MVD) contributes to stroke, dementia, depression, retinopathy and chronic kidney disease. The determinants of MVD, however, are incompletely identified. Greater blood pressure variability (BPV) may be such a determinant. To investigate whether greater very short- to mid-term BPV is associated with various MVD measures, we used cross-sectional data of The Maastricht Study ( $n=2,773$, age 59.9 years; 51.9\% men; 28.2\% type 2 diabetes mellitus [oversampled by design]). We standardized and averaged within-visit, 24-hour and 7-day BPV into a systolic and a diastolic BPV composite score. Measures of MVD included a composite score of MRI cerebral small vessel disease (CSVD) features (total brain parenchymal volume, white matter hyperintensity volume, lacunar infarcts and cerebral microbleeds), a composite score of retinal arteriolar and venular dilation response, albuminuria, skin hyperaemia and a composite score of plasma biomarkers of MVD (sICAM-1, sVCAM-1, sE-selectin and von Willebrand Factor). We used linear regression analyses with adjustments for age, sex, glucose metabolism status, mean 24-hour systolic or diastolic blood pressure and cardiovascular risk factors. We found that higher systolic and diastolic BPV composite scores (per SD) were associated with higher albuminuria (higher ratio in albuminuria, $1.04[95 \% \mathrm{Cl} 1.00-1.08]$ and 1.07 [1.03-1.11], respectively), but not with other MVD measures. In conclusion, greater systolic and diastolic BPV was associated with higher albuminuria, but not with CSVD features, retinal arteriolar and venular dilation response, skin hyperaemia and plasma biomarkers of MVD. This may suggest that the microvasculature of the kidneys is most vulnerable to the detrimental effects of greater BPV.
\end{abstract}




\section{Introduction}

Microvascular dysfunction (MVD) is an important contributor to various diseases that are (in part) of microvascular origin, including stroke, ${ }^{1}$ dementia, ${ }^{1}$ depression, ${ }^{1}$ retinopathy, ${ }^{2}$ and chronic kidney disease. ${ }^{3}$ However, the determinants of MVD are incompletely identified, but greater blood pressure variability (BPV), i.e. greater fluctuations of blood pressure over time, may be involved.

Greater BPV may lead to MVD both via increases in pulsatile pressure that can penetrate distally and damage the microcirculation, ${ }^{4}$ and sudden falls in blood pressure leading to reduced microvascular perfusion. ${ }^{5}$ The microvascular beds of organs with low vascular impedance (i.e. the microvasculature of the brain, eyes and kidneys) may be particularly vulnerable for these fluctuations in blood pressure. ${ }^{4}$

Microvascular function can be measured noninvasively in various organs. These measures include magnetic resonance imaging (MRI) features of cerebral small vessel disease (CSVD, i.e. lower total brain parenchyma volume, higher white matter hyperintensity volume, and presence of lacunar infarcts and cerebral microbleeds); ${ }_{i}^{6}$ flicker light-induced retinal arteriolar and venular dilation response; ${ }^{7}$ albuminuria ("urinary albumin excretion", UAE); heat-induced skin hyperaemia; ${ }^{7}$ and plasma biomarkers of MVD (i.e. soluble intercellular adhesion molecule-1 [sICAM-1], soluble vascular adhesion molecule-1 [sVCAM-1], soluble E-selectin [sE-selectin] and von Willebrand factor [vWF]). ${ }^{9}$

The associations between BPV and most of these various MVD measures remain, however, incompletely understood. To date, only five studies have evaluated the association between BPV and CSVD features. These studies found an association between greater very short- to short-term systolic and diastolic BPV and cerebral atrophy, ${ }^{10,11}$ higher white matter hyperintensity volume, ${ }^{10-13}$ lacunar infarcts, ${ }^{10,12}$ and enlarged perivascular spaces. ${ }^{10,}$ ${ }^{14}$ However, these studies were relatively small $(n=<155),{ }^{11,13}$ done in selected populations (i.e. individuals with hypertension, ${ }^{12}$ aged 70 years and older, ${ }^{15}$ or admitted to the hospital ${ }^{10,}$ ${ }^{14}$ ) or did not adjust for potentially important confounders (i.e. mean blood pressure ${ }^{11,13}$ or lifestyle factors ${ }^{12}$ ). For UAE, most previous studies, ${ }^{16-27}$ but not all, ${ }^{28-30}$ found an association with greater very short-to mid-term systolic or diastolic BPV. However, these studies did not adjust for potentially important confounders, including dietary habits and physical activity. For plasma biomarkers of MVD, only one study has been done, which included 190 individuals with newly diagnosed hypertension. This study found an association between greater short-term systolic BPV and higher sE-selectin. ${ }^{31}$ Currently, no studies have investigated the association between BPV and retinal arteriolar and venular dilation or skin hyperaemia.

In view of the above, we investigated, in a large population-based cohort, whether very short- to mid-term BPV (i.e. within-visit, 24-hour and 7-day BPV) is associated with a comprehensive set of MVD measures, including CSVD features, retinal arteriolar and venular dilation response, UAE, skin hyperaemia and plasma biomarkers of MVD. We hypothesized that greater BPV would be more strongly associated with MVD in organs with a low vascular impedance, i.e. brain, eyes and kidneys, and would not be associated with MVD in organs with a high vascular impedance, e.g. skin. 


\section{Material and methods}

\section{Study population and design}

We used data from The Maastricht Study, an observational population-based cohort study. The rationale and methodology have been described previously. ${ }^{32}$ In brief, the study focuses on the aetiology, pathophysiology, complications and comorbidities of diabetes mellitus type 2 (T2D) and is characterized by an extensive phenotyping approach. Eligible for participation were all individuals aged between 40 and 75 years and living in the southern part of the Netherlands. Participants were recruited through mass media campaigns, the municipal registries and the regional Diabetes Patient Registry via mailings. Recruitment was stratified according to known T2D status, with an oversampling of individuals with T2D for reasons of efficiency. The present report includes cross-sectional data from 3,451 participants who completed the baseline survey between November 2010 and September 2013. The examinations of each participant were performed within a time window of three months. The study has been approved by the institutional medical ethical committee (NL31329.068.10) and the Minister of Health, Welfare, and Sports of the Netherlands (Permit 131088-105234-PG). All participants gave written informed consent. Data are available from The Maastricht Study for any researcher who meets the criteria for access to confidential data, and the corresponding author may be contacted to request data.

\section{Blood pressure measurements and determination of blood pressure variability}

A detailed description of the office, 24-hour ambulatory and 7-day home blood pressure measurements and determination of BPV has been reported previously. ${ }^{33}$ Briefly, withinvisit BPV was calculated as the standard deviation (SD) of three consecutive office blood pressure measurements, with a 1-minute interval, after ten minutes of rest. 24-hour BPV was calculated as the average real variability of blood pressure readings taken every 15 minutes between 08:00 A.M. and 11:00 P.M., and every 30 minutes between 11:00 P.M. 08.00 A.M.. 7-day BPV was calculated as the SD of home blood pressure measurements taken twice, with a 1-minute interval, each morning and evening, for 7 consecutive days.

\section{Microvascular dysfunction measures}

For all MVD measures, participants were asked to refrain from smoking and drinking caffeine-containing beverages three hours before the measurement. ${ }^{34} \mathrm{~A}$ light meal was allowed until $\geq 90$ minutes prior to the examination. For retinal measurements, pupils were dilated with $0.5 \%$ tropicamide and $2.5 \%$ phenylephrine $\geq 15$ minutes before the start of the examination. Skin blood flow measurements were performed in a climatecontrolled room at $24^{\circ} \mathrm{C} .35$

\section{Features of cerebral small vessel disease}

Brain MRI measurements were implemented from December 2013 onwards and were available in 2,313 of the 3,451 participants (67\%). Brain MRI was performed on a 3T MRI scanner (Siemens Magnetom Prisma-fit Syngo MR D13D, Erlangen, Germany). We evaluated four MRI CSVD features, i.e. total brain parenchyma volume, white matter hyperintensity volume, lacunar infarcts and cerebral microbleeds. A detailed description of the MRI protocol is provided in Item S1 (Supplementary Material). Briefly, the MRI 
protocol consisted of a 3DT1-weighted sequence, T2-weighted fluid-attenuated inversion recovery (FLAIR), and a gradient recalled echo (GRE) pulse sequence with susceptibilityweighted imaging (SWI). ${ }^{36} \mathrm{~T} 1$-weighted images and FLAIR images were analyzed by use of an automated method. ${ }^{37,38}$ T1-weighted images were segmented into grey matter, white matter and cerebrospinal fluid volumes. ${ }^{37}$ Intracranial volume was calculated as the sum of grey matter, white matter (including white matter hyperintensity volume) and cerebrospinal fluid volumes. Total brain parenchyma volume was calculated as the sum of grey and white matter volumes. T1-weighted and FLAIR images were used to identify white matter hyperintensities. ${ }^{38}$ White matter hyperintensity volume was summed to assess total white matter hyperintensity burden. Lacunar infarcts were defined as focal brain parenchyma defects of $\geq 3 \mathrm{~mm}$ and $<15 \mathrm{~mm}$ in size with a similar signal intensity as cerebrospinal fluid on all sequences and a hyperintense rim on FLAIR images. ${ }^{6}$ Cerebral microbleeds were rated on three-dimensional T2* GRE imaging with SWI by use of the Microbleed Anatomical Rating Scale, ${ }^{39}$ and were defined as focal lesions of $\geq 2 \mathrm{~mm}$ and $\leq 10 \mathrm{~mm}$ in size with a hypointense signal. ${ }^{6}$ The presence of lacunar infarcts and cerebral microbleeds was rated manually by three neuroradiologists. The intraclass correlation coefficients for the three raters based on 50 randomly selected scans were 0.84 (95\% confidence interval $[95 \% \mathrm{Cl}] 0.74-0.91)$ and $0.83(0.72-0.90)$ for the presence of lacunar infarcts and cerebral microbleeds, respectively.

\section{Flicker light-induced retinal arteriolar and venular dilation response}

We measured retinal arteriolar and venular dilation to flicker light exposure by the Dynamic Vessel Analyzer (Imedos, Jena, Germany), as previously described.7, 40 Briefly, a baseline recording of 50 seconds was followed by 40 -second flicker light exposure followed by a 60 -second recovery period. We calculated baseline diameters (in measurement units) as the average diameter during the $20-50$ seconds recording. For both the arteriolar and venular dilation, percentage dilation over baseline was calculated using the average dilation achieved at time points 10 and 40 seconds during the flicker stimulation period.

\section{Urinary albumin excretion}

To assess UAE, participants were requested to collect two 24-hour urine samples. Urinary albumin concentration was measured with a standard immunoturbidimetric assay by an automatic analyzer (due to a change of supplier, by the Beckman Synchron LX20 and the Roche Cobas 6000) and multiplied by collection volume to obtain 24-hour UAE. A urinary albumin concentration below the detection limit of the assay was set at $1.5 \mathrm{mg} / \mathrm{L}(2 \mathrm{mg} / \mathrm{L}$ for the Beckman Synchron LX20 and $3 \mathrm{mg} / \mathrm{L}$ for the Roche Cobas 6000) before multiplying by collection volume. Only urine collections with a collection time between 20 and 28 hours were considered valid. If needed, UAE was extrapolated to 24-hour excretion. For this study, UAE was preferably based on the average of two (available in $91.3 \%$ of participants) 24-hour urine collections.

\section{Heat-induced skin hyperaemia}

We measured heat-induced skin hyperaemia by laser Doppler flowmetry (Perimed, Järfälla, Sweden), as previously described. ${ }^{7}$ Briefly, skin blood flow at the wrist, expressed in arbitrary perfusion units (PU), was recorded unheated for two minutes to serve as a baseline. After two minutes, the temperature of the laser Doppler probe was rapidly 
and locally increased to $44^{\circ} \mathrm{C}$ and was kept constant until the end of the registration. Skin hyperaemia was expressed as the percentage increase in average PU during the 23 minutes heating phase over the two minutes average baseline PU.

\section{Plasma biomarkers of microvascular dysfunction}

We measured four plasma biomarkers of MVD: sICAM-1, sVCAM-1, sE-selectin and vWF. ${ }^{41}$ sICAM-1, sVCAM-1 and sE-selectin were measured in EDTA plasma samples with commercially available 4-plex sandwich immunoassay kits with different standards and antibodies (Meso Scale Discovery, Rockville, Maryland, United States of America). For this technique in this study, the intra- and inter-assay coefficients of variation were 10.3 and $8.4 \%$ for sICAM-1, 5.0 and $4.7 \%$ for sVCAM-1, and 2.9 and $7.4 \%$ for sE-selectin, respectively. Von Willebrand Factor (VWF) was quantified in citrate plasma using ELISA (Dako, Glostrup, Denmark). The intra- and inter-assay coefficients of variation were 3.0 and $4.3 \%$, respectively.

\section{Covariates}

We determined glucose metabolism status according to the World Health Organization 2006 criteria as normal glucose metabolism, prediabetes or T2D. ${ }^{42}$ Education level was classified into three groups: low (none, primary or lower vocational education only), intermediate (intermediate general secondary, intermediate vocational or higher general secondary education) and high (higher vocational education or university level of education). We determined alcohol consumption (none, low [women $\leq 7$, men $\leq 14$ units/ week], high [women $>7$, men $>14$ units/week]), smoking status (never, former, current), medication use, body mass index, total/high density lipoprotein (HDL) cholesterol ratio and prior cardiovascular disease as described previously.7, 8, 32 Estimated glomerular filtration rate (eGFR) was computed with the CKD-EPI (Chronic Kidney Disease Epidemiology collaboration) formula using serum creatinine and cystatin $C .{ }^{43}$ Plasma biomarkers of low-grade inflammation (i.e. high-sensitive C-reactive protein, serum amyloid A, interleukin-6, interleukin-8 and tumor necrosis factor alpha) were determined as described previously. ${ }^{32,44}$ Carotid-femoral pulse wave velocity, a measure of aortic stiffness, ${ }^{44}$ was measured according to international guidelines ${ }^{45}$ with the use of applanation tonometry (Sphygmocor, Atcor Medical, Sydney Australia) at the right common carotid and right common femoral arteries. As described previously, we used questionnaires to assess the Mediterranean diet score ("diet score") ${ }_{1}^{46}$ moderate-to-vigorous physical activity ${ }^{32}$ and socio-economic status (income level and occupation status). ${ }^{47}$ 


\section{Statistical analysis}

We inversed (multiplying by -1) total brain parenchyma volume, retinal arteriolar and venular dilation response and skin hyperaemia so that higher values indicated worse microvascular function. White matter hyperintensity volume and UAE were logtransformed (base 2) to normalize their skewed distribution.

We summarized the three BPV measures (i.e. within-visit, 24-hour and 7-day BPV) into a systolic and diastolic BPV composite score, as done previously. ${ }^{48}$ We hypothesized that each BPV measure is associated with MVD according to similar underlying mechanisms. Furthermore, a composite score reduces the influence of the biological variability of its components, ${ }^{49}$ and it reduces the chance of a type 1 error. The BPV composite scores were calculated when at least data on two of the three BPV measures were available. The scores were calculated by summation and averaging of the z-scores of the three systolic and diastolic BPV measures, respectively.

We also calculated separate composite scores for the CSVD features, for the retinal arteriolar and venular dilation response and for the plasma biomarkers of MVD, respectively. The CSVD composite score was calculated as described previously; ${ }^{50}$ one point per CSVD feature was assigned based on the following cut-offs: for lower total brain parenchyma volume quartile 1 vs. quartiles 2 to 4; for higher white matter hyperintensity volume quartile 4 vs. quartiles 1 to 3; and for lacunar infarcts and cerebral microbleeds presence vs. absence. The points for each feature were combined to compute the CSVD composite score (range 0-4). The composite scores for retinal arteriolar and venular dilation and plasma biomarkers of MVD were calculated by summation and averaging of the z-scores of the retinal arteriolar and venular dilation responses and the four plasma biomarkers of MVD, respectively.

We used linear regression to investigate the association between the systolic and diastolic BPV composite scores and the CSVD composite score, the retinal arteriolar and venular dilation composite score, UAE, skin hyperaemia and the plasma biomarkers of MVD composite score. All analyses were adjusted for age and sex (model 1), and additionally for glucose metabolism status (model 2), mean 24-hour systolic or diastolic blood pressure (where appropriate) (model 3), and education level, body mass index, smoking status, alcohol consumption, total/HDL cholesterol ratio, lipid-modifying medication, and the individual classes of antihypertensive medication (i.e. beta blockers, diuretics, calcium channel blockers, angiotensin-converting enzyme inhibitors and angiotensin II receptor blockers) (model 4). For analyses with log-transformed UAE as the outcome, regression coefficients were back-transformed and expressed as higher ratio per SD higher systolic and diastolic BPV.

We tested interaction terms with age ${ }^{51}$ sex $^{52}$ and glucose metabolism status ${ }^{53}$ to evaluate whether the association between the BPV composite scores and the MVD measures differed according to these factors. 
Several sensitivity analyses were performed. First, we repeated the analysis with the individual BPV measures as the determinant, i.e. within-visit, 24-hour and 7-day systolic and diastolic BPV. Second, we repeated the analysis using as the outcome the individual CSVD features, the individual retinal arteriolar and venular dilation response and the individual plasma biomarkers of MVD, respectively. Third, we repeated the analysis with additional adjustment for eGFR, prior cardiovascular disease, plasma biomarkers of low-grade inflammation, and carotid-femoral pulse wave velocity. These covariates were entered into a separate model because of the risk of overadjustment bias: these factors may be confounders, but may also mediate any association between BPV and MVD. Fourth, we repeated the analysis additionally adjusting for the diet score, and moderate-to-vigorous physical activity, and for income level and occupation status (instead of education level). Adjustment for these potential confounders was not included in the main analysis, because data were missing in a relatively large number of participants $(n=1,133$ missed data on one or more of these variables). Fifth, we used micro-albuminuria defined as $\geq 30$ $\mathrm{mg} / 24 \mathrm{~h}$ vs. $<30 \mathrm{mg} / 24 \mathrm{~h}$ as the outcome instead of UAE per $\mathrm{mg} / 24 \mathrm{~h} .{ }^{54} \mathrm{Sixth}$, we repeated the analysis with eGFR (continuously and categorically [ $\geq 60 \mathrm{vs} .<60 \mathrm{ml} / \mathrm{min} / 1.73 \mathrm{~m}^{2}$ ) as the outcome.

All statistical analyses were performed with Statistical Package for Social Sciences (v22.0; IBM, Chicago, Illinois). A P value of $<.05$ was considered statistically significant.

\section{Results}

\section{Study population}

Figure 1 shows the derivation of the study population. In total, 2,773 participants had data available on the BPV composite scores, all potential confounders and at least one MVD measure, and were included in the analysis. CSVD features were available in 1,837 participants, retinal arteriolar and venular dilation response in 1,844, UAE in 2,748, skin hyperaemia in 1,320, and plasma biomarkers of MVD in 2,726. These subpopulations were comparable with regard to age, sex and cardiovascular risk profile (Supplemental Table S1). Participants excluded due to missing data had greater BPV and higher body mass index and more often had prior cardiovascular disease compared with those without missing data (Supplemental Table S1).

Table 1 and Supplemental Table S2 show the general characteristics for the total study population and according to tertiles of the systolic BPV composite score. Supplemental Table S3 shows the characteristics according to tertiles of the diastolic BPV composite score. The mean age was 59.9 years, $51.9 \%$ were men and $26.9 \%$ had T2D. In general, participants with the highest compared with the lowest tertile of the systolic BPV composite score were older, less often male, had a worse cardiovascular risk profile and more often used lipid-modifying and antihypertensive medication.

\section{Blood pressure variability and microvascular dysfunction}

Higher systolic and diastolic BPV composite scores were associated with higher UAE (1.04 [95\% Cl 1.00-1.08] and 1.07 [1.03-1.11] higher ratio per 1 SD higher systolic and diastolic 
BPV composite score, respectively), after adjustment for all potential confounders (Table 2, model 4). Systolic and diastolic BPV composite scores were not associated with the other MVD measures: the CSVD composite score, the retinal arteriolar and venular dilation response composite score, skin hyperaemia, and the plasma biomarkers of MVD composite score, after full adjustment (Table 2, model 4).

We did not observe consistent interactions with age, sex or glucose metabolism status for the associations between systolic and diastolic BPV and any of the MVD measures (Supplemental Table S4).

\section{Sensitivity analyses}

Of the individual systolic and diastolic BPV measures, 24-hour diastolic BPV was associated with a higher CSVD composite score, retinal arteriolar and venular dilation response composite score and UAE; 7-day systolic BPV was associated with a higher CSVD composite score and plasma biomarkers of MVD composite score; and 7-day diastolic BPV with higher UAE and a higher plasma biomarkers of MVD composite score (Supplemental Table S5). When we repeated the analysis using each individual MVD measure as the outcome, the systolic and diastolic BPV composite scores were associated with higher levels of sVCAM-1 and the systolic BPV composite score with higher levels of vWF (Supplemental Table S6). Results were similar when we additionally adjusted for eGFR, prior cardiovascular disease, plasma biomarkers of low-grade inflammation, carotid-femoral pulse wave velocity, the diet score, moderate-to-vigorous physical activity, or income level and occupation status (Supplemental Tables S7-S14). Each SD higher BPV composite score was associated with higher odds of $U A E \geq 30 \mathrm{mg} / 24 \mathrm{~h}$; odds ratios were $1.19(95 \% \mathrm{Cl} 1.02-1.38)$ for systolic BPV and $1.19(95 \% \mathrm{Cl} 1.02-1.37)$ for diastolic BPV (Figure 2 and Supplemental Table S15). The systolic and diastolic BPV composite scores were not associated with eGFR (Supplemental Table S16).

\section{Discussion}

We found that greater very short- to mid-term systolic and diastolic BPV are associated with higher UAE, but not with other measures of MVD tested, i.e. the CSVD composite score, retinal arteriolar and venular dilation response composite score, skin hyperaemia and the plasma biomarkers of MVD composite score. The association with higher UAE was independent of age, sex, mean 24-hour systolic or diastolic blood pressure, education level, and lifestyle and cardiovascular risk factors. The strength of this association corresponds to a 1.2 higher odds of UAE $\geq 30 \mathrm{mg} / 24 \mathrm{~h}$ as compared to a UAE of $<30 \mathrm{mg} / 24 \mathrm{~h}$ per SD higher systolic or diastolic BPV composite score.

Our study findings are in agreement with most, ${ }^{16-27}$ but not all, ${ }^{28-30}$ previous studies that investigated the association between BPV and UAE. Our study adds to the existing literature on $\mathrm{UAE}$, because we were able to study this association in the context of various other MVD measures, and adjusted for potentially important confounders, including dietary habits physical activity. Previous studies on BPV and UAE did not adjust for these potential confounders. 
In disagreement with our hypothesis, we did not find an association between greater BPV and MVD measured in organs with low microvascular impedance other than the kidneys, i.e. the brain and eyes, and with plasma biomarkers of MVD, which at least partly reflect MVD in organs with low microvascular impedance. A possible explanation is that the kidney microvasculature has a lower impedance than the brain and eye microvasculature, e.g. blood flow to the kidneys relative to organ weight ( $360 \mathrm{ml} / \mathrm{min} / 100 \mathrm{~g}$ kidney tissue) is higher than to the brain (50 ml/min/100 g brain tissue). ${ }^{55}$ The kidney microvasculature may, therefore, in comparison be most vulnerable to the detrimental effects of BPV.

Although we found no significant associations between greater BPV and CSVD features, retinal arteriolar and venular dilation response and plasma biomarkers of MVD, these measures nevertheless reflect MVD in organs with low vascular impedance and may thus be vulnerable to an increased pulsatile load, ${ }^{56}$ albeit to a lesser extent than UAE. Indeed, we found positive associations that were quantitatively similar for CSVD features, retinal arteriolar and venular dilation response, and plasma biomarkers of MVD. Estimations of these associations may have been more inaccurate (i.e. broader confidence intervals), because of higher measurement errors in these MVD measures as compared with UAE; CSVD features, retinal arteriolar and venular dilation response, and plasma biomarkers of MVD were measured only once, whereas UAE was based on two 24-hour urine samples. In addition, estimations of the associations may also have been more inaccurate with CSVD features and retinal arteriolar and venular dilation response due to relatively few available data ( $n=1,837$ and $n=1,844$, respectively) as compared with UAE $(n=2,748)$.

As expected, we did not find an association between BPV and skin hyperaemia. The skin has relatively high microvascular impedance, ${ }^{4}$ and, therefore, most of the increased pulsatile energy related to greater BPV may be dissipated by arteries and large arterioles proximal to the skin capillaries. ${ }^{57}$

Strengths of this study include the large study population of community-dwelling participants, assessment of microvascular function in various vascular beds and the extensive adjustment for potential confounders.

Our study has several limitations. First, our cross-sectional data preclude reaching causal conclusions about the study findings. Indeed, the reverse association may hold true as well, i.e. higher UAE (as a reflection of worse kidney function) may lead to greater BPV. ${ }^{58}$ However, when we additionally adjusted our analyses for estimated glomerular filtration rate, results were similar. Second, the association between greater BPV and UAE may be the result of residual confounding due to low-grade inflammation, ${ }^{59,60}$ arterial stiffening, ${ }^{4,}$ ${ }^{61}$ activation of the renin-angiotensin system, ${ }^{62,63}$ unhealthy dietary habits, ${ }^{64,65}$ physical inactivity ${ }^{66,67}$ and lower socio-economic status. ${ }^{68,69}$ However, when we adjusted for lowgrade inflammation, carotid-femoral pulse wave velocity, the diet score, moderate-tovigorous physical activity and factors related to socio-economic status (i.e. education, income level and occupation status), results did not materially change. In this study, no data were available on activation of the renin-angiotensin system, however, and this issue requires further study. Third, we may have underestimated the association between greater BPV and MVD, because individuals excluded for the present analysis due to 
missing data had greater BPV and a higher prevalence of prior cardiovascular disease than those included in the analysis. Fourth, the study population consisted mainly of middleaged individuals who were relatively well-educated and whose cardiovascular risk factors were relatively well-controlled. This may have led to an underestimation of the association between BPV and MVD. Finally, the study population consisted mainly of individuals from Caucasian ethnicity and the results may not be generalizable to other ethnicities.

\section{Perspectives}

In conclusion, this large, relatively healthy population-based study showed that greater very short- to mid-term systolic and diastolic BPV was associated with higher UAE, but not with other measures of MVD tested, i.e. CSVD features, retinal arteriolar and venular dilation response, skin hyperaemia and plasma biomarkers of MVD. This may suggest that the microvasculature of the kidneys is most vulnerable to the detrimental effects of greater BPV. Future longitudinal studies should be performed to assess the temporality of these associations, and, if confirmed, intervention studies should assess whether lowering BPV will prevent albuminuria. 


\section{References}

1. Rensma SP, van Sloten TT, Launer LJ and Stehouwer CDA. Cerebral small vessel disease and risk of incident stroke, dementia and depression, and all-cause mortality: A systematic review and meta-analysis. Neurosci Biobehav Rev. 2018;90:164-173.

2. Stehouwer CDA. Microvascular Dysfunction and Hyperglycemia: A Vicious Cycle With Widespread Consequences. Diabetes. 2018;67:1729-1741.

3. Bidani AK, Polichnowski AJ, Loutzenhiser R and Griffin KA. Renal microvascular dysfunction, hypertension and CKD progression. Curr Opin Nephrol Hypertens. 2013;22:1-9.

4. Mitchell GF. Effects of central arterial aging on the structure and function of the peripheral vasculature: implications for end-organ damage. J Appl Physiol (1985). 2008;105:1652-60.

5. Rothwell PM. Limitations of the usual blood-pressure hypothesis and importance of variability, instability, and episodic hypertension. Lancet. 2010;375:938-48.

6. Wardlaw JM, Smith EE, Biessels GJ, Cordonnier C, Fazekas F, Frayne R, Lindley RI, O'Brien JT, Barkhof F, Benavente OR, Black SE, Brayne C, Breteler M, Chabriat H, Decarli C, de Leeuw FE, Doubal F, Duering M, Fox NC, Greenberg S, Hachinski V, Kilimann I, Mok V, Oostenbrugge R, Pantoni L, Speck O, Stephan BC, Teipel S, Viswanathan A, Werring D, Chen C, Smith C, van Buchem $M$, Norrving B, Gorelick PB, Dichgans M and nEuroimaging STfRVco. Neuroimaging standards for research into small vessel disease and its contribution to ageing and neurodegeneration. Lancet Neurol. 2013;12:822-38.

7. Sorensen BM, Houben AJ, Berendschot TT, Schouten JS, Kroon AA, van der Kallen CJ, Henry RM, Koster A, Sep SJ, Dagnelie PC, Schaper NC, Schram MT and Stehouwer CD. Prediabetes and Type 2 Diabetes Are Associated With Generalized Microvascular Dysfunction: The Maastricht Study. Circulation. 2016;134:1339-1352.

8. Martens RJ, Henry RM, Houben AJ, van der Kallen CJ, Kroon AA, Schalkwijk CG, Schram MT, Sep SJ, Schaper NC, Dagnelie PC, Muris DM, Gronenschild EH, van der Sande FM, Leunissen KM, Kooman JP and Stehouwer CD. Capillary Rarefaction Associates with Albuminuria: The Maastricht Study. J Am Soc Nephrol. 2016;27:3748-3757.

9. van Sloten TT, Schram MT, Adriaanse MC, Dekker JM, Nijpels G, Teerlink T, Scheffer PG, Pouwer F, Schalkwijk CG, Stehouwer CD and Henry RM. Endothelial dysfunction is associated with a greater depressive symptom score in a general elderly population: the Hoorn Study. Psychol Med. 2014;44:1403-16.

10. Yang S, Yuan J, Qin W, Yang L, Fan H, Li Y and Hu W. Twenty-four-hour ambulatory blood pressure variability is associated with total magnetic resonance imaging burden of cerebral small-vessel disease. Clin Interv Aging. 2018;13:1419-1427.

11. Goldstein IB, Bartzokis G, Guthrie D and Shapiro D. Ambulatory blood pressure and the brain: a 5-year follow-up. Neurology. 2005;64:1846-52.

12. Filomena J, Riba-Llena I, Vinyoles E, Tovar JL, Mundet X, Castane X, Vilar A, Lopez-Rueda A, Jimenez-Balado J, Cartanya A, Montaner J, Delgado P and Investigators I. Short-Term Blood Pressure Variability Relates to the Presence of Subclinical Brain Small Vessel Disease in Primary Hypertension. Hypertension. 2015;66:634-40.

13. Gunstad J, Cohen RA, Tate DF, Paul RH, Poppas A, Hoth K, Macgregor KL and Jefferson AL. Blood pressure variability and white matter hyperintensities in older adults with cardiovascular disease. Blood Press. 2005;14:353-8. 
14. Yang S, Qin W, Yang L, Fan H, Li Y, Yin J and Hu W. The relationship between ambulatory blood pressure variability and enlarged perivascular spaces: a cross-sectional study. BMJ Open. 2017;7:e015719.

15. Yamaguchi $Y$, Wada M, Sato H, Nagasawa H, Koyama S, Takahashi Y, Kawanami T and Kato T. Impact of ambulatory blood pressure variability on cerebral small vessel disease progression and cognitive decline in community-based elderly Japanese. Am J Hypertens. 2014;27:1257-67.

16. Kawai T, Ohishi M, Kamide K, Onishi M, Takeya Y, Tatara Y, Oguro R, Yamamoto K, Sugimoto $K$ and Rakugi $\mathrm{H}$. The impact of visit-to-visit variability in blood pressure on renal function. Hypertens Res. 2012;35:239-43.

17. Kilpatrick ES, Rigby AS and Atkin SL. The role of blood pressure variability in the development of nephropathy in type 1 diabetes. Diabetes Care. 2010;33:2442-7.

18. Okada H, Fukui M, Tanaka M, Inada S, Mineoka Y, Nakanishi N, Senmaru T, Sakabe K, Ushigome E, Asano M, Yamazaki M, Hasegawa G and Nakamura N. Visit-to-visit variability in systolic blood pressure is correlated with diabetic nephropathy and atherosclerosis in patients with type 2 diabetes. Atherosclerosis. 2012;220:155-9.

19. Kristensen KS, Hoegholm A, Bang LE, Gustavsen PH and Poulsen CB. No impact of blood pressure variability on microalbuminuria and left ventricular geometry: analysis of daytime variation, diurnal variation and 'white coat' effect. Blood Press Monit. 2001;6:125-31.

20. de la Sierra A, Pareja J, Yun S, Acosta E, Aiello F, Oliveras A, Vazquez S, Armario P, Blanch P, Sierra C, Calero F and Fernandez-Llama P. Central blood pressure variability is increased in hypertensive patients with target organ damage. J Clin Hypertens (Greenwich). 2018;20:266-272.

21. Tatasciore A, Renda G, Zimarino M, Soccio M, Bilo G, Parati G, Schillaci G and De Caterina R. Awake systolic blood pressure variability correlates with target-organ damage in hypertensive subjects. Hypertension. 2007;50:325-32.

22. Yin LH, Yan WJ, Guo ZX, Zhou FZ and Zhang HY. Relation between blood pressure variability and early renal damage in hypertensive patients. Eur Rev Med Pharmacol Sci. 2017;21:2226-2231.

23. Kagitani $\mathrm{H}$, Hoshide $\mathrm{S}$ and Kario K. Optimal indicators of home BP variability in perimenopausal women and associations with albuminuria and reproducibility: The J-HOT home BP study. Am J Hypertens. 2015;28:586-94.

24. Ushigome E, Fukui M, Hamaguchi M, Senmaru T, Sakabe K, Tanaka M, Yamazaki M, Hasegawa G and Nakamura $\mathrm{N}$. The coefficient variation of home blood pressure is a novel factor associated with macroalbuminuria in type 2 diabetes mellitus. Hypertens Res. 2011;34:1271-5.

25. Matsumoto S, Ushigome E, Matsushita K, Fukuda T, Mitsuhashi K, Majima S, Hasegawa G, Nakamura N, Ushigome H, Yamazaki M and Fukui M. Home Blood Pressure Variability From the Stored Memory Is Correlated With Albuminuria, but From the Logbook Is not. Am J Hypertens. 2017;30:993-998.

26. Li CL, Liu R, Wang JR and Yang J. Relationship between blood pressure variability and target organ damage in elderly patients. Eur Rev Med Pharmacol Sci. 2017;21:5451-5455.

27. Mule G, Calcaterra I, Costanzo M, Geraci G, Guarino L, Foraci AC, Vario MG, Cerasola G and Cottone S. Relationship Between Short-Term Blood Pressure Variability and Subclinical Renal Damage in Essential Hypertensive Patients. J Clin Hypertens (Greenwich). 2015;17:473-80.

28. Ceriello A, De Cosmo S, Rossi MC, Lucisano G, Genovese S, Pontremoli R, Fioretto P, Giorda C, Pacilli A, Viazzi F, Russo G, Nicolucci A and Group AM-AS. Variability in HbA1c, blood pressure, lipid parameters and serum uric acid, and risk of development of chronic kidney disease in type 2 diabetes. Diabetes Obes Metab. 2017;19:1570-1578. 
29. Wei FF, LiY, Zhang L, Xu TY, Ding FH, Wang JG and Staessen JA. Beat-to-beat, reading-to-reading, and day-to-day blood pressure variability in relation to organ damage in untreated Chinese. Hypertension. 2014;63:790-6.

30. Madden JM, O'Flynn AM, Dolan E, Fitzgerald AP and Kearney PM. Short-term blood pressure variability over $24 \mathrm{~h}$ and target organ damage in middle-aged men and women. $J$ Hum Hypertens. 2015;29:719-25.

31. Tatasciore A, Zimarino M, Renda G, Zurro M, Soccio M, Prontera C, Emdin M, Flacco M, Schillaci $\mathrm{G}$ and $\mathrm{R} D E C$. Awake blood pressure variability, inflammatory markers and target organ damage in newly diagnosed hypertension. Hypertens Res. 2008;31:2137-46.

32. Schram MT, Sep SJ, van der Kallen CJ, Dagnelie PC, Koster A, Schaper N, Henry RM and Stehouwer $\mathrm{CD}$. The Maastricht Study: an extensive phenotyping study on determinants of type 2 diabetes, its complications and its comorbidities. Eur J Epidemiol. 2014;29:439-51.

33. Zhou TL, Kroon AA, Reesink KD, Schram MT, Koster A, Schaper NC, Dagnelie PC, van der Kallen $\mathrm{CJH}$, Sep SJS, Stehouwer CDA and Henry RMA. Blood pressure variability in individuals with and without (pre)diabetes: The Maastricht Study. J Hypertens. 2018;36:259-267.

34. Garhofer G, Resch H, Sacu S, Weigert G, Schmidl D, Lasta M and Schmetterer L. Effect of regular smoking on flicker induced retinal vasodilatation in healthy subjects. Microvasc Res. 2011;82:351-5.

35. Pettersson A, Bostrom KB, Gustavsson P and Ekselius L. Which instruments to support diagnosis of depression have sufficient accuracy? A systematic review. Nord J Psychiatry. 2015;69:497-508.

36. van Agtmaal MJM, Houben A, de Wit V, Henry RMA, Schaper NC, Dagnelie PC, van der Kallen CJ, Koster A, Sep SJ, Kroon AA, Jansen JFA, Hofman PA, Backes WH, Schram MT and Stehouwer CDA. Prediabetes Is Associated With Structural Brain Abnormalities: The Maastricht Study. Diabetes Care. 2018;41:2535-2543.

37. Vrooman HA, Cocosco CA, van der Lijn F, Stokking R, Ikram MA, Vernooij MW, Breteler MM and Niessen WJ. Multi-spectral brain tissue segmentation using automatically trained k-NearestNeighbor classification. Neurolmage. 2007;37:71-81.

38. de Boer R, Vrooman HA, van der Lijn F, Vernooij MW, Ikram MA, van der Lugt A, Breteler MM and Niessen WJ. White matter lesion extension to automatic brain tissue segmentation on MRI. Neurolmage. 2009;45:1151-61.

39. Gregoire SM, Chaudhary UJ, Brown MM, Yousry TA, Kallis C, Jager HR and Werring DJ. The Microbleed Anatomical Rating Scale (MARS): reliability of a tool to map brain microbleeds. Neurology. 2009;73:1759-66.

40. Houben A, Martens RJH and Stehouwer CDA. Assessing Microvascular Function in Humans from a Chronic Disease Perspective. J Am Soc Nephrol. 2017;28:3461-3472.

41. Muris DM, Houben AJ, Schram MT and Stehouwer CD. Microvascular dysfunction: an emerging pathway in the pathogenesis of obesity-related insulin resistance. Rev Endocr Metab Disord. 2013;14:29-38.

42. Correction: Neighbourhood socioeconomic position and risks of major chronic diseases and all-cause mortality: a quasi-experimental study. BMJ Open. 2019;9:e18793corr1.

43. Inker LA, Schmid CH, Tighiouart H, Eckfeldt JH, Feldman HI, Greene T, Kusek JW, Manzi J, Van Lente F, Zhang YL, Coresh J, Levey AS and Investigators C-E. Estimating glomerular filtration rate from serum creatinine and cystatin C. NEngl J Med. 2012;367:20-9. 
44. van Dooren FE, Schram MT, Schalkwijk CG, Stehouwer CD, Henry RM, Dagnelie PC, Schaper NC, van der Kallen CJ, Koster A, Sep SJ, Denollet J, Verhey FR and Pouwer F. Associations of low grade inflammation and endothelial dysfunction with depression - The Maastricht Study. Brain Behav Immun. 2016;56:390-6.

45. Van Bortel LM, Laurent S, Boutouyrie P, Chowienczyk P, Cruickshank JK, De Backer T, Filipovsky J, Huybrechts S, Mattace-Raso FU, Protogerou AD, Schillaci G, Segers P, Vermeersch S, Weber T, Artery S, European Society of Hypertension Working Group on Vascular S, Function and European Network for Noninvasive Investigation of Large A. Expert consensus document on the measurement of aortic stiffness in daily practice using carotid-femoral pulse wave velocity. J Hypertens. 2012;30:445-8.

46. Trichopoulou $A$, Orfanos $P$, Norat $T$, Bueno-de-Mesquita $B$, Ocke MC, Peeters $P H$, van der Schouw YT, Boeing H, Hoffmann K, Boffetta P, Nagel G, Masala G, Krogh V, Panico S, Tumino R, Vineis P, Bamia C, Naska A, Benetou V, Ferrari P, Slimani N, Pera G, Martinez-Garcia C, Navarro C, Rodriguez-Barranco M, Dorronsoro M, Spencer EA, Key TJ, Bingham S, Khaw KT, Kesse E, ClavelChapelon F, Boutron-Ruault MC, Berglund G, Wirfalt E, Hallmans G, Johansson I, Tjonneland A, Olsen A, Overvad K, Hundborg HH, Riboli E and Trichopoulos D. Modified Mediterranean diet and survival: EPIC-elderly prospective cohort study. BMJ. 2005;330:991.

47. Qi Y, Koster A, van Boxtel M, Kohler S, Schram M, Schaper N, Stehouwer C and Bosma H. Adulthood Socioeconomic Position and Type 2 Diabetes Mellitus-A Comparison of Education, Occupation, Income, and Material Deprivation: The Maastricht Study. Int J Environ Res Public Health. 2019;16.

48. Zhou TL, Henry RMA, Stehouwer CDA, van Sloten TT, Reesink KD and Kroon AA. Blood Pressure Variability, Arterial Stiffness, and Arterial Remodeling. Hypertension. 2018;72:1002-1010.

49. O'Brien PC. Procedures for comparing samples with multiple endpoints. Biometrics. 1984;40:1079-87.

50. van Sloten TT, Sigurdsson S, van Buchem MA, Phillips CL, Jonsson PV, Ding J, Schram MT, Harris TB, Gudnason V and Launer LJ. Cerebral Small Vessel Disease and Association With Higher Incidence of Depressive Symptoms in a General Elderly Population: The AGES-Reykjavik Study. Am J Psychiatry. 2015;172:570-8.

51. James MA, Tullett J, Hemsley AG and Shore AC. Effects of aging and hypertension on the microcirculation. Hypertension. 2006;47:968-74.

52. Schiebinger L, Leopold SS and Miller VM. Editorial policies for sex and gender analysis. Lancet. 2016;388:2841-2842.

53. Burke M, Pabbidi MR, Farley J and Roman RJ. Molecular mechanisms of renal blood flow autoregulation. Curr Vasc Pharmacol. 2014;12:845-58.

54. National Kidney Foundation. K/DOQI clinical practice guidelines for chronic kidney disease: evaluation, classification, and stratification. Am J Kidney Dis. 2002;39:S1-266.

55. Hall J.E. Guyton and Hall textbook of medical physiology. 13th ed. Philadelphia, PA: Elsevier; 206.

56. van Sloten TT, Protogerou AD, Henry RM, Schram MT, Launer LJ and Stehouwer CD. Association between arterial stiffness, cerebral small vessel disease and cognitive impairment: A systematic review and meta-analysis. Neurosci Biobehav Rev. 2015;53:121-30.

57. van Sloten TT, Czernichow S, Houben AJ, Protogerou AD, Henry RM, Muris DM, Schram MT, Sep SJ, Dagnelie PC, van der Kallen CJ, Schaper NC, Blacher J, Hercberg S, Levy BI and Stehouwer CD. Association Between Arterial Stiffness and Skin Microvascular Function: The SUVIMAX2 Study and The Maastricht Study. Am J Hypertens. 2015;28:868-76. 
58. Sarafidis PA, Ruilope LM, Loutradis C, Gorostidi M, de la Sierra A, de la Cruz JJ, Vinyoles E, DivisonGarrote JA, Segura J and Banegas JR. Blood pressure variability increases with advancing chronic kidney disease stage: a cross-sectional analysis of 16546 hypertensive patients. $J$ Hypertens. 2018;36:1076-1085.

59. Pietri P, Vlachopoulos $C$ and Tousoulis D. Inflammation and Arterial Hypertension: From Pathophysiological Links to Risk Prediction. Curr Med Chem. 2015;22:2754-61.

60. Virdis A, Masi S, Colucci R, Chiriaco M, Uliana M, Puxeddu I, Bernardini N, Blandizzi C and Taddei S. Microvascular Endothelial Dysfunction in Patients with Obesity. Curr Hypertens Rep. 2019;21:32.

61. Zhou TL, Henry RMA, Stehouwer CDA, van Sloten TT, Reesink KD and Kroon AA. Blood Pressure Variability, Arterial Stiffness, and Arterial Remodeling: The Maastricht Study. Hypertension. 2018;72:1002-1010.

62. Ozkayar N, Dede F, Akyel F, Yildirim T, Ates I, Turhan T and Altun B. Relationship between blood pressure variability and renal activity of the renin-angiotensin system. Journal of Human Hypertension. 2016;30:297-302.

63. Min SH, Kong SH, Lee JE, Lee DH, Oh TJ, Kim KM, Park KS, Jang HC and Lim S. Association of angiotensin-II levels with albuminuria in subjects with normal glucose metabolism, prediabetes, and type 2 diabetes mellitus. Journal of Diabetes and Its Complications. 2017;31:1499-1505.

64. Maseli A, Aeschbacher S, Schoen T, Fischer A, Jung M, Risch M, Risch L and Conen D. Healthy Lifestyle and Blood Pressure Variability in Young Adults. Am J Hypertens. 2017;30:690-699.

65. Schwingshackl L and Hoffmann G. Mediterranean dietary pattern, inflammation and endothelial function: a systematic review and meta-analysis of intervention trials. Nutr Metab Cardiovasc Dis. 2014;24:929-39.

66. Simmons GH, Wong BJ, Holowatz LA and Kenney WL. Changes in the control of skin blood flow with exercise training: where do cutaneous vascular adaptations fit in? Exp Physiol. 2011;96:822-8.

67. Pagonas N, Dimeo F, Bauer F, Seibert F, Kiziler F, Zidek W and Westhoff TH. The impact of aerobic exercise on blood pressure variability. J Hum Hypertens. 2014;28:367-71.

68. Campbell TS, Seguin JR, Vitaro F, Tremblay RE and Ditto B. Childhood socioeconomic position and blood pressure dipping in early adulthood: a longitudinal study. Ann Behav Med. 2013;46:227-31.

69. Kim D, Glazier RH, Zagorski B, Kawachi I and Oreopoulos P. Neighbourhood socioeconomic position and risks of major chronic diseases and all-cause mortality: a quasi-experimental study. BMJ Open. 2018;8:e018793. 


\section{Figure legend}

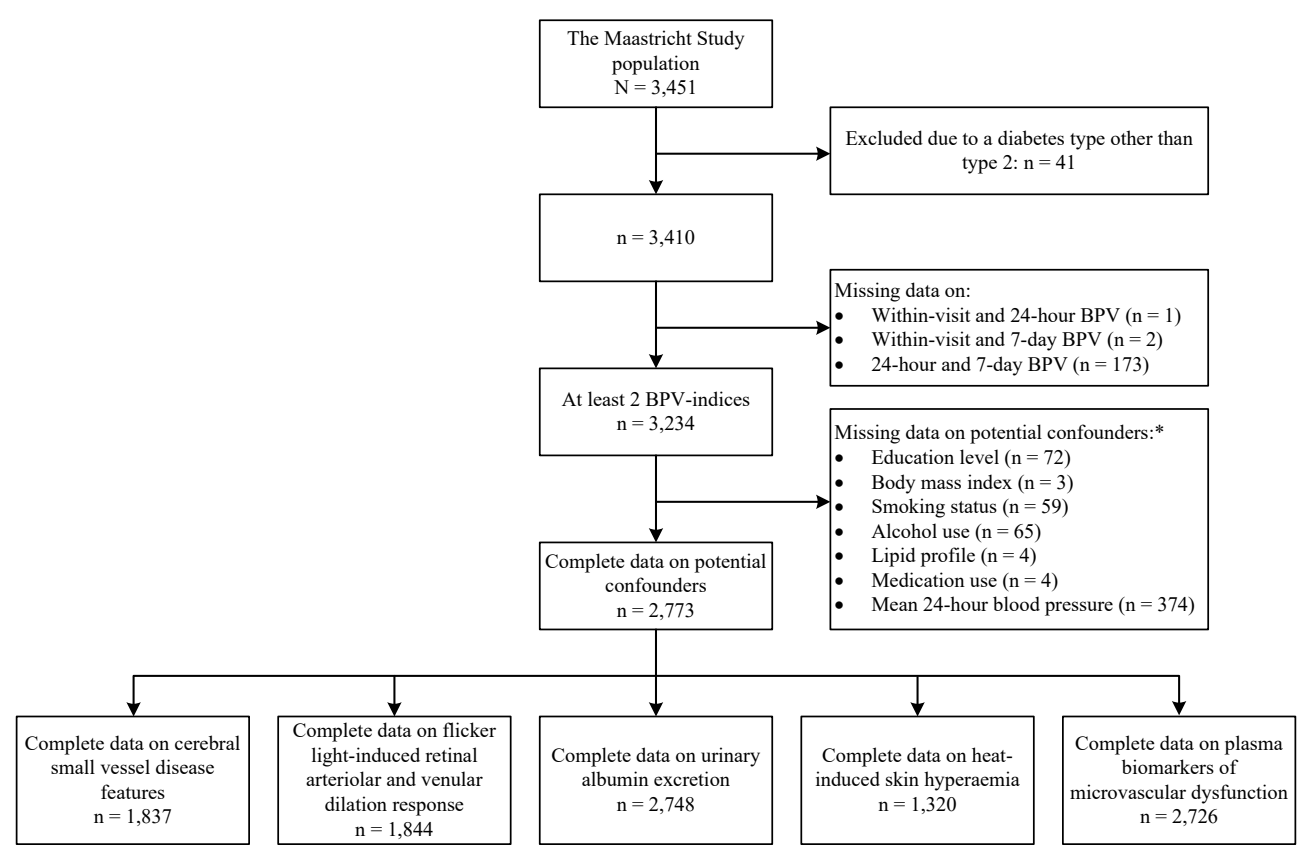

Figure 1 Flowchart delineating the derivation of the study population.

*not mutually exclusive.

Abbreviations: BPV, blood pressure variability 
Systolic BPV composite score

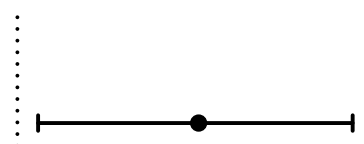

O R $(95 \%$ C I $)$

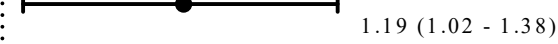

$1.19(1.02-1.38)$

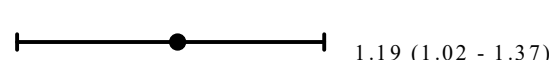

Diastolic B PV composite score

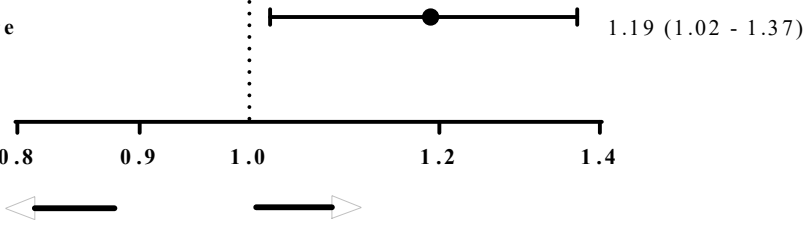

lower odds UAE $>=30 \mathrm{mg} / 24 \mathrm{~h}$

higher odds UAE $>=30 \mathrm{mg} / 24 \mathrm{~h}$

Figure 2. Associations of systolic and diastolic blood pressure variability composite scores with urinary albumin excretion dichotomized as $\geq 30 \mathrm{mg} / 24 \mathrm{~h}$ vs. $<30 \mathrm{mg} / 24 \mathrm{~h}$. Point estimates represent the odds ratio of urinary albumin excretion per standard deviation higher systolic or diastolic BPV composite score. Results are adjusted for age, sex, glucose metabolism status, mean 24-hour systolic or diastolic blood pressure (where appropriate), education level, body mass index, smoking status, alcohol consumption, total/high density lipoprotein cholesterol ratio, lipid-modifying medication, and the individual classes of antihypertensive medication. Abbreviations: BPV, blood pressure variability; $\mathrm{Cl}$, confidence interval; $\mathrm{OR}$, odds ratio; $\mathrm{UAE}$, urinary albumin excretion. 


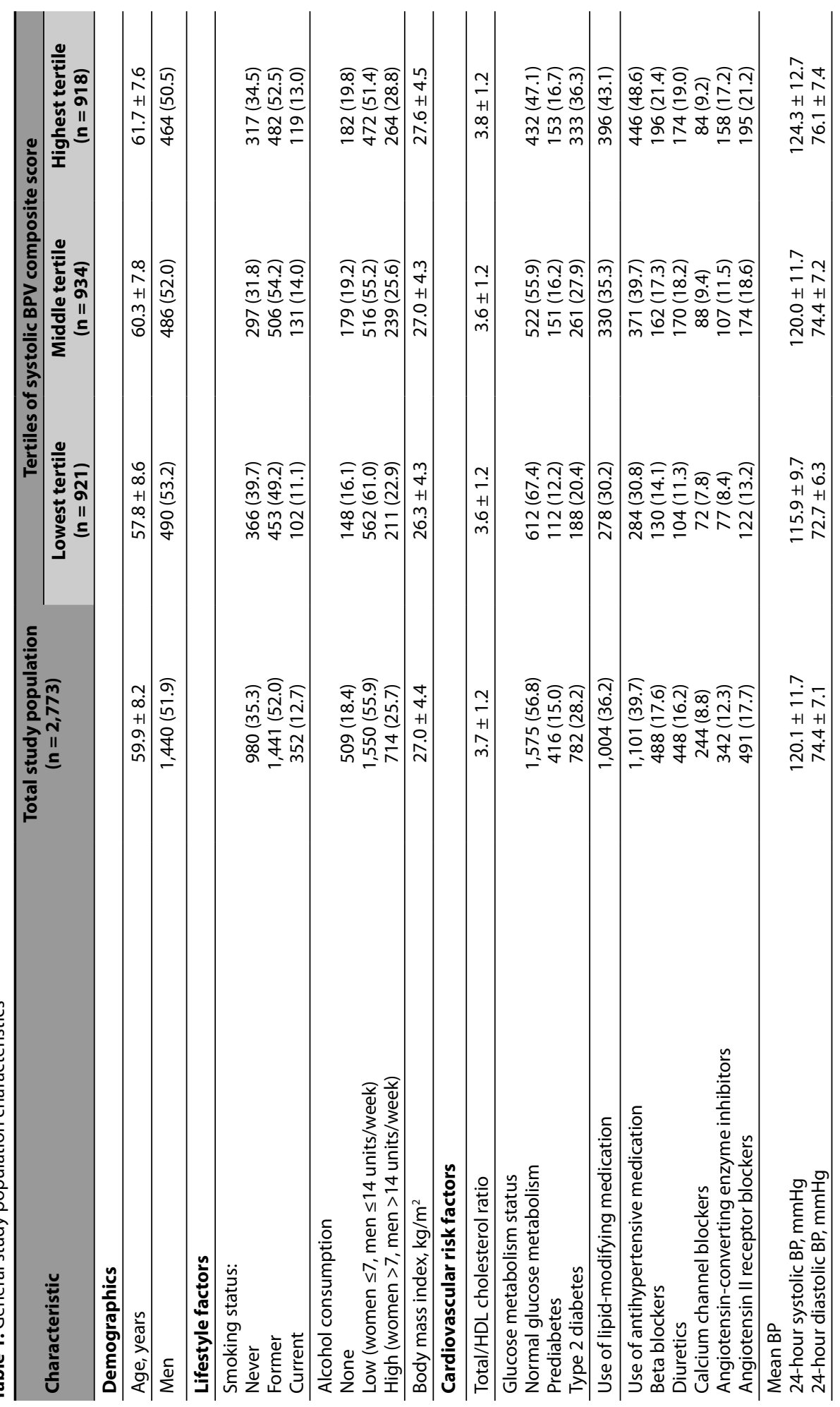




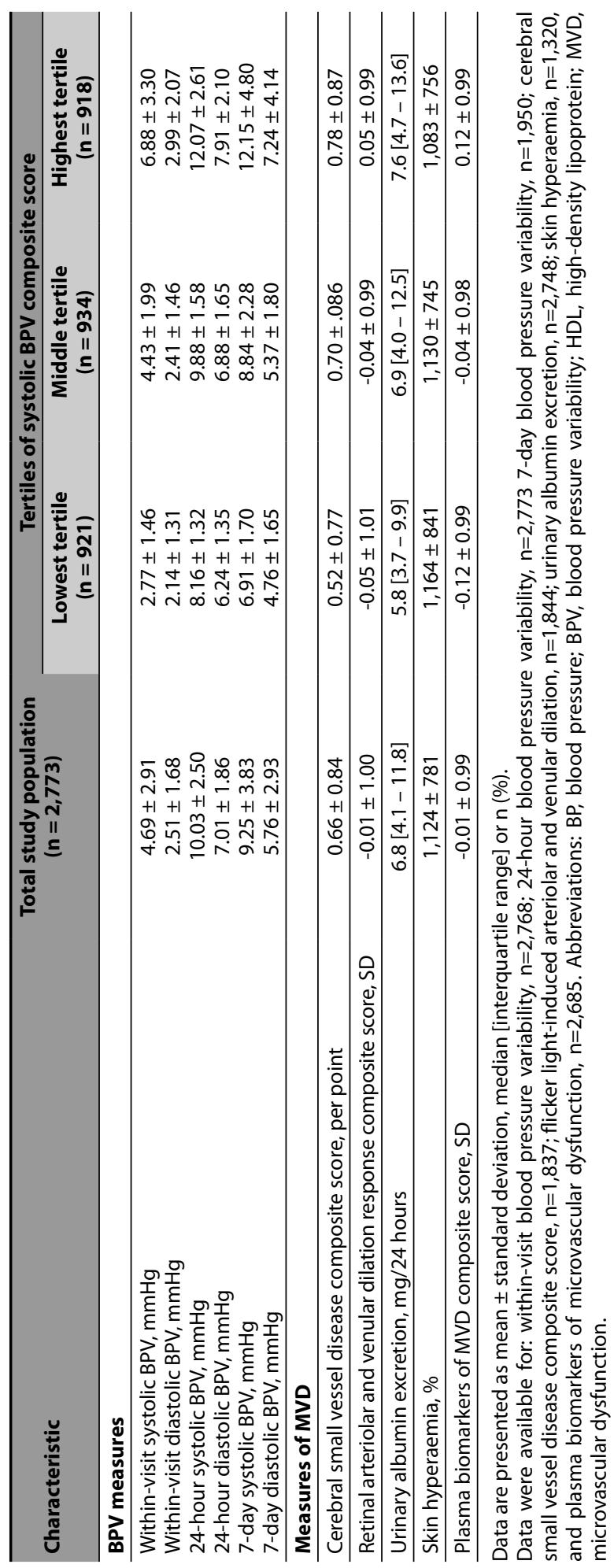


Table 2. Associations between systolic and diastolic blood pressure variability composite scores and microvascular dysfunction measures

\begin{tabular}{|c|c|c|c|c|c|}
\hline \multirow[b]{2}{*}{ Microvascular dysfunction measure } & \multirow[b]{2}{*}{ Model } & \multicolumn{2}{|c|}{$\begin{array}{l}\text { Systolic blood pressure } \\
\text { variability composite } \\
\text { score, per SD }\end{array}$} & \multicolumn{2}{|c|}{$\begin{array}{l}\text { Diastolic blood pressure } \\
\text { variability composite } \\
\text { score, per SD }\end{array}$} \\
\hline & & $\boldsymbol{\beta}$ & $(95 \% \mathrm{Cl})$ & $\boldsymbol{\beta}$ & $(95 \% \mathrm{Cl})$ \\
\hline \multirow{4}{*}{$\begin{array}{l}\text { Cerebral small vessel disease features } \\
\text { composite score, per point }\end{array}$} & 1 & 0.047 & $(0.011-0.083)$ & 0.049 & $(0.013-0.088)$ \\
\hline & 2 & 0.036 & $(0.000-0.073)$ & 0.043 & $(0.005-0.081)$ \\
\hline & 3 & 0.023 & $(-0.015-0.051)$ & 0.036 & $(-0.003-0.074)$ \\
\hline & 4 & 0.016 & $(-0.021-0.054)$ & 0.030 & $(-0.008-0.069)$ \\
\hline \multirow{4}{*}{$\begin{array}{l}\text { Retinal arteriolar and venular dilation } \\
\text { composite score, per SD }\end{array}$} & 1 & 0.033 & $(-0.014-0.081)$ & 0.021 & $(-0.030-0.071)$ \\
\hline & 2 & 0.021 & $(-0.027-0.069)$ & 0.014 & $(-0.036-0.064)$ \\
\hline & 3 & 0.030 & $(-0.020-0.081)$ & 0.027 & $(-0.023-0.078)$ \\
\hline & 4 & 0.031 & $(-0.019-0.082)$ & 0.025 & $(-0.025-0.076)$ \\
\hline \multirow{4}{*}{$\begin{array}{l}\text { Urinary albumin excretion, higher } \\
\text { ratio }\end{array}$} & 1 & 1.14 & $(1.10-1.18)$ & 1.13 & $(1.09-1.17)$ \\
\hline & 2 & 1.11 & $(1.07-1.15)$ & 1.11 & $(1.09-1.15)$ \\
\hline & 3 & 1.05 & $(1.01-1.09)$ & 1.09 & $(1.09-1.13)$ \\
\hline & 4 & 1.04 & $(1.00-1.08)$ & 1.07 & $(1.03-1.11)$ \\
\hline \multirow[t]{4}{*}{ Skin hyperaemia, per SD } & 1 & 0.027 & $(-0.029-0.083)$ & 0.007 & $(-0.050-0.064)$ \\
\hline & 2 & 0.006 & $(-0.051-0.063)$ & -0.009 & $(-0.066-0.048)$ \\
\hline & 3 & -0.001 & $(-0.060-0.058)$ & -0.006 & $(-0.064-0.052)$ \\
\hline & 4 & 0.005 & $(-0.054-0.065)$ & -0.003 & $(-0.061-0.055)$ \\
\hline \multirow{4}{*}{$\begin{array}{l}\text { Plasma biomarkers of microvascular } \\
\text { dysfunction composite score, per SD }\end{array}$} & 1 & 0.089 & $(0.052-0.126)$ & 0.082 & $(0.043-0.120)$ \\
\hline & 2 & 0.052 & $(0.015-0.088)$ & 0.054 & $(0.017-0.092)$ \\
\hline & 3 & 0.057 & $(0.019-0.095)$ & 0.056 & $(0.018-0.093)$ \\
\hline & 4 & 0.035 & $(-0.001-0.072)$ & 0.023 & $(-0.013-0.060)$ \\
\hline
\end{tabular}

Model 1: adjusted for age, sex; model 2: model 1 + glucose metabolism status; model 3: model $2+$ mean $24-$ hour systolic or diastolic blood pressure (where appropriate); model 4: model 3 + education level, body mass index, smoking status, alcohol consumption, total/high density lipoprotein cholesterol ratio, lipid-modifying medication, and the individual classes of antihypertensive medication (i.e. beta blockers, diuretics, calcium channel blockers, angiotensin-converting enzyme inhibitors and angiotensin II receptor blockers).

Abbreviations: $\mathrm{Cl}$ : confidence interval; SD: standard deviation. 


\section{Supplemental Material}

\section{Item S1 Brain magnetic resonance imaging}

Brain magnetic resonance imaging (MRI) was performed on a 3T MRI scanner (Siemens Magnetom Prisma-fit Syngo MR D13D, Erlangen, Germany) by use of a 64-element head/neck coil for parallel imaging. The MRI protocol consisted of a 3D $\mathrm{T}_{1}$-weighted magnetization prepared rapid acquisition gradient echo (MPRAGE) sequence (TR/TI/ TE 2300/900/2.98 ms, 176 slices, $256 \times 240$ matrix size, $1.00 \mathrm{~mm}$ cubic voxel size); a fluidattenuated inversion recovery (FLAIR) sequence (TR/TI/TE 5000/1800/394 ms, 176 slices, $512 \times 512$ matrix size, $0.49 \times 0.49 \times 1.00 \mathrm{~mm}$ voxel size); a combined proton density (PD) and $\mathrm{T}_{2}$-weighted turbo spin echo (TSE) pulse sequence (TR/TE1/TE2 3200/9.4/94 ms, 30 slices, $640 \times 540$ matrix size, $0.36 \times 0.36 \times 4.00 \mathrm{~mm}$ voxel size); and a susceptibility-weighted imaging (SWI) sequence (TR/TE $28 / 20 \mathrm{~ms}, 144$ slices, $384 \times 312$ matrix size, $0.57 \times 0.57 \times 1.00$ $\mathrm{mm}$ voxel size).

Contra-indications for MRI assessments were the presence of a cardiac pacemaker or implantable cardioverter-defibrillator, neurostimulator, non-detachable insulin pump, metallic vascular clips or stents in the head, cochlear implant, metal-containing intrauterine device, metal splinters or shrapnel, dentures with magnetic clip, an inside bracket, pregnancy, epilepsy, and claustrophobia.

$\mathrm{T}_{1}$-weighted images and FLAIR images were analyzed by use of an ISO-13485:2012 certified, automated method (which included visual inspection)., ${ }^{1,2} \mathrm{~T}_{1}$-weighted images were segmented into grey matter, white matter and cerebrospinal fluid volumes (1 voxel $\left.=1.00 \mathrm{~mm}^{3}=0.001 \mathrm{ml}\right){ }^{1}$ Intracranial volume was calculated as the sum of grey matter, white matter (including white matter hyperintensity volume) and cerebrospinal fluid volumes. Total brain parenchyma volume was calculated as the sum of grey and white matter volumes. White matter hyperintensities identified were summed to assess total white matter hyperintensities burden in milliliter. Lacunar infarcts were defined as focal brain parenchyma defects of $\geq 3 \mathrm{~mm}$ and $<15 \mathrm{~mm}$ in size with a similar signal intensity as cerebrospinal fluid on all sequences and a hyperintense rim on $T_{2}$ and FLAIR images. ${ }^{3}$ Cerebral microbleeds were rated on $\mathrm{T}_{2}$-weighted and SWI images by use of the Microbleed Anatomical Rating Scale, ${ }^{4}$ and were defined as focal lesions of $\geq 2 \mathrm{~mm}$ and $\leq 10 \mathrm{~mm}$ in size with a hypointense signal. ${ }^{3}$ The presence of lacunar infarcts and cerebral microbleeds was rated manually by three neuroradiologists. The two-way mixed effects, consistency, intraclass correlation coefficients for the three raters based on 50 randomly selected scans were $0.84(95 \%$ confidence interval $0.74 ; 0.91)$ and $0.83(0.72 ; 0.90)$ for the presence of lacunar infarcts and cerebral microbleeds, respectively. 


\section{References}

1. Vrooman HA, Cocosco CA, van der Lijn F, Stokking R, Ikram MA, Vernooij MW, Breteler MM and Niessen WJ. Multi-spectral brain tissue segmentation using automatically trained k-NearestNeighbor classification. Neurolmage. 2007;37:71-81.

2. de Boer R, Vrooman HA, van der Lijn F, Vernooij MW, Ikram MA, van der Lugt A, Breteler MM and Niessen WJ. White matter lesion extension to automatic brain tissue segmentation on MRI. Neurolmage. 2009;45:1151-61.

3. Wardlaw JM, Smith EE, Biessels GJ, Cordonnier C, Fazekas F, Frayne R, Lindley RI, O'Brien JT, Barkhof F, Benavente OR, Black SE, Brayne C, Breteler M, Chabriat H, Decarli C, de Leeuw FE, Doubal F, Duering M, Fox NC, Greenberg S, Hachinski V, Kilimann I, Mok V, Oostenbrugge R, Pantoni L, Speck O, Stephan BC, Teipel S, Viswanathan A, Werring D, Chen C, Smith C, van Buchem $M$, Norrving $B$, Gorelick PB, Dichgans $M$ and nEuroimaging STfRVco. Neuroimaging standards for research into small vessel disease and its contribution to ageing and neurodegeneration. Lancet Neurol. 2013;12:822-38.

4. Gregoire SM, Chaudhary UJ, Brown MM, Yousry TA, Kallis C, Jager HR and Werring DJ. The Microbleed Anatomical Rating Scale (MARS): reliability of a tool to map brain microbleeds. Neurology. 2009;73:1759-66. 


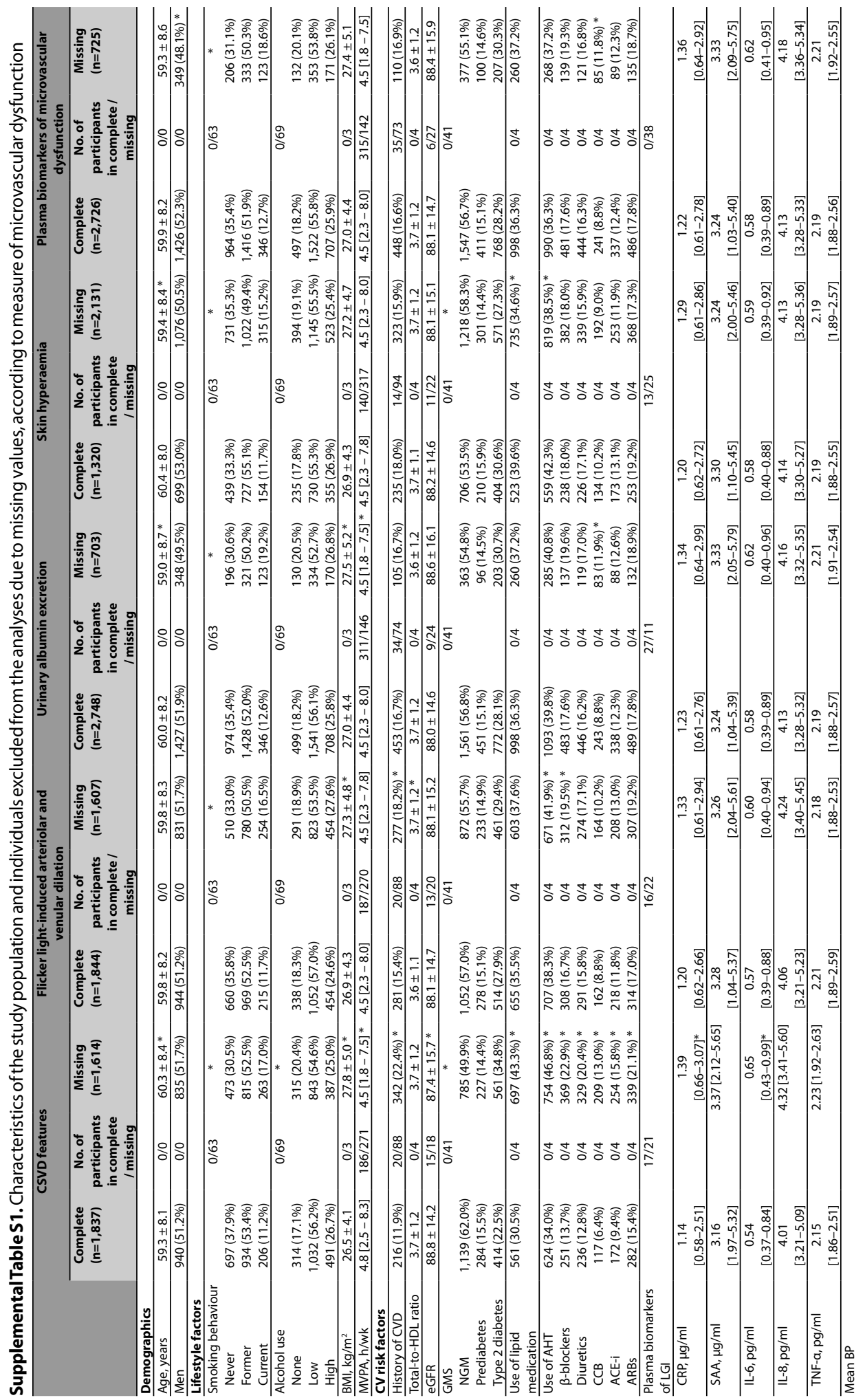




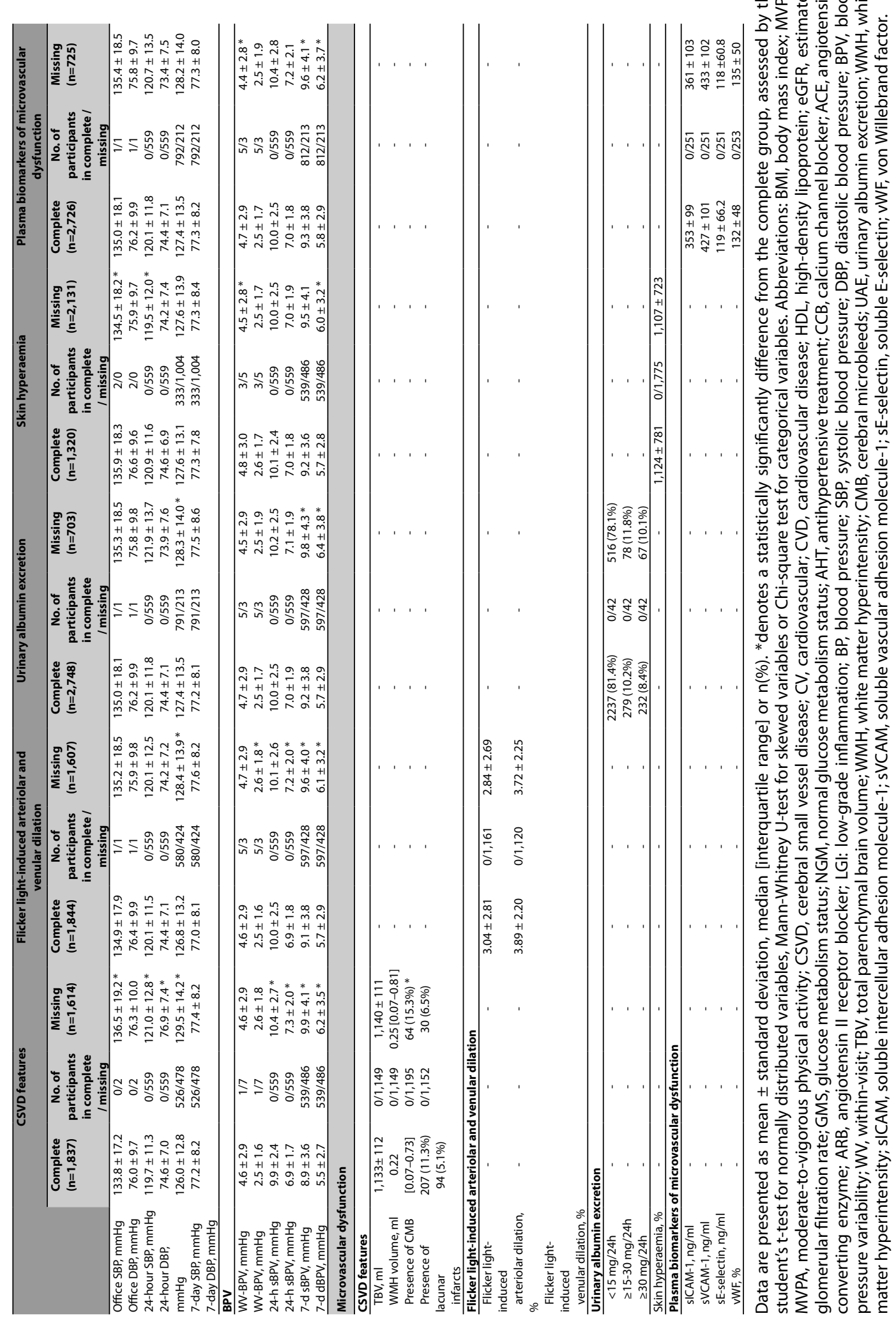




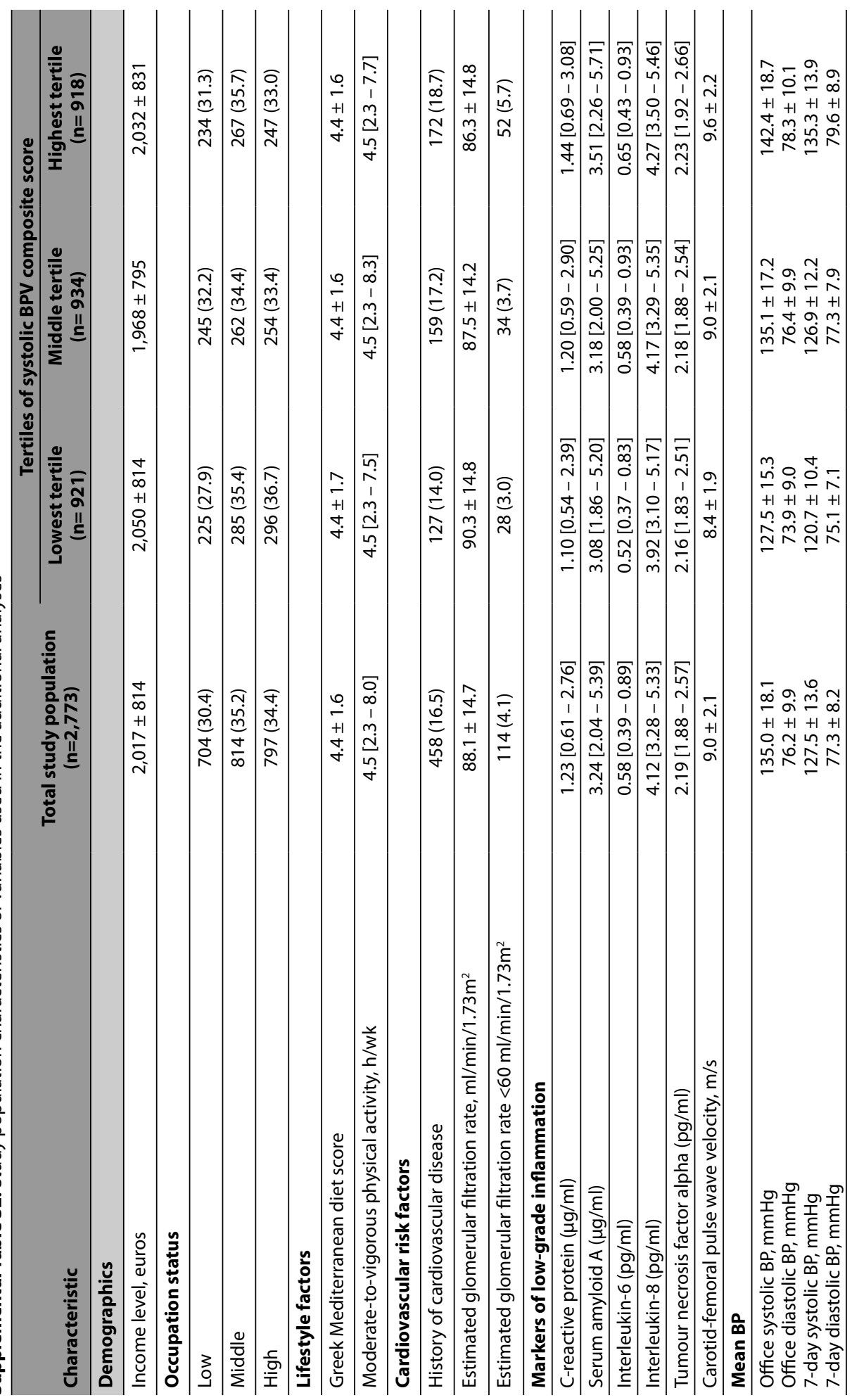




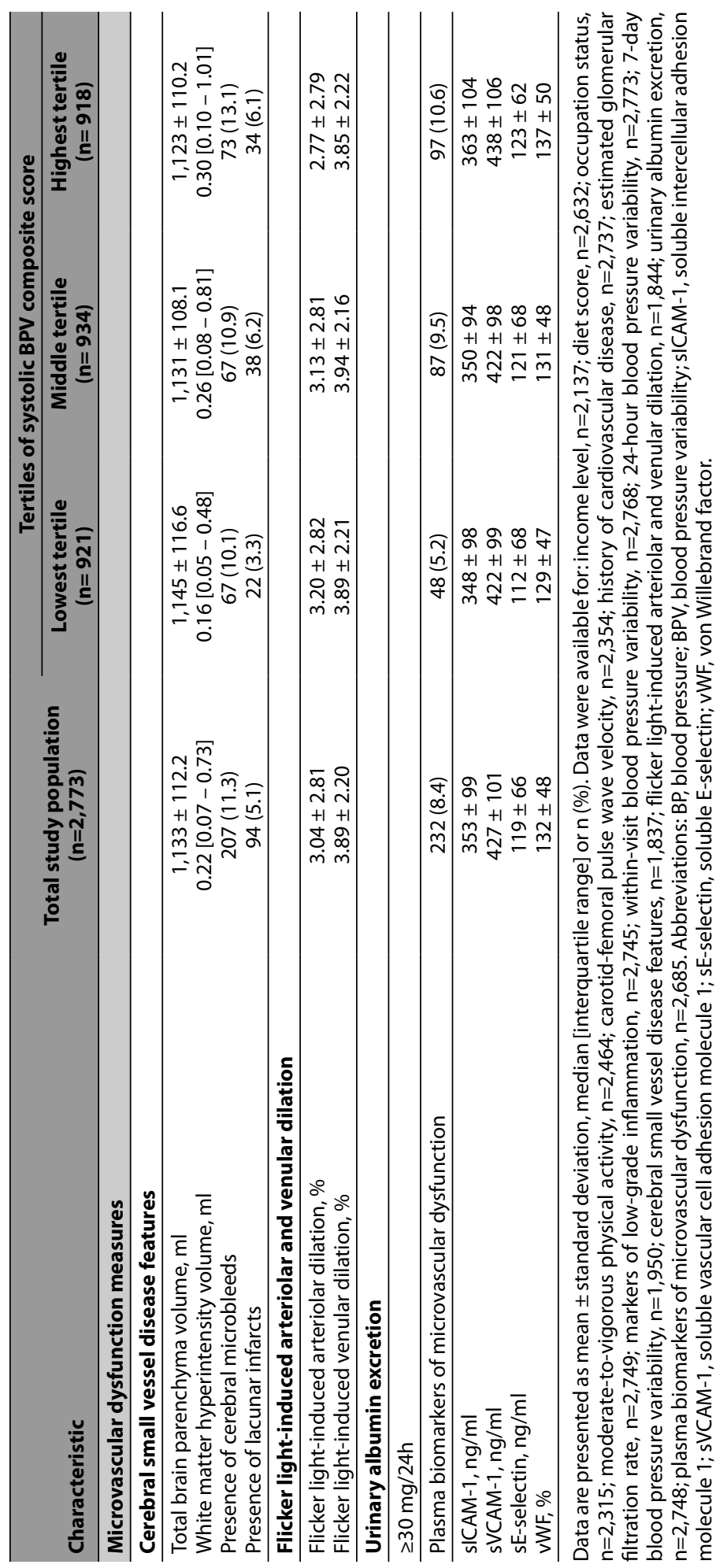




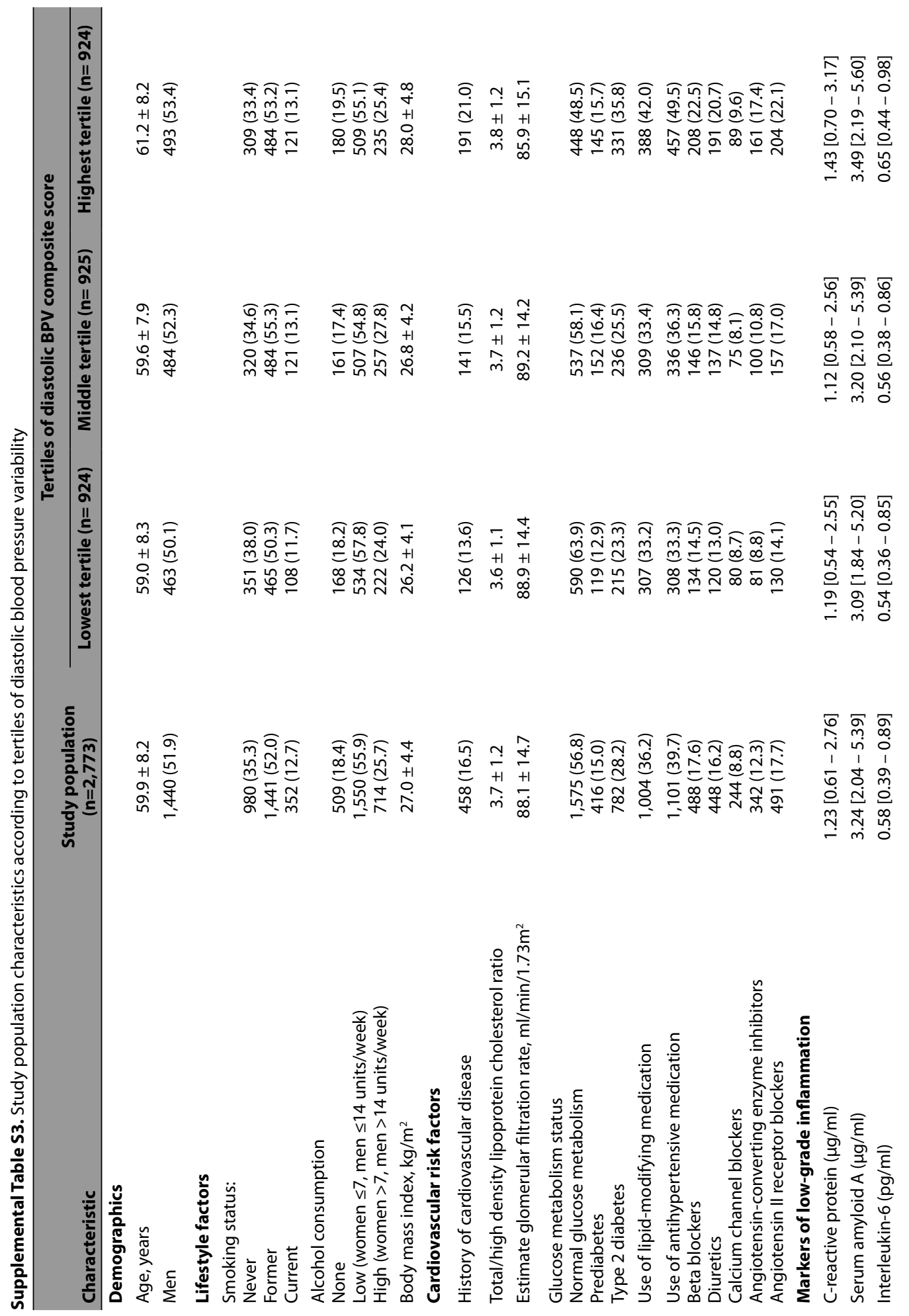




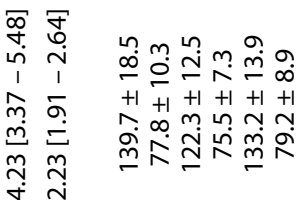

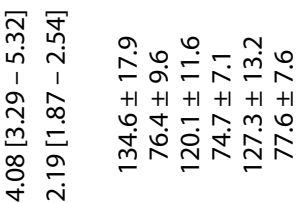

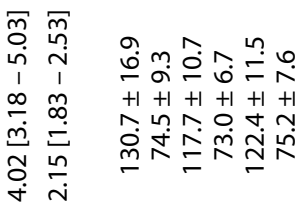

m

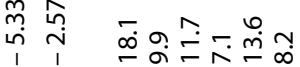

$\stackrel{\infty}{\infty} \infty \begin{array}{lll}\infty & +1+1+1+1+1+1\end{array}$

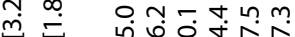

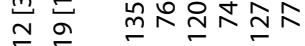

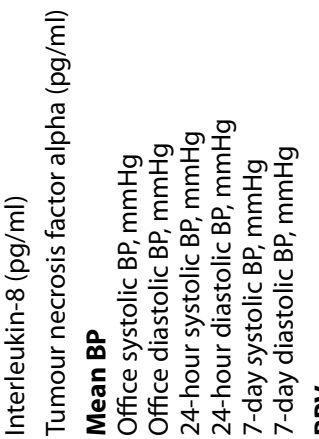

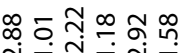

$+1+1+1+1+1+1$

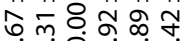

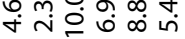

ำ ino$+1+1+1+1+1+1$

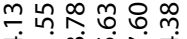

бํํำ $\dot{\mathrm{i}}-\dot{\mathrm{N}}+\dot{m} \boldsymbol{i}$ $+1+1+1+1+1$

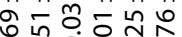

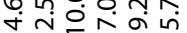

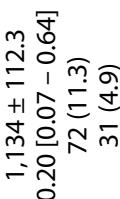

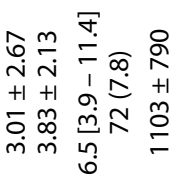

๑ீ:

$\because 0$.

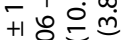

栗造

o

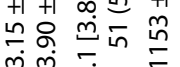

mi $\overline{0}=$

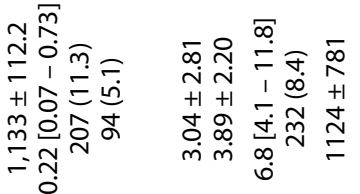

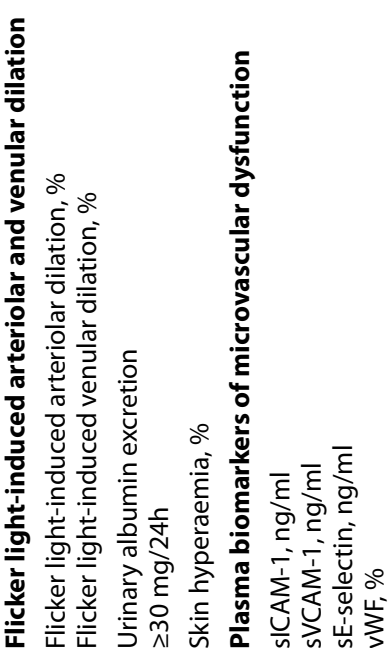

$+1+1+1$
응ㅇㅇ

$+1+1+1+1$

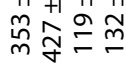

प운

중은 흥

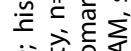

守产哓导

$+1+1+1+100$

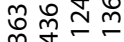

สํำ

宁 $\stackrel{2}{\sim} \div \bar{m}$

สํำร

$+1+1+1$

$\stackrel{\infty}{m} \underset{\sim}{\sim} \stackrel{n}{\leftarrow} \stackrel{m}{\sim}$

II $\frac{1}{2} \frac{\bar{c}}{\mathrm{~N}}$

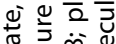

ᄃ 仓ै 㝏

음흔드

흉ㅎㅇ응

능 은 등

중

눙

흥 ồ

춴

है $\frac{\lambda}{\sqrt{2}} \frac{0}{0}$

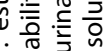

응 部文

ه

त्ञ

흐응

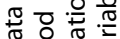

응흔

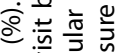

ᄃ

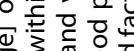

了다은

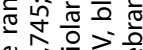

철 일

元

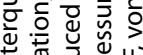

$\leqq$ ह 흥ㅎㄱ

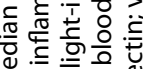

这市

бँ

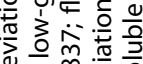

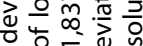

읗 $\stackrel{1}{\frac{1}{4}}$

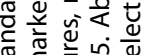

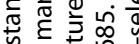

$+1$

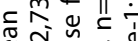

है II む す

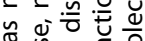

ช

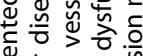

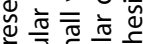

这记

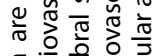


Supplemental Table S4. $P$ values of interactions with age, sex, and glucose metabolism status

\begin{tabular}{|c|c|c|c|c|}
\hline & \multicolumn{2}{|c|}{$\begin{array}{l}\text { Systolic blood pressure } \\
\text { variability composite } \\
\text { score }\end{array}$} & \multicolumn{2}{|c|}{$\begin{array}{l}\text { Diastolic blood pressure } \\
\text { variability composite score }\end{array}$} \\
\hline \multicolumn{5}{|l|}{ Interaction with age ( $<60$ vs. $\geq 60$ years) } \\
\hline Cerebral small vessel disease features & \multicolumn{2}{|c|}{0.465} & \multicolumn{2}{|c|}{0.226} \\
\hline Retinal arteriolar and venular dilation & \multicolumn{2}{|c|}{0.916} & \multicolumn{2}{|c|}{0.461} \\
\hline Urinary albumin excretion & \multicolumn{2}{|c|}{$0.039 *$} & \multicolumn{2}{|c|}{0.171} \\
\hline Skin hyperaemia & \multicolumn{2}{|c|}{0.579} & \multicolumn{2}{|c|}{0.779} \\
\hline Plasma biomarkers of MVD & \multicolumn{2}{|c|}{0.389} & \multicolumn{2}{|c|}{$0.046 *$} \\
\hline \multicolumn{5}{|l|}{ Interaction with sex } \\
\hline Cerebral small vessel disease features & \multicolumn{2}{|c|}{0.782} & \multicolumn{2}{|c|}{0.955} \\
\hline Retinal arteriolar and venular dilation & \multicolumn{2}{|c|}{0.458} & \multicolumn{2}{|c|}{0.788} \\
\hline Urinary albumin excretion & \multicolumn{2}{|c|}{$<0.001+$} & \multicolumn{2}{|c|}{$<0.001+$} \\
\hline Skin hyperaemia & \multicolumn{2}{|c|}{0.450} & \multicolumn{2}{|c|}{0.413} \\
\hline Plasma biomarkers of MVD & \multicolumn{2}{|c|}{0.150} & \multicolumn{2}{|c|}{$0.013+$} \\
\hline Interaction with glucose metabolism status & Prediabetes & $\begin{array}{c}\text { Type } 2 \\
\text { diabetes }\end{array}$ & Prediabetes & $\begin{array}{c}\text { Type } 2 \\
\text { diabetes }\end{array}$ \\
\hline Cerebral small vessel disease features & 0.803 & $0.030 \neq$ & 0.503 & 0.080 \\
\hline Retinal arteriolar and venular dilation & 0.959 & 0.132 & 0.473 & 0.066 \\
\hline Urinary albumin excretion & 0.639 & 0.121 & 0.628 & 0.057 \\
\hline Skin hyperaemia & 0.681 & 0.799 & 0.449 & 0.816 \\
\hline Plasma biomarkers of MVD & 0.050 & 0.652 & 0.107 & $0.011 \neq$ \\
\hline
\end{tabular}

*For statistically significant interactions with age, associations appeared stronger in individuals $\geq 60$ years. + For statistically significant interactions with sex, associations appeared stronger in men. ¥For statistically significant interactions with glucose metabolism status, associations with cerebral small vessel disease features appeared stronger in individuals with normal glucose metabolism status, whereas associations with plasma biomarkers of MVD appeared stronger in individuals with type 2 diabetes. Abbreviations: MVD, microvascular dysfunction. 


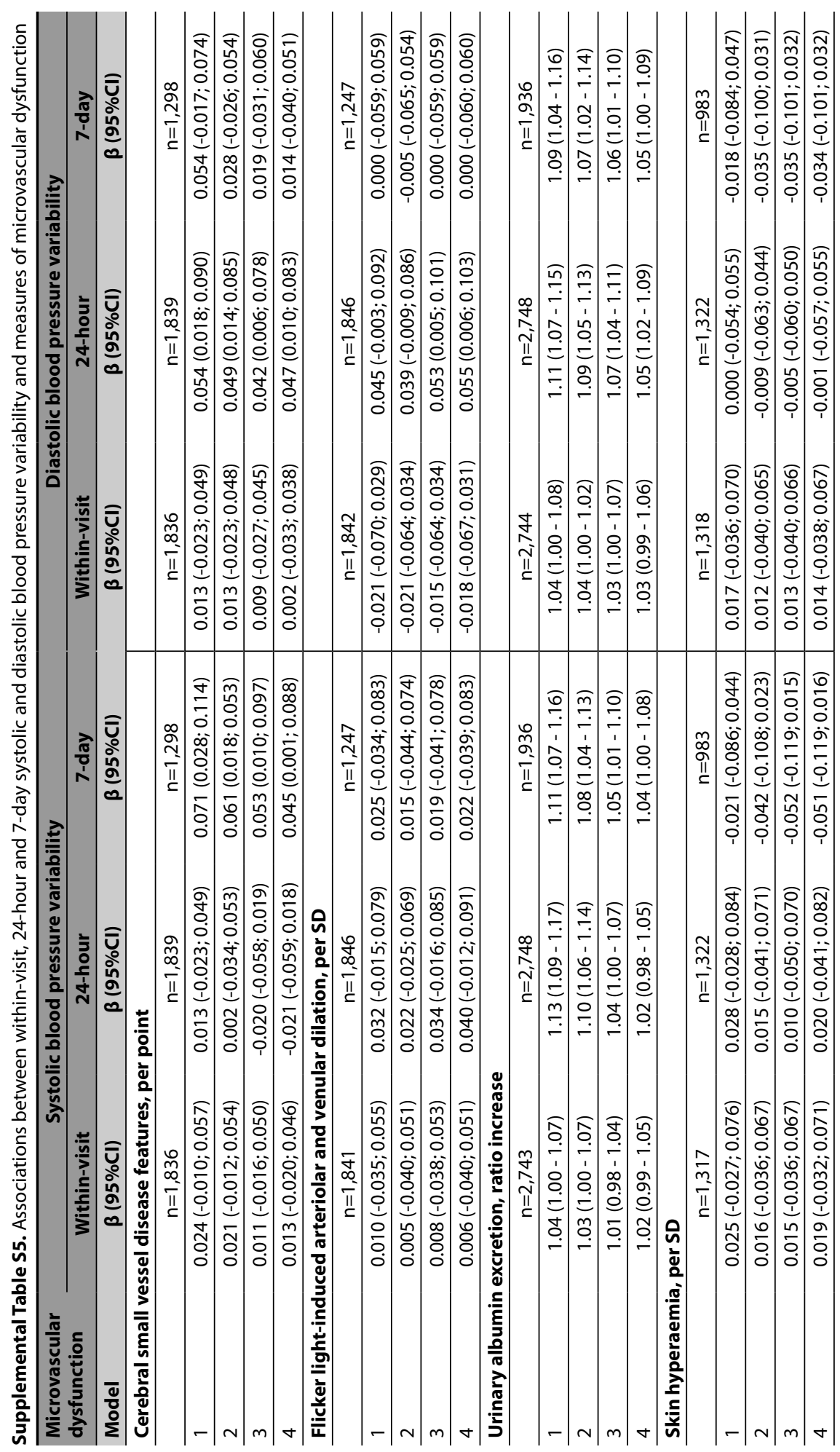




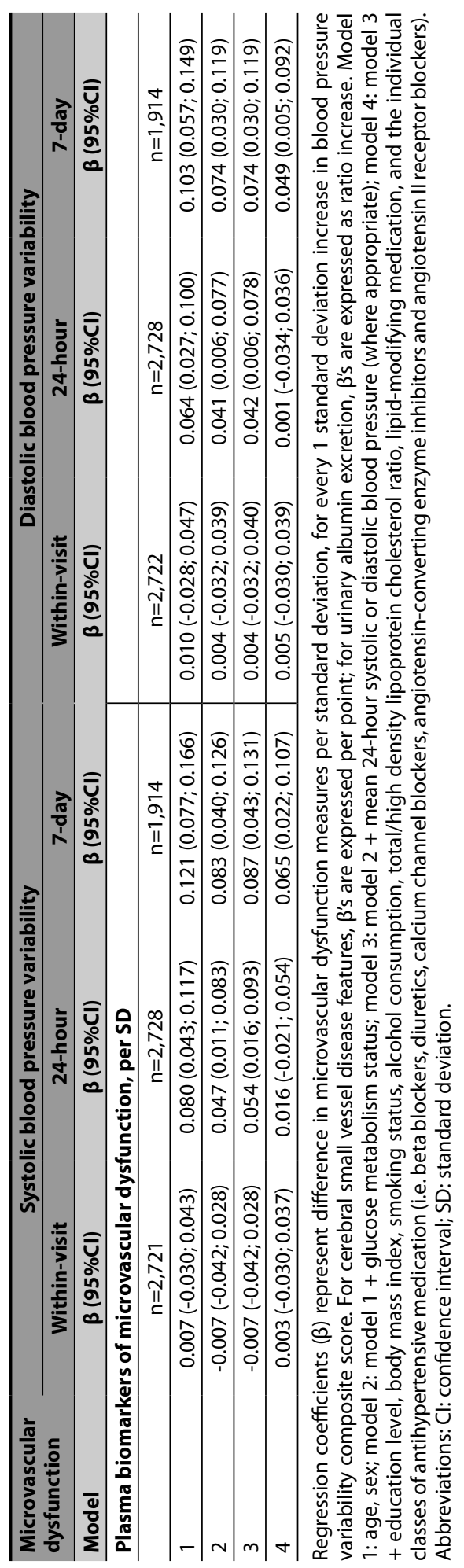


Supplemental Table 6. Associations between systolic and diastolic blood pressure variability and individual measures of microvascular dysfunction

\begin{tabular}{|c|c|c|c|c|c|}
\hline \multirow[b]{2}{*}{ Microvascular dysfunction } & \multirow[b]{2}{*}{ Model } & \multicolumn{2}{|c|}{$\begin{array}{l}\text { Systolic blood pressure } \\
\text { variability composite } \\
\text { score, per SD }\end{array}$} & \multicolumn{2}{|c|}{$\begin{array}{l}\text { Diastolic blood pressure } \\
\text { variability composite } \\
\text { score, per SD }\end{array}$} \\
\hline & & OR & $(95 \% \mathrm{Cl})$ & OR & $(95 \% \mathrm{Cl})$ \\
\hline \multicolumn{6}{|c|}{ Cerebral small vessel disease features } \\
\hline Total parenchymal brain volume, & 1 & 1.05 & $(0.93-1.19)$ & 1.12 & $(0.98-1.28)$ \\
\hline \multirow[t]{3}{*}{ low vs. high } & 2 & 1.02 & $(0.90-1.16)$ & 1.11 & $(0.97-1.27)$ \\
\hline & 3 & 1.05 & $(0.92-1.20)$ & 1.12 & $(0.98-1.29)$ \\
\hline & 4 & 1.01 & $(0.88-1.16)$ & 1.09 & $(0.94-1.25)$ \\
\hline White matter hyperintensity volume, & 1 & 1.13 & $(1.01-1.28)$ & 1.06 & $(0.93-1.20)$ \\
\hline \multirow[t]{3}{*}{ high vs. low } & 2 & 1.11 & $(0.98-1.25)$ & 1.04 & $(0.92-1.19)$ \\
\hline & 3 & 1.01 & $(0.89-1.15)$ & 0.97 & $(0.85-1.11)$ \\
\hline & 4 & 1.00 & $(0.87-1.14)$ & 0.96 & $(0.84-1.11)$ \\
\hline Cerebral microbleeds, presence vs. & 1 & 1.12 & $(0.96-1.30)$ & 1.09 & $(0.92-1.28)$ \\
\hline \multirow[t]{3}{*}{ absence } & 2 & 1.11 & $(0.96-1.29)$ & 1.08 & $(0.92-1.27)$ \\
\hline & 3 & 1.08 & $(0.92-1.27)$ & 1.07 & $(0.91-1.26)$ \\
\hline & 4 & 1.09 & $(0.92-1.28)$ & 1.07 & $(0.91-1.27)$ \\
\hline Lacunar infarcts, presence vs. & 1 & 1.20 & $(0.98-1.47)$ & 1.25 & $(1.01-1.55)$ \\
\hline \multirow[t]{3}{*}{ absence } & 2 & 1.17 & $(0.95-1.45)$ & 1.23 & $(0.99-1.53)$ \\
\hline & 3 & 1.15 & $(0.93-1.44)$ & 1.23 & $(0.99-1.52)$ \\
\hline & 4 & 1.16 & $(0.93-1.45)$ & 1.22 & $(0.98-1.52)$ \\
\hline $\begin{array}{l}\text { Flicker light-induced retinal } \\
\text { arteriolar and venular dilation }\end{array}$ & Model & $\boldsymbol{\beta}$ & $(95 \% \mathrm{Cl})$ & $\boldsymbol{\beta}$ & $(95 \% \mathrm{CI})$ \\
\hline \multirow{4}{*}{$\begin{array}{l}\text { Flicker light-induced arteriolar } \\
\text { dilation, per SD }\end{array}$} & 1 & -0.028 & $(-0.076 ; 0.020)$ & -0.013 & $(-0.064 ; 0.037)$ \\
\hline & 2 & -0.010 & $(-0.058 ; 0.038)$ & -0.004 & $(-0.054 ; 0.046)$ \\
\hline & 3 & -0.021 & $(-0.071 ; 0.029)$ & -0.014 & $(-0.064 ; 0.037)$ \\
\hline & 4 & -0.021 & $(-0.072 ; 0.030)$ & -0.014 & $(-0.066 ; 0.037)$ \\
\hline \multirow{4}{*}{$\begin{array}{l}\text { Flicker light-induced venular dilation, } \\
\text { per SD }\end{array}$} & 1 & -0.015 & $(-0.063 ; 0.032)$ & -0.018 & $(-0.067 ; 0.032)$ \\
\hline & 2 & -0.013 & $(-0.061 ; 0.035)$ & -0.016 & $(-0.066 ; 0.033)$ \\
\hline & 3 & -0.014 & $(-0.064 ; 0.036)$ & -0.027 & $(-0.077 ; 0.024)$ \\
\hline & 4 & -0.016 & $(-0.066 ; 0.034)$ & -0.022 & $(-0.073 ; 0.028)$ \\
\hline $\begin{array}{l}\text { Plasma biomarkers of microvascular } \\
\text { dysfunction }\end{array}$ & Model & $\beta$ & $(95 \% \mathrm{Cl})$ & $\boldsymbol{\beta}$ & $(95 \% \mathrm{Cl})$ \\
\hline \multirow{4}{*}{$\begin{array}{l}\text { Soluble intracellular adhesion } \\
\text { molecule-1, per SD }\end{array}$} & 1 & 0.074 & $(0.035-0.112)$ & 0.055 & $(0.016-0.094)$ \\
\hline & 2 & 0.041 & $(0.003-0.079)$ & 0.032 & $(-0.007-0.070)$ \\
\hline & 3 & 0.041 & $(0.002-0.081)$ & 0.031 & $(-0.008-0.069)$ \\
\hline & 4 & 0.022 & $(-0.016-0.060)$ & 0.005 & $(-0.033-0.042)$ \\
\hline \multirow{4}{*}{$\begin{array}{l}\text { Soluble vascular adhesion molecule-1, } \\
\text { per SD }\end{array}$} & 1 & 0.056 & $(0.018-0.094)$ & 0.067 & $(0.028-0.105)$ \\
\hline & 2 & 0.038 & $(0.000-0.076)$ & 0.054 & $(0.016-0.093)$ \\
\hline & 3 & 0.044 & $(0.005-0.084)$ & 0.057 & $(0.018-0.096)$ \\
\hline & 4 & 0.042 & $(0.003-0.082)$ & 0.045 & $(0.006-0.084)$ \\
\hline \multirow[t]{4}{*}{ E-selectin, per SD } & 1 & 0.053 & $(0.014-0.092)$ & 0.047 & $(0.007-0.087)$ \\
\hline & 2 & 0.009 & $(-0.028-0.047)$ & 0.016 & $(-0.022-0.055)$ \\
\hline & 3 & 0.002 & $(-0.037-0.042)$ & 0.009 & $(-0.030-0.048)$ \\
\hline & 4 & -0.019 & $(-0.057-0.019)$ & -0.022 & $(-0.059-0.016)$ \\
\hline Von Willebrand Factor, per SD & 1 & 0.058 & $(0.021-0.096)$ & 0.054 & $(0.015-0.093)$ \\
\hline
\end{tabular}




\begin{tabular}{cccccc}
\hline & & $\begin{array}{c}\text { Systolic blood pressure } \\
\text { variability composite } \\
\text { score, per SD }\end{array}$ & $\begin{array}{c}\text { Diastolic blood pressure } \\
\text { variability composite } \\
\text { Score, per SD }\end{array}$ \\
\hline Microvascular dysfunction & Model & OR & $\mathbf{( 9 5 \% ~ C I )}$ & OR & $\mathbf{( 9 5 \% ~ C I ) ~}$ \\
\hline & 2 & 0.045 & $(0.007-0.083)$ & 0.045 & $(0.006-0.083)$ \\
\hline 3 & 0.062 & $(0.023-0.102)$ & 0.054 & $(0.014-0.093)$ \\
\hline 4 & 0.051 & $(0.012-0.091)$ & 0.036 & $(-0.003-0.075)$ \\
\hline
\end{tabular}

Regression coefficients $(\beta)$ represent difference in markers of microvascular dysfunction for every 1 standard deviation increase in blood pressure variability composite score. Model 1: age, sex. Model 2: model $1+$ glucose metabolism status. Model 3: model $2+$ mean 24-hour systolic or diastolic blood pressure (where appropriate). Model 4: model 3 + body mass index, smoking behaviour, alcohol use, education level, total-to-high density lipoprotein cholesterol ratio, (individual classes of) antihypertensive medication, lipid-modifying medication. Abbreviations: $\mathrm{Cl}$, confidence interval; $\mathrm{SD}$, standard deviation; OR, odds ratio. 
Supplemental Table S7. Associations between systolic and diastolic blood pressure variability and measures of microvascular dysfunction, additionally adjusted for estimated glomerular filtration rate

\begin{tabular}{|c|c|c|c|c|c|}
\hline \multirow[b]{2}{*}{ Microvascular dysfunction } & \multirow[b]{2}{*}{ Model } & \multicolumn{2}{|c|}{$\begin{array}{l}\text { Systolic blood pressure } \\
\text { variability composite } \\
\text { score, per SD }\end{array}$} & \multicolumn{2}{|c|}{$\begin{array}{c}\text { Diastolic blood pressure } \\
\text { variability composite } \\
\text { score, per SD }\end{array}$} \\
\hline & & $\boldsymbol{\beta}$ & $(95 \% \mathrm{Cl})$ & $\boldsymbol{\beta}$ & $(95 \% \mathrm{CI})$ \\
\hline \multirow{2}{*}{$\begin{array}{l}\text { Cerebral small vessel disease features, } \\
\text { per point }\end{array}$} & 1 & 0.045 & $(0.009-0.082)$ & 0.048 & $(0.009-0.086)$ \\
\hline & 2 & 0.035 & $(0.001-0.071)$ & 0.041 & $(0.003-0.079)$ \\
\hline \multirow[t]{3}{*}{$\mathrm{n}=1,822$} & 3 & 0.021 & $(-0.017-0.059)$ & 0.034 & $(-0.005-0.073)$ \\
\hline & 4 & 0.014 & $(-0.023-0.052)$ & 0.027 & $(-0.011-0.066)$ \\
\hline & 5 & 0.014 & $(-0.024-0.052)$ & 0.028 & $(-0.010-0.067)$ \\
\hline \multirow{2}{*}{$\begin{array}{l}\text { Flicker light-induced arteriolar and } \\
\text { venular }\end{array}$} & 1 & 0.033 & $(-0.015-0.081)$ & 0.019 & $(-0.031-0.070)$ \\
\hline & 2 & 0.020 & $(-0.028-0.069)$ & 0.013 & $(-0.037-0.063)$ \\
\hline dilation, per SD & 3 & 0.030 & $(-0.021-0.080)$ & 0.026 & $(-0.024-0.077)$ \\
\hline \multirow[t]{2}{*}{$\mathrm{n}=1,831$} & 4 & 0.031 & $(-0.020-0.082)$ & 0.025 & $(-0.026-0.076)$ \\
\hline & 5 & 0.031 & $(-0.020-0.082)$ & 0.025 & $(-0.026-0.076)$ \\
\hline \multirow{5}{*}{$\begin{array}{l}\text { Urinary albumin excretion, ratio } \\
\text { increase } \\
n=2,724\end{array}$} & 1 & 1.14 & $(1.10-1.18)$ & 1.13 & $(1.09-1.17)$ \\
\hline & 2 & 1.10 & $(1.07-1.14)$ & 1.10 & $(1.07-1.15)$ \\
\hline & 3 & 1.05 & $(1.01-1.09)$ & 1.09 & $(1.05-1.13)$ \\
\hline & 4 & 1.04 & $(1.00-1.08)$ & 1.07 & $(1.03-1.11)$ \\
\hline & 5 & 1.04 & $(1.00-1.08)$ & 1.07 & $(1.03-1.11)$ \\
\hline Skin hyperaemia, per SD & 1 & 0.028 & $(-0.028-0.085)$ & 0.006 & $(-0.051-0.064)$ \\
\hline \multirow[t]{4}{*}{$n=1,309$} & 2 & 0.007 & $(-0.050-0.064)$ & -0.009 & $(-0.067-0.048)$ \\
\hline & 3 & -0.000 & $(-0.060-0.059)$ & -0.007 & $(-0.065-0.051)$ \\
\hline & 4 & 0.007 & $(-0.053-0.066)$ & -0.003 & $(-0.061-0.055)$ \\
\hline & 5 & 0.007 & $(-0.053-0.066)$ & -0.003 & $(-0.061-0.055)$ \\
\hline \multirow[t]{2}{*}{ Plasma biomarkers of microvascular } & 1 & 0.090 & $(0.053-0.127)$ & 0.083 & $(0.044-0.121)$ \\
\hline & 2 & 0.053 & $(0.016-0.089)$ & 0.055 & $(0.018-0.092)$ \\
\hline dysfunction, per SD & 3 & 0.057 & $(0.019-0.095)$ & 0.056 & $(0.019-0.094)$ \\
\hline \multirow[t]{2}{*}{$\mathrm{n}=2,720$} & 4 & 0.036 & $(-0.001-0.072)$ & 0.024 & $(-0.013-0.060)$ \\
\hline & 5 & 0.037 & $(0.001-0.073)$ & 0.025 & $(-0.010-0.061)$ \\
\hline
\end{tabular}

Regression coefficients $(\beta)$ represent difference in microvascular dysfunction measures per standard deviation, for every 1 standard deviation increase in blood pressure variability composite score. For cerebral small vessel disease features, $\beta$ 's are expressed per point; for urinary albumin excretion, $\beta$ 's are expressed as ratio increase. Model 1: age, sex. Model 2: model $1+$ glucose metabolism status. Model 3: model $2+$ mean 24-hour systolic or diastolic blood pressure (where appropriate). Model 4: model 3 + body mass index, smoking behaviour, alcohol use, education level, total-to-high density lipoprotein cholesterol ratio, (individual classes of) antihypertensive medication, lipid-modifying medication. Model 5: model 4 + estimated glomerular filtration rate. Abbreviations: $\mathrm{Cl}$, confidence interval; SD, standard deviation. 
Supplemental Table S8. Associations between systolic and diastolic blood pressure variability and measures of microvascular dysfunction, additionally adjusted for prior cardiovascular disease

\begin{tabular}{|c|c|c|c|c|c|}
\hline \multirow[b]{2}{*}{ Microvascular dysfunction } & \multirow[b]{2}{*}{ Model } & \multicolumn{2}{|c|}{$\begin{array}{l}\text { Systolic blood pressure } \\
\text { variability composite } \\
\text { score, per SD }\end{array}$} & \multicolumn{2}{|c|}{$\begin{array}{c}\text { Diastolic blood pressure } \\
\text { variability composite } \\
\text { score, per SD }\end{array}$} \\
\hline & & $\boldsymbol{\beta}$ & $(95 \% \mathrm{CI})$ & $\boldsymbol{\beta}$ & $(95 \% \mathrm{Cl})$ \\
\hline \multirow{5}{*}{$\begin{array}{l}\text { Cerebral small vessel disease } \\
\text { features, per point } \\
n=1,817\end{array}$} & 1 & 0.044 & $(0.008-0.080)$ & 0.049 & $(0.011-0.088)$ \\
\hline & 2 & 0.034 & $(-0.002-0.070)$ & 0.043 & $(0.005-0.081)$ \\
\hline & 3 & 0.020 & $(-0.018-0.058)$ & 0.036 & $(-0.003-0.074)$ \\
\hline & 4 & 0.013 & $(-0.025-0.051)$ & 0.030 & $(-0.009-0.069)$ \\
\hline & 5 & 0.012 & $(-0.026-0.050)$ & 0.028 & $(-0.011-0.066)$ \\
\hline \multirow{2}{*}{$\begin{array}{l}\text { Flicker light-induced arteriolar } \\
\text { and venular }\end{array}$} & 1 & 0.032 & $(-0.015-0.080)$ & 0.019 & $(-0.032-0.069)$ \\
\hline & 2 & 0.020 & $(-0.028-0.068)$ & 0.012 & $(-0.038-0.062)$ \\
\hline dilation, per SD & 3 & 0.031 & $(-0.019-0.081)$ & 0.026 & $(-0.025-0.076)$ \\
\hline \multirow[t]{2}{*}{$\mathrm{n}=1,824$} & 4 & 0.030 & $(-0.020-0.081)$ & 0.023 & $(-0.027-0.074)$ \\
\hline & 5 & 0.029 & $(-0.021-0.080)$ & 0.023 & $(-0.028-0.074)$ \\
\hline \multirow{5}{*}{$\begin{array}{l}\text { Urinary albumin excretion, ratio } \\
\text { increase } \\
n=2,714\end{array}$} & 1 & 1.14 & $(1.07-1.15)$ & 1.13 & $(1.06-1.14)$ \\
\hline & 2 & 1.11 & $(1.01-1.09)$ & 1.10 & $(1.05-1.12)$ \\
\hline & 3 & 1.05 & $(1.00-1.08)$ & 1.08 & $(1.03-1.10)$ \\
\hline & 4 & 1.04 & $(1.00-1.08)$ & 1.07 & $(1.03-1.10)$ \\
\hline & 5 & 1.04 & $(1.09-1.17)$ & 1.07 & $(1.03-1.10)$ \\
\hline Skin hyperaemia, per SD & 1 & 0.022 & $(-0.034-0.079)$ & 0.008 & $(-0.050-0.065)$ \\
\hline \multirow[t]{4}{*}{$n=1,306$} & 2 & 0.002 & $(-0.055-0.059)$ & -0.008 & $(-0.065-0.050)$ \\
\hline & 3 & -0.004 & $(-0.064-0.056)$ & -0.004 & $(-0.062-0.054)$ \\
\hline & 4 & 0.002 & $(-0.057-0.062)$ & 0.000 & $(-0.059-0.058)$ \\
\hline & 5 & 0.002 & $(-0.057-0.062)$ & 0.000 & $(-0.059-0.058)$ \\
\hline \multirow{2}{*}{$\begin{array}{l}\text { Plasma biomarkers of } \\
\text { microvascular }\end{array}$} & 1 & 0.092 & $(0.055-0.129)$ & 0.081 & $(0.042-0.120)$ \\
\hline & 2 & 0.056 & $(0.019-0.092)$ & 0.054 & $(0.016-0.092)$ \\
\hline dysfunction, per SD & 3 & 0.061 & $(0.023-0.099)$ & 0.056 & $(0.017-0.093)$ \\
\hline \multirow[t]{2}{*}{$n=2,691$} & 4 & 0.040 & $(0.003-0.077)$ & 0.023 & $(-0.014-0.059)$ \\
\hline & 5 & 0.038 & $(0.001-0.075)$ & 0.020 & $(-0.017-0.056)$ \\
\hline
\end{tabular}

Regression coefficients $(\beta)$ represent difference in microvascular dysfunction measures per standard deviation, for every 1 standard deviation increase in blood pressure variability composite score. For cerebral small vessel disease features, $\beta$ 's are expressed per point; for urinary albumin excretion, $\beta$ 's are expressed as ratio increase. Model 1: age, sex. Model 2: model $1+$ glucose metabolism status. Model 3: model $2+$ mean 24-hour systolic or diastolic blood pressure (where appropriate). Model 4: model 3 + body mass index, smoking behaviour, alcohol use, education level, total-to-high density lipoprotein cholesterol ratio, (individual classes of) antihypertensive medication, lipid-modifying medication. Model 5: model $4+$ prior cardiovascular disease. Abbreviations: $\mathrm{Cl}$, confidence interval; SD, standard deviation. 
Supplemental Table S9. Associations between systolic and diastolic blood pressure variability and measures of microvascular dysfunction, additionally adjusted for plasma biomarkers of low-grade inflammation

\begin{tabular}{|c|c|c|c|c|c|}
\hline \multirow[b]{2}{*}{ Microvascular dysfunction } & \multirow[b]{2}{*}{ Model } & \multicolumn{2}{|c|}{$\begin{array}{l}\text { Systolic blood pressure } \\
\text { variability composite } \\
\text { score, per SD }\end{array}$} & \multicolumn{2}{|c|}{$\begin{array}{l}\text { Diastolic blood pressure } \\
\text { variability composite } \\
\text { score, per SD }\end{array}$} \\
\hline & & $\beta$ & $(95 \% \mathrm{Cl})$ & $\beta$ & $(95 \% \mathrm{CI})$ \\
\hline \multirow{2}{*}{$\begin{array}{l}\text { Cerebral small vessel disease } \\
\text { features, per point }\end{array}$} & 1 & 0.046 & $(0.010-0.083)$ & 0.051 & $(0.012-0.090)$ \\
\hline & 2 & 0.036 & $(-0.001-0.072)$ & 0.045 & $(0.007-0.083)$ \\
\hline \multirow[t]{3}{*}{$n=1,820$} & 3 & 0.021 & $(-0.017-0.059)$ & 0.037 & $(-0.002-0.076)$ \\
\hline & 4 & 0.015 & $(-0.023-0.053)$ & 0.031 & $(-0.008-0.070)$ \\
\hline & 5 & 0.015 & $(-0.023-0.053)$ & 0.031 & $(-0.007-0.070)$ \\
\hline \multirow{2}{*}{$\begin{array}{l}\text { Flicker light-induced arteriolar } \\
\text { and venular }\end{array}$} & 1 & 0.035 & $(-0.013-0.083)$ & 0.019 & $(-0.031-0.069)$ \\
\hline & 2 & 0.023 & $(-0.026-0.071)$ & 0.013 & $(-0.038-0.063)$ \\
\hline dilation, per SD & 3 & 0.032 & $(-0.018-0.083)$ & 0.026 & $(-0.025-0.077)$ \\
\hline \multirow[t]{2}{*}{$\mathrm{n}=1,828$} & 4 & 0.034 & $(-0.017-0.085)$ & 0.024 & $(-0.027-0.075)$ \\
\hline & 5 & 0.033 & $(-0.018-0.083)$ & 0.025 & $(-0.026-0.076)$ \\
\hline \multirow{5}{*}{$\begin{array}{l}\text { Urinary albumin excretion, } \\
\text { ratio increase } \\
n=2,721\end{array}$} & 1 & 1.14 & $(1.10-1.18)$ & 1.13 & $(1.09-1.17)$ \\
\hline & 2 & 1.10 & $(1.07-1.14)$ & 1.10 & $(1.07-1.15)$ \\
\hline & 3 & 1.05 & $(1.01-1.09)$ & 1.09 & $(1.05-1.13)$ \\
\hline & 4 & 1.04 & $(1.00-1.08)$ & 1.07 & $(1.03-1.11)$ \\
\hline & 5 & 1.04 & $(1.00-1.08)$ & 1.07 & $(1.03-1.11)$ \\
\hline Skin hyperaemia, per SD & 1 & 0.025 & $(-0.031-0.082)$ & 0.005 & $(-0.052-0.063)$ \\
\hline \multirow[t]{4}{*}{$\mathrm{n}=1,307$} & 2 & 0.005 & $(-0.052-0.062)$ & -0.010 & $(-0.068-0.047)$ \\
\hline & 3 & -0.002 & $(-0.061-0.058)$ & -0.007 & $(-0.066-0.051)$ \\
\hline & 4 & 0.005 & $(-0.054-0.065)$ & -0.004 & $(-0.062-0.054)$ \\
\hline & 5 & 0.002 & $(-0.054-0.065)$ & -0.004 & $(-0.062-0.054)$ \\
\hline \multirow{2}{*}{$\begin{array}{l}\text { Plasma biomarkers of } \\
\text { microvascular }\end{array}$} & 1 & 0.089 & $(0.052-0.126)$ & 0.082 & $(0.043-0.120)$ \\
\hline & 2 & 0.056 & $(0.015-0.088)$ & 0.054 & $(0.017-0.092)$ \\
\hline dysfunction, per SD & 3 & 0.057 & $(0.019-0.095)$ & 0.056 & $(0.018-0.093)$ \\
\hline \multirow[t]{2}{*}{$n=2,726$} & 4 & 0.035 & $(-0.001-0.072)$ & 0.023 & $(-0.013-0.060)$ \\
\hline & 5 & 0.033 & $(-0.002-0.069)$ & 0.026 & $(-0.009-0.061)$ \\
\hline
\end{tabular}

Regression coefficients $(\beta)$ represent difference in microvascular dysfunction measures per standard deviation, for every 1 standard deviation increase in blood pressure variability composite score. For cerebral small vessel disease features, $\beta$ 's are expressed per point; for urinary albumin excretion, $\beta$ 's are expressed as ratio increase. Model 1: age, sex. Model 2: model $1+$ glucose metabolism status. Model 3: model $2+$ mean 24-hour systolic or diastolic blood pressure (where appropriate). Model 4: model 3 + body mass index, smoking behaviour, alcohol use, education level, total-to-high density lipoprotein cholesterol ratio, (individual classes of) antihypertensive medication, lipid-modifying medication. Model 5: model 4 + composite score of plasma biomarkers of lowgrade inflammation. Abbreviations: $\mathrm{Cl}$, confidence interval; SD, standard deviation; OR, odds ratio. 
Supplemental Table S10. Associations between systolic and diastolic blood pressure variability and measures of microvascular dysfunction, additionally adjusted for carotid-femoral pulse wave velocity

\begin{tabular}{|c|c|c|c|c|c|}
\hline \multirow[b]{2}{*}{ Microvascular dysfunction } & \multirow[b]{2}{*}{ Model } & \multicolumn{2}{|c|}{$\begin{array}{c}\text { Systolic blood pressure } \\
\text { variability composite score, } \\
\text { per SD }\end{array}$} & \multicolumn{2}{|c|}{$\begin{array}{l}\text { Diastolic blood pressure } \\
\text { variability composite score, } \\
\text { per SD }\end{array}$} \\
\hline & & $\beta$ & $(95 \% \mathrm{CI})$ & $\boldsymbol{\beta}$ & $(95 \% \mathrm{Cl})$ \\
\hline \multirow{5}{*}{$\begin{array}{l}\text { Cerebral small vessel disease } \\
\text { features, per point } \\
n=1552\end{array}$} & 1 & 0.053 & $(0.013 ; 0.092)$ & 0.048 & $(0.006 ; 0.089)$ \\
\hline & 2 & 0.043 & $(0.004 ; 0.082)$ & 0.041 & $(0.001 ; 0.082)$ \\
\hline & 3 & 0.032 & $(-0.009 ; 0.072)$ & 0.031 & $(-0.010 ; 0.073)$ \\
\hline & 4 & 0.021 & $(-0.020 ; 0.061)$ & 0.022 & $(-0.020 ; 0.063)$ \\
\hline & 5 & 0.018 & $(-0.023 ; 0.059)$ & 0.022 & $(-0.020 ; 0.063)$ \\
\hline \multirow{5}{*}{$\begin{array}{l}\text { Flicker light-induced retinal } \\
\text { arteriolar and venular dilation, } \\
\text { per SD } n=1,519\end{array}$} & 1 & 0.013 & $(-0.039 ; 0.065)$ & 0.020 & $(-0.035 ; 0.074)$ \\
\hline & 2 & 0.002 & $(-0.05 ; 0.055)$ & 0.013 & $(-0.041 ; 0.068)$ \\
\hline & 3 & 0.015 & $(-0.040 ; 0.070)$ & 0.027 & $(-0.028 ; 0.082)$ \\
\hline & 4 & 0.013 & $(-0.042 ; 0.069)$ & 0.023 & $(-0.032 ; 0.079)$ \\
\hline & 5 & 0.013 & $(-0.042 ; 0.069)$ & 0.024 & $(-0.031 ; 0.079)$ \\
\hline \multirow{5}{*}{$\begin{array}{l}\text { Urinary albumin excretion, } \\
\text { ratio increase } n=2,335\end{array}$} & 1 & 1.13 & $(1.09-1.17)$ & 1.12 & $(1.08-1.16)$ \\
\hline & 2 & 1.10 & $(1.06-1.14)$ & 1.10 & $(1.06-1.14)$ \\
\hline & 3 & 1.05 & $(1.01-1.09)$ & 1.08 & $(1.04-1.13)$ \\
\hline & 4 & 1.04 & $(1.00-1.08)$ & 1.07 & $(1.03-1.11)$ \\
\hline & 5 & 1.04 & $(1.00-1.08)$ & 1.07 & $(1.03-1.11)$ \\
\hline \multirow{5}{*}{$\begin{array}{l}\text { Skin hyperaemia, per SD } \\
n=1,142\end{array}$} & 1 & 0.047 & $(-0.014 ; 0.109)$ & 0.024 & $(-0.037 ; 0.086)$ \\
\hline & 2 & 0.025 & $(-0.037 ; 0.087)$ & 0.007 & $(-0.054 ; 0.069)$ \\
\hline & 3 & 0.019 & $(-0.046 ; 0.084)$ & 0.011 & $(-0.052 ; 0.073)$ \\
\hline & 4 & 0.030 & $(-0.036 ; 0.095)$ & 0.017 & $(-0.046 ; 0.080)$ \\
\hline & 5 & 0.030 & $(-0.035 ; 0.095)$ & 0.017 & $(-0.046 ; 0.080)$ \\
\hline \multirow{5}{*}{$\begin{array}{l}\text { Plasma biomarkers of } \\
\text { microvascular dysfunction, per } \\
\text { SD } n=2,313\end{array}$} & 1 & 0.072 & $(0.032 ; 0.112)$ & 0.083 & $(0.043 ; 0.124)$ \\
\hline & 2 & 0.038 & $(-0.001 ; 0.077)$ & 0.059 & $(0.020 ; 0.098)$ \\
\hline & 3 & 0.045 & $(0.005 ; 0.086)$ & 0.060 & $(0.021 ; 0.100)$ \\
\hline & 4 & 0.029 & $(-0.010 ; 0.068)$ & 0.031 & $(-0.007 ; 0.069)$ \\
\hline & 5 & 0.028 & $(-0.011 ; 0.067)$ & 0.031 & $(-0.007 ; 0.069)$ \\
\hline
\end{tabular}

Regression coefficients $(\beta)$ represent difference in microvascular dysfunction measures per standard deviation, for every 1 standard deviation increase in blood pressure variability composite score. For cerebral small vessel disease features, $\beta$ 's are expressed per point; for urinary albumin excretion, $\beta$ 's are expressed as ratio increase. Model 1: age, sex. Model 2: model $1+$ glucose metabolism status. Model 3: model $2+$ mean 24-hour systolic or diastolic blood pressure (where appropriate). Model 4: model $3+$ body mass index, smoking behaviour, alcohol use, education level, total-to-high density lipoprotein cholesterol ratio, (individual classes of) antihypertensive medication, lipid-modifying medication. Model 5: model 4 + carotid-femoral pulse wave velocity. Abbreviations: BPV, blood pressure variability; $\mathrm{Cl}$, confidence interval; SD, standard deviation; OR, odds ratio. 
Supplemental Table S11. Associations between systolic and diastolic blood pressure variability and measures of microvascular dysfunction, additionally adjusted for diet score

\begin{tabular}{|c|c|c|c|c|c|}
\hline \multirow[b]{2}{*}{ Microvascular dysfunction } & \multirow[b]{2}{*}{ Model } & \multicolumn{2}{|c|}{$\begin{array}{l}\text { Systolic blood pressure } \\
\text { variability composite score, } \\
\text { per SD }\end{array}$} & \multicolumn{2}{|c|}{$\begin{array}{l}\text { Diastolic blood pressure } \\
\text { variability composite score, } \\
\text { per SD }\end{array}$} \\
\hline & & $\boldsymbol{\beta}$ & $(95 \% \mathrm{CI})$ & $\boldsymbol{\beta}$ & $(95 \% \mathrm{CI})$ \\
\hline \multirow{5}{*}{$\begin{array}{l}\text { Cerebral small vessel disease } \\
\text { features, per point } \\
n=1,748\end{array}$} & 1 & 0.050 & $(0.013 ; 0.087)$ & 0.048 & $(0.009 ; 0.088)$ \\
\hline & 2 & 0.040 & $(0.003 ; 0.076)$ & 0.042 & $(0.003 ; 0.081)$ \\
\hline & 3 & 0.026 & $(-0.013 ; 0.064)$ & 0.034 & $(-0.006 ; 0.074)$ \\
\hline & 4 & 0.021 & $(-0.017 ; 0.060)$ & 0.030 & $(-0.009 ; 0.069)$ \\
\hline & 5 & 0.021 & $(-0.017 ; 0.060)$ & 0.030 & $(-0.009 ; 0.069)$ \\
\hline \multirow{5}{*}{$\begin{array}{l}\text { Flicker light-induced retinal } \\
\text { arteriolar and venular dilation, } \\
\text { per SD } n=1,758\end{array}$} & 1 & 0.033 & $(-0.017 ; 0.082)$ & 0.014 & $(-0.038 ; 0.065)$ \\
\hline & 2 & 0.021 & $(-0.029 ; 0.070)$ & 0.008 & $(-0.044 ; 0.059)$ \\
\hline & 3 & 0.029 & $(-0.022 ; 0.081)$ & 0.021 & $(-0.031 ; 0.073)$ \\
\hline & 4 & 0.032 & $(-0.021 ; 0.084)$ & 0.021 & $(-0.032 ; 0.073)$ \\
\hline & 5 & 0.032 & $(-0.021 ; 0.084)$ & 0.021 & $(-0.032 ; 0.073)$ \\
\hline \multirow{5}{*}{$\begin{array}{l}\text { Urinary albumin excretion, ratio } \\
\text { increase } n=2,602\end{array}$} & 1 & 1.14 & $(1.09-1.18)$ & 1.12 & $(1.08-1.17)$ \\
\hline & 2 & 1.10 & $(1.07-1.15)$ & 1.10 & $(1.06-1.14)$ \\
\hline & 3 & 1.05 & $(1.01-1.09)$ & 1.08 & $(1.04-1.12)$ \\
\hline & 4 & 1.04 & $(1.00-1.08)$ & 1.06 & $(1.03-1.10)$ \\
\hline & 5 & 1.04 & $(1.00-1.08)$ & 1.06 & $(1.03-1.10)$ \\
\hline \multirow{5}{*}{$\begin{array}{l}\text { Skin hyperaemia, per SD } \\
n=1,249\end{array}$} & 1 & 0.040 & $(-0.018 ; 0.098)$ & 0.019 & $(-0.039 ; 0.078)$ \\
\hline & 2 & 0.019 & $(-0.039 ; 0.078)$ & 0.004 & $(-0.054 ; 0.063)$ \\
\hline & 3 & 0.014 & $(-0.047 ; 0.075)$ & 0.008 & $(-0.051 ; 0.067)$ \\
\hline & 4 & 0.018 & $(-0.043 ; 0.079)$ & 0.009 & $(-0.050 ; 0.068)$ \\
\hline & 5 & 0.018 & $(-0.043 ; 0.08)$ & 0.010 & $(-0.050 ; 0.069)$ \\
\hline \multirow{5}{*}{$\begin{array}{l}\text { Plasma biomarkers of } \\
\text { microvascular dysfunction, per } \\
\text { SD } n=2,575\end{array}$} & 1 & 0.090 & $(0.051 ; 0.128)$ & 0.081 & $(0.041 ; 0.121)$ \\
\hline & 2 & 0.052 & $(0.014 ; 0.089)$ & 0.055 & $(0.016 ; 0.094)$ \\
\hline & 3 & 0.057 & $(0.018 ; 0.097)$ & 0.057 & $(0.018 ; 0.096)$ \\
\hline & 4 & 0.036 & $(-0.002 ; 0.074)$ & 0.025 & $(-0.013 ; 0.062)$ \\
\hline & 5 & 0.036 & $(-0.002 ; 0.074)$ & 0.025 & $(-0.013 ; 0.063)$ \\
\hline
\end{tabular}

Regression coefficients $(\beta)$ represent difference in microvascular dysfunction measures per standard deviation, for every 1 standard deviation increase in blood pressure variability composite score. For cerebral small vessel disease features, $\beta$ 's are expressed per point; for urinary albumin excretion, $\beta$ 's are expressed as ratio increase. Model 1: age, sex. Model 2: model $1+$ glucose metabolism status. Model 3: model $2+$ mean 24-hour systolic or diastolic blood pressure (where appropriate). Model 4: model 3 + body mass index, smoking behaviour, alcohol use, education level, total-to-high density lipoprotein cholesterol ratio, (individual classes of) antihypertensive medication, lipid-modifying medication. Model 5: model $4+\operatorname{diet}$ score. Abbreviations: $\mathrm{Cl}$, confidence interval; SD, standard deviation . 
Supplemental Table S12. Associations between systolic and diastolic blood pressure variability and measures of microvascular dysfunction, additionally adjusted for physical activity

\begin{tabular}{|c|c|c|c|c|c|}
\hline \multirow[b]{2}{*}{ Microvascular dysfunction } & \multirow[b]{2}{*}{ Model } & \multicolumn{2}{|c|}{$\begin{array}{c}\text { Systolic blood pressure } \\
\text { variability composite score, } \\
\text { per SD }\end{array}$} & \multicolumn{2}{|c|}{$\begin{array}{l}\text { Diastolic blood pressure } \\
\text { variability composite score, } \\
\text { per SD }\end{array}$} \\
\hline & & $\beta$ & $(95 \% \mathrm{CI})$ & $\beta$ & $(95 \% \mathrm{Cl})$ \\
\hline \multirow{5}{*}{$\begin{array}{l}\text { Cerebral small vessel disease } \\
\text { features, per point } \\
n=1,651\end{array}$} & 1 & 0.048 & $(0.010 ; 0.086)$ & 0.042 & $(0.000 ; 0.083)$ \\
\hline & 2 & 0.039 & $(0.001 ; 0.077)$ & 0.036 & $(-0.005 ; 0.076)$ \\
\hline & 3 & 0.023 & $(-0.016 ; 0.063)$ & 0.027 & $(-0.015 ; 0.068)$ \\
\hline & 4 & 0.017 & $(-0.023 ; 0.056)$ & 0.021 & $(-0.020 ; 0.062)$ \\
\hline & 5 & 0.016 & $(-0.023 ; 0.056)$ & 0.021 & $(-0.020 ; 0.062)$ \\
\hline \multirow{5}{*}{$\begin{array}{l}\text { Flicker light-induced retinal } \\
\text { arteriolar and venular dilation, } \\
\text { per SD } n=1,657\end{array}$} & 1 & 0.029 & $(-0.021 ; 0.079)$ & 0.014 & $(-0.040 ; 0.068)$ \\
\hline & 2 & 0.017 & $(-0.034 ; 0.067)$ & 0.006 & $(-0.048 ; 0.060)$ \\
\hline & 3 & 0.025 & $(-0.028 ; 0.077)$ & 0.020 & $(-0.035 ; 0.074)$ \\
\hline & 4 & 0.023 & $(-0.030 ; 0.076)$ & 0.017 & $(-0.038 ; 0.072)$ \\
\hline & 5 & 0.023 & $(-0.030 ; 0.076)$ & 0.017 & $(-0.038 ; 0.072)$ \\
\hline \multirow{5}{*}{$\begin{array}{l}\text { Urinary albumin excretion, } \\
\text { ratio increase } n=2,437\end{array}$} & 1 & 1.14 & $(1.10-1.19)$ & 1.13 & $(1.08-1.17)$ \\
\hline & 2 & 1.11 & $(1.07-1.16)$ & 1.10 & $(1.06-1.15)$ \\
\hline & 3 & 1.05 & $(1.01-1.10)$ & 1.08 & $(1.04-1.12)$ \\
\hline & 4 & 1.04 & $(1.00-1.08)$ & 1.06 & $(1.02-1.11)$ \\
\hline & 5 & 1.04 & $(1.00-1.08)$ & 1.06 & $(1.02-1.11)$ \\
\hline \multirow{5}{*}{$\begin{array}{l}\text { Skin hyperaemia, per SD } \\
n=1,180\end{array}$} & 1 & 0.036 & $(-0.024 ; 0.097)$ & 0.014 & $(-0.048 ; 0.076)$ \\
\hline & 2 & 0.017 & $(-0.044 ; 0.078)$ & -0.001 & $(-0.063 ; 0.061)$ \\
\hline & 3 & 0.011 & $(-0.053 ; 0.075)$ & 0.004 & $(-0.059 ; 0.067)$ \\
\hline & 4 & 0.020 & $(-0.044 ; 0.084)$ & 0.006 & $(-0.057 ; 0.070)$ \\
\hline & 5 & 0.019 & $(-0.045 ; 0.083)$ & 0.006 & $(-0.058 ; 0.069)$ \\
\hline \multirow{5}{*}{$\begin{array}{l}\text { Plasma biomarkers of } \\
\text { microvascular dysfunction, } \\
\text { per } S D \\
n=2,411\end{array}$} & 1 & 0.089 & $(0.050 ; 0.128)$ & 0.073 & $(0.032 ; 0.115)$ \\
\hline & 2 & 0.055 & $(0.016 ; 0.093)$ & 0.048 & $(0.008 ; 0.088)$ \\
\hline & 3 & 0.056 & $(0.016 ; 0.096)$ & 0.046 & $(0.006 ; 0.087)$ \\
\hline & 4 & 0.036 & $(-0.002 ; 0.075)$ & 0.016 & $(-0.023 ; 0.055)$ \\
\hline & 5 & 0.037 & $(-0.002 ; 0.076)$ & 0.017 & $(-0.022 ; 0.057)$ \\
\hline
\end{tabular}

Regression coefficients $(\beta)$ represent difference in microvascular dysfunction measures per standard deviation, for every 1 standard deviation increase in blood pressure variability composite score. For cerebral small vessel disease features, $\beta$ 's are expressed per point; for urinary albumin excretion, $\beta$ 's are expressed as ratio increase. Model 1: age, sex. Model 2: model $1+$ glucose metabolism status. Model 3: model $2+$ mean 24-hour systolic or diastolic blood pressure (where appropriate). Model 4: model 3 + body mass index, smoking behaviour, alcohol use, education level, total-to-high density lipoprotein cholesterol ratio, (individual classes of) antihypertensive medication, lipid-modifying medication. Model 5: model $4+$ physical activity. Abbreviations: $\mathrm{Cl}$, confidence interval; SD, standard deviation. 
Supplemental table S13. Associations between systolic and diastolic blood pressure variability and measures of microvascular dysfunction, additionally adjusted for income level

\begin{tabular}{|c|c|c|c|c|c|}
\hline \multirow[b]{2}{*}{ Microvascular dysfunction } & \multirow[b]{2}{*}{ Model } & \multicolumn{2}{|c|}{$\begin{array}{c}\text { Systolic blood pressure } \\
\text { variability composite score, } \\
\text { per SD }\end{array}$} & \multicolumn{2}{|c|}{$\begin{array}{c}\text { Diastolic blood pressure } \\
\text { variability composite } \\
\text { score, per SD }\end{array}$} \\
\hline & & $\boldsymbol{\beta}$ & $(95 \% \mathrm{CI})$ & $\boldsymbol{\beta}$ & $(95 \% \mathrm{CI})$ \\
\hline \multirow{4}{*}{$\begin{array}{l}\text { Cerebral small vessel disease } \\
\text { features, per point } \\
n=1,445\end{array}$} & 1 & 0.054 & $(0.014 ; 0.095)$ & 0.048 & $(0.005 ; 0.091)$ \\
\hline & 2 & 0.042 & $(0.003 ; 0.082)$ & 0.038 & $(-0.004 ; 0.081)$ \\
\hline & 3 & 0.026 & $(-0.015 ; 0.068)$ & 0.031 & $(-0.011 ; 0.074)$ \\
\hline & 4 & 0.026 & $(-0.016 ; 0.068)$ & 0.031 & $(-0.012 ; 0.074)$ \\
\hline \multirow{4}{*}{$\begin{array}{l}\text { Flicker light-induced retinal } \\
\text { arteriolar and venular dilation, } \\
\text { per SD } n=1,439\end{array}$} & 1 & 0.017 & $(-0.037 ; 0.071)$ & 0.006 & $(-0.052 ; 0.065)$ \\
\hline & 2 & 0.005 & $(-0.049 ; 0.060)$ & -0.002 & $(-0.061 ; 0.056)$ \\
\hline & 3 & 0.011 & $(-0.045 ; 0.068)$ & 0.010 & $(-0.05 ; 0.069)$ \\
\hline & 4 & 0.017 & $(-0.040 ; 0.075)$ & 0.010 & $(-0.05 ; 0.07)$ \\
\hline \multirow{4}{*}{$\begin{array}{l}\text { Urinary albumin excretion, } \\
\text { ratio increase } n=2,121\end{array}$} & 1 & 1.14 & $(1.10-1.19)$ & 1.13 & $(1.08-1.17)$ \\
\hline & 2 & 1.11 & $(1.06-1.15)$ & 1.10 & $(1.05-1.14)$ \\
\hline & 3 & 1.05 & $(1.01-1.10)$ & 1.08 & $(1.03-1.12)$ \\
\hline & 4 & 1.05 & $(1.01-1.09)$ & 1.06 & $(1.02-1.11)$ \\
\hline \multirow{4}{*}{$\begin{array}{l}\text { Skin hyperaemia, per SD } \\
n=1,017\end{array}$} & 1 & 0.031 & $(-0.030 ; 0.092)$ & 0.027 & $(-0.037 ; 0.091)$ \\
\hline & 2 & 0.014 & $(-0.048 ; 0.077)$ & 0.012 & $(-0.052 ; 0.077)$ \\
\hline & 3 & 0.006 & $(-0.059 ; 0.071)$ & 0.015 & $(-0.050 ; 0.080)$ \\
\hline & 4 & 0.011 & $(-0.054 ; 0.077)$ & 0.021 & $(-0.045 ; 0.087)$ \\
\hline \multirow{4}{*}{$\begin{array}{l}\text { Plasma biomarkers of } \\
\text { microvascular dysfunction, per } \\
\text { SD } n=2,097\end{array}$} & 1 & 0.094 & $(0.052 ; 0.137)$ & 0.087 & $(0.042 ; 0.131)$ \\
\hline & 2 & 0.058 & $(0.016 ; 0.099)$ & 0.057 & $(0.014 ; 0.100)$ \\
\hline & 3 & 0.067 & $(0.023 ; 0.110)$ & 0.058 & $(0.014 ; 0.102)$ \\
\hline & 4 & 0.048 & $(0.006 ; 0.090)$ & 0.025 & $(-0.018 ; 0.067)$ \\
\hline
\end{tabular}

Regression coefficients $(\beta)$ represent difference in microvascular dysfunction measures per standard deviation, for every 1 standard deviation increase in blood pressure variability composite score. For cerebral small vessel disease features, $\beta$ 's are expressed per point; for urinary albumin excretion, $\beta$ 's are expressed as ratio increase. Model 1: age, sex. Model 2: model 1 + glucose metabolism status. Model 3: model 2 + mean 24-hour systolic or diastolic blood pressure (where appropriate). Model 4: model 3 + body mass index, smoking behaviour, alcohol use, education level, total-to-high density lipoprotein cholesterol ratio, (individual classes of) antihypertensive medication, lipid-modifying medication. Model 5: model 4 + income level. Abbreviations: $\mathrm{Cl}$, confidence interval; $\mathrm{SD}$, standard deviation. 
Supplemental table S14. Associations between systolic and diastolic blood pressure variability and measures of microvascular dysfunction, additionally adjusted for occupation status

\begin{tabular}{|c|c|c|c|c|c|}
\hline \multirow[b]{2}{*}{ Microvascular dysfunction } & \multirow[b]{2}{*}{ Model } & \multicolumn{2}{|c|}{$\begin{array}{c}\text { Systolic blood pressure } \\
\text { variability composite score, } \\
\text { per SD }\end{array}$} & \multicolumn{2}{|c|}{$\begin{array}{l}\text { Diastolic blood pressure } \\
\text { variability composite score, } \\
\text { per SD }\end{array}$} \\
\hline & & $\beta$ & $(95 \% \mathrm{Cl})$ & $\boldsymbol{\beta}$ & $(95 \% \mathrm{Cl})$ \\
\hline \multirow{4}{*}{$\begin{array}{l}\text { Cerebral small vessel disease } \\
\text { features, per point } \\
n=1,568\end{array}$} & 1 & 0.037 & $(-0.002 ; 0.077)$ & 0.050 & $(0.008 ; 0.091)$ \\
\hline & 2 & 0.025 & $(-0.014 ; 0.064)$ & 0.040 & $(-0.001 ; 0.081)$ \\
\hline & 3 & 0.012 & $(-0.030 ; 0.053)$ & 0.034 & $(-0.007 ; 0.075)$ \\
\hline & 4 & 0.007 & $(-0.035 ; 0.048)$ & 0.029 & $(-0.013 ; 0.070)$ \\
\hline \multirow{4}{*}{$\begin{array}{l}\text { Flicker light-induced retinal } \\
\text { arteriolar and venular dilation, } \\
\text { per SD } n=1,552\end{array}$} & 1 & 0.038 & $(-0.016 ; 0.091)$ & 0.025 & $(-0.031 ; 0.080)$ \\
\hline & 2 & 0.024 & $(-0.029 ; 0.078)$ & 0.017 & $(-0.038 ; 0.073)$ \\
\hline & 3 & 0.031 & $(-0.026 ; 0.087)$ & 0.030 & $(-0.026 ; 0.086)$ \\
\hline & 4 & 0.033 & $(-0.024 ; 0.090)$ & 0.030 & $(-0.027 ; 0.086)$ \\
\hline \multirow{4}{*}{$\begin{array}{l}\text { Urinary albumin excretion, } \\
\text { ratio increase } \\
n=2,302\end{array}$} & 1 & 1.15 & $(1.11-1.20)$ & 1.14 & $(1.09-1.18)$ \\
\hline & 2 & 1.12 & $(1.07-1.16)$ & 1.11 & $(1.07-1.16)$ \\
\hline & 3 & 1.06 & $(1.02-1.10)$ & 1.09 & $(1.05-1.14)$ \\
\hline & 4 & 1.06 & $(1.01-1.10)$ & 1.08 & $(1.04-1.12)$ \\
\hline \multirow{4}{*}{$\begin{array}{l}\text { Skin hyperaemia, per SD } \\
n=1,113\end{array}$} & 1 & 0.068 & $(0.007 ; 0.128)$ & 0.048 & $(-0.013 ; 0.110)$ \\
\hline & 2 & 0.046 & $(-0.016 ; 0.107)$ & 0.031 & $(-0.031 ; 0.093)$ \\
\hline & 3 & 0.041 & $(-0.023 ; 0.105)$ & 0.032 & $(-0.031 ; 0.094)$ \\
\hline & 4 & 0.044 & $(-0.021 ; 0.108)$ & 0.028 & $(-0.035 ; 0.091)$ \\
\hline \multirow{4}{*}{$\begin{array}{l}\text { Plasma biomarkers of } \\
\text { microvascular dysfunction, per } \\
\text { SD } n=2,284\end{array}$} & 1 & 0.099 & $(0.058 ; 0.141)$ & 0.087 & $(0.043 ; 0.130)$ \\
\hline & 2 & 0.058 & $(0.017 ; 0.098)$ & 0.057 & $(0.015 ; 0.098)$ \\
\hline & 3 & 0.064 & $(0.022 ; 0.107)$ & 0.057 & $(0.015 ; 0.099)$ \\
\hline & 4 & 0.042 & $(0.001 ; 0.083)$ & 0.028 & $(-0.014 ; 0.069)$ \\
\hline
\end{tabular}

Regression coefficients $(\beta)$ represent difference in microvascular dysfunction measures per standard deviation, for every 1 standard deviation increase in blood pressure variability composite score. For cerebral small vessel disease features, $\beta$ 's are expressed per point; for urinary albumin excretion, $\beta$ 's are expressed as ratio increase. Model 1: age, sex. Model 2: model 1 + glucose metabolism status. Model 3: model 2 + mean 24-hour systolic or diastolic blood pressure (where appropriate). Model 4: model 3 + body mass index, smoking behaviour, alcohol use, education level, total-to-high density lipoprotein cholesterol ratio, (individual classes of) antihypertensive medication, lipid-modifying medication. Model 5: model $4+$ occupation status. Abbreviations: $\mathrm{Cl}$, confidence interval; SD, standard deviation. 
Supplemental Table S15. Associations between systolic and diastolic blood pressure variability and urinary albumin excretion as a categorical variable

\begin{tabular}{lccccc}
\hline & & \multicolumn{2}{c}{$\begin{array}{c}\text { Systolic blood pressure } \\
\text { variability composite score, } \\
\text { per SD }\end{array}$} & $\begin{array}{c}\text { Diastolic blood pressure } \\
\text { variability composite } \\
\text { score, per SD }\end{array}$ \\
\hline Microvascular dysfunction & Model & OR & $\mathbf{( 9 5 \% ~ C I )}$ & OR & $\mathbf{( 9 5 \% ~ C I ) ~}$ \\
\hline $\begin{array}{l}\text { Urinary albumin excretion, } \geq 30 \\
\text { mg/24h vs. }<30 \mathrm{mg} / 24 \mathrm{~h}\end{array}$ & 1 & 1.39 & $(1.22-1.59)$ & 1.32 & $(1.16-1.50)$ \\
\cline { 2 - 6 } $\mathrm{n}=2,748$ & 2 & 1.30 & $(1.14-1.49)$ & 1.25 & $(1.10-1.43)$ \\
\cline { 2 - 6 } & 3 & 1.19 & $(1.03-1.38)$ & 1.20 & $(1.05-1.38)$ \\
\hline
\end{tabular}

Regression coefficients $(\beta)$ represent odds ratio of $\geq 30 \mathrm{mg} / 24 \mathrm{~h}$ urinary albumin excretion per 1 SD increase in blood pressure variability composite score. Model 1: age, sex. Model 2: model $1+$ glucose metabolism status. Model 3: model $2+$ mean 24-hour systolic or diastolic blood pressure (where appropriate). Model 4: model $3+$ body mass index, smoking behaviour, alcohol use, education level, total-to-high density lipoprotein cholesterol ratio, (individual classes of) antihypertensive medication, lipid-modifying medication. Abbreviations: BPV, blood pressure variability; $\mathrm{Cl}$, confidence interval; $\mathrm{OR}$, odds ratio.

Supplemental Table S16. Associations between systolic and diastolic blood pressure variability and estimated glomerular filtration rate

\begin{tabular}{|c|c|c|c|c|c|}
\hline \multirow[b]{2}{*}{ Estimated glomerular filtration rate } & \multirow[b]{2}{*}{ Model } & \multicolumn{2}{|c|}{$\begin{array}{c}\text { Systolic blood pressure } \\
\text { variability composite score, } \\
\text { per SD }\end{array}$} & \multicolumn{2}{|c|}{$\begin{array}{l}\text { Diastolic blood pressure } \\
\text { variability composite } \\
\text { score, per SD }\end{array}$} \\
\hline & & $\boldsymbol{\beta}$ & $(95 \% \mathrm{CI})$ & $\boldsymbol{\beta}$ & $(95 \% \mathrm{Cl})$ \\
\hline \multirow{5}{*}{$\begin{array}{l}\text { Lower estimated glomerular filtration } \\
\text { rate, per SD } \\
n=2,748\end{array}$} & 1 & 0.007 & $(-0.026-0.041)$ & 0.026 & $(-0.008-0.060)$ \\
\hline & 2 & 0.002 & $(-0.032-0.035)$ & 0.022 & $(-0.012-0.057)$ \\
\hline & 3 & 0.017 & $(-0.018-0.053)$ & 0.026 & $(-0.008-0.061)$ \\
\hline & 4 & -0.004 & $(-0.038-0.030)$ & -0.006 & $(-0.040-0.028)$ \\
\hline & Model & OR & $(95 \% \mathrm{Cl})$ & OR & $(95 \% \mathrm{Cl})$ \\
\hline \multirow{4}{*}{$\begin{array}{l}\text { Estimated glomerular filtration rate, } \\
\geq 60 \text { vs. }<60 \mathrm{ml} / \mathrm{min} / 1.73 \mathrm{~m}^{2} \text {, odds } \\
\text { ratio } \\
n=2,748\end{array}$} & 1 & 1.135 & $(0.947-1.36)$ & 1.173 & $(0.984-1.397)$ \\
\hline & 2 & 1.055 & $(0.874-1.274)$ & 1.103 & $(0.923-1.318)$ \\
\hline & 3 & 1.098 & $(0.906-1.332)$ & 1.142 & $(0.957-1.363)$ \\
\hline & 4 & 1.042 & $(0.842-1.29)$ & 1.021 & $(0.842-1.239)$ \\
\hline
\end{tabular}

Regression coefficients $(\beta)$ represent standard deviation lower estimated glomerular filtration rate, and odds ratio for $\geq 60$ vs. $<60 \mathrm{ml} / \mathrm{min} / 1.73 \mathrm{~m} 2$ estimated glomerular filtration rate, for every $1 \mathrm{SD}$ increase in blood pressure variability composite score. Model 1: age, sex. Model 2: model $1+$ glucose metabolism status. Model 3: model $2+$ mean 24-hour systolic or diastolic blood pressure (where appropriate). Model 4: model $3+$ body mass index, smoking behaviour, alcohol use, education level, total-to-high density lipoprotein cholesterol ratio, (individual classes of) antihypertensive medication, lipid-modifying medication. Abbreviations: $\mathrm{Cl}$, confidence interval; SD, standard deviation. 


\section{CHAPTER 7}
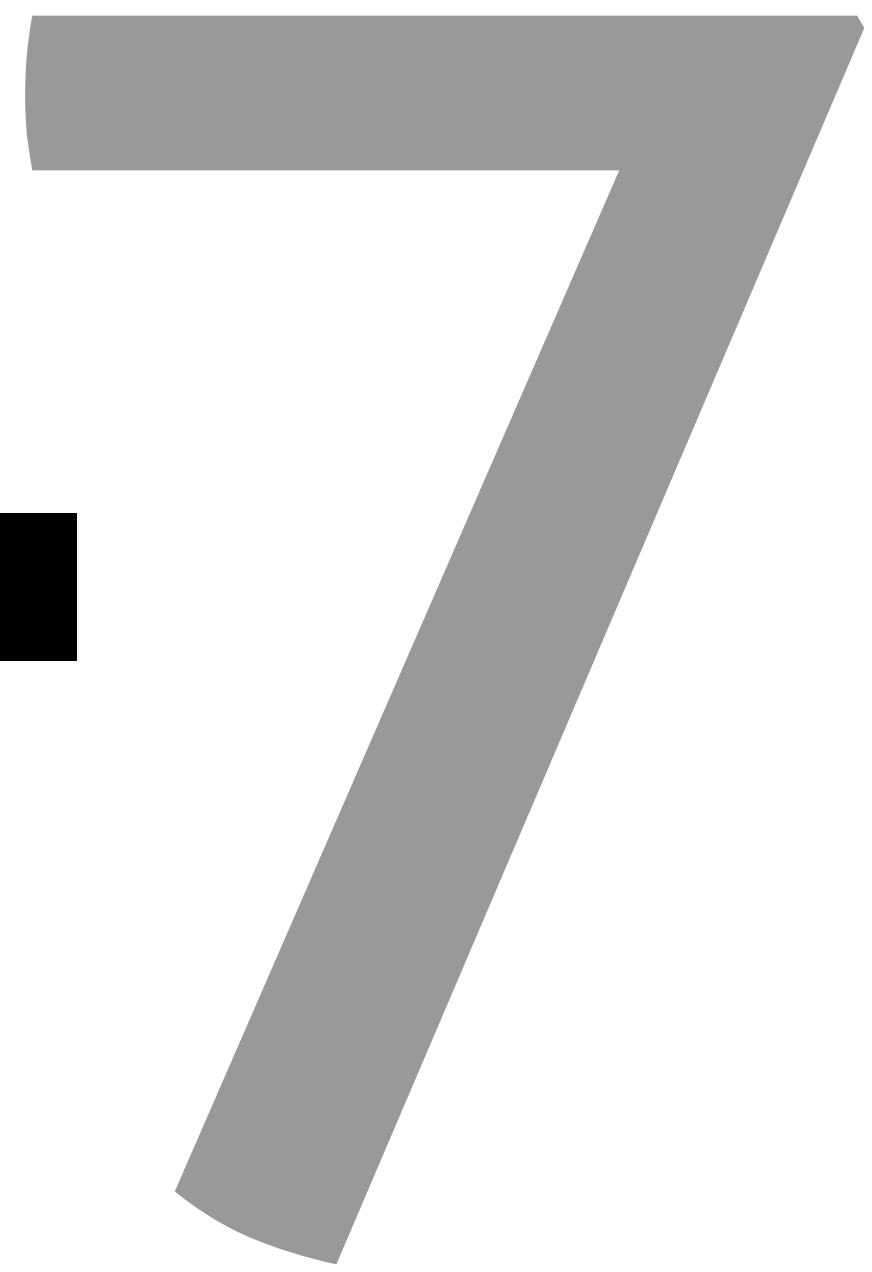
General discussion 



\section{General discussion}

The microvasculature (i.e., the vascular meshwork comprised of arterioles, capillaries and venules) provides local blood perfusion, blood-tissue diffusion and haemostatic balance ${ }^{1}$ needed for nutrient distribution and waste product collection in tissues. Deterioration of the microvasculature (i.e., microvascular dysfunction) is emerging as a possible factor in adverse cerebral outcome, such as dementia, late-life depression and stroke. ${ }^{2-6}$ With the ageing of the population ${ }^{7}$ and the increasing amount of individuals with a high burden of cardiovascular risk factors, ${ }^{8}$ the identification of possible contributors to the development of adverse cerebral outcomes is needed. ${ }^{5}$ Several possible risk factors for microvascular dysfunction have thus far been identified, such as arterial stiffening, ${ }^{9}$ type 2 diabetes, ${ }^{10}$, 11 hypertension, ageing and obesity. ${ }^{4}$ However, other determinants of microvascular dysfunction may be present, and the mechanisms by which microvascular dysfunction may lead to adverse cerebral outcome remains poorly understood.

In this thesis, we evaluated the causes of microvascular dysfunction and investigated whether microvascular dysfunction is associated with adverse cerebral outcomes (i.e., dementia, late-life depression and stroke). In addition, we evaluated whether microvascular dysfunction mediates the pathways between cardiovascular risk factors and adverse cerebral outcome. In this thesis, we had several key findings, which we will discuss in this chapter. The key findings are:

1. Microvascular dysfunction is associated with dementia, late-life depression, stroke and all-cause mortality.

2. Cerebral small vessel disease features additively increase stroke risk.

3. Microvascular dysfunction is implicated in the pathway between arterial stiffness and type 2 diabetes, and adverse cerebral outcome.

4. Greater blood pressure variability is associated with albuminuria.

5. In addition, we will propose a pathophysiological model that links these findings, and we will discuss several methodological considerations that apply to the findings of this thesis. Finally, we will discuss the clinical implications of the findings in this thesis and propose recommendations for future studies. 


\section{Key findings}

\section{Microvascular dysfunction is associated with dementia, late-life depression, stroke and all-cause mortality}

In chapter two of this thesis, we tested the hypothesis that cerebral microvascular dysfunction is associated with incident adverse cerebral outcome., 2,5 For this, we conducted a systematic review and meta-analysis on the association between cerebral small vessel disease and incident dementia, late-life depression and stroke, and all-cause mortality. We found a strong and consistent association between various cerebral small vessel disease features and these adverse cerebral outcomes during follow-up. Presence of cerebral small vessel disease increases the risk of adverse outcome with a degree similar to that of presence of type 2 diabetes ${ }^{12-15}$ or hypertension. ${ }^{16-20}$ These findings imply that the cerebral microvasculature is important for optimal organ function, at least in cerebral tissue. The longitudinal design of the analysis sheds light on the temporality of the associations; if these associations are causal, cerebral small vessel disease is implicated in the pathophysiological processes that later lead to adverse cerebral outcome.

In addition, it has been hypothesised that measures of generalised microvascular dysfunction also reflect microvascular dysfunction in cerebral tissue and that this is associated with adverse cerebral outcome. In accordance, previous studies have shown that measures of generalised microvascular dysfunction (i.e., albuminuria ${ }^{21}$ and plasma biomarkers of microvascular dysfunction) ${ }^{22-25}$ are associated with worse cognitive performance. To further test this hypothesis, we investigated, in chapter four, whether a composite score of microvascular dysfunction measures (i.e., cerebral small vessel disease features, flicker light-induced retinal arteriolar and venular dilation response, albuminuria, plasma biomarkers of microvascular dysfunction and heat-induced skin hyperaemia) was associated with worse cognitive performance. We found that this composite score was indeed associated with worse cognitive performance, even after excluding cerebral microvascular dysfunction (i.e., cerebral small vessel disease) from this score. These findings contribute to the hypothesis that generalised microvascular dysfunction reflects cerebral microvascular disease and is implicated in the pathophysiological process of adverse cerebral outcome.

\section{Cerebral small vessel disease features additively increase stroke risk}

In chapter two, we showed that the combination of two cerebral small vessel disease features was more strongly associated with incident stroke than individual features. The existence of additive effects among cerebral small vessel disease features implies that a dose-response relationship may be present between cerebral small vessel disease severity and adverse cerebral outcome. From a clinical point of view, this finding may be important, because it may help better predict disease course and identify patients at risk for adverse cerebral outcome. This suggests that imaging scales that integrate multiple cerebral small vessel disease feature ${ }^{26}$ are most suitable to assess cerebral small vessel disease and most likely to enable improved risk prediction of clinical outcomes beyond established risk factors. 


\section{Microvascular dysfunction is implicated in the pathway between arterial stiffness and type 2 diabetes, and adverse cerebral outcome}

Several cardiovascular risk factors are associated with adverse cerebral outcome, and this association may be mediated by microvascular dysfunction. ${ }^{11,27-29}$ In chapter three and five, we therefore investigated whether microvascular dysfunction mediates the associations between arterial stiffness and type 2 diabetes, and adverse cerebral outcome.

Greater arterial stiffness leads to excessive pressure and flow pulsatility, which may transmit distally and damage the microcirculation. ${ }^{27,28}$ Previous studies ${ }^{90-43}$ have shown an association between greater arterial stiffness and measures of adverse cerebral outcomes (i.e., cognitive decline and incident dementia). In chapter five, we investigated the associations between arterial stiffness (measured as aortic stiffness and carotid stiffness) and worse cognitive performance, and whether any such associations were mediated by a composite score of various microvascular dysfunction measures. Aortic stiffness, but not carotid stiffness, was associated with worse cognitive performance, and this association was mediated, in part, by a composite score of microvascular dysfunction. Although aortic stiffness (i.e., higher carotid-femoral pulse wave velocity) and carotid stiffness (i.e., higher carotid distensibility coefficient) reflect, at least partly, a similar process of arterial stiffenning, ${ }^{44}$ aortic stiffness may be a more precise reflection. ${ }^{44,45}$ Accordingly, aortic stiffness may be more strongly associated with microvascular dysfunction and worse cognitive performance.

Type 2 diabetes is associated with hyperglycaemia, impaired insulin-dependent arteriolar dilation, advanced glycation, excessive oxidative stress and epigenetic changes, which may damage the microcirculation. ${ }^{11,29,46}$ In addition, type 2 diabetes is associated with a higher incidence of depressive symptoms. ${ }^{47}$ However, no previous study has investigated whether the association between type 2 diabetes and depressive symptoms is mediated by microvascular dysfunction. In chapter 3, we showed, in a longitudinal study, that baseline type 2 diabetes is associated with greater change in depressive symptoms over time, and that this association was, in part, mediated by cerebral microvascular dysfunction (i.e., cerebral small vessel disease features).

From a clinical point of view, the finding that microvascular dysfunction mediates, in part, the association between classical cardiovascular risk factors and adverse cerebral outcome is important, as it identifies microvascular dysfunction as potential target for prevention of brain diseases in patients with cardiovascular risk factors. However, a significant portion of the associations between arterial stiffness and type 2 diabetes, and adverse cerebral outcome, was not mediated by microvascular dysfunction. This remaining association may be due to microvascular dysfunction that is not directly captured in our measures of microvascular dysfunction. For example, cerebral microvascular dysfunction measures such as microinfarctions, loss of white matter integrity and lower cerebral blood flow reactivity may contain additional information but were not available in this thesis. In addition, it is possible that only a subset of individuals with arterial stiffness or type 2 diabetes develop adverse cerebral outcome that are related to microvascular dysfunction. Worse cognitive performance in arterial stiffness may be related to macrovascular disease or $A \beta$ deposition. ${ }^{48}$ Additionally, depressive symptoms in type 2 diabetes may be related 
to other mediators such as psychosocial factors, ${ }^{47}$ diabetes-related comorbidities ${ }^{47}$ and glucose neurotoxicity. ${ }^{49}$

\section{Greater blood pressure variability is associated with albuminuria}

It has been hypothesised that greater blood pressure variability (i.e., greater fluctuations of blood pressure) is associated with microvascular dysfunction. ${ }^{50,51}$ This association may be implicated in the pathway between arterial stiffness and type 2 diabetes, and microvascular dysfunction. ${ }^{52,53}$ However, the association between blood pressure variability and microvascular dysfunction remains incompletely understood. In chapter six, we therefore investigated whether blood pressure variability (i.e., within-visit, 24hour and 7-day blood pressure variability) is associated with microvascular dysfunction measures including brain (i.e., cerebral small vessel disease features), eye (i.e., flicker light-induced retinal arteriolar and venular dilation response), kidney (i.e., albuminuria), plasma biomarkers of microvascular dysfunction and skin measures (i.e., heat-induced skin hyperaemia). We hypothesised that the effect of greater blood pressure variability on microvascular dysfunction is stronger in organs with a low vascular impedance (i.e., brain, eyes and kidneys) and weaker in organs with a high vascular impedance (e.g., skin). In partial disagreement with this hypothesis, we found that greater very short- to mid-term blood pressure variability was associated with higher albuminuria but not with other measures of microvascular dysfunction tested. Kidney microvasculature has a lower impedance than the brain and eye microvasculature; e.g., blood flow to the kidneys relative to organ weight $(360 \mathrm{ml} / \mathrm{min} / 100 \mathrm{~g})$ is higher than to the brain $(50 \mathrm{ml} / \mathrm{min} / 100 \mathrm{~g}$ brain).$^{54}$ Therefore, the kidney microvasculature may be comparatively more vulnerable to the detrimental effects of blood pressure variability.

\section{Microvascular dysfunction and brain diseases: mechanisms}

The findings of this thesis may be summarized into the following pathophysiological model (see Figure 7.1). Microvascular dysfunction is associated with a marked increase in adverse cerebral outcome, irrespective of whether microvascular dysfunction is located in brain tissue or in other organs; these measures appear to reflect overlapping changes that hamper brain tissue function. In addition, type 2 diabetes and arterial stiffness are associated with adverse cerebral outcome, and microvascular dysfunction is at least partly implicated in this pathway. Blood pressure variability may, at least in the kidney, lead to microvascular dysfunction. Microvascular dysfunction may lead to adverse cerebral outcome through multiple pathways, including impaired cerebral perfusion, impaired neurogenesis, impaired neurovascular coupling, impaired blood-brain barrier permeability, impaired haemostatic regulation and impaired cerebral autoregulation, which eventually causes ischaemia and neuronal dysfunction. ${ }^{55}$ 


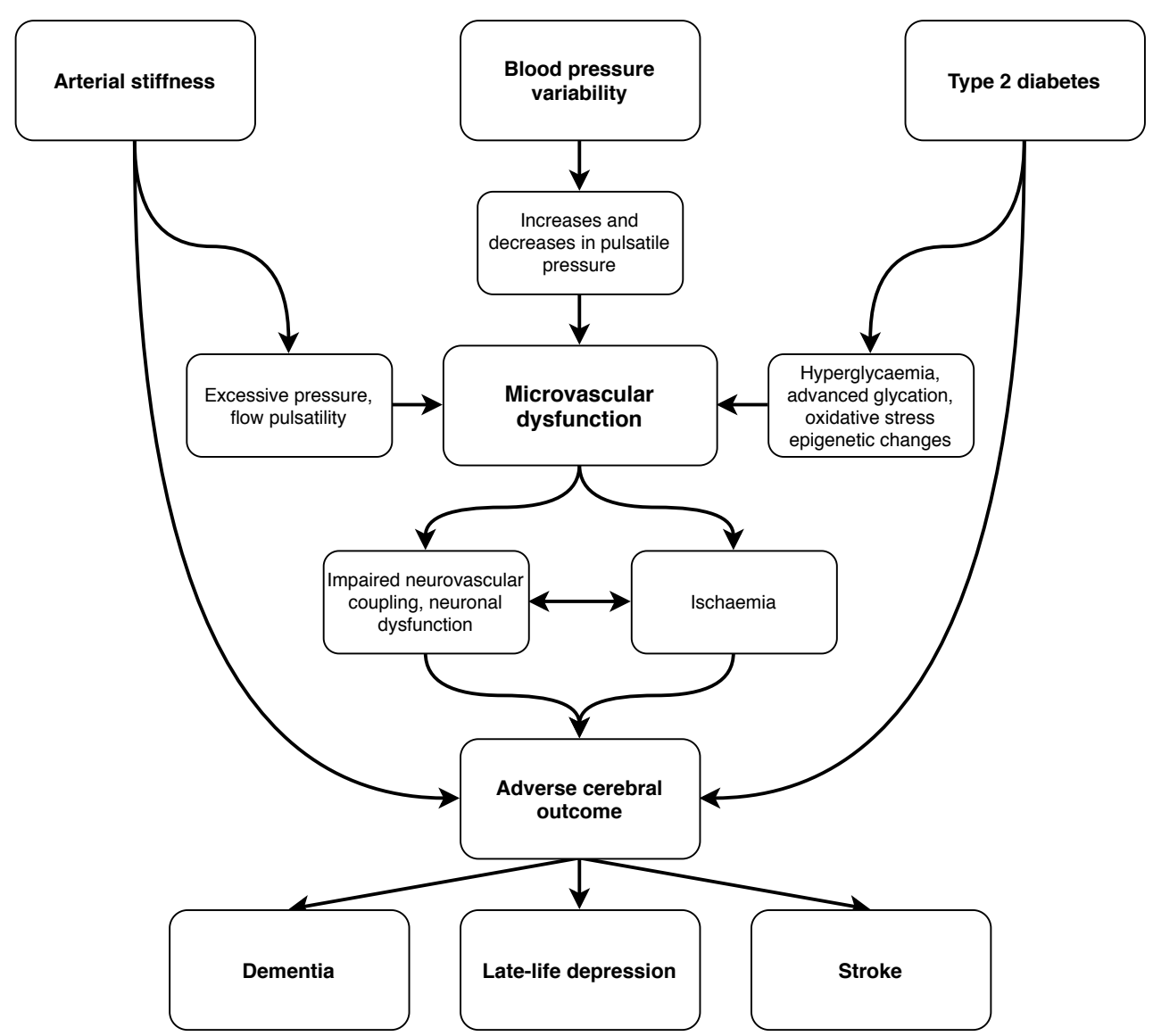

Figure 7.1. Potential pathways for causes and consequences of microvascular dysfunction.

\section{Methodological considerations}

There are several methodological aspects of this thesis that need to be taken into consideration when interpreting the results. First, this thesis includes a collection of observational cohort studies, and data in these studies are subject to biases such as confounding bias, overadjustment bias and reverse causation. Second, in this thesis, composite scores are often used to summarize measures of the same (patho)physiological construct. The construction of composite scores is based on certain assumptions, and these need to be taken into consideration when interpreting the results.

\section{Confounding bias}

Confounding bias arises when an observed association between an exposure variable and an outcome variable is erroneously assumed to be direct, although in reality, they are both separately associated with another variable (i.e., a 'confounder factor').$^{56}$ Changes (or variation) in a confounding factor are reflected in both the exposure variable and the 
outcome variable, which creates statistical dependence between the two (illustrated in Figure 7.2). Alternatively, the exposure variable may influence the confounding factor (and thus the outcome variable) via a mechanism that is unrelated to the causal pathway of interest.

Due to the non-randomized nature of observational studies, confounder bias has an important influence on the validity of the results. However, all analysis with observational studies in this thesis are adjusted for a large set of possible confounding factors, which helps reduce this bias. Nevertheless, residual confounding remains possible due to or an unknown or unmeasured factor or due to complex factor interaction.

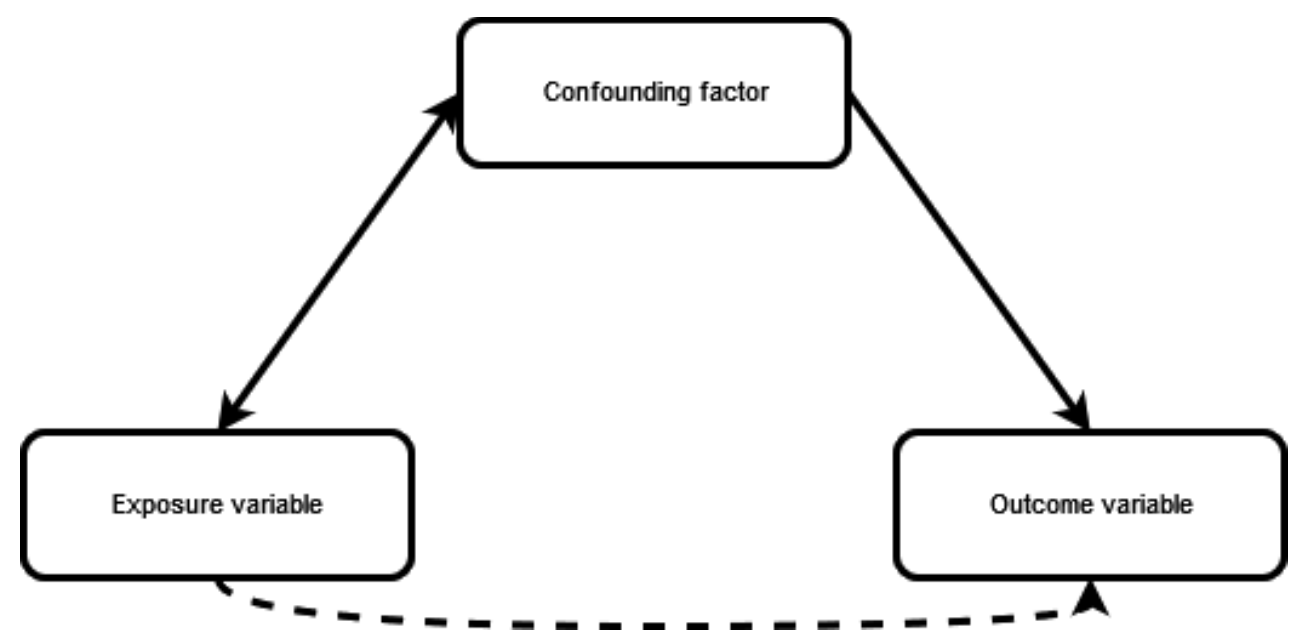

Figure 7.2. A confounding factor is associated with both the exposure variable and the outcome variable (solid lines). An erroneous direct association between the exposure variable and the outcome variable may be assumed (dashed line).

\section{Overadjustment bias}

Adjustment for a large set of variables may, on the one hand, help reduce confounding bias, but may, on the other hand, induce overadjustment bias. Overadjustment bias occurs when the adjustment variable mediates the causal pathway of interest between the exposure variable and the outcome variable (illustrated in Figure 7.3). Some of the potential confounding factors that were adjusted for in this thesis may also, in part, mediate the association between the exposure variables and the outcome variables. For example, the association between microvascular dysfunction and cognitive function may be confounded by type 2 diabetes but also be mediated. ${ }^{3,11,57}$ In general, adjustment for these factors will (partly) mask the observed association between the exposure variable and the outcome variable..$^{58}$

In addition to overadjustment by a mediating factor, overadjustment bias may occur when the adjusted factor is a proxy of the exposure variable or outcome variable, and is measured with greater precision (illustrated in Figure 7.3). Because this proxy variable 
reflects one of the variable, it may account for part of the covariation that is attributable to the exposure variable and the outcome variable. ${ }^{58}$

The effect of overadjustment bias needs to be taken into consideration when interpreting the results of this thesis. The possible adjustment for mediating factors may have led to an underestimation of the strength of the associations in this thesis. However, when overadjustment bias risk was present, these variables were often added to separate models, and its results were interpreted with caution.

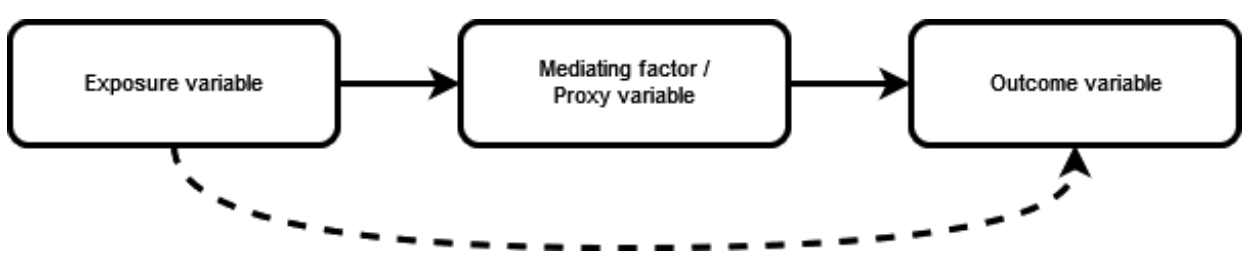

Figure 7.3. A mediating factor is associated with the exposure variable, and subsequently influences the outcome variable (solid lines). A proxy variable reflects the exposure variable or the outcome variable with higher precision. Adjustment for the mediating factor or proxy variable will mask the observed association between the exposure variable and outcome variable (dashed line).

\section{Reverse causation}

Most of the analyses in this thesis are based on cross-sectional data, making it difficult to ascertain the temporality of the relationship between the exposure variable and the outcome variable. ${ }^{59}$ In other words, for causal inference, it is important to know which of the variables changes before the other. With cross-sectional measurements, it is not possible to discern the temporal relationship from the data, and any interpretation regarding causation should thus be done carefully. However, in chapter two and three, we established longitudinal relationships between cerebral small vessel disease and dementia, late-life depression, stroke and all-cause mortality. From this, the argument can be made that the associations found in chapter four and five follow the same temporal relation. Nevertheless, even when temporality has been established, it is not possible to discern correlation from causation in observational studies. ${ }^{60}$ To discern correlation from causation, interventional studies are needed.

\section{Composite scores}

A composite score is used to organize multiple correlated variables into more meaningful, conceptual information. By grouping together multiple measures of the same construct, the influence of the biological variability of its components is reduced. Furthermore, when a single composite score is used instead of all its components separately, it reduces the chance of a type 1 error. Substantial conceptual or statistical overlap among the components of the composite score must be present. ${ }^{61}$ In this thesis, we often constructed composite scores for microvascular dysfunction and for cognitive function, based on prior evidence that all measures used for the composite scores reflect microvascular 
dysfunction $^{1-3,5,10,57,62,63}$ or cognitive function. ${ }^{64-67}$ Nevertheless, these components may vary in relationship strength with the outside variables (e.g., outcome variables) and may reflect slightly varying underlying pathophysiological processes, which influences statistical power and interpretability of the composite scores. Therefore, these factors should be taken into consideration when interpreting the results. In this thesis, robustness of composite scores that were not yet established in literature was tested by individually excluding components of the composite scores.

\section{Clinical implications and recommendations for future studies}

The present thesis contributes to increasing evidence that microvascular dysfunction contributes to adverse cerebral outcome. In addition, this thesis shows that individuals with cerebral microvascular dysfunction (i.e., the presence of cerebral small vessel disease features) are at high risk of developing dementia, late-life depression, stroke and mortality; a risk similar to that of individuals with type 2 diabetes ${ }^{12-15}$ or hypertension. ${ }^{16-20}$ The presence of microvascular dysfunction should be recognized as a prognostic factor for adverse cerebral outcome and should prompt work-up and treatment of relevant risk factors, including type 2 diabetes, hypertension and hypercholesterolaemia. Additionally, hospital-admitted patients with microvascular dysfunction may be at a higher risk of low tissue oxygenation in the presence of dehydration and poor saturation and may correspondingly benefit from fluid supplementation and oxygen therapy. ${ }^{1}$

Provided that the associations described in this thesis are causal, microvascular dysfunction might be an important target for prevention strategies of adverse cerebral outcome. However, effective evidence for treatment of microvascular dysfunction is presently lacking. Trials are therefore needed that target suspected mechanisms of microvascular dysfunction, including capillary rarefaction, glycocalyx degeneration, impaired capillary flow regulation, impaired arteriolar and venular dilation response, blood-brain barrier dysfunction, increased inflammatory response and procoagulant activation. ${ }^{1,3,55}$ Recent research suggests that lifestyle modifications, such as weight loss and exercise, may, at least in part, favorably influence microvascular function. ${ }^{11}$ In addition, drugs such as reninangiotensin-aldosterone system inhibitors, antihyperglycemic agents (i.e., metformin and glucagon-like peptide 1 receptor [GLP-1R] agonists) and statins may improve microvascular function, ${ }^{11,68,69}$ possibly beyond their blood pressure- or glucose-lowering effects. ${ }^{11,68}$ However, only one previous study ${ }^{70,71}$ found that inhibiting the progression of microvascular dysfunction correlated with reduced occurrence of cognitive decline and stroke, whereas others ${ }^{72,73}$ did not. Future longitudinal studies are needed to further evaluate the association between microvascular dysfunction and adverse cerebral outcome, and the effect of microvascular dysfunction treatment. 
1. Ostergaard L, Engedal TS, Moreton F, Hansen MB, Wardlaw JM, Dalkara T, Markus HS and Muir KW. Cerebral small vessel disease: Capillary pathways to stroke and cognitive decline. $J$ Cereb Blood Flow Metab. 2016;36:302-25.

2. Wardlaw JM, Smith EE, Biessels GJ, Cordonnier C, Fazekas F, Frayne R, Lindley RI, O'Brien JT, Barkhof F, Benavente OR, Black SE, Brayne C, Breteler M, Chabriat H, Decarli C, de Leeuw FE, Doubal F, Duering M, Fox NC, Greenberg S, Hachinski V, Kilimann I, Mok V, Oostenbrugge R, Pantoni L, Speck O, Stephan BC, Teipel S, Viswanathan A, Werring D, Chen C, Smith C, van Buchem $M$, Norrving $B$, Gorelick PB, Dichgans $M$ and nEuroimaging STfRVco. Neuroimaging standards for research into small vessel disease and its contribution to ageing and neurodegeneration. Lancet Neurol. 2013;12:822-38.

3. Muris DM, Houben AJ, Schram MT and Stehouwer CD. Microvascular dysfunction: an emerging pathway in the pathogenesis of obesity-related insulin resistance. Rev Endocr Metab Disord. 2013;14:29-38.

4. Houben A, Martens RJH and Stehouwer CDA. Assessing Microvascular Function in Humans from a Chronic Disease Perspective. J Am Soc Nephrol. 2017;28:3461-3472.

5. Pantoni L. Cerebral small vessel disease: from pathogenesis and clinical characteristics to therapeutic challenges. Lancet Neurol. 2010;9:689-701.

6. Wardlaw JM, Smith $C$ and Dichgans M. Small vessel disease: mechanisms and clinical implications. Lancet Neurol. 2019;18:684-696.

7. Christensen K, Doblhammer G, Rau R and Vaupel JW. Ageing populations: the challenges ahead. Lancet. 2009;374:1196-208.

8. Saklayen MG. The Global Epidemic of the Metabolic Syndrome. Curr Hypertens Rep. 2018;20:12.

9. van Sloten TT, Protogerou AD, Henry RM, Schram MT, Launer LJ and Stehouwer CD. Association between arterial stiffness, cerebral small vessel disease and cognitive impairment: A systematic review and meta-analysis. Neurosci Biobehav Rev. 2015;53:121-30.

10. Umemura T, Kawamura $T$ and Hotta N. Pathogenesis and neuroimaging of cerebral large and small vessel disease in type 2 diabetes: A possible link between cerebral and retinal microvascular abnormalities. J Diabetes Investig. 2017;8:134-148.

11. Stehouwer CDA. Microvascular Dysfunction and Hyperglycemia: A Vicious Cycle With Widespread Consequences. Diabetes. 2018;67:1729-1741.

12. Gregg EW, Li Y, Wang J, Burrows NR, Ali MK, Rolka D, Williams DE and Geiss L. Changes in diabetesrelated complications in the United States, 1990-2010. N Engl J Med. 2014;370:1514-23.

13. Xu WL, Qiu CX, Wahlin A, Winblad B and Fratiglioni L. Diabetes mellitus and risk of dementia in the Kungsholmen project: a 6-year follow-up study. Neurology. 2004;63:1181-6.

14. Yu M, Zhang X, Lu F and Fang L. Depression and Risk for Diabetes: A Meta-Analysis. Can J Diabetes. 2015;39:266-72.

15. Gregg EW, Cheng YJ, Saydah S, Cowie C, Garfield S, Geiss L and Barker L. Trends in death rates among U.S. adults with and without diabetes between 1997 and 2006: findings from the National Health Interview Survey. Diabetes Care. 2012;35:1252-7.

16. Imano H, Kitamura A, Sato S, Kiyama M, Ohira T, Yamagishi K, Noda H, Tanigawa T, Iso H and Shimamoto T. Trends for blood pressure and its contribution to stroke incidence in the middle-aged Japanese population: the Circulatory Risk in Communities Study (CIRCS). Stroke. 2009;40:1571-7.

17. Verdecchia P, Reboldi GP, Angeli F, Schillaci G, Schwartz JE, Pickering TG, Imai Y, Ohkubo T and Kario K. Short- and long-term incidence of stroke in white-coat hypertension. Hypertension. 2005;45:203-208. 
18. Li G, Rhew IC, Shofer JB, Kukull WA, Breitner JC, Peskind E, Bowen JD, McCormick W, Teri L, Crane PK and Larson EB. Age-varying association between blood pressure and risk of dementia in those aged 65 and older: a community-based prospective cohort study. J Am Geriatr Soc. 2007;55:1161-7.

19. Sharp SI, Aarsland D, Day S, Sonnesyn H, Ballard C and Syst AsSVD. Hypertension is a potential risk factor for vascular dementia: systematic review. Int J Geriatr Psychiatry. 201 1;26:661-669.

20. Barengo NC, Antikainen R, Kastarinen M, Laatikainen T and Tuomilehto J. The effects of control of systolic and diastolic hypertension on cardiovascular and all-cause mortality in a communitybased population cohort. J Hum Hypertens. 2013;27:693-7.

21. Georgakis MK, Dimitriou NG, Karalexi MA, Mihas C, Nasothimiou EG, Tousoulis D, Tsivgoulis $\mathrm{G}$ and Petridou ET. Albuminuria in Association with Cognitive Function and Dementia: A Systematic Review and Meta-Analysis. J Am Geriatr Soc. 2017;65:1190-1198.

22. Heringa SM, van den Berg E, Reijmer YD, Nijpels G, Stehouwer CD, Schalkwijk CG, Teerlink T, Scheffer PG, van den Hurk K, Kappelle LJ, Dekker JM and Biessels GJ. Markers of low-grade inflammation and endothelial dysfunction are related to reduced information processing speed and executive functioning in an older population - the Hoorn Study. Psychoneuroendocrinology. 2014;40:108-18.

23. Huang CW, Tsai MH, Chen NC, Chen WH, Lu YT, Lui CC, Chang YT, Chang WN, Chang AY and Chang CC. Clinical significance of circulating vascular cell adhesion molecule-1 to white matter disintegrity in Alzheimer's dementia. Thromb Haemost. 2015;114:1230-40.

24. Rafnsson SB, Deary IJ, Smith FB, Whiteman MC, Rumley A, Lowe GD and Fowkes FG. Cognitive decline and markers of inflammation and hemostasis: the Edinburgh Artery Study. J Am Geriatr Soc. 2007;55:700-7.

25. Yoon CY, Steffen LM, Gross MD, Launer LJ, Odegaard A, Reiner A, Sanchez O, Yaffe K, Sidney S and Jacobs DR, Jr. Circulating Cellular Adhesion Molecules and Cognitive Function: The Coronary Artery Risk Development in Young Adults Study. Front Cardiovasc Med. 2017;4:37.

26. Huijts M, Duits A, van Oostenbrugge RJ, Kroon AA, de Leeuw PW and Staals J. Accumulation of MRI Markers of Cerebral Small Vessel Disease is Associated with Decreased Cognitive Function. A Study in First-Ever Lacunar Stroke and Hypertensive Patients. Front Aging Neurosci. 2013;5:72.

27. Fazekas F, Kleinert R, Offenbacher H, Payer F, Schmidt R, Kleinert G, Radner H and Lechner $H$. The morphologic correlate of incidental punctate white matter hyperintensities on MR images. AJNR Am J Neuroradiol. 1991;12:915-21.

28. Saji N, Toba K and Sakurai T. Cerebral Small Vessel Disease and Arterial Stiffness: Tsunami Effect in the Brain? Pulse (Basel). 2016;3:182-9.

29. Forbes JM and Cooper ME. Mechanisms of diabetic complications. Physiol Rev. 2013;93:137-88.

30. Taniguchi Y, Fujiwara Y, Nofuji Y, Nishi M, Murayama H, Seino S, Tajima R, Matsuyama $Y$ and Shinkai S. Prospective Study of Arterial Stiffness and Subsequent Cognitive Decline Among Community-Dwelling Older Japanese. J Epidemiol. 2015;25:592-9.

31. Hajjar I, Goldstein FC, Martin GS and Quyyumi AA. Roles of Arterial Stiffness and Blood Pressure in Hypertension-Associated Cognitive Decline in Healthy Adults. Hypertension. 2016;67:171-5.

32. Tsao CW, Himali JJ, Beiser AS, Larson MG, DeCarli C, Vasan RS, Mitchell GF and Seshadri S. Association of arterial stiffness with progression of subclinical brain and cognitive disease. Neurology. 2016;86:619-26. 
33. Meyer ML, Palta P, Tanaka H, Deal JA, Wright J, Knopman DS, Griswold ME, Mosley TH and Heiss G. Association of Central Arterial Stiffness and Pressure Pulsatility with Mild Cognitive Impairment and Dementia: The Atherosclerosis Risk in Communities Study-Neurocognitive Study (ARIC-NCS). J Alzheimers Dis. 2017;57:195-204.

34. Muela HCS, Costa-Hong VA, Yassuda MS, Moraes NC, Memoria CM, Machado MF, Bor-Seng-Shu E, Nogueira RC, Mansur AJ, Massaro AR, Nitrini R, Macedo TA and Bortolotto LA. Higher arterial stiffness is associated with lower cognitive performance in patients with hypertension. $J$ Clin Hypertens (Greenwich). 2018;20:22-30.

35. Rouch L, Cestac P, Sallerin B, Andrieu S, Bailly H, Beunardeau M, Cohen A, Dubail D, Hernandorena I, Seux ML, Vidal JS and Hanon O. Pulse Wave Velocity Is Associated With Greater Risk of Dementia in Mild Cognitive Impairment Patients. Hypertension. 2018;72:1109-1116.

36. Palta P, Sharrett AR, Wei J, Meyer ML, Kucharska-Newton A, Power MC, Deal JA, Jack CR, Knopman D, Wright J, Griswold M, Tanaka H, Mosley TH and Heiss G. Central Arterial Stiffness Is Associated With Structural Brain Damage and Poorer Cognitive Performance: The ARIC Study. J Am Heart Assoc. 2019;8:e011045.

37. Pase MP, Beiser A, Himali JJ, Tsao C, Satizabal CL, Vasan RS, Seshadri S and Mitchell GF. Aortic Stiffness and the Risk of Incident Mild Cognitive Impairment and Dementia. Stroke. 2016;47:2256-61.

38. Huck DM, Hanna DB, Rubin LH, Maki P, Valcour V, Springer G, Xue X, Lazar J, Hodis HN, Anastos K, Kaplan RC and Kizer JR. Carotid Artery Stiffness and Cognitive Decline Among Women With or at Risk for HIV Infection. J Acquir Immune Defic Syndr. 2018;78:338-347.

39. DuBose LE, Voss MW, Weng TB, Kent JD, Dubishar KM, Lane-Cordova A, Sigurdsson G, Schmid P, Barlow PB and Pierce GL. Carotid beta-stiffness index is associated with slower processing speed but not working memory or white matter integrity in healthy middle-aged/older adults. J Appl Physiol (1985). 2017;122:868-876.

40. Lim SL, Gao Q, Nyunt MS, Gong L, Lunaria JB, Lim ML, Ling A, Lam CS, Richards AM, Ling LH and Ng TP. Vascular Health Indices and Cognitive Domain Function: Singapore Longitudinal Ageing Studies. J Alzheimers Dis. 2016;50:27-40.

41. Poels MM, van Oijen M, Mattace-Raso FU, Hofman A, Koudstaal PJ, Witteman JC and Breteler MM. Arterial stiffness, cognitive decline, and risk of dementia: the Rotterdam study. Stroke. 2007;38:888-92.

42. Tarumi T, Gonzales MM, Fallow B, Nualnim N, Pyron M, Tanaka H and Haley AP. Central artery stiffness, neuropsychological function, and cerebral perfusion in sedentary and endurancetrained middle-aged adults. J Hypertens. 2013;31:2400-9.

43. Geijselaers SL, Sep SJ, Schram MT, van Boxtel MP, van Sloten TT, Henry RM, Reesink KD, Kroon AA, Koster A, Schaper NC, Dagnelie PC, van der Kallen CJ, Biessels GJ and Stehouwer CD. Carotid stiffness is associated with impairment of cognitive performance in individuals with and without type 2 diabetes. The Maastricht Study. Atherosclerosis. 2016;253:186-193.

44. Koivistoinen T, Virtanen M, Hutri-Kahonen N, Lehtimaki T, Jula A, Juonala M, Moilanen L, Aatola $\mathrm{H}$, Hyttinen J, Viikari JS, Raitakari OT and Kahonen M. Arterial pulse wave velocity in relation to carotid intima-media thickness, brachial flow-mediated dilation and carotid artery distensibility: the Cardiovascular Risk in Young Finns Study and the Health 2000 Survey. Atherosclerosis. 2012;220:387-93. 
45. Laurent S, Cockcroft J,Van Bortel L, Boutouyrie P, Giannattasio C, Hayoz D, Pannier B, Vlachopoulos C, Wilkinson I, Struijker-Boudier $\mathrm{H}$ and European Network for Non-invasive Investigation of Large A. Expert consensus document on arterial stiffness: methodological issues and clinical applications. Eur Heart J. 2006;27:2588-605.

46. Geijselaers SLC, Sep SJS, Stehouwer CDA and Biessels GJ. Glucose regulation, cognition, and brain MRI in type 2 diabetes: a systematic review. Lancet Diabetes Endocrinol. 2015;3:75-89.

47. Badescu SV, Tataru C, Kobylinska L, Georgescu EL, Zahiu DM, Zagrean AM and Zagrean L. The association between Diabetes mellitus and Depression. J Med Life. 2016;9:120-5.

48. Hughes TM, Wagenknecht LE, Craft S, Mintz A, Heiss G, Palta P, Wong D, Zhou Y, Knopman D, Mosley TH and Gottesman RF. Arterial stiffness and dementia pathology: Atherosclerosis Risk in Communities (ARIC)-PET Study. Neurology. 2018;90:e1248-e1256.

49. Tomlinson DR and Gardiner NJ. Glucose neurotoxicity. Nat Rev Neurosci. 2008;9:36-45.

50. Mitchell GF. Effects of central arterial aging on the structure and function of the peripheral vasculature: implications for end-organ damage. J Appl Physiol (1985). 2008;105:1652-60.

51. Rothwell PM. Limitations of the usual blood-pressure hypothesis and importance of variability, instability, and episodic hypertension. Lancet. 2010;375:938-48.

52. Zhou TL, Kroon AA, Reesink KD, Schram MT, Koster A, Schaper NC, Dagnelie PC, van der Kallen $\mathrm{CJH}$, Sep SJS, Stehouwer CDA and Henry RMA. Blood pressure variability in individuals with and without (pre)diabetes: The Maastricht Study. J Hypertens. 2018;36:259-267.

53. Parati G, Ochoa JE, Lombardi C and Bilo G. Assessment and management of blood-pressure variability. Nat Rev Cardiol. 2013;10:143-55.

54. Hall J.E. Guyton and Hall textbook of medical physiology. 13th ed. Philadelphia, PA: Elsevier; 206.

55. De Silva TM and Faraci FM. Microvascular Dysfunction and Cognitive Impairment. Cell Mol Neurobiol. 2016;36:241-58.

56. Skelly AC, Dettori JR and Brodt ED. Assessing bias: the importance of considering confounding. Evid Based Spine Care J. 2012;3:9-12.

57. Sorensen BM, Houben AJ, Berendschot TT, Schouten JS, Kroon AA, van der Kallen CJ, Henry RM, Koster A, Sep SJ, Dagnelie PC, Schaper NC, Schram MT and Stehouwer CD. Prediabetes and Type 2 Diabetes Are Associated With Generalized Microvascular Dysfunction: The Maastricht Study. Circulation. 2016;134:1339-1352.

58. Schisterman EF, Cole SR and Platt RW. Overadjustment bias and unnecessary adjustment in epidemiologic studies. Epidemiology. 2009;20:488-95.

59. Yarmolinsky J, Wade KH, Richmond RC, Langdon RJ, Bull CJ, Tilling KM, Relton CL, Lewis SJ, Davey Smith G and Martin RM. Causal Inference in Cancer Epidemiology: What Is the Role of Mendelian Randomization? Cancer Epidemiol Biomarkers Prev. 2018;27:995-1010.

60. Aldrich J. Correlations genuine and spurious in Pearson and Yule. Statistical Science. 1995;10:364-376.

61. Song MK, Lin FC, Ward SE and Fine JP. Composite variables: when and how. Nurs Res. 2013;62:45-9.

62. van Sloten TT, Schram MT, Adriaanse MC, Dekker JM, Nijpels G, Teerlink T, Scheffer PG, Pouwer F, Schalkwijk CG, Stehouwer CD and Henry RM. Endothelial dysfunction is associated with a greater depressive symptom score in a general elderly population: the Hoorn Study. Psychol Med. 2014;44:1403-16.

63. Martens RJ, Henry RM, Houben AJ, van der Kallen CJ, Kroon AA, Schalkwijk CG, Schram MT, Sep SJ, Schaper NC, Dagnelie PC, Muris DM, Gronenschild EH, van der Sande FM, Leunissen KM, Kooman JP and Stehouwer CD. Capillary Rarefaction Associates with Albuminuria: The Maastricht Study. J Am Soc Nephrol. 2016;27:3748-3757. 
64. Van der Elst W, van Boxtel MP, van Breukelen GJ and Jolles J. Rey's verbal learning test: normative data for 1855 healthy participants aged 24-81 years and the influence of age, sex, education, and mode of presentation. J Int Neuropsychol Soc. 2005;11:290-302.

65. Van der Elst W, Van Boxtel MP, Van Breukelen GJ and Jolles J. The Stroop color-word test: influence of age, sex, and education; and normative data for a large sample across the adult age range. Assessment. 2006;13:62-79.

66. Van der Elst W, Van Boxtel MP, Van Breukelen GJ and Jolles J. The Concept Shifting Test: adult normative data. Psychol Assess. 2006;18:424-32.

67. van der Elst W, van Boxtel MP, van Breukelen GJ and Jolles J. The Letter Digit Substitution Test: normative data for 1,858 healthy participants aged 24-81 from the Maastricht Aging Study (MAAS): influence of age, education, and sex. J Clin Exp Neuropsychol. 2006;28:998-1009.

68. Batzias K, Antonopoulos AS, Oikonomou E, Siasos G, Bletsa E, Stampouloglou PK, Mistakidi CV, Noutsou M, Katsiki N, Karopoulos P, Charalambous G, Thanopoulou A, Tentolouris N and Tousoulis D. Effects of Newer Antidiabetic Drugs on Endothelial Function and Arterial Stiffness: A Systematic Review and Meta-Analysis. J Diabetes Res. 2018;2018:1232583.

69. Ling MC, Ruddy TD, deKemp RA, Ukkonen H, Duchesne L, Higginson L, Williams KA, McPherson $\mathrm{R}$ and Beanlands R. Early effects of statin therapy on endothelial function and microvascular reactivity in patients with coronary artery disease. Am Heart J. 2005;149:1137.

70. Dufouil C, Chalmers J, Coskun O, Besancon V, Bousser MG, Guillon P, MacMahon S, Mazoyer B, Neal B, Woodward M, Tzourio-Mazoyer N, Tzourio C and Investigators PMS. Effects of blood pressure lowering on cerebral white matter hyperintensities in patients with stroke: the PROGRESS (Perindopril Protection Against Recurrent Stroke Study) Magnetic Resonance Imaging Substudy. Circulation. 2005;112:1644-50.

71. Arima H and Chalmers J. PROGRESS: Prevention of Recurrent Stroke. J Clin Hypertens (Greenwich). 2011;13:693-702.

72. Launer LJ, Miller ME, Williamson JD, Lazar RM, Gerstein HC, Murray AM, Sullivan M, Horowitz KR, Ding J, Marcovina S, Lovato LC, Lovato J, Margolis KL, O'Connor P, Lipkin EW, Hirsch J, Coker L, Maldjian J, Sunshine JL, Truwit C, Davatzikos C, Bryan RN and investigators AM. Effects of intensive glucose lowering on brain structure and function in people with type 2 diabetes (ACCORD MIND): a randomised open-label substudy. Lancet Neurol. 2011;10:969-77.

73. Williamson JD, Launer LJ, Bryan RN, Coker LH, Lazar RM, Gerstein HC, Murray AM, Sullivan MD, Horowitz KR, Ding J, Marcovina S, Lovato L, Lovato J, Margolis KL, Davatzikos C, Barzilay J, Ginsberg HN, Linz PE, Miller ME and Action to Control Cardiovascular Risk in Diabetes Memory in Diabetes I. Cognitive function and brain structure in persons with type 2 diabetes mellitus after intensive lowering of blood pressure and lipid levels: a randomized clinical trial. JAMA Intern Med. 2014;174:324-33. 



\section{Nederlandse samenvatting}

Ouderdomsgerelateerde hersensziekten zoals dementie en beroertes, maar ook depressie, maken de laatste jaren een sterke opmars als veroorzakers van sterfte en ziektelast. Eén van de veroorzakers van deze ziekten kan schade aan de kleinste bloedvaatjes van het lichaam, de haarvaatjes, zijn. De haarvaatjes, ook wel de microcirculatie genoemd, vervullen een belangrijke rol in het gezond houden van het lichaam, door een veelvoud aan taken zoals het leveren van voedingsstoffen aan, en het weghalen van afvalstoffen uit de organen. Daarbij vervullen ze (onder andere) een belangrijke rol in het reguleren van de bloeddruk. Schade aan de haarvaten (microvasculaire dysfunctie), kan ertoe leiden dat deze processen verstoord raken. Dit is vooral het geval in organen die sterk afhankelijk zijn van een goede bloedvoorziening, zoals de hersenen. Daarom wordt microvasculaire dysfunctie genoemd als een mogelijke oorzaak van hersenproblematiek zoals dementie, depressie en beroertes. Nu de bevolking steeds ouder wordt, zijn er steeds meer mensen die lijden onder een ongunstig vasculair risicoprofiel met 'klassieke' cardiometabole risicofactoren zoals overgewicht, hoge bloeddruk (hypertensie) en suikerziekte (type 2 diabetes). Het is belangrijk om te onderzoeken hoe deze risicofactoren bijdragen aan microvasculaire dysfunctie en daardoor hersenproblematiek. Er zijn al meerdere risicofactoren voor microvasculaire dysfunctie geïdentificeerd, zoals stijfheid van de grote slagaderen (arteriën) van het lichaam (vaatstijfheid), type 2 diabetes, hypertensie, leeftijd en overgewicht. We weten momenteel niet welke andere factoren ook bijdragen aan microvasculaire dysfunctie, en het mechanisme waardoor deze risicofactoren en microvasculaire dysfunctie leiden tot hersenproblematiek is nog onduidelijk.

Dit proefschrift richt zich op het evalueren van de oorzaken van microvasculaire dysfunctie en de effecten ervan op hersenproblematiek (i.e. dementie, depressie en beroertes). Daarbovenop onderzoekt dit proefschrift of microvasculaire dysfunctie een spil is in de reeds bekende associatie tussen cardiometabole risicofactoren en hersenproblematiek. De hoofdbevindingen in deze thesis zijn:

1. Microvasculaire dysfunctie is geassocieerd met dementie, depressie, beroerte en mortaliteit;

2. Hoe meer verschillende vormen van microvasculaire dysfunctie in de hersenen aanwezig zijn, des te hoger het risico op een beroerte;

3. Microvasculairedysfunctiekanderelatietussenvaatstijfheidenhersenproblematiek, en type 2 diabetes en hersenproblematiek deels verklaren;

4. Grotere fluctuaties in bloeddruk zijn geassocieerd met albuminurie, een maat van microvasculaire dysfunctie.

Aan het eind van deze samenvatting wordt er een pathofysiologisch model beschreven dat de relatie tussen bovenstaande bevindingen beschrijft. Tot slot worden de gevolgen van deze bevindingen voor de dagelijkse praktijk besproken, alsmede de aard van de studies die verricht dienen te worden om de kennis verder uit te breiden. 


\section{Hoofdbevindingen}

\section{Microvasculaire dysfunctie is geassocieerd met dementie, depressie, beroerte en mortaliteit}

Inhet tweedehoofdstukvan deze thesis hebben we dehypothesegetest dat microvasculaire dysfunctie in de hersenen gerelateerd is aan het krijgen van hersenproblematiek. Om dit uit te zoeken, hebben wij een grote literatuurstudie uitgevoerd, waarin we systematisch alle artikelen over dit onderwerp hebben bekeken. Vervolgens hebben wij de vergelijkbare data ervan hebben samengevat middels een test, waarmee op statistische wijze wordt vastgesteld of deze associatie bestaat. Hiertoe hebben we gekeken naar alle studies die een relatie hebben onderzocht tussen bepaalde kenmerken van microvasculaire dysfunctie in de hersenen, cerebral small vessel disease genoemd, en het krijgen van dementie, depressie, en beroerte, of het optreden van sterfte. We vonden een sterke en ook consistente associatie tussen verschillende van deze kenmerken van cerebral small vessel disease, en het optreden van bovenstaande uitkomsten. Om een idee te geven van de relevantie van cerebral small vessel disease; als er cerebral small vessel disease aantoonbaar is, dan is iemands risico op het krijgen van dementie, depressie, en beroerte hetzelfde als bij aanwezigheid van type 2 diabetes ${ }^{1-4}$ of hypertensie..$^{5-9}$ Hieruit kunnen we opmaken dat de microcirculatie in de hersenen belangrijk is voor optimale hersenfunctie. Als de gemeten microvasculaire functie in de hersenen een weerspiegeling is van de rest van het lichaam, betekent dit dat de microcirculatie belangrijk is voor optimale orgaanfunctie. Een belangrijk gegeven voor de interpretatie van deze data is dat de geïncludeerde onderzoeken in deze literatuurstudie van longitudinale aard zijn, dat wil zeggen, iedere deelnemer is voor een lange periode gevolgd nadat cerebral small vessel disease is gemeten. Hierdoor weet je vrij zeker dat er éérst microvasculaire dysfunctie in de hersenen moet optreden, voordat de klinische uitkomstmaten meetbaar zijn, in plaats van andersom.

Microvasculaire dysfunctie in andere organen dan de hersenen zouden de mate van cerebral small vessel disease kunnen weerspiegelen, en daarom dus ook geassocieerd kunnen zijn met hersenproblematiek. Andere studies hebben al aangetoond dat bepaalde tekenen van microvasculaire dysfunctie, zoals albumineverlies via de urine, ${ }^{10}$ en verhoogde bloed biomarkers van microvasculaire dysfunctie, aanwezig zijn bij mensen met verslechterde geheugenfunctie. Om dit principe verder te onderzoeken, hebben we in hoofdstuk vier gekeken of een composietscore, een soort optelsom van verschillende maten van microvasculaire dysfunctie, weerspiegelt of iemand een slechtere geheugenfunctie heeft. Hiervoor hebben we verschillende maten voor microvasculaire dysfunctie samengevat in een score, namelijk: maten van cerebral small vessel disease, vaatreactiviteit van netvliesvaten op lichtflitsen, albumineverlies in de urine, bloed biomarkers van microvasculaire dysfunctie en vaatreactiviteit van de huid op warmtestimulatie. We concludeerden dat deze composietscore inderdaad verhoogd (i.e. ongunstiger) is bij mensen met een slechtere geheugenfunctie, en dat deze associatie aanwezig bleef wanneer we cerebral small vessel disease uit de score haalden. Dit betekent dat ook microvasculaire dysfunctie in andere organen dan de hersenen geassocieerd is met een slechtere geheugenfunctie. Deze studie is dus een onderbouwing voor de hypothese dat microvasculaire dysfunctie in het hele lichaam de (dys)functie van de 
microcirculatie in de hersenen weerspiegelt, en dus ook een rol zou kunnen spelen bij het pathofysiologische proces dat leidt tot hersenproblematiek.

\section{Hoe meer verschillende vormen van microvasculaire dysfunctie in de hersenen aanwezig zijn, des te hoger het risico op een beroerte}

In hoofdstuk twee toonden we aan dat de aanwezigheid van twee maten van cerebral small vessel disease sterker geassocieerd is met het optreden van een beroerte dan alleen enkelvoudig aanwezige maten. Deze bevinding impliceert dat er een dosis-respons relatie zou kunnen zijn tussen de mate van cerebral small vessel disease en de mate van hersenproblematiek die daarbij optreedt. Dit is een relevante bevinding voor clinici, omdat het kan leiden tot een betere voorspelling voor patiënten die een risico lopen op bijvoorbeeld dementie of beroerte. Een speciale schaal om de mate van cerebral small vessel disease te scoren zou dan nog een risicopredictie kunnen geven bovenop reeds bekende risicofactoren.

\section{Microvasculaire dysfunctie kan de relatie tussen vaatstijfheid en type $\mathbf{2}$ diabetes, en hersenproblematiek (deels) verklaren}

Zoals boven al aangegeven, zijn meerdere cardiovasculaire risicofactoren geassocieerd met hersenproblematiek, en zou deze associatie veroorzaakt (ook wel gemedieerd genoemd) kunnen worden door microvasculaire dysfunctie. ${ }^{11-14}$ Het doel van hoofdstuk drie en vijf was om te onderzoeken of microvasculaire dysfunctie inderdaad een mediërende rol heeft in de associatie tussen zowel vaatstijfheid en hersenproblematiek, als type 2 diabetes en hersenproblematiek.

De aanvoerende slagaderen in het lichaam, de arteriën, werken als een buffer voor de bloeddrukgolven vanuit het hart, door middel van hun meeverende elastische wand. Stijvere arteriën, bijvoorbeeld door aderverkalking, leiden tot een ongunstig bloeddrukpatroon, waardoor schade kan ontstaan. ${ }^{11,12}$ Voorgaande studies $^{15}$ 16-29 toonden al aan dat er een associatie bestaat tussen arteriële stijfheid en de aanwezigheid van dementie, of het optreden van cognitieve achteruitgang. In hoofdstuk vijf hebben we deze associatie opnieuw onderzocht, door te kijken of twee verschillende maten van vaatstijfheid, namelijk buikslagaderstijfheid (aortastijfheid) en halsslagaderstijfheid (carotisstijfheid), een associatie vertonen met een slechtere geheugenfunctie. Het bleek dat aortastijfheid geassocieerd is met een slechtere geheugenfunctie. Vervolgens hebben we met een statistische analyse aangetoond dat deze associatie deel verklaard kon worden door microvasculaire dysfunctie. We vonden in onze studie geen associatie tussen carotisstijfheid en geheugenfunctie, dit kan komen doordat de meting voor aortastijfheid betrouwbaarder is dan de meting voor carotisstijfheid, ${ }^{30,31}$ waardoor eventuele associaties eerder kunnen worden aangetoond met aortastijfheid dan met carotisstijfheid.

Type 2 diabetes kan, net als vaatstijfheid, leiden tot microvasculaire dysfunctie. Het wordt verondersteld dat in patiënten met type 2 diabetes, het hebben van o.a. hoge bloedsuikers, verminderde insulineafhankelijke vaatfunctie, aantasting van eiwitten en cellen door reactie met glucose (glycolysering) en zuurstofradicalen (oxidatieve stress), kan leiden tot deze schade aan de microcirculatie. ${ }^{13,14,32}$ De aanwezigheid van type 2 diabetes bleek eerder al geassocieerd met het optreden van depressieve klachten, hetgeen dus 
mogelijk veroorzaakt wordt door microvasculaire dysfunctie. In hoofdstuk drie hebben we bevestigd dat type 2 diabetes geassocieerd is met een toename van depressieve klachten over de tijd. Tevens hebben we aangetoond dat deze associatie deels verklaard wordt door microvasculaire dysfunctie in de hersenen.

Debevinding datmicrovasculaire dysfunctie deassociatie tussen'klassieke'cardiovasculaire risicofactoren en hersenproblematiek medieert is belangrijk, omdat microvasculaire dysfunctie daarmee een doel kan worden voor het behandelen en voorkomen van hersenziekten bij mensen met deze cardiovasculaire risicofactoren. Het is echter wel belangrijk vast te stellen dat een aanzienlijk deel van de gevonden associaties tussen cardiovasculaire risicofactoren en hersenproblematiek niet (statistisch) gemedieerd werd door microvasculaire dysfunctie in onze studies. Dit 'niet-verklaarde deel' kan bestaan uit een effect van microvasculaire dysfunctie dat niet goed geobjectiveerd kan worden met onze gemeten maten van microvasculaire dysfunctie. Wij hebben bijvoorbeeld geen onderzoek gedaan naar functionele uitkomstmaten voor microvasculaire dysfunctie, zoals het adaptatievermogen van de microcirculatie in de hersenen op bepaalde stimuli (cerebrale autoregulatie genoemd). Dit adaptievermogen kan echter wel een belangrijke weerspiegeling zijn van microvasculaire dysfunctie, en eerder afwijkingen vertonen dan structurele metingen van de hersenen, zoals het geval is bij cerebral small vessel disease. ${ }^{33}$ Het is ook mogelijk dat slechts een deel van de mensen met vaatstijfheid of type 2 diabetes hersenproblematiek krijgt die direct gerelateerd is aan microvasculaire dysfunctie. Zo kan slechtere cognitie bij vaatstijfheid of type 2 diabetes ook een gevolg zijn van macrovasculaire schade, of de ziekte van Alzheimer. ${ }^{34}$ Daarnaast kunnen depressieve symptomen in type 2 diabetes ook veroorzaakt worden door aan diabetes gerelateerde risicofactoren, zoals psychosociale factoren, ${ }^{35}$ comorbiditeit $^{35}$ en directe zenuwschade door hoge bloedsuikers. ${ }^{36}$

\section{Grotere fluctuaties in bloeddruk zijn geassocieerd met albuminurie, een maat van microvasculaire dysfunctie}

Naast 'klassieke' risicofactoren voor microvasculaire dysfunctie, worden er ook nieuwe risicofactoren beschreven. Een mogelijke risicofactor voor microvasculaire dysfunctie is het hebben van fluctuaties in de bloeddruk. Fluctuaties in de bloeddruk zijn normaal, maar wanneer dit te veel wordt (wanneer het lichaam het verschil in bloeddrukken minder goed kan opvangen), kan het leiden tot microvasculaire dysfunctie. ${ }^{37,}{ }^{38} \mathrm{Om}$ deze hypothese te testen, hebben we in hoofdstuk 6 bekeken of grote fluctuaties in de bloeddruk leiden tot microvasculaire dysfunctie. We hadden hierbij de verwachting dat organen die bloeddruk(fluctuaties) makkelijk doorlaten, namelijk de nieren en hersenen, meer schade zouden ondervinden dan andere organen. We vonden dat een grotere bloeddrukvariabiliteit alleen was geassocieerd met microvasculaire dysfunctie in de nieren, maar niet in de hersenen of andere organen. Mogelijk komt dit omdat de nieren van alle organen de grootste bloedtoevoer hebben, waardoor zij meer blootgesteld worden aan bloeddrukfluctuaties dan andere organen. ${ }^{39}$ 


\section{Conclusie}

Dit proefschrift laat zien dat microvasculaire dysfunctie een centrale rol speelt in de relatie tussen cardiometabole risicofactoren en het krijgen van hersenproblematiek, zoals dementie, depressie en beroertes. In onderstaande figuur zijn de belangrijkste bevindingen van dit proefschrift schematisch weergegeven. Wij hopen dat deze thesis aanknopingspunten geeft voor vervolgonderzoek dat kan helpen het risico op hersenziektes te verminderen.

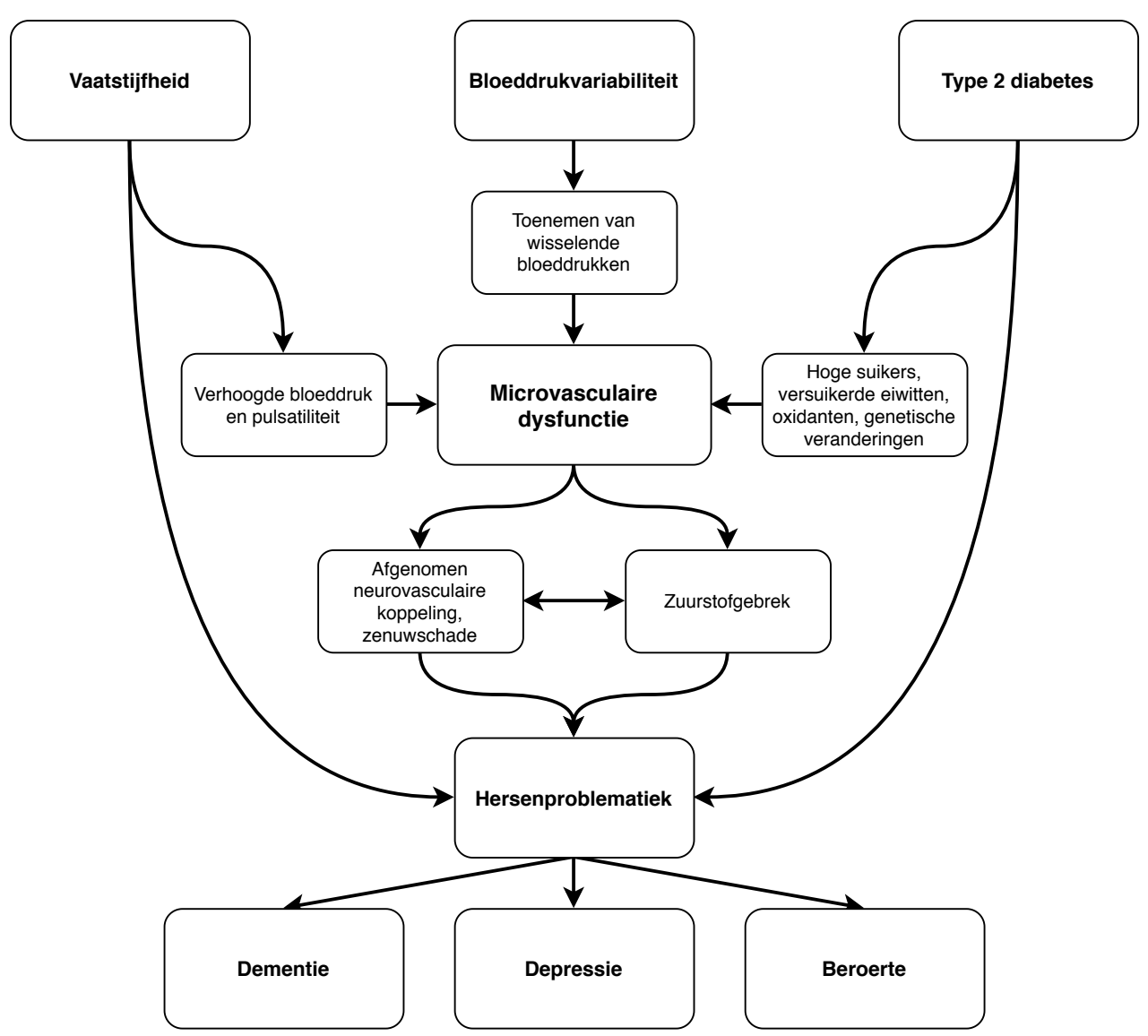

Figuur. Potentiele mechanismen voor de oorzaken en gevolgen van microvasculaire dysfunctie 
1. Gregg EW, Li Y, Wang J, Burrows NR, Ali MK, Rolka D, Williams DE and Geiss L. Changes in diabetes-related complications in the United States, 1990-2010. N Engl J Med. 2014;370:151423.

2. Xu WL, Qiu CX, Wahlin A, Winblad B and Fratiglioni L. Diabetes mellitus and risk of dementia in the Kungsholmen project: a 6-year follow-up study. Neurology. 2004;63:1181-6.

3. Yu M, Zhang X, Lu F and Fang L. Depression and Risk for Diabetes: A Meta-Analysis. Can J Diabetes. 2015;39:266-72.

4. Gregg EW, Cheng YJ, Saydah S, Cowie C, Garfield S, Geiss L and Barker L. Trends in death rates among U.S. adults with and without diabetes between 1997 and 2006: findings from the National Health Interview Survey. Diabetes Care. 2012;35:1252-7.

5. Imano H, Kitamura A, Sato S, Kiyama M, Ohira T, Yamagishi K, Noda H, Tanigawa T, Iso H and Shimamoto $\mathrm{T}$. Trends for blood pressure and its contribution to stroke incidence in the middle-aged Japanese population: the Circulatory Risk in Communities Study (CIRCS). Stroke. 2009;40:1571-7.

6. Verdecchia P, Reboldi GP, Angeli F, Schillaci G, Schwartz JE, Pickering TG, Imai Y, Ohkubo T and Kario K. Short- and long-term incidence of stroke in white-coat hypertension. Hypertension. 2005;45:203-208.

7. Li G, Rhew IC, Shofer JB, Kukull WA, Breitner JC, Peskind E, Bowen JD, McCormick W, Teri L, Crane PK and Larson EB. Age-varying association between blood pressure and risk of dementia in those aged 65 and older: a community-based prospective cohort study. J Am Geriatr Soc. 2007;55:1161-7.

8. Sharp SI, Aarsland D, Day S, Sonnesyn H, Ballard C and Syst AsSVD. Hypertension is a potential risk factor for vascular dementia: systematic review. Int J Geriatr Psychiatry. 2011;26:661-669.

9. Barengo NC, Antikainen R, Kastarinen M, Laatikainen T and Tuomilehto J. The effects of control of systolic and diastolic hypertension on cardiovascular and all-cause mortality in a communitybased population cohort. J Hum Hypertens. 2013;27:693-7.

10. Georgakis MK, Dimitriou NG, Karalexi MA, Mihas C, Nasothimiou EG, Tousoulis D, Tsivgoulis $G$ and Petridou ET. Albuminuria in Association with Cognitive Function and Dementia: A Systematic Review and Meta-Analysis. J Am Geriatr Soc. 2017;65:1190-1198.

11. Fazekas F, Kleinert R, Offenbacher H, Payer F, Schmidt R, Kleinert G, Radner H and Lechner H. The morphologic correlate of incidental punctate white matter hyperintensities on MR images. AJNR Am J Neuroradiol. 1991;12:915-21.

12. Saji N, Toba K and Sakurai T. Cerebral Small Vessel Disease and Arterial Stiffness: Tsunami Effect in the Brain? Pulse (Basel). 2016;3:182-9.

13. Forbes JM and Cooper ME. Mechanisms of diabetic complications. Physiol Rev. 2013;93:137-88.

14. Stehouwer CDA. Microvascular Dysfunction and Hyperglycemia: A Vicious Cycle With Widespread Consequences. Diabetes. 2018;67:1729-1741.

15. van Sloten TT, Protogerou AD, Henry RM, Schram MT, Launer LJ and Stehouwer CD. Association between arterial stiffness, cerebral small vessel disease and cognitive impairment: A systematic review and meta-analysis. Neurosci Biobehav Rev. 2015;53:121-30.

16. Taniguchi Y, Fujiwara Y, Nofuji Y, Nishi M, Murayama H, Seino S, Tajima R, Matsuyama $Y$ and Shinkai S. Prospective Study of Arterial Stiffness and Subsequent Cognitive Decline Among Community-Dwelling Older Japanese. J Epidemiol. 2015;25:592-9.

17. Hajjar I, Goldstein FC, Martin GS and Quyyumi AA. Roles of Arterial Stiffness and Blood Pressure in Hypertension-Associated Cognitive Decline in Healthy Adults. Hypertension. 2016;67:171-5. 
18. Tsao CW, Himali JJ, Beiser AS, Larson MG, DeCarli C, Vasan RS, Mitchell GF and Seshadri S. Association of arterial stiffness with progression of subclinical brain and cognitive disease. Neurology. 2016;86:619-26.

19. Meyer ML, Palta P, Tanaka H, Deal JA, Wright J, Knopman DS, Griswold ME, Mosley TH and Heiss G. Association of Central Arterial Stiffness and Pressure Pulsatility with Mild Cognitive Impairment and Dementia: The Atherosclerosis Risk in Communities Study-Neurocognitive Study (ARIC-NCS). J Alzheimers Dis. 2017;57:195-204.

20. Muela HCS, Costa-Hong VA, Yassuda MS, Moraes NC, Memoria CM, Machado MF, Bor-Seng-Shu E, Nogueira RC, Mansur AJ, Massaro AR, Nitrini R, Macedo TA and Bortolotto LA. Higher arterial stiffness is associated with lower cognitive performance in patients with hypertension. $J$ Clin Hypertens (Greenwich). 2018;20:22-30.

21. Rouch L, Cestac P, Sallerin B, Andrieu S, Bailly H, Beunardeau M, Cohen A, Dubail D, Hernandorena I, Seux ML, Vidal JS and Hanon O. Pulse Wave Velocity Is Associated With Greater Risk of Dementia in Mild Cognitive Impairment Patients. Hypertension. 2018;72:1109-1116.

22. Palta P, Sharrett AR, Wei J, Meyer ML, Kucharska-Newton A, Power MC, Deal JA, Jack CR, Knopman D, Wright J, Griswold M, Tanaka H, Mosley TH and Heiss G. Central Arterial Stiffness Is Associated With Structural Brain Damage and Poorer Cognitive Performance: The ARIC Study. J Am Heart Assoc. 2019;8:e011045.

23. Pase MP, Beiser A, Himali JJ, Tsao C, Satizabal CL, Vasan RS, Seshadri S and Mitchell GF. Aortic Stiffness and the Risk of Incident Mild Cognitive Impairment and Dementia. Stroke. 2016;47:2256-61.

24. Huck DM, Hanna DB, Rubin LH, Maki P, Valcour V, Springer G, Xue X, Lazar J, Hodis HN, Anastos K, Kaplan RC and Kizer JR. Carotid Artery Stiffness and Cognitive Decline Among Women With or at Risk for HIV Infection. J Acquir Immune Defic Syndr. 2018;78:338-347.

25. DuBose LE, Voss MW, Weng TB, Kent JD, Dubishar KM, Lane-Cordova A, Sigurdsson G, Schmid P, Barlow PB and Pierce GL. Carotid beta-stiffness index is associated with slower processing speed but not working memory or white matter integrity in healthy middle-aged/older adults. J Appl Physiol (1985). 2017;122:868-876.

26. Lim SL, Gao Q, Nyunt MS, Gong L, Lunaria JB, Lim ML, Ling A, Lam CS, Richards AM, Ling LH and $\mathrm{Ng}$ TP. Vascular Health Indices and Cognitive Domain Function: Singapore Longitudinal Ageing Studies. J Alzheimers Dis. 2016;50:27-40.

27. Poels MM, van Oijen M, Mattace-Raso FU, Hofman A, Koudstaal PJ, Witteman JC and Breteler MM. Arterial stiffness, cognitive decline, and risk of dementia: the Rotterdam study. Stroke. 2007;38:888-92.

28. Tarumi T, Gonzales MM, Fallow B, Nualnim N, Pyron M, Tanaka H and Haley AP. Central artery stiffness, neuropsychological function, and cerebral perfusion in sedentary and endurancetrained middle-aged adults. J Hypertens. 2013;31:2400-9.

29. Geijselaers SL, Sep SJ, Schram MT, van Boxtel MP, van Sloten TT, Henry RM, Reesink KD, Kroon AA, Koster A, Schaper NC, Dagnelie PC, van der Kallen CJ, Biessels GJ and Stehouwer CD. Carotid stiffness is associated with impairment of cognitive performance in individuals with and without type 2 diabetes. The Maastricht Study. Atherosclerosis. 2016;253:186-193.

30. Koivistoinen T, Virtanen M, Hutri-Kahonen N, Lehtimaki T, Jula A, Juonala M, Moilanen L, Aatola $\mathrm{H}$, Hyttinen J, Viikari JS, Raitakari OT and Kahonen M. Arterial pulse wave velocity in relation to carotid intima-media thickness, brachial flow-mediated dilation and carotid artery distensibility: the Cardiovascular Risk in Young Finns Study and the Health 2000 Survey. Atherosclerosis. 2012;220:387-93. 
31. Laurent S, Cockcroft J,Van Bortel L, Boutouyrie P, Giannattasio C, Hayoz D, Pannier B, Vlachopoulos C, Wilkinson I, Struijker-Boudier $\mathrm{H}$ and European Network for Non-invasive Investigation of Large A. Expert consensus document on arterial stiffness: methodological issues and clinical applications. Eur Heart J. 2006;27:2588-605.

32. Geijselaers SLC, Sep SJS, Stehouwer CDA and Biessels GJ. Glucose regulation, cognition, and brain MRI in type 2 diabetes: a systematic review. Lancet Diabetes Endocrinol. 2015;3:75-89.

33. Purkayastha S, Fadar O, Mehregan A, Salat DH, Moscufo N, Meier DS, Guttmann CR, Fisher ND, Lipsitz LA and Sorond FA. Impaired cerebrovascular hemodynamics are associated with cerebral white matter damage. J Cereb Blood Flow Metab. 2014;34:228-34.

34. Hughes TM, Wagenknecht LE, Craft S, Mintz A, Heiss G, Palta P, Wong D, Zhou Y, Knopman D, Mosley TH and Gottesman RF. Arterial stiffness and dementia pathology: Atherosclerosis Risk in Communities (ARIC)-PET Study. Neurology. 2018;90:e1248-e1256.

35. Badescu SV, Tataru C, Kobylinska L, Georgescu EL, Zahiu DM, Zagrean AM and Zagrean L. The association between Diabetes mellitus and Depression. J Med Life. 2016;9:120-5.

36. Tomlinson DR and Gardiner NJ. Glucose neurotoxicity. Nat Rev Neurosci. 2008;9:36-45.

37. Mitchell GF. Effects of central arterial aging on the structure and function of the peripheral vasculature: implications for end-organ damage. J Appl Physiol (1985). 2008;105:1652-60.

38. Rothwell PM. Limitations of the usual blood-pressure hypothesis and importance of variability, instability, and episodic hypertension. Lancet. 2010;375:938-48.

39. Hall J.E. Guyton and Hall textbook of medical physiology. 13th ed. Philadelphia, PA: Elsevier; 206. 


\section{Valorisation addendum}

The goal of scientific research is to establish new facts and to reach new conclusions, but without any impact to society, these new conclusions would have little consequences. The goal of this chapter is to discuss the impact on society of the conclusions reached in this thesis, and to discuss any recommendations for further research on this topic in order to maximize this impact.

\section{Relevance of this research}

In the Netherlands and most other parts of the world, life expectancy has been increasing for the last couple of decades and will continue to do so for some more decades to come. With the increasing age of the population, the amount of individuals with a high burden of cardiovascular risk factors increases. More importantly, so does the number of individuals with age-related brain diseases such as dementia, late-life depression and stroke. The findings in this thesis suggest that deterioration of the microvasculature, i.e. the vascular meshwork comprised of arterioles, capillaries and venules, is an important contributor to the development of these age-related brain diseases. In addition, this thesis suggests that microvascular deterioration, also called microvascular dysfunction, mediates the association between cardiovascular risk factors and age-related brain diseases.

The conclusions in this thesis provide an important contribution to our current understanding of the pathophysiology of age-related brain diseases and indicate that prevention and/or treatment of microvascular dysfunction may be an important clinical goal. In practice, to prevent or slow down progression of age-related brain diseases in individuals with microvascular dysfunction, early and adequate cardiometabolic health must be pursued. Moreover, interventions aiming to favourably influence microvascular function on top of cardiometabolic management may provide additional prevention of age-related brain diseases.

\section{Future research}

Before studies on prevention of and intervention for microvascular dysfunction can be conducted, further longitudinal observational studies are needed to confirm the causal relationship between cardiovascular risk factors, microvascular dysfunction, and agerelated brain diseases. Although the results in this thesis are consistent across all chapters, only chapter 2 and chapter 3 describe longitudinal relationships from which temporal associations, and thus causality, may be implied. Furthermore, in the present thesis, microvascular dysfunction was defined as a higher composite score of several measures of microvascular dysfunction, and sometimes specifically by measures of cerebral small vessel disease, instead of clinically relevant microvascular disease. There is currently no scale to define clinically relevant microvascular dysfunction based on the measures of microvascular dysfunction used in this thesis. Future studies are therefore needed to evaluate at what point microvascular dysfunction becomes clinically relevant, and whether the observed associations with microvascular dysfunction and age-related brain diseases are also present at this point. This thesis already demonstrated that the combination of two cerebral small vessel disease features is most strongly associated with incident stroke. This suggests that scales that incorporate the effect of multiple measures of microvascular 
function are most suitable to assess microvascular dysfunction, and most likely to enable improved risk prediction of clinical outcomes beyond established risk factors.

In addition to observational studies, randomized controlled trials are needed to evaluate the possible effectiveness of interventions for microvascular dysfunction. Currently, evidence for improved outcome with treatment programs aimed at strict cardiovascular risk management in patients with microvascular dysfunction is lacking. It has been suggested however, that statins, ACE inhibitors and aspirin improve microvascular function by mechanisms beyond their respective lipid-lowering, blood pressure-lowering and anticoagulant effects; the so-called pleiotropic effect.

\section{Clinical recommendations}

As stated above, there are currently no comprehensive guidelines available for the diagnosis and treatment of microvascular disease. In 2013, the STRIVE neuroimaging standards to aid in the standardized assessment of microvascular disease in the brain were published. However, it is not advisable for a clinician to actively screen for microvascular dysfunction using neuroimaging or other techniques, given the current lack of guidelines for intervention. However, features of microvascular dysfunction are often found as incidental findings on scans with other primary indications. A clinician should, upon diagnosing a patient with microvascular dysfunction, be prompted to perform adequate cardiovascular risk assessment. The risk factors that are associated to macrovascular disease appear to be similarly associated with microvascular dysfunction; e.g. smoking, type 2 diabetes, obesity, hypertension and hyperlipidaemia. As such, treatment aimed at cardiovascular risk factor management, including lifestyle counselling regarding smoking cessation, nutrition and physical activity is warranted.

\section{Conclusion}

The findings in this thesis suggest that identification and treatment of microvascular dysfunction can be helpful in prevention of age-related brain disease. 


\section{Dankwoord}

Dit proefschrift is het resultaat van 4 jaar intensieve, inspirerende, humoristische en prijzenswaardige samenwerking met vele collega's, familieleden en vrienden. Ik had mij geen fijnere start van mijn werkend leven kunnen wensen dan als onderdeel van het team van promovendi bij De Maastricht Studie. Ik ben iedereen met wie ik de afgelopen 4 jaar heb samengewerkt erg dankbaar voor hun prettige omgang en wil een aantal mensen graag in het bijzonder bedanken.

Mijn promotor, prof. dr. C.D.A. Stehouwer.

Beste Coen, ik ben heel dankbaar dat ik jou als promotor heb mogen hebben voor dit proefschrift. ledere hypothese, onderzoeksmethode en conclusie werd minutieus door je uitgeplozen en verbeterd, maar ook bij een spel- of taalfout kon ik op een uitgebreide uitleg rekenen. Ik heb ontzettend veel van je geleerd en ben hierdoor een scherpzinniger onderzoeker en persoon geworden.

Mijn copromotor, dr. T.T van Sloten.

Beste Thomas, als het gaat om mensen met kwaliteiten zoals het minutieus overwegen van iedere aspect van het verrichten van onderzoek, sta jij ook bovenaan. Ik ben je ontzettend dankbaar voor de zeer prettige, rustige en behulpzame begeleiding in de afgelopen jaren. Zonder jouw bijdrage zou dit werk niet half zo mooi en leeswaardig zijn geweest. Het was soms frustrerend te noemen hoe we ellenlange discussies konden hebben over iets, waarbij jij uiteindelijk toch weer gelijk bleek te hebben. Ik bewonder je doelmatige en overzichtelijke manier van het benaderen van problemen.

De leden van de beoordelingscommissie.

Graag wil ik Prof. dr. H.J.G.M. Crijns, Prof. dr. D.E.J. Linden, Prof. dr. F.E. de Leeuw, Prof. dr. M. Muller en Prof. dr. P.W. de Leeuw bedanken voor het beoordelen van mijn proefschrift. Geachte Dr. V.P.M. van Empel, hartelijk dank voor het deelnemen aan de corona en het voorzitten van de promotiezitting.

Alle collega's bij De Maastricht Studie en Interne Geneeskunde.

Mijn kamergenoten Tan Lai en Yuri. Ik weet niet of ik meer hulp of oponthoud heb ondervonden aan de samenwerking met jullie, maar een ding is zeker, zonder de slechte (woord)grappen en bijzondere verhalen die wij samen vertelden zou ik met veel minder plezier mijn promotie-traject hebben afgerond. Beste Tan Lai, wij kennen elkaar al sinds het eerste jaar van onze studie en werken nog steeds in het zelfde gebied. Je bent steevast een goede vriend en collega geweest met bijzonder veel kennis van zaken en altijd hulpvaardig. Ik hoop dat deze samenwerking nog lang zal blijven! Beste Yuri, al snel bleek dat er achter het masker van een zeer welbespraakt en net gekleed onderzoeker een flauwe humor verscholen zat die gelukkig vooral binnen de vier muren van onze kamer 
bleef (helaas niet altijd, vanwege de dunne wandjes). Naast je humoristische bijdrage heb ik ook inhoudelijk zeer veel hulp van je gehad, op taalkundig en wetenschappelijk gebied.

Carla, Yvette, Nadine en Miranda: bedankt voor de uitstekende, zowel inspirerende als laagdrempelige supervisie. Mede-promovendi Rianneke, Niki, Frank, April, Anouk, Cindy, Laura, Wenjie en Jerremy, bedankt voor de gezellige samenwerking en de uitputtende pingpong- en squashsessies. Marnix, Ben, Ellis, Marja, Charlotte, Peggy, Remy, Yannick en Veronica, bedankt voor de hulp aan een goede start van mijn promotie-traject. Mijn zeer gewaardeerde collega's met wie ik meerdere jaren lang intensief heb samengewerkt bij en rondom de metingen: Jos, Jeroen, Marion, Michiel, Anouk, Ingeborg, Sara, Lina, Lisanne, Ramona, Michiel, Marleen, Anke, Brigitte, Josephine, Manuela, Ank, Carine, Chantalle, Daniel, Else, Robin, Roel, Hannah, Demi, Ineke, Kayleigh, Laura, Simone, Myrthe en Paula.

Graag wil ik de co-auteurs die geholpen hebben bij het schrijven van de artikelen bedanken voor hun uitgebreide feedback en fijne samenwerking.

Dr. L. Launer, dear Lenore, thank you for the extensive help in writing our paper using data from de AGES-Reykjavic study.

Dr. A. Houben, beste Boy, bedankt voor de interessante gesprekken over de pathofysiologie van microvasculaire dysfunctie. Die hebben ervoor gezorgd dat ik ook op een meer basaal-geneeskundige wijze ben na gaan denken over de associaties die wij vonden in onze artikelen.

Dr. S. Köhler, beste Seb, bedankt voor je hulp bij de soms zeer ingewikkelde statische vraagstukken, waarbij je altijd tijd vrij maakte om dit zeer rustig uit te leggen.

Prof. Dr. P. Dagnelie, Beste Pieter, ook van jou heb ik ontzettend veel hulp ervaren bij het uitvogelen van statische probleemstukken, bedankt voor je hulp!

Prof. Dr. A. Kroon, Dr. R. Henry, Beste Bram, Ronald, bedankt dat jullie mij, Tan Lai en Frank zo goed geholpen hebt bij het schrijven van een stuk met zijn drieën.

Dr. K. Reesink, beste Koen, bedankt voor de interessante discussies over wetenschap en wetenschapsfilosofie. Dankzij jouw rustige uitleg en brede kennis heb ik veel geleerd.

Graag wil ik alle overige co-auteurs bedanken voor hun uitgebreide feedback en fijne samenwerking bij het tot stand komen van de artikelen:

Dr. M. van Boxtel, Dr. T. Berendschot, Dr. J. Jansen, Prof. Dr. F. Verhey, Prof. Dr. A. Kroon, Dr. A. Koster, Prof. Dr. W. Backes, Prof. Dr. N. Schaper, Prof. Dr. G. Dinant, Prof. Dr. C. Schalkwijk, Else M.L. Wolfs, Mike J.A. van Heumen, Dr. M. van Dongen, Dr. S. Eussen, Prof. Dr. J.H.A. Bosma, Dr. J. Schouten, Dr. M. van Dongen en Prof. Dr. C. Webers.

I would like to thank all other co-authors from foreign collaborations: Dr. J. Ding, Dr. S. Sigurdsson and Dr. V. Gudnason. 
De overige collega's van de onderzoeksgroep Interne Geneeskunde, bedankt voor de interessante discussies tijdens de Journal Club.

Aan mijn studievriendengroep; Giel, Robin, Mark, Marisya en Kim, bedankt voor de gezellige avonden, spelletjes en bijeenkomsten.

Aan al mijn vrienden van de Maastrichtse Studenten Alpen Club (MaasSAC), bedankt voor de leuke afleiding gedurende de weekenden en avonden middels klimuitjes. Een weekend naar de rotsen in België of Luxemburg voelt altijd aan als een kleine vakantie.

Aan alle vrienden uit mijn studentenhuis; Timo, Guus, Stefan, Alicia, Mohamed, Veerle, Lise, Jennie, Bernard en Lobke, jullie hebben er mede voor gezorgd dat ik succesvol door de studie ben heen gekomen, dankzij het gezellige gezamenlijke koken, en de vele activiteiten die wij nog steeds met enige regelmaat ondernemen, zelfs al wonen we al vele jaren niet meer in hetzelfde studentenhuis.

Aan mijn collega's van het Zuyderland MC, mijn promotie-traject was natuurlijk erg leuk, maar ik ben ook erg blij met hoe ik inmiddels driekwart jaar met jullie heb kunnen samenwerken!

Aan Birgit, bedankt dat je deze mooie kaft van mijn boekje hebt willen ontwerpen!

Lieve papa en mama, bedankt voor jullie steun en hulp de afgelopen jaren. Ik heb een fantastisch voorbeeld aan jullie. Lieve Hanneke, Pauline en Leonie, gelukkig krijgen wij het voor elkaar om, ondanks dat we allemaal artsen zijn geworden, we het aan de eettafel nog over andere zaken kunnen laten gaan dan patiëntenzorg. Bedankt voor jullie steun!

Liefste Nienke, bedankt dat je altijd klaarstaat om me te helpen, of het nu om hulp bij moeilijke wetenschappelijke vragen gaat, of om het maken van een lekkere koffie. Ik ben heel blij met jou in mijn leven! 



\section{Curriculum Vitae}

Sytze Rensma was born on May 7, 1991 in Nieuwegein, the Netherlands. He graduated from secondary school in 2009 (Gymnasium [VWO], Mill-Hillcollege, Goirle). In that year, he started his medical education at Maastricht University and in Augustus 2015 he obtained his medical degree. During his study, he conducted research as a student assistent at the Division of Clinical and Experimental Immunology of the Department of Internal Medicine. In October 2015, he started his PhD research under supervision of Prof. Dr. Coen Stehouwer at the Department of Internal Medicine of Maastricht University Medical Centre, within the CARIM School for Cardiovascular Disease. As of Januari 2020, he has worked as a resident Internal Medicine at Zuyderland Medical Centre. 



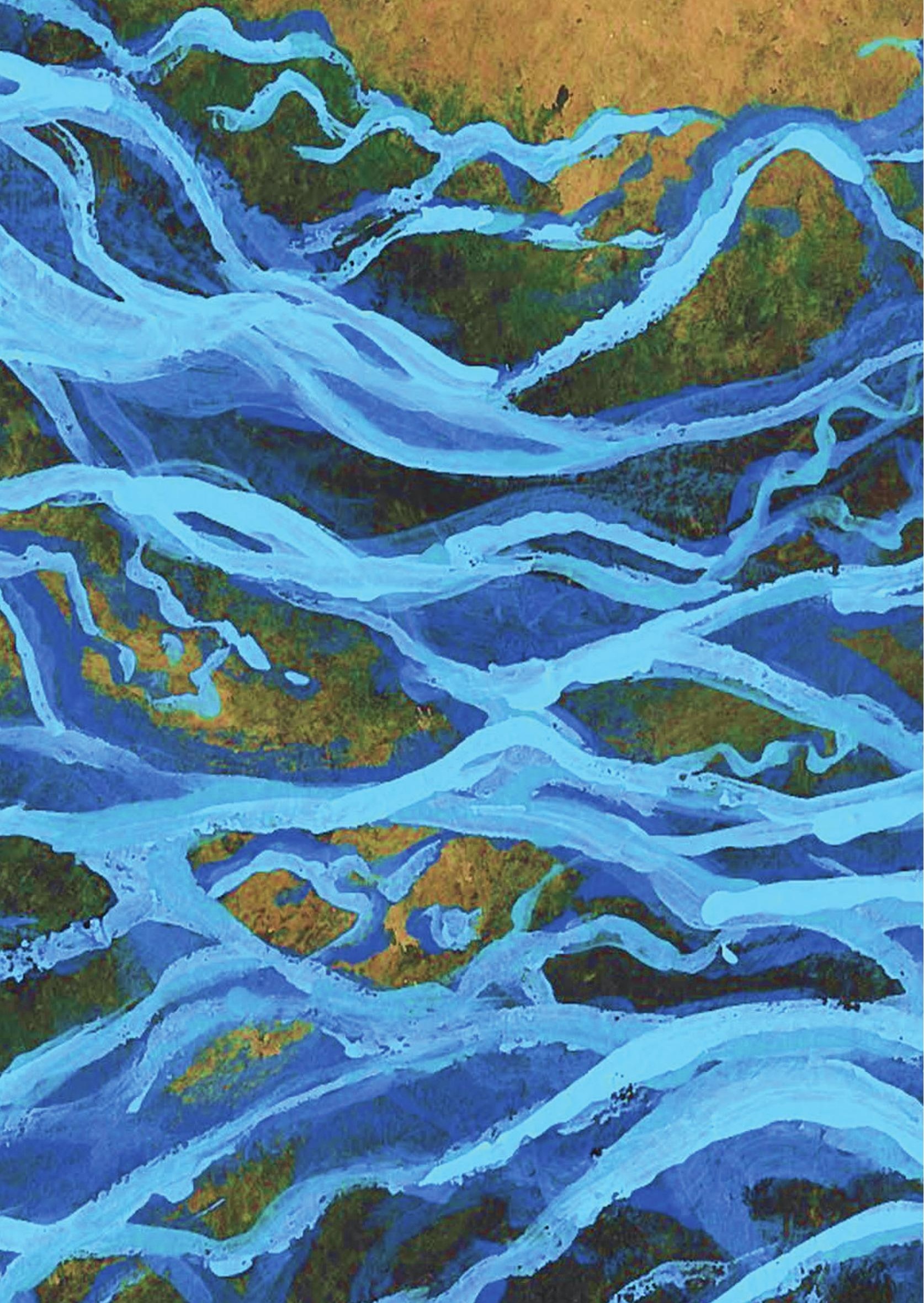

